\title{
Identity, Discourse, and the Media: The Case of the Kurds
}

\author{
by \\ Jaffer Sheyholislami \\ B.A. Honours, M.A., Carleton University
}

\author{
A thesis submitted to \\ The Faculty of Graduate Studies and Research \\ in partial fulfilment of \\ the requirements for the degree of
}

\section{Doctor of Philosophy}

School of Journalism and Communication

Faculty of Public Affairs

Carleton University

Ottawa, Ontario, Canada

August 10, 2008

(C2008, Jaffer Sheyholislami 


$\begin{array}{ll}\begin{array}{l}\text { Library and } \\ \text { Archives Canada }\end{array} & \begin{array}{l}\text { Bibliothèque et } \\ \text { Archives Canada }\end{array} \\ \begin{array}{l}\text { Published Heritage } \\ \text { Branch }\end{array} & \begin{array}{l}\text { Direction du } \\ \text { Patrimoine de l'édition }\end{array} \\ \begin{array}{l}\text { 395 Wellington Street } \\ \text { Ottawa ON K1A 0N4 } \\ \text { Canada }\end{array} & \begin{array}{l}\text { O95, rue Wellington } \\ \text { Ottawa ON K1A 0N4 } \\ \text { Canada }\end{array}\end{array}$

Your file Votre référence ISBN: 978-0-494-43911-1

Our file Notre référence

ISBN: 978-0-494-43911-1

NOTICE:

The author has granted a nonexclusive license allowing Library and Archives Canada to reproduce, publish, archive, preserve, conserve, communicate to the public by telecommunication or on the Internet, loan, distribute and sell theses worldwide, for commercial or noncommercial purposes, in microform, paper, electronic and/or any other formats.

The author retains copyright ownership and moral rights in this thesis. Neither the thesis nor substantial extracts from it may be printed or otherwise reproduced without the author's permission.
AVIS:

L'auteur a accordé une licence non exclusive permettant à la Bibliothèque et Archives Canada de reproduire, publier, archiver, sauvegarder, conserver, transmettre au public par télécommunication ou par l'Internet, prêter, distribuer et vendre des thèses partout dans le monde, à des fins commerciales ou autres, sur support microforme, papier, électronique et/ou autres formats.

L'auteur conserve la propriété du droit d'auteur et des droits moraux qui protège cette thèse. $\mathrm{Ni}$ la thèse ni des extraits substantiels de celle-ci ne doivent être imprimés ou autrement reproduits sans son autorisation.
In compliance with the Canadian

Privacy Act some supporting forms may have been removed from this thesis.

While these forms may be included in the document page count, their removal does not represent any loss of content from the thesis.
Conformément à la loi canadienne sur la protection de la vie privée, quelques formulaires secondaires ont été enlevés de cette thèse.

Bien que ces formulaires aient inclus dans la pagination, il n'y aura aucun contenu manquant.

\section{Canada}


PAGINATION ERROR.

TEXT COMPLETE.
ERREUR DE PAGINATION.

LE TEXTE EST COMPLET. 


\begin{abstract}
This dissertation focuses on the interrelationships between national identities, discourses, and communication technologies in the context of Kurdish people. Informed by the interdisciplinary approach of Critical Discourse Analysis (CDA), the study investigates the ways Kurds use satellite television and the Internet to reproduce, construct, disseminate and articulate discursive and semiotic constructions of their identities. The television data consists of approximately 168 hours of Kurdistan Television (KTV) broadcasting, from August 6 to 12,2005. The Internet data was accumulated over a decade of observation of Kurdish online activities and sources such as web directories, websites, chat-rooms, weblogs, forums and social networking tools (e.g. YouTube). The data are enriched by email interviews and personal communication with television viewers and Internet users and also by drawing on various media outlets reporting on the discourse practices and socio-cultural aspects of the media under investigation. The data are analyzed, interpreted and explained at three levels. At the discourse practice level, the types of television programs and internet constituents used for the practices of identity construction are mapped. At the textual analysis level, multimodal and micro analyses of verbal language, images and music are carried out. At the socio-cultural level, findings from the other levels of analysis are explained in light of the historical and political contexts that bear upon the discursive formation of Kurdish identities.

The findings reveal that KTV's discourse practices are carried out within the ideological framework and political interests of its owner, Kurdistan Democratic Party, an organization that aspires to regional autonomy for Iraqi Kurdistan as opposed to establishment of Greater Kurdistan. Representations of pan-Kurdism are often subtle on KTV. The Internet, on the other hand, provides alternative communicative spaces for explicit and overt construction and reproduction of a cross-border and pan-Kurdish identity. Although there is not one single Kurdish identity, it can be said that within the last decade or so, Kurds from many places have started to learn more about themselves and their "Others" than they had ever known. In recent years, various socio-political developments, from the US led war in Iraq and Turkey's bid for membership in the European Union to the expansion of Kurdish diasporas, have transformed Kurdish communities. In addition, new communication technologies have enabled Kurds to begin overcoming the geographical and political barriers that have kept them apart and fragmented. As a result, since the mid1990 s, alongside several regional Kurdish identities, a pan or cross-border Kurdish identity has been strengthening. It is suggested that the implications of this development can be significant for Kurds and the entire region.

The findings also lend themselves to making more general observations. Far from being agents of only homogenizing the world, satellite television and the Internet have enabled non-state actors and marginalized minorities to reify both their regional and crossborder identities in multimodal discourses. The research has also suggested that the nationstate ideology which primarily conceives of a national identity as culturally and linguistically homogenous may no longer be tenable. Finally, the study calls for further investigation into the practices of identity formation as mediated by the discourses of new communication technologies in more local contexts.
\end{abstract}


To

my wife Narmin,

my daughters Hauna and Sarah, and my parents Khidir and Zêneb.

And,

to the memory of Hêmin. 


\section{Acknowledgments}

It is difficult to acknowledge everyone who has helped me in ways both small and large in completing this project. First and foremost, I offer my sincere thanks to the members of my thesis committee and the examination board: to my thesis supervisor and the Director of the School of Journalism and Communication, Dr. Karim H. Karim, for his invaluable counsel and guidance, his constant encouragement to perform to the best of my ability, and his critical and insightful feedback which demonstrated his keen interest in the significance of my research. My sincere thanks also to Dr. Ross Eaman for co-supervising my research so effectively at the earlier stages, for his ongoing support throughout the research process, and for encouraging my determination to achieve my academic goals; to Dr. Ellen Cray, who supported and encouraged me to continue my research over the years and provided generous critical input and meticulous editorial efforts at various stages of the writing of this dissertation; to Dr. Elliot Tepper for his insightful comments and suggestions as the internal examiner; and finally to Dr. Amir Hassanpour, the external examiner, whose pioneering research on Kurdish identity, language and media not only inspired my research but informed it in significant ways. His thoughtful, thorough and critical examination of this work proved an enormous contribution to the final product.

I owe as well a debt of gratitude to the many others who helped me in crucial ways to complete this dissertation. Sincere thanks to my mentor, colleague and friend, Dr. Lynne Young, who was always generous with her time and provided vital advice on major aspects of this work, from initial methodological considerations through to the analysis stage. Thanks also to my friend and colleague, Jennifer Gilbert, who was exceedingly helpful and supportive throughout my research; each chapter of this dissertation has benefited from Jennifer's brilliant editorial and writing skills. In addition to Dr. Cray, Dr. Young, and Jennifer Gilbert, I owe thanks to many other colleagues and friends from the School of Linguistics and Applied Language Studies here at Carleton, who provided ongoing emotional and academic support over the years: Catherine MacNeil, Professor Ian Pringle, Tracey Poirier, Roxanne Ross, Julia Carey, Dr. Devon Woods, Dr. Randall Gess, Dr. Natasha Artemeva, and Dr. Graham Smart.

I wish also to thank all those in the Kurdish communities who helped me with data collection, answered my many questions and provided important insights into my research on Kurdish identity and media. Some members of this group include Hassan Ghazi, Leyla (Tewar), Golper (Gulagenim), Beroj Akreyi, Nasser Sina, Behzad Naghib, Behroz Hasan, Berdeqani, A. Sohrabi, and Aram Ahmed. I acknowledge and thank also those whose names I cannot mention here.

It is impossible for me to think of this journey without recalling the invaluable emotional and motivational support I received from so many friends. I sincerely thank Catherine MacNeil, Gafer Hossainpour, Hassan Ghazi, Ali Nanvazadeh, Marcy Balouch, Saladdin Ahmed, the Babaei family (Mohsen, Farideh, Asad, and Jalila), Kemal Musulchi, Hashem Ahmadzadeh, Taha Khaleyi, Mo Hadisi, Taha Hassaniani, Shirley Cameron, Dragana Polovina-Vukovic, Carrie Buchanan, Claire Harrison, and Rhonda Walker.

Finally, I offer heartfelt thanks to my wife Narmin, who released me from many parental responsibilities throughout the writing of this dissertation and ensured that our daughters Hauna and Sarah thrived with her love and care. After writing over 400 pages, I 
am at a loss to find words that can adequately acknowledge and honor their patience and support. 


\section{Table of Contents}

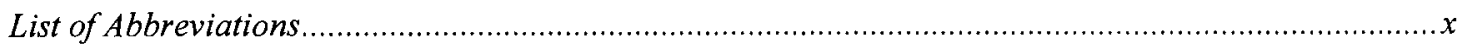

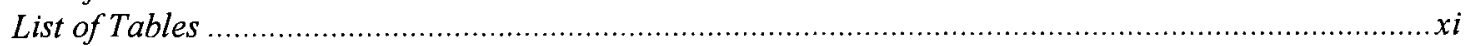

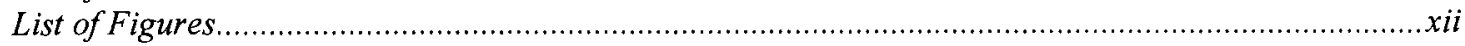

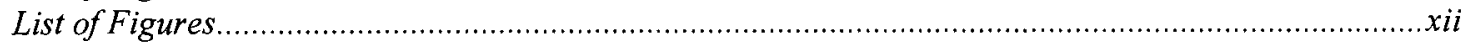

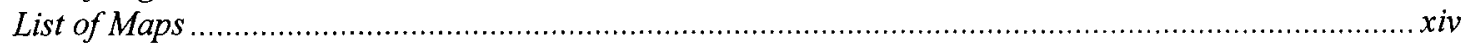

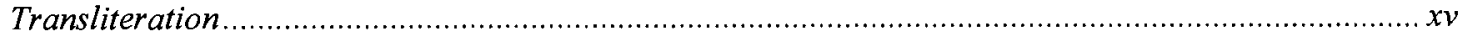

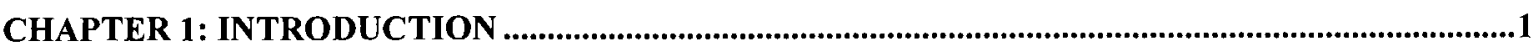

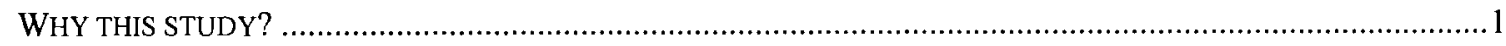

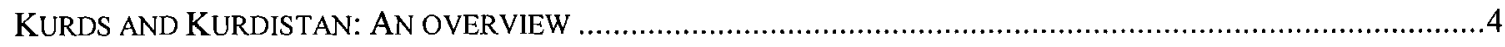

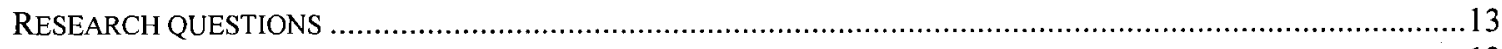

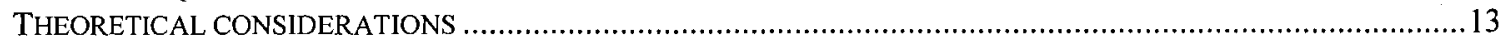

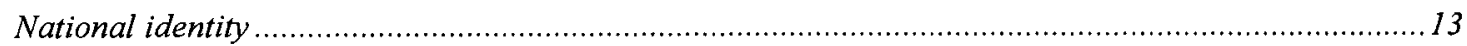

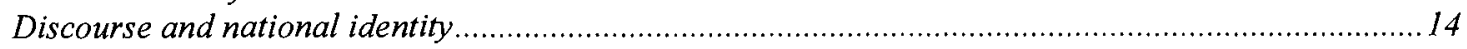

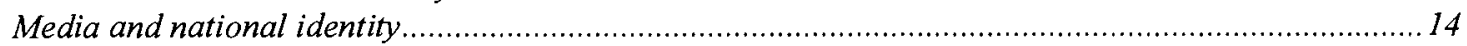

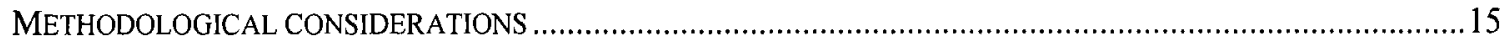

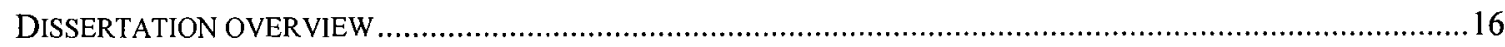

CHAPTER 2: NATION AND NATIONALISM ..........................................................................23

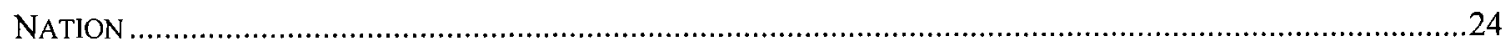

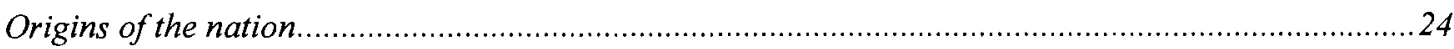

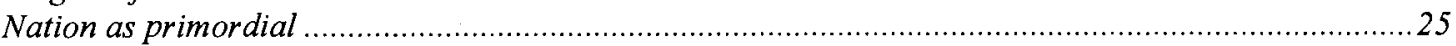

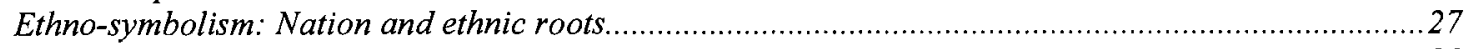

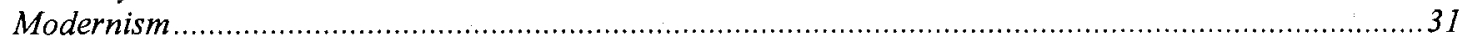

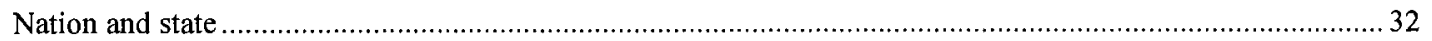

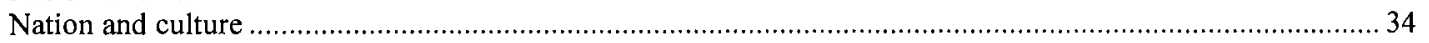

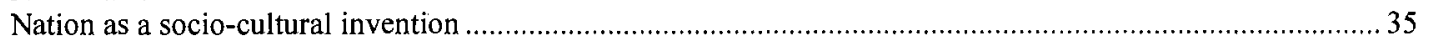

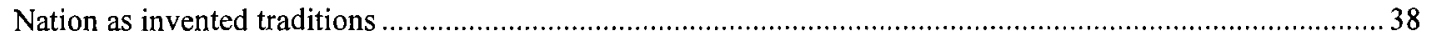

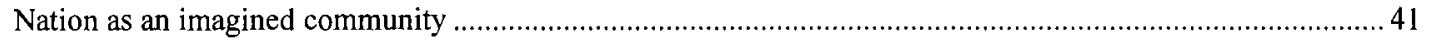

An alternative perspective: Nations without state ................................................................48

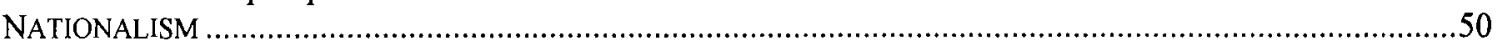

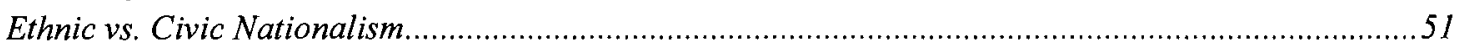

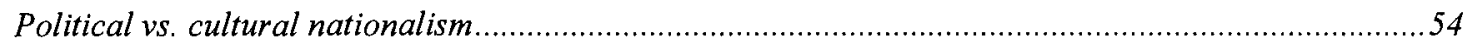

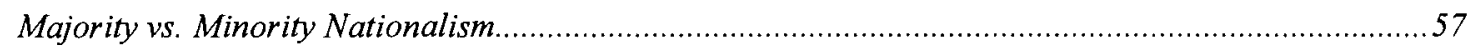

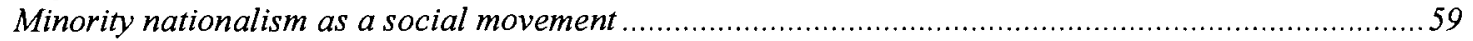

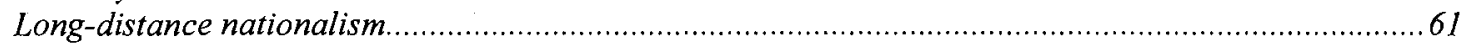

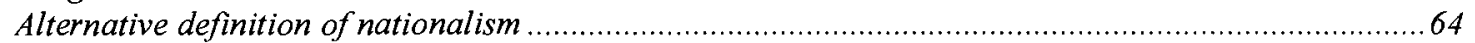

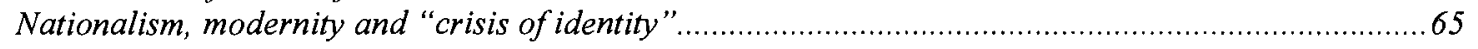

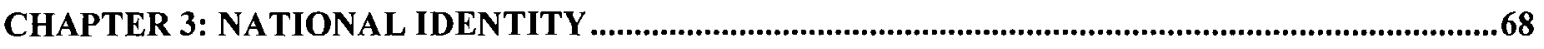

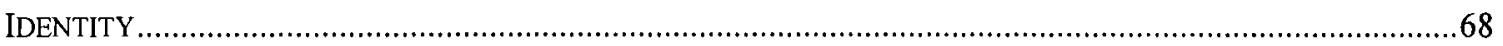

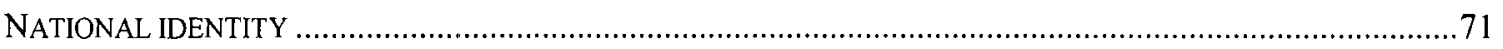

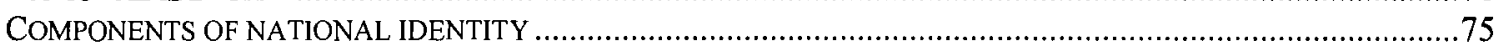

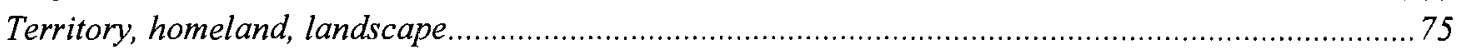

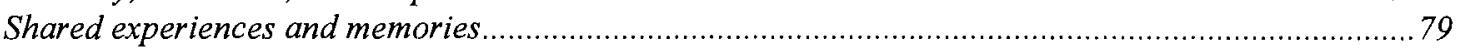

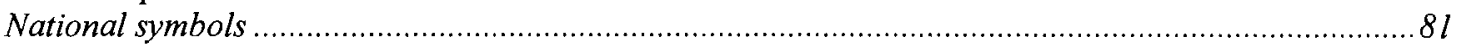

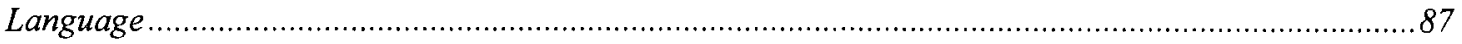

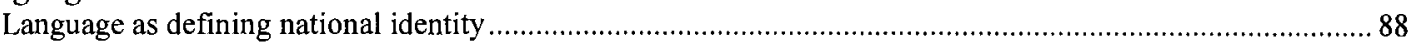

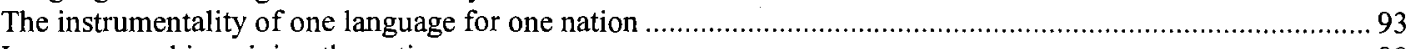

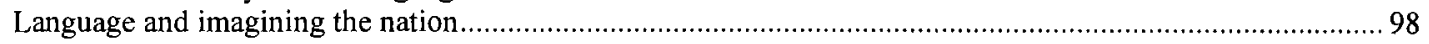

CHAPTER 4: DISCURSIVE CONSTRUCTION OF NATIONAL IDENTITIES AND THE MEDIA102

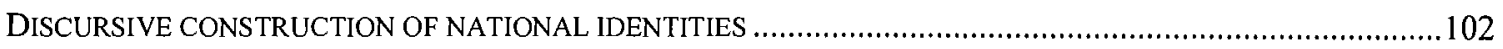

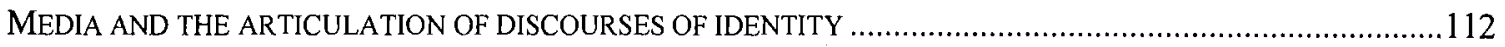




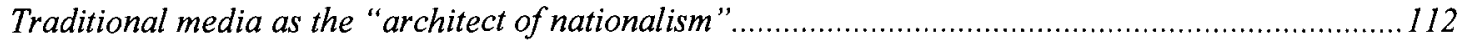

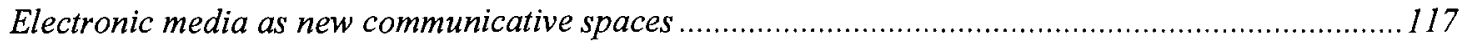

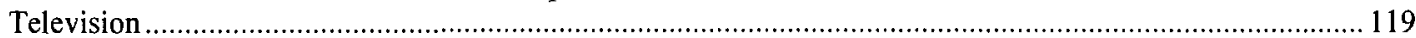

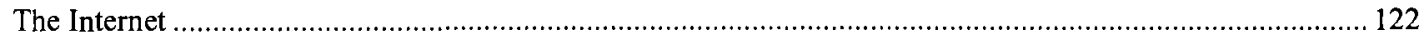

CHAPTER 5: CDA: AN INTERDISCIPLINARY APPROACH TO MEDIA DISCOURSE.................129

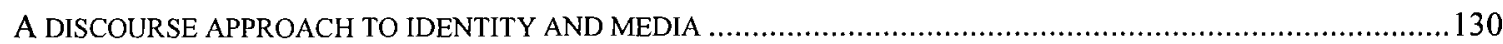

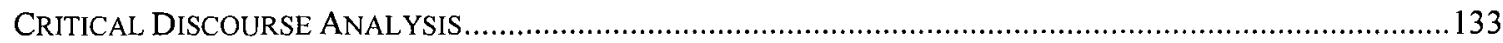

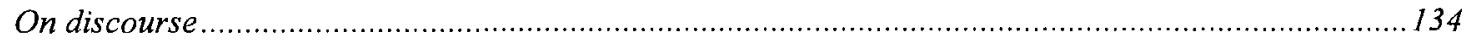

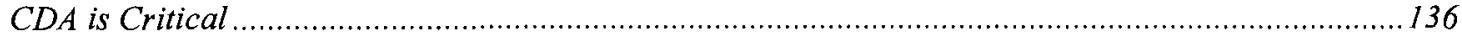

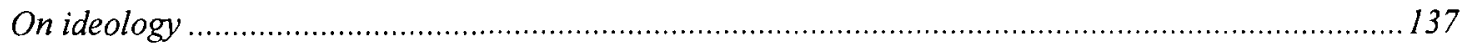

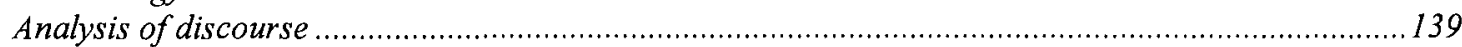

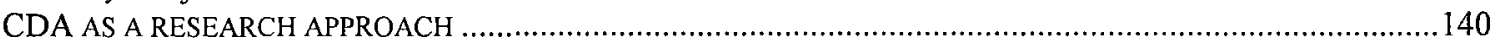

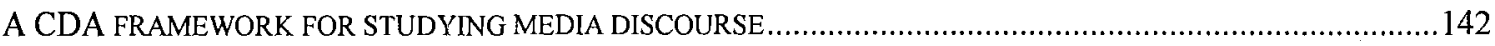

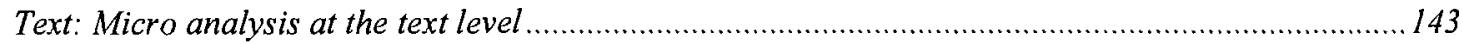

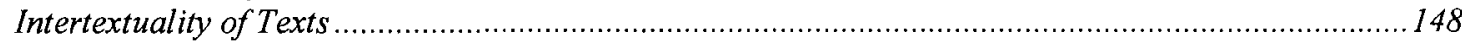

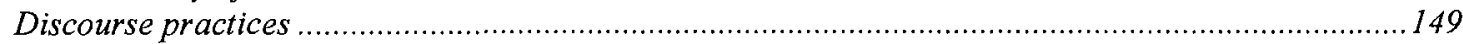

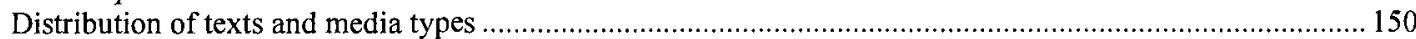

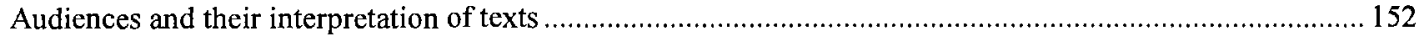

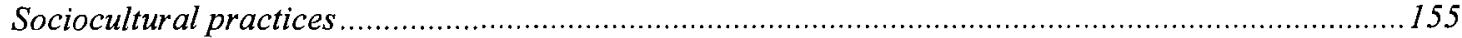

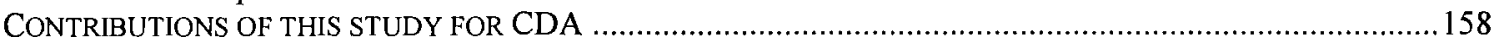

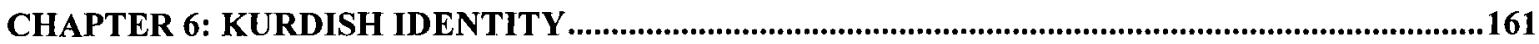

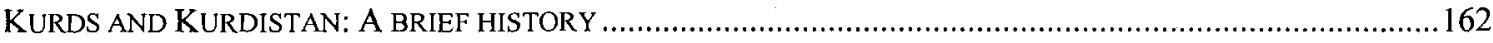

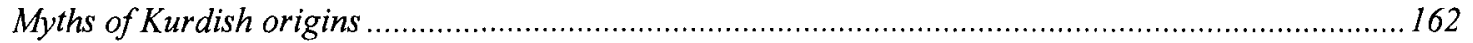

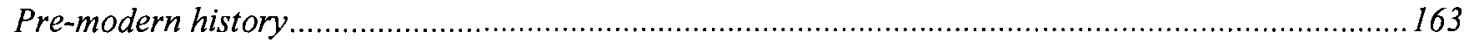

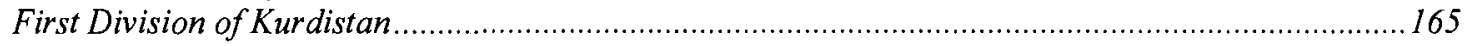

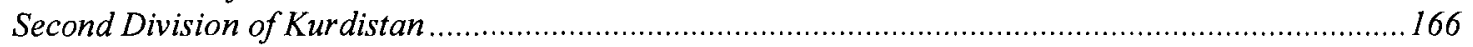

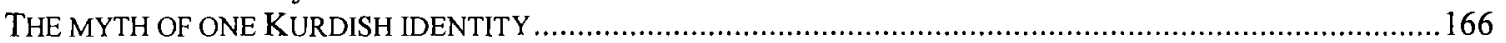

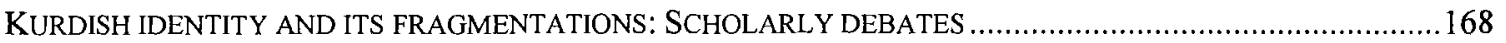

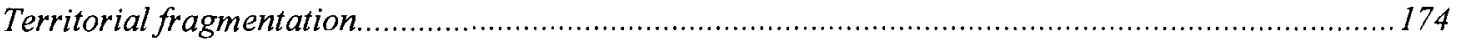

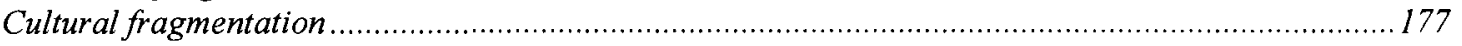

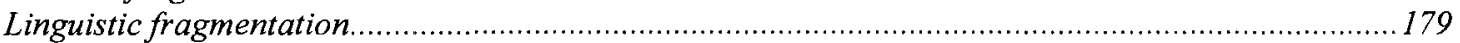

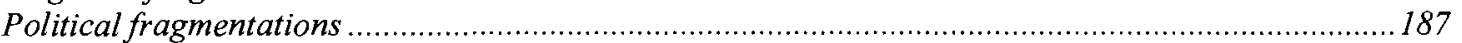

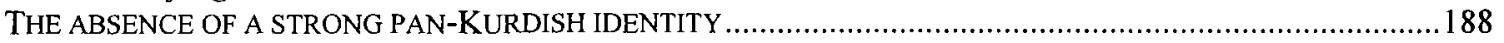

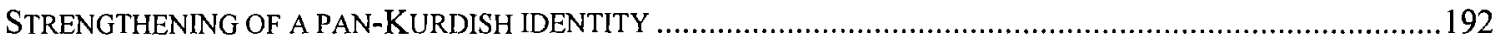

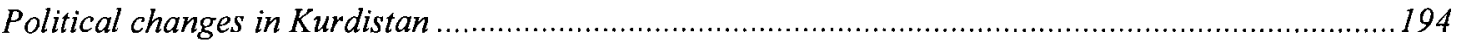

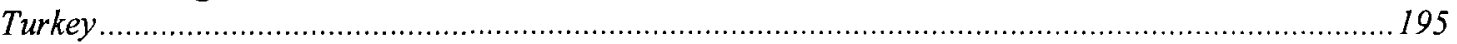

Iran

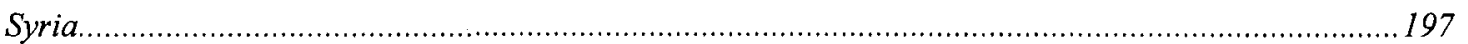

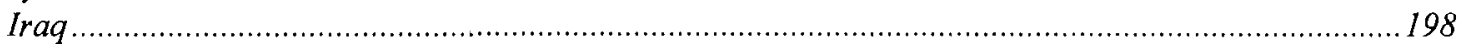

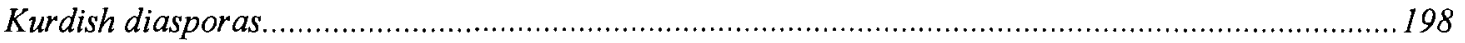

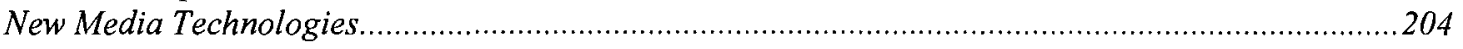

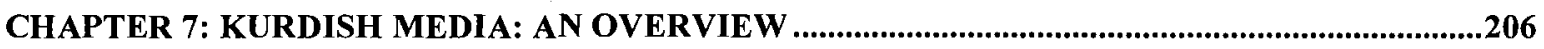

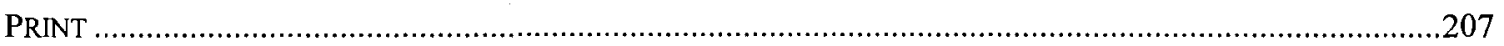

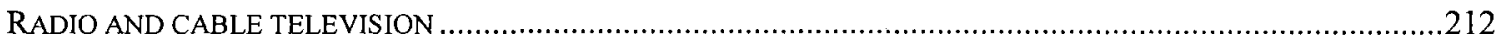

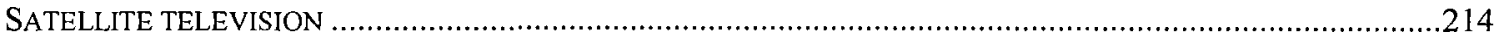

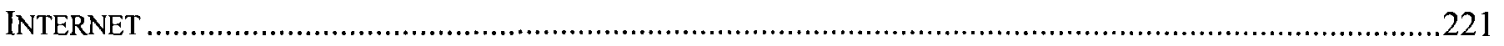

CHAPTER 8: DISCOURSE PRACTICES OF KURDISTAN TV (KTV),...........................................228

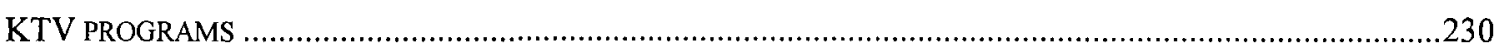

KTV programming and the construction of a pan-Kurdish identity ...............................................23

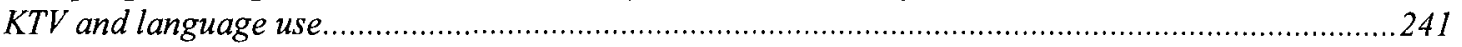

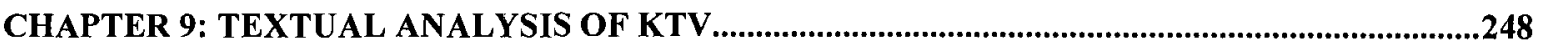




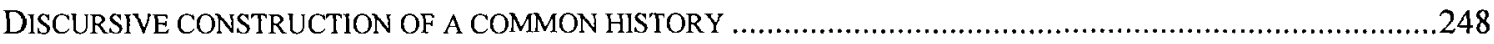

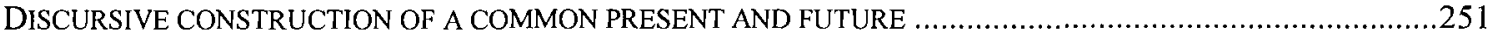

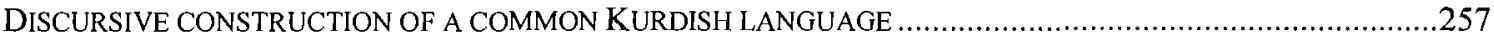

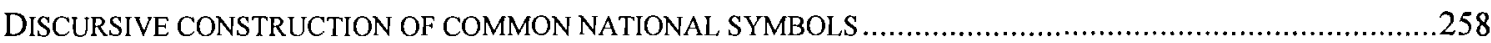

DISCURSIVE CONSTRUCTION OF A COMMON TERRITORY AND HOMELAND .............................................2.

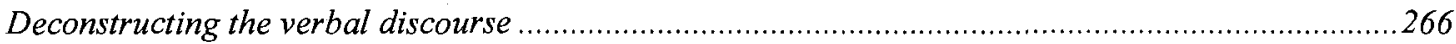

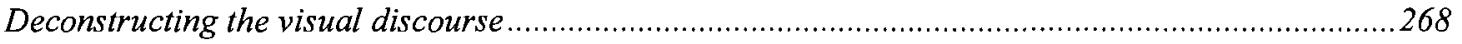

CHAPTER 10: TEXTUAL ANALYSIS OF A PATRIOTIC SONG.......................................................271

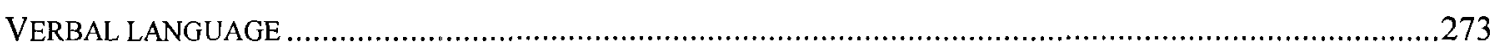

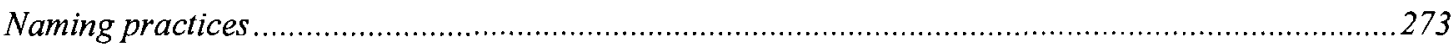

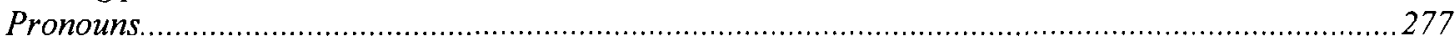

Tense

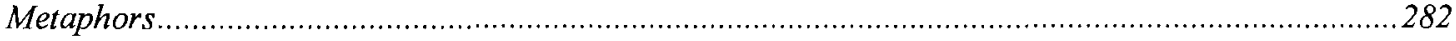

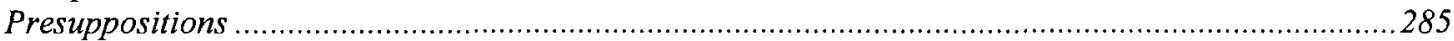

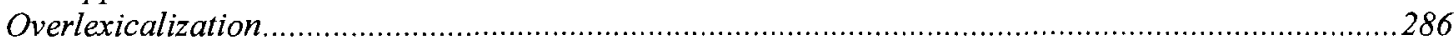

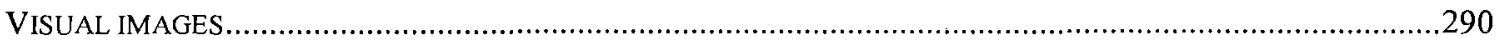

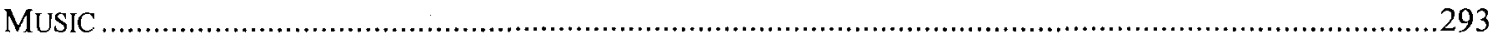

CHAPTER 11: DISCOURSE PRACTICES OF KURDISH INTERNET ..................................................300

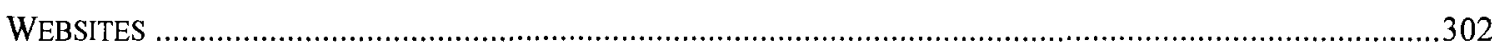

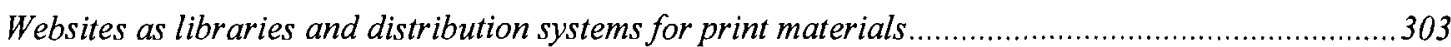

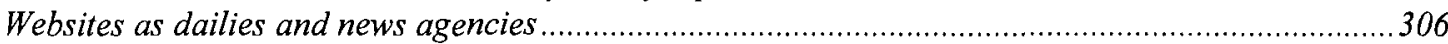

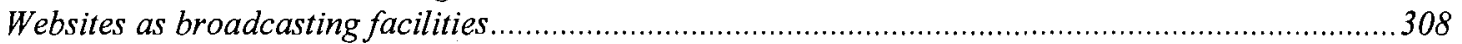

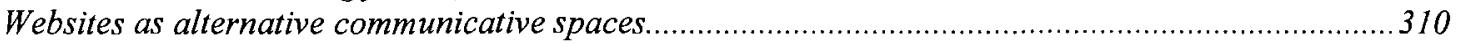

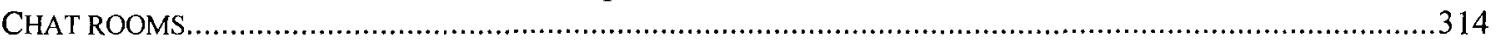

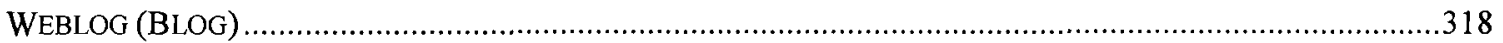

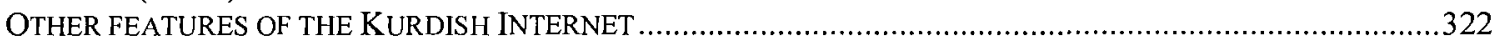

CHAPTER 12: TEXTUAL ANALYSIS OF KURDISH INTERNET .....................................................326

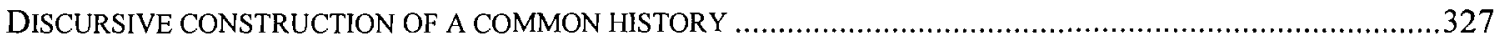

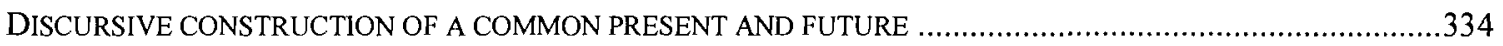

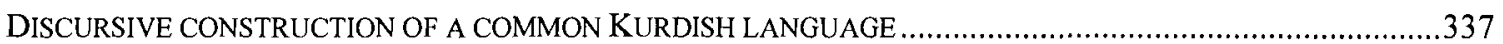

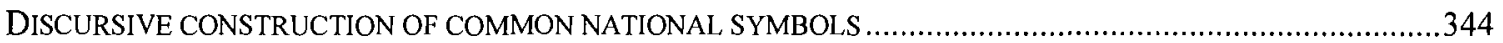

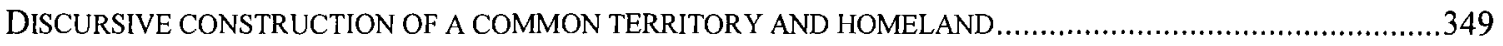

CHAPTER 13: DISCUSSION AND CONCLUSION ................................................................................355

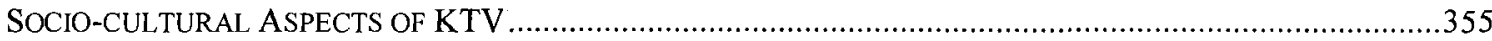

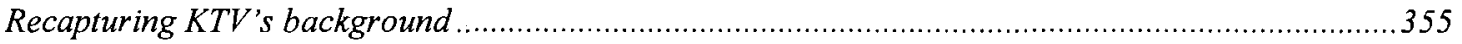

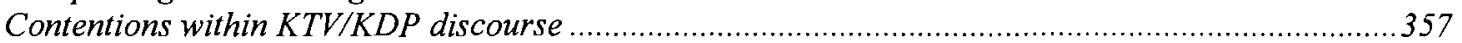

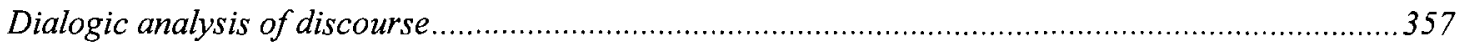

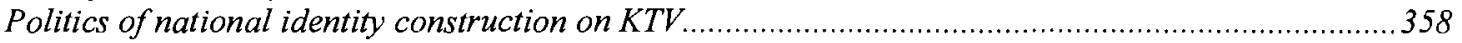

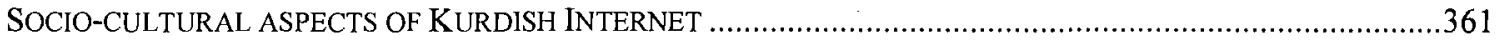

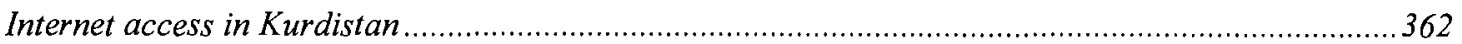

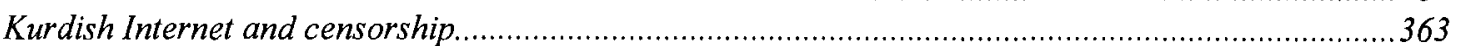

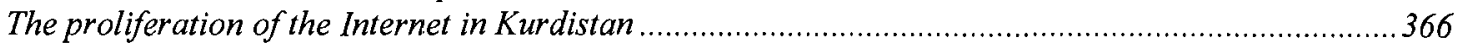

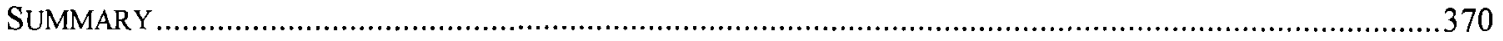

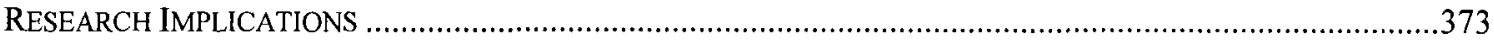

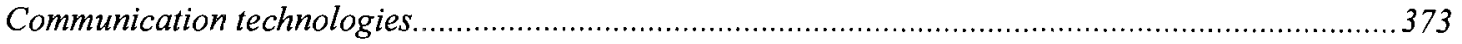

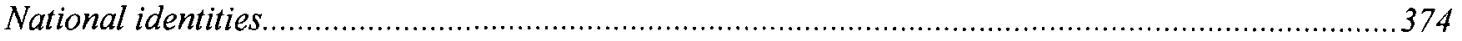

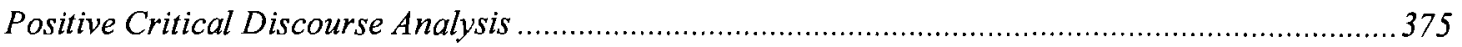

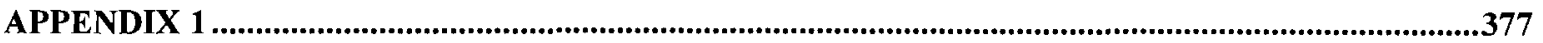

SEMANTIC MACRO-AREAS OF NATIONAL IDENTITY AND LINGUISTIC REALIZATIONS ...................................377

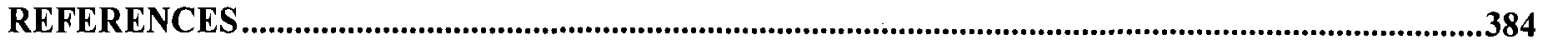




\section{List of Abbreviations}

$\begin{array}{ll}\text { AFP } & \text { Agence France Presse } \\ \text { BBC } & \text { British Broadcasting Corporation } \\ \text { CDA } & \text { Critical Discourse Analysis } \\ \text { EU } & \text { European Union } \\ \text { HRW } & \text { Human Rights Watch } \\ \text { HRW/ME } & \text { Human Rights Watch-Middle East } \\ \text { KDP } & \text { Kurdistan Democratic Party } \\ \text { KDPI } & \text { Kurdistan Democratic Party of Iran } \\ \text { KTV } & \text { Kurdistan Television } \\ \text { PKK } & \text { Partîya Karkerên Kurdistanê (Kurdistan Workers Party) } \\ \text { PUK } & \text { Patriotic Union of Kurdistan } \\ \text { SFL } & \text { Systemic Functional Linguistics } \\ \text { UK } & \text { United Kingdom } \\ \text { US/USA } & \text { The United States of America }\end{array}$




\section{List of Tables}

TABLE 1 POPULATION OF THE KURDS ESTIMATED BY MCDOWELL (2004, PP. 3-4) .............................................

TABLE 2 THE SIZE OF KURDISH DIASPORAS (HASSANPOUR \& MOJAB, 2005, P. 214) ..................................200

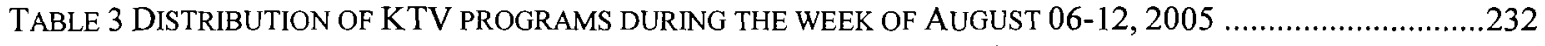

TABLE 4 A SUMMARY OF THE LIST OF THE CITIES AS PRESENTED IN KTV'S WEATHER FORECAST IN AUGUST

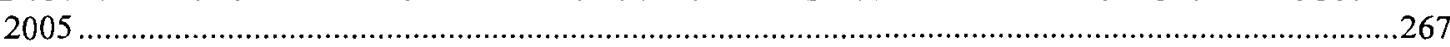

TABLE 5 NAMING AS REUNITING KURDISH TOWNS AND REGIONS REGARDLESS OF THE STATES THEY ARE PARTS

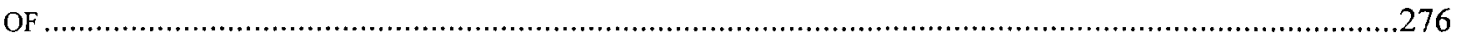

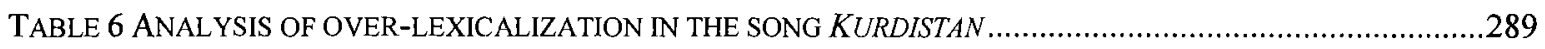

TABLE 7 PATRIOTIC SONG KURDISTAN: LYRICS, IMAGES AND MUSIC DESCRIPTIONS ......................................296 


\section{List of Figures}

FIGURE 1 A FRAMEWORK FOR CRITICAL DISCOURSE ANALYSIS OF A COMMUNICATIVE EVENT. ADAPTED FROM FAIRCLOUGH (1995A, P. 59; 1989, P. 25)

FIGURE 2 KURDISTAN MAP AS PRESENTED IN THE WASHINGTON POST (1999) ............................................ 167

FIGURE 3 DISTRIBUTION OF KURDISH SPEECH VARIETIES (HASSANPOUR, 1992, P. 22) …................................181

FIGURE 4 PHOTOGRAPH OF A SATELLITE DISH HIDDEN BEHIND A STABLE IN IRANIAN KURDISTAN, IN FEBRUARY

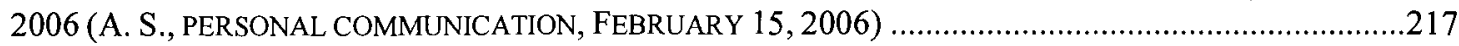

FiguRE 5 PHOTOGRAPH OF SATELLITE DISHES IN A KURDISTAN VILlAGE, SARGALU, IN IRAQ (S. AHMAD,

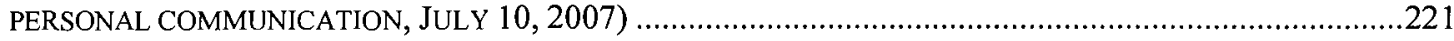

FIGURE 6 ONE OF KURDISTAN TV'S LOGOS DISPLAYED PERIODICALLY BETWEEN PROGRAMS ........................229

FIGURE 7 KURDISH LESSONS PROGRAM AS A PART OF CHILDREN'S SHOW ON KTV .....................................240

FIGURE 8 SCREENSHOT OF A DUBBED CARTOON IN CHILDREN'S PROGRAM ON KTV ….................................243

FIGURE 9 NEWS PRESENTED BY SPEAKERS OF THE TWO MAIN KURDISH VARIETIES: SORANI ON THE LEFT AND

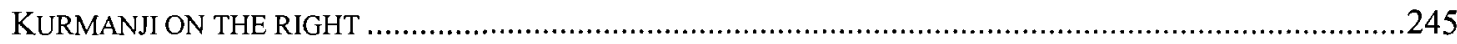

FIGURE 10 SCREENSHOT OF THE OPENING OF THE ASSYRIAN PROGRAM ON KTV .........................................246

FIGURE 11 SCREENSHOT OF THE OPENING OF A KTV SHOW, EMR̆O LE MÊJUU DA (TODAY IN HISTORY) ............249

FIGURE 12 KTV'S WEBSITE BANNER. DIFFERENT NAVIGATION BUTTONS ARE PLACED FOR THE TWO VARIETIES

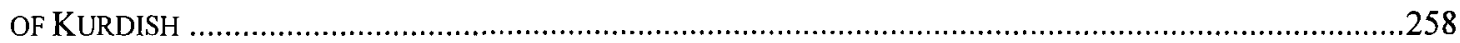

FIGURE 13 SCREENSHOT OF THE NEWS PROGRAM DENG U BAS: KURDISH FLAG DISPLAYED IN A MEETING WITH

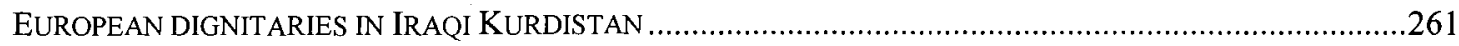

FIGURE 14 KTV NEWS. KURDISH FLAG DISPLAYED IN A SPORTS CENTER ..................................................261

FIGURE 15 SCREENSHOTS FROM KTV'S CHILDREN'S PROGRAM AND ONE OF THE STATION'S LOGOS DISPLA YED

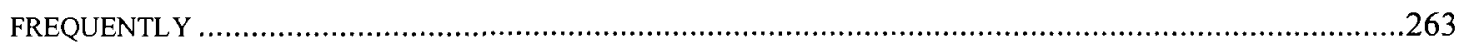

FIGURE 16 SCREENSHOT FROM A KTV SHOW, SIRUSTİ KURDISTAN (KURDISTAN NATURE)...............................265

FIGURE 17 VISUAL ANALYSIS OF KTV'S WEATHER FORECAST ..................................................................269

FIGURE 18 SCREENSHOT OF THE SONG KURDISTAN FEATURED ON YOUTUBE, RETRIEVED 2007-07-12 FROM

HTTP://WWW.YOUTUBE.COM/WATCH?V=FN1S_HVQWCC ..............................................................273

FIGURE 19 A SCENE FROM THE VIDEO CLIP KURDISTAN SHOWS A CLOSE-UP OF A YOUNG BOY STANDING ON THE

SHOULDER OF AN ADULT AND WITH THE KURDISH FLAG PAINTED ON HIS FACE …………........................29

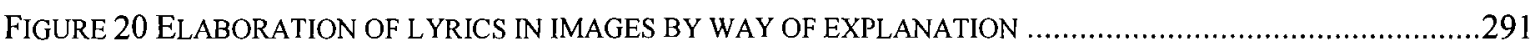

FIGURE 21 ELABORATION OF LYRICS IN IMAGES BY WAY OF EXEMPLIFICATION …….................................292

FIGURE 22 ELABORATION OF LYRICS IN IMAGES BY WAY OF EXEMPLIFICATION EXTENSION............................292

FIGURE 23 A SCREENSHOT OF THE WEBSITE KOORD. RETRIEVED DECEMBER 20, 2006, FROM

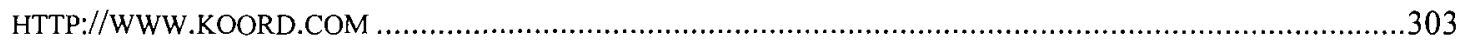

FIGURE 24 A SCREENSHOT OF THE WEBSITE KITEEBXANEY KURDîl(THE KURDISH LIBRARY). RETRIEVED JUNE 28,

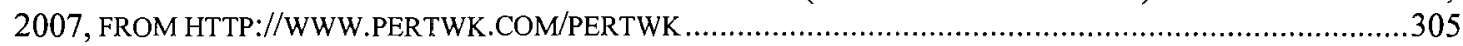

FIGURE 25 A SCREENSHOT OF THE WEBSITE RIZGARI ONLINE (EMANCIPATION ONLINE). RETRIEVED JULY 03, 2007, FROM HTTP://KURDISH.RIZGARI.COM ....................................................................................... 307

FIGURE 26 A SCREENSHOT OF THE WEBSITE $P N A$. RETRIEVED JUNE 28, 2007, FROM

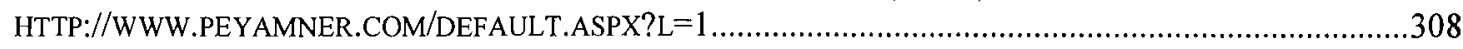

FIGURE 27 A SCREENSHOT OF THE WEBSITE JIN--KURDISH WOMEN NETWORK. RETRIVED JULY 10, 2006, FROM

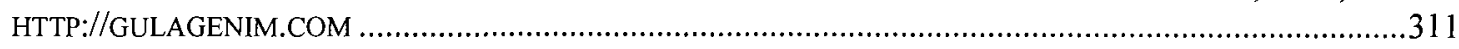

FIGURE 28 A SCREENSHOT OF THE WEBSITE KURDISTAN POST DISPLAYING JALAL TALABANI'S (THE IRAQI PRESIDENT) PORTRAIT. RETRIEVED JULY 08, 2007, FROM HTTP://KURDISTANPOST.COM/INDEX.PHP?ID $=374$

FIGURE 29 A SCREENSHOT OF THE WEBSITE KURDISTAN POST FEATURING MASOUD BARZANI ON SEPTEMBER 23, 2007. RETRIEVED SEPTEMBER 24, 2007, FROM HTTP://KURDISTANPOST.COM/INDEX.PHP?ID=1642.313

FIGURE 30 A SCREENSHOT OF KURD CHAT, AN IRC (TEXT-BASED) KURDISH CHAT ROOM. RETRIEVED OCTOBER 23, 2007, FROM HTTP://WWW.KURDCHAT.NET/KURDCHAT/LOGIN.PHP ...................................315

FIGURE 31 A SCREENSHOT OF PALTALK'S DIRECTORY OF CHAT ROOMS FOR "ETHNIC GROUPS." THE RIGHT COLUMN SHOWS THE NUMBER OF KURDISH ROOMS ON PALTALK ON JULY 05, 2007. RETRIEVED JULY 05,

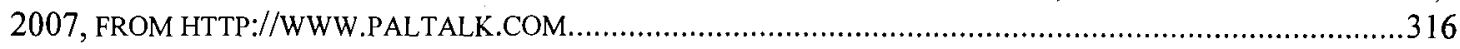

FIGURE 32 A SCREENSHOT OF PALTALK SHOWING THE LIST OF KURDISH CHAT ROOMS. RETRIEVED FEBRUARY 03, 2007, FROM HTTP://WWW.PALTALK.COM... 
FIGURE 33 A SCREENSHOT OF THE FIRST KURDISH WEBLOG GULAGENIM. RETRIEVED DECEMBER 12, 2005, FROM HTTP://GULAGENIM.BLOGSPOT.COM/2005/12/BLOG-POST.HTML

FIGURE 34 A SCREENSHOT OF FACEBOOK SHOWING A FEW PRO-KURDISH GROUPS. RETRIEVED OCTOBER 24, 2007, FROM HTTP://WWW.FACEBOOK.COM/S.PHP?N $=-1 \& \mathrm{~K}=200000010 \& \mathrm{Q}=$ KURDISTAN..

FIGURE 35 A SCREENSHOT OF THE FORUM ROJ BASH KURDISTAN. RETRIEVED OCTOBER 18, 2007, FROM HTTP://NORTHERNIRAQ.INFO/FORUMS/INDEX.PHP 325

FIGURE 36 A SCREENSHOT OF THE VIDEO MEDIAN EMPIRE AND [THE] FALL OF NINEVEH. RETRIVED OCTOBER 11,2007 , FROM HTTP://CA.YOUTUBE.COM/WATCH? V=2LF W9ADW4A

FIGURE 37 A SCREENSHOT OF THE BANNER OF THE FORUM MALí KURDAN (HOME OF KURDS). RETRIEVED AUGUST 07, 2007, FROM WWW.HOME4KURD.COM.

FIGURE 38 A SCREENSHOT OF THE VIDEO CLIP "KURDISTAN AND KURD LIBERATION" ON YOUTUBE. RETRIEVED AUGUST 05, 2007, FROM HTTP://WWW.YOUTUBE.COM/WATCH?V=PRMVWKsXZOW ........333

FIGURE 39 THE CONSTRUCTION OF A COMMON KURDISH FUTURE ON THE FORUM ROJ BASH KURDISTAN (GOOD DAY/MORNING KURDISTAN): THERE IS NO NORTHERN IRAQ [SIC]. RETRIEVED JULY 10, 2007, FROM HTTP://WWW.NORTHERNIRAQ.INFO/FORUMS/VIEWTOPIC.PHP? $\mathrm{F}=1 \& \mathrm{~T}=2471 \ldots$

FIGURE 40 A SCREENSHOT OF THE WEBSITE FÊRBÛNî ZIMANî KURDî (LEARNING THE KURDISH LANGUAGE). RETRIEVED OCTOBER 30, 2007, FROM HTTP://WWW.KURDI.FI

FIGURE 41 A SCREENSHOT OF THE WEBSITE DIBISTANA KURDî: DIMLî/ZAZAKÎ (KURDISH SCHOOL: DIMLI/ZAZAKI). RETRIEVED JANUARY 15,2007 , FROM HTTP://MODERSMAL.SKOLUTVECKLING.SE/NORDKURDISKA/ZAZAKI/START.HTM

FIGURE 42 THE TOP BANNER OF THE WEBSITE KOORD. RETRIEVED DECEMBER 17, 2006, FROM HTTP://WWW.KOORD.COM

FIGURE 43 THE TOP BANNER OF THE WEBSITE ISLAM PAIK. RETRIEVED DECEMBER 13, 2006, FROM HTTP://WWW.ISLAMIPAIL.ORG

FIGURE 44 THE KURDISH FLAG PRECEDING THE URL OF KURDISTAN NET: WWW.KURDISTANNET.ORG

FIGURE 45 A TYPICAL LANDSCAPE OF KURDISTAN (THE REGION ALAN LOCATED ON THE OFFICIAL BORDER BETWEEN IRAN AND IRAQ, CLOSE TO THE TOWN OF SARDASHT IN IRANIAN KURDISTAN. RETRIEVED OCTOBER 19, 2006, FROM HTTP://KOORD.VIEWBOOK.COM/ID/2558/CC9A602B732C44EB343B1B0B6ECBA743

FIGURE 46 EXAMPLES OF THE MAP OF THE GREATER KURDISTAN PLACED ON THE BANNER OF THREE WEBSITES: PARTî SERBESTÎ KURDISTAN (KURDISTAN INDEPENDENCE PARTY), RIZGARí ONLINE, AND KURDISH WWW, RESPECTIVELY FROM TOP TO BOTTOM.

FIGURE 47 A SCREENSHOT OF THE MOST POPULAR LINKS ON THE WEBSITE KOORD. THE KURDISH AFFILIATIONS OF THE LINKS (TURKISH, IRAQI, IRANIAN OR SYRIAN) ARE IDENTIFIED. RETRIEVED JULY 10, 2007, FROM HTTP://WWW.KOORD.COM

FIGURE 48 SAMPLE OF TURKISH TEXT INTRUSION INTO THE KURDISH CHAT ROOM KURDI NETEWEYI (KURDISH NATIONALIST) ON THE PROTOCOL PAL TALK. RETRIEVED MARCH 17, 2007, FROM HTTP://WWW.PALTALK.COM

FIGURE 49 BEING HACKED THE HOMEPAGE OF THE KURDISH WEBSITE DENGEKAN IS COVERED WITH A MAP OF TURKEY AND ITS FLAG. RETRIEVED JULY 04, 2007, FROM HTTP://WWW.DENGEKAN.COM.. .365

FIGURE 50 A NON-KURDISH WEBSITE, EU MINORITY, IS HACKED FOR CARRYING THE KURDISH FLAG AND USING THE WORD KURDISTAN. RRETRIEVED FEBRUARY 30, 2007, FROM EUROMINORITY.ORG/VERSION/ENG/PROJECTS-SHOP-NATION-WHOLE.ASP 


\section{List of Maps}

MAP 1 A MAP OF GREATER KURDISTAN. MCDOWELL, 2004, P. XIV.

MAP 2 “MAJOR KURDISH PRINCIPALITIES FROM THE SEVENTEENTH CENTURY TO THE 1860S” (O'SHEA, 2004,

P. 86) 164 


\section{Transliteration}

Since this study is addressed to audiences who may not be familiar with Kurdish and other Middle Eastern languages, transcription and transliteration are reduced to minimum.

English translation of Kurdish texts is provided without transcription of the original text whenever possible. Anglicized names have not been transliterated, for example, the name of an Iranian Kurdish filmmaker has been written as Ghobadi instead of its Romanized Kurdish transliteration Qubadî. However, when the same name (i.e. Ghobadi) is part of a transliterated text the Kurdish version of the name (i.e. Qubadî) is used. To transcribe Kurdish texts I have used the Latin-based writing system that has been in use since the 1930s predominantly among Kurds from Turkey and Syria. This system has been used for the transcription of personal and geographical names, title of publications, television programs and websites, and parts of texts that are transliterated for the purpose of illustrating specific aspects of textual analysis. Romanization is done according to the following list of transliteration.

\section{Vowels and diphthongs}

\begin{tabular}{|c|c|}
\hline Lا LI & $\mathrm{a}$ \\
\hline D & $\mathrm{e}$ \\
\hline وّ & o \\
\hline كى & $\hat{\mathrm{e}}$ \\
\hline وو & $\hat{\mathrm{u}}$ \\
\hline g & $\mathrm{u}$ \\
\hline ى، يـى & $\hat{1}$ \\
\hline- & $\mathrm{i}$ \\
\hline ويّ & wê \\
\hline
\end{tabular}


Consonants

\begin{tabular}{|c|c|}
\hline 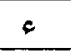 & 1 \\
\hline ب & $\mathrm{b}$ \\
\hline$\ddot{v}$ & $\mathrm{p}$ \\
\hline$\Xi$ & $t$ \\
\hline ج & c \\
\hline ङ & $\oint$ \\
\hline$\tau$ & $\hat{\mathrm{h}}$ \\
\hline$\dot{\tau}$ & $\mathrm{x}$ \\
\hline 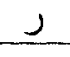 & $r$ \\
\hline 2 & $\check{\mathrm{r}}$ \\
\hline$j$ & $\mathrm{z}$ \\
\hline$j$ & $j$ \\
\hline س & $s$ \\
\hline ش & $\$$ \\
\hline$\varepsilon$ & . \\
\hline$\dot{\varepsilon}$ & $\dot{\mathrm{g}}$ \\
\hline$\dot{3}$ & $f$ \\
\hline$\stackrel{3}{3}$ & $\mathrm{v}$ \\
\hline ق & $\mathrm{q}$ \\
\hline 5 & $\mathrm{k}$ \\
\hline 3 & $g$ \\
\hline J & 1 \\
\hline$J$ & 1 \\
\hline p & $\mathrm{m}$ \\
\hline$\dot{u}$ & $\mathrm{n}$ \\
\hline 9 & $\mathrm{w}$ \\
\hline$\Delta$ & $\mathrm{h}$ \\
\hline$\checkmark$ & $\mathrm{y}$ \\
\hline
\end{tabular}




\section{Chapter 1: Introduction}

This study uses the interdisciplinary research approach of critical discourse analysis (henceforth CDA) to investigate the ways the Kurds utilise satellite television and the Internet to articulate and disseminate discursive and semiotic constructions of their national identities. In this introductory chapter, I establish the significance of studying the relationship between national identity, communications technology and discursive practices and suggest that there is a need for the re-examination of this relationship. It has been suggested that this reassessment should take place in different local contexts. The Kurdish case is an excellent example of such a local context, which I will illustrate with a brief description of Kurds, Kurdistan, the complexity of Kurdish identity, and by posing the research question(s). This will be followed by a summary of theoretical issues and methodological considerations that will be further explored throughout the study. Finally, I will provide an overview of the dissertation.

\section{Why this study?}

Although a number of scholars predicted the demise of nationalism and nation in the age of 'globalization'1 (Appadurai, 1996, p. 19; Hobsbawm, 1990, pp.181-182)2 ${ }^{2}$, nationalism has

\footnotetext{
${ }^{1}$ Globalization is understood as "the movement of objects, signs and people across regions and intercontinental space. The globalization of culture entails the movement of all three" (Held et al., 1999, p. 329).
} 
been identified as "one of the most powerful forces in the modern world" (Hutchinson \& Smith, 1994, p. 3, see also Anderson, 1991, p. 3; Billig, 1995, p. 22; Delanty \& Kumar, 2006, p. 1-2; Hall, 1993, p. 1; Malešević, 2006, p. 309). Whereas previously nationalism was primarily viewed as the architect of the modern nation-state from the late eighteenth century onward (Deutsch, 1966; Gellner, 1997, 1983; Hobsbawm, 1990; Smith, 1998), its surge in recent decades has been seen as a response to the need for collective identities. Many scholars believe that nationalism is a force and resource promoting national identities both in nation-states (Billig, 1995; Calhoun, 1997; Madianou, 2005; Wodak, de Cillia, Reisigl \& Liebhart, 1999; Wodak, 2006) and also among nations without states (Castells, 1997; Kane, 2000; Guibernau, 1999, 1996).

Morley (1992) has suggested that "the construction and emergence of national identities cannot properly be understood without reference to the role of communications technology" (p. 267, see also Silverstone, 1999, pp. 19-27). Research on the place of communication in general (Deutsch, 1953, 1966), and mass communication in particular, in the processes and practices of building modern nation-states started almost half a century ago (Anderson, 1991/[1983]; Innis, 1951; McLuhan, 1962, 1964). In recent decades, more studies have focused on the place of media in forming and sustaining national identities in nation-states (Billig, 1995; Drummond, Paterson \& Willis, 1993; Madianou, 2005; Price, 1995; Wodak et al., 1999) and also among stateless nations and national minorities

\footnotetext{
${ }^{2}$ Hobsbawm (1990, p. 182) predicted: "the world history of the late twentieth and early twenty-first centuries...will inevitably have to be written as the history of a world which can no longer be contained within the limits of 'nations ' and 'nation-states' as these used to be defined, either politically, or economically, or culturally, or even linguistically. It will see 'nation-states' and 'nations' or ethnic/linguistic groups primarily as retreating before, resisting, adapting to, being absorbed or dislocated by, the new supranational restructuring of the globe".
} 
(Castells, 1997; Guibernau, 1999; Hazel, 2001; Hassanpour, 1998; Higgins, 2004; Law, $2001)^{3}$

The question to be asked then is why are the media deemed so important in this respect? In other words, how does media use contribute to the formation and maintenance of national identities? This is the question that is not often asked; rather it is assumed that the links between media, nationalism and national identity are there and all researchers have to do is to take the links for granted and map them out (Schlesinger, 1991, p. 172; Law, 2001). Despite the fact that a number of studies have aimed at delineating the interrelationship between national identity and media, Schlesinger (1991) has noted that, in communication studies, the nation and national identity have not been sufficiently theorized; at the same time, " in the nationalism literature the mass media are usually quite untheorized" (p. 156). In 1991, Schlesinger called for a reassessment of the relationship between media and nationalism. However, as Law (2001) notes, "little progress has been made since" (p. 299). ${ }^{4}$ This study contributes to this line of research. The study is also a contribution to a more recent approach to national identity: Critical discourse analysis (Billig, 1995; Wodak et al., 1999; Wodak, 2006). In addition to focusing on the crucial role of the media in the practices of collective identity construction, a discourse analytical approach elucidates the ways identities are constructed discursively in each specific local

\footnotetext{
${ }^{3}$ It has been suggested that the establishment and maintenance of even larger and transnational communities such as the European Union are dependent on mass communication (Schlesinger, 1999). Schlesinger maintains that the supranational economic and political practices of the EU have started to erode the function of the nation-state, which has been "the key framework for the practice of democratic politics and the exercise of citizenship" (p. 264). The EU, however, is primarily "class inflicted" and undemocratic. Thus, in order to democratize the EU, according to Schlesinger, there is the need for "supranational communication." In other words, the democratization and thus the survival of the ideal EU as a supranational but still European entity is only possible through the utilization of "supranational" means of communication, something that is not in place yet (1999).

${ }^{4}$ Some notable attempts made in response to this concern are Billig (1995), Madianou (2005), Schlesinger (1999), and Wodak et al. (1999).
} 
context. Wodak (2006) identifies a need for more interdisciplinary research in order to better address the complexity of national identity formation:

Although ... discourse analytical approaches [e.g. CDA] have been adapted and applied to other cultures and the study of national identities elsewhere, more interdisciplinary research is needed that would make the historical and contextual specificities of each social group/collective/community under investigation more explicit. Moreover, the interdependence of local, regional, national and global dimensions has to be studied in their vast complexity. (2006, pp. 114-5)

The Kurdish case qualifies as a complex instance of identity formation.

\section{Kurds and Kurdistan: An overview}

The Kurds are the largest people claiming the status of a non-state nation (Gunter, 2005;

Kreyenbroek \& Allison, 1996; Mojab, 2001; Vali, 2003). Estimated at about 25 to 30

million people (Ciment, 1996, p. 76; see Table 1), Kurds predominantly live in the Middle

East, in an area called Kurdistan, which comprises parts of Turkey, Iraq, Iran, and Syria

(henceforth the four states; see Map 1). ${ }^{5}$ Although there has never been a state called

Kurdistan (van Bruinessen, 1992, p. 11), as McDowell (2004) suggests, "Kurdistan exists

within relatively well defined limits in the minds of most Kurdish political groups" (p. 3)

and also a great number of Kurdish intelligentsia and masses. ${ }^{6}$

\footnotetext{
${ }^{5}$ Armenia, which used to be a part of USSR, is sometimes included in the list of the countries where parts of Kurdistan is said to be located. However, the vast majority of Kurds refer only to chiwar parchey Kurdistan (four parts of Kurdistan) straddling Turkey, Iraq, Iran, and Syria.

${ }^{6}$ According to McDowell (2004), "the term Kurdistan was first used in the twelfth century as a geographical term by the Saljuqs" (p. 6). However, "Kurdistan has been virtually wiped from the map in the twentieth century. Only in Iran is a single, truncated province labelled Kordistan [sic]. This cartographic obliteration has its origins in politics. No country, with the partial exception of the old Soviet Union, has been keen on promoting Kurdish identity" (Ciment, 1996, p. 75; see also McDowell, 2004, p. 3).
} 
Map 1 A map of greater Kurdistan. McDowell, 2004, p. xiv

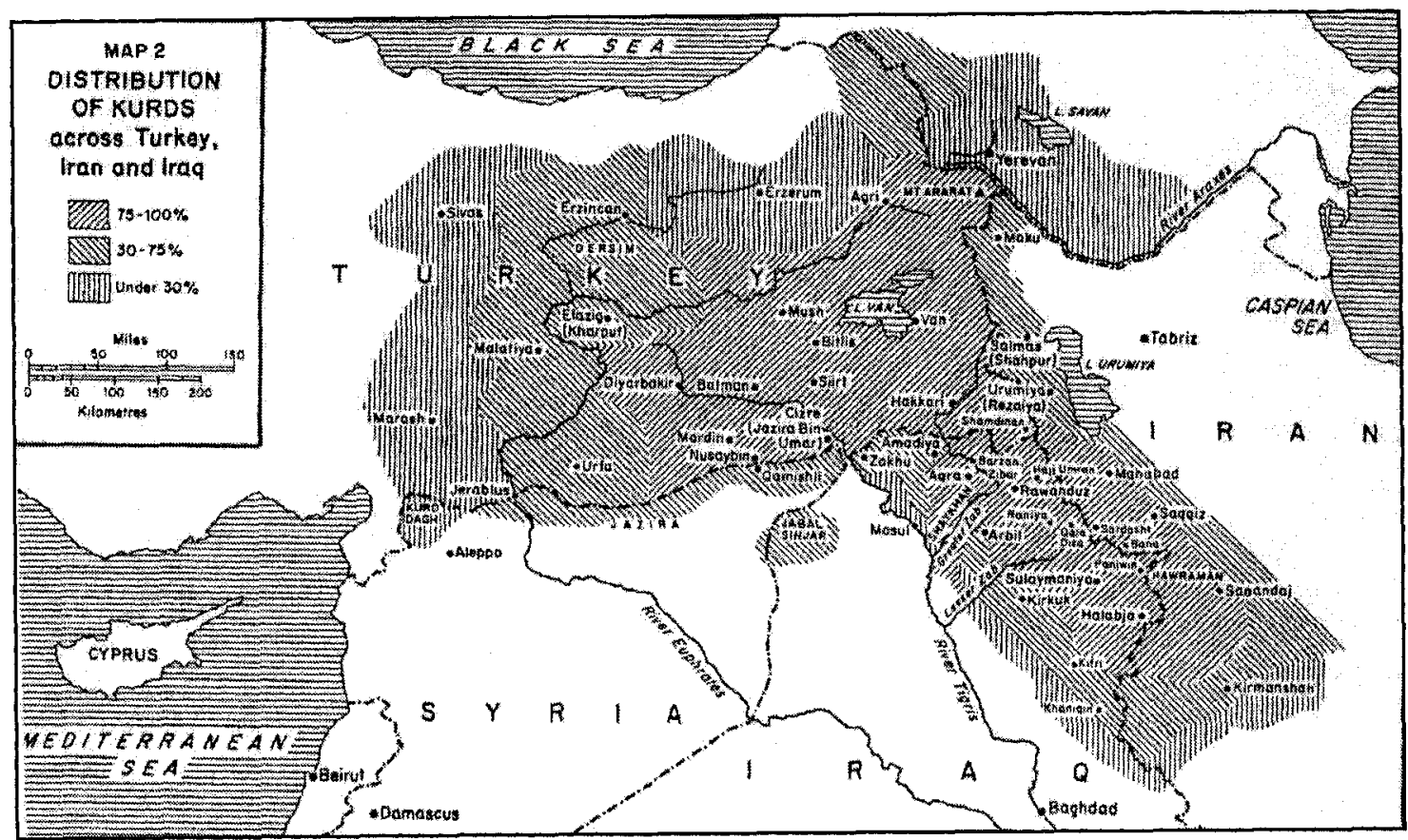

Table 1 Population of the Kurds estimated by McDowell (2004, pp. 3-4)

\begin{tabular}{lll}
\hline Country & Number of Kurds & Percentage of the population \\
& & \\
\hline Turkey & $13,000,000^{7}$ & 19 \\
Iran & $5,700,000$ & 10 \\
Iraq & $4,200,000$ & 23 \\
Syria & $1,000,000^{8}$ & \\
Europe & 700,000 & \\
Former USSR & 400,000 & \\
\hline Total & $25,000,000$ & \\
\hline
\end{tabular}

The history of Kurdish dynasties and principalities goes back as far as the 8th century (Hassanpour, 1992, p. 50). There were 40 Kurdish principalities by the end of the

\footnotetext{
${ }^{7}$ Hassanpour \& Mojab's (2005, p. 214) estimates are higher. They estimate the number of Kurds in Turkey at $13,700,000$, in Iran at 6,600,000, in Iraq at 4,400,000 and in Syria at 1,300,000. Whereas McDowell's total estimate is $25,000,000$, Hassanpour \& Mojab's estimate reaches $27,100,000$.

${ }^{8}$ McDowell does not give an estimate for the population of Kurds in Syria but he states that they are over one million.
} 
17 th century (ibid.). However, by the mid- $19^{\text {th }}$ century no Kurdish self-governing entity remained in the region as a result of the division of Kurdistan by the Ottoman and Persian empires. Kurdistan was further divided among the four countries of Turkey, Iraq, Iran, and Syria following the European powers' (i.e. Britain and France) re-mapping of the Middle East, right after the First World War.

Kurdish nationalism emerged at the turn of the last century mainly as a reaction to the denial of Kurdish identities by the four states (Vali, 1998, 2003). ${ }^{9}$ However, to this day, Kurdish nationalism has failed to create a strong cross-border or trans-state ${ }^{10}$ Kurdish identity because of both external and internal obstacles. There were more than 20 Kurdish movements and revolts involving armed struggle in the twentieth century (Romano, 2002), but not one was successful. ${ }^{11}$ The reactions of the four states to Kurdish demands for cultural and political autonomy and rights have been fierce and violent, accompanied by imprisonment, torture, disproportionate military campaigns, and acts of genocide (Fernandes, 2007). Kurdish national liberation movements have been ineffective because they have been too parochial (Vali, 1998), and they have often been used as pawns against each other by the four states and the superpowers involved in the politics of the region

\footnotetext{
${ }^{9}$ Kurdish national identity is understood as a shared collective identity denoting feelings of belonging to Kurds and Kurdistan, but at the same time feelings of difference from neighbouring nationalities such as Turks, Arabs, and Persians.

${ }^{10}$ An alternative term for cross-border or trans-state would have been "transnational." However, following van Bruinesssen (2000b) I am using cross-border/trans-state and sometimes pan-Kurdish identity instead of Kurdish transnational identity. Van Bruinessen suggests: "The term 'transnational' is commonly used to refer to various types of social relations and interactions that transcend 'national' boundaries ... It is obviously an appropriate term to refer to the network of contacts and the complex of activities connecting Kurdish communities in Germany, Great Britain and Turkey, but I would object to its use for networks linking the Turkish, Iraqi and Iranian parts of Kurdistan because in the latter case the essential element of distance from the homeland is lacking" (2000b).

${ }^{11}$ Although Iraqi Kurds have been running their own affairs since 1991, it is no secret that they owe their success primarily to the involvement of the United States and its allies in Iraq.
} 
(Romano, 2006). ${ }^{12}$ Since World War One, the dynamics and patterns of Kurdish identity formation have been determined not only by its own internal factors but also by various nation-building policies and practices of different states straddling Kurdistan (Vali, 1998, p. 82). Kurdish identity within each state has taken a different shape (ibid).

Thus, until very recently Kurds remained deeply fragmented territorially, politically, culturally, and linguistically. These fragmentations made communication difficult among the Kurds. Less than two decades ago it would take several months for news concerning major events in Kurdistan to reach most of the Kurds who were not directly affected by those events. Two examples from Iraqi Kurdistan should suffice. In 1988, the Iraqi regime embarked on the infamous Anfal ${ }^{13}$ campaign in Iraqi Kurdistan during which about 100,000 people were killed and disappeared (Black, 1993). A report by the Human Rights Watch-Middle East (HRW/ME) designated the perpetuated atrocities against Iraqi Kurds "crimes against humanity and genocide" (1995, p. 20; see also Randall, 1997). Next to Anfal one can recall the town of Halabja where the Iraqi regime's warplanes gassed 5000 Kurds on March 16, 1988. According to Bulloch \& Morris (1992), the Halabja incident "did more than any other single incident in seventy years of rebellion against central authority to remind Kurds everywhere of their separate Kurdish identity" (p. 43). Human Rights Watch designated the incident as "genocide." Despite this, both the Anfal campaign and Halabja incident generated very little, if any, reaction among the Kurds in Turkey, Syria, and Iran. ${ }^{14}$ Even many Iraqi Kurds did not realize the magnitude of the atrocities

\footnotetext{
${ }^{12}$ The Kurdish patriotic poet Ahmad Khani, about 300 years ago, lamented Kurdish disunity. His observations are still echoed in recent studies of Kurds and Kurdistan (Romano, 2002; Ignatieff, 1993). ${ }^{13}$ It is also referred to as Al Anfal.

${ }^{14}$ The situation was a little bit different in Iran. Immediately after the incident, Iranian journalists were present at the scene. Being at war with Iraq, the Iranians disseminated the images to the world as well.
} 
perpetuated by Iraqi regime until moths and years later. Kurds did not have the means to communicate with each other sufficiently; they lacked a collective identity even in Iraqi Kurdistan let alone across the borders of four-nation states. To have a collective identity requires having not only the means of articulating it (i.e. in discursive practices) (Billig, 1995) but also communicating it dialogically among the members of a prospective community. ${ }^{15}$ Kurds could not enjoy this communication for almost a century; their identities remained greatly fragmented.

However, there have been suggestions that a strong Kurdish cross-border identity has begun to emerge since the mid 1990s (van Bruinessen, 2000a, p. 62; Romano, 2005, p. 231). Several major events in recent years point to some substantial changes in the state of communication between Kurds of different countries. Among these events are the abduction of the Kurdish rebel leader Abdullah Ocalan by Turkey in 1999, which sparked a swift and spontaneous and worldwide protest by the Kurds in the four states and diasporic communities (Romano, 2002; Siddiqui, 1999; BBC, 1999). Solidarity was also expressed worldwide in 2004 for the Kurdish uprising in the town of Qamishli/Qamishlo in Syria and its violent repression by the state (O'Leary \& Khalid, 2005, p. 15). The appointment of Masoud Barzani as the Iraqi Kurdistan's President in 2005 was a cause for celebrations throughout Kurdistan and diasporas (AFP, 2005; Institut Kurde de Paris, 2005).

A strengthening cross-border Kurdish identity has started to emerge since the mid1990 s due to some significant political developments in the region ${ }^{16}$ but more importantly

However, the world for the most part chose to either ignore the incident or to downplay it (Buloch \& Morris, 1992, p. 143; Sheyholislami, 2007).

15 "To be means to communicate dialogically" (Bakhtin, 1984, p. 252).

${ }^{16}$ This is not to hold the new media solely responsible for these developments. The region has witnessed and experienced a number of significant political and social developments over the past two decades or so, 
because of an increasing and effective use of digital broadcasting satellite (DBS) among the Kurds. Kurds themselves have viewed Kurdish satellite television as a catalyst. When the first Kurdish satellite television, MED-TV, was launched in 1995, a Kurdish newspaper wrote that the step was "more important than all [Kurdish] armed revolutions" (as cited in Hassanpour, 1998, p. 44). MED-TV's director, Hikmet Tabak, has been quoted as saying that Kurds all over the world were excited about the station because "they think this is the first step on the last, long part of the road to the formation of a Kurdish state" (Ryan, 1997, p. 5, my emphasis). The Turkish state managed to jam MED TV in September 1996 (Hassanpour, 2003), but since then more than ten Kurdish satellite TV stations have been launched. This is in addition to the proliferation of the Internet and its publishing, communication, and broadcasting facilities. Christiane Bird, after travelling throughout Kurdistan in 2002, wrote:

The Kurds remain a fractured people on many levels--torn between countries, regions, political parties, tribes, families, dialects, outlooks, the old and the new. And yet, and yet...Modern technology, coupled with oppression, has changed everything. Through satellite communications and the Internet, the Kurds have their own television shows, radio broadcasts, publications, and websites, all of which are theoretically available to every Kurd anywhere in the world ... The Kurds may not have their own physical nation, but they do have an international cyberspace state, along with a quickening sense of national identity that, decades from now, may yet give rise to Pan-Kurds unification - perhaps in the form of a federated Kurdish nation-state. (Bird, 2004, p. 373)

Bird, however, like many commentators who have heralded this development, offers no analysis as to how this "modern technology" might "give rise to Pan-Kurds unification."

changes that have inevitably affected the Kurds. The First Gulf War in 1991 and more importantly the invasion of Iraq by the United States and its allies since 2003, the reformist movement in Iran in the mid 1990s, and the consideration of Turkey's application for full membership by the European Union. 
The suggestion that the new media technologies can foster "Pan-Kurd unification" is built on the assumption that when people connect and communicate, they begin sharing a sense of belonging and identity. The assumption tends to ignore messages, what is communicated. Communication among the members of a prospective community is essential for the creation and maintenance of a collective identity, but it is doubtful if connection or even communication alone can create a collective sense of belonging. When human beings come into contact, they do not just begin sharing similarities, they also notice differences because communication technologies carry messages that may or may not concur with the ideas and beliefs of audiences (Connor, 1994). In other words, there is clearly more to the media than their technological attributes, namely the messages they disseminate. For example, Connor (1994) observes that ethnic consciousness in most of the world "involves not the nature or density of the communication media, but the message" (p. 38). Kurds have lived under different hegemonic cultures (e.g. Arabic, Turkish, Persian) for at least a century. Seeing their fellow Kurds on television or communicating with them on the Internet after all this time might make them realize how different they are from each other instead of bringing them closer. More communication might actually cause them to abandon aspirations for the establishment of a greater Kurdistan state or belonging to a cross-border Kurdish identity. Thus, for instance, Iranian Kurds might realize that they share more with the rest of the Iranians than with Kurds from Turkey or Syria.

The belief that the new media technologies by themselves may create "Pan-Kurdish unification" not only ignores the messages that these technologies disseminate but also the socio-cultural and historical contexts that bear upon the use of the media and the production and consumption of their messages. One cannot ignore the issue of media ownership when 
studying Kurdish satellite television channels. The vast majority, if not all, of these stations belong to political organizations that advocate cultural or/and political autonomy for the Kurds of each part of Kurdistan within the respective states where they reside. For example, the Kurdistan Democratic Party, which owns KTV, openly aspires not to establishing a greater Kurdistan state but to securing regional autonomy for Iraqi Kurdistan within a federal Iraq. This begs the question: how and why does the existence of KTV or its broadcasts contribute to "Pan-Kurd unification" when its owner, KDP, is not a pan-Kurdish organization? The issue of ownership, along with other important issues such as access, need to be taken into consideration also when looking at the Internet and its use and impact on the processes of identity reproduction and construction. Every individual, small groups and alternative voices can access the Internet, not only as recipients of information, which is often the case with television, but also as producers and distributors of information. Does this mean that the Internet makes a different contribution to the process of identity formation as opposed to television?

A comprehensive examination of the place of communication technologies in the processes of identity formation requires investigation at least at three levels: (1) messages: describing strategies of identity construction and their materialization in linguistic and other semiotic forms (e.g. images); (2) the medium: interpreting the significance of these semiotic realizations of identity against relevant discourse practices that constrain or facilitate the consumption of media messages (e.g. media type used for the dissemination of messages); (3) context: contextualizing the discursive constructs and practices of identity formation socio-culturally, politically and historically. 
I submit that KTV's discourse practices are carried out within the ideological framework and political interests of its owner, Kurdistan Democratic Party, an organization that aspires to regional autonomy for Iraqi Kurdistan as opposed to establishment of Greater Kurdistan. Representations of pan-Kurdism are often subtle on KTV. The Internet, on the other hand, provides alternative communicative spaces for explicit and overt construction and reproduction of a cross-border and pan-Kurdish identity. Although there is not one single Kurdish identity, it can be said that within the last decade or so, Kurds from many places have started to learn more about themselves and their "Others" than they had ever known. This change, however, cannot be entirely attributed to the new media technologies. In recent years, various socio-political developments, from the US led war in Iraq and Turkey's bid for membership in the European Union to the expansion of Kurdish diasporas, have transformed Kurdish communities. It is within this socio-political and historical context that the new communication technologies have enabled Kurds to begin overcoming the geographical and political barriers that have kept them apart and fragmented. As a result, since the mid-1990s, alongside several regional Kurdish identities, a pan or cross-border Kurdish identity has been strengthening. The implications of this development can be significant for Kurds and the entire region. Finally, investigating the interrelationship between collective identity, discourse and media can lead to more general observations. Far from being agents of only homogenizing the world, satellite television and the Internet have enabled non-state actors and marginalized minorities to reify both their regional and cross-border identities in multimodal discourses. Finally, I suggest that the nation-state ideology which primarily conceives of a national identity as culturally and linguistically homogenous may no longer be tenable. 


\section{Research questions}

The statement above leads to the following questions.

- Why is it that, in the case of the Kurds, it is only recently that this strong connection has been made between a collective Kurdish identity and the mass media? What are satellite television and the Internet capable of doing for the Kurds that other media have failed to do?

- How do the Kurds use satellite TV and the Internet to construct, articulate and negotiate their identities? What are the discursive strategies and practices used in this process?

- What Kurdish identities are constructed, who constructs them, and why?

- What might be the socio-cultural and political implications of these Kurdish identity formations?

- What can be learned from the Kurdish case for our understanding of the interrelationships between identity, discourse, and media?

\section{Theoretical considerations}

\section{National identity}

National identity denotes shared feelings of belonging to a cultural or national group (Kane, 2000 , p. 247), but at the same time it denotes differences from other groups and national identities (Billig, 1995, p. 66; Riggins, 1997, pp. 6-7; Wodak et al., 1999, p. 17). It is primarily a social construct; however, it has historical and ethnic roots, even if such roots are invented (Smith, 1998, p. 130). According to Castells, "most successful nationalisms presume some prior community of territory, language, or culture, which provide the raw material for the intellectual project of nationality" (1997, p. 29). In other words, nationalist ideologies use history and memory, territory and landscape, language and a great number of other cultural and political symbols and myths, with the aim of strengthening national ties 
(Smith, 1999; Hobsbawm, 1988). It should also be stressed that national identity is dynamic; it is neither primordial nor it will remain the same forever. It is contextdependent, which means that "the various discursive constructs of national identity are given different shapes according to the context and to the public in which they emerge" (Wodak et al., 1999, p. 3).

\section{Discourse and national identity}

The construction of national identity is discursive in crucial ways. As Billig suggests, "to have a national identity is to possess ways of talking about nationhood" (Billig, 1995, p. 8). Ways of communicating about nationhood, especially in the age of television and the Internet, include not only verbal language but also audio-visual means of communication. To encompass this multimodality of the new media I use the term discourse. Discourse and discursive practices contribute to the construction, reproduction and maintenance of national identities (Wodak, 2006). Therefore, the "study of identity should involve the detailed study of discourse" (Billig, 1995, p. 8). Components of a nationalist discourse often include the discursive construction of a common culture, language, territory, symbols, history, and a shared present and future.

\section{Media and national identity}

Collective identities are understood primarily in terms of shared meanings and understandings among social actors. It follows that discursive constructs of national identity need to be disseminated and negotiated among prospective members of a community (Ainsworth \& Hardy, 2004, p. 237; Hall, 1992, p. 292; Triandafyllidou \& Wodak, 2003, p. 210). Mass media have proven to be excellent tools and sites for the dissemination and articulation of national identity discourses (Anderson, 1991; Billig, 
1995; Bishop \& Jaworski, 2003; Chouliaraki, 1999; Madianou, 2005). For nations without states, such as the Kurds, which lack institutions like schools, ministries of culture, and the military, mass communication technologies are important sources of mediation and negotiation of discursive identity constructs.

Media technologies, however, differ with respect to their degree of reach, accessibility, resourcefulness for creating semiotic and discursive constructs and finally the messages and images they disseminate. Communication scholars such as Deutsch (1966) and McLuhan, 1962), and a number of nationalism scholars such as Gellner (1983, p.127) have emphasized the form and technological characteristics of the media and have ignored the content of media. In contrast, other scholars, notably discourse analysts, concerned with the interface between media and nationalism, have paid little attention, if any, to the technological characteristics of the media and instead they have focused on the content of the media (Billig, 1995; Wodak et al., 1999). Many scholars of nationalism have also confirmed the importance of media content and messages (Smith, 1998; Connor, 1994). This study proposes a more balanced approach to the role of the media discourse in the processes of identity construction. The medium matters, but so does the content. Of great importance also are the socio-cultural contexts that bear upon the construction and consumption of media products.

\section{Methodological considerations}

To explicate the interface between identity, discourse, and media, this study is informed by the interdisciplinary approach of Critical Discourse Analysis. CDA is an interdisciplinary approach in the sense that it blends social theories with theories of language and discourse. According to Chouliaraki \& Fairclough (1999), CDA facilitates a dialogue between various 
social and linguistic theories (p. 16). Discourse is a social practice, simultaneously constitutive of and constituted by social structures, relations and identities. For example, national identities are reflected and articulated in the use of language and discourse, and at the same time, they are constructed, reproduced and sustained through discursive practices. However, two points need to be clarified. First, discourses do not construct identities on their own; they do so because they are produced and used by human beings who subscribe to certain ideologies and worldviews (Weiss \& Wodak, 2003, p. 14). The second point is that national identities do exist outside discourse. However, to paraphrase Hall (1988), identities are constantly mediated by and through discourse.

The CDA framework that is proposed here for studying media discourse consists of three interrelated dimensions: Text, discourse practices, and socio-cultural practices. At the text level, CDA involves detailed analysis of text properties such as linguistic elements and audiovisual signs. At the discourse practice level, issues of text production and consumption are addressed. Analysis at the sociocultural level attempts to explain how social, cultural and political contexts influence the ways texts are produced, distributed and consumed.

\section{Dissertation overview}

Chapter Two undertakes a comprehensive survey of the main theories of nation and nationalism. In expounding the definitions, origins and nature of nations, I adopt a position based on a critical evaluation of three major approaches: primordialism, ethno-symbolism and modernism. I reject an essentialist view of nation, the view that nations are natural categorizations of human beings and as such they have always existed (Fichte, 1986). I also reject the extreme constructivist position which states that nations are mere cultural and 
political inventions and fabrications (Gellner, 1983). I argue for a middle ground to suggest that although nations are social constructs, they are not built out of nothing; nations have historical and ethnic roots even if such roots are fictive (Smith, 1998, 1999). Without such roots, nations cannot resonate with people's memories and emotions and thus they cannot earn community members' allegiance. In line with this position, I distinguish between a nation-as-people and a nation-state to capture the critical stance that a nation as people can exist without a state or nation-state (Calhoun, 1993, pp. 220-21). ${ }^{17}$

Nationalism reconstructs and recreates desired nations. In connection to nations without states, the best typology of nationalism is majority versus minority nationalism. This categorization encapsulates the idea that minority nationalisms are social movements, reactions to the oppression of assimilationist and oppressive majority nationalisms or nation-state ideologies. To contest assimilation, minority nationalisms embark on creating and reproducing national identities. Minority nationalisms aim for two objectives. First, preserving and promoting cultural identities, and second earning the support of the masses in their efforts to achieve some sort of political autonomy either separate from or within the political boundaries of existing states. Given this objective of minority nationalisms, I suggest that discourses of minority nationalisms are involved in the creation of resistance national identity.

Defining and explicating national identity is the focus of Chapter Three. After defining identity as primarily "people's source of meaning and experience," I describe the following components of national identity: territory; past, present and future; national

\footnotetext{
${ }^{17}$ Calhoun (1993) suggests that recognizing a people without a state of its own but who aspires to statehood as a nation is an ideological stance which legitimates such a people's ambition for political autonomy and vice versa.
} 
symbols; and language. I argue that language, for stateless people such as the Welsh, the Catalan, the Quebecois, the Imazighen and the Kurds, is the most important ingredient of cultural identity, for at least two reasons. First, language is often the most salient identity marker that, on the one hand, indicates important similarities among people (e.g. speaking the same mother tongue), and on the other, differentiates one people or cultural group from others. Second, language use and discursive practices are means by which other components of national identity are constructed, reproduced and articulated. Without language, it is doubtful whether people could define themselves and relate to others (Billig, 1995; Joseph, 2004; Fishman, 1989).

In Chapter Four, the instrumentality of language in identity construction is illustrated with an extensive survey of several studies that have a discourse analytical orientation investigating discursive constructions of national identities (Billig, 1995; Bishop \& Jaworski, 2003; Higgins, 2004; Law, 2001; Sutherland, 2005; Wodak et al., 1999). Having an identity entails the ability to talk about it and articulate it in language and other semiosis (Billig, 1995, p. 5; Hall, 1992). Thus, the study of identity needs to involve the study of discourse. However, it is also underscored that identities are not exclusively discursive constructs. Identity does exist outside language and discourse, but it is constantly mediated through discourse.

The second part of the chapter illustrates the significance of communication technologies, from the printing press to the Internet, in the projects of identity construction. It is argued that in order to be effective and experienced, discursive constructs of identity need to be disseminated and negotiated among people and by people. Emphasis here is not only on the form of media (Deutsch, 1956; McLuhan, 1964; Anderson, 1991) but also their 
content, the linguistic and audio-visual constructions they articulate and disseminate (Billig, 1995; Law, 2001; Higgins, 2004).

The study's methodological approach, Critical Discourse Analysis, is defined and explained in Chapter Five (Fairclough \& Chouliaraki, 1999; Fairclough \& Wodak, 1997; Luke, 2002; Wodak \& Meyer, 2001). First, the usefulness of a discourse analytical approach to the study of national identities is established. Given the dynamism and intricacy of identity/discourse/media relationship, I argue that the discourse approach needs to be interdisciplinary and critical to account for contentions and contradictions embedded in the discourses of identities. Second, I explain key terms and notions in CDA such as critical, discourse, analysis, ideology and intertextuality. In the third part of the chapter, based on Fairclough (2001; 1995a), I present an analytical framework for analyzing communicative events mediated by media discourse. I conclude the chapter by suggesting that more studies such as this are needed, to apply CDA not only to dominant discourses and ideologies but also to discourses of resistance, identity construction and social movements (Martin, 2002; Luke, 2002; Wodak, 2006).

To define, describe and contextualize Kurdish identity, Chapter Six begins with a history of the Kurds, ancient and contemporary (McDowell, 2004; Hassanpour, 1992, 2003). This is followed by illustrating the diversification and fragmentation of Kurdish identities along political, cultural, territorial and linguistic lines. The chapter continues to examine Kurdish nationalism, its origins in the turn of the last century (Vali, 2003, 1998) and its failure to create a strong cross-border Kurdish identity. I discuss both external and internal barriers to the formation of a cross-border Kurdish identity, along with the consequences of this lack. Finally, it is suggested that in recent years a strong Kurdish 
cross-border identity has started to emerge. The chapter concludes with the question of why this trend has started to take place now, and whether this is connected to the use of satellite television and the Internet among the Kurds.

Possible answers to this puzzle are explored in Chapter Seven. Based on the assumption that mass media have been foundational to most, if not all, nation-building projects, I extrapolate why traditional media have not been able to fulfil their mission in the case of the Kurds, as they did in the case of many nations in the eighteenth century (Anderson, 1990). A brief history of Kurdish media is presented to illustrate why none of the press, radio or cable television has been able to become the Kurdish mass medium capable of creating a truly imagined Kurdish community. Finally, the history of Kurdish satellite television and Internet is presented partially in light of several studies that have been devoted either entirely or partially to these two Kurdish communication technologies (e.g. Erikson, 2007; Hassanpour, 1998, 2003a; Romano, 2002). The main objective here is to establish that, with the emergence of satellite television and Internet, the Kurds for the first time have started to communicate dialogically and spontaneously in unprecedented ways. It is further surmised that this change in communication among the Kurds cannot be without influence on the ways Kurdish identities are constructed.

The next three chapters (Eight, Nine, and Ten) are devoted to analyzing the national identity discourse of Kurdistan TV. In Chapter Eight, I present an overview of Kurdistan TV and the empirical data collected from the station, which consists of KTV programs recorded during a one-week period. After organizing the data into several categories, the types of programs that KTV broadcasts are identified. Then explanations are provided as to 
how such programs seem to contribute to the construction of Kurdish identities, particularly a cross-border or pan-Kurdish identity.

Textual and micro analysis of KTV discourse is carried out in Chapter Nine, with attention given to both verbal and visual languages of KTV. The aim of the analysis at this level is to map out the kind of discursive strategies and constructs that are used on KTV to produce, redefine and articulate various aspects of Kurdish identities: history, present and future projects, language, national symbols, and territory. These discursive strategies and constructs are further illustrated in Chapter Ten by the multi-modal and detailed analysis of a Kurdish patriotic song. The objective of this chapter is to show how the particular version of CDA employed can be used to conduct analyses of the main communicative modes of an audio-visual text such as a video clip. Power relations and ideological intentions invested in multi-mode texts are made transparent. The complexities of the ways ideological tensions are articulated in a single text are also shown.

Similar analyses of the discourses of Kurdish Internet are carried out in subsequent chapters. In Chapter Eleven, the Internet data collected for this study are presented. This is followed by a description of the Kurdish Internet constituents (i.e. webpages, chat rooms, blogs, forums and other social networking tools) and a discussion of the ways and the degree to which the Internet components used among the Kurds contribute to the construction of Kurdish identities. The content of these Internet components are the subject of detailed textual analysis in Chapter Twelve. The analyses consist of both linguistic and visual analysis in order to map out identity discursive constructs, on the one hand, and the kind of Kurdish identities they articulate, on the other. 
In Chapters Eight through Twelve, I look at who constructs Kurdish national identities on KTV and the Internet, and just how those technologies enable that construction. In the final chapter (Thirteen), the focus is on why these social actors are engaged in Kurdish identity construction at this point in time, and the possible implications. The results of the analyses at the discourse practices and textual analysis levels will be explained further, against the backdrop of the socio-cultural and political contexts within which the media discourses under investigation have been produced and consumed. This is followed by a summary of the overall findings of the study and a discussion of some of the implications of this dissertation for further studies of the interrelationship between collective identities, discourse, and communication technologies. 


\section{Chapter 2: Nation and Nationalism}

I start this chapter by looking at the origins of nation from three theoretical positions (primordialism, ethno-symbolism and modernism), I illustrate that none of these approaches alone is adequate to conceptualize the concept "nation-without-state," which is the focus of this study. For analytical purposes and in line with the focus of this study, I will distinguish between a nation without state, ethnic group, nation-state and state (Castells, 1999; Guibernau, 1999). In this section I establish the view that although nations are modern social constructs, they are not without historical and sometimes ancient roots even if such roots happen to be invented.

After establishing the argument that nation is a social and historical construct and that it can be distinguished from a state, I contend that nations are created by nationalism. Nationalism, however, is not one thing. Civic versus ethnic, political versus cultural and majority versus minority nationalism are only a few commonly discussed types of nationalism in the literature that I cover in this chapter. It is suggested that minority nationalism of a stateless people is both an ideology and a social movement aiming at national emancipation. Minority nationalism, similar to other nationalisms, can be cultural, political or a combination of both. However, whether to preserve the culture of a people or to mobilize masses in a political movement, minority nationalism's immediate and fundamental objective is the creation of a national identity. 


\section{Nation}

\section{Origins of the nation}

Hastings (1997), making references to Johnson's Dictionary of 1755, John Milton's appeal

to English parliament in the 1640s and Bacon's advice to Prince Charles in the 1620s, believes that the word "nation" with the meaning we associate with the word today goes back to the fourteenth century. According to Hastings, as early as the beginning of the fourteenth century, "Englishmen felt themselves to be a nation" (p. 15). Primordialists believe nations have existed from time immemorial. On the other hand, Hobsbawm (1990) believes that the modern meaning of nation started to be expressed by the word nation from the late eighteenth century when nations, from a modernist perspective, came into existence. ${ }^{18}$ In a similar vein, Gellner $(1983 ; 1997)$ believes that nation is an "invention" of nationalism, a modern phenomenon by most accounts. From this modernist perspective there is no nation without a state and no nation could have emerged prior to the emergence of nationalism in the late eighteenth century.

These contradictory views on the origins of the nation lead to various questions that have been discussed extensively in the literature: what is a nation? What are the origins of nation? Is there a difference between a nation and a nation-state? Can there be a nation without a state? If so, are we talking about a nation or an ethnic group? If we are talking about nations without states, what are the differences between an ethnic group or ethnic community and a nation? The various answers to these questions have commonly been clustered into three camps: primordialist, ethno-symbolist and modernist. I will briefly

\footnotetext{
${ }^{18}$ According to Smith (1998, p. 17), historians differ on when nationalism was born. While for Hans Kohn, the date is the English Revolution, for others it is the American Revolution. For Kedouri (1993), the date coincides with Fichte's address to the German Nation, but for the majority of historians the French Revolution, 1789, marks the "first full blown manifestation" of nationalism.
} 
discuss each approach and then arrive at a workable definition and understanding of the nation for this study.

\section{Nation as primordial}

Primordialists take an essentialist view on the origins and nature of nation although they may differ in their reasoning or degree of naturalizing the phenomenon. From this perspective, people are born into nations. Nations are "natural" social groupings based on the congruency of "blood, speech and custom" (Geertz, 1973, p. 259), and their existence predates the modern nation-state.

Primordialism, however, is not a unified single view but a cluster of positions. Among different perspectives, one can speak of "biological primordialism" as reflected in the writing of Pierre van den Berghe (1995) for whom nation is an extension of kinship, race and/or ethnic group all of which have a genetic basis. One interpretation of this, as presented by Smith (1998) is that "ethnicity or race cannot be invented or imagined out of nothing. It can be manipulated, used...but it must correlate with a pre-existing population ...Ethnicity is both primordial and instrumental" (p. 148-9, original emphasis). What van den Berghe seems to be overlooking is that over time kinship and biological connections become less important and possibly irrelevant to ethnicity due to ever-evolving social relations, such as intermarriage and immigration (Smith, 1998).

Joshua Fishman, who is said to hold a perennialist (Smith, 1998) or a "modern primordialist" view (Madianou, 2005, p. 9), suggests that,

ethnicity has always been experienced as a kinship phenomenon, a continuity within the self and within those who share an intergenerational link to common ancestors. Ethnicity is partly experienced as being 'bone of their bone, flesh of their flesh, and blood of their blood'. The human body itself is viewed as an expression of ethnicity and ethnicity is commonly felt to be the blood, bones and flesh. (as cited in Smith, 1998, p. 160, my emphasis) 
For Fishman, ethnicity is given and natural, but the nation is not. The nation is a historical formation. It is this position, not equating ethnicity with nationality, that distinguishes Fishman from those that advocate an essentialist and primordialist approach to nation.

Fishman is not alone in advocating a perennialist approach to the origins of nation. Walker Connor (1994) contends that a nation is "a group of people who feel that they are ancestrally related" (p. 202, my emphasis). He continues to say that nation "is the largest group that can command a person's loyalty because of felt kinship ties; it is, from this perspective, the fully extended family" (ibid. my emphasis). Prioritizing "kinship ties" in the formation of nation obviously suggests that nations of today are the ethnic groups of yesterday. In other words, ethnic groups become nations. Connor, however, is quick to note that not all ethnic groups can become nations overnight. He suggests that although "nearly all nations are the variegated offsprings of numerous ethnic strains ...the sentiment of ethnic solidarity does not by itself make a "nation"” (p. 162). For Connor, "while an ethnic group may, therefore, be other-defined, the nation must be self-defined" (p. 163). In other words, a nation comes into existence when an ethnic group or groups become selfconscious in the sense that they aspire to statehood and self-determination because they feel and believe themselves to be a nation.

The assertion that nations are extensions of ethnic communities and thus all nations have ethnic roots has been appropriated with a modernist twist by another approach, ethnosymbolism. Since this approach shares much of the criticism directed at Primordialism, and also to avoid repetition, I will provide a brief survey of these criticisms at the end of my discussion of ethno-symbolism. 


\section{Ethno-symbolism: Nation and ethnic roots}

The proposition that all nations have ethnic roots is also put forward by Smith $(1999,1998$, 1996,1991 ), the main proponent of ethno-symbolism. For Smith the nation is neither as natural and perennial as primordialists claim nor has it been fabricated without historical and cultural roots and ethnic connections as some modernists would have it. Whereas modernists like Hobsbawm (1990) dismiss the importance of ethnicity in the rise of nationalism, for Smith, nations have come about around "ethnic cores." According to Smith (1998), the 'creation' of national identities without ethnic bases is doomed to oblivion. Successful projects of 'nationhood' are based on 'rediscovering' and 'reappropriating' ethnic pasts to which people can connect and relate. This strong emphasis on ethnicity as a necessary root for all nations has placed Smith's ethno-symbolist view in the primordialist camp from the point of view of some scholars (Madianou, 2005, p. 9).

There are, however, a few important differences between the views of the primordialist camp and Smith's ethno-symbolism. First, whereas from a primordialist view the concepts nation and ethnicity often overlap, Smith distinguishes between the two. For Smith a nation is "a group of human beings, possessing common and distinctive elements of culture, a unified economic system, citizenship rights for all members, a sentiment of solidarity arising out of common experience, and occupying a common territory" (1998, p. 188). Ethnic groups ${ }^{19}$ do not meet a number of the identifying elements mentioned in this definition such as "a clearly delimited territory or 'homeland', a public culture, economic unity and legal rights and duties for everyone" (p. 196). According to Smith, nations are

\footnotetext{
${ }^{19}$ According to De Vos (1995), "There is as yet no acceptable single word in English for the phrase "ethnic group," no one word equivalent to "class," "caste," or "family" to describe a group self-consciously united around particular cultural traditions, although French anthropologists have suggested the word ethne for technical usage." (p. 18). "Ethne" is Greek originally and the plural form of "ethnos".
} 
different also from ethnic communities. Ethnic communities are "named human populations with shared ancestry myths, histories and cultures, having an association with a specific territory, and a sense of solidarity" (Smith, 1998, p. 191). What they lack, in comparison to nations, is a nationalist movement as an expression of their political aspirations for self-determination. ${ }^{20}$

Making the distinction between a nation and an ethnic group seems to be fundamental to Smith's theory, which posits that nations are formed on their ethnic roots. However, from a somewhat more critical point of view the distinction does not seem to be innocent:

The distinction between nation and mere ethnic group is precisely the attribution to the former of the right to an autonomous state, or at least an autonomy of some sort within the state. On such an account it doesn't matter whether the nation is an ethnic group that has proved its superiority in historical struggle (material or ideological), or a multi-ethnic population. (Calhoun, 1993, pp. 220-21)

To put this differently, recognizing a group of people as a nation is legitimizing their claim to political and cultural autonomy either in the form of an independent state or an autonomous entity within a state. In contrast, labeling a group of people "ethnic" could imply rejecting their claim to political rights (i.e. some form of self-rule). In line with Calhoun's argument, I will be conscious of my choice of word between nation and ethnic group.

Although all nations have ethnic roots, according to Smith $(1999,1996)$ not all ethnic groups become nations. Here Smith echoes Connor (1994), although his reasoning is different. According to Smith, nationalists cannot turn ethnic groups into nations whenever

\footnotetext{
20 "The distinction between nation and mere ethnic group is precisely the attribution to the former of the right to an autonomous state or at least an autonomy of some sort within the state. On such an account it doesn't matter whether the nation is an ethnic group that has proved its superiority in historical struggle (material or ideological), or a multi-ethnic population" (Calhoun, 1993, pp. 220-21).
} 
and wherever they please. The success of a nationalist project depends on several factors of which access to symbolic resources is the most important one. These resources are the memories of a golden age (e.g. memories of old dynasties and great rulers), ethnic election that is often religious (i.e. the belief that a people is the chosen one-e.g. Armenian or Jewish), and finally an ancestral homeland. The three ethno-symbolic resources, a golden age, ethnic election and an ancestral homeland are composed of the memories, myths, symbols and values that ethnic communities share. According to Smith (1999), the continuing power of these ethno-symbolic resources to a great extent has been the driving force behind the surge of minority nationalism in recent decades especially after the Cold War and the collapse of the Soviet Union (p. 19). Possessing a strong ethno-history is also essential to the existence of nations: "those nations that have a strong 'ethno-history' at their core, with resonant myths, memories, values and symbols, are more likely to endure and become viable political communities" (p. 191). It might be inferred from this that the stronger and richer the ethno-history of an ethnic community the more persistent and popular its nationalism.

According to Smith (1996), the existence of this ethno-history, however, will not tell us when a nationalist movement will take place, because the timing or the success of a nationalist movement depends on more than one factor. In addition to geo-political conditions, it depends on the presence of an active intelligentsia that can translate the ethno-historical resources and traditions (golden age, territory, language, nationalist symbols) into the discourse of modern nationalism. The success of the intelligentsia in turn largely depends on the effective utilization of cultural institutions such as schools and the media like newspapers and television (Smith, 1999, p. 593). For nationalist objectives of 
the intelligentsias of a nation without a state of its own, such as the Kurds, who do not exercise power over their own public education system, effective utilization of the media becomes of paramount importance.

One of the strongest criticisms of Smith's view comes from Gellner (1997), who argues that ethno-history and ethnic roots matter very little in the project of nation building: "Some nations have navels [ethnic roots], some achieve navels, some have navels thrust upon them. Those possessed of genuine ones are probably in a minority, but it matters little. It is the need for navels engendered by modernity that matters" (p. 101). As an example of nations without 'navels', Gellner speaks of Estonia and reports that prior to becoming a nation-state Estonians did not even have a name for themselves. They called themselves "people who work on the farm" (ibid.).

On the ethnic ties of the nation Smith also has been criticized for implying the naturalness of "ethnic conflict," something that has become an important part of the politics of the late $20^{\text {th }}$ and the beginning of the $21^{\text {st }}$ centuries. Madianou (2005), directing her criticism at the primordialists as well as Smith, contends that "Underlying the term ethnic conflict is the assumption that the causes of the conflict are based on ethnic differences. Consequently, conflicts are seen as inevitable since their causes lie in what are considered 'natural', and thus insurmountable, ethnic differences" (pp. 10-11). Viewing "ethnic conflicts" as being mostly rooted in the traditionalist nationalist discourse tends to "depoliticize" them and ignores the historical, social and economic factors that more often underlie these conflicts (Spencer \& Wollman, 2002, p. 29). In addition to instigating adverse political outcomes of this kind, such a view could also ascribe a negative trait to its 
advocates who seem to speak the language of the nationalists and thus become "complicit in the human suffering they legitimate" (Madianou, 2005, p. 11).

These criticisms are intriguing and for the most part legitimate; however, in fairness to Smith, one cannot help but realize that even the most "civic" nation, for example France, does have ethnic roots. Both during the Revolution and afterwards, French nationalism appealed to "'nos ancêtres les Gaulois' and a single French people" and the "suppression of regional languages in favour of Parisian French" (Smith, 1998, p. 126). Despite sharing some ideas and also criticisms with the primordialists, Smith most importantly differs from them in that he views both nation and nationalism as modern phenomena, an unmistakably modernist position.

\section{Modernism}

Although there is not a totally homogeneous modernist approach, there is a consensus among the proponents of this camp. They all agree that the nation is a product of modernity and its birth, marked by the French Republic or the American Declaration of Independence, goes back to the late eighteenth century. Modernists, however, differ on at least two issues: the reasons for the emergence of nations, and the ways the nation was built, invented or imagined. I will elaborate on some of the main approaches to these concerns: the statist view of nation, Gellner's socio-cultural approach and Anderson and Hobsbawm's constructivist views. I will point out the limits of a statist view towards nation and the fact that it does not help our understanding of the nations without state. The approaches of the latter three scholars are important for this study because they emphasize the cultural dimensions of nation. Furthermore, since both Hobsbawm and Anderson have taken a social constructivist view of nation, an exploration into their theories should provide an 
informative background for my later discussion of the discursive construction of national identities.

\section{Nation and state}

One modernist version that is in sharp contrast to primordialism can be called the "statist" view, the view that there can be no nation without a state (an independent political entity). Anthony Giddens' definition of nation is an example of this view. To Giddens, a nation is "a collectivity existing within a clearly demarcated territory, which is subject to a unitary administration, reflexively monitored both by the internal state apparatus and those of other states" (as cited in Smith, 1998, p. 71, my emphasis). According to this "statist" definition, a "nation" exists only in connection to a state of its own. ${ }^{21}$ As such, neither Quebec in Canada, nor Catalonia in Spain or Kurdistan in Iraq could be referred to as a nation. ${ }^{22}$ There are important implications of such a position because it has been used to deny nationhood and political sovereignty to any group of people which has not had a history of political independence, for example Wales (Williams, 1999). I will elaborate these implications.

Several problems can be identified with the "state-based" explanation of nation. First, as Smith (1998) observes, "limitations of state-centred views is their ethnocentric, that is, western European, bias" (p. 74) because this viewpoint is based on the Western Europe experience of nation-building where for the most part states became nation-states, or to put it differently, nation-states were built on existing states (i.e. kingdoms). A view of

\footnotetext{
${ }^{21}$ The roots of this approach can be traced back to Hegel who believed that the history of a nation only begins with the establishment of its state.

${ }^{22}$ One option here would be to refer to these peoples as "ethnic communities." But, if we do that, then we are not able to distinguish these "ethnic communities" from other communities or "ethnic groups" who do posses distinct ethnic characteristics but do not necessarily have nationalist claims to political institutions or territorial sovereignty where they live, for example Chinese or Persians in Toronto.
} 
nation-building based on these examples is ethnocentric because it over-generalizes this European experience to other parts of the world (e.g. Eastern Europe and Asia) where nationhood has been experienced differently, i.e. nations without states ${ }^{23}$ became nationstates (Smith, 1998).

Another powerful argument that, so to speak, turns the statist view on its head is put forward by Williams (1999). In her discussion of the need for the recognition of Europe's national minority rights in the context of the new European Union, Williams criticizes those who deny a people the right to self-rule on the basis of not experiencing the right (i.e. the right to statehood) previously. She argues that to pronounce that no people should have the right to nationhood unless they have had a history of statehood (i.e. a history of political independence) for example Wales, is similar to saying that a slave should not have the right to freedom on the grounds that she/he has never experienced freedom before (p. 12). Although the analogy pertains to individuals, there is no good reason why it should not also apply to collective groups. It follows that a minority group which reaches the maturity and self-consciousness to call itself a nation in the sense of a people and thus make claims to distinct cultural or political identities should be respected in a similar way to those nations who have enjoyed such rights for decades or centuries as nation-states.

Finally, reducing the nation to a political entity and ignoring nation's cultural aspects cannot answer the question that has motivated so many scholars to investigate nation and nationalism in the first place: why are so many people willing to die and even

\footnotetext{
${ }^{23}$ Nations without states or stateless nations are defined as "territories in which identification with the nation is greater than that with the state of which they are currently a part" (McCrone, as cited in Law, 2001, p. 315). However, as Law points out England is not a stateless nation although the nation-state it belongs to is called Britain and not England. Thus, one can add to the above definition that the stateless nation is not the dominant but the dominated nation within the state it is located.
} 
kill in the name of the nation? As Anderson (1991) tells us, it cannot be because of “...market zones, 'natural'-geographic or politico-administrative" reasons since these "do not create attachments." He promptly asks: "Who will willingly die for Comecon or the EEC?" (1991, p. 53). Of course he implies that no one will and I think he is correct. However, people might be, and they have been, willing to die for those things to which they feel attached and belong, such as culture (Castells, 1997, p. 29). Culture, it has been suggested, is not just a set of shared meanings, understandings and doings but also something that is worth fighting for (ibid.).

\section{Nation and culture}

One can suggest that while all modernist approaches subscribe to the statist view, they differ in their emphasis on the importance of culture in the building and maintaining the nation. For example, although Gellner has been labeled a statist, and rightly so, because he believes that one state meant one culture and one nation (Kennedy, 2004, p. 500), he underscores the significance of culture in the nation-building project. Gellner believes that modern men and women's loyalty to culture outweighs all other loyalties: "modern man [sic] is not loyal to a monarch or a land or a faith, whatever he may say, but to a culture" (1983, p. 36). Discussion of culture is important also because along with "a set of beliefs... a national culture, common to and shared by all members of the nation" forms "the basis of a given national identity" (Spencer \& Wollman, 2002, p. 69). Two other modernists, Benedict Anderson and Eric Hobsbawm, among others, have highlighted the significance of culture and cultural artefacts in the processes and practices of nation building and national identity formation. 


\section{Nation as a socio-cultural invention}

Gellner contends that nation is an invention of nationalism $(1997,1983,1981)$ and both phenomena are clearly modern. His approach is in a sharp contrast to primordialism as is evident in the following quotation:

Nations as a natural, God-given way of classifying men, as an inherent though longdelayed political destiny, are a myth; nationalism, which sometimes takes preexisting cultures and turns them into nations, sometimes invents them, and often obliterates pre-existing cultures: that is a reality, for better or worse, and in general an inescapable one. (Gellner, 1983, pp. 48-9)

In Gellner's approach, a nation is conceptualized in terms of a single and unified "high culture" the existence of which enables effective communication in a standard language among groups of people from different socioeconomic backgrounds. A "high culture" is defined as a "literate and training-sustained" culture (Gellner, 1983, p. 38) and its engendering and maintaining depends on state-run education.

Without education through which literacy can be taught in a common language, there can be no high culture, as perceived by Gellner. He contrasts a "high culture" with an "uncultivated culture." An "uncultivated culture" belongs to oral and traditional societies which reproduce themselves from one generation to the next. A "high culture," on the other hand, "possesses a complexity and richness, most usually sustained by literacy and by specialized personnel, and would perish if deprived of [its] distinctive nourishment in the form of specialized institutions of learning..." (p. 50). ${ }^{24}$ Belonging to a high culture, in which modern men and women are taught the same language, "becomes the core of one's identity" (p. 61). Thus, a high culture, according to Gellner, among other things, means a

\footnotetext{
${ }^{24}$ In a similar vein, Hastings (1997) suggests that "oral languages are proper to ethnicities; widely written vernaculars to nations" (p. 21). Hastings believes that once a language is written down and is used in legal, religious and educational domains it becomes more stable, less changing and enjoys uniformity. The existence of a nation is invested in fundamental ways in uniformity.
} 
standardized language that holds a community together not because language might be an index of ethnicity but because a standard language among a community facilitates distant and context-free communication (p. 43). Thus, in the modern world there is the need for both literacy and linguistic unity.

Despite the fact that Gellner's approach has been highly praised and well respected in the literature, it has not been without criticism. First, as Smith (1998) points out, if nationalism creates the nation, and if the nation is represented by the state, how can the state, which has not yet emerged, be responsible for a public education that is said to engender a high culture/nation? Put differently, a public system education cannot be run by a nation-state that has not come to existence yet. Thus, it appears that "mass education systems and their values are the product, not the cause, of the nationalist movement once it has come to power" (Smith, 1998, p. 39). ${ }^{25}$

Second, and still on the issue of education, one could suggest that although education is very important in creating national identities it could not alone explain a people's loyalty to a nation-state (Smith, 1998). Many state-run education systems that have aimed at cultural homogenization through assimilating ethnic groups within a single nation-state have failed. A clear example of this is Turkey and its attempt to "acculturate" its Kurdish minority. From its early establishment in 1923, the modern Turkish state banned the use of Kurdish language in public, and all Kurds were sent to Turkish-only medium schools. After about six decades, in most urban centres, the majority of Kurds

\footnotetext{
${ }^{25}$ A nationalist movement, for Gellner, "is one actuated by a sentiment of [nationalist] kind... Nationalist sentiment is the feeling of anger aroused by the violation of the principle [of nationalism], or the feeling of satisfaction aroused by its fulfillment" $(1983$, p. 1$)$.
} 
forgot their mother tongue, but that did not stop the re-emergence of their nationalist movement starting in the mid-1980s (White, 2000). ${ }^{26}$

Third, Gellner's assertion that nationalism and by extension the nation are products of industrialism has been criticized on two grounds. For one thing national movements predate industrialism and "high culture" (Smith, 1998, p. 37; Spencer \& Wollman, 2002, p. 35; Guibernau, 1996, pp. 77-8; Hastings, 1997, p. 12; Hroch, 1996, p. 85). There are instances in history, for example the Greek independence, where the emergence of nationalist movements did not await the arrival of industrialism, (Hall, 2006, p. 37). Hastings (1997) also talks about fourteenth-century nationalism in Scotland and locates the emergence of first nations, such as England, in the medieval era (pp. 9-112). ${ }^{27}$

Fourth, many have criticised Gellner's linking of the emergence of nation to industrialism (Smith, 1998; Guibernau, 1996; Spencer \& Wollman, 2002). As Smith (1998) points out "nationalisms emerge in all kinds of socioeconomic settings and social systems" (p. 37) and not just in an industrial (Gellner, 1983) or capitalist (Anderson, 1991;

Hobsbawm, 1990) system. In many non-Western parts of the world, nationalism and even the modern nation-states have emerged where sometimes there have been a few if any signs of modernity, industrialism or capitalism (Guibernau, 1996, p. 77). In fairness to Gellner, however, one should note that he has not totally ruled out the existence of national sentiments prior to modernity:

It is not denied that one may on occasion have an overlay of pre-industrial structures and nation sentiment. A tribal nation may for a time be tribal internally and national

\footnotetext{
${ }^{26} \mathrm{I}$ lived in Turkey from mid 1986 until February 1988.

${ }^{27}$ For Hastings (1997), "A nation is a far more self-conscious community than an ethnicity. Formed from one or more ethnicities, and normally identified by a literature of its own, it possesses or claims the right to political identity and autonomy as a people, together with the control of specific territory, comparable to that of biblical Israel and of other independent entities in a world thought of as one of nation-states" (p. 3).
} 
externally. It is in fact easy to think of one or two marked cases of this kind (for example, Somalis and Kurds). (1983, p. 138)

By acknowledging that "nation sentiment" might exist in pre-industrial societies, Gellner reiterates his position on validating the place of culture in the projects of nation building even in the context of what he calls a "tribal nation."

\section{Nation as invented traditions}

Similar to Gellner, Hobsbawm $(1990,1988)$ argues that nations are products and inventions of nationalism, and in this inventing process he emphasizes the important position of cultural artifacts and traditions. According to Hobsbawm (1988), nations are, among other things, a collection of "invented traditions." By invented traditions, he means "a set of practices, normally governed by overtly or tacitly accepted rules and of a ritual or symbolic nature, which seek to inculcate values and norms of behaviour by repetition, which automatically implies continuity with the past" (p. 1). These traditions could be recent inventions, but it is the nationalist discourse that presents them as ancient and deeply rooted in the history of a people.

As Hobsbawm (1988) contends, "'[t]raditions which appear to claim to be old are often quite recent in origin and sometimes invented" (p. 1). Striking examples of these invented traditions that pretend to a strong link to the past are "the deliberate choice of a Gothic style for the nineteenth-century rebuilding of the British parliament, and the equally deliberate decision after World War II to rebuild the parliamentary chamber on exactly the same basic plan as before" (Hobsbawm, 1988, p. 1-2). Invented traditions encompass "signs of group membership" that are "emotionally and symbolically charged...such as flags and anthems" (Smith, 1998, p. 119, my emphasis). I will say more about these symbols when discussing components of national identity. 
At this point, however, it should be emphasized that invented traditions need to be linked to the past, even if such links are fictive. Further, entrenching these links depend largely on re-presenting and repeating the signs, symbols, rituals and practices that make up the traditions. According to Hobsbawm, "all invented traditions, so far as possible, use history as a legitimator of action and cement of group cohesion...even revolutionary movements [back] their innovations by reference to a 'people's past"' (Hobsbawm, 1988, pp. 12-13). Thus, inventing traditions is not unique to the nation-building experiences of Europe in the late eighteenth century. The elites and intellectuals of stateless people engage in similar practices. Cultural traditions and national symbols, as observed by Hobsbawm, engender social cohesion and an emotionally charged community membership.

Hobsbawm has been criticized for viewing nations as "invented traditions" for several reasons (Calhoun, 1994, p. 14; see also Hutchinson, 1999). Calhoun perceives Hobsbawm's theorization as an attack on essentialist, primordialist and nationalist views which perceive the nation to be ancient, natural and everlasting. Although criticizing an essentialist view of nation is quite valid, and in fact necessary, Calhoun warns that there might be risks in an extreme "social constructionist" view of identity, including national identity:

There is some risk, though, that simply showing a process of construction fails to grapple with the real, present day political and other reasons why essentialist identities continue to be invoked and often deeply felt. There is also risk that the "social construction" story will become a social determinism, too easily paired with an overly fixed "essentialist" notion of society or culture. (1994, p. 14)

Similar to Calhoun, Smith (1998) disapproves of an extreme social constructionist view, and advocates a middle ground, between an essentialist and a constructivist view. Smith argues that the nation could not have been a total invention, because in order for a 
nationalist discourse to be able to strike a chord with a people it must resonate with them, with the myths, symbols and cultural values that are familiar to them. If not, and if all the national traditions, practices, symbols and ceremonies are only inventions, one has to wonder how nationalist discourses manage to appeal to the sentiments of their followers and compel them even to sacrifice their lives in the name of the nation. Smith (1998) supports Calhoun's point by saying:

In arguing against social constructionism and invention as valid categories of explanation, I do not mean to deny the many instances of attempted 'construction' and 'fabrication'. My point is only that, to be successful, these attempts need to base themselves on relevant pre-existing social and cultural networks" (p. 130).

From a social constructionist view, including Hobsbawm's, two responses can be given here. First, most theorists who take a social constructivist view on national identity do not deny the suggestion that traditions, symbols and cultural/national signs and practices have to have connections to the past, even if such connections are invented. Another socialconstructivist response would be to say that simply because national symbols and traditions are invented it does not mean that they cannot have powerful effects. Neal Ascherson elaborates on this eloquently,

To demonstrate that traditions are wrong or invented does not put an end to this story. A claim to national independence does not fall simply because its legitimizing version of national history is partly or wholly untrue - as it often is. The sense of belonging to a distinct cultural tradition, or 'ethnic identity', can be subjectively real to the point at which it becomes an objective social-political fact, no matter what fibs are used for its decoration. (as cited in Spenser \& Wollman, 2002, p. 82)

In addition to having links to the past, invented traditions also need to be represented and repeated as often as possible in order for them to become indispensable parts of a collective identity. It is the power of these re-presentations of messages and images that in prevailing ways could facilitate the imagining of a community of sentiments. The 
repeatability of national traditions and symbols are crucial for it "stabilizes and reifies national identity as both singularly novel and reassuringly the same" (Law, 2001, p. 301). Landscapes, monuments, artists, school curriculum and media products are all means of repeating and continuous reinforcement of these signs and symbols.

This task of repeating and reinforcing traditions and symbols is mostly carried out by media among the stateless people since these people have no or limited access to other means of disseminating and repeating signs and images of traditions. ${ }^{28}$ I will have more to say about the place of communication technologies in the processes of nation-building among the stateless people in this chapter, but at this point it is important to turn to another theorist, Benedict Anderson, who has not only made arguably the strongest case for the decisive role of communication technologies in the emergence of nation-states, but who invites researchers to see both nation and nationalism as cultural artifacts (1991, p. 4).

\section{Nation as an imagined community}

For Anderson (1991), the nation "is an imagined political community—and imagined as both inherently limited and sovereign" (p. 6). In this statement, which is arguably one of the most quoted phrases in the literature on nation and nationalism, several keywords beg elaboration: imagined, community, limited and sovereign. According to Anderson, the nation is "imagined because the members of even the smallest nation will never know most of their fellow-members, meet them, or even hear of them, yet in the minds of each lives the image of their communion" (p. 6). In other words, whereas in the "primordial villages of face-to-face contact" people constantly see and communicate with each other, in the

\footnotetext{
${ }^{28}$ Among other effective means of disseminating and repeating these signs and images of traditions one can think of holding ceremonies in public or the school curriculum. Stateless people may not have the freedom to do the former and not the power to be in control of their schooling. Kurds in Turkey, for example, are clear examples of this.
} 
larger community of nation most people do not know each other personally yet they share sentiments, symbols and beliefs as a single community. The use of the term "imagined," has been criticized on semantic grounds. Smith (1998) suggests that the term is illusory and could easily imply "illusion" or "fabricated," and "as such, the nation possesses no reality independent of its images and representations" (p. 137). Anderson, however, is well aware of this semantic implication. He stresses that in relation to his definition, imagination does not mean "fabrication" or the opposite of "true." In fact, he criticizes both Gellner and Hobsbawm, who suggest that the nation is an "invention" of nationalism which, according to Anderson, could imply "fabrication" and "falsity" (p. 6). ${ }^{29}$

Can we call any imagined community a nation? The simple answer, according to Anderson, is no. According to Anderson, any community larger than a "primordial village" is imagined for the same reason just explained, but it is the manner in which communities are imagined that distinguishes them. The nation is imagined as limited, sovereign, and a community. It "is limited because even the largest of them, encompassing perhaps a billion living human beings, has finite, if elastic, boundaries, beyond which lie other nations" ( $p$. 7). Smith (1998) puts the very same idea differently: "The nation is spatially finite category, a nation among nations, each defined in the first place by a set of clearcut and internationally recognized borders" (p. 95).

In order to distinguish the nation from other imagined communities, one also has to realize that "it is imagined as sovereign" that which denotes freedom and "selfdetermination." According to Anderson, sovereignty was established as a crucial criterion for a nation at the dawn of modernity "because the concept was born in an age in which

\footnotetext{
${ }^{29}$ Gellner has famously declared that "Nationalism is not the awakening of nations to self-consciousness: it invents nations where they do not exist" (As cited in Anderson, 1991, p. 6, emphasis in original).
} 
Enlightenment and Revolution were destroying the legitimacy of divinely-ordained, hierarchical dynastic realm [and]...nations dream of being free... The gage and emblem of this freedom is the sovereign state" (p. 7). The sovereignty of such a state no longer resides with the monarch, but rather with the people.

Finally, the nation "is imagined as a community, because, regardless of the actual inequality and exploitation that may prevail in each, the nation is always conceived as a deep, horizontal comradeship" (p. 7). The belonging is not vertical-not between the monarch and the people, or a loyalty from below—but a sentiment and a sense of comradeship across the community. It is this comradeship, for Anderson, that has compelled millions of people "not so much to kill, as willingly to die for such limited imaginings" (p. 7). ${ }^{30}$ This horizontal comradeship was also fostered by using one single language in which both the elite and the common people simultaneously read the same novels and newspapers. In this sense, the nation was imagined through print.

Whereas Gellner situates the origin of nation in its functionality and necessity for the industrial society, Anderson ([1983] 1991) sees the emergence of the national culture as an alternative to the religious culture. According to him, in the second half of the $18^{\text {th }}$ century, first in Western Europe and then elsewhere, when people lost confidence in three "links of certainty," and "all of great antiquity," Latin, monarchy, and the conception of temporality, ${ }^{31}$ they started to look "for a new way of linking fraternity, power and time

\footnotetext{
${ }^{30}$ By saying that "nationalism" is more about "willing to die" than "to kill," Anderson has been criticized for almost downplaying the number of deaths and destruction that nationalism has brought to the world (Balakrishnan, 1996, p. 207; Spencer \& Wollman, 2002, p. 40).

${ }^{31}$ Latin represented the script-language that is believed to offer "privileged access to ontological truth, precisely because it was an inseparable part of that truth" (p. 36). Latin lost its sacredness with the emergence of the vernaculars as the print-languages. Monarchs were perceived as the natural high centres of society, "who were person apart from other human beings and who ruled by some form of cosmological (divine) dispensation" (p. 36). This "natural rule" of the monarchy was declined after the French Revolution. Finally,
} 
meaningfully together" (Anderson, 1991, p. 36). This is when print presented itself as the best alternative making it "possible for rapidly growing numbers of people to think about themselves, and to relate themselves to others, in profoundly new ways" (p. 36). The two most widespread products of print, the novel and newspaper, "provided the technical and discursive means for 're-presenting' the kind of imagined community that is the nation" ( $p$. 25).

Printing in vernaculars, according to Anderson (1991), "laid the bases for national consciousnesses" (p. 43). "Print-languages" contributed to the standardization of the vernaculars so they furnished new ways of communication not only apart from Latin but also different from and above the spoken language. This also contributed to the stability and durability of the languages, something that "helped to build that image of antiquity so central to the subjective idea of the nation" (pp. 44). Finally, print-languages created "languages-of-power" which refers to the languages that often belonged to economically and socially powerful centres such as Paris and London. These languages became the language of the centre and administration often, although not necessarily deliberately, at the expense of minority languages (Billig, 1995, p. 27; Dalby, 2002, pp. 133-5; Kilborn, 1993, p. 641).

Thus, for Anderson, the nation was imagined through print-languages. The following quote from Anderson (1991) provides a clear explanation of that assertion:

Speakers of the huge variety of Frenches, Englishes, or Spanishes, who might find it difficult or even impossible to understand one another in conversation, became capable of comprehending one another via print and paper. In the process, they have

the significance of the conception of temporality is that for the mediaeval people "cosmology and history were indistinguishable, the origins of the world and of men essentially identical" (p. 36). In other words, it was the "Messianic time, a simultaneity of past and future in an instantaneous present" in which the word "meanwhile" had no meaning or significance (p. 24). 
gradually became aware of the hundreds of thousands, even millions, of people in their particular language-field, and at the same time that only those hundreds of thousands, or millions, so belonged. These fellow-readers, to whom they were connected through print, formed, in their secular, particular, visible invisibility, the embryo of the national imagined community. (p. 44)

In other words, communicating in the same code, the same language, enabled a national community to bond and develop a sense of belonging among its members albeit from different regions with different speech varieties. ${ }^{32}$ In this sense, print-languages gave birth to a feeling of immortality and fraternity among the members of a collective community.

Anderson, similar to Gellner, recognizes the importance of communicating in a unified and standardized language. However, whereas in Gellner's account it is engendered by the educational system, which is controlled by the state, in Anderson's a standardized language is a product of print technology. In this sense, while for Anderson the comradeship is horizontal, that is, among members of the community, for Gellner it seems to be vertical, that is, top down and imposed on its subjects by the sovereign. One can suggest that while Anderson's conceptualization of the nation is democratic, it does not appear to be the case with Gellner's.

On the issue of language, Anderson and Gellner further differ in that they have different reasons for emphasizing its importance in nationalism. For Anderson, standard languages pave the way for the consumption of the same print materials, for example reading the same newspaper across a territory, but for Gellner the unified language is essential for production in general and not just that of the printed matters. Furthermore, in Anderson's account, "capitalism contributed to the creation of nationalism through its

\footnotetext{
${ }^{32}$ The use of the term "speech variety" instead of "dialect" is intentional, because I find the term "dialect" which is often used in contrast to the term "language" politically charged.
} 
desire to increase consumption [of printed books]," whereas for Gellner, "capitalism contributed to the creation of nationalism in its drive to increase production" (Ockey, 2001, p. 63). Capitalism is the drive in both approaches, but whereas furthering capitalism, or as Gellner prefers to call it industrialism, is the result for Gellner, in Anderson's approach the result is engendering cultural artefacts. I will elaborate on the place of print media in Anderson's approach later on when discussing the relationship between media and nationalism. At this point let us turn to more critical evaluation of Anderson's ideas.

Anderson's conceptualization of the nation has not been without criticism (see for example, Balakrishnan, 1996, pp. 203-212; Smith, 1998, pp. 131-142; Guibernau, 1996, p. 66-67; Spencer \& Wollman, 2002, pp. 37-40; Wogan, 2001). The first major criticism relates to Anderson's emphasis on print technology for which he has been called a "technological determinist." Although Anderson contends that the nation is imagined in print-language, he does not overlook the economic (e.g. progress of capitalism) and social (people's losing faith in monarchy and longing for horizontal comradeship rather than a top down one) factors that are at play along with the print media. Thus, accusing Anderson of being a "technological determinist" is to a large extent unfair.

In a similar vein and again related to the power Anderson sees in print media, he has been criticized for overlooking other means of communication influencing the nationbuilding project:

the view of the nation as primarily a text and discourse inevitably suggests a leading causal role for print technology and print-capitalism, one which leaves little room for other modes of cultural representation and omits other vital factors in the rise of nations and the spread of nationalism. (Smith, 1998, p. 138)

\footnotetext{
${ }^{33}$ Technological determinism is referred to the view that a technology on its own can be the cause of social change apart from social, economic, political or institutional workings of that technology.
} 
Among other means of communication, some of which pre-date print, one can think of songs, folktales, plays and other cultural symbols and values. As Smith (1998) points out, when Italians fought in the Risorgimento wars, people joined nationalist movements, not because of being able to read, but because of being mobilized in whatever way possible for the nationalists. This could be songs, symbols, images, reports and rituals, all of which could be in oral form rather than print (p. 39). This is a very crucial observation regarding creating and reproducing national and ethnic identities particularly in the age of satellite television and the Internet to which I will return later in this chapter. On the issue of language as well I will have more to say when I discuss it as one of the main components of national identity.

To sum up this section, it is clear that the modernist approaches to nation have undoubtedly presented some of the most plausible explanations about the origins of nation and the practices that go into their creation and maintenance. The modernists' strongest point, as far as this study is concerned, is the assertion that nations are not given; they are social and historical constructs, and in significant ways these constructions are discursive and symbolic. However, it is my position that a modernist approach no matter how sophisticated will not do justice to conceptualizing the emergence and existence of stateless people, because the modernist approaches, especially those presented in this review, are only based on the experiences of the first nation-states that began to emerge in the late eighteenth century in Europe. Thus, it is my intension to take the liberty of drawing upon all the approaches I have discussed here (primordialist, ethno-symbolist and modernist) in addition to other approaches that have specifically focused on nations without states 
(Guibernau, 1999, 1996; Castells, 1997) in order to arrive at an adequate theoretical position on national identity construction in the context of stateless nations.

\section{An alternative perspective: Nations without state}

What is a nation? Here, I am adopting a definition midway between the extreme modernist and primordialist positions. Following Guibernau (1996), I understand a nation as "a human group conscious of forming a community, sharing a common culture, attached to a clearly demarcated territory, having a common past and a common project for the future and claiming the right to rule itself" (p. 47). This conceptualization of nation, on the one hand, refutes an essentialist view of the nation as a natural and perennial entity, and on the other, it acknowledges that a nation can exist without a state.

As Castells suggests, "nations are, historically and analytically, entities independent from the state" (Castells, 1997, p. 30; see also Billig, 1995, pp. 24-26). Thus, here "nation" and "nation-state" are understood as being different. A nation-state is

a modern phenomenon, characterized by the formation of a kind of state which has the monopoly of what it claims to be the legitimate use of force within a demarcated territory and seeks to unite the people subjected to its rule by means of homogenization, creating a common culture, symbols, values, reviving traditions and myths of origin, and sometimes inventing them. (Guibernau, 1996, p. 47)

Whatever the definition of the nation, almost all theorists consider the nation-state a modern phenomenon. Then one might ask: how does a nation-state differ from a nation?

Guibernau makes the following useful distinction:

The main differences between a nation and a nation-state ... are that, while the members of a nation are conscious of forming a community, the nation-state seeks to create a nation and develop a sense of community stemming from it. While the nation has a common culture, values and symbols, the nation-state has as an objective the creation of a common culture, symbols and values. (p. 47, my emphasis) 
From this perspective it is conceivable to talk about those nations without state that along with their nationalism, as Castells observes, "did not reach modern nation-statehood (for example, Scotland, Catalonia, Quebec, Kurdistan, Palestine), and yet they display, and some have displayed for several centuries, a strong cultural/territorial identity that expresses itself as a national character" (1997, p. 29-30).

In addition to differentiating the nation and the nation-state, one also needs to distinguish between a nation and an ethnic group. Having touched on this in my discussion of Smith's ethno-symbolism, I will only reiterate that when a group of people is called an "ethnic group," it is implied that they should stay within a nation-state without having rights to political autonomy, but calling a group of people a "nation" acknowledges their rights to rule themselves culturally and politically (Calhoun, 1993, pp. 220-21; see also Billig, 1995, p. 63). The labelling or naming of concepts, people or places is not neutral; it is the expression and reinforcement of an ideological position which shows the speaker's stance on a social or political issue (Fowler \& Kress, 1993, pp. 200-201), for example whether a group of people should have the right to self-rule or not. It seems more democratic to side with the wish of the people rather than imposing an identity on them they cannot or do not want to identify with especially in those cases where the rights of such a group of people have not been recognized within a state even at a cultural and linguistic level let alone political, as it is the case with the majority of the Kurds. A nation might consist of one ethnic group or of a multi-ethnic population that collectively aspires to the same nationalist goal of achieving political and cultural rights. This is particularly true of nations without states. Schlesinger (1991), suggests that "...the stateless nation is judged to be of special significance as a prototype of potentially innovative forms of post-nation- 
state affiliation, as an exemplar of flexible networking, and as offering multiple identities and allegiances to its inhabitants" (p. 267).

These submissions are meant to clarify my own position as far as the use of terminologies (nation, ethnic group, nation-state, nation without state) and the scope of their meanings is concerned. The aim is not to bring about a convergence between the farthest sides of the debate on the origins and nature of nation (i.e. the primordialist and modernist views). Although this seems to be a noble goal and deemed necessary by some scholars (e.g. Smith, 1998; Fishman, 2002), it is certainly beyond the scope and focus of this study. Nonetheless, most scholars in the two camps, and in-between, seem to agree on one important point: the discourses of all nations are inhabited by nationalism ideologies. Thus, understanding nationalism should tell a great deal about nations and national identities.

\section{Nationalism}

There is really no consensus on the definition of nationalism. A quick look at the labels that theorists have chosen for the phenomenon testifies to this: "a common bond of sentiment..." (Weber, as cited in Smith, 1983, p. 174), a set of "sentiments..." (Guibernau, 1996, p. 47), "a state of mind..." (Hans Kohn, as cited in Smith, 1983, p. 174), "a form of collective consciousness" (Habermas, as cited in Poster, 1999, p. 237), "a political principle..." (Gellner, 1983, p. 1), a "political movement..." (John Breuilly, as cited in Smith, 1998, p. 84), "a theory and practice ..." (Hastings, 1997, p. 3), "a doctrine..."

\footnotetext{
34 "Nationalism is a form of collective consciousness which both presupposes a reflective appropriation of cultural traditions that ... spreads only via channels of modern mass communication ... [This lends] nationalism the artificial traits of something that is to a certain extent a construct, thus rendering it by definition susceptible to manipulative misuse by political elites" (Habermas, as cited in Poster, 1999, p. 237).
} 
(Kedouri, 1993, p. 9), and finally "a way of thinking, an ideological consciousness" (Billig, 1995, p. 10) or in Collins' (1991) words “a belief system or ideology” (p. 11).

According to Hall (1993), it should not be surprising that definitions of nationalism can vary so much, because "[a]s the historical record is diverse, so too must be our concepts" (p. 1). This, however, should not mean that we should be satisfied with its various localized conceptualizations and can do without a comprehensive and general theory of nationalism: "To the contrary, middle ground can be cultivated by delineating various ideal types of nationalism ..." (ibid.). Therefore, before presenting and elaborating on the definition of nationalism that has been adopted for this study, I find it helpful to outline some categorizations of nationalism that are commonly entertained in the literature and which are relevant to this study.

\section{Ethnic vs. Civic Nationalism}

Ethnic nationalism opens membership in a nation only to those who belong ethnically, for example linguistically or racially. ${ }^{35}$ Ethnic nationalism is said to be exclusive, emotional, and irrational. The first home for ethnic nationalism is believed to be Germany where the

Romantics such as Herder and Fichte

argued that it was not the state that created the nation, as the Enlightenment believed, but the nation, its people, that created the state. What gave unity to the nation, what made it a home, a place of passionate attachment, was not the cold contrivance of shared rights but the people's preexisting ethnic characteristics: their language, religion, customs, and traditions. (Ignatieff, 1993, p. 7)

\footnotetext{
${ }^{35}$ The origin of this classification (civic vs. ethnic nationalism) is rooted in Hans Kohn's work (1945) in which he distinguished between a Western (political, e.g. American) nationalism and an Eastern nationalism-East of Rhein-("genealogical-organic", e.g. Germany). Hobsbawm (1991) distinguishes between civic and ethno-linguistic (after 1914) kinds of nationalism. Whereas the former is recognized as the political force behind the modern and progressive nation building project, the latter is viewed as destructive and unproductive. Roger Brubaker (1992) labels the same conceptualization of civic versus ethnic nationalism, made, for example, by Smith and Ignatieff, as the 'state-centred and assimilationist' and the 'ethno-cultural and differentialist' nationalisms respectively (as cited in Zimmer, 2003, p. 3).
} 
According to Smith (1998), ethnic nationalism has been the most common type of nationalism around the world (p. 213).

Conversely, civic nationalism is said to be rational, inclusive and integrative.

Within one territory and under the same political unit (i.e. state), civic nationalism accepts everyone who want to join the community voluntarily regardless of their ethnic characteristics (e.g. language, race, religion) (Hargreaves, 1992, p. 569). This nationalism has been labeled civic, according to Ignatieff (1993), because "it envisages the nation as a community of equal, rights-bearing citizens, united in patriotic attachment to a shared set of political practices and values. Most scholars, who suggest this distinction between civic and ethnic nationalism, view the French Revolution as the prime example of civic type of nationalism. This type of nationalism is said to be dominant also in countries like Britain, the United States, Canada and Australia.

This typological approach to nationalism, however, has been viewed problematic on several grounds (Hargreaves, 1998; Smith, 1998; Zimmer, 2003). First, the categorization of nationalisms as civic or ethnic is not always readily available. As Smith (1998) points out, "even the most 'civic' nationalisms [e.g. French] often turn out on closer inspection to be also 'ethnic' and 'linguistic"' (p. 126). For example, the French Revolution decree strictly prohibited the use of languages such as German and English in addition to the regional and minority languages such as Breton and Basque (Dalby, 2002, pp. 133-5). According to Dalby, regional languages were not allowed to be taught in schools until 1951 when the authorities were convinced that people from every region of France knew enough 
French to raise their children in the official and dominant language of the country as opposed to minority languages (p. 135). ${ }^{36}$

In a similar vein, holding civic nationalism in contrast to ethnic nationalism, which is often viewed as irrational, divisive and destructive, implies that civic nationalism is all good, democratic and progressive. To offset this claim I have already talked about the suppression of minority languages in France in the name of civic nationalism, but there are more instances (Billig, 1995, p. 27). In the eighteenth century, in the United Kingdom, while English was "the official/standard language," speaking or even singing in Gaelic was forbidden in Scotland (Kilborn, 1993, p. 641). Furthermore, "in the nineteenth century, Welsh and Lowland Scottish were officially banned in British schools" (Billig, 1995, p. 27).

Thus, a closer and more critical examination of this classification of nationalism (i.e. civic vs. ethnic) reveals that there are certain ideological underpinnings at work here. Civic nationalism seems to be a state ideology that justifies homogenization, often by way of assimilation, to achieve unity and the establishment of equal citizenship and legal rights among the population of a nation-state regardless of their ethnic differences. Those who praise civic nationalism over ethnic nationalism often avoid talking about the negative consequences of homogenization: assimilation of cultures, languages, religions and other identity characteristics and cultural values of less powerful national minorities. Whether

\footnotetext{
36 "The Rights of Man and the Citizen did not spread to the rights of Bretons and Occitans to use their own tongue in the schoolrooms of France: the northern langue d'oil was enforced, with the backing of legal statutes, over la language d'oc. In the nineteenth century, Welsh and Lowland Scottish were officially banned in British schools ... The Argentinean government, in a curious by-way of national history, discouraged the use of Welsh in Patagonia ... Sometimes when hegemony is assured, or when it is later threatened, this legal suppression of language is relaxed, either in the interests of recapturing a harmless heritage, or to ward off demands from separatist or irredentists groups" (Billig, 1995, p. 27).
} 
advocates of this categorisation of nationalism realize it or not, their approach seems to have been used to legitimize the hegemony of majority nationalism and the suppression of minority nationalism and, by extension, minority rights.

Finally, the civic-ethnic dichotomy is problematic because the distinction cannot be so easily made when it comes to stateless nations such as the Kurds, Catalans or Basques. Civic nationalism is said to advocate equal citizenship rights, but stateless people, even those with considerable autonomy such as the Catalans, do not enjoy the institutional and jurisprudence power to grant citizenship to their members (Hargreaves, 1998, p. 571). The power of issuing citizenship and passports is held rather by the states which some national minorities (e.g. Kurds in Turkey, Iran, Iraq and Syria) often find themselves at odds with because the states do not recognize their cultural, linguistic and political rights. Since this dichotomy of 'civic' and 'ethnic' nationalism does not seem to be necessarily useful with respect to understanding the nationalism of stateless people, we need to look into other forms of categorizations and explanations of the concept.

\section{Political vs. cultural nationalism}

Another common classification scheme of nationalism distinguishes political nationalism and cultural nationalism. For some, nationalism is essentially a political principle (Breuilly, 1996; Hobsbawm, 1990; Gellner, 1983), but for others, nationalism could be both political and cultural (Hutchinson, 1999; Smith, 1998, pp. 177-180). Political nationalists aim at establishing a representative state for a people. The aim of cultural nationalists, on the other hand, is "to revive what they regard as a distinctive and primordial collective personality which has a name, unique origins, history, culture, homeland, and social and political 
practices" (Hutchinson, 1999, p. 394) ${ }^{37}$ Although the distinction between cultural and political nationalism appears to be very straightforward and also plausible, at the end it turns out to be not so helpful since all nationalisms in the long term end up being political. The literature on nationalism has witnessed a vigorous debate over the connection or disconnection of these two types of nationalism. Proponents of nationalism-as-political only exclude cultural nationalism from their theorizations because they argue that, whatever the aim of a cultural organization or group (e.g. intelligentsia, poets, etc.) is said to be (i.e. upholding cultural identity), ${ }^{38}$ at its core, it is political; the goal is to achieve political sovereignty or legitimate a group's existence. In reply, Hutchinson (1999) states, "I agree that nationalism is a political movement, but it is not always directed to to [sic] the state, for there is a separate cultural nationalism whose goal is the defence and activation of the historical community" (p. 398, see also Kennedy, 2004, p. 501). ${ }^{39}$ Hutchinson has a valid point in that the two types of nationalism could exist in the same society and they could operate in distinct domains. For example, in today's Iran, Kurdish cultural activities (i.e. materializations of cultural nationalism) are tolerated as long as they do not openly promote and advance claims to Kurdish political autonomy within or separation from Iran.

\footnotetext{
${ }^{37}$ This categorization (political and cultural) is different from the former (civic and ethnic) in that whereas civic and ethnic nationalism are said to be in very opposing terms with each other, political and cultural nationalisms are believed to coexist sometimes and often reinforce each other. For instance, with the Kurds cultural nationalism often flourishes when the political nationalism ceases to operate either because it is defeated, as it has been the case with the Iranian Kurds since late 1980s, or because there is no need for antagonism with the central government because a sort of autonomy has been granted to the Kurdish national minority as is the case with the Iraqi Kurds currently.

${ }^{38}$ Griffiths (1993), defines cultural identity as "codified systems and ideological forms that contribute to the sense of a collective experience based on a range of shared assumptions and ideas" (p. 9).

${ }^{39}$ Investigating Quebec nationalism in relation to the Canadian's "bi-nationalism," Kennedy (2004) suggests: "nationalism is not only linked with the desire to establish an independent state; it may also be content with a form of political or cultural autonomy within an existing state" (p. 501).
} 
Conversely, the Iranian Kurdish political parties that advance claims to Kurdish political autonomy within Iran are outlawed.

Political nationalism and cultural nationalism could work in cooperation and for the same agenda or they can work separately (Hutchinson, 1999). However, these relationships cannot always be easily investigated since in practice "it can be difficult to distinguish between the two forms of nationalism" (ibid.). In light of this acknowledgement it seems more plausible to strike a middle ground between the two camps of the debate. We need to see nationalism as a political movement, and at the same time we need to recognize its cultural aspects. Following Smith (1998), I would suggest that viewing nationalism as a political movement alone overlooks the fact that even the most political nationalist movements are also investing in the social and cultural aspects of the nation (language, religion, land and territory) and its symbols (memories, monuments, flag, etc.). As Smith suggests,

....the ideology and symbolism of nationalism must be treated as having just as much 'significance' as political institutions and political movements. The ability of nationalism to portray and forge a collective cultural identity is integral to its statecapturing capacity, for it seeks state power in virtue of its unique cultural values. $(1998$, p. 92)

For this reason, nationalist political parties and elites strive to revive, maintain and strengthen the very cultural constituents of a nation such as language, territory, history, and symbols to build a collective national identity that is cultural and social as much as it is political (Smith, 1998, pp. 90-91). Nationalism can be both political and cultural at the same time, because nationalism, even in its political sense, involves deliberate efforts to create, reproduce and modify cultural symbols, myths and images. This is often the case 
with the movements of national minorities. The distinction between political and cultural nationalism is, thus, of little theoretical significance.

\section{Majority vs. Minority Nationalism}

For this study, the most useful classification of nationalism is majority nationalism versus minority nationalism. The former is an example of the dominant and often oppressive type of nationalist discourse. The latter, in contrast, is associated with minority nationalist discourse that resists and opposes the domination of majority nationalism. Majority nationalism is the ideology engendering the hegemonic and assimilationist discourse of the nation-state; in contrast, minority nationalism is the voice of the minority resistance, minorities who are often deprived of their cultural and political rights within that nationstate. As Sutherland (2005) contends "[i]n the realm of nationalism, there exist as many conservative (nation-state) ideologies as antagonistic, revolutionary ones" (p. 194). Analysts have observed that the conflict between state/majority nationalism and minority nationalism has been an insidious feature of the history of the twentieth century (Kymlicka \& Straehle, 1999). In this century we are witnessing the persistence of many of these unresolved conflicts.

To conceptualize this conflict between majority and minority nationalism it is important to realize that nation-states have not always existed, but have been built and constructed by nationalism (Gellner, 1983). During these processes of building nations, time and again other nations have been destroyed (Connor, 1994; Billig, 1995, p. 28). In most of the world, nation building has entailed imposing one major ethnic group's language, culture and politics on minority groups. This nation-state building practice seems to be a violation of human rights, yet it is important to note that these practices of nation- 
state building have been legitimated, consciously or unconsciously, by many theorists of nationalism. For example, Gellner contends that

The nationalist principle requires that the political unit and the 'ethnic' one be congruent. In other words, given that ethnicity is basically defined in terms of shared cultures, it demands that everyone, or very nearly everyone, within the political unit be of the same culture, and that all those of the same culture be within the same political unit. Simply put one culture, one state. $(1997$, p. 45)

In other words, for Gellner, one nation means one territory, one state, one ethnic group and one culture. To achieve the building of such a homogenous nation, Gellner, elsewhere suggests that "some nationalisms should become strong" because it is a "sociological necessity" to have the world consist of "culturally homogenous pools" (1981, p. 767). This strong nationalism that Gellner talks about is what more commonly has been termed majority nationalism (Kymlicka \& Straehle, 1999). For majority nationalism, cultural and ethnic diversity, including linguistic diversity, threaten the project of nation building and the maintenance of the nation (Phillipson, Rannut \& Skutnab-Kangas, 1995, p. 5). Kedouri believes that cultural and ethnic "differences are divisive and therefore treasonable" (as cited in Gellner, 1981, p. 767). Thus, as one of its most important and urgent tasks, majority nationalism (the state nationalist ideology) embarks on unifying and homogenizing the population.

It has been suggested that the process of homogenization sometimes has gone "smoothly," for example in France (Kymlicka \& Straehle, 1999, p. 73). However, it has also involved racist practices, for example in Turkey where the Turkish language, culture, history and politics were deemed superior to those of the national minorities such as Armenians and Kurds (Maksudyan, 2005). In the West as well, nation-building has involved racist and discriminatory practices: "nation-building projects [of liberal 
democracies] are sometimes perceived as inherently illiberal, and as rooted in an attitude of cultural imperialism and ethnocentric prejudice" (Kymlicka \& Patten, 2003, p.12). Due to being imposed violently, processes of homogenization in the form of forced assimilation have sometimes faced resistance especially from minorities. This has been typical within states where minorities have been denied some of the most basic human rights, such as the right to have education in the mother tongue or the right to free association. In these states, majority nationalism is conservative, assimilationist and hegemonic, whereas minority nationalism is revolutionary in that it resists domination and assimilation and strives for the national liberation of oppressed minorities. According to Kymlicka \& Straehle (1999), minority nationalism will remain durable as long as majority nationalism in the oppressive states pursue the unrealistic and naïve idea that national minorities will have no choice but to assimilate into the dominant nation or ethnic group.

\section{Minority nationalism as a social movement}

Guibernau (1996) suggests that minority nationalism is a "progressive social movement" for several reasons. First, minority nationalism attempts "to give a voice to those who had been silenced" (p. 143). In this sense, this type of nationalism is like the feminist or Green movements. Second, this nationalism of "minorities such as the Catalans, the Scots or the Kurds raises ethical issues by questioning the legitimacy of certain states as representatives of the people they rule" (ibid.). These minorities protest that they do not have political representatives in the state that runs their lives. Minority nationalist movements, "[arise] out of a sense of alienation, on the one hand, and resentment against unfair exclusion, whether political, economic or social" (Thomas Scheff, as cited in Castells, 1997, p. 9). Thirdly, at a cultural level, minority nationalism is committed to the preservation of the 
minority people's culture by which it "vindicates rights for all members of the community, particularly the right to be 'different"' (Guibernau, 1996, p. 143). Finally, on the political front, this type of nationalism pursues some form of autonomy so that a minority group that has been excluded from the decision-making processes could enjoy some sort of control over its affairs and territory (ibid.)

Neo-Marxists have also praised minority nationalism as revolutionary and emancipatory because, as Tom Nairn has suggested, it could serve the advancement of socialism (Spencer \& Wollman, 2002). For example, Nairn sees Scottish nationalism "as a force that could be harnessed by socialists to break up the British state and drive forward socialist and progressive politics" (Spencer \& Wollman, 2002, p. 41). Criticizing the "metropolitan left" for opposing all kinds of nationalism as fundamentally evil bourgeois ideologies, Nairn contends that opposing minority nationalism implicitly serves the interests of empires old and new (Spencer \& Wollman, 2002, p. 42). For example, he believes that viewing Scottish nationalism as bad, for whatever reason but especially on the ground that all nationalisms are bad, is to imply that there is no longer an English or British nationalism. Billig (1995), however, has compellingly illustrated that a 'banal nationalism' is ubiquitous in Britain where Britishness or Englishness is flagged daily. In light of these views, one could suggest that downplaying the importance of minority nationalism and degrading it often with labels such as "secessionist," "divisive," "hot" or even "ethnic" might be interpreted as denouncing minorities' claims to cultural and political rights but, at the same time, legitimating the dominance of the state nationalism which could amount to the domination of one ethnic group over the rest. 
Domination imposes constraints. Minority nationalists in many cases cannot freely engage in the political or even cultural activities within the states they resist. Of course the degree and nature of constraints vary from nation to nation, but when the constraints involve persecution or imprisonment, minority nationalism most frequently operates from outside the borders of the state it opposes. In fact, to conduct any comprehensive analysis of stateless people's nationalist movements, such as the Kurds, one needs to consider crossborder activities of minority nationalists as well. This branch of nationalism, although not exclusive to stateless people, has been called long-distance nationalism (Anderson, 1992).

\section{Long-distance nationalism}

In the age of globalization, nationalism in general and minority nationalism in particular is not confined to the borders of a nation-state or the territorial boundaries of a nation. Nationalism at home is often linked to nationalism abroad or what has been termed longdistance nationalism (Anderson, 1992; Schiller \& Fouron, 2001). If one can think of the homeland as home, in this day and age one could say that home is no longer where one lives but more frequently "where one leave[s]" (Morley, 2000, p. 54).

Back in 1999, the lead of a news item in the Toronto Star reads:

A Kurdish rebel leader is caught in Kenya and flown to Turkey. Within hours, protests break out all over Europe and North America. Canadians who couldn't tell a Turk from a Kurd are, suddenly, confronted with pictures of a Mountie on fire, hit by a Molotov cocktail at an Ottawa rally. He escapes unhurt and the police pepperspray the crowd away.

But the images and the headlines - "Kurd War Comes to Canada," and such endure. (Siddiqui, 1999)

There are numerous similar stories that tell of members of immigrant communities demonstrating their involvement with the cultural or political life of a community that is situated far away from where they physically live. These are instances of long-distance 
nationalism. Thus, following Schiller \& Fouron (2001), long-distance nationalism can be defined as

a claim to membership in a political community that stretches beyond the territorial borders of a homeland. It generates an emotional attachment that is strong enough to compel people to political action that ranges from displaying a home country flag to deciding to 'return' to fight and die in a land they may never have seen. (p. 4)

Lord Acton, the British historian-politician, has been quoted as saying, "exile is the nursery of nationality" (Anderson, 1992, p. 3). Exiled people are those who have either been forced to leave their homeland or have voluntarily done so to escape political, social or cultural hardship and injustices. Some of these people find themselves trapped in a third space so to speak, somewhere between the hostland, where they live now, and the homeland, where they originally come from. Although the immediate reference of exile is a geographical location other than the homeland, it is also "a process of becoming, involving separation from home, a period of liminality and in-betweenness that can be temporary or permanent, and finally incorporation into the dominant host country" (Naficy, 1993, p. xvi). Some exilic people can neither detach themselves from the homeland nor immerse themselves in a new way of life in the hostland. Although for the most part they experience their material life (e.g. working, studying, shopping, paying taxes, voting, etc.) in the hostland, strong emotional attachment to the homeland and feelings of nostalgia compel them to engage in the politics and identity crisis of the homeland (Vertovec, 1999, p. 455). Anderson (1992) contends that participating (or assuming to do so) in long-distance nationalism and long-distance politics is "a politics without responsibility and accountability" (pp. 19-20), because a person involved in long-distance nationalism dreams of a land where he does not want to live, pay taxes and where he cannot be arrested or brought before courts. Anderson exemplifies such as a person by referring to a Toronto 
Sikh who is quite "enthusiastic about the sacrifices of young Sikh activists as well as about their terroristic campaigns against non-Sikhs in the Punjab" (p. 19). Anderson could be right in that there might be many who practice "a politics without responsibility and accountability," but one should also note the fact that some people do return to the homeland where they either lead a normal life or continue their activism and pursue their nationalistic, or what many prefer to call, patriotic beliefs. For example, since the fall of Saddam Hussein in Iraq, many Iraqi Kurds including Kurds from other parts of Kurdistan, have returned to the Kurdish region in Iraq. A number of these people have returned to their birthplace to live their ordinary lives, but there are also those who have continued their political activism and have become a part of the Kurdish regional government. Most of these people are those, who while residing outside Kurdistan, continued to be loyal to their Kurdish cause by engaging in Kurdish cultural and political activities. In fact, many of the people who lead the Kurdish Regional Government in Iraq these days returned to their region from exile in 1991 when the Kurds started to enjoy a semi-autonomous status in the no-fly zone in northern Iraq under the protection of the American and British military. Exilic life or life in diasporas ${ }^{40}$ engenders what might be termed a crisis of identity. Long-distance nationalism appears to be a response to this crisis especially for two groups:

\footnotetext{
${ }^{40}$ Diaspora which means dispersion is derived from the Greek diaspeirein meaning to scatter (Karim, 2003, p. 1). The term originally referred to Greeks who were away from Greece. Later, however, it started to become more associated with the Jewish communities who were exiled from the Palestine to Babylonia. In modern times, the term is commonly used to refer to immigrant communities, the people and their current places of residence. Some scholars have presented a narrow notion of the word by linking diasporic populations to specific homelands. For example, for Connor (1994), "diasporas are people living outside of their homeland who have not assimilated to the host's identity" (p. 80). This definition, like many others, connects diasporas to an ancestral territory or a country other than the host-land. There are scholars, however, who suggest that "[a]ll diasporas do not have homeland myths at the centre of their consciousness" (Karim, 2003, p. 2). I understand diaspora as "a whole range of phenomena that encourage multi-locale attachments, dwelling and traveling" (James Clifford, cited in Karim, 1998, p. 4). To capture the political activism of diasporas, Hassanpour \& Mojab (2005) talk about "diasporic nationalism" rather than long-distance nationalism.
} 
those who are lost in the in-betweenness of the host country and the homeland, and those who resist any sort of assimilation into the culture and way of living of the host country. Some exilic people seem to take comfort in the ideology of long-distance nationalism, in the idea of still belonging to a place, a culture and a people that they can identify with without much difficulty and that they dream of returning to one day. Participating in longdistance nationalism, whether in the form of preserving home's cultural values, or in the form of involvement in the politics of the homeland, seems to offer some exiled people the means to keep the memory of home fresh in their imaginations. This way, the community, group or the nation continue to be imagined. As Kaiser (2002) observes, "[r]emembered places have, of course, often served as symbolic anchors of community for dispersed people" (p. 244). ${ }^{41}$

\section{Alternative definition of nationalism}

In this study, following Smith (1998), I understand nationalism as both an ideology and a social or political movement aimed at the establishment and maintenance of selfgovernment and/or the creation and reconstruction of collective cultural/national identity

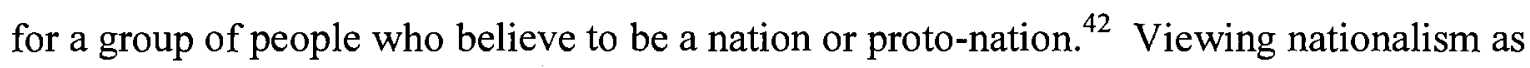
both an ideology and a movement synthesizes many of the major definitions and

\footnotetext{
${ }^{41}$ The idea of returning home/homeland is often based on an image of the home as stable, unchangeable and frozen in time and space. It is always questionable whether one can return to the same place one abandons. Gaffer Hossainpour, a Kurdish poet and a friend, devoted most of his poems written over two decades while in "exile" to express his nostalgia for home and dreams of returning to the homeland. After being away from "home" for eighteen years, in the early 2000s he paid a visit to Kurdistan-Iran. At the time he thought that this first trip would have been followed by many visits to Kurdistan. But, he has not been back since then simply because the home he returned to was not the home he once left. The image he had of home was of the time he left. In two decades, home had changed a great deal; the homeland was no longer "the home."

${ }^{42}$ For Hobsbawm (1990), proto-nations are not full-fledged nations (nation-states) but they demonstrate the potential to be one. Hobsbawm recognizes the Kurds as an example of a proto-nation. What separates a protonation from a nation, which is synonym to nation-state for Hobsbawm, is the lack of a polity, a state. Protonations live on a large territory, share similar or closely related language varieties and other cultural traits and most importantly believe they share the same ethnic roots and similar ambition for a state and political recognition. Basically, what Hobsbawm calls "proto-nation" I have called nation in this study.
} 
conceptualizations of nationalism. Whereas the term "ideology"43 refers to the cultural, ethnic and linguistic aspects of nationalism (with the aim of preserving one's culture and identity and not necessarily pursuing political independence-e.g. Catalans in Spain), the term "political movement" refers to nationalism's political nature (with the explicit agenda of pursuing some sort of regional autonomy or independence, for example Québec nationalism) (Smith, 1999). Conceptualizing nationalism in the sense of an ideology in addition to a social and political movement will encompass both categories of nationalism (Hutchinson and Smith, 1994, p. 4).

\section{Nationalism, modernity and "crisis of identity"}

Whatever nationalism might be, it is unmistakably a modern phenomenon (Anderson, 1991; Gellner, 1983; Hobsbawm, 1988, 1991; Smith, 1998). According to Deutsch (1953), among other things, modernity is also marked by an increasing "self-doubt". In the modern world, because people are uprooted from their small towns, traditions, and contextdependent meaning systems (e.g. face-to-face interaction), more than ever the answer to the question "who am I?" is illusive (p. 184, see also Dascal, 2003, p. 160). In a similar vein, Hall (1992) speaks of "crisis of identity" in the sense of "fragmenting the modern individual as a unified subject" (p. 274). According to Deutsch, in the search for themselves, people discover those who are similar, and "they may discover once again the connection between ethnic nationality and the capacity for fellowship" (p. 184). ${ }^{44}$ Thus, the realization and maintenance of cultural fellowship and collective identity has been one of the objectives of

\footnotetext{
${ }^{43}$ More on nationalism as an ideology will follow.

${ }^{44}$ Deutsch reminds us that seeking fellowship with those who are similar ethnically or in nationality goes back to the time of antiquity: "Socrates enjoined upon his pupils the imperative, 'Know thyself,' and that Socrates' pupil, Plato, proposed that all Greeks should henceforth cease to plunder or enslave their fellow Greeks, but should rather do these things to the barbarians" (1966, p. 184-185).
} 
nationalism (Billig, 1995, p. 24; Deutsch, 1953; Guibernau, 1996, p. 142; Smith, 1998, p. 90).

Similarly, in recent decades, the need for collective identities such as national identity has been identified as one of the major reasons for the surge of nationalism (Castells, 1997, p. 32; Guibernau, 1996, p. 142). ${ }^{45}$ In discussing Irish nationalism, for example, Kane (2000, p. 247) identifies three conceptualizations of the phenomenon to explain the reasons for its undeniable presence: Aiming at achieving political autonomy, constructing and promoting national identity, and striving for nation building. Whereas the first aim entails campaigning for national independence, the third concept denotes the materialization of that independence in the form of a state. However, both of these, according to Kane, depend "on the second process of national identity construction" (p. 247). This is particularly true of a stateless people such as the Kurds whose identity is fragmented territorially, culturally, linguistically, ethnically, and politically. In similar cases, to achieve political autonomy and a nation-state, nationalists need to mobilize populations that can identify themselves with the claims of their elites, mostly based on cultural similarities among the members of the community in question and differences between that community and the "Other." It is from this perspective that Castells (1997) sees nationalism "as a renewed source of collective identity" (p. 32). In a similar vein, Guibernau (1999) perceives the revival of nationalism in the $1990 \mathrm{~s}$ "as a response to a need for collective as well as individual identity" (p. 74). Discussing Kurdish nationalism, Vali

\footnotetext{
${ }^{45}$ Guibernau (1999) says that "the re-emergence of nationalism in nations without states is directly related to the intensification of globalization processes which have proven capable of altering the political, economic and culture structures of current societies" (p. 20). Globalization, she argues, makes people aware of their differences with others, but at the same time it threatens them with its power and tendency to homogenize. It is the fear of homogenization and thus the loss of less powerful cultures that compels minority cultures to resort to identity construction practices.
} 
(2003) suggests that "[n]ationalist discourse in important ways is a discourse of identity"

(p. 68). ${ }^{46}$ Minority nationalism, before everything else, is about the construction,

reproduction or maintenance of a national identity for a stateless people. The next chapter is

devoted to defining and explaining national identity.

${ }^{46}$ In discussing colonized nations national movements against the colonizers in Africa, Asia and elsewhere, Tom Nairn has observed that,

Real, uneven development has invariably generated an imperialism of the centre over the periphery; one after another, these peripheric areas have been forced into a profoundly ambivalent reaction against this dominance, seeking at once to resist it and to take over its vital forces for their own use. This could only be done by a kind of highly 'idealist' political and ideological mobilization, by a painful forced march based on their own resources: that is, employing their 'nationality as a basis ... This meant the conscious formation of a militant, inter-class community rendered strongly (if mythically) aware of its own separate identity vis-à-vis the outside forces of domination. (Cited in Spencer \& Wollman, 2002, p. 41) 


\section{Chapter 3: National Identity}

... The urge to express one's identity, and to have it recognized tangibly by others, is increasingly contagious and has to be recognized as an elemental force even in the shrunken, apparently homogenizing, high-tech world of the end of the twentieth century.

(David Hooson, as cited in Castells, 1997, p. 28)

This chapter defines and describes national identity and provides a critical discussion of its main components. They are territory/homeland, shared experience and memory/past, national symbols, and language. Prior to discussing national identity, however, I find it appropriate to articulate a workable definition of identity.

\section{Identity}

It is desirable to start this section with a straightforward definition of identity. However, Brubaker (2004) suggests that the term "identity" is "richly-indeed for an analytical concept, hopelessly-ambiguous" (p. 33). He identifies at least five types of understanding or conceptualization of the term: "a ground or basis of social or political action," "a collective phenomenon," "a core aspect of (individual or collective) selfhood," "a product of social or political action," and "as the evanescent product of multiple and competing discourses" (Brubaker, 2004, pp. 33-34). This rather diverse understanding of the term "identity" has compelled Charles Tilly to call it "blurred" but "indispensable" (as cited in Brubaker, 2004, p. 39).

For Tilly, identity is conceptualized primarily in relation to social actors' experience and also the representation of these experiences in narratives that are shared publicly, for 
example through mass media. In similar veins, Castells (1997) defines identity as "people's source of meaning and experience" (p. 6). It is what combines people's names, languages, cultures, behaviours, ways of living and ways of relating to others. Thus, for the purpose of this study, "identity, as it refers to social actors...[is understood as] the process of construction of meaning on the basis of a cultural attribute, or related set of cultural attributes, that is/are given priority over other sources of meaning" (p. 6). Others have consistently defined identity in terms of meaning making in the sense of shared understanding among social actors (Ainsworth \& Hardy, 2004, p. 237; Hall, 1992, p. 292; Triandafyllidou \& Wodak, 2003, p. 210). Ainsworth \& Hardy (2004) contend that "the construction of identity in discourse is also the construction of meaning and relationships" (p. 237).

Meanings and relationships, including identities, are formed and acted out in contexts. From a sociological perspective, all human identities are social and socially constructed (Triandafyllidou \& Wodak, 2003). ${ }^{47}$ Construction, however, does not occur in a vacuum. To capture the complexity of identity construction, Castells (1997) suggests that we need to ask, "how, from what, by whom, and for what" identities are constructed (p. 7, my emphasis; see also p. 32)? These questions call attention to the importance of context. Every group and collective entity constructs identity according to their available social, cultural and historical resources and within their "space/time framework" (Castells, 1997, p. 7). This context-based construction of identities applies to national identities as well:

\footnotetext{
${ }^{47}$ The idea that identities are constructed is often said to be a "post-modern" position. Joseph (2004), however, believes that the notion is older than this and suggests that the misconception is rooted in lack of historical knowledge. To prove this, he quotes Jan Christiaan Smuts (1870-1950), the South African general and prime minister, in one of his books saying, "[M]y very self, so uniquely individual in appearance, is [..] largely a social construction" (p. 7).
} 
"the various discursive constructs of national identity are given different shapes according to the context and to the public in which they emerge" (Wodak et al., 1999, p. 3).

Castells (1997) proposes three kinds of identity building: legitimizing identity, ${ }^{48}$ project identity, ${ }^{49}$ and resistance identity. The latter is particularly relevant to this study. It is

generated by those actors that are in positions/conditions devalued and/or stigmatized by the logic of domination, thus building trenches of resistance and survival on the basis of principles different from, or opposed to, those permeating the institutions of society. (Castells, 1997, p. 8)

I would submit that the struggle of minority nationalism against the assimilationist majority nationalism is an example of resistance identity.

According to Castells, "identity for resistance, leads to the formation of communes, or communities" (p. 9), or what Anderson (1991) has famously called "imagined communities." This kind of identity, for Castells, is the most important type of identitybuilding because "it constructs forms of collective resistance against otherwise unbearable oppression usually on the basis of identities that were, apparently, clearly defined by history, geography, or biology, making it easier to essentialize the boundaries of resistance" (Castells, 1997, p. 9). According to Hall (2006),

... social movements characteristically take their character from the states with which they interact. Politically conscious movements tend to arise when states act in an arbitrary manner, whether in terms of taxation, repression, exclusion or conscription. This most certainly applies to nationalism. (Hall, 2006, p. 40)

\footnotetext{
${ }^{48}$ Legitimizing identity is "introduced by the dominant institutions of society to extend and rationalize their domination vis a vis social actors" (Castells, 1997, p. 8). This fits Billig's (1995) view of the nationalism of the nation-states as "banal nationalism" in which the job is carried out by the state apparatus.

${ }^{49}$ Project identity building takes place "when social actors... seek the transformation of overall social structure" (Castells, 1997, p. 8). An example of this is the feminism movement.
} 
According to Hall, there are instances, for example in India, when satisfying nationalist demands of national groups and minorities has encouraged abandoning or delaying secessionist ambitions and movements and thus preventing conflicts, warfare, violence and loss of life. Thus it should not come as a surprise to learn that resistance identity is a prominent characteristic of the nationalist discourse of the minorities whose rights and demands are not respected (Guibernau, 1999, 1996). For example, it has been suggested that the Kurdish nationalist movement has come about partially as a reaction to the assimilation policies of the dominant nationalist states, Iraq, Iran, Turkey, and Syria (van Bruinessen, 2000a, p. 44; see also Vali, 1998, 2003; McDowell, 2004). In this case, a clear example of resistance identity seems to be national identity the construction of which, as discussed earlier, is the fixation of all sorts of nationalisms.

\section{National identity}

National identity here is understood as a collective identity denoting feelings and beliefs of groups of people to belong to a cultural/national group or groups but at the same time to be different from other groups. According to Kane, "National identity, like all forms of collective identity, is a subjectively shared sense of belonging and connection to a particular community, based on symbolic conceptualization of similarity between oneself and one's groups, especially in relation to others" (2000, p. 247 , my emphasis). Similarities, depending on specific contents, could encompass various cultural, social and historical elements, some of which will be discussed in detail shortly.

In addition to conceptualizing similarities between the members of a group, constructing national identity is also about establishing differences between one group and other groups. According to Calhoun, "we know of no people without names, no languages 
or cultures in which some manner of distinction between self and other, we and they are not made" (as cited in Brubaker, 2004, p. 40; see also Billig, 1995, p. 66).$^{50}$ For example, many researchers have suggested that the Canadian national identity is mostly defined in relation to the United States: "The notion that Canadian identity is defined out of difference from that of the U.S. has become fundamental to Canadian social memory" (Jackson \& Ponic, 2001, p. 49), thus "...Canadian identity ... continues to be defined as different from the American" (p. 46, see also Stieve, 2005). In other words, an important component of national identity discourse is the construction and articulation of "Otherness."

The discourse of "Otherness" is often attributed to the dominant majority which is said to aim at marginalizing and subordinating minorities (Riggins, 1997, pp. 6-7). However, as Riggins points out, the minorities also engage in constructing their "Others". A distinction, however, needs to be made between the ways "Otherness" is constructed by the majority versus minority groups. According to Riggins, because the majority groups often monopolize the public discourse and can define their shared identity more easily than minorities, their discourses of identity tend to be "univocal and monologic" (p 6). Conversely, "the discourses of identity articulated by members of subordinate minorities tend to be contradictory, complex, and ironic" (ibid.). Another difference between the two discourses of identity, as observed by Riggins, is that whereas the discourse of the majority is assertive and self-justified, the discourse of the minority elites is often hampered by "elements of shame and self-hatred" which seems to be the product of exposure to the majority's institutionalized acculturation, for example education (p. 7) or the mainstream media. Finally, one can assume that the minority discourses of identity aimed at

\footnotetext{
${ }^{50}$ Billig (1995, p. 66) states, "to be a member of an 'ingroup' entails a categorical distinction from an 'outgroup'."
} 
constructing the other or "them" may not be directed only at the majority but also other minorities. This could be the case especially in places where the identity discourses of a larger minority might find itself at odds with the discourses of other or smaller minorities in addition to those of the majority. It will be interesting to see how this plays out in the identity discourses of the Iraqi Kurds who have been in conflict with the Iraqi central government for decades over territories to which other minorities such as the Iraqi Turkomans (also spelled Turkomen, Turkman) and Assyrians have claims as well (i.e. in the oil-rich city of Kirkuk/Kerkuk). ${ }^{51}$

With respect to the concept of national identities as social constructs, certain other significant assumptions about this phenomenon should be pointed out. First, the construction of identity although not exclusively but in important ways is discursive and symbolic (Billig, 1995; Hall, 1992; Wodak et al., 1999; Wodak, 2006). ${ }^{52}$ Secondly, national identity is dynamic, which means that it is neither primordial nor stable. As Kymlicka \& Straehle (1999) suggest, "[t]he successful diffusing of a common national identity is, in many countries, a contingent and vulnerable accomplishment-an ongoing process, not an achieved fact" (1999, p. 73). Thirdly, it is context-dependent, which means that "the various discursive constructs of national identity are given different shapes according to the context and to the public in which they emerge" (Wodak et al., 1999, p. 3). According to Guibernau (1996), "community of culture and unity of meaning are the main sources that allow the construction and experience of national identity" (p.73). In other

\footnotetext{
${ }^{51}$ The population of Kirkuk comprises Kurds, Turkomans, Assyrians, and Arabs. The dispute between the Kurds and Turkomans is not necessarily over the ownership of the city but rather over what jurisdiction the city should fall under, Kurdistan or Baghdad. Many believe that some Turkomen are not willing to live under the Kurdish rule because of Turkey's strong influence among the Turkomans. Turkey, which has about 15 million Kurds demanding their own cultural and political rights within Turkey, worries that a strong and rich Kurdish autonomous region in northern Iraq may advance the "claims" of the Kurds in Turkey.

${ }^{52}$ More on this follows.
} 
words, it is the process of sharing meaning in the sense of understanding within a common culture that allows individuals to experience national identity and to feel that they belong to a collective identity. For example, investigating discursive construction of Americanism, Ricento (2003) concludes that "[o]ne of the most salient [revealed] themes [in this study] is the idea that Americanism requires, or is constituted by, thought-sharing. That is, Americans know who Americans are because they 'think alike,' they 'see eye to eye' on the essence of Americanism, they share the same 'ideas' about national identity" (p. 7). This "thought-sharing" and similar-meaning-making is not primordial but rather constructed, changed, reinforced and modified. As Guibernau reminds us, "national identity needs to be upheld and reaffirmed at regular intervals" (p. 73).

Finally, as Castells (1997) suggests, “[m]ost successful nationalisms presume some prior community of territory, language, or culture, which provide the raw material for the intellectual project of nationality" (p. 29, my emphasis). In other words, nationalist ideologies use a great number of symbols, such as territory, landscapes, language, cultural and political symbols with the aim of strengthening the national ties among members of a people so that they could imagine themselves as a distinct people or community (Smith, 1999; Spencer \& Wolman, 2001, pp. 57-93; Gilbert, 1998). Explaining and articulating the most relevant of these national symbols and cultural values is the focus of the next section. 


\section{Components of national identity}

\section{Territory, homeland, landscape}

According to Kaiser (2002), "whatever else it may be, nationalism is always a struggle for control of land" (p. 231). Most scholars of nation and nationalism agree on the great importance of territory, homeland and landscape in relation to the formation and maintenance of national identities, albeit they may have different reasons for their stance.

For Smith (1996) nations have ethnic roots, and the history of ethnic communities is in crucial ways defined by an ancestral homeland or territory. It is one of the most important 'deep resources' of ethno-history; it is the setting where sufferings, happenings and experiences of the community take place. It is where a community is formed. According to Smith, the events and shared memories of the community are engraved with the mountains, rivers, deserts, trees and even the dust of such a territory. This territory becomes a sacred homeland and without it, the ethnic community is unthinkable.

From a nationalist point of view land is sacred, and this sacrilization undermines the fluidity of borders. Land is sacred, according to Ignatieff (1994), "because this is where ...ancestors lie.... Land is worth dying for, because strangers will profane the graves" (Ignatieff, 1994, p. 93). ${ }^{53}$ However, sacralization of land and territory creates some serious analytical problems. For example, it overshadows the fact that the borders of what nationalists consider as the birthplace of their ancestors and by extension their natural home to live and die in have often been drawn forcefully as a result of wars, forceful inclusion which has often been followed by forced exile of others (Spencer \& Wollman, 2002, p. 87). This leads to another problem: sacralization of territory overlooks the very fact that borders

\footnotetext{
${ }^{53}$ Of course one cannot help but to recognize the fact that there have been millions of victims of conflicts, including nationalist wars, whose perished bodies never met a grave.
} 
of those 'sacred' territories are fluid and subject to change (p. 87) especially with respect to nations without states and also newly established nation-states that still have disputed territories, such as Azerbaijan and Armenia in central Asia. Finally, sacralization of historical homeland tends to depoliticize claims to territory when claims to historical homelands are fundamentally political rather than natural tendencies to one's roots in nature. If the borders of most nation-states have been fixed for a century or so, frequently through complex political processes and disputes, those of the nations without states are ever-changing and they are in a constant process of becoming.

Despite this, territory or land remains as one of the most decisive defining component of national identity. As Kaiser (2002) reminds us, all over the world these days "national homeland images continue to exert a powerful influence on popular perceptions of identity and remain among the most effective instruments that nationalists have at their disposal to mobilize their national communities" (p. 243). The importance of territory and borders as defining political boundaries of nation-states hardly needs to be proven. But territory is also important for nations without states and minorities who are said to have reached national awakening or what some scholars prefer to identify as "ethnic consciousness." For example, a map of the Iranian "ethnic grouping" presented on BBC's website in spring 2006 created a war of words between the Iranian Azerbaijanis and Kurds. Azerbaijanis complained that the map had marked a large section of Azeri territory as Kurdish. Some prominent Azeris, including Reza Baraheni, the past president of PEN Canada, wrote to the $\mathrm{BBC}$ and urged them to change the map. Also, about thirty Azerbaijani organizations started collecting signatures to endorse a petition addressed to the UN, some world leaders and human rights organizations (Prevent ethnic conflict, 2006). 
The petition warned of an imminent conflict between the Kurds and Azerbaijanis. The dispute over the map continued for several months.

This example nicely supports Kaiser's assertion that "[m]aps of the national homeland help to naturalize and historicize the images being created of the 'primordial nation' and its intimate connection to the sacred soil of its ancestral homeland" (Kaiser, 2002, p. 233). Maps do not just record what is real, i.e. by marking the internationally recognized borders, but they also represent the nationalist imaginations of the homeland, of the historical sacred land and of what that land should have been or ought to be. According to Edward Said, "struggle over geography... [is] not only about soldiers and cannons but about ideas, about forms, about images and imaginings" (as cited in Watts, 1999, p. 86). In light of this, it appears that the Azerbaijanis' response is not so irrational after all. They have realized the significance of maps:

Maps and other cartographic representations, motherland and fatherland images ... work to nationalize space and territorialize the nation. In addition, nationalists have employed localized place attachments in order to reterritorialize identity toward more geographically expansive notions of homeland. (Kaiser, 2002, p. 2232)

Nationalists have long recognized the power of maps and iconography not only to show where home is but also where it should and could be and where power can be exercised, because they have believed "map-making, presenting a nationally particularistic image of place as homeland, is among the most widespread and persuasive of instruments" (Kaiser, 2002, p. 232).

Although the increasing expansion of globalization has made the nation-state's territory less and less relevant to the community's political, economic and cultural life, territory for the nations without states has stayed as important as ever if not more so (Guibernau, 1999, pp. 156-160). According to Guibernau 
For [nations without state], territory is becoming a quasi-sacred component of their identity. Territory is turned into a symbolic space containing memories of the communities' history, sacred shrines, holy places, battlefields, and specific geographical features endowed with a highly emotional charge. Furthermore, territory also contains a strong political dimension since the nation's territory defines the limits within which self-government is to be exercised. (p. 157)

Studying the significance of territory and landscape in the Catalonian nationalist discourse, Nogué \& Vicente (2004) finds landscapes, particularly mountains, "a fundamental element" in the formation of the Catalan national identity from the emergence of Catalan nationalism in the late $19^{\text {th }}$ century until now (p. 113). Investigating territory as a national symbol in Northern Ireland, Kuusisto (2001) observes that "symbolized local boundaries are part of the bigger picture of the still ongoing nationalistic struggle in Northern Ireland" (p. 64).

Nogué \& Vicente (2004) makes a useful distinction between territory and landscape. According to this study, whereas territory is the special expression of the nation's political power, and also defines the limits of that power, landscape is an important component of the cultural identity inhibiting the ideological dimension of nationalism in significant ways. According to the authors,

Landscapes imbue the territory with identity, but landscapes are not territory... The national territory is...the geographical space occupied by a nation onto which a relationship of territoriality is established, while the national landscape can be defined as the landscape or set of landscapes that represent and identify the values and essence of the nation in the collective imagination. In this sense, the landscape constitutes the soul of the territory. (p. 117)

Landscapes as "souls" live on, for they are indispensable parts of a culture, a people's worldview and imagination, but territories change; they expand and shrink, come and go. One reason that landscapes become so intertwined with the identity of a people or nation is that "the landscape can be interpreted as a dynamic code of symbols that speak of the culture of the past, present and maybe also the future (p. 117). In other words, they 
contribute to the construction and maintenance of another crucial component of national identity: shared experience and memory.

\section{Shared experiences and memories}

About one hundred years ago, in his famous piece, "What is a nation?" Renan (1991) said that a nation is "a soul" constituted by two things, common memories rooted in the past, and the consent and the "will" to live together at the present day and with the hope to stay together in the future. This will of living together, however, can best be achieved if the memories of the past are deeply rooted in the heritage and values of the community (p. 19):

The nation, like the individual, is the culmination of a long past of endeavours, sacrifice, and devotion... A heroic past, great men, glory (by which I understand genuine glory), this is the social capital upon which one bases a national idea. To have common glories in the past and to have a common will in the present; to have performed great deeds together, to wish to perform still more-these are the essential conditions of being a people. (p. 19)

It is in keeping the proud collective memories, especially the sacrifices and sufferings, alive in the minds of the community that the present and staying together can be meaningful, and a common future can be imagined. Knowing that a group of people was great together in the past provides confidence and motivation to stay great at present and gives hope that further greatness will be shared together in the future.

Shared experiences are the building blocks of a national identity. Castells (1997) asserts that, "[ $[\mathrm{t}] \mathrm{o}$ be sure, ethnicity, religion, language, territory, per se, do not suffice to build nations, and induce nationalism. Shared experience does" (p. 29). He continues to illustrate this point by comparing the United States and Japan. According to him, in both the US and Japan strong patriotism and nationalism are present, yet, while Japan is ethnically very homogenous, the US is not. What brings the US and Japan together is a 
shared history (past experience), shared project (the will to live together) and dreams (the hope in staying together in the future).

Memories and shared experiences are to a large extent constructed or recreated and reinterpreted (Martin \& Wodak, 2003; Brewer, 2006). As Martin \& Wodak (2003) puts it,

Every country has 'skeletons' in its cupboard, and every society which has to deal with traumatic events, creates myths and taboos around these event. Pasts are rearranged, transformed, recontextualized, substituted or totally changed. Such strategies also relate to the construction of national and also individual identities. Identities need founding myths and certain pasts, which they can integrate easily and positively. (p. 11)

Memories are not ready-made, objective and uncontested narratives about a past, and they are not experienced in the same way by all the individual members of a community. For one thing, individual memories of the same past could be different because each individual observes and interprets events according to his/her own values and personal experience. As Martin \& Wodak (2003, p. 10) reminds us, "Memories are highly subjective." Secondly, as Bourdon (2003) observes, "content of memories ... is always affected by our various collective belongings" (p. 7). In this sense, although the past is experienced and recollected and remembered or forgotten individually, memories are often collective: "every memory is to some extent collective ... collective memory is generally understood as the memory of important events, rituals and ceremonies shared at the level of large geographical collectives" (p. 7, see also Brewer, 2006, p. 215) or nations. It follows that to possess a national identity is to share memories that are familiar to all or most of the members of a community partially because "memories are always, to some extent, meant to be shared" (p. 8) and belonging to a national identity is in crucial ways about sharing memories. As Brewer (2006) suggests, "memories help in the construction of collective identities and boundaries, whether these are national, culture, ethnic, religious or otherwise" (p. 215). 
A national identity is constructed not by remembering the past and shared experiences alone but also through forgetting some of them. Nations also need to remember to forget. Remembering to forget is done in at least two ways, either through not bearing in mind certain historical events and figures and simply keeping silent about them, or through denying and distancing them. As Brewer (2006) suggests, "these items might be anything that prevents the construction of the nation as an imagined community and which blurs the social boundaries that mark the nation or disrupts the formation of a common identity" ( $p$. 216). Wodak et al. (1999), for example, observe that remembering to forget the WWII because of Austria's alliance with Germany is very much a part of the Austrian discourses of identity construction.

Finally, in addition to forgetting some parts of history, the discourse of nationhood also demands prioritizing those items that are chosen to be remembered and commemorated. To know which item is more important for which nationalist discourse and try to find out why that might be the case one first needs to find out how the past is, how memories and experiences are narrated, and how they are expressed and retold. Typical devices, of course, include folktales, history books, historical novels, biographies, autobiographies and other media products. All these, as Brewer (2006, p. 216) suggests, "[s]ocialize us in what to remember," as do commemorations, annual events and rituals, and finally national symbols.

\section{National symbols}

The shared experience of a community, its memories of the past and its dreams for the future, are in important ways preserved, reinforced and reproduced in symbols that are recognized nationally. National symbols have been produced in ways that when used prove 
to be charged with inflaming deep emotions aimed at generating political reactions. In this sense, one can assert that "national symbols are charged with the difficult task of creating $a$ nation" (Geisler, 2005, p. xv, emphasis in original).

Smith (1991) presents a comprehensive list of national symbols:

flags, anthems, parades, coinage, capital cities, oaths, folk costumes, museums of folklore, war memorials, ceremonies of remembrance for the national dead, passports, frontiers...the countryside, popular heroes and heroines, fairy tales, forms of etiquette, styles of architecture, arts and crafts, modes of town planning, legal procedures, educational practices and military codes-all those distinctive customs, mores, styles and ways of acting and feeling that re shared by the members of a community of historical culture. (Smith, 1991, p. 77)

Some of these symbols exclusively belong to nations with independent states, such as coinage and passports. Most of them, however, are present in the cultural history and practices of nations without states. Due to limited space, and in line with the objectives of this study, I will talk about two of these symbols in particular, flag and anthem.

A flag, by some, has been considered the most important national symbol (Geisler, 2005 , p. xxii). For one thing, the flag is perhaps the oldest of symbols. It has been suggested that the first flag as a sign of power may have been used in China, in $1122 \mathrm{BC}$ (Geisler, 2005, p. xxi). According to Geisler, in ancient times, the flag was used for at least three purposes: in battles to separate friends from the enemy, as a sign of power and authority and thirdly as means of communication. ${ }^{54}$ In modern times, the flag still serves these functions especially the first two: as a way of identifying oneself as belonging not just to one side of a battle but to a particular national identity in other contexts as well and also as a carrier of the power of the nation invested in it by the people or on their behalf by the states, political groups or intellectuals and artists.

\footnotetext{
${ }^{54}$ Flags have been used for "signalling," to indicate the peaceful intentions as opposed to confrontational ones and so forth.
} 
With respect to identification, a flag perhaps more than other symbols enables individuals to indicate their loyalty to one collective identity but not the other. A typical example is when tourists stitch the flag of their country to their bag to say two things: that they are not from where they are visiting and that they are from another particular place (i.e. as opposed to any other place). Both intentions serve the identity construction process: establishing difference with one group (Them) while producing or reinforcing similarity with another (Us). For example, a Canadian in Sweden might be mistaken for an American upon speaking English with an accent that is more American than British or Australian. The flag sewed on his bag, however, could confirm that he is not American but Canadian. Thus, as Geisler (2005) puts it, "symbols have served the purpose of distinguishing one collective from another by virtue of who shares the "code"' (p. xviii). ${ }^{55}$

The national flag is also invested with political power. ${ }^{56}$ For example, on fragment television news we see the American flag set on fire in various parts of the world as clear symbolic attacks on Washington as a sign of denouncing the decision makers in the White House and disrespecting them. As an official from the Indian government has said, a flag,

\footnotetext{
${ }^{55}$ One's passport might be the most decisive identification of nationality, but it is highly unlikely that anyone would find a passport suitable for public display.

${ }^{56}$ In 2003, the Premier of the Canadian province Newfoundland and Labrador, Danny Williams, ordered the removal of the Canadian flag from the public buildings in his province after he became frustrated with Ottawa's treatment of the province. After six months of talks over offshore revenue sharing between the federal government and the province, the Premier was displeased with Ottawa's handling of the matter and for not responding to the Premier's three letters and his request for a meeting with the Prime Minister of Canada. However, when the Canadian flag was removed in Newfoundland and Labrador apparently it took the federal government only a few days to agree to the province's demands. Later, the Premier said: "History has proven that the only way to get the attention of the federal government in Newfoundland and Labrador is to get the attention of Canadians. This is exactly what we achieved when we removed the flags... Not everyone may have agreed with our decision, but we were able to focus the attention of the country on our issue (Government of Newfoundland ..., 2005; my emphasis). This example illustrates the power of flag as a national symbol at both political and cultural level. One segment of the above quote is particularly telling. The removal of the Canadian flag was to "get the attention of Canadians" which would be, as it were, translated to the reaction of their political representative, the federal government.
} 
along with the emblem and national anthem, "command instantaneous respect and loyalty. In themselves they reflect the entire background, thought and culture of a nation" (as cited in Hobsbawm, 1988, p. 11).

A flag could also be the site of struggle over political or cultural hegemony between political factions from the same nation. This is particularly the case among political parties and groups of a stateless people. In the context of nation-states, symbols are often nationalized and institutionalized through the state apparatus. In the absence of a state, political groups that claim to be leading the nationalist movement strive to popularize their own symbols as a way of establishing their political legitimacy. One might suggest that having one single national flag for a stateless people, accepted by all parties, amidst such a predictable contestation over legitimacy, could be a sign of the existence of a collective identity. In this study, looking at the type and the frequency of the flag(s) that the Kurdish media display could say a great deal about the Kurdish identity (i.e. if the projected identity is fragmented along party lines or a collective and national).

Next to the flag, the national anthem is perhaps the most emotionally charged national symbol that has, in powerful ways, contributed to the creation of the imagined community of a nation and a collective national identity. Geisler (2005) observes that national anthems are "part and parcel of [the] myth of blood sacrifice typical of most nascent nationalist movements" (p. xxiv). In addition to national anthems, revolutionary songs, particularly in times of struggle for national emancipation or during national crisis, are often used to reinforce the idea of blood sacrifice in the name of a nation and for its sake. For Anderson (1991) the significance of these songs is in that they connect the members of a national community: 
Take national anthems, for example, sung on national holidays. No matter how banal the words and mediocre the tunes, there is in this singing an experience of simultaneity. At precisely such moments, people wholly unknown to each other utter the same verses to the same melody... Nothing connects us all but imagined sound. (p. 145)

The function Anderson attributes to national anthems, "an experience of simultaneity," is also what he saw in print media that engendered, according to him, imagining the nation by allowing the members of a geographically dispersed community, whose members may never see each other face to face, experience a similar world together and simultaneously.

According to Geisler (2005) national symbols are important aspects of discourses of nations because these symbols preserve the past and memories of the nation on a continuous basis. They provide the means by which the past can be appropriated to serve today's discourse of the nation. This way the nation becomes ever-present. At the same time, both media and national symbols enable community members to envisage the nation in the future. This, however, should not imply that national symbols are stable. To the contrary, Geisler (2005) suggests that national symbols are dynamic and subject to change simply because they historical constructs and products of social agency. This quality of symbols, therefore, needs to be kept in mind when studying them. Geisler says,

we need to look at the role played by national symbols in the formation and maintenance of collective identity as an ongoing, dynamic process in which historical symbolic meanings are constantly recycled, actualized, challenged, renegotiated, and reconfirmed - or rewritten, depending on changes in public consensus or the ability or inability of a particular hegemonic societal group to maintain its hold on the collective imaginary. (2005, p. xviii)

It is the dynamism of national symbols that enables them to facilitate the discursive reiteration of values, historical events and traditions that are fundamental to the existence of a nation. As discussed earlier, to Hobsbawm (1988) the power that is invested in "invented traditions" owes much to their repetition to the extent that they become or appear to have 
become indispensable parts of a nation. In the case of national anthems for example, Kelen, 2003), suggests, "[t]his is the paradox of 'anthem quality' that applies as much to an overplayed pop song as to a hymn: that the more the words are sung and accepted (i.e., the stronger the sign they constitute), the less meaning they are permitted to carry" (p. 166). It is in this repetition that the power of national anthems and revolutionary songs lies, a repetition that evokes and strengthens the myth of an everlasting nation:

The 'eternal feel' of anthems works by means of their unconscious articulation. The anthem is the words that must always be sung, that have always been sung. That is how those words and that tune seem like permanent signs. That is how they make entities like nations appear to be permanent. (ibid.)

Studying national symbols in understanding the creation and maintenance of national identities is also important because they can be easily disseminated by the media technology and thus their impact can be augmented (Smith, 1991). According to Smith, national symbols "give concrete meaning and visibility to the abstractions of nationalism. The representations and images of the nation exert a profound influence over large numbers of people, exactly because they can be very widely disseminated by the media" (p. 73). Partially because of being exposed to the members of a community almost on daily basis, either through the mass media or otherwise, national symbols serve the function of maintaining "a stable experience of the world among collectives" (Geisler, 2005, p. xxvii). Maintaining this "stable" and continuous experience of the same world partially through the use of national symbols is particularly important among those people who have been physically and politically distant from each other (e.g. the Kurds living in four nationstates) because "as soon as members of the group lose physical contact with each other, cohesiveness begins to fade" (ibid.). It is especially in these circumstances that "the 
transference of emotions onto totemic emblems maintains the collective identity of the group" (ibid.).

Finally, I need to point out that national symbols recognized as such have not always existed, they have been constructed, recreated and appropriated intermittently regardless of the fact that nationalist discourses tend to present them as ancient or as old as possible. National symbols are examples of what Hobsbawm (1988) calls "invented traditions." They have been created by artists and intellectuals whenever and wherever nationalism comes to prominence; symbol formation is a part of the nation-building or nation-maintaining project (Geisler, 2005, p. xxiii). In sum, although national symbols contribute to the formation of national identities in significant ways, they are themselves social and historical constructs. In fact the formation of most of them (flags, anthems, monuments, coins and so on) is quite recent especially compared to another national symbol such as language, which happens to be an important constituent of many national symbols.

\section{Language}

Although an essentialist view of the link between language and nationality is undesirable for many theorists (May, 2001, p.10), almost all of the approaches to nation and nationalism such as modernism, primordialism and ethno-symbolism believe that language plays a "central role ... in the nationalist project" (Spencer \& Wollman, 2002, p. 76; also see Joseph, 2004, p. 94). ${ }^{57}$ According to Anderson (1991), "one notes the primordialness of languages, even those known to be modern" (p. 144). As I will explain in more detail shortly, whereas primordialists believe that language is the most salient marker of identity

\footnotetext{
57 "A consistent theme within studies of national identity over the last four decades has been the central importance of language in its formation" (Joseph, 2004, p. 94).
} 
be it individual, ethnic or national, proponents of the modernist view find language vital not because of being an index of ethnicity but because it is a decisive factor in the creation and maintenance of a unified nation-state. Language is also important from a social constructivist perspective because it is precisely through language that other cultural and national values are negotiated, constructed and constantly modified and articulated.

\section{Language as defining national identity}

Fishman (1989) argues that "language equals nationality and nationality equals language" (p. 279) and he presents several reasons for his claim (pp. 269-287). For example, he perceives "language as the link with the glorious past" (p. 275). The language spoken by the previous generations is passed on to the present generation and it will be handed over to future ones. In this sense a common language is one of the strongest links to the past. Even a modernist such as Anderson unmistakably supports this suggestion: "Languages thus appear rooted beyond almost anything else in contemporary societies. At the same time, nothing connects us effectively to the dead more than language" (Anderson, 1991, p. 145). Connections to the past fostered by language are significant because greatness in the past legitimates claims to greatness (e.g. self-rule) today:

The heirs of past greatness deserve to be great again. The heirs of triumphant unity in the past must themselves be united in the present and future. The heirs of past independence cannot but be independent again. The purported continuity of the language was the authenticating device for finding, claiming and utilizing one's inheritance. (Fishman, 1989, p. 276)

Language establishes, Fishman suggests, "the link with authenticity," in two ways:

directly through the language per se, i.e. the mother tongue, but also through the medium of either oral or written imagery (p. 276) (I will discuss the latter further down). The first highlights the emotional and spiritual links of the mother tongue with the individual and the 
community of those individuals who speak and share it. Fishman contends, "The essence of a nationality is its spirit, its individuality, its soul. This soul is not only reflected and protected by the mother tongue but, in a sense, the mother tongue is itself an aspect of the soul, a part of the soul, if not the soul made manifest" (p. 276, emphasis in original).

Fishman (1989) also reminds us that the German Romantics were perhaps the first to place language in the centre of nationalism's strive for authenticity. Arguably one of the strongest arguments to make this sentimental connection between language and national identity was put forward by Fichte in his "address to the German nation" in 1806 :

The first, original, and truly natural boundaries of states are beyond doubt their internal boundaries. Those who speak the same language are joined to each other by a multitude of invisible bonds by nature herself, long before any human art begins; they understand each other and have the power of continuing to make themselves understood more and more clearly; they belong together and are by nature one and an inseparable whole. (as cited in Joseph, 2004, p. 110)

Since for Fichte language and nationality were so naturally linked, the possession of a language was sufficient for a people to call itself a nation and express its claim to self-rule.

Fichte's compatriot Johann Gottfried Herder found a people (Volk) without its own language "an absurdity" and "a contradiction in terms" (Fishman, 1989, p. 279).

Despite the tremendous influence that the ideas of Fichte, Herder and more recent perennialists such as Fishman with respect to the indispensability of language in defining national identities have had on the scholarship on nationalism and language, there are those researchers who reject this essentialist view. One of the objections to the so-called German Romantic thought, that language defines nation, is the suggestion that these Romantic ideas developed to "scientific racism" from the mid-nineteenth to the mid-twentieth century (Joseph, 2004, p. 111). For example, Fichte claimed, 
Such a whole [as the nation defined by language], if it wishes to absorb and mingle with itself any other people of different descent and language, cannot do so without itself becoming confused, in the beginning at any rate, and violently disturbing the even progress of its culture. (as cited in Joseph, 2004, p. 111)

As Joseph (2004) suggests, there are different interpretations as to whether the architect of such ideas could foresee the upcoming calamitous and genocidal actions that were perpetuated by Nazism. However, Joseph (2004) is confident that Fichte did not see it and that the primary concern for him was to "rescue the German nation, language and culture from what seemed at the time like an overwhelming domination by the French" (p. 111, see also Fishman, 1989 , p. 277). ${ }^{58}$ Since Germany was "politically, religiously, and behaviourally" fractionated ... Only language implied an ideal genotypic unity that could counteract the phenotypic horrors of the day" (Fishman, 1989, p. 277). Furthermore, for Fichte language was the most obvious sign of distinctiveness from the French. ${ }^{59}$

One of the earliest and the most well-known arguments against Fichte's idea was put forward by a French linguist, Ernest Renan, in his 1882 address 'What is a nation?' (Renan, 1990). Renan states that "languages are historical formations, which tell us very little about the blood of those who speak them and which, in any case, could not shackle human liberty when it is a matter of deciding the family with which one unites oneself for life or for death" (p.17). For Renan, in defining and describing a nation, other human attributes such as "memories" and "the will" are more superior to language as it is

\footnotetext{
${ }^{58}$ The idea that identity construction might be a deliberate and strong mechanism in the face of alien domination and threat can be exemplified elsewhere. Stieve (2005) suggests that "Canada owes its national identity in part to American aggression" (p. 6).

${ }^{59}$ There are similar cases in recent times when the linguistic difference argument has been used to settle very serious social and political matters. According to Scollon (1999), "in the Estonian struggle for independence from the Soviet regime, a crucial move was to found national identity on the ability to speak the Estonian language" (p. 22) since the rest of the cultural traits were so similar between the Estonians and Russians. The significance of the move becomes more obvious when we learn that "this clearly political move positioned the non-Estonian speaking population of Estonia who were largely Russian speakers outside the community of relevance to the political process of achieving independence" (ibid.).
} 
illustrated in the case of Switzerland (p. 16) where people speak different languages but still make up a nation that is a "soul" and a "spiritual principle" by which they share past experiences and memories and have agreed or are willing to live together.

Another way of questioning the validity of the thought that assigns such a central role to language in defining national identity is to say that language is not always an element of exclusion or inclusion in ethnic or national communities. For example, there have been communities whose languages have been lost or they have gone through a process of decay and shift yet their ethnicity or national loyalties have not changed. A frequently cited example comes from Ireland where many people whose language has been shifted to English still consider themselves to be Irish and not English (Fishman, 2002, p. 84). In this case, the importance of language is only symbolic. Thus, despite its importance, language may not always be the defining component of national identities. Smith (1998) tells us,

National communities do purvey great historical and linguistic narratives, which are vital to their survival and renewal. But they contain much else besides-symbols, myths, values and memories, attachments, customs and traditions, laws, institutions, routines and habits - all of which make up the complex community of the nation. (p. 138)

In other words, a nation or even an ethnic community is much more than a language. There are over a dozen Arab nation-states, all of which have Arabic language as their official language, but this has not prevented them from being separate nation-states and cultivating and maintaining other different cultural values and symbols, such as different flags, anthems, myths and even regional speech varieties and vernaculars. Furthermore, Balakrishnan (1996) argues that "there are several ways in which nations are not "conceived in language"" (1996, p. 207). One can think of nation-states with more than one 
official language such as Canada, with several languages but only adopting one single language as their official language such as Iran or Turkey, and finally nation-states with an official language (e.g. English) that may not be the mother tongue of the majority members of the "imagined community," such as India. ${ }^{60}$

There are, however, instances where language is the most important ingredient of national identity. For example, Williams (2003) asserts that "the one feature of Welsh life which makes Wales clearly distinctive from any other country is the Welsh language" (35). This is despite the fact that in 1991 only 18.6 percent of Wales could speak the language (ibid.). The centrality of language in defining Kurdish identity has also been noted (Hassanpour, 1992). It is instances like these that have convinced theorists like Kymlicka \& Patten (2003) to note that "language is not just a tool of communication, but also, for some people, a central feature of identity" (Kymlicka \& Patten, 2003, p. 15; see also Phillipson, Rannut \& Skutnabb-Kangas, 1995, p. 7). Given these contradictory views on the place of language in defining group identities, it appears to be more reasonable to say that the importance of language in relation to national identity is context dependent. This in no way means, as I will show, that language might be irrelevant in any case of nationalism. This is rather to say that the degree to which language can be regarded important varies from one situation to another. For example, functionalist theorists of nationalism, such as Gellner, may not see any particular language as an indispensable component of a particular national identity, but even he finds a national/official language instrumental in the formation and maintenance of a nation.

\footnotetext{
${ }^{60}$ There are over a dozen official languages in India such as Hindi, Bengali, Telugu, Marathi, Tamil, Urdu, Gujarati, Malayalam, Kannada, Oriya, Punjabi, Assamese, and Kashmiri.
} 
The instrumentality of one language for one nation

Language is regarded as instrumental in Ernest Gellner's influential socio-economic approach to nation and nationalism. His validation of language as instrumental has set the tone for most of the contemporary scholarship on nationalism and national identity (Joseph, 2004, p. 114). For Gellner (1983), a nation is characterised as a high culture defined by a high level of literacy. Thus the formation and maintenance of a modern nation depends on a publicly run education system. This education, however, could only achieve its goal of engendering a high literate culture if it was conducted in the same standardized national language. From this functional view, a language per se, i.e. in its vernacular form, is not important in defining a national identity. The national language instead is the one that is purposefully and systematically codified, elaborated and is given the power and official status so that it could legitimately serve the purpose of unifying and homogenizing communication among the citizens and facilitating their acculturation into a unitary culture regardless of their ethnic and linguistic diversity.

Gellner (1983) contends that the "invention" of the modern nation-state was necessitated by industrialization and the successes and progress of an industrialized society depended on communication in one single standardized language for the entire nation. An industrial society brought about a division of labour among a population that was characterised by cultural, ethnic and linguistic diversity. Thus, for Gellner, industrialization necessitated a homogeneous, unified and monolithic culture that needed to be characterized by national literacy, and this had to be taught and facilitated in the same standardized language in each nation. He says,

Universal literacy and a high level of numerical, technical and general sophistication are among [industrial society's] functional prerequisites. Its members are and must be mobile, and ready to shift from one activity to another, and must posses that generic 
training which enables them to follow the manuals and instructions of a new activity or occupation... Communications must be in the same shared and standardized linguistic medium and script. (Gellner, 1983, p. 35)

Gellner emphasized that the nation needed one single national language in which all citizens could communicate. In other words, he endorsed "the conventional nation state ideology" which guided the nation-building project on the premise that an ideal nation had to be unified politically, ethnically and linguistically: "According to the conventional nation state ideology, the ideal state is homogenous, consists of one nation/ethnic group only, and has one language" (Phillipson, Rannut \& Skutnabb-Kangas, 1995, p. 5). Almost all the European nation-states were built on this premise and their practice was replicated elsewhere, for example in Turkey, Iran and Syria where the state in both theory and practice pursued the policy of imposing one national language, that of the dominant ethnic groups-Turkish, Persian and Arabic respectively-on multiethnic populations (see also Bourdieu, 1991, pp. 43-65; Cormack, 1993, p. 101; Costa, 2000, p. 413).

To really understand how powerful this idea of one nation, one language is, and how much it has permeated ideas on the building and maintenance of nations and nationstates, one finds it interesting to look at the case of the United States. It is well known that the American national unity has never rested on language, i.e. on English, which is also the official or dominant language of many other nations (Romaine, 2000, p. 228). ${ }^{61}$ Despite this, as Romaine tells us, "a multimillion-dollar lobby group with links to the immigrationrestriction lobby, seeking to obtain a constitutional amendment making English the official language of the USA, is trying to stir up support for a language-related national identity

\footnotetext{
${ }^{61}$ The US does not have an official language, albeit in recent years the movement for making English the only official language has become stronger.
} 
politics" (ibid.). Theodore Roosevelt, the US president from 1901 to 1909 , has been quoted as saying:

We have room for but one language here, and that is the English language, for we intend to see that the crucible turns our people out as Americans, of American nationality, and not as dwellers in a polyglot boarding house and we have room for but one loyalty, and that is a loyalty to the American people." (as cited in Romaine, 2000 , p. 228, my emphasis)

Thus, from the state ideology perspective the loyalty to one people/nation is equal to the possession of one language only.

The first problem with this "conventional state ideology" is that the national language is privileged at the expense of minority languages which have often been repressed, marginalized or even banned from the public use. ${ }^{62}$ This has been done because from the conventional state ideology perspective "fostering diversity is necessarily seen as a threat to the political unity and territorial integrity of a state: at some point, so the argument goes, the minorities will themselves start striving towards this 'natural' ideal political organization, a nation state of their own" once they are granted linguistic and cultural rights (Phillipson, Rannut \& Skutnabb-Kangas, 1995, p. 5). There are, however, examples contradicting this prediction. Catalans for example enjoy their cultural and linguistic rights in Spain, but so far they have shown no ambition for an independent state of their own. There are over a dozen nation-states embracing bilingual and multilingual policies (e.g. Canada, South Africa, Switzerland, Belgium, India and Spain, ${ }^{63}$ just to name a

\footnotetext{
${ }^{62}$ For example, in UK, in the eighteenth C., while English became "the official/standard language" speaking or even singing in Gaelic was forbidden in Scotland, and the same thing happened in Franco's Spain with respect to the Catalan language (Kilborn, 1993, p. 641). More recently, in Turkey where a drastically reformed Turkish became the official language in 1943, Kurdish, a minority language of several million citizens of the country, was totally banned (Hassanpour, 1992).

${ }^{63}$ Costa (2003) points out that in Spain's multilingualism "citizens are not equal as far as language rights and duties are concerned" (p.416), because whereas having access to a regional language such as Catalan in Catalonia is a right, knowing Spanish in the entire country of Spain is not only a right but also a duty. Catalan
} 
few) which by many standards have been much better off with respect to cultural harmony, welfare and political stability compared to the states pursuing linguistic and cultural assimilation of the minorities. Often the latter are plagued with ethnic violence and civil wars and guerrilla warfare, for example Sri Lanka and Turkey. In fact it has been suggested that the modern nation-state is inseparable from participatory democracy, and this may not be possible when speakers of other languages are forced to abandon their own and only communicate in the language of others. Kymlicka \& Straehle (1999) suggest that "democratic politics is politics in the vernacular. The average citizen only feels comfortable debating political issues in their own language" (p. 70).

Despite all this shortcomings of the nation state ideology, it is rather surprising how persistent the doctrine has been to the extent that it has also influenced the nation-building endeavours of minority nationalist movements. Since they have been victimized by the state ideology, one would expect the minorities not to subscribe to the same oppressive ideology. Surprisingly, however, they do. They too pursue the construction and validation of a single language as the pinnacle of their collective identity even if it is at the expense of less powerful speech varieties. Later in this study, I will provide examples from the Kurdish language.

The other problem with the state ideology, which is committed to the project of homogenization on all fronts, especially language, is that it is based on the pretext that a single national language is necessary for communication. Although true to some extend, the claim tends to undermine the political implications of homogenization and unification of 
languages and dialects. Looking at the language unification process in France as part of the nation-building project, Bourdieu (1991) suggests that

It would be naïve to attribute the policy of linguistic unification solely to the technical needs of communication between the different parts of the territory, particularly between Paris and the provinces, or to see it as the direct product of a state centralism determined to crush 'local characteristics'. The conflict between the French of the revolutionary intelligentsia and the dialects or patois was a struggle for symbolic power in which what was at stake was the formation and re-formation of mental structures. (p. 48)

In other words, imposing one national language in a country is more than facilitating an easier means of communication among its population. It is also legitimizing a particular political authority (ibid.), a certain style of social control (Kilborn, 1993, p. 641) and finally an ideological way of socializing the public, which results in their indoctrination into a more or less similar way of seeing, understanding and interpreting the world, of seeing themselves and others. This is particularly carried out in the schooling of children where "the schoolmaster" by teaching in the same fixed language "inclines [students] quite naturally to see and feel things in the same way; and he works to build the common consciousness of the nation" (Bourdieu, 1991, p. 49). Further, even in the domain of media, the use of a single language is more than assisting the population to access information in a common language. It is also a way of representing events, ideas, issues and subjects in the same language and reinforce "the common consciousness of the nation" that Bourdieu notes. The print media, for example, have been credited with the same affect (Anderson, 1991; McLuhan, 1962). Anderson (1991) has famously declared that the modern nation was “imagined in language" (p. 146). 


\section{Language and imagining the nation}

Anderson (1991) suggests that "from the start the nation was conceived in language" (p.

145) and it continued to be a "community imagined through language" (p. 146). To be sure, however, by language here Anderson means print-language and not any language per se: "Print-language is what invents nationalism, not $a$ particular language per se" (1991, p. 134). In fact he is very explicit about his stand against any essentialist view of the links between language and nation:

Nothing suggests that Ghanaian nationalism is any less real than Indonesian simply because its national language is English rather than Ashanti. It is always a mistake to treat languages in the way that certain nationalist ideologues treat them-as emblems of nation-ness, like flags, costumes, folk-dances, and the rest. Much the most important thing about language is its capacity for generating imagined communities, building in effect particular solidarities. (p. 133)

One of his reasons is that any language can be learned, although none of us lives long enough to learn them all. Thus language cannot be and has not been a definite sign of exclusion or "othering" which is an indispensable part of identity construction practices (Barth, 1969). ${ }^{64}$ To Anderson language has always been inclusive (p. 135). Therefore, it does not matter in which language a nation is imagined; the crucial thing is the imagining, and it is only done in print-language and not the oral form because it is only the printed text that can be shared by those members of the nation that may never see each other face to face. Of course one can suggest that with the emergence of radio, television and the Internet print has lost that unique position.

\footnotetext{
${ }^{64}$ One should note that learning additional languages is not so easily achieved and it depends on so many social, cultural, temporal, political and economic factors. For example, age of the learner could make a tremendous difference not to mention her aptitude, attitude, motivation and other personality traits. An immigrant can live in Canada for fifty years but not being able to lose the accent that tells others he was not born in Canada. Secondly, one could argue that if languages can be learned, so can other cultural aspects, which Anderson and others consider important in defining national identity such as folkdance, music, national anthem and many other cultural traits. And if national identity is not these, one wonders what it might be then.
} 
For Anderson, print-language and oral language function differently in the nationbuilding project. Whereas the print-language facilitates the simultaneous imagining of the nation across time and space, the oral vernacular strengthens the emotional aspect of national identity. Print-languages unify the nation, whereas the emotional feelings attached to the oral makes one die for that nation (Wogan, 2001). As Wogan argues, for Anderson "orality is associated with emotion, particularism, and multilingualism, which are contrasted with print and seen as threats to national unification, with the exception of emotion harnessed to national attachment" (p. 408). One problem that arises here has to do with the extent and level of literacy in the mid and late seventeenth century when, according to Anderson, the first modern nations came to existence. Smith asserts that at the time, "[e]ven in Europe, literacy was often confined to small coteries of intellectuals and upper classes" (Smith, 1998, p. 139). This is problematic for Anderson's thesis because for nationalism to be successful in building the nation mobilization and indoctrination of the masses is necessary. Thus privileging print-language does not seem to be quite helpful in answering Anderson's own question: why nationalism has inspired so many to die for the nation?

However, Anderson is not alone in privileging print-languages in contrast to orality in the processes of nation building and national identity formation. For Hastings (1997) the possession of a written language and literature is the decisive criterion by which an ethnicity can be distinguished from a nation: "Oral languages are proper to ethnicities; widely written vernaculars to nations"' (p. 21). Echoing Anderson (1991) and Hastings (1997), Hobsbawm (1990) believes that it is the printed-languages used by the literary elite and that serve an administrative usage that "become an important element of proto-national 
cohesion" (p. 59). In other words, language could only be "a criterion for nationhood" when used by the ruler and the elite and not the ordinary people (p. 56). Hobsbawm does not deny the relevance of language "in the Herederian sense of language spoken by the Volk," to the formation of nationalism, but he sees the role as non-central and indirect. Despite this he acknowledges that in some circumstances where language becomes a major group differentiation marker, it could occupy an important place in the discourse of nationalism. In a similar vein, Guibernau (1996) argues that, "the existence of a vernacular language is not an indispensable basis for the creation of national consciousness" (p. 67), but at the same time, he continues, "although, where it exists, it facilitates that creation [of national consciousness]."

Fishman (1989) takes a different approach from Anderson and Hobsbawm, an approach that is very useful in conceptualising the language-nation link in relation to a stateless nation like Kurds. About a decade earlier than Anderson, Fishman ([1972] 1989) realized the importance of vernacular literature, both print and oral, in the nation-building project:

...vernacular literature (oral and written) provides the masses with the emotionalized link between language and nationals that exists for elites at the level of ideological and intellectual program. The beauty of the vernacular, the greatness of the nationalist, the purity of the common cause are grasped by many for the first time-and thus associated with their personal emotional and intellectual 'rebirth'via the popular literature of nationalism. (Fishman, 1989, p. 283)

Whereas for Anderson the nation could be imagined in any language, as long as it is printlanguage, for Fishman the print-language becomes important when it is in the vernacular or what he prefers to call "the mother tongue." For him, the same vernacular in both oral and print form serves the nationalism project. This is certainly the position of those nationalisms that perceive the vernacular as an indispensable component of national 
identity whether it is that of the North American Quebec, European Flanders or Asian Kurdistan. As Fishman (1989, p. 272) suggests, in an age when neither radio or television, and one can add the Internet, were available, the spread and success of mass nationalism significantly depended on both printed word, and literacy and education. These days, however, one could suggest that television and the Internet have provided new means of facilitating communication and simultaneous imagining of the nation across time and space among the members of a nation. This especially appears to be more significant for groups of people like the Kurds who for the most part do not have their own education system.

By now it should have become clear once again that an essentialist view of the connection between language and national identity is not desirable. As Joseph (2004) rightly reminds us “... there are no 'universals' where language and national identity are concerned. Even the concepts of 'language' and 'nation' themselves are subject to local variation" (p. 94). He continues to say that "we can, however, find certain patterns running through the linguistic construction of national identity worldwide, and they provide the matrix within which the vicissitudes of local construction can be read and compared" ( $p$. 94). This is to suggest that depending on context and each specific case, language may or may not be central in defining national identities. What is clear, however, is that almost all components of national identity, including language itself, one way or another, are articulated, shaped and imagined through language. In other words, the creation of the nation and formation of a national identity, not entirely, but in crucial ways, is discursive. 


\section{Chapter 4: Discursive Construction of National Identities and the Media}

To have a national identity is to possess ways of talking about nationhood.

(Billig, 1995, p. 8)

... the construction and emergence of national identities cannot properly be understood without reference to the role

of communications technology. (Morley, 1992, p. 267)

In the previous two chapters, I have laid out the theoretical background with respect to three concepts: nation, nationalism, and national identity. In this chapter, I will expand the theoretical background by explicating some key assumptions about two more concepts: discursive constructions of national identities, and the role of communication technologies in the projects of national identity constructions and reproductions. I will suggest that in crucial ways national identities are constructed and reproduced discursively. In order to be effective and experienced, discursive constructs of national identity need to be disseminated and negotiated within particular audiences and groups of people. Mass media are among the most effective means of executing this task.

\section{Discursive construction of national identities}

Although Anderson's publication in 1983, Imagined communities: Reflections on the origin and spread of nationalism, was the first major work on nation and nationalism from a discourse constructivist approach, we had to wait another decade to witness a series of studies that started to engage in the detailed analysis of the language and discursive practices of the construction of national identities. The two pioneer works in this respect are 
Billig (1995) and Wodak et al. (1999). ${ }^{65}$ While a few studies have specifically drawn upon Wodak et al. (e.g. Ricento, 2003; Karner, 2005; Higgins, 2004), these studies and more have been influenced by Billig (1995) (e.g. Bishop \& Jaworski, 2003; Dixon \& Durrheim, 2000; Kösebalaban, 2004; Law, 2001; Sutherland, 2005; Yumul \& Uzkirimli, 2000).

Wodak et al. (1999) have studied the discursive construction of national identity in Austria. In addition to interviews and focus-group discussions, the bulk of their data encompasses media products: newspaper articles, posters, slogans and direct mail in time of election campaigns, and politicians' speeches, most of which are mediated by the media. The findings in this study illustrate that discourses facilitate the construction of national identities. Wodak et al. identify three components of discourse and textual analysis: contents, strategies, and linguistic means and forms of realization (p. 30).

Contents can be viewed as the meaning-making sources for the discourse of national identity. Wodak et al. (1999) identify the following thematic contents (ibid.):

1. the linguistic construction of the homo Austriacus

2. the narration and confabulation of a common political past

3. the linguistic construction of common culture

4. the linguistic construction of common political present and future

5. the linguistic construction of a "national body"

Similar to Billig's (1995) study, these thematic contents, resources for the discourses of national identity, are based on a study of an established nation-state. When studying the identity of stateless people, one expects the above list to be modified accordingly (See Appendix 1). For example, whereas language in Wodak et al. is treated as only one part of culture, in the case of the Kurds language needs to be viewed as one of the most important identity markers. Since Austria shares its language with another national

\footnotetext{
${ }^{65}$ A summarized version of Wodak et al. is presented in de Cillia et al. (1999).
} 
identity, Germany, it is not surprising that language is not on top of the list. For the Kurds, however, it needs to be different. Whereas language in the case of Austria is a sign of similarity with the "Other," in the case of the Kurds language is perceived to be the most salient sign of difference with Turks, Persians and Arabs, the three dominant ethnic groups in the states where Kurds reside.

The thematic sources upon which discourses of identity draw are packaged through strategies. ${ }^{66}$ The strategies are discursive construction, perpetuation, transformation, and dismantling of national identities. According to Wodak et al. (1999), the nationalist discourses employ a number of strategies to represent and materialize the semantic areas in terms of language and other discursive means (e.g. images). The following macro-strategies are identified: constructive, perpetuating, transformational and destructive. Constructive strategies refer to the attempts aimed at constructing and establishing "a certain national identity by promoting unification, identification and solidarity, as well as differentiation" (p. 33). Perpetuating strategies "attempt to maintain and to reproduce a threatened national identity, i.e. to preserve, support and protect it" (p. 33). This involves strategies of justification, which are "employed primarily in relation to problematic actions or events in the past which are important in the narrative creation of national history" (p. 33).

\footnotetext{
${ }^{66}$ Drawing on Bourdieu's work, Wodak et al. (1999) posit that "strategic action is oriented towards a goal but not necessarily planned to the last detail or strictly instrumentalist; strategies can also be applied automatically" (p. 32). Following Bourdieu, they "argue for 'soft, relative determinism"' to declare that actors are not completely free to act, and their actions are conditioned by "the socialisation of individual acting" ( $p$. 32). Nonetheless, they are quick to assert that despite this individuals cannot be absolved from the responsibilities they aught to assume for their actions including their discoursal activities. "For CDA, language is not powerful on its own-it gains power by the use powerful people make of it" (Weiss \& Wodak, 2003, p.14). This is where these CDA researchers differ from some extreme post-structuralist and post-modernist views claiming that all social constructions are purely discursive. The same applies to institutions, groups and political entities involved in the construction, reproduction, and maintenance of national identities. Owners and webmasters of television stations and web pages are good examples. The degree of intention, however, may vary according to the type of data under analysis, for example a political speech is often much more intentional and purposeful than a casual conversation among "ordinary" people.
} 
Transformational strategies "aim to transform a relatively well-established national identity and its components into another identity the contours of which the speaker has already conceptualised" (ibid.). Finally, destructive strategies "aim at dismantling or disparaging parts of an existing national identity construct, but usually cannot provide any new model to replace the old one" (p. 33).

The last dimension of Wodak et al.'s analytical framework is means and forms of realization (p. 35). Although the study acknowledges that the list is by no means complete, the focus is on lexical units and syntactic devices that "serve to construct unification, unity, sameness, difference, uniqueness, origin, continuity, gradual or abrupt change, autonomy, heteronomy and so on" (ibid.). Similar to Billig (1995), Law (2001) and Higgins (2004), Wodak et al. (1999) underscore deixis (personal, spatial and temporal references) as "the most important" linguistic devices of national identity discourse. ${ }^{67}$ In addition to deixis, they pay close attention to euphemisms, linguistic slips, metaphors, rhetorical questions, passive versus active voice, agency and personification (pp. 35-42).

Among the findings in Wodak et al., the following are particularly important for this study. First, national identities are engendered and reproduced through discourses. The study, however, reiterates that the formation of national identities is not exclusively discursive. In substantial ways, extra-discursive (e.g. institutional and material social) structures decide national identities. For example, the study confirms Higgins's (2004) findings that political functions and affiliations of both the addressers and the addressees could affect the kind of national identity that is imagined and projected (Wodak et. al, 1999,

\footnotetext{
${ }^{67}$ Deixis (from Greek) means "pointing" with language (Yule, 1996, p. 9). "Any linguistic from used to accomplish this 'pointing' is called a deictic expression" (ibid.). Examples of deixis are: pronouns I or we (personal deixis), here or there (spatial deixis) and now or then (temporal deixis).
} 
pp. 188-9). Second, the study demonstrates that "there is no such thing as one national identity in an essentialist sense" (p. 186, emphasis in original). Discourses of national identity are susceptible to the context within which they are formed, negotiated and disseminated. Context here refers to the extent to which a discourse is exposed publicly, the situation and mode of the exposure and the addressees, among other things (pp. 186-7). For example, the study shows that whereas the public discourse of Austrian national identity does not excludes minorities, the semi-public and quasi-private interviews (e.g. individual interviews) excluding ethnic minorities, in the sense of not considering them as "Austrians," is a "constitutive element of national identity" (p. 192). Third, the study highlights the importance of intertextual connections (p. 189). Some examples are, literal repetitions of passages from commemorative addresses and text extracts from books and articles by historians, political scientists and essayists, and hackneyed formulations transferred from the areas of politics and the media into semi-public formulations transferred from the areas of public and the media into semi-public and quasi-private areas (recontextualisations). (p. 189)

Fourth, the study shows that Austrians perceive their language to be an important feature of their national identity (p. 193). Since they realize their language is also German, similar to their neighbour, Germany, Austrians tended to emphasize the differences between the two varieties of German. Most Austrians also wanted to distinguish themselves from Germany especially in relation to the "common Nazi past" (p. 192). Fifth, the study illustrates that the discourse of an Austrian national identity encompasses both state-based and culture-based (Staatsnation and Kulturnation) features of national identity. State-based features include citizenship, the country's social and economic progress, and its "neutrality"(p. 190). Culture-based features include culture, sport, language and "a frequently invoked 'Austrian mentality', and 'typical Austrian ways of behaviour"” (ibid.). Wodak et al.'s final finding 
compares the discursive identity constructs produced by the politicians and media elites, on the one hand, and the semi-public and quasi private situation, on the other. The study concludes that

[t]he discursive national identification 'products' offered by these political and media élites to their targeted audiences was influenced partly by the demand of these target groups for images to reinforce their national confidence. At the same time, these élites endeavoured to satisfy such demands for national identity, at times by creating, emphasising, or-as illustrated by the myth of permanent neutralityby playing down particular features of this identity. (p. 202)

Put differently, the discourses of the elites, including media, not only reinforce the national identity that is desired by the public, but they also modify, reshape and rearticulate that identity.

Focusing on the discursive identity constructs promulgated by the media elites is more prominent in Billig (1995) and other works that have drawn upon that study. Billig (1995) introduces the term banal nationalism "to cover the ideological habits which enable the established nations of the West to be reproduced" (p. 6). Refuting the suggestions of some observers that the age of nationalism in the West is over, Billig argues that the ideological habits of banal nationalism are embedded in the daily lives of the citizenry to the extent that albeit quietly but persistently and effectively "the nation is indicated, or 'flagged"” (ibid.). Billig illustrates that different kinds of British newspapers, right or left wing, spreadsheet or tabloids, discursively and symbolically "flag" the nation and homeland daily. Banal nationalism, in contrast to "hot" or "ethnic nationalism," often "operates with prosaic, routine words, which take nations for granted, and which, in so doing, inhabit them. Small words, rather than grand memorable phrases, offer constant, but barely conscious, reminders of the homeland, making 'our' national identity unforgettable" (p. 59). 
For example, both journalists and politicians quoted in the newspapers use, reinforce, and redefine the word "nation" constantly (p. 116). The nation is often reproduced through the use of non-designated nouns such as "the nation," "the country," "the region." These flag the British national identity as a given, a context within which the daily life is carried out. In contrast, 'other' places and nations are explicitly identified, for example the United States, France and so on.

This routine reproduction of national identity is also, and more frequently, carried out by deixis, encompassing some of "the most basic things we do with utterances" to point at things, people, spaces and time (Yule, 1996, p. 9). Some examples of deixis are, 'here' versus 'there' (spatial), 'we' versus 'they' (personal) and 'now' versus 'then' (temporal). According to Fowler (1991), deixis "links a text with the time and place of communication and with the participants, which 'orient' speaker and addressee to the context of the discourse" (p. 93). Billig (1995) shows that in newspapers, for example, editorials routinely use the syntax of hegemony and unity by using words like "we" and "us" which encompass not only the paper, the writers and the readers, but also the entire "nation" (pp. 114-5). The discourse of the media, according to Billig (1995), presents England as the homeland, centre of the continent of Europe, and the nation to be appreciated by its citizens. He observes that when reporting the weather, papers display a map of Europe with England placed in the centre, and this way they emphasize the prominence of the "homeland" ( $p$. 117). The nation is "here" and the rest of the world is "there."

Billing (1995) observes that focusing on and validating the nation and homeland is also achieved by the national news coverage compared to international stories in the British press (p. 117). Whereas focus on the national news could flag the nation, national identity 
could also be reinforced through foreign news coverage. Home news (ours) is always more than the international (theirs). Thus, a "'biased' interest in 'ourselves"” is reinforced (p. 84). Other studies have come to the same conclusion. For example, a study of the Greek newspapers' coverage of the Macedonian question in 1992-1993 shows that the Greek press contributed to the flourishing of Greek nationalism by adapting an ethnocentric outlook towards the foreign news (Demertzis et al., 1999; also see Chouliaraki, 1999).

Billig's research further demonstrates that whereas the flagging of the nation concerning the editorials and the news sections of the press is implicit, when it comes to the sports section, the national flag is waved quite explicitly. Bishop \& Jaworski (2003), analyzing news reporting in the British press of soccer game between England and Germany, also conclude that sport reportage in the British press formulates English nationalism and reproduces the nation-state as a sovereign and homogeneous entity. This unified entity, in turn, constrains the behaviour of its citizens within the boundaries defined by the values and the ideology of nationalism.

Bishop \& Jaworski (2003) identify three strategies used by the British press to reproduce English national identity: separation, conflict and typification. Separation refers to the rhetoric of "us" versus "them" through which self-representation contrasted with other-negative-representation. The differences between "us" and "them" is intensified through the portrayal of war imagery. Through the use of a military metaphoric language past animosities between Germany and Britain are invoked and "our" nation's victories are glorified to say that we have to "beat'em" again. Finally, typification strategy reproduces the nation as both homogeneous and timeless. Through the use of modals with high probability, a national future is projected as in these examples: "there will always be an 
Ingerland," or, "[the England's visory] was a moment to savour and one which, while it may not lead to England winning this competition, will be remembered for years to come" (p. 255, my emphasis). This way, the continuity and eternity of the nation is heralded. Similar observations have been made in different parts of the world, for example in Turkey (Kösebalaban, 2004), where the Turkish press's sports reportage has been investigated for its discursive practices in reproducing a collective national identity. Replicating Billig's methodology, Yumul \& Uzkirimli (2000) have further researched the Turkish newspapers' sports coverage. They have concluded that "...the discourse used by the Turkish press is crammed with the constituent elements of the nationalist ideology" (2000, p. 15).

Law (2001) and Higgins (2004), investigating the Scottish press and Scottish national identity, primarily draw upon Billig's study, and confirm the importance of deixis in reproducing national identities in Scotland. However, they make several useful observations in relation to Billig's study. Law observes that "unlike banal British nationalism, able to sink around England vitally unnoticed in the shadows of deixis, national identity in Scotland is more explicitly enunciated" (p. 314). I expect this to be the case with Kurdish identity as well since Kurdistan, similar to Scotland, more or less, is a stateless nation. This compels Law (2001) to call for a revision to Billig's approach when applied to stateless nations (p. 300). In the case of Scotland and Kurdistan, in addition to the small words one also needs to look for the more obvious and discernible symbols and discursive practices of national identity.

Unlike Law (2001), Higgins (2004) wants to find out "what distinctions may be made between" Scots (p. 466), instead of looking for commonalities among them. Investigating several Scottish newspapers' coverage of 1999 elections for the Scottish 
parliament, Higgins analyzes the language choices of the papers in naming the location of the elections, i.e. Britain versus Scotland. He concludes that "various newspapers engage in particular textual strategies of articulating nation and politics, based upon a politically charged distinction between Scotland and Britain" (p. 469). Thus, Higgins highlights the influence of media's political affiliations on their discourse of national identity. The findings show that the newspapers' stance on the constitutional arrangement between Britain and Scotland at the time (whether they favoured the mutual arrangement as opposed to total independence for Scotland) seemed to determine the textual choices made in the papers with respect to naming locations. A valuable outcome of this study, especially for studying Kurdish media, is that lexical choices and other discursive practices related to national identity are often politically and ideologically charged. Thus, it will be interesting to see if the discourse of both Kurdish TV stations under investigation name locations the same way or differently. It is well known in the political circles that PUK, the Kurdish party affiliated with the current Iraqi president, Jalal Talabani, avoids indications of separating Kurdistan from Iraq. Conversely, KDP, which is affiliated with Masoud Barzani, the president of the Kurdistan-Iraq, portrays itself as more nationalist, more Kurdistani and less Iraqi. It will be interesting to see if these different political positions are reaffirmed in the two TV stations' discursive identity constructs.

These studies (i.e. Bishop \& Jaworski, 2003; Law, 2001; Higgins, 2004), in their own ways, confirm Wodak's (2006) assertion that "discourses serve to construct national identities" (p. 112). The place of language and discourse in the construction of national identity is well explicated by Billig (1995): “... an identity is to be found in the embodied habits of social life. Such habits include ways of thinking and using language. To have a 
national identity is to possess ways of talking about nationhood' (p. 8, my emphasis). "[Possessing] ways of talking about nationhood" can mean at least two things. First, it means as Fishman (1989) says, that "nationalist beliefs, like all societally patterned beliefs, are language dependent" (p. 287). In other words, defining one's identity and its continuous remaking is done through language, not entirely of course, but in very significant ways. Second, "possessing ways of talking of nationhood" also means having access to ways of producing and disseminating discursive constructs of national identities, for example having access to mass communication technologies. As Michael Mann has suggested, [if an ideology], such as nationalism, "[is] to spread, [it] must be organized through specific channels of communication" (as cited in Spencer \& Wollman, 2002, p. 47).

Billig (1995) and other studies discussed here have underscored the crucial role of communication technologies in the formation, reproduction and articulation of national identities. These studies, however, have been more concerned with the language, messages and contents of the media rather than their technological characteristics per se. As I will discuss in the next section, focusing on both aspects of media is important because identity discursive constructs of a stateless people are mostly shaped and distributed through communication technologies. Among the most important technologies are satellite television and the Internet, for reasons that I will present shortly.

\section{Media and the articulation of discourses of identity}

\section{Traditional media as the "architect of nationalism"}

Contrary to Billig (1995), Wodak et al. (1999) and other researchers with a discourse analytical orientation reviewed in the previous section, some prominent scholars have deemed mass media of communication important in the emergence of nationalism and 
formation of national identities not because of their content but because of their technical characteristics or their forms (Deutsch, 1966; McLuhan, 1962, 1964; Gellner, 1983). For these scholars, communication technologies enable people from far away distances to connect and interact, regardless of their messages. This interaction, over time, especially when it is in the same language, brings about commonality, unity, homogeneity or sameness and finally loyalty to a collective entity, the nation.

McLuhan $(1962,1964)$ posited that print technology was the architect of "nationalism" in Western Europe and gave birth to the nation in a deterministic way: "What we call 'nations' did not and could not precede the advent of Gutenberg technology" (McLuhan, 1962, p. ix). Traces of this claim can be found in the writings of Innis (1951): "By the end of the sixteenth century the flexibility of the alphabet and printing had contributed to the growth of diverse vernacular literatures and had provided a basis for divisive nationalism in Europe" (p. 55). ${ }^{68}$

McLuhan (1964) speculated that printing turned vernaculars into an "extensive mass medium" (p. 177) that engendered homogenization in the sense of being able to communicate in one single code or language. Because print fostered "uniformity" and then "repeatability" of such unified forms, it prompted the standardization of vernaculars by codifying the spelling, syntax and pronunciation of vernaculars of the masses (p. 175). As a result of printing, "visual images of group destiny and status" (p. 177), started to disperse with unprecedented speed over vast territories (p. 177). Because these images were in the

\footnotetext{
${ }^{68}$ McLuhan credits Innis (1951) as the "first" who explained "why print causes nationalism and not tribalism; ... Harold Innis was the first person to hit upon the process of change as implicit in the forms of media technology" (1962, p. 50, emphasis in original). McLuhan called his first major contribution (1962) "a footnote of explanation" to Innis's work.
} 
same code ${ }^{69}$ for a large group of people living on the same territory, they fostered commonalities and similarities. This, according to McLuhan, resulted in "political unification," centralization and thus the establishment of nation-states (p. 175).

Aside from the social and cultural effects, print also caused significant political changes. According to McLuhan, as products of "the printed book and the printed page, uniformity and repeatability gave to the political ruler a new instrument of centralism and homogeneity" (1960, p. 571). Within the boundaries of the vernacular, the ruler could use printed materials to spread the same information to different corners, and this enabled him to mobilize the population. Since nationalism has often been identified as a political and at the same time mass movement (Gellner, 1983; Smith, 1998), this capability of printing must have been crucial in the success of the nationalism project. The printed words, as also noted by Anderson (1991), brought about fraternity and loyalty to a common sovereign, something that nationalism is meant to achieve. It is from this perspective that McLuhan sees nationalism as the child of print.

McLuhan's perspective, which attributes a direct causal role to media, for example print as the creator of nationalism, has been identified as "technological determinism." McLuhan's "technological determinism," which suggests that a technology on its own can be the cause of social change apart from social, economic, political or institutional workings of that technology, may have not been all that convincing to scholars of nationalism (e.g. Deutsch, 1966; Gellner, 1983; Anderson, 1991; ${ }^{70}$ Smith, 1998;

${ }^{69}$ Code here is understood "in the sense of a system of norms regulating linguistic practices" (Bourdieu, 1993, p. 45).

${ }^{70}$ Although Anderson (1991), similar to McLuhan, underscores the importance of print in imagining the nation, he differs from McLuhan's view in that he believes that the creation of the nation was mediated 
Hobsbawm, 1991) or of cultural studies (Williams, 1974, pp. 126-34). However, his famous saying, "the medium is the message," has enjoyed popularity with commentators on the relationship between media and nationalism. For example, Gellner (1983), who unlike McLuhan adopts a socio-economic approach to nationalism and the invention of the nation, sounds unmistakably McLuhanian when he comments on the role of modern communication technology with regards to nationalism:

The media do not transmit an idea which happens to have been fed into them. It matters precious little what has been fed into them: it is the media themselves, the pervasiveness and importance of abstract, centralized, standardized, one to many communication, which itself automatically engenders the core idea of nationalism, quite irrespective of what in particular is being put into the specific messages transmitted. (p. 127)

This position of Gellner can be traced back to one of McLuhan's most famous sayings which wass written about twenty years earlier: "the medium is the message," which more closely resembles another statement by Gellner: "The most important and persistent message is generated by the medium itself" (p. 127). ${ }^{71}$ Both believe that the content of media, the messages they carry, should matter very little, for "the 'content' of any medium blinds us to the characteristics of the medium" (p. 9; see also Deutsch, 1966, p. 90).

However, there is clearly more to the media than their technological attributes, namely the messages they disseminate. For example, Connor (1994) observes that ethnic consciousness in most of the world "involves not the nature or density of the communication media, but the message" (p. 38). The idea of "self-determination" is an example in point. Although this idea goes back to the mid-nineteenth century, it started to be viewed as a "universal truth" after the Second World War when it was publicized to

${ }^{71}$ However, Gellner makes no reference to McLuhan. 
mean that "any self-differentiating people, simply because it is a people, has the right, should it so desire, to rule itself" (p. 38). The idea, as Connor sees it, has been a "catalyst" for "ethnic" nationalist movements: "The spreading of effective communications has had an evident impact upon ethnic consciousness, but the full impact of the communications media did not precede the message of self-determination" (1994, p. 39). Thus, one can suggest that in the projects of creating national identities, mass media of communication are important because they carry messages that inject new ideas and values or reinforce old myths and memories which can instigate national awareness, start or intensify nationalist movements, or preserve and reconstruct national identities.

In addition to privileging the technological aspect of media over their contents, traditional conceptualizations of the place of media in projects of nationalism have tended to privilege print over other forms of communication (Smith, 1998). Even in the era of tremendous technological advances (e.g. radio, television, satellite, Internet) Anderson only briefly alludes to television in his major work on nations and nationalism (1991), which was originally published in 1983: “... advances in communications technology, especially radio and television, give print allies unavailable a century ago. Multilingual broadcasting can conjure up the imagined community to illiterates and populations with different mother-tongues" (1991, p. 135). ${ }^{72}$ What seems to be evident to Anderson is that the

\footnotetext{
${ }^{72}$ This assertion from Anderson in built on a presupposition, that there is no need for literacy with radio and television. Williams (1974) has likened the ability to watch television to being able to "watch and listen to people in our immediate circle, we can watch and listen to television" (pp.131-132). Fisk \& Hartley (1978), however, disagree, particularly with respect to television. They quote Diamond who has suggested that "actually, television is a very demanding mode of communication. Television's information is ephemeral; there is no way for the viewer to go back over material, in the way a newspaper reader or book reader can glance back over the page" (p. 16). Fisk \& Hartley suggest that "we should not mistake an oral medium for an illiterate one. We have the example of Shakespeare to remind us that non-literate entertainment can be a demanding, and satisfying, as the most profound works of literature" (1978, pp. 16-17).
} 
electronic media are only new allies for print rather than being media capable of doing what print has done, namely facilitating the standardization of languages, engendering horizontal comradeship and creating mass audiences who could simultaneously experience and imagine belonging to the same collective identity called the nation. It is, however, important to note Anderson's appreciation for the significance of the new media among the "illiterates and populations with different mother-tongues." Although he sees new media as only good to "conjure up," not to imagine or create the community that is already imagined supposedly by print, it can point one to the right direction: focusing on the significance of electronic media in the processes of constructing and maintaining national identities.

\section{Electronic media as new communicative spaces}

According to McLuhan (1962), whereas print gave birth to nationalism, electronic media would go against it: "What we call 'nations' did not and could not precede the advent of Gutenberg technology any more than they can survive the advent of electric circuitry with its power of totally involving all people in other people" (p. ix, my emphasis, also see McLuhan, 1964, p. 67). In recent years too, some scholars have seen electronic media at the forefront of cultural globalization (e.g. Appadurai, 1996, p. 19). Although the connection between globalization and electronic media cannot be denied, it has also been suggested that the same technologies, in different contexts, have been fostering the articulation of regional and national identities (Drummond, Paterson \& Willis, 1993; Fisk \& Hartley, 2003; Hartley, 2004; Hassanpour, 2003a, 1998; Morley, 2004, 1992; Price, 1995; Thussu, 2000; Yoshimi, 2003). The multilayered connection of cable and satellite television with globalization, nationalism and regionalism is well captured in this quote from Straubhaar (2002, p. 202): 
Overall, within an increasingly internationalized world of television, we find a fairly compelling argument for looking at global, regional and national levels fairly equally ... Now the new technologies of cable and satellite television present a new level of globalization, simultaneous global exposure to some channels delivered by satellite. These media also present an equal if not larger opportunity for a new level of regionalization, channels targeted at geolinguistic groups across national borders.

Thussu (2000, p. 168) believes that television is essential to what Stuart Hall has called "global mass culture" and suggests that "[T]his mass culture may be influencing the way people think about their regional or national identities, as they are increasingly exposed to global, which in most part are American, messages" (p. 168). In other words, the concern seems to be over the domination of a homogenous American culture and the withering away of other national and regional identities. In $1996,82 \%$ of webpages in the world were in English (Warschauer, 2000, p. 156) and this led to some premature predictions that as a result of this overwhelming domination by English, thousands of languages will be lost. It is, however, estimated that in the first decade of $2000 \mathrm{~s}$, the percentage of English webpages will decrease from $80 \%$ to $40 \%$ (ibid.). ${ }^{73}$ According to Warschauer (2000),

the Net is now growing fastest in developing countries... Web browsers are being adapted for an increasing number of languages and character sets. Thus, while Internet users around the world still must use English for global communication, today they are increasingly turning to their own language to reach websites or join discussion in their own country or region. (p. 157)

Smith suggests that "the electronic media serve to reinforce old ethnic identities or encourage the (re-)creation of new ones" (1998, p. 215). For example, studies of ethnic communities in diasporas have shown that the new electronic media, such as satellite television, can in important ways "enhance and consolidate subcultural identities based on

\footnotetext{
${ }^{73}$ At the end of 2007, according to the Internet world stats (2007) only 30.01 percent of the internet is in English. Other top ten languages of the internet are: Chinese, Spanish, Japanese, French, German,
} 
location, ethnicity...language and nationality" (Naficy, 1993, p. xvi). Further, the nationalist movements of minorities, such as Kurds, whose demands for cultural or political autonomy often have been silenced within the borders of the nation-states in which they live (van Bruinessen, 2000a; McDowell, 2004), have been altered in important ways because of the utilization of these media (Erikson, 2006; Romano, 2002; Ryan, 1997). Of the new media which are believed to facilitate the processes of identity and community formation, satellite television and the Internet have enjoyed most attention.

\section{Television}

Television has become an integrated part of both theoretical and empirical investigations into the constructing, reproducing and sustaining of collective identities concerning different parts of the world and at different levels of global, regional or local. Within the nation-state context, Hartley, in 1987, suggested that "television ... is one of the prime sites upon which a given nation is constructed for its members" (p. 124, cited in Morley, 1992, p. 267). During the 1990s and 2000s, the significance of television broadcasting in the processes of defining and changing national identities has been reiterated (Ashuri, 2005; Drummond, Paterson \& Willis, 1993; Griffiths, 1993; Madianou, 2005; Price, 1995). Ashuri (2005) compares three versions of a television documentary on the same topic, The Fifty Years War, co-produced by three networks, British BBC2, American PBS and Middle Eastern MBC. Analyses of the audio-visual contents of the documentaries reveal that each documentary frames the story within the discourse of its own nation. $\mathrm{He}$ concludes that "stories of the past, which television producers tell their 'imagined' (national) audiences in the present, to be meaningful may not be global" (p. 440). They ought to be national; if not, they may not resonate with today's audiences. It is only within 
the frame of the nation, in the eyes and ears of the national audiences, that narratives of the past can turn into shared memories. As Martin \& Wodak (2003) have observed, "media produce and reproduce ideologies, beliefs and also histories. Elites depend on the media, and the media are used for the construction of histories and the past" (p. 11).

Another study (Griffiths, 1993), focusing on a Welsh soap opera on television, looks into the "ideological effect" of this TV production in "offering definitions and redefinitions of a 'Welshness' and contributing to (re)formations of cultural identity" (p. 9). He finds that textually the program serves the definition and re-making of Welshness. Further, audiences' reflections on their viewing experience of the program indicate "a sense of national pride and desire for cultural autonomy" (p. 22). Investigating the ways in which television mediates national identity construction in Greece, Madianou (2005) analyzed 473 news stories. The author observes that 'the nation, the common 'we', is continually invoked both through the text and the form of the news" (p. 5). In addition to conducting a qualitative analysis of the news, Madianou conducts interviews with audiences to investigate the ways viewers interpret the news and draw on the contents and themes of the news to articulate their own identities. Underscoring the different interpretations of the discourse of identity among audiences due to a variety of factors such as ethnic background, age, class and gender, Madianou makes two crucial observations. First, she reports that "most interviewees [audiences] challenged the national in the news and the dominant identity discourses it projected" (p. 131). This rejects the assumption that banal nationalism in the established nations is too implicit and at the same time has permeated the society for too long and in too many ways to be contested (Billig, 1995). Second, and in line with the previous finding, Madianou observes that discourses of national identity are 
not monolithic and unvarying (p. 139). This is not to suggest that people can switch their identity from Greeks to Turks overnight, but it means that identities are always in making and they are, to various degrees, susceptible to change.

Drummond, Paterson \& Willis (1993) suggest that since television discourse is the site of identity negotiations, television production and programs provide a convenient context for studying and understanding the ways in which the new identities (European, national and ethnic) are defined, are changing and coexisting. By extension, one could suggest that discursive practices of Kurdish television can be convenient contexts for studying the ways in which Kurdish identity is articulated. However, for the Kurds and many other minorities who do not have an easy access to cable television it might be more appropriate to focus on satellite television.

If there has been a strong connection between print and television and national identity in Europe, there might be a similar, if not a stronger, connection between satellite television and national identities among peoples without states. The Kurds, for example, have a better and easier access to satellite television than print or even cable television. One of the main reasons is that satellite television can cross borders of nation-states more freely since the messages and images it disseminates cannot be easily prevented from reaching potential audiences. Investigating the utilization of a satellite television, Med TV, by the Kurds from Turkey, Hassanpour suggests

As an audiovisual medium, television is more effective than radio and print media [in the practices of centralizing political power and nation-building]. Televisual messages generally cross the social boundaries of illiteracy, language, regionalism, age, gender, and religion. Combining visuality with sound and language, both spoken and written, television is a powerful vehicle for creating national culture and identity. (1998, p. 53) 
As Poster posits, "digital information may be transported without regard to the posts the nation established to monitor and control its movement" (Poster, 1999, p. 235). This way, satellite television technology fosters cross-border reproduction and formation of cultural artifacts including discursive constructs of national identities. Unlike print, radio or cable television, satellite television has, not entirely but in significant ways, overcome the political constraints that nation-state or majority nationalism imposes on discursive practices of minority identities. For example, Kurdish audiences in Turkey, who had their language banned for decades, and still cannot freely broadcast in their language, have been able to receive television programs beamed at their homes from Europe since 1995 (Hassanpour, 2003a, 1998; Karim, 1998; Price, 2001; Ryan, 1997). ${ }^{74}$

\section{The Internet}

Similar to satellite television, the Internet is also endowed with this quality of disrespect for nation-state borders. Further, utilization of the Internet among the minorities and diasporic communities tends to be more common than satellite television. The main reason is that the Internet is more accessible. Karim (2003) states that,

The extensive use by diasporic groups of online services like the Internet $\ldots$ is allowing for relatively easy connections of members of communities residing in various continents. As opposed to the broadcast model of communication which, apart from offering little access to minority groups, is linear, hierarchical and capital-intensive, online media allow easier access and are non-linear, largely nonhierarchical and relatively cheaper. (p. 13)

The Internet is more accessible than other types of broadcast media such as print, cable and satellite television. Five 164

\footnotetext{
${ }^{74}$ For a brief account of the emergence of satellite technology among minorities and diasporic communities see Karim (2003, pp. 11-15; 1998, pp. 11-14).
} 
years later, this observation is still applicable. However, a few points can be added here. First, in many parts of the developing world the majority of people do not use the Internet. For example, Bargh \& McKenna (2004) report that "in 2001 only 1 in 250 people in Africa was an Internet user" (p. 574). Limited use of the Internet has also been reported among diasporic communities, such as the Salvadoran immigrants in the Washington DC area (Benítez, 2006). Benítez identifies several factors that could contribute to this factor, such as "level of education, technological skills, family and cultural capital as well as the socioeconomic conditions in the local economic structure" (p. 195). In a similar vein, Ackah \& Newman (2003) report on the scarce use of the Internet among the members of a Ghanaian diaspora. They suggest that "the assumption that ICTS inherently will be beneficial certainly cannot be taken for granted" (p. 207).

Notwithstanding these difficulties with respect to accessing the Internet, many commentators have found the Internet more accessible to those groups and individuals whose access to traditional communication technologies such as print and television for various reasons (e.g. financial and political) is limited. The use of the Internet for producing and distributing information is relatively cheap, but at the same time it can be done much more freely since the medium is not so easy to control or regulate. Kluver (2001) suggests that, "the Internet makes everyone a publisher and everyone a librarian, in that anyone can both produce and retrieve an unprecedented amount of information." It might be more accurate to say that anyone who wants to and has the technical means (e.g. access to a computer and Internet service) can "produce and retrieve an unprecedented amount of information." The point here is not to praise the Internet as an agent of social change, a 
position akin to technological determinism, but to simply say that it is cheap, and it bypasses state or market regulations and constraints (Poster, 1999).

Being more accessible than the more traditional media, the Internet provides the social space for dissenting voices, particularly those of individuals and smaller groups (Mautner, 2005, p. 813) that might be different from the voices of the states, commercial enterprises, mainstream media and political parties (see also Bargh \& McKenna, 2004, p. 573). As Hargreaves suggests, "what we are witnessing here is the emergence ... of the voices of those who have previously been unheard, neglected, rejected, ignored - the voices of those who have been marginalized and disposed" (as cited in Almasude, 1999, p. 117).

One of the first dissenting voices amplified on the Internet was that of the Zapatistas in Chiapas, Mexico, in the mid-19990s (Castells, 1997; Knudson, 1998). According to Castells (1997), "[t]he Zapatistas ability to communicate [primarily through the Internet] with the world, and with Mexican society, and to capture the imagination of people and of intellectuals, propelled a local, weak insurgent group to the forefront of world politics" (p. 79). Everyone may not believe in a deterministic role of the Internet in any social movement including that of the Chiapas. However, many analysts have praised this utilization of the Internet as a progressive development, not just because it helped a minority's voice to be heard but also because it helped the Zapatistas to shed more ink than blood in making themselves heard and having their indigenous rights recognized (Knudson, 1998).

Almasude (1999) provides another example which proves that the Internet can be a catalyst in meeting minorities' need for articulating their long-suppressed identities. The 
author reports on the Imazighen people from North Africa. ${ }^{75}$ According to Almasude, prior to the 1990 s and the use of the Internet, the Imazighen demands for the recognition of their distinct cultural and linguistic identity were largely ignored internally (e.g. in Morocco) and were unheard of internationally. However, according to the author, with the establishing of the first online Amazigh forums in 1992, "the Amazigh cause took an internal dimension," and the Imazighen in Morocco, Algeria, Tunisia, or Mali, joined voices to articulate their distinct identity and started "to perceive themselves as one community" (p. 124). Only then, according to Almasude, North African countries started to recognize Imazighen as a distinct cultural identity; they were pressured to do so after the utilization of the computer technology by the Imazighen (p. 125). One important aspect of the utilization of the Internet has to do with the language, Tamazight. Fonts for this suppressed language with an ancient alphabet have been developed, and software aimed at learning and teaching the language has been produced. The language that for centuries was considered "inferior" and "illegitimate" in places like Morocco and Algeria has started to gain some respect and recognition (p. 118).

The Internet has been credited with accommodating the revitalization of other minority languages, for example Hawaiian indigenous languages (Warschauer, 2001, 2000). According to Warschauer, "the Internet is proving to be effective for linking together learners of minority languages and is being used extensively in language revitalisation programs in Hawaii and elsewhere" (2001, p. 58). According to Warschauer (2000), "Hawaiian-language computing took on an important symbolic value, allowing

\footnotetext{
${ }^{75}$ Imazighen are commonly referred to as Berbers in the West, but the author prefers the native term Imazighen (Almasude, 1999, p. 117). According to Almasude, Imazighen is the name of the people (or Berbers), Amazigh is the adjective as in "Amazigh cause," or "Amazigh person," and the name of the language family is Tamazight.
} 
them to say to themselves and to the world that they are Hawaiian and proud of it" (p. 167). At the same time, the Internet seems to be a fertile ground for the growth of English as an international language since it is the language used the most on the Internet (Crystal, 1997). While fostering the development of a lingua franca (i.e. English) for business and professional communication at the international level, the Internet has also facilitated personal communication in the mother tongue and local speech varieties. ${ }^{76}$ For example, Warschauer (2001) observes that Egyptian professionals conduct most of their email communication in English, even among themselves, but they switch to the Egyptian colloquial Arabic (as opposed to Standard Arabic which is formal) when it comes to faceto-face communication (pp. 54-55). Thus, the Internet has provided the means to access the language of power (i.e. English), and at the same time, it has fostered the language of the soul and the self to express one's individual identity and feelings of belonging to collective and group identities. In other words, the Internet has provided a social space for resisting the homogeneity of English and other dominant languages.

Dissenting voices have used the Internet also to reveal the multiplicity and hybridity of national identities, and to question and contest the nationalist discourse of the status quo which presents national identity as uniform and homogenous. An example of this kind of dissenting voices is described in Chan's (2005) study of the use of the Internet by Chinese workers and immigrants in Singapore. She observes that the Internet provides a liminal space for the Chinese in Singapore to oppose various discourses of national identities perpetuated from the homeland, such as "the hegemonic discourse of state as nation," "the

\footnotetext{
${ }^{76}$ Several years ago when the vast majority of web pages, email communication and online forums were in English, most commentators believed that this trend will lead to language homogenization (i.e. domination of English) and the death of smaller languages (see Thussu, 2000, p. 182; Warschauer, 2002, pp. 165-166).
} 
pan-Chinese identity," and "the dominant Han national identity" (p. 362). They also reject the marginalization practices directed at them in the host country, Singapore. These Chinese immigrants and workers cultivate a national identity discourse that they prefer, which is different from both the Chinese and the Singaporean states. Their online activities enable them "to produce an online imaginary of China as a superpower and an empire" (p. 362) which could compensate for China's current weakness. Such a fanaticized China could not only stand up to the hegemony of another superpower, the United States, but also to the marginalizing and "disciplining practices" of the host country.

In summary, both satellite television and the Internet provide communicative spaces for the articulation of identities, spaces that to a large extent cannot be controlled and regulated by the states and powerful commercial enterprises. These media amplify dissenting but otherwise unheard or ignored voices. However, I have tried to highlight a difference, among others, between the two technologies. Production on the Internet, notwithstanding its technological challenges, is much cheaper than television. For example, among the minorities such as the Kurds, it is only the most powerful political parties that can operate a satellite television station. But, almost every individual, small groups and alternative voices can access the Internet, not only as recipients of information, which is often the case with television, but also as producers and distributors of information. Individuals and marginal groups can use the Internet to contest dominant nationalist discourse of states or political parties and construct their own cultural or individual identities. In this study, I am very interested to see if discourses of Kurdishness disseminated on the Internet by individuals and small groups are different from those of the satellite television stations that are owned by the dominant Kurdish political parties. If there 
are differences, it is important to see what the implications of these differences might be for the processes of Kurdish identity constructions. 


\section{Chapter 5: CDA: An Interdisciplinary Approach to Media Discourse}

Given the focal position of mass media in contemporary social systems, there can be little argument about their relevance to the study of sociocultural change. What will be less obvious to most social scientists, and more contentious, is that analysis of the language of the mass media can make a substantive contribution to such research.

(Fairclough, 1995a, p. 3)

In the previous chapter I have illustrated the significance of media discourse in the construction and articulation of national identities. In this chapter I will suggest that a discourse approach to the discursive construction of identities as mediated by the mass media is both useful and appropriate. In the following pages, I will further rationalize this choice by identifying the approach that I employ in this study, Critical Discourse Analysis (henceforth CDA). First, I will outline the main tenets and assumptions of critical discourse analysis. This will provide the necessary theoretical background to introduce the specific CDA framework that I have adapted (Fairclough, 1995a). My aim is to illustrate that a CDA approach to media discourse enables one, first, to describe strategies of identity construction and their materialization in linguistic and other semiotic forms (e.g. images), second, to interpret the significance of these semiotic realizations of identity against relevant discourse practices that constrain or facilitate the consumption of media messages (e.g. media type used for the dissemination of messages, audiences meaning-making resources and the possibilities for audiences to arrive at interpretations different from those of the analyst), third, to explain the social, cultural and political significance of discursive 
constructs by contextualizing them within the socio-cultural/historical contexts that bear upon these specific discursive practices of identity construction. A CDA approach is helpful in investigating how identities are constructed or reproduced and who is involved in those constructions and for what purposes.

\section{A discourse approach to identity and media}

It is both useful and productive to employ a discourse approach to the study of discursive identity construction as mediated by communication technologies. Such an approach encapsulates the notion that discourses serve the construction and maintenance of national identities (Wodak, 2006). Since discursive practices of identity construction are at the forefront of nationalism projects (Billig, 1995), a discourse approach can provide an understanding of the discoursal aspects of nationalist ideologies and nationalist discourses. One aspect of this discourse already discussed in previous chapters is the idea that minority nationalism (e.g. Kurdish nationalism) primarily emerges in reaction to the forced assimilationist ideologies and practices perpetuated by majority nationalisms (e.g. the state nationalism ideology of Iran, Iraq, Turkey and Syria). Sutherland (2005) contends that, "nationalism can be usefully understood in terms of discourse in general and ideology in particular" (p. 185) because "a discursive approach theorises the dynamics of conflicting minority and majority nationalisms as they compete for conceptual hegemony...and deconstructs both the products of this ideological project and the dynamics of dissent and resistance it creates" (p. 186). This makes a discourse approach particularly suitable to this study for it focuses on the tensions between majority and minority nationalism and how the latter engages in discursive identity constructions to resist the assimilationist and hegemonic discourses of majority nationalism. 
A discourse approach is also useful in investigating the place of the media in the articulation and circulation of discourses of identities. As Mcdonald (2003) suggests, "discourse acknowledges more readily than other analytical concepts that the media are now at the best partial originators of ideas and values" (p. 2). The use of the term media discourse (the combination of the two terms discourse and media) signals the fact that there is much more to media than their technological characteristics and forms. As I have illustrated, some prominent scholars and theorists have deemed communication technologies to be catalysts in nation building projects and national identity formations because of their ability to connect audiences and community members across time and space, regardless of the messages they carry (Deutsch, 1953; McLuhan, 1962, 1964; Gellner, 1983). This position has been called "technological determinism" for it holds the media as technologies responsible for engendering social change regardless of the sociopolitical and economic contexts that bear upon them. ${ }^{77}$ A discourse approach to the relationship between media and identity rejects technological determinism and instead underscores the significance of media content. Such an approach emphasizes the idea that the importance of the media is owed as much to the content and messages they disseminate as to their technological characteristics. As Madianou (2005) observes, "we cannot abandon the text [messages and content] when investigating the relationship between the media and identity. It is a combination of the sheer presence of the media [as technologies] and representations [as texts and contents] that affect discourses about identities" (p. 138).

A discourse approach also bars a top-down approach to the impact of media on identity construction. According to Mcdonald (2003), "[d]iscourse reminds us that the

\footnotetext{
${ }^{77}$ I have introduced "technological determinism" in chapter four.
} 
media's forms of talking and thinking interact with those of the wider society-sometimes setting an agenda, but frequently reacting to perceived public desires or concerns" (p. 2). This view of media discourse sets it apart from a top-down or a hypodermic needle model approach to media, the view that media are all powerful and capable of influencing weak audiences in manipulating ways. Wodak et al. (1999), in investigating the discursive constructions of national identities in Austria, have found that the discourses of the media elite are to a large extent akin to that of the public at large because the former seems to be generated partially in response to the demands and desires of the latter (p. 202). In other words, the media often portray the national identity image that is desired by their audiences who are seeking confidence about their nationality (ibid.).

According to Mcdonald (2003), "analyzing the media through the lens of discourse also emphasizes the relations between and across different media forms" (p. 2). Instead of focusing on one medium and privileging the impact of one over others due to its technological characteristics (e.g. television or print), a focus on a particular set of discursive practices and its mediation by different types of media broadens one's perspective on the intricate relationships among different media and the way all of them contribute to the processes of reproducing, maintaining and redefining social relations. ${ }^{78}$

\footnotetext{
${ }^{78}$ This is not to undermine the importance of taking into account the technological characteristics of different media and, thus, their different potentials in mediating discourses. For example, it seems self-evident that an audience with a lower rate of literacy might be more capable of decoding television than print messages, and it is important to note such differences across media forms. However, it is less evident that any reliable paradigm, including that of "medium theory" (Meyrowitz, 1994, 1985), which attempts to draw boundaries between media types (e.g. print vs. television) in order to map out their patterns of impact on social change, can be empirically tested. Nor does this attempt seem to be viable at a time when media theorists and researchers can hardly keep up with the rapid and constant changes and developments that are happening in communication technologies. As a practical alternative, analyzing the discursive construction of national identity in each medium (e.g. television, internet and print media in this study) helps to see how each medium serves the discursive practices of identity construction. Rather than assuming ahead of time what impact each medium has on national identities, analyzing the messages disseminated by each medium combined with
} 
For these reasons it becomes evident that a discourse approach to the role of media in processes of identity formation will be productive. But, which discourse approach is appropriate? There are numerous approaches to discourse (see Jorgensen \& Phillips, 2002) and media discourse (see Fairclough, 1995a, pp. 20-34; Garrett \& Bell, 1998, pp. 1-20). For reasons that will become clear, I have chosen to work within the broad research approach of critical discourse analysis. At this point it should suffice to say that because this study is concerned with not only how identities are constructed discursively (textual—verbal and visual analysis) but also who constructs them (analysis related to questions of agency) and for what purposes (analysis of ideologies), critical discourse analysis seems to be the discourse approach most relevant to the questions, focuses and aims of this study.

\section{Critical Discourse Analysis}

Critical Discourse Analysis (CDA) is a type of discourse analysis which takes the view that discourse is a social practice, it is simultaneously constitutive of and constituted by social structures, relations and identities, and it is ideological. Language and other semiotic elements (e.g. images) not only represent the world, realities and identities but also contribute to their formation and maintenance. One of the areas that CDA has addressed is construction and reproduction of national identities (Billig, 1995; Wodak et al., 1999). From a CDA perspective, national identities are reflected and articulated in the use of language and discourse, and at the same time, they are constructed, shaped and sustained through discursive practices including those of the media. To expand my discussion of CDA, I find it useful to start by explaining four keywords that enjoy prominence in the title of the approach and its literature: discourse, critical, ideology and analysis. 


\section{On discourse}

Fairclough (1995a) identifies two notions of discourse. One, used mostly in language studies, sees "discourse as social action and interaction, people interacting together in real social situations" (p. 18). The other notion is associated with post-structuralist social theory such as Foucault's work (1972). Fairclough aims at bringing the two notions together by viewing discourse as a "social construction of reality, a form of knowledge" (ibid.). Following Hodge \& Kress (1988) and Fairclough (1995a), I take discourse to be more than spoken language, as it is commonly thought of. The term discourse in this study encompasses speech, both written and oral, and also audiovisual features of meaningmaking that contribute to the construction of realities, relations and identities. I understand discourse as a systematic combination of language, image and sound that is intertwined with the wider social, cultural, historical and political practices, and which manifests representations of and contributions to the construction, reproduction and maintenance of worldviews, ideologies and social relations and identities. ${ }^{79}$

Conceptualization of discourse in the core versions of CDA (e.g. approaches developed by Fairclough, 2001, 1995b, Wodak, 1995, and van Dijk, 1993b) differs from those of many post-structuralist and post-modernist views that see discourses as the sole sources of social construction and knowledge making and perceive their workings to be independent from the will and actions of social agents (see Fairclough, 2003, p. 160; Mcdonald, 2003, pp. 32-40; Wodak et al., 1999, p. 32). For example, in Fairclough (2003), it is problematic to say that identity construction is entirely discursive as though identification is not possible beyond linguistic or discursive means (p. 160). According to

\footnotetext{
${ }^{79}$ Macdonald (2003) defines discourse as "a system of communicative practices that are integrally related to wider social and cultural practices, and that help to construct specific frameworks of thinking" (p. 1).
} 
him, "people are not only pre-positioned in how they participate in social events and texts, they are also social agents who do things, create things, change things" (p. 160). People define themselves and others in activities and life experiences and interactions that are not all discursive or linguistic (Bourdieu, 1991, p. 51). Both discursive practices and the people involved in these practices are conditioned by certain social, economic and material circumstances. Discourses do not construct certain realities on their own, but do so because they are produced and used by social actors and real human beings who subscribe to certain ideologies and worldviews and are committed to pursue certain economic, political and moral values and interests (Weiss \& Wodak, 2003, p. 14).

Discursive constructs of national identities, for example, are perpetuated by nationalists or those who have consciously or unconsciously internalized nationalism ideologies. Despite the fact that CDA calls attention to social agency and the sociocultural and historical aspects of discourse (more on these follows), analyses of linguistic and discursive practices remain one of the prime focuses in CDA research. The CDA view of language, and by extension audiovisual texts, is very much akin to Hall's (1980) view: "[R]eality exists outside language, but it is constantly mediated by and through language" (p. 131). One of the main assumptions in this study is that nationalist discourses are among the chief sources for constructing, articulating and reinforcing belonging to nations and national identities (Billig, 1995; Bishop \& Jaworski, 2003; Chouliaraki, 1999; Hall, 1992; Higgins, 2004; Sutherland, 2004; Wodak et al., 1999; Wodak, 2006). However, it would be ineffective to study how and out of what Kurdish identities are constructed discursively without giving due considerations to the socio-cultural and historical dimensions that bear 
upon specific discursive practices. It follows that a discourse analysis of national identity needs to be critical.

\section{CDA is Critical}

One of the major strengths of $\mathrm{CDA}$ is its critical aspect, something that has driven vigorous debates over $\mathrm{CDA}$ as well. $\mathrm{CDA}$ is critical in the following respects. CDA practitioners take a political stance in that they side with the oppressed and unprivileged by investigating and analyzing the discourse of the powerful and making the ideological aspects of these discourses of domination transparent. In other words, CDA strives to bring about awareness "of what is, how it has come to be, and what it might become, on the basis of which people may be able to make and remake [other people's] lives" (Fairclough \& Chouliaraki, 1999, p. 4). The objective is to contribute to social change. Thus, CDA situates itself within the broad approach of critical social science (ibid). Drawing upon Habermas, Fairclough \& Wodak (1997) suggest that "a critical science has to be self-reflective (reflecting on the interests that underlie it) and it must consider the historical context in which linguistic and social interactions take place" (p. 261). Furthermore, self-reflexivity in CDA calls upon analysts to make transparent the interests that are invested in texts (i.e. by their producers), and also to be candid about the analysts' own interests in analyzing discourse.

According to Martin \& Wodak (2003), critical could be also "understood as having distance from the data, embedding the data in the social, making a political stance explicit, and having a focus on self-reflection as scholars doing research" (p. 6). For many CDA analysts (e.g. Wodak \& Ludwig, 1999, p. 12), being critical is not limited to making transparent "the negative sides of social interaction and processes" and thus "painting a black and white picture of societies" (p. 12). Critical also denotes "distinguishing 
complexity and denying easy, dichotomous explanations. It means making contradictions transparent" (ibid.). Finally, being critical entails showing how "our use of language in particular [is] bound up with causes and effects which we may not be at all aware of under normal conditions" (Fairclough, 1995a, p. 54). Put another way, critical analysis in CDA demystifies "discourses by deciphering ideologies" (Weiss \& Wodak, 2003, p. 14).

\section{On ideology}

For van Dijk (1998), ideology is "a shared framework of social beliefs that organize and coordinate the social interpretations and practices of groups and their members, and in particular also power and other relations between groups" (p. 8). This definition of ideology is similar to that of prominent researchers such as Eagleton, who has emphasised that "ideology should be reserved for shared ways of thinking that have a specific interest in gaining power" (Mcdonald, 2003, p. 29). ${ }^{80}$ This view of ideology suggests that ideologies are not held only by those in power but also by those who strive for power and pursue specific interests, or those who struggle for emancipation. Repressed groups can also have ideologies and could aspire to "specific interests in gaining power."

An example of ideology is nationalism which can exemplify both sides of ideology, as the worldview system of oppressors and the worldview of social movements as well. According to Mann, nationalism is "an elaborated ideology shared by many people right across a territory" (as cited in Spencer \& Wollman, 2002, p. 47). The ideology of nationalism "is organised around the core principle of prioritising the nation" (Sutherland, 2005, p. 188). Not only state nationalism or majority nationalism but also "nationalism in

\footnotetext{
${ }^{80}$ This conceptualization of ideology is akin to the definition of the term given by the political philosopher Martin Seliger: "sets of ideas by which men [sic] posit, explain and justify ends and means of organized social action, and specifically political action, irrespective of whether such action aims to preserve, amend, uproot or rebuild a given social order" (as cited in Mcdonald, 2003, p. 30).
} 
stateless nations would qualify as clearly ideological, because it seeks the establishment of power" (Mcdonald, 2003, p. 29) and more importantly it is a "shared way of thinking" for mobilizing a shared social action such as the construction of a collective national identity and/or the establishment of a political entity. Viewing nationalism as an ideology, in fact, underscores the significance of communication technologies in nationalist projects and the production of national identities, because as Mann asserts, "if ideologies are to spread, they must be organized through specific channels of communication" (as cited in Spencer \& Wollman, 2002, p. 47).

According to van Dijk (1998), "ideologies are typically reproduced by social practices, and especially by discourse" (p. 228). It follows that the nation and national identities are partially but in important ways re-produced or constructed through nationalist discourses. In other words, nationalism ideologies or shared ways of thinking about a nation are established through textual and discursive practices. This is not to suggest that textual and discursive practices are the only ways of producing, sustaining and ratifying ideologies. It is rather to suggest that all discursive practices and language use, including discursive practices of national identities, are permeated by ideological positions. As Eggins (1994) puts it, "whatever genre we are involved in, and whatever the register of the situation, our use of language will also be influenced by our ideological positions: the values we hold (consciously or unconsciously), the biases and perspectives we adopt" (p.10). Fairclough \& Wodak (1997) assert that "it is useful to think of ideology as a process which articulates together particular representations of reality, and particular constructions of identity, especially of the collective identities of groups and communities" (p. 276). A 
CDA analysis makes the ideologies of nationalism transparent by analyzing discourses of national identity.

\section{Analysis of discourse}

The major trends in CDA have in common the principle that discourse analysis needs to be carried out at two levels: micro and macro (Luke, 2002). Whereas analysis at the micro level is concerned with conducting textual analysis using linguistic, literary and semiotic analytical tools (e.g. lexicon, grammar, camera angels and shots), analysis at macro level is concerned with the ways in which the textual and discursive elements are connected to social structures and power relations that constitute texts, on the one hand, and are constituted by them, on the other (Luke, 2002).

Macro analysis of text is crucial in that it draws attention to the context of discourse. According to Fairclough \& Wodak (1997), "discourse is not produced without context" thus it "cannot be understood without taking the context into consideration" (p. 276). To arrive at any genuine understanding of any discursive event one has to contextualize discursive events. A piece of discourse needs to be perceived as a complex communicative event that also embodies a social context, featuring participants, their properties, as well as production and reception processes (van Dijk, 1988, p. 2). Fowler (1991) makes the same point:

The significance of discourse derives only from an interaction between language structure and the context in which it is used: so the discourse analyst must always be prepared to document the circumstances in which communication takes place, and consider their relevance to the structure of the text. (p. 90)

From a CDA perspective focusing on context is also essential because it is only this consideration that can prevent "any simple prejudging of ideological effect" and which reminds the analyst that any conclusion with respect to the consequences of discourse 
"requires detailed and specific analysis of how meaning systems operate" (Mcdonald, 2003, p. 30). Our understanding of the significance of context and discourse analysis at the macro level owes a great deal to the tremendous contribution of social theory and the work of Foucault (1972) in particular (Fairclough, 1995a). However, while acknowledging Foucault's influence in generating interest in discourse analysis among social scientists, Fairclough \& Wodak (1997) find the approach inadequate in that it has only focused on "analysis of a rather abstract sort that is not anchored in close analysis of particular texts" (p. 261). Needless to say, much more needs to be said about micro analysis of texts. I will do this later when introducing the CDA framework for studying media discourse.

\section{CDA as a research approach}

CDA is not a unified and single theory or methodology; it has never been and no attempt has been made to make it such (Bell \& Garret, 1998, p. 7; Martin \& Wodak, 2003, pp. 5-6). It is rather a research approach, "a school" or "a programme" (Weiss \& Wodak, 2003, p. 12). A broad description of this sort might not be as clear and straightforward as some would like to see. However, as Weiss \& Wodak (2003) assure us, there are some advantages in that:

Such a heterogeneous school [CDA] might be confusing for some, but on the other hand it allows for open discussion and debate, for changes in the aims and goals, and for innovation. In contrast to 'total and closed' theories (such as Chomsky's Generative Transformational Grammar or Michael Halliday's Systemic Functional Linguistics), CDA has never had the image of a 'sect' and does not want to have such an image. (Weiss \& Wodak, 2003, p. 13; see also Chouliaraki \& Fairclough, 1999, p. 17)

Instead of a "holistic or closed paradigm," CDA is an interdisciplinary (Weiss \& Wodak, 2003), multidisciplinary or transdisciplinary (Chouliaraki \& Fairclough, 1999) approach to discourse in general and language use in particular. CDA is interdisciplinary in 
that it blends social theories with theories of language and discourse. It aims to make transparent the link between language/discourse and the social. This objective stems from the assumption that what is happening socially happens linguistically and no linguistic use happens outside the social (p. 113). According to Chouliaraki \& Fairclough (1999), CDA facilitates a dialogue between various social and linguistic theories (p. 16). Thus, they see a CDA theory as "a shifting synthesis of other theories," and continue to suggest that what CDA "itself theorises in particular is the mediation between the social and the linguistic" (ibid.)

CDA is "a form of discourse analysis which can contribute to social and cultural analysis" (Fairclough, 1995a, p. 53). To do so, it combines insights in social studies of language and discourse "with traditions of close textual analysis which have developed in linguistics and language studies - to make them 'operational', practically usable, in analysis of specific cases" (p. 54). This approach is well summarized in the following quote from Chouliaraki \& Fairclough (1999):

CDA of a communicative interaction sets out to show that the semiotic and linguistic features of the interaction are systematically connected with what is going on socially, and what is going on socially is indeed going on partly or wholly semiotically or linguistically. Put differently, CDA systematically charts relations of transformation between the symbolic and non-symbolic, between discourse and the non-discursive. (p. 113)

From this perspective, $\mathrm{CDA}$ is useful in combining theories of nationalism and national identities, discourse and media, the three main areas with which this study is concerned. A CDA approach to the study of identity construction is specifically helpful in exploring how identities are constructed, who construct them and why they are constructed. 


\section{A CDA framework for studying media discourse}

Here, I will outline the CDA framework that I have found useful in the study of media discourse (Fairclough, 1995a). From a CDA perspective, media discourse "is a recontextualizing principle for appropriating other discourses and bringing them into a special relation with each other for the purposes of their dissemination and mass consumption" (Chouliaraki, 1999, p. 39). Fairclough's (1995a) framework for analyzing "communicative events" such as media discourse consists of three interrelated parts (see Figure 1):

- Text (verbal language, images and other textual elements)

- Discourse practices (processes of producing, disseminating, receiving and receiving texts)

- Socio-cultural practices (social, historical and political contexts and processes that bear upon the production and consumption of a text)

According to Fairclough (1995a), showing, or attempting to show, systematic links between text, discourse practices and socio-cultural practices constitutes discourse analysis (pp. 16-17). Systematic links between these three parts of a communicative event are made by three kinds of analyses: description, interpretation and explanation. Whereas description of the textual elements corresponds to the micro analysis of text, interpretation and explanation of the results of micro analysis correspond to macro analysis. 
Figure 1 A framework for critical discourse analysis of a communicative event. Adapted from Fairclough (1995a, p. 59; 1989, p. 25)

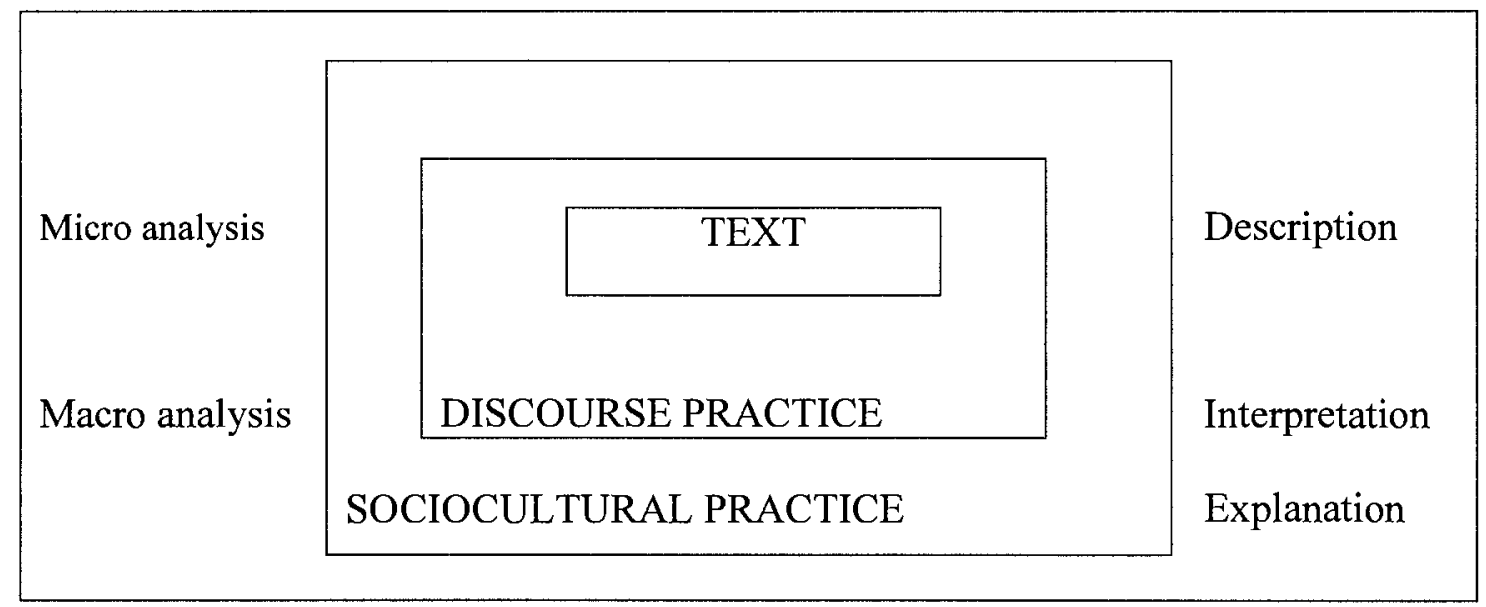

\section{Text: Micro analysis at the text level}

Fairclough (1989) makes the following distinction between text and discourse:

A text is a product rather than a process - a product of the process of text production. But I shall use the term discourse to refer to the whole process of social interaction of which a text is just a part. This process includes in addition to the text the process of production, of which the text is a product, and the process of interpretation, for which the text is a resource. Text analysis is correspondingly only a part of discourse analysis, which also includes analysis of productive and interpretative processes. (p. 24, emphasis in original)

Texts could be written, spoken or multimodal (e.g. visual, music, sound), for instance in the case of television and the Internet. At the text (textual) level, discourse analysis involves detailed analysis of text properties. These properties could include: linguistic elements (e.g. lexicon, grammar, sound, and accent) in the case of spoken and written text, images and graphics in the case of still images (Kress \& van Leeuwen, 1996), camera shots, sound effects, voiceover and music in the case of film or television (Iedema, 2000), and some or all of the above, depending on the text—e.g. a multimodal web page, in the case of the Internet (Lemke, 2002). In order to illustrate the meaning-making potential of text properties, however, an analyst is not only concerned with multisemiotic elements that are 
present in a text but also with what has been implied. As van Dijk (1988) states, "what is not said may even be more important, from a critical point of view, than what is explicitly said or meant" (p. 17).

Another important consideration that an analyst needs to keep in mind when dealing with multimodal texts is the meaning-making interplay between the verbal language and other semiosis (e.g. images). Engaging in textual analysis without considering the multimodality of texts, especially when dealing with modern advertising or television (Fairclough, 1989, p. 27) and the Internet (Lemke, 2002) is unrealistic and the effort may not be as productive as hoped for. According to Lemke (2002), "the specificity and precision which is possible with an imagetext [--combination of verbal text and image--] is vastly greater than what is possible with text alone or with image alone" (p. 303).

Consideration of all the meaning-making semiosis in a text, however, bears its own challenges. The main challenge facing the analyst is "how ... other semiotic modalities [such as images and music] interact with language in producing meanings, and how such interactions define different aesthetics for different media" (Fairclough, 1995a, p. 58). Kress \& van Leeuwen (1996) suggest that "the visual component of a text is an independently organized and structured message - connected with the verbal text, but in no way dependent on it: and similarly the other way around" (p. 17). This means two things at least. First, each semiotic mode (e.g. verbal language) has its own meaning-making potential and thus deserves distinct analysis. Second, despite being independently organized, the two modes of verbal and visual (and other modes for that matter) are connected in the contents and meanings they carry. As Fairclough (1989) puts it, "visuals and "verbals" operate in a mutually reinforcing way which makes them very difficult to 
disentangle" (p. 28). We need to keep in mind as well that sometimes the verbal part of a text may tell a different story from the visual aspect of the same text (Young \& Fitzgerald, 2006, p. 177; van Leeuwen, 2005). Thus, the final verdict on the relationship between different modes of text (e.g. image, verbal, music) seems to be that while each has its own distinct meaning-making potential, and as such each deserves to be described and analyzed in its own terms, the final analysis of a text as a whole rests on explicating the connections between those modes and the ways they contextualize (Lemke, 2002, p. 322) each other and the ways they create a multimodal meaning-making system.

In order to arrive at a coherent conceptualization of such a multimodal meaningmaking system, a number of scholars have built on the linguistic theory of systemic functional linguistics (SFL hereafter) (Halliday, 1994; Eggins, 1994). SFL has enabled the development of a consistent theory of verbal and visual signs and a consistent way of talking about them. SFL has provided the theoretical foundations in the critical analyses of not only verbal texts (Brookes, 1996; Chouliaraki \& Fairclough, 1999; Fairclough, 1995a, 2003; Fowler, 1991; Hodge \& Kress, 1988, 1993; Martin \& Wodak, 2003; Teo, 2000) but also visual texts or texts encompassing both verbal and visual modes (Kress \& van Leeuwen, 1996; Goodman, 1996; MacKen, 2004; Teo, 2004), multimodal texts on the Internet (e.g. web pages) (Lemke, 2002), and finally multimodal texts of film and television (Iedema, 2000; van Leeuwen, 1996a, 2005).

From an SFL perspective, any instance of language use simultaneously serves three functions: Ideational, interpersonal, and textual. The ideational function maps out the representations of the world and what texts portray as reality. It refers to the speakers/writers experience of the world and its phenomena through their doings and 
sayings: "Whatever use we put language to, we are always talking about something or someone doing something" (Eggins, 1994, p.12). This aspect of using language, or any other meaning-making sign (Lemke, 2002), reveals how the world looks according to the producers of texts (e.g. authors, speakers, photographers). ${ }^{81}$

The interpersonal metafunction expresses the author/speaker's attitude, feelings and stance towards the event, issue and subject in question and the kind of relationship she attempts to establish with other participants in the text and also audiences. According to Lemke (2002), "these are the meanings by which we orient to each other in action and feeling, and to our community in terms of point of view, attitudes, and values" (p. 304). A focus on mood (e.g. what has been stated and asked or demanded of us), modality, ${ }^{82}$ and naming (e.g. how something or someone is labeled or called), for example, makes this function the most relevant to the question of identities because they indicate and reinforce

${ }^{81}$ This function can be understood as an answer to this question: who is doing what, to whom, how, when and where? One of the analytical tools that is often used to reveal the ideational function is transitivity. Transitivity analysis maps out the kind of doing (material, saying, being) that is talked about, the role of the participants that are involved in the doing (actor/agent or patient/affected), and the circumstances (where and when) in which the doing is taking place. Attention is also paid to whether the language structure is in an active or passive voice. Compare these two sentences which seemingly express the same action: (a) John ate the apple; (b) The apple was eaten by John. The item (a) is an active voice. It is clear that John has carried out the action of eating and the entity that is affected by the action of eating is the apple. In (b), however, two things have happened. First, John, as the doer, has been removed from the focal point in the sentence. Secondly, the phrase "by John" can be easily removed without affecting the grammar of the sentence: The apple was eaten. In this case, the agent is removed and we may not know who has done the eating. Nominalization processes by which verbs turn into nouns could also be interesting and important features of analysis. Consider these two sentences which again seemingly express the same event: (a) Ford laid off several workers who were disappointed; (b) The layoff disappointed many workers. In the first instance because the action of "laying off" is in verb form (finite) it is preceded by a noun, the agent responsible for carrying out the layoff. In (b), however, because the verb "laid off" has been changed to "the lay off," that is it has been nominalized, the agent has been hidden, so to speak, yet the sentence is still grammatical.

${ }^{82}$ According to Eggins, "Modalization is the expression of the speaker's attitude towards what s/he's saying. It is the way the speaker gets into the text: expressing a judgment about the certainty, likelihood, or frequency of something happening or being. Modalization is always expressing the implicit judgment of the speaker" (Eggins, 1994, p.180). 
the kind of relationship, the degree of closeness or distance, that a speaker or writer wants to have with the audiences.

Finally, the textual metafunction refers to the organizational aspect of discourse. The focus here is on the cohesion and coherence in discourse, the organizational patterns that makes a communication act the meaningful whole we call "text." Of textual elements that analysts focus on here are theme/rheme (what comes before or after what and in what structural combination in a clause), pronouns, articles, lexical chains and anaphoric references.

Lemke (2002) extends this multifunction view of language in SFL and applies it to all modes of communication, albeit re-labeling the metafunctions:

All semiosis, I believe, on every occasion, and in the interpretation of every sign, makes meaning in three simultaneous ways....Every text and image makes meaning presentationally, orientationally, and organizationally...

Presentational meanings are those which present some state of affairs...For image, one could apply the same terms, recognizing what is shown or portrayed, whether figural or abstract...

Orientational meanings are more deeply presupposed... Visually, there is also a presumptive communicative or rhetorical relationship in which the image mediates between creators and viewers and projects a stance or point of view both toward the viewer and toward the content presented in the image.

Organizational meanings are largely instrumental and backgrounded; they enable the other two kinds of meaning to achieve greater degrees of complexity and precision... (p. 304, my emphasis; see also Lemke, 1995, pp. 39-41)

With this view of sign systems and their functions, when analyzing media texts, one can start by asking the following questions:

1. How is the world (events, relationships, etc.) represented?

2. What identities are set up for those involved in the programme or story (reporters, audiences, "third parties" referred to or interviewed)?

3. What relationships are set up between those involved (e.g. reporter-audience, expert-audience or politician-audience relationships)? (Fairclough, 1995a, p. 5) 
The assumption underlying these questions is that any text "will be simultaneously representing, setting up identities, and setting up relations" (ibid.). Any given text, however, does not carry out these set of functions solely on its own and in isolation from other texts. The meaning-making resources of a text should always be defined in terms of its intertextuality as well. ${ }^{83}$

\section{Intertextuality of Texts}

On the borderline between the analyses of text and discourse practices, which I will discuss shortly, is intertextual analysis. The concept of the intertextuality of texts is derived from Bakhtin's dialogic view of language and text $(1981 ; 1986)$. According to Bakhtin (1986), all texts and discourses (although he refers to discourse with the term "utterance") are connected to other discourses and texts, those of the past, those that are simultaneously created and consumed, and those of the future. Every text is inherently dialogic because no text can stay alone and in isolation from other texts. Thus, from a CDA perspective, "intertextual analysis is basically the property texts have of being full of snatches of other texts, which may be explicitly demarcated or merged in, and which the text may assimilate, contradict, ironically echo, and so forth" (Fairclough, 1992, p. 84). Quotations, for instance, are obvious examples of texts borrowing from other texts. However, other properties of texts may appear in other texts in more subtle ways.

It is necessary to do intertextual analysis to make sense of the linguistic/textual analysis because intertextual analysis is "an interpretation which locates the text in relation to social repertoires of discourse practices" (p. 61). Whereas textual analysis is "descriptive in nature," "intertextual analysis is more interpretative" (p. 61) in that it attempts to make

\footnotetext{
${ }^{83}$ Throughout the study, specific linguistic and visual analytical tools will be defined and explained before they are applied to texts.
} 
sense of the findings of textual analysis by drawing on other texts across genres and discursive fields, texts that provide not only meaning-making resources for the text in question but also interpretation resources (e.g. as background knowledge) for the audiences of the text in question. Intertextual analysis is especially important in analyzing media discourse because media texts can be viewed as "a class of texts which are specialized for moving resources for meaning-making between texts, and more abstractly between different social practices, fields, domains and scales of social life" (Fairclough, 2006, p. 23). The aim of intertextual analysis then is to identify those "resources for meaningmaking" (e.g. political speeches, commentaries, news reports, historical records, iconic images and so on) that bear upon the production and interpretation of a text and which facilitate a more plausible interpretation and also explanation of texts.

\section{Discourse practices}

In addition to micro analysis which involves detailed description of textual elements, there is also macro analysis. Macro analysis has two dimensions: discourse practices, and sociocultural practices. The primary concern at the discourse practices level is with the ways texts are produced and consumed. It is based on the analyst's understanding of text

production and consumption that the findings established at the micro level can be properly interpreted. In other words, in order to interpret descriptions of texts we need to know or have an understanding of at least three aspects of producing and consuming texts: first, "the ways in which texts are produced by media workers in media institutions," second, "how media texts are socially distributed," and third, "the ways in which texts are received by audiences (readers, listeners, viewers)" (Fairclough, 1995a, p. 16). I will conduct necessary analysis of programming routines later in this study. At this point, however, I will discuss 
some issues regarding the last two points: distribution of texts and the way audiences receive texts.

\section{Distribution of texts and media types}

When discussing media discourse we deal with texts that are distributed through communication technologies. Fairclough (1995a) suggests that the differences various media have in their channels of communication "have significant wider implications in terms of the meaning potential of the different media" (p. 38). Having different meaning potential, primarily due to possessing different technological attributes, could result in having different impact on social behaviours and relations (Meyrowitz, 1985).

Medium theory (McLuhan, 1962, 1964; Meyrowitz, 1985, 1994) is very helpful in formulating the right questions with respect to media types and the significance of their attributes. For example, one could ask the following questions. What human senses are involved when using the medium ${ }^{84}$ Is the message directional, bi-directional or multidirectional ${ }^{85}$ How fast can information travel using the medium? How easy is it to access the medium? How easy is it to use the medium? How easy is it to code or decode messages on the medium? How wide can the audiences of the medium be at a time (Meyrowitz, 1994, p. 50)?

Compared to print, television, is much more personal, here and now, immediate and with a much wider appeal and larger audience (Fairclough, 1995a, pp. 38-39). Compared to print, television allows for more human senses (e.g. audiovisual capability) to be involved in receiving messages, it enables information to travel much faster and relatively without

\footnotetext{
${ }^{84}$ Marshal McLuhan has famously declared that the media are "the extensions of [the senses of] man."

${ }^{85}$ As examples, one can think of radio, telephone, and the Internet respectively.
} 
much difficulty, ${ }^{86}$ and it allows for a much easier coding and decoding practices (Meyrowitz, 1985). While reading a written text requires one to be literate in a particular language and versed in the genre of the printed material, watching and following a television program requires no or very little skill. This is agreed upon by both proponents of medium theory (Meyrowitz, 1985) and its opponents (Williams, 1974). Although Williams does not share medium theory's proposition that media technologies can create social change apart from social, political and economic forces, he still believes that "[i]f we can watch and listen to people in our immediate circle, we can watch and listen to television" (Williams, 1974, pp. 131-132; see also Meyrowitz, 1985, p. 76).

Looking at the place of communication technologies in the processes of nation building and national identity construction, Deutsch (1966) observes that one of the major concerns for communication engineers has always been "the need to get messages quickly, with least effort and with least distortion" (p. 90, my emphasis). Texts distributed through satellite television signals, in contrast to print, travel more simultaneously to a much wider audience, at a much faster speed and in a much more convenient way in that they cross borders of the states where they are not welcomed. Satellite television and the Internet, albeit to a lesser degree, enable texts to challenge border guards and barbed wires in unprecedented ways.

Similar to satellite television, the Internet has also been among the ideal media for distributing texts that contribute to identity construction and reproduction at a transnational and cross-border level. One of the greatest features of the Internet is that it combines many features of the previous communication technologies in one single mass medium (Bargh \&

\footnotetext{
${ }^{86}$ Compare a pamphlet or book in Kurdish with Kurdish satellite television signals crossing the borders of a state that is hostile to Kurdish culture and language.
} 
McKenna, 2004, p. 577). It is interactive like the telephone (e.g. online messaging), it can be used for person-to-person communication like telegraph and letter writing (e.g. email), it is a mass medium and can reach millions of people simultaneously like radio and television, it can be a convenient place for publishing like the printing press, it can store and distribute texts and images like a great library, and finally, similar to satellite television, it is the medium that has the least respect for national-political borders. Thus, the Internet has proven to be a truly multimodal medium unlike any other in the human history that makes it ideal for distributing images and symbols of national identity (Bargh \& McKenna, 2004, p. 574; also see Poster, 1999; Erikson, 2006; Mills, 2002).

\section{Audiences and their interpretation of texts}

If satellite television and the internet are ideal media for the distribution and dissemination of identity discursive constructs, how do we know what the effects of those texts and discursive practices are among the audiences that receive them? Of course the most reliable method of knowing this is to ask the audiences about their understandings of and reactions to the texts they receive. However, when audiences are not accessible for various reasons, the texts remain to be reliable and suitable sources of investigation. Investigating the content of texts and the ways they are distributed should tell us a great deal about their possible impacts among audiences such as their influence on shaping prospective audiences' beliefs and ideas about issues such as the dynamics of identity formation and maintenance.

The most important aspect of discourse consumption is the issue of audiences' interpretation of texts. Because CDA research is mostly rooted in the analysis of written texts, it has been criticized for not incorporating audience research into its methodology. In 
other words, it has been suggested that CDA analysts assume how audiences interpret texts without asking the audiences themselves. Suggestions have been made that textual analysis needs to be accompanied by reception studies. That is, we should not only assume how a text might be interpreted by audiences but ask them what interpretations they arrive at and what they actually do with their understandings of texts.

While acknowledging that there might be different interpretations of a text, CDA analysts warn that we should not dismiss the power of texts and the ideologies invested in them by media owners. Fairclough (1995a) is right to point to the importance of reception studies for their contribution to our understanding of the actual interpretation practices that audiences engage in. He is, however, equally correct not to grant these studies too much importance at the expense of texts' power of persuasion and influence. He says, "I fully accept the importance of reception studies for understanding meanings and effects [of media texts and discourse]. But reception studies sometimes lead to a disregard for the text itself, which I do not accept" (p. 16). Audience research often ignores issues of power associated with the text and undermines the political-economy of media texts, the political and economic aspects of text production and consumption (Madianou, 2005, p. 45). Fairclough (1995a) states,

It strikes me as self-evident that although readings may vary, any reading is a product of an interface between the properties of the text and the interpretative resources and practices which the interpreter brings to bear upon the text. The range of potential interpretations will be constrained and delimited according to the nature of the text...If this is so, text analysis remains a central element of media analysis ... (Fairclough, 1995a, p. 16, see also p. 122) 
This is not to dismiss the importance of reception studies and the possibility of the fact that audiences might have different interpretations of texts, but to underscore the importance of text and textual analysis. ${ }^{87}$

CDA analysts address the absence of audience research also by stating that their interpretations are not final. Therefore, CDA practitioners have called for a hermeneutic approach when it comes to interpretation of text (Wodak \& Ludwig, 1999, p. 13). This means an acknowledgment of the possibility that different readers might interpret similar texts differently (Fairclough, 1995a, pp. 15-16; Lemke, 1995). It is also acknowledged that "media recipients [are] active, and up to a point independent, information users" (van Dijk, 1993a, p. 242) and they may form interpretations and opinions of media texts different from those intended by authors, broadcasters and webmasters. Texts could be interpreted differently because interpretation of texts is based on "cultural differences embedded within the structure of society"; however, it is crucial to realize that the same cultural differences that guide audiences' interpretations of texts "limit the individual's interpretation of messages" (Morley, 1992, p. 118). This indicates that audiences are not at full liberty to interpret texts in ways that are opposite to what has been intended by the producers of texts. In other words, audiences may not be able to read or interpret differently from what Hall

${ }^{87}$ Madianou (2005), studying the impact of television on identity formation in Greece, is at pains to illustrate the importance of reception studies by taking a bottom-up approach to investigate how audiences interpret or react to television discourses of cultural identity. At the same time, she reminds us that "we cannot abandon the text when investigating the relationship between the media and identity. It is a combination of the sheer presence of the media and representations that affect discourses about identities" (p. 138). Textual analysis becomes more important when carrying out ethnographic research, personal interviews with audiences or observation of focus groups, for various reasons, become practically impossible. The absence of audience research should not undermine the importance of textual analysis particularly when such analyses are accompanied by intertextual analysis carried out against the sociocultural and historical backgrounds that text production and consumption draw upon. 
(1980) calls "preferred reading," the particular reading that is aimed at and hoped for by the producer.

Although possible, it is not easy for all audiences to come up with alternative readings, because most of the time text producers' know their audiences; they have particular audiences in mind. They consider what those audiences might already know about the topic, how they might decode messages and what cultural, social and historical contexts they may draw upon in their processes of comprehension and interpretation. In other words, text producers have ways of constraining audiences' interpretations. On this assumption then textual analysis should be considered not only valid but particularly important on its own. According to Riggins (1997), "if it is assumed that texts have the power to constrain readers' interpretations because words are not neutral, then it is essential to have a comprehensive understanding of the properties of texts" (Riggins, 1997, p. 3). Regardless of whether one can incorporate other methods in his/her study or not, texts remain to be rich, intricate and appropriate sources of discursive and ideological analyses (see also Luke, 1989, p. 30; Ricento, 2003, p. 615).

\section{Sociocultural practices}

The second dimension of macro analysis is analysis at the socio-cultural, political and historical level. At this level of analysis, the focus is on the social and historical contexts to which the communicative event belongs. The role of texts in social practices cannot be understood by linguistic or semiotic analysis of the text alone (2002, p. 10). Textual analysis needs to be accompanied by analyses of context. With respect to television discourse, Hall (1980) says that

though the production structures of television originate the television discourse, they do not constitute a closed system. They draw topics, treatments, agendas, 
events, personnel, images of the audiences, 'definitions of the situation' from other sources and other discursive formations within the wider socio-cultural and political structure of which they are a differentiated part. (p. 129)

Whereas analysis at the text level is devoted to describing the multimodal components of the text, and analysis at the discourse practices level is concerned with interpreting the description of the text, analysis at the sociocultural level attempts to explain what social, cultural and political motives could have been behind the ways in which texts are produced, distributed and consumed.

Politics and economics of the media are two major parts of the context which ought to be analyzed along with textual/semiotic analysis. For example, studying the use of location in Scottish newspapers to illustrate the political use of discourses in the construction of national identity, Higgins (2004) observes that "various newspapers engage in particular textual strategies of articulating nation and politics, based upon a politically charged distinction between Scotland and Britain" (p. 469). Luther (2002), in his comparison of the representations of American and Japanese national identities in the American press, finds that there is an "interplay of national identities and political economic conditions on the formations of images of nations" (p. 78). Therefore, it is important to ask who has access to media production and distribution and thus dissemination of ideas, or in the case of this study, discourses of national identity construction. According to Guibernau (1996),

Access to the tremendous power of the media depends on the resources available to each nationalist organization. The uneven use of the media by nationalist groups reflects the various degrees of power they enjoy and has significant repercussions upon the public image they are able to display both to the national community and the international audience. (p. 148) 
In Kurdistan-Iraq, it is clear that only those organizations that have political power and also economic means have access to satellite television. They are the ones that set the agenda in Kurdistan for example regarding what Kurdishness is and what a Kurdish identity is believed to be or should be.

The political aspect of media is closely related to their economy. According to Fairclough (1995a, p. 42), "the economics of an institution is an important determinant of its practices and its texts." An analyst needs to question the ownership aspect of media. Whereas the private mainstream media are under the influence of commercial and advertising pressures or of the state, public broadcasting could be more in the control of the citizens in a democratic society, or it could be in the hands of the state in totalitarian environments.

Finally, in analyzing discourse critically, one needs to situate discursive events not only politically and economically but also historically (Wodak, 2006). According to Wodak \& Ludwig (1999), discourse "is always historical" (12). This means that discourse "is connected synchronically and diachronically with other communicative events which are happening at the same time or which have happened before" (ibid). Consideration of the historical context of discourse is particularly important in studying discourses of national identity. This is because discursive practices of sharing memories, even though they are fictitious, myths and narratives of the origins of the nation are the building blocks of national identities.

As suggested earlier, discourse analysis of a communicative event entails making connections between text, discourse practices and sociocultural practices. However, according to Fairclough (1995a), an analyst may not focus equally on all levels of analysis. 
Despite granting this flexibility with the framework, Fairclough asserts: "it is, I believe, important to maintain the comprehensive orientation to communicative events which is built into the framework, even if one is concentrating upon only certain aspects of them in analysis" (p. 62). Similar to Fairclough (1995a) and most CDA practitioners, my main focus in this study is on textual analysis. However, the findings at the textual analysis and their significations will be interpreted and explained by drawing upon the discourse practices and sociocultural/historical contexts that bear upon the production and distribution of the texts under investigation.

\section{Contributions of this study for CDA}

The first contribution that I am hoping to make to CDA research has to do with investigating the discursive construction of national identities as they are mediated by satellite TV and the Internet. Practitioners of CDA have concentrated on various social, political and cultural issues (see Luke, 2002, p. 99-100), and among these, media discourse has received notable attention to the extent that a good number of pioneering scholars in CDA have devoted a significant portion of their work to theorizing and studying media discourse (e.g. Fairclough, 1995a; Fowler, 1991; Garret \& Bell, 1998; van Dijk, 1993a). None of these studies, however, has dealt with the discursive construction of national identities. As discussed in the previous chapters, Billig's (1995) study is one of the first attempts in this area, and it has influenced some other studies, which I have reported on. Billig's study, however, focuses more on the linguistic analysis of the press and not other media types such as television and the Internet. This gap can also be identified in Wodak's work which has arguably contributed the most to our understanding of the ways in which 
national identities are constructed, reproduced and maintained in discourse (see Wodak, 2006, 2002; Wodak et al., 1999).

The great majority of CDA studies of national identity construction have focused on the national identity of established nation-states such as Austria (Wodak et al., 1999; de Cillia et al., 1999), Britain (Billig, 1995; Bishop \& Jaworski, 2003), the United States of America (Ricento, 2003) and Turkey (Kösebalaban, 2004; Yumul \& Uzkirimli, 2000). Law (2001) and Higgins (2004), which focus on Scotland as a nation without state, are exceptions rather than the norm. It is hoped that this study will add to this line of research that is concerned with the ways in which discursive practices contribute to the reproducing and construction of national identities among peoples without states.

Finally, by studying the discursive construction of identity among an oppressed and stateless people, this study hopes to make a modest contribution to what Martin (2002) has called "positive [critical] discourse analysis" (PDA hereafter) (see also Martin \& Rose, 2003). In a comprehensive review article of CDA research, Luke (2002) suggests that CDA needs to

move beyond a focus on ideology [in its original sense] critique and to document 'other' forms of text and discourse-subaltern, diasporic, emancipatory, local, minority, call them what we may - that may mark the productive use of power in the face of economic and cultural globalization. (p. 94)

One example of these groups and social movements is Kurdish nationalism, which is challenging the dominant and majority nationalist discourses and is striving for national emancipation (Guibernau, 1996).

Martin (2002) rightly points out that CDA practitioners have not investigated the discourses of the oppressed and thus have failed to be a part of the very struggle for emancipation which it claims to be a part of (Wodak, 1995). For the most part, CDA 
practitioners have devoted their attention to the discourses of the powerful because they have been concerned with how domination works discursively (Weiss \& Wodak, 2003, p.14-15; Fairclough \& Wodak, 1997, p.258; Martin \& Wodak, 2003, p. 6, 15). However, it is safe to suggest that becoming aware of the discourses of the dominant groups does not automatically make the oppressed better able to counter discourses of domination. What the oppressed also need is the discursive means to carry on meaningful and effective struggle. Empowering the oppressed with these discursive means should be the concern for discourse analysts. If discourse constitutes social relations and identities as well as representing them, and if CDA is committed to critical theory and social emancipation, then it should be quite natural for CDA analysts to create the kind of discourse and language awareness that the oppressed can use to challenge the dominant discourses.

At this point I find it useful to restate my reasons for choosing a CDA approach to studying the discursive construction of Kurdish identities as mediated by the Internet and satellite television. CDA posits that discursive practices are simultaneously constituted by and constitutive of social structures, relations and identities. Put differently, what is happening socially, culturally or politically is also happening discursively and vice versa. It follows that the construction of national identities, like other social constructs, is partially discursive. A CDA approach also assumes that discursive practices are ideological, and ideologies (such as nationalism) belong to social agents (e.g. nationalist elites and movements) who engage in purposeful discursive practices (e.g. of identity formation) in their pursuit of certain interests (e.g. preservation of culture, or mobilization of the masses). Therefore, studying the discursive practices of identity construction with a CDA approach should reveal how and out of what identities are constructed, who constructs them and why. 


\section{Chapter 6: Kurdish Identity}

In this chapter, I present a critical account of Kurdish identity. Since nationalist discourses tend to historicise the nation, I find it appropriate to start with a brief overview of the history of the Kurds and Kurdistan. Then I submit that a Kurdish national identity emerged around the beginning of the twentieth century bearing strong ethnic roots. In line with this conception of national identity, a Kurdish national identity is defined by a shared culture, language, territory, set of symbols, memory and experience, and future political aspirations. I will show, however, that most of these components of Kurdish national identity are deeply fragmented due to both internal and external factors. Fragmented components of Kurdish identity along with external oppression of the four states (i.e. Turkey, Iraq, Iran, and Syria) have prevented Kurdish nationalists from achieving national emancipation whether in the form of an independent Kurdistan or several autonomous smaller Kurdistans within the political boundaries of different states. In other words, the lack of a strong panKurdish sentiment and cross-border identity has been one of the greatest obstacles to Kurdish national emancipation. A pan-Kurdish or cross-border Kurdish identity here is understood as a collective identity to which most Kurds, regardless of what nation-state they live in, have or could have a sense of belonging. The absence of a strong pan-Kurdish identity has resulted in the Kurdish parochial movements becoming pawns in the hands of the host states and being used against each other ${ }^{88}$ It has also continued to weaken regional

\footnotetext{
${ }^{88}$ I am not suggesting that any Kurdish nationalist movement has started with the aim of being used against other Kurdish movements. This outcome rather has been the result of an imbalance in relationship between Kurdish movements and the states straddling Kurdistan.
} 
and autonomist movements and to deepen cultural and political fragmentation in Kurdistan. I will end this chapter by exploring the suggestion that since the beginning of the 1980 s and more importantly since the mid-1990s the Kurdish situation has changed profoundly; a cross-border or trans-state Kurdish identity has started to strengthen.

\section{Kurds and Kurdistan: A brief history}

\section{Myths of Kurdish origins}

Like all nationalist discourses, accounts of the origins of the Kurds have relied on myth making. McDowall (2004) summarizes some of these myths as follows:

The myths that the Kurds are descended from children hidden in the mountains to escape Zahhak, a child-eating giant, links them mystically with 'the mountain' and also implies, since the myth refers to children rather than one couple, that they may not all be of one origin. A similar story suggests that they are descended from the children of slave girls of King Solomon, sired by a demon named Jasad, and driven by the angry king into the mountains. Another myth claims that Prophet Abraham's wife Sarah was a Kurd, a native of Harran, and thus validates Kurdish identity within the mainstream of monotheism. (p. 4)

Although one might easily dismiss such accounts of the origins of Kurds as unfounded, doing so may not be constructive in understanding nationalist discourses. As McDowall asserts, these myths "are valuable tools in nation building, however dubious historically, because they offer a common mystical identity, exclusive to the Kurdish people" (ibid.). ${ }^{89}$ Another account, yet controversial, traces the origins of the Kurds back to the first millennium B.C., to an ancient people, the Medes, who established the Median Empire (728-550 B.C.) in the present areas of western Iran, northern Iraq and south-eastern Turkey

\footnotetext{
${ }^{89}$ Actually not all these myths are exclusive to the Kurds, especially the most common one, the story of Zahhak. The myth of Zahhak, with some variations, is common among all ethnic groups and nationalities that once were a part of the Persian Empire, including Persians, Azerbaijanis, Tajiks and so forth.
} 
(Hassanpour 1992, p. 49; Kreyenbroek, 1992, p. 70). ${ }^{90}$ To nationalist Kurds, the fall of the Median Empire marked the end of their most ancient glory.

\section{Pre-modern history}

Following the fall of the Median empire, the areas inhibited by the Kurds made up parts of many other empires and powers ruling over the region, such as the Achaemenid $\left(6^{\text {th }}-4^{\text {th }} B C\right)$ and Sassanian $\left(3^{\text {rd }}-7^{\text {th }}\right.$ AD) Empires, Arab Caliphate $\left(7^{\text {th }}-13^{\text {th }}\right.$ AD), and the Mongols $\left(13^{\text {th }}\right.$ $\left.16^{\text {th }} \mathrm{AD}\right)$. During the tenth and eleventh centuries, while part of the Arab Caliphate, a number of Kurdish dynasties took control over local matters (McDowall, 2004, p. 21). Many of these dynasties, however, were wiped out by the invasions of the Seljuk Turks $\left(11^{\text {th }}-12^{\text {th }}\right.$ AD) and the Mongols $\left(13^{\text {th }}\right.$ AD) (Hassanpour, 1992, p. 50). From the $15^{\text {th }}-17^{\text {th }}$ centuries, most parts of Kurdistan again came under the rule of local governments (hukumats), under the central rule of the Ottomans and Safavids (Persia) (McDowall, 2004, pp. 27-29; see Map 2). The local governments enjoyed a considerable autonomy. Local self-rule, however, never turned into the formation of a unified Kurdistan under the rule of a Kurdish king, even though the idea was not alien to some members of the Kurdish literati at the time (Hassanpour, 2003b, p. 113)..$^{91}$

\footnotetext{
${ }^{90}$ According to Hassanpour there are scholars who have challenged this attempt to link Kurds to the Medes (1992, p. 66; see also Kreyenbroek, 1992, p. 70). Nonetheless, the importance of the claim may not be in its proximity to the truth but its function in the construction of national identity.

${ }^{91}$ Among the early notable Kurds one can speak of two people, Sharaf Khan Bitlisi, the Kurdish prince who wrote the first history of the Kurds, Sherefname, in 1597, and Ahmad Khani, a Kurdish poet, who in his epic poem of Mam u Zin (Mem $\hat{u}$ Zin), written in 1693-94, conceptualized the idea of "Kurdish nation" distinct from the ruling nations of Arabs, Turks and Persians (Hassanpour, 1992, p. 56).
} 
Map 2 "Major Kurdish Principalities from the Seventeenth Century to the $1860 \mathrm{~s}^{\text {" (O'Shea, 2004, p. 86) }}{ }^{92}$

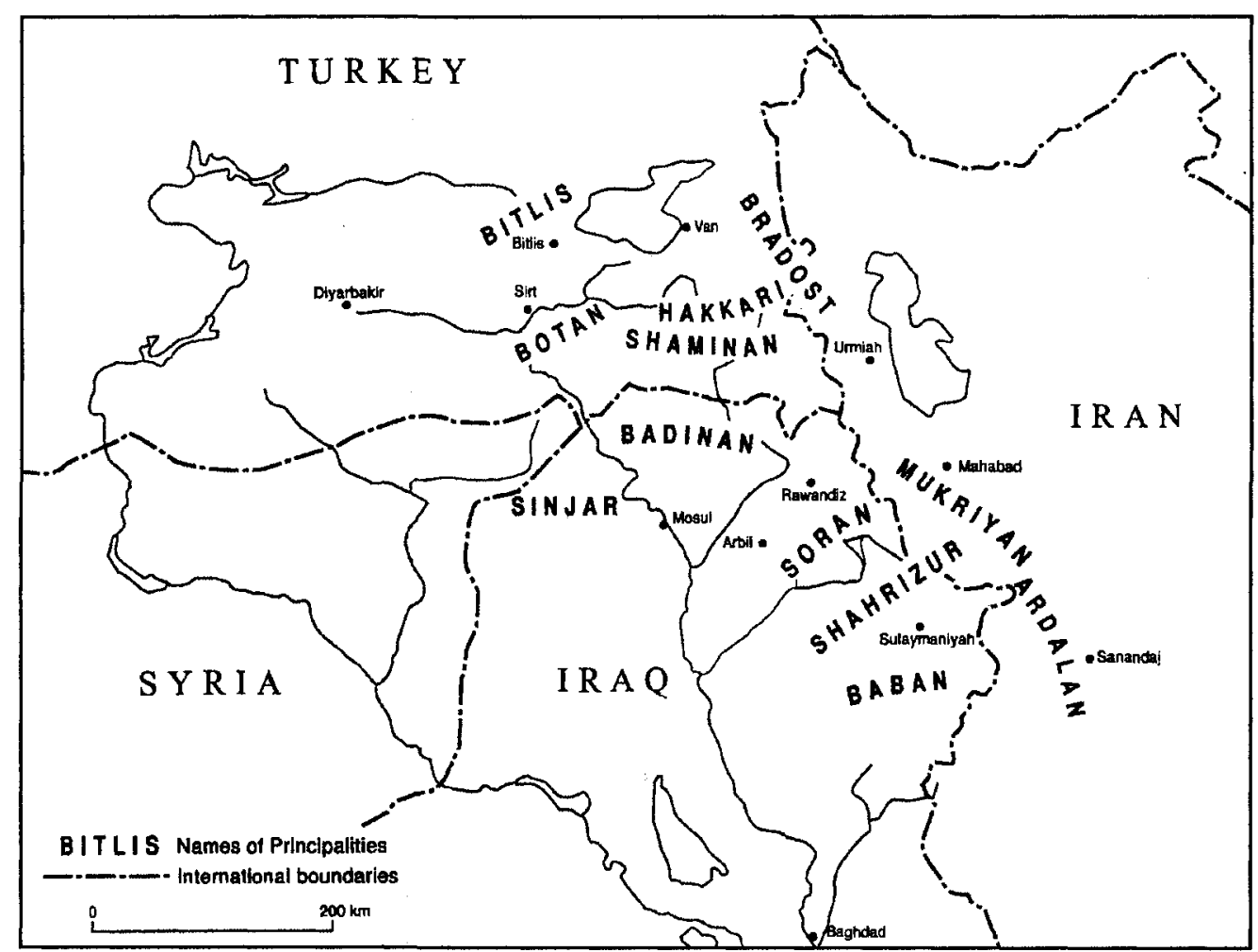

In fact, being situated between the two powerful and hostile empires, the Ottomans and Safavids brought misery, devastation and rivalry among the Kurdish principalities (McDowall, 2004; Hassanpour, 1992). ${ }^{93}$ In the late seventeenth century, Ahmad Khani (or Ehmedê Xanî, d. 1706/7), a Kurdish Mullah, in his poetic epic Mem $\hat{u}$ Zîn (Mam and Zin) wrote:

Look, from the Arabs to the Georgians, The Kurds have become like towers.

The Turks and Persians are surrounded by them

The Kurds are on all four corners.

\footnotetext{
${ }^{92}$ It appears that $O$ 'Shea has made a mistake in recording the name of one of the Kurdish principalities, Shaminan. I believe that it should be Shamzinan.

${ }_{93}$ Rivalry among Kurdish chiefs and Hokkams (governors), however, had a longer history, according to McDowall (2004): "[t]the pattern of nominal submission to central government, be it Persian, Arab or subsequently Turkic, alongside the assertion of as much local independence as possible, became an enduring theme in Kurdish political life" (p. 21).
} 
Both sides have made the Kurdish people,

Targets for arrow of fate.

They are said to be keys to the borders,

Each clan (tayife) forming a formidable bulwark.

Whenever the Ottoman Sea [Ottomans] and the Tajik Sea [Persians]

Flow out and agitate,

The Kurds get soaked in blood

Separating them [the Ottomans and Persians] like an isthmus (cc 220-25).

(as cited in Hassanpour, 2003b, p. 119)

Kurdistan, along with Armenia and Azerbaijan, often were the battlefields for the constant wars between the Ottomans and the Safavids. In addition, the Safavids wanted to replace Kurdish princes and rulers, except for the House of the Ardalan (Emaret-î Erdelan) ${ }^{94}$ with administrators and governors appointed by the centre. The intentions of the Persian Empire faced fierce opposition among the Kurdish principalities as a result of which thousands of Kurds in those principalities were massacred or deported to other parts of the empire (Hassanpour, 1992, p. 53). ${ }^{95}$ The Safavids' mistreatment of the populations in Kurdistan motivated many Kurdish princes and chiefs to ally with the Ottomans and thus played an important role in the defeat of the Safavids in the infamous Chaldiran war in 1514. In return, the Ottoman Sultan Salim respected the autonomy of over a dozen Kurdish principalities.

\section{First Division of Kurdistan}

In 1639 a treaty between the Ottomans and Safavids resulted in drawing the first official border line between the two empires. It ran through Kurdistan and separated what is known today as Iranian Kurdistan from the rest of Kurdistan that today is made up of parts of

\footnotetext{
${ }^{94}$ The House of Ardalan was a Kurdish municipality ruling in Sine (Sanandaj) located in today's northwest Iran.

${ }^{95}$ Eskandar Monshi (1557-1642), the official chronicler of Shah Abbas Safavid, has reported that 15000 Kurds were deported from around the town of Urumiyeh (Wirmê in Kurdish), northwest Iran, to Khorasan province in the Eastern part of Iran where their ancestors continue to identify themselves as Kurds (see also Ivanov, 1925).
} 
Turkey, Iraq and Syria. Not seeing the threat of invasion by each other as imminent any more, the two empires started centralizing their powers and one by one eliminated local governments including those in Kurdistan. After over a century of revolt by the Kurdish principalities against the central powers, by the mid-nineteenth century all of the principalities were overthrown.

\section{Second Division of Kurdistan}

In the aftermath of WWI, most of the Ottoman territories fell into the hands of the Europeans. The Treaty of Sévres (1920) signed between the Allies and the Ottomans called for the establishment of two states, one Armenian and one Kurdish, in today's southeast Turkey or north Kurdistan. The Treaty of Lausanne in 1923, however, modified the agreement, and instead the Ottoman part of Kurdistan was divided between four countries (the new Republic of Turkey, Iraq and Syria, and the Soviet Union). The Iranian part remained intact (Hassanpour, 1992, p 59). This political and geographical division has separated Kurds from each other for almost a century. Being part of or dominated by different cultures and social and political systems have further divided the Kurds culturally, linguistically, territorially and politically.

\section{The myth of one Kurdish identity}

A typical short description of the Kurds that can be found in numerous Western sources, be it scholarly literature, journalistic piece or online sources reads as follows:

A largely Sunni Muslim people with their own language [Kurdish] and culture, most Kurds live in the generally contiguous areas of Turkey, Iraq, Iran, Armenia and Syria - a mountainous region of southwest Asia generally known as Kurdistan ("Land of the Kurds")... (The Washington Post, 1999) 
Or, "The 22 million Kurdish people ... constitute the world's largest ethnic group without a nation [nation-state] of its own" (Randal \& Mintz, 1996). These typical descriptions are often accompanied by a map of Kurdistan as shown in figure 2 .

Figure 2 Kurdistan map as presented in The Washington Post (1999)

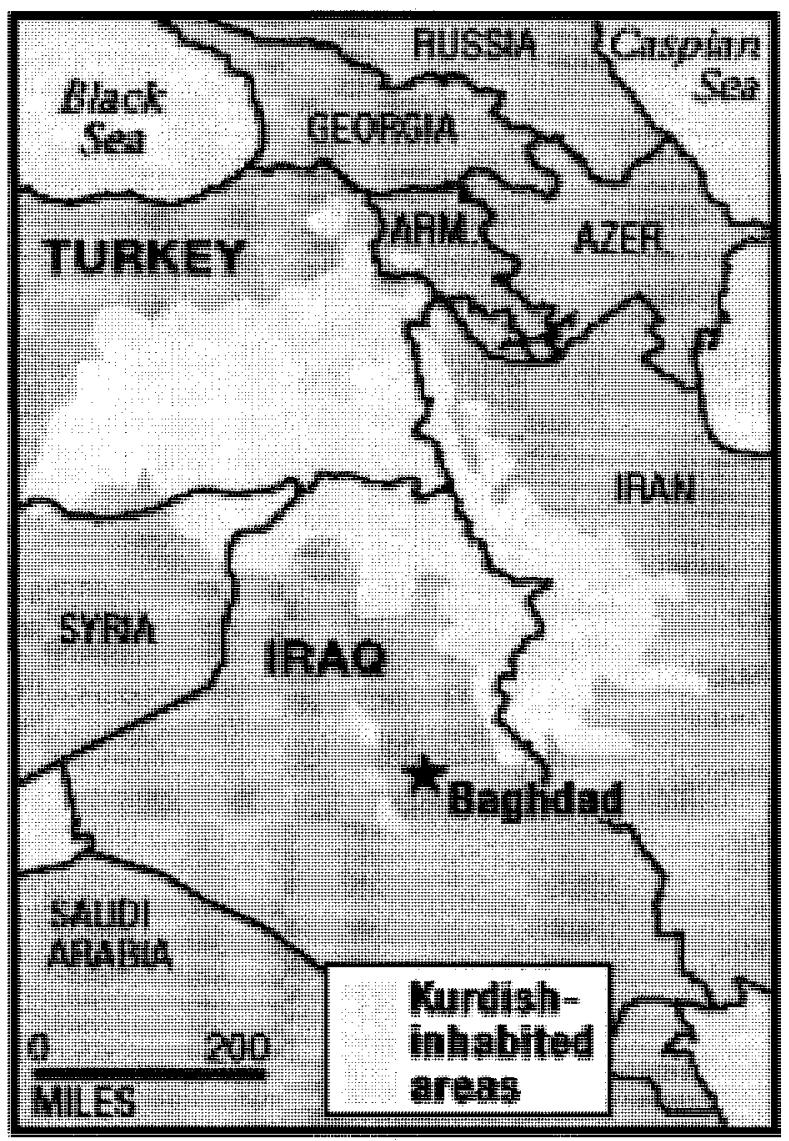

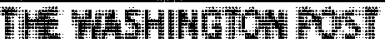

This image of Kurds is very much in line with the Kurdish nationalist discourse: Kurds are a homogenous group of people who are unified ethnically, territorially, linguistically, culturally, and politically in the sense of having common aspirations and long-term goal of establishing a unified and independent Kurdistan. However, there are some scholarly sources which take a critical approach that points to various fragmentations among the 
Kurds as one might expect to be the case in any group of people (van Bruinessen, 2000a,

1992; Kreyenbroek \& Allison, 1996; Hassanpour, 2003; Vali, 2003).

\section{Kurdish identity and its fragmentations: Scholarly debates}

Kurdish nationalists who adhere to the primordialist approach to nation and nationalism

believe that the Kurds have existed since time immemorial as one nation, and they have

always lived in their homeland, Kurdistan. They also believe that due to external factors,

such as being invaded by other dominant nations, and also internal factors, such as disunity

among the Kurds, their land has been divided and occupied, and consequently Kurdish

identity has been violently and unjustly fragmented. A prime example of a primordialist

conceptualization of Kurdish identity and nationalism can be found in the literature of the

pan-Kurdist society Kajîk (Kazhik). ${ }^{96}$ Kajîk literature, primarily resting on pan-Kurdish

ideas of the Kurdish linguist Jamal Nabaz, asserts that "Kurdayetî [Kurdish nationalism]

movement, as we see it, is not the construction of any class or group or any particular point

in history ... Kurdayetî is a natural, dynamic and everlasting movement. It has been present

since the emergence of the Kurdish nation" (Edebîyatî Kajîk, pp. 73-74). ${ }^{97}$ Nabaz firmly

\footnotetext{
${ }^{96}$ Kajîk is a pan-Kurdist organization founded in 1959 in the Iraqi Kurdistan. Among its leading figures were the well-known Kurdish linguist and nationalist Jamal Nabaz and the poet Ehmed Herdi (Ahmad Hardi). Kajîk called upon Kurds everywhere to unite and struggle for the independence of Kurdistan. The organization discredited the regional politics of the vast majority of Kurdish parties and renounced their aims of achieving autonomy within different states of Turkey, Iran, Iraq and Syria. Kajîk no longer exists, but its ideas of pan-Kurdism live on and are reflected in various Kurdish nationalist discourses including that of some regional organizations. Today, there are several small political parties and also some cultural organizations that share most of Kajîk's ideas. Some examples of these organizations are: the Democratic National Union of Kurdistan (Yekyetî Neteweyî Dêmokratî Kurdistan): http://www.yndk.com/ , Kurdistan National Congress: http://www.knc.org.uk/.

${ }^{97}$ A number of scholars writing in English on the Kurds have mistranslated or even misunderstood the word Kurdayetî. For Dahlman (2002), "Kurdaity," means "Kurdishness" (p. 294). Similarly, Denis (2002) renders "Kurdayeti" as "Kurdish identity." In contrast, at least three of the most reliable sources on Kurds and Kurdish language (Hassanpour, 1992, p. 46; Hejar, 1990, p. 629; Wahby \& Edmonds, 1966, p. 80) have provided different and more reliable definitions of the term Kurdayetî. They translate the word as "the Kurdish nationalist movement and ideology," "Kurdish patriotic movement," and "to act in the interest of Kurdish people" respectively. Although it is arguable whether the two concepts of nationalism and patriotism
} 
believes that "the Kurdish nation is comprised of one ethnic unit, and has one history, one language and one geography. But it lacks a political structure. Kurds' land has been forcefully divided among Turkey, Iran, Iraq, Syria and the Soviet Union" (Nabaz, 1985, p. 16). For Nabaz, since Kurds everywhere have always comprised one nation it is all logical and natural that they "re-establish" their glorious past in the form of an independent, unified and homogenous Greater Kurdistan.

Hassanpour, while rejecting a primordial and essentialist approach to nation and nationalism, believes that the formation of Kurdish identities began in the $17^{\text {th }}$ century with the rise of "linguistic nationalism" which emerged in the feudal, agrarian, tribal and traditional society of Kurdistan. For Hassanpour $(2003 \mathrm{~b}, 1992)$ the prime example of this national awakening is reflected in the writing of Ahmad Khani (1651-1706), who wrote the poetic romance Mem u Zîn based on a popular ballad. Khani was highly aware that his culture was different from that of the dominating Ottoman Turks and Safavid Persians:

I am a pedlar, not of noble origins

Self-grown, not educated.

I am a Kurmanj (Kurd), from the mountains and distant lands.

There [are] a few stories of Kurdish way of life (Kurdewarî), Endorse [them] with good intentions ... (as cited in Hassanpour, 2003b, p. 126)

are the same, the crucial point is that Kurdayetî refers to a movement or action that is carried out on behalf of the Kurds. It can also refer to an ideology or belief system that makes claims about Kurdish identity or Kurdishness. Ahmadzadeh (2003) also defines Kurdayetî as "Kurdish nationalism and struggling for the rights of the Kurds" (p. 245). These leave no doubt that in Kurdish the word Kurdayet î is not used to mean "Kurdish identity" or "Kurdishness." C. J. Edmonds, in an article titled "Kurdish Nationalism," summarizes Kurdayetî's main beliefs:

The Kurds constitute a single nation which has occupied its present habitat for at least three thousand years. They have outlived the rise and fall of many imperial races: Assyrians, Persians, Greeks, Romans, Arabs, Mongols, and Turks. They have their own history, language, and culture. Their country has been unjustly partitioned. But they are the original owners, not strangers to be tolerated as minorities with limited concession granted at the whim of the usurpers. (as cited in Hassanpour, 1992, p. 62) 
Khani was equally aware that an important factor that identified Kurds was their language. At the time, the most prestigious literary language throughout the Ottoman Empire was Persian, as it was also in India and Iran, but Khani chose to write his Mem $u$ Zîn in Kurdish. He wrote,

Whether a product of obstinacy or injustice He [=Khani] made this innovation (bid 'et) against tradition He cleared from its dregs, The Kurdish language, [and put it] on par with Persian, Put it into order and system, Tolerated much suffering for it.

(as cited in Hassanpour, 1992, p. 86)

As van Bruinessen (2003) notes, Khani knew that he would have had a much wider audience had he written his work in Persian, but "he deliberately opted for the Kurdish language in order to raise the standing of Kurdish culture in the eyes of the Kurds' neighbours" (p. 42; see also Hassanpour, 1996, p. 61).

According to Hassanpour (2003b), although Khani, as a Kurd, came from and wrote in the context of a feudal society, "his ideas and literary effort resemble, on the surface, the beginnings of the linguistic and literary movement that is often referred to as 'linguistic nationalism"' (pp. 126-127). Hassanpour, however, is quick to note that Khani did not advocate the ideas of modernity that are intertwined with western nationalism such as "bourgeois democracy or popular sovereignty" (p. 132; see also Vali, 2003, p. 92). Khani did not envision a Kurdish nation that would be marked by what Anderson (1991) has called "horizontal comradeship." Instead, Khani wished for a king that would unite the Kurdish princes to elevate the status of the Kurds in the eyes of the dominating empires of Ottoman and Safavid, and would even attempt to subjugate the Turks and Persians (van 
Bruinessen, 2003, p. 45). ${ }^{98}$ van Bruinessen (2003) believes that at the time of Khani, the term Kurd only referred to "the Kurdish tribes and a part of the urban aristocratic elites, but not to the non-tribal peasantry" (p. 44). Furthermore, van Bruinessen doubts if Khani's readers at the time inferred the same political messages from Mem $u$ Zin as Kurdish intelligentsia and nationalists did a few centuries later (p. 46).

For van Bruinessen, the formation of Kurds as a nation and the emergence of Kurdish nationalism are modern and relatively recent phenomena going back to the beginning of the last century. He believes that a sense of belonging to one people has existed for a long time among the Kurds, but that is not the same as saying Kurds were always a nation in the modern sense. Writing in the late 1990s, he suggests that, "what unites [the Kurds] is not any set of objective, economic, political or cultural characteristics, but only the awareness among many of them that they constitute one people" (2000, p. 45). He contends that "this [modern nationalist] awareness is a result of a series of historical developments, the most important of which was the rise of Kurdish nationalism" (ibid.), at the beginning of the $20^{\text {th }}$ century (Vali, 2003, p. 104; Smith, 1996, p. 594; van Bruinessen, 2000a, p. 44). According to van Bruinessen, the emergence of Kurdish nationalism had two main causes. Firstly, it was a reaction to Turkish, Persian and Arab nationalisms which were aiming at the assimilation of the Kurds and other ethnic groups in Turkey, Iran, Iraq

\footnotetext{
${ }^{98}$ Precisely for these reasons, Vali (2003) believes that Khani could not be called a "nationalist," but a "patriot" (p. 92). Bruinessen (2003) is also reluctant to call Khani a nationalist; nonetheless, he refers to him as "the father of Kurdish nationalism," because he believes that Khani's Mem u Zin contributed to the emergence and development of Kurdish nationalist throughout Kurdistan.
} 
and Syria (2000, p. 44; see also Vali, 2003, 1998). Secondly, it was inspired by the

European nation-building success. ${ }^{99}$

Vali (2003, 1998), who like Hassanpour and van Bruinessen, is among the few scholars who have contributed to the theorization of Kurdish identity, also believes that "Kurdish national identity is unmistakably modern" (p. 104). Vali finds the primordialist view of Kurdish national identity essentialist and historicist. Vali $(2003$, p. 59, 66) characterizes Hassanpour's position as "ethnicist" and van Bruinessen's as constructivist, and contends that, "while the ethnicist approach derives national identity from a uniform ethnic origin given to and ever-present in history, the constructivist conception reduces it to a mythical origin constructed by capitalism and modernity" (p. 66). ${ }^{100}$ Vali calls for a total separation between a modern national identity and an ethnic identity, a discourse of identity and a discourse of origins. He contends that "nationalist discourse is not a discourse of origin, given or constructed. Rather it is primarily a discourse of identity in which the popular claim to sovereignty is posed" (p. 68). For Vali, whereas ethnic identity is inscribed in discourses of origins and historicization, national identity is expressed and articulated in discourses of rights and citizenship and claims to popular sovereignty.

To Vali, all identities, individual or collective, are always relational. National identities are defined in terms of differences and are inscribed in "otherness" (1998, p. 83). Kurdish identity, Vali contends, emerged as a reaction to the affirmation of official national

\footnotetext{
${ }^{99}$ Both Bruinessen and Hassanpour believe that the emergence of Kurdish nationalism as a modern force was marked by the formation of first Kurdish political organizations. The first Kurdish organizations were formed in Turkey around the $1900 \mathrm{~s},{ }^{99}$ and then in Iran during the WW II, followed immediately by the establishment of the Kurdistan Democratic Party (KDP) in Iraq. Although movements with nationalist tendencies are dated back to around the WW I, Kurdish nationalism as a mass movement only came to prominence in the 1960s in Iraq, followed by populous movements in Iran and then in the mid 1980s in Turkey.

${ }^{100}$ Hassanpour (2003) has contested Vali's reading of his position on the nature of ethnicity. Hassanpour says: "ethnicity is itself social, constructed, contingent and changing, even in the most ethno-centrist nationalist theories and practices" (p. 147).
} 
identities in Turkey, Iran, Iraq and Syria because they hinged on "the denial of Kurdish ethnicity and ethnic and national identities" (1998, p. 82; also see Vali, 2003, p. 73). Vali defines Kurdish identity entirely in terms of "otherness" and leaves no room for historical and ethnic roots of national identity. This position runs into two problems. First, as Smith $(1999,1991)$ has demonstrated time after time, we hardly know of any nation or national identity that has not been conceptualized around ethnic cores at least at its inception. Second, as I will show, Vali's own argument implies that a pre-modern Kurdish identity had existed.

Vali states that "the denial of Kurdish ethnicity and ethnic and national identities was the necessary condition of [the processes of modern state building and national identity constructions in Turkey, Iran, Iraq and Syria]" (1998, p. 82, my emphasis). He also contends that Kurdish national identity was non-existent prior to the emergence of Turkish, Arab, and Persian national identities. One cannot help but ask: how could "Kurdish ... national identities" be denied if they did not exist prior to the establishment of those new states and their official national identities? If Vali is correct that the discourse of any identity is solely invested in "otherness," or in differences from other identities, then there must have been a Kurdish identity, or identities, opposing the Turkish, Persian and Arab identities in order for these identities to confirm themselves. This Kurdish identity or identities that Vali has in mind, I submit, were Kurdish ethnic identities. This way, the link between Kurdish ethnic identities and Kurdish modern national identity becomes apparent in Vali's very own argument. ${ }^{101}$

\footnotetext{
${ }^{101}$ By denying the historical and ethnic connections of Kurdish national identity, and seeing identity formation solely as a discourse of opposition, Vali runs the risk of having his approach come across as essentialist, the very thing that he is at pains to escape. Hassanpour (2003, p. 146) also asserts that "far from
} 
To sum up, Kurdish national identity is not entirely modern, but Kurdish nationalism is. Kurdish national identity, similar to all national identities, has historical and ethnic roots, even if such roots happen to be constructed or fictive. In the beginning of the twentieth century, at the time when Turkish, Persian and Arab nationalisms started to affirm themselves partially by denying the ethnic identities of the Kurds, Kurdish nationalism emerged to engineer a Kurdish national identity. The construction of a modern Kurdish national identity has depended on the appropriation of ethnic and historical origins such as language, culture and territory coupled with newly created nationalist symbols and finally by political claims to modern values such as sovereignty and the right to selfdetermination. In addition to these characteristics, which aim at in-group solidarity, Kurdish identity has also born differences from other identities. However, a strong collective Kurdish national identity is yet to form. The majority of scholars of Kurds and Kurdistan, despite their differences on many historical, political and theoretical issues, agree at least on one point: Kurdish identity is deeply fragmented. Notwithstanding the oppression imposed by the states, it has been suggested that the formation of a strong collective Kurdish identity has for the most part suffered from internal fragmentations: territorial, cultural, linguistic, and political.

\section{Territorial fragmentation}

Kurdistan can be literally translated as the land/homeland of the Kurds, and it is divided by the internationally recognized borders of four nation-states of Iraq, Iran, Turkey and Syria. As Ciment (1996) notes, "Kurdistan has been virtually wiped from the map in the twentieth century" (p. 75). The only exception is the province of Kordestan in Iran encompassing 
about one third of the total area inhabited by the Kurds in Iran. ${ }^{102}$ Most Kurds and Kurdish sympathizers refer to Turkish Kurdistan as northern Kurdistan or Kurdistan north, Iraqi Kurdistan as southern Kurdistan or Kurdistan south, Iranian Kurdistan as eastern Kurdistan or Kurdistan east, and Syrian Kurdistan as western Kurdistan or Kurdistan west. However, except for today's Iraq, the other states where most Kurds live refer to parts of Kurdistan as southeast Turkey, northern Iraq, and in Iran and Syria various names of provinces and regions are used. Kurdistan as conceptualized by the vast majority of Kurds and scholars of Kurdish studies is non-existent for those states.

Kurdistan's mountainous make-up, especially where the four nation-states of Turkey, Iraq, Iran and Syria meet, is deemed very important to the host states. According to McDowell (2004), "the mountains certainly provide Iran and Iraq with a defensible strategic frontier; to move the boundary either west or east of Kurdistan would not make strategic sense to either states" (p. 7). As McDowall observes, the four states have proven that they are committed to keep these borders, which run through Kurdistan, intact at all costs. Turkey has perhaps demonstrated the highest degree of antipathy towards not only the concept of a distinct territory as Kurdistan but also the very word describing it. For example, numerous researchers and ordinary people, Kurdish or non-Kurdish, traveling to Iraqi Kurdistan through Turkey have reported that their documents and laptops have been searched by Turkish border guards for the word Kurdistan. They have been asked to delete instances of the word from their documents and equipment (O'Leary \& Salih, 2005, pp. 34); in other cases, documents, print materials and pictures containing the word have been destroyed altogether. According to McDowall, Turkey "has an emotional and ideological

\footnotetext{
${ }^{102}$ Kurds also make up the majority of the population of three other provinces: West Azerbaijan, Kermanshah (Kirmashan in Kurdish), and Ilam.
} 
view that its frontiers (except with Iraq) cannot be changed without threatening the foundations of the republic ... The loss of Kurdistan, despite its great poverty, would be perceived as a grievous blow to the spatial identity of Turkey" (ibid.). The same can be said about the other three states.

The rugged, mountainous and harsh terrain of Kurdistan, while being important for the four nation-states, has been both a blessing and a curse for the Kurds themselves. These rugged mountains have been blessing because as O'Shea (2004, p. 162) observes "to most Kurds, even urbanites or dwellers of the plains, Kurdistan is defined by its mountainous topography. A common theme in Kurdish culture is the mountains as allies in the many Kurdish military struggles". The Kurdish saying, "the only friends of the Kurds are the mountains" (O'Leary, McGarry \& Salih, 2005, p. xix) became the title of a book in 1992 , No friends but the mountains (Bulloch \& Morris, 1992; see also Izady, 1992, p. 188). Mountains have become a national symbol and one of the most salient markers of Kurdish identity.

Kurdistan's rugged landscape has also been a curse on the unity of the Kurds because it has isolated communities of Kurds for centuries, especially since the final division of Kurdistan in 1923. According to Izady (1992),

Just as the mountains create autonomy for the Kurds, they often prohibit easy communication between them ... The mountains have broken down the language of the Kurds to a babble of dialects, their religions to a case study in diversity, and their art and costumes to a zoo of colourful variety. (p. 188)

In a similar vein, Yavuz (2005) suggests that Kurdistan's "rugged geographic conditions have been a major impediment to the formation of Kurdish unity" (p. 232). Physical barriers such as mountains have been among the biggest obstacles in the way of easy communication among the Kurds. Until very recently, most communication between the 
Kurds of different parts was between and through a small population of inter-related tribes living on the borders, as well as through smugglers, rebels of different parts, and a handful of the intelligentsia who were aware of each other mostly through clandestine short-wave radio stations and literary or political pamphlets. ${ }^{103}$ The absence of easy communication among the Kurds living in different states gradually deepened cultural, linguistic and political differences.

\section{Cultural fragmentation}

Van Bruinessen (2000a), contends that "Kurds were (and are) certainly not a culturally homogeneous group" (p. 45). For van Bruinessen, cultural differences among the Kurds are so great that he hesitates to call them an ethnic group. Van Bruinessen (2000a) observes that "judging by objective criteria, one would be inclined to consider the Kurds as conglomerates of different ethnic groups rather than as a single one" (p. 9). In light of this critical observation, I submit that when referring to Kurds in general the appropriate terms would be nation or people.

Cultural differences in Kurdistan are not due to internal and ethnic fragmentations alone. They also bear the traces of the different dominant cultures of the states in which Kurds have lived (van Bruinessen, 2000a, p. 52). ${ }^{104}$ Vali’s (1998) observations are particularly insightful here. He suggests that the dynamics and patterns of Kurdish identity formation have been determined not only by its own internal factors but also by nation-

\footnotetext{
${ }^{103}$ In 1979, when the Iranian Revolution took place and Iranian Kurds started to gain a populous ethnic awareness, those interested in Kurdish print materials would pay a great deal of money to buy a Kurdish magazine or book smuggled over the mountains from the Iraqi Kurdistan. The publications, however, were often months old. The publications even were obtained and read by only a very small group of Iranian Kurds who could read and write.

104 "During the past half century, the Kurds of Turkey, Iran, Iraq and Syria - and not only those who migrated to the cities-have very clearly become more integrated into the economic, political, social and cultural life of these countries, although not always on equal terms with the dominant ethnic groups ... the Kurds [in the four states] developed different tastes and attitudes" (van Bruinessen, 2000, p. 52).
} 
building policies and practices of the "other," the national identities that have been imposed by the states ruling over Kurdistan. Since each state has adhered to different practices of nation-building with different cultures and languages and thus identity formation, Kurdish identity within each state has taken a different shape:

...the emergent national states in [Turkey, Iran, Iraq, Syria], and the official nationalist discourses which were constructed to legitimize their authoritarian rule and hegemonist political culture, varied substantially in form and character ... Kurdish identity has borne the mark of this political and cultural diversity of the "other"; it has been deeply fragmented since its inception. (Vali, 1998, p. 82)

Cultural differences among the Kurds relate to music (Izady, 1992, p. 68), clothing and costume, food and religion (Kreyenbroek \& Alliston, 1996), marriage and many other cultural traits and attitudes. The cultural diversity is indeed remarkable; for example, there have been (and are) different religions and sects in Kurdistan. Although the majority of

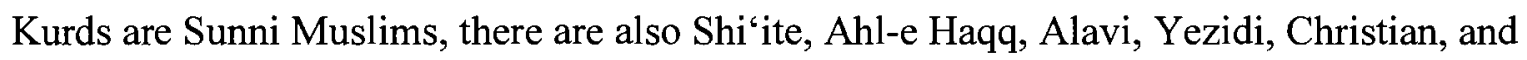
Jewish Kurds (Kreyenbroek, 1996; O'Shea, 2004, pp. 28-33). Religious differences seem to be a disadvantage for the Kurdish movement and quest for identity recognition. Van Bruinessen (2000a) observes that the vast majority of Shi'ite Kurds of Iran (residing in the provinces of Kirmashan and Ilam) have refrained from joining the Kurdish movement and instead have sided with the central government in Iran where a particular brand of Shi 'ism is the official religion of the country. On the other hand, because the government in Baghdad until 2003 was dominated by Sunni Muslims, Kurdish Shi' ites in Iraq have been actively participating in the Kurdish national movement in Iraq (p. 26). Since the vast majority of Kurds are Muslims, as are the vast majority of the neighboring nationalities and ethnic groups, religion has not been a major factor distinguishing the Kurds from the dominant national and ethnic groups; it has not been a key factor in defining 
Kurdishness. ${ }^{105}$ In addition to religion, many cultural traits of the Kurds have become similar to those of the Turks, Persians and Arabs as a result of being dominated by these cultures for about a century. Language, however, has remained as one of the most salient defining elements of Kurdish identity.

\section{Linguistic fragmentation}

Language has been considered as one of the main indices of Kurdish identity (Vali, 2003, p.

100; McDowell, 2004, p. 9; Kreyenbroek \& Allison, 1996, p.1). Hassanpour (1992)

believes that language is like the air for the Kurdish nationalist struggle because it is the most obvious characteristic that differentiates the Kurds from the neighboring nationalities.

Both Kurdish nationalists and the states where Kurds reside have realized the importance of language in defining Kurdish identity.

Unmistakably influenced by the nation-state ideology, which holds that an ideal nation has no room for more than one language, Kurdish nationalists have contested any suggestion that Kurds speak more than one language, a proposition that has been put forward by some linguists (e.g. Kreyenbroek, 1992, p. 71). Seeing Kurdish language as a decisive factor defining Kurdish distinct identity, the host states "have sought to 'assimilate' the Kurds by attempting to suppress Kurdish altogether, or to discourage its

\footnotetext{
${ }^{105}$ Kurdish nationalists, especially non-secular ones, have always taken pride in the famous Muslim Kurdish commander Saladin (in Kurdish pronounced Selaheddin) Ayyubi, who "decisively defeated the Crusaders and established the Ayyubid dynasty in Egypt, Syria and Iraq" (McDonald, 2004, pp. 22-23). It is safe to suggest that neither he nor other Kurdish heroes at the time gained fame in the name of Kurdayeti (Kurdish nationalism/patriotism) but in the name of Islam. This, however, has not prevented many Kurds to consider Saladin a part of the Kurdish glorious past. It should be also stressed that religious affiliations in Kurdistan played important roles at the time when Kurdish emirates and principalities $\left(15^{\text {th }}-17^{\text {th }}\right.$ AD) would often shift loyalties either to the Ottomans (Sunnis) or Iranian Safavids (Shi'ites) in order to preserve their hereditary rule (Hassanpour, 1992, p. 56). Finally, one may argue that religion has been a factor in processes of Kurdish identity formation in Iranian Kurdistan. The vast majority of Iranian Kurds from those regions that are known to be hotbed of Kurdish nationalism (e.g. the provinces of Kordestan and West Azerbaijan) are Sunni Muslim. The official religion of Iran, however, is a particular brand of Shi' ism (see Entessar, 2006, pp. 194-195).
} 
development" (Kreyenbroek, 1992, p. 68). The official repression along with the linguistic differences among Kurdish varieties has left the Kurdish language deeply fragmented.

The fragmentation of Kurdish language is twofold: different speech varieties, and different written scripts. In addition to many local dialects (e.g. Mukri, Sorani, Ardalani, Suleimani, Harki, Jalali, and so forth), ${ }^{106}$ there are four major speech varieties spoken by Kurds: Kurmanji, Sorani, Zazaki/Dimli and Hawrami/Gorani, and Kirmashani (Hassanpour, 1992, p. 20) (see Figure 3). ${ }^{107}$ These varieties are not mutually intelligible in most contexts. Kurmanji is spoken by about $70-75 \%$ of all Kurds, most of whom live in Turkey. Kurmanji speakers also combine about $20-25 \%$ of Iraqi Kurds, Syrian Kurds (about 1-1.5 million), and Kurds living in Armenia and other republics of central Asia, and a small number of Kurds living to the north of the city of Urumiye (Wirmê in Kurdish) in Iran. Sorani is spoken by about $20-25 \%$ of all Kurdish speakers, all of whom reside in Iraq and Iran. Zazaki is spoken by about one million people living in northern Kurdistan (or southeast Turkey, to use the state's official discourse) in the triangle between Diyarbakir, Sivas and Erzurum (Kreyenbroek, 1992, p. 68). Hawrami or Gorani, considered by Kurds as the oldest Kurdish variety (Hassanpour, 1992), has fewer speakers living in the southern parts of Iranian and Iraqi Kurdistan. Finally, Kirmashani is spoken by the vast majority of Kurdish speakers in the southern part of Iranian Kurdistan (e.g. in and around the cities of Kermanshah and Kamyaran) and in and around the city of Khanaghin (Xaneqîn in Kurdish) in Iraqi Kurdistan. Of these varieties, Kurmanji and Sorani, as the two varieties with the

\footnotetext{
${ }^{106}$ In Kurdish: Mukrî, Soranî, Erdelanî, Suleymanî, Herkî, Jelalî respectively.

107 There are no consensuses on the naming of Kurdish varieties. Most Kurdish nationalists do not accept the naming that I have adapted here, following Hassanpour (1992) and Kreyenbroek (1992). For example, they prefer [Kurdish] North and [Kurdish] Central, instead of Kurmanji and Sorani, respectively because they find the use of terms like Kurmanji and Sorani divisive. For a detailed survey of various approaches to Kurdish language typology see Hassanpour (1992, pp. 19-23).
} 
majority of speakers, are for the most part standardized. They are used in Kurdish media, in all parts of Kurdistan and diasporas, and also for education and administration in KurdistanIraq. $^{108}$

Figure 3 Distribution of Kurdish speech varieties (Hassanpour, 1992, p. 22)

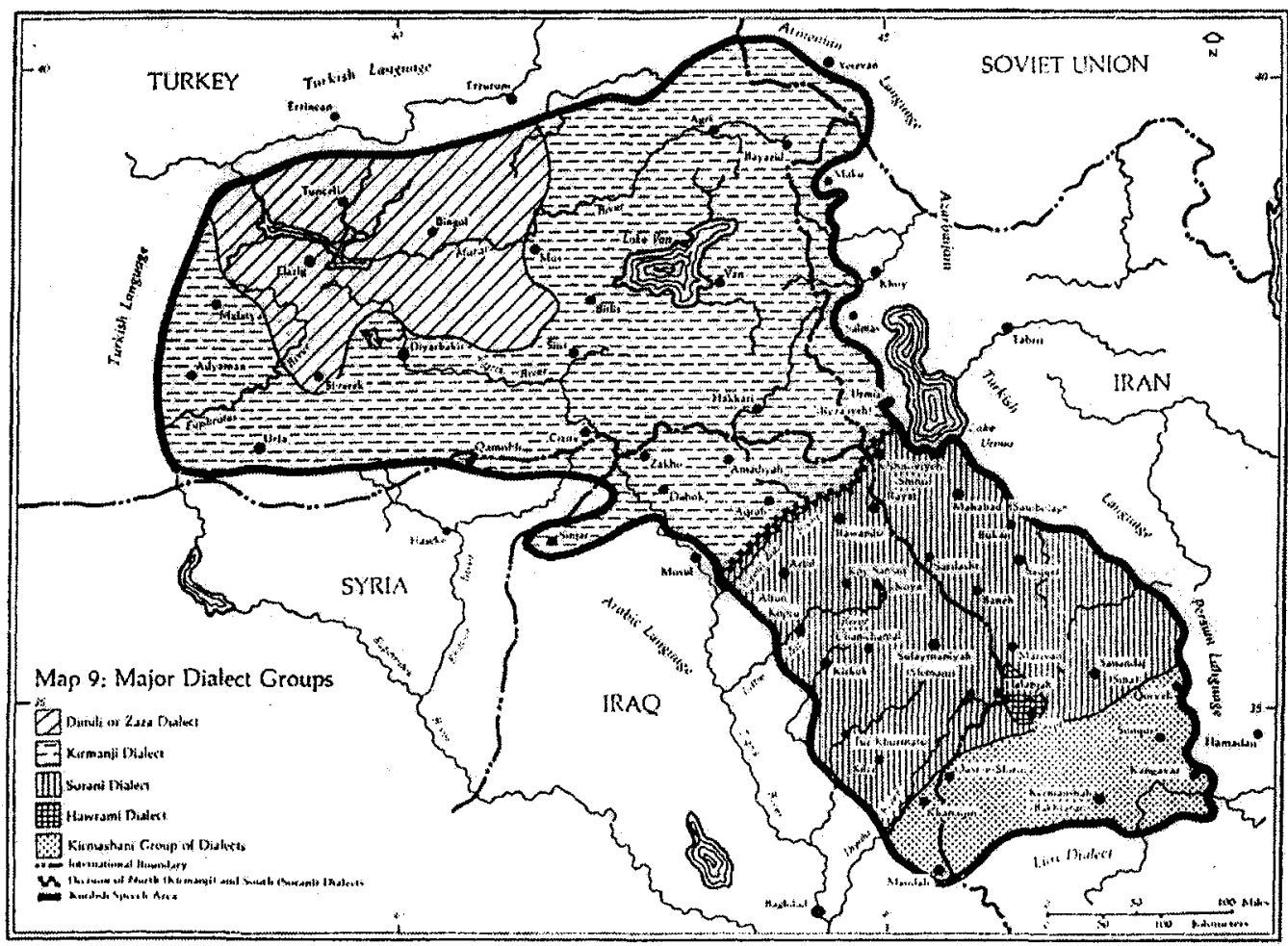

Kreyenbroek (1992) finds Kurmanji and Sorani as different as English and German (p. 71) particularly with respect to phonology and morphology, but not vocabulary. ${ }^{109}$ These differences have compelled some scholars to call Kurdish varieties "languages" (ibid.). In fact some researchers have even exaggerated the diversity of Kurdish varieties

\footnotetext{
${ }^{108}$ Hassanpour (1992) has conducted the most comprehensive study to date of the standardization processes of these two Kurdish varieties especially Sorani.

${ }^{109}$ For example, Sorani does not have gender case but Kurmanji does. For a brief account of these differences between Sorani and Kurmanji, see Hassanpour (1992, pp. 23-24).
} 
and reported that there are over a dozen Kurdish "languages" (Jenkins, 2001). In contrast, almost all Kurdish nationalists and a great number of researchers (e.g. Hassanpour, 1992; McDowell, 2004; van Bruinessen, 2000a) prefer the word "dialect." I have opted for the term Kurdish varieties because I find the terms language and dialect politically loaded. ${ }^{110}$ The crucial point of all this, especially for this study, is that Sorani and Kurmanji are not mutually intelligible. While referring to Sorani and Kurmanji as Kurdish "dialects," Hassanpour (1992) confirms that "until they have had considerable previous contact, the speakers of Kurmanji and Sorani are not able to communicate effectively in all contexts" (Hassanpour, 1992, p. 24, emphasis in original; see also van Bruinessen, 2000a, p. 27).

The gulf between Kurdish speech varieties is further widened by the fact that they are written in different scripts. While Sorani speakers use a modified Arabic alphabet system, the Kurmanji speakers use both the Arabic modified (Kurds from Iraq) and a Roman script based on the modern Turkish alphabet (all Kurds from Turkey and Syria and some from Iraq). Kurds from central Asia (Armenia, Azerbaijan, Kazakhstan), however, use Cyrillic. ${ }^{111}$ Although there have been some attempts (e.g. Nabaz, 1976) to unify the two major Kurdish varieties, Kurmanji and Sorani, grammatical differences between the two varieties, the absence of a unified state in Kurdistan, and the official repression against the language have made the efforts unsuccessful. The influence of the dominant languages on Kurdish is not only evident in different writing systems of Kurdish but also in very important aspects of the language such as vocabulary, phonetics, grammar and style. The

\footnotetext{
${ }^{110}$ Max Weinreich, a German linguist, is often quoted as saying, "a language is a dialect with an army and a navy" (as cited in Romaine, 2000, p. 13). Languages are traditionally perceived to belong to nation-states but dialects to ethnic groups and minorities.

${ }^{111}$ There are, however, those who also use the Latin-based alphabet writing system just like Kurds from Turkey.
} 
internal diversification of Kurdish language has been intensified by the state repression of the language.

From its birth, the new republic of Turkey saw no place for non-Turkish peoples and languages. The Kurds were called "mountain Turks" (Kreyenbroek, 1992, p. 73) and their language was officially banned in 1938 in all public domains. Kurmanji survived in homes and villages and it started to be written and standardized by Kurdish intellectuals in diasporic communities, first in Syria (1942-1945), when Syria was still under French Mandate, and then in the West. ${ }^{112}$ In fact, it is safe to suggest that today's Kurdish Kurmanji was mainly developed, codified and flourished in the West, notably in Germany and Sweden. As of 1991, more was published in Turkey than in diasporas to the extent that many diasporic journals either migrated to Turkey or ceased publishing.

Although the use of Kurdish was legalized in Turkey in May 1991, SkutnabbKangas \& Fernandes (forthcoming) report that the status of Kurdish in Turkey has not changed that much:

Kurdish-medium schools are not allowed in Turkey. Neither do Kurdish children have the right to study their mother tongue as a subject in schools. In theory, courses in the Kurdish language can be taught to teenagers and adults but in practice the obstacles and conditions have been so many and so bureaucratically and legally demanding that there are next to no courses at the time of writing this article. (p. 2)

The authors provide numerous examples of court cases in Turkey (during the time period of 2002-2006) in which "the Kurdish language and expressions in support of Kurdish culture/language are either overtly prohibited, or prohibited on the basis of being labelled "terrorist activities," which fall under the vague definition of terrorism in various articles in

\footnotetext{
112 There was some publishing in Turkey beginning in the 1960s.
} 
the Turkish Penal Code" (p. 3). ${ }^{113}$ Since the mid-1990s private Kurdish lessons have been offered in major urban centres such as Istanbul and Diyarbakir. However, these classes are usually short-lived, mainly because they are not supported by the government, and as a result pupils find them too expensive to attend or those who run the courses cannot secure sufficient financial support to run them.

The language policy of Iran has not changed since the first constitution of 1906 (Hassanpour, Skutnabb-Kangas \& Chyet, 1996, p. 369), in which Persian or Farsi was declared as the official language of Iran. The local languages, such as Kurdish, have been allowed theoretically to be used in the mass media. ${ }^{114}$ Broadcasting, however, has always been a monopoly of the state. Thus, broadcasting in Kurdish has tended to be a propaganda vehicle for the central government. Currently, and much more than in the Shah's time, Kurdish books and magazines are published in Iran, but permission needs to be granted by the government for each publication. Also, heavy censorship is often at work, and many Kurdish periodicals that emerged in the mid 1990s, after the reformists took power in Iran, have been closed down. Kurdish does not have any official status in Iran and it is not taught in schools let alone being the medium of instruction. In recent years, a couple of universities (e.g. University of Kurdistan in the city of Sanandaj) have started offering a few courses on Kurdish language and literature; however, these courses and programs,

\footnotetext{
${ }^{113}$ Fernandes (2007, p. 46) reports on the following exchange between British MPs and Turkey's ruling party members during a meeting in Turkey in 2007. A British MP asks: "Will you add the Kurdish language into the [newly proposed 'civilian'] constitution as an educational right and provision?" The ruling party's official replies: "Is there a language called Kurdish? ... It's not a real language ..." (emphasis in original).

${ }^{114}$ Article 15 of the current Iranian Constitution states, "The Official Language and script of Iran, the lingua franca of its people, is Persian. Official documents, correspondence, and texts, as well as text-books, must be in this language and script. However, the use of regional and tribal languages in the press and mass media, as well as for teaching of their literature in schools, is allowed in addition to Persian" (International Constitutional Law, 1992).
} 
similar to Kurdish periodicals, are short-lived. Also, in a number of Kurdish cities, privately run Kurdish courses are offered. ${ }^{115}$

In Syria, Kurdish is not recognized as an official language and it is not taught in schools, public or private (Amnesty International, 2005). From 1920-1937, under the French Mandate, Kurds in Syria could publish in Kurdish and use it in broadcasting until the French authorities realized that Kurds were supporting the Syrian movement for independence. In 1941, publication and broadcasting in Kurdish, mostly for war propaganda purposes, were resumed and continued beyond Syria's independence in 1948 . However, Syria's treatment of Kurdish from 1955 onward has been characterized as linguicide (Hassanpour, Skutnabb-Kangas \& Chyet, 1996, p. 370). According to these Kurdish specialists, "Beginning in the mid-1950s ... the [Syrian] government seized and destroyed Kurdish publications. Schools built in Kurdish communities banned language instruction in any language other than Arabic, which is still true today" (ibid.).

Whereas Kurdish Kurmanji has been prohibited in Turkey, it has been the language of schooling, media and public institutions in Kurdistan-Iraq since 1991, especially in the predominantly Kurmanji-populated province of Duhok. Prior to 1991, however, only Kurdish Sorani had an official status. From the early 1920s, under the British Mandate, Kurds in Iraq were entitled to use their language in primary education and administration. Kurdish was recognized as a "local language" in Iraq and the "official" language in the Kurdish region (Hassanpour, Skutnabb-Kangas \& Chyet, 1996, p. 369). The Iraqi state, however, showed no serious interest in promoting Kurdish until the aftermath of the coup

\footnotetext{
${ }^{115}$ For example, in the city Mahabad, Binkey Soma [Aso Centre] offers Kurdish lessons to a limited number of students. Not many people can afford the cost of private lessons especially to learn how to read and write a language only for intrinsic reasons and not for gaining external rewards such as a job or passing grades in the formal school system.
} 
of General Qasim in 1958 which turned Iraq from a kingdom to a republic. Significant developments at that time with respect to Kurdish language included the establishment of a Chair of Kurdish Studies in the University of Baghdad in 1959, devoting a special Kurdish department in the Ministry of Education, and the publication of many periodicals and books and radio broadcasting in Kurdish.

The Ba thist coup in 1968 restricted publishing in Kurdish for several months. In 1970, however, after a mutual agreement between the Kurdish movement leadership and the Iraqi central government was reached, Sorani Kurdish was recognized as the second official language of Iraq. Sorani was further developed to a full-fledged standard language, and used in education, media and the public institutions in most of the Kurdish region of Iraq. ${ }^{116}$ In 1974, however, the war between the central government and Kurds of Iraq resumed, and the status of the Kurdish language started to decline. Despite this, Kurdish, especially the Sorani variety, has never been banned from public or private domains in Iraqi Kurdistan. Even under the rule of Saddam Hussein Kurdish continued to be a language of instruction along with Arabic in publicly-run education, and it continued to be used in broadcasting and publishing. However, secret documents obtained after the fall of Saddam Hussein in Iraq indicate that his regime was planning to put an end to the use of Kurdish as a language of instruction in Kurdistan-Iraq (Taha, 2006).

In the aftermath of the first Gulf War (1991), the Kurds in Iraq started to enjoy a de facto autonomy within which Kurdish (the variety is not explicitly stated, but it appears to

\footnotetext{
${ }^{116}$ In 1970, a Kurdish "Scientific Board" was established in Baghdad. The board's contribution to the cultivation of Kurdish language and literature has been unparalleled in the history of the Kurds. However, after with the resumption of war between the Iraqi central government and the Kurdish movement under the leadership of Mustafa Barzani in 1974, the Board's cultural activities slowed down considerably. Political relations between the Kurds and the government have often determined the status of the Kurdish language in Iraq.
} 
mean Sorani Kurdish) has been the official language. In the new Iraqi constitution, Kurdish is recognized as one of the official languages of Iraq, Arabic being the other. Currently, in Kurdistan-Iraq, Kurdish is the language of public institutions, all levels of education, and the dominant language of publications, radio and television programmes.

As for many other shortcomings in the Kurdish societies, Kurdish nationalists have blamed the central governments of the four states for the absence of a "unified Kurdish language" or a "Kurdistan national language." What have the Kurds done about their language in over fifteen years of self-rule in Iraqi Kurdistan? The media provide an excellent context for investigating this and other questions with respect to language; for example, how has Kurdish with all its varieties been used to define Kurdishness?

\section{Political fragmentations}

Political rivalry among the Kurds goes back to pre-modern times. For example, the Kurdish poet Ahmad Khani (1605-1706) protested the lack of unity among Kurdish principalities and their inability to unite under the rule of one king or emperor (Hassanpour, 2003b, p. 113). Kurdish disunity has persisted in modern times. In 1933, Kurds had their best opportunity to gain political autonomy under the British mandate in Iraq. When Iraq became a member of UN, it was required to honour Kurdish autonomy in the northern part of the country (Kurdistan). Iraq backed off from the agreement without much trouble because of the lack of unity among the Kurds: "the absence of an effective and united Kurdish leadership capable of mustering internal and international support made it easy for the Iraqi government to drag its feet and eventually renege on the agreement" (Vali, 2003, p. 100). Internal conflicts within KDP that started in the mid-1960s led to the formation of 
PUK in June 1975. Dreadful hostilities between PUK and KDP continued during 1970s and 1990s (see McDowall, 2004, pp. 343-352).

More recently, from 1982 to 1986 , the two most prominent Kurdish organizations in Iranian Kurdistan, Kurdistan Democratic Party of Iran (KDPI) and Komala fought each other while both continued their animosity towards KDP of Iraqi Kurdistan. Similarly, the fierce fighting between the two Kurdish Iraqi organizations, KDP and PUK, from 1994 to 1996 resulted in thousands of casualties from both sides and a major setback in the Iraqi Kurds' first opportunity to establish their own democratic institutions in their region. In the late 1990s PUK and PKK clashed with KDP forces. In 2000, however, fighting between PUK and PKK broke out. As Ignatieff (1993) says, "Kurds themselves admit that, for all the shared talk about a common homeland, they have actually fought each other more often than they have fought side by side" (p. 181). Why has factionalism persisted in Kurdistan?

\section{The absence of a strong pan-Kurdish identity}

Conflicts often occur among those who cannot or do not want to share belonging. Many factors have contributed to disunities among the Kurds, including tribalism, regional differences, factionalism within the same region, class struggle, and religious and ideological differences among Kurdish organizations. External factors such as pressures from the host states and international stakeholders have also played roles. None of these factors contributing to the fragmentations of Kurdish disunity, however, may have been more powerful than the lack of a pan-Kurdish sentiment. The absence of this sentiment has not only prevented the emergence of a strong and durable pan-Kurdistani movement (Izady, 1992, p. 182) but has crippled movements in each part of Kurdistan (Romano, 2006, p. 251). 
Writing in 1992, Izady rightly contends that "in the past, and some may argue even today, the Kurds have never achieved sufficient unity to produce even the prototype of an organized pan-Kurdish political movement for independence" (Izady, 1992, p. 188). The first Kurdish movements and nationalist organizations, at the end of the ninetieth and the beginning of the twentieth centuries, aimed at independence for the Greater Kurdistan (Olson, 1991). However, the vast majority of Kurdish movements, over twenty of them in the last century (Romano, 2006, p. 4), have been led by regional and autonomist organizations.

Vali calls Kurdish autonomous movements "Kurdish nationalists without Kurdish nationalism" (1998, p. 84). They are without nationalism because they are not sovereignist. For Vali, akin to Gellner's view (1983), nationalism is first and foremost a political principle that pursues sovereignty and citizenship rights for a nationality. Vali (1998) believes that the only Kurdish movement which has qualified as a nationalist movement was the Kurdish movement in Turkey, led by PKK (Kurdistan Workers Party), in the $1980 \mathrm{~s}$, because it bore the characteristics of a modern nationalist movement; it was secessionist (1998, p. 93). PKK, however, started to abandon its pan-Kurdish ambitions in the early 1990s (van Bruinessen, 2000a, p. 282). In fact, by mid-1990s, PKK was willing to negotiate with the Turkish authorities as long as the Turks were willing to show some sort of "concession to Kurdish cultural demands" (ibid.). Vali (1998) finds Kurdish movements, particularly in recent decades, parochial and ineffective because they have been driven by regional interests instead of striving for popular sovereignty for Kurdistan. He contends that these regional and autonomous movements have effectively intensified Kurdish divisions (p. 82). 
However, many have found secessionism and quest for sovereignty whether of one part of Kurdistan or four parts altogether not the option for now or years to come.

According to Romano (2006),

a Kurdish project for statehood at this time seems both plagued with incredible obstacles as well as ill-advised. Turkey, Syria, and Iran could all be expected to continue collaborating in order to prevent such a development, and the chances of other states coming to the aid of repressed Kurds in Turkey, Iraq, or Iran appear extremely small. (p. 259)

International powers have not been in favour of the formation of any independent Kurdish state either. They have not approved of the idea even for Iraqi Kurds who have been considered one of the most important allies of the US and Britain-led invasion of Iraq in 2003. This is despite the fact that the partition of Iraq, as a result of which the Iraqi Kurds would have a state of their own, has been entertained seriously by western diplomats and academics as one of the ways out of the difficulty and confusion that Americans have found themselves in, in Iraq (see O'Leary \& Salih, 2005; Galbraith, 2005). In fact, the Iraqi Kurds are worried that the neighbouring countries with sizable Kurdish populations, such as Turkey, may even interfere with the implementation of federalism in Iraq, which has been enshrined in the first draft of the Iraqi new constitution (O'Leary, 2002).

Whereas Kurdish secession anywhere has been considered impractical and "illadvised" (Romano, 2006), the idea of establishing a greater Kurdistan state has been called a "dream" (O'Leary \& Salih, 2005, p. 15). The creation of a greater Kurdistan could only be formed out of parts of four nation-states in the Middle East-Turkey, Iran, Iraq and Syria. Horowitz (1992) calls this hypothetical formation "irredentism" as opposed to 
"secessionism" (p. 119). ${ }^{117}$ Whereas secessionism upsets one state, irredentism would mean instability for four states and major reconstruction of borders and states in the region, something that no major world power has been willing to tolerate. Thus, for all practical purposes, Kurdish political parties and many Kurdish intellectuals ${ }^{118}$ have erased explicit references to their desire for creating a greater Kurdistan. The idea and dream, however, has been nurtured in Kurdish literature, poetry, music and arts for over a century and it will continue to be so perhaps as long as Kurds in different states find their ethnic identities and human rights denied.

In contrast to Vali (1998), Romano (2006) believes that the greatest obstacle to Kurdish emancipation is not so much that Kurdish movements are autonomist, as opposed to being secessionist. He contends that a pan-Kurdish sentiment, or what can also be called a Kurdish collective identity, is not present among the Kurds. He believes that as long as a pan-Kurdish sentiment is absent the host states continue to make the political parties of different parts of Kurdistan their pawns and use them against each other. Romano contends that,

Ankara, Tehran, Damascus, and non-Kurdish Iraqis are of course increasingly weary of growing pan-Kurdish sentiment, which accounts for their hostility to any Kurdish state in the region. While many Kurds would like to see pan-Kurdish sentiment produce a situation wherein their leaders refuse to be made the pawns of these powers and played off against each other ... all the states of the region are determined to keep the Kurds divided. (Romano, 2006, p. 251)

In other words, the formation of a pan-Kurdish identity may never lead to the formation of a greater Kurdistan. However, the existence of such a sentiment might motivate Kurdish

\footnotetext{
117 "Secessionism is an attempt by an ethnic group claiming a homeland to withdraw with its territory from the authority of a larger state of which it is a part. Irredentism is a movement by members of an ethnic group in one state to retrieve ethnically kindred people and their territory across borders" (Horowitz, 1992, p. 119). ${ }^{118}$ Although some scholars have made distinctions between "intelligentsia" and "intellectuals", in this paper, following Collins (1990), I will use the two terms synonymously.
} 
populations not to allow regional organizations to turn against each other. In effect, a strong cross-border Kurdish identity might be helpful for achieving autonomy and cultural rights within different states.

\section{Strengthening of a pan-Kurdish identity}

As discussed in the introductory chapter, there have been suggestions that a strong Kurdish cross-border identity has begun to emerge since the mid-1990s (Bird, 2004, p. 373; van Bruinessen, 2000a, p. 62; Romano, 2005, p. 231). Until the mid-1990s communication among different parts and regions of Kurdistan was limited. In 1992, Izady suggested that "the western Kurds [i.e. Kurds from Turkey and Syria] are novelties to the other Kurds and vice versa" (p. 208). Major political, social or cultural events occurring in one region of Kurdistan had few consequences, if any, in other Kurdish regions. A prime example is the chemical bombardment of the town of Halabja in Iraqi Kurdistan in March 1988, during which about 5000 Iraqi Kurds were killed after the town was hit by Iraqi planes (Black, 1993; Randal, 1997). The event generated no or very little immediate reaction in other parts of Kurdistan. On the one hand, the Kurds of other regions were not immediately aware of the atrocities that had taken place in Halabja. On the other hand, they became aware of the incident through non-Kurdish media, mainly the Iranian media. ${ }^{119}$ Informed this way, the majority of Kurds seemed unable to experience the suffering of the Iraqi Kurds.

\footnotetext{
119 There was some impact of the event in the Iranian Kurdistan mainly due to the presence of the Iranian military in or around Halabja at the time. O'Leary (2002) recalls the event: "Between 40,000 and 50,000 people were living [in Halabja] at the time. The Iranian army had previously pushed Iraqi forces out of the area. During three days, the town and surrounding district were attacked with conventional bombs, artillery fire, and chemicals--including mustard gas and nerve agents (Sarin, Tabun, and VX). At least 5,000 people died immediately as a result of the chemical attack and it is estimated that up to 12,000 people died during those three days." After the bombardment, Iranian cameramen managed to film and take pictures of the horrific aftermath of the tragedy. The Iranian state television broadcasted video clips and still images in Iran, which were then redistributed by few international media outlets. It is interesting to note that the mainstream media in the West for the most part either ignored the incident or downplayed its seriousness (Sheyholislami, 2001, 2007).
} 
Specifically, simultaneous awareness of the Iraqi Kurds' predicament by other Kurds through a Kurdish channel that Kurds could trust and relate to was absent.

One of the first signs of the recent rise of a pan-Kurdish sentiment surfaced in February 1999, following the kidnapping of Abdullah Ocalan, the leader of the largest Kurdish political organization in Turkey, Partiya Karkerên Kurdistanê-Kurdish Workers' Party-(PKK). In a matter of hours simultaneous demonstrations took place in diasporic communities (Romano, 2002, p. 145). These were followed by demonstrations of the Kurds in Iraq, Iran and Syria in a matter of days (p. 146), even in cities where Kurdish nationalism never had a significant prominence such as Kirmashan in Iran (BBC, 1999). In more recent years, nearly all major events in Kurdistan-Iraq, where the region has gone through some unprecedented changes (see further down) since the first Gulf War in 1991, have generated reactions among Kurds living elsewhere. For example, on May 16, 2005, the Agence France Presse reported that rioting erupted in the Kurdish city of Mahabad in Iran after Masoud Barzani, the Iraqi Kurdish leader, was sworn in as "the president of Iraqi Kurdistan" (AFP, 2005). According to a bulletin from the Institute Kurde de Paris, signs of welcoming the news and expressions of joy were demonstrated also in Turkey, Syria and Kurdish diasporic communities (Institut Kurde de Paris, 2005). In March 2004, after the recognition of the Kurdistan of Iraq in the Transitional Administrative Law of Iraq, "the Kurds of Syria showed surprising cohesion and coordination in Qamishli [,Syria]" (O’Leary \& Khalid, 2005, p. 15).

Why this strengthening of a pan-Kurdish sentiment in recent years? In other words, what could have caused these changes among the Kurds? I submit that there are at least three reasons: Political developments in Kurdistan in the past two decades, the emergence 
and expansion of Kurdish diasporic communities during almost the same years, and the use of new communication technologies such as satellite television and the Internet in the last decade or so.

\section{Political changes in Kurdistan}

In the mid-1990s van Bruinessen wrote:

The political developments of the past decade have strengthened contact between the Kurds of Turkey, Iran and Iraq; there is now a stronger awareness of belonging together than there was in the past. The wish for a separate state, uniting the various parts of Kurdistan, has also become stronger. (2000a, p. 62)

This is a plausible observation, to which I would add two points. First, Syrian Kurds have also been affected by recent political developments in the region. Second, these changes have continued in the $2000 \mathrm{~s}$, but have taken different forms.

One of the major political changes, which can be traced back to the 1960 s, is the spread of war between the central governments and the Kurdish armed organizations (i.e. Iraq: intermittently from 1960-2003, $1975-1988$ being the worst; Iran: intermittently from 1980-present, 1980-1988 being the worst; Turkey: intermittently from 1984-present) (Hassanpour \& Mojab, 2005, p. 218). As a result of these wars tens of thousands of people have lost their lives, the mental and physical well-being of more people have been compromised, and tens of thousands of civilian Kurds have been displaced and their villages and towns have been destroyed. The Iraq-Iran war and periodic conflicts among Kurdish rivals have added to the devastation.

These wars have engendered a constant movement of Kurdish populations throughout Kurdistan bringing Kurds of various regions into contact with each other sometimes for the first time. Despite their possible linguistic, cultural, and political differences, Kurds have managed to share experiences of struggle, displacement and 
homelessness. In what follows I will take a brief look at how political events in Turkey, Iran, Syria and Iraq have shaped the experiences and aspirations of Kurds in each of the four parts. I will particularly focus on some positive developments.

\section{Turkey}

Under pressure from Kurds' continuous struggle to achieve their rights and from the European Union, the government of Turkey started to show some flexibility towards Kurdish language and culture in the early 1990s. Now, Turkish citizens can use the term "Kurd," (but not Kurdistan ${ }^{120}$ ), without the fear of outright persecution; as well private institutions of Kurdish teaching have been established, Kurdish can be published, including a daily newspaper Azadiya Welat (The Freedom of Country/Homeland), and civil organizations and pro-Kurdish political parties have managed to introduce a dialogue on the Kurdish issue to Turkey's public sphere.

However, Turkey's war with Kurdish rebels belonging to the PKK continues. On the pretext of fighting these rebels, who are said to be stationed in the Ghandil (Qendîl) mountains of Iraqi Kurdistan, the Turkish military has conducted several incursions into that region. Turkey has also been concerned about the fate of the oil-rich city of Kirkuk in northern Iraq. Kurds make up the largest ethnic group of the city, but the city is not a part of the Kurdish Regional Government's (KRG) jurisdiction. According to Iraq's interim constitution, the Kurds' long-time claim to that city is to be tested through a referendum. Turkey has expressed its displeasure with the possibility of Kirkuk's annexation to the jurisdiction of KRG. Although the city has a sizable Turkoman population about whom

\footnotetext{
${ }^{120}$ The use of the term "Kurdistan" is still prohibited in Turkey. It is believed that the word is against "the indivisibility of the Turkish nation," and the "territorial integrity of the state" (Hassanpour \& Mojab, 2005, p. 215).
} 
Turkey claims to be concerned, the majority of observers believe that Turkey is fearful of a strong Kurdish autonomous region in Iraq, because it may inspire the Kurds of Turkey to demand the same status within Turkey (O'Leary \& Salih, 2005; Fraser, 2007).

Iran

In Iran, the election of the reformist Mohammad Khatami as the Iranian president gave some hope to the Kurds in 1997 (Koohi-Kamali, 2003, pp. 212-213; Entessar, 2007, pp. 198-199). However, the Kurds, along with the rest of the Iranian population, were ultimately disappointed in the reformists' inability to deliver on their promises made during the presidential elections, to advance Kurdish cultural, political and economic demands through legal channels. While the reformists were in power, the Kurds in Iran managed to revive some aspects of their culture and language. In the late 1990s, about twenty Kurdish periodicals were being published in Iran, and in some places, such as the Kurdish-populated town of Mahabad, privately owned classes for teaching the Kurdish language were in operation. It became easier for some Iranian Kurds to legally visit Iraqi Kurdistan. Many Kurds who were outside Iran for several years and decades managed to return and visit family members and relatives.

The reformists officially lost power when president Ahmadinejad won the Iranian presidential election in June 24, 2005. Since then, Kurdish cultural activities have decreased considerably. ${ }^{121}$ Finally, it is important to note that since the mid-1990s most of the Iranian Kurdish organizations have abandoned armed struggle. Their rebels and cadres have either immigrated to the West or remained in Iraqi Kurdistan under the condition (set

\footnotetext{
${ }^{121}$ A number of periodicals have been closed down (e.g. Aso, meaning horizon, banned in August 2005), Kurdish courses cancelled, and journalists and editors of Kurdish periodicals have either been put on trial or imprisoned (Amnesty International, 2007).
} 
by the Kurdish administration in Iraqi Kurdistan) that they will not engage in any cross-

border armed activities against the Iranian state. ${ }^{122}$

Syria

The Kurdish reawakening in Syria started in 1999 when the Kurds began their campaign to gain linguistic and cultural rights in that country. In March 2004, during a soccer match in the predominantly Kurdish-populated town of Qamishli, fighting broke out between Kurdish and Arab fans. According to Amnesty International, more than thirty people from Kurdish communities were killed, hundreds were injured and about 2000 people were arrested by Syrian security forces. At the beginning of 2005 , there were still 200 detainees in Syrian jails. Amnesty International paints a gloomy picture of the status of Kurds in Syria:

Kurds in Syria have been subjected to serious human rights violations, as other Syrians, but as a group they also suffer from identity-based discrimination, including restrictions placed upon the use of the Kurdish language and culture. In addition, a large proportion of the Syrian Kurds are effectively stateless and, as such, they are denied the full provision of education, employment, health and other rights enjoyed by Syrian nationals, as well as being denied the right to have a nationality and passport.

More recently, some flexibility with respect to publishing in Kurdish has been shown by the Syrian government. Diasporic communities, the Internet, and satellite television remain the most reliable and secure communicative spaces for the Kurds from Syria to continue their struggle to gain their rights.

${ }^{122}$ An exception to this is Partî Jiyan $\hat{u}$ Azadî Kurdistan (Life and Freedom Party of Kurdistan), better known by its Kurdish acronym PJAK. It is a small organization which emerged on the political scene of KurdistanIran several years ago, and it believes to be an off-shoot of PKK. 


\section{Iraq}

Compared to other parts, Iraqi Kurdistan has witnessed and experienced the most profound change in recent years. From the aftermath of the first Gulf War and under the protection of the United States and its allies, the Kurds in Iraq have been governing themselves since 1992; there is a quasi-independent Kurdish state in Iraqi Kurdistan. It is often referred to as the "free Kurdistan" or "little Kurdistan" (O'Leary \& Salih, 2005). Although the "existing free Kurdistan is no paradise" it cannot be denied that it has become a source of hope for all Kurds that one day other parts of Kurdistan will enjoy similar freedom in the form of autonomy or independence (ibid.). Non-Iraqi Kurds observe events unfolding in KurdistanIraq with interest, and they do this mostly with the help of the media. In addition, many Kurds originally from other parts of Kurdistan live, work and study in the Iraqi part. The establishment of two airports in Hawler and Suleimania has made it possible for Iraqi and other Kurds to depend less on Turkey for travelling to and from Iraqi Kurdistan and connecting with the rest of the world.

\section{Kurdish diasporas}

As discussed earlier, Kurds in general and Kurdish armed movements in particular have admired mountains as their only friends for decades (Bulloch \& Morris, 1992). More recently, however, Kurdish diasporas have become arguably one of the best friends of the Kurds. Kurdish diasporas reproduce the fragmentations of Kurdish identity but they have also become places of convergence, cultural and political revival, and collective identity formation. Diasporas have become pan-Kurdish communicative spaces. The dispersion of 
Kurds can be traced back to the pre-modern times (Hassanpour \& Mojab, 2005, p. 215). ${ }^{123}$ However, in this study, by Kurdish diasporas or Kurdish diasporic communities I mainly refer to Kurdish communities and settlements located in the West and not to all Kurds who live outside the Kurdistan proper (e.g. Kurds living in Khurasan, Istanbul, Baghdad, Tehran, Damascus, Armenia, and so forth).

In Europe, the first Kurds, albeit in small numbers, arrived at the end of the nineteenth century (Hassanpour \& Mojab, 2005, p. 217). The first notable Kurdish diasporic organization was the Kurdish Studies Society in Europe, established in 1956. It consisted of Kurds from all parts of Kurdistan and campaigned for Kurdish self-rule (ibid.). The second notable wave of immigrants to the West was comprised of economic immigrants from Turkey who settled in Germany and other neighboring countries in the 1960s. However, the most significant wave of Kurdish immigrants to Europe, North America and Australia occurred around 1980 due to three important changes in Iran, Iraq and Turkey: (1) The Iranian revolution in 1979 and the war over Iranian Kurdistan starting in 1980; (2) the Iraq-Iran war (1980-1988) and Kurdish armed resistance in Iraqi Kurdistan; (3) the military coup in Turkey in 1980 (van Bruinessen, 1999; van Den Box \& Nell, 2006). Table 2 shows the size of Kurdish diasporas in the early 2000 s.

\footnotetext{
${ }^{123}$ For example, Ivanov (1926) reports on the "transferring" of thousands of Kurds from the Kurdistan proper (in the western part of Iran) to Khorasan/Khurasan (a province located in the eastern part of Iran) in the sixteenth century: "some tribes of Kurds from Kurdistan proper were transferred as early as the middle of the sixteenth century. In the beginning of the seventeenth century a new party had arrived; some of these tribes still live there ... some more of them arrived later on in the eighteenth century, under Nadir ... At present there is no connection with the West [of Iran-Kurdistan], and the Khurasani Kurds are gradually undergoing 'Turkomanization"' (p. 150).
} 
Table 2 The Size of Kurdish Diasporas (Hassanpour \& Mojab, 2005, p. 214)

\begin{tabular}{|c|c|c|}
\hline Region & Country & Number \\
\hline Europe & \begin{tabular}{l} 
Germany \\
France \\
Netherlands \\
Switzerland \\
Belgium \\
Austria \\
Sweden \\
United Kingdom \\
Greece \\
Denmark \\
Norway \\
Italy \\
Finland \\
Russia \\
\multicolumn{1}{c}{ Siberia } \\
Krasnodar
\end{tabular} & $\begin{array}{l}500,000 \\
100,000-120,000 \\
70,000-80,000 \\
7,531 \\
50,000-60,000 \\
50,000-60,000 \\
25,000-30,000 \\
20,000-25,000 \\
20,000-25,000 \\
8,000-10,000 \\
4,000-5,000 \\
3,000-5,000 \\
3,916 \\
35,000 \\
30,000\end{array}$ \\
\hline Central Asia & $\begin{array}{l}\text { Kazakhstan } \\
\text { Turkmenistan } \\
\text { Kirghizia } \\
\text { Uzbekistan } \\
\text { Taijikistan }\end{array}$ & $\begin{array}{l}30,000 \\
50,000 \\
20,000 \\
10,000 \\
3,000\end{array}$ \\
\hline Caucasia & $\begin{array}{l}\text { Armenia } \\
\text { Azerbaijan } \\
\text { Georgia }\end{array}$ & $\begin{array}{l}75,000 \\
12,000-30,000 \\
40,000\end{array}$ \\
\hline $\begin{array}{l}\text { Middle East } \\
\text { North America }\end{array}$ & $\begin{array}{l}\text { Lebanon } \\
\text { Canada } \\
\text { United States }\end{array}$ & $\begin{array}{l}75,000-100,000 \\
7,140 \\
15,000-20,000\end{array}$ \\
\hline Oceania & $\begin{array}{l}\text { Australia } \\
\text { New Zealand }\end{array}$ & $\begin{array}{l}2,845 \\
603 \\
\end{array}$ \\
\hline Total & & $1,267,035-1,385,035$ \\
\hline
\end{tabular}

Kurdish diasporas are diverse because they are influenced by different factors such as the socio-cultural dimensions of immigration in different host countries, ${ }^{124}$ the

\footnotetext{
${ }^{124}$ On the influence of the host countries on the dynamics of Kurdish diasporic communities Wahlbeck (1999) observes that in Denmark due to the "assimilationist" immigration policies of the country Kurds seem to be less organized and isolated, and thus have much difficulty to integrate and settle. In contrast, Kurds of the UK take advantage of the "multicultural" policies of the UK towards immigrants and refugees; they are more organized, cooperative among themselves, and are more successful in finding employment (although most of them are low-paid jobs) and settling in the country.
} 
diasporans relations with the countries of origin (e.g. the four states) and Kurdish nationalism and the politics of the homeland, Kurdistan. Kurdish nationalism and the politics of Kurdistan, in particular, reproduce Kurdish fragmentations and at the same time strengthen a collective Kurdish identity. Wahlbeck observes that Kurdish nationalism "commits many Kurdish refugees to the restoration of their homeland" (1999, p. 180). However, because the movement is divided in Kurdistan it continues "to divide diasporans, especially in their first generation" (Hassanpour \& Mojab, 2005, p. 219). The relationship between Kurdish political parties often directly affects the relationship between Kurdish diasporans who are affiliated with political parties within Kurdistan.

Regarding the effect of country of origin, Wahlbeck (1999) also observes that, depending on where Kurds come from, they identify themselves differently. For example, whereas most of the Iraqi Kurds in the UK and Finland identify themselves as Kurds only, Kurds from Turkey see themselves as part of both Kurdish and Turkish communities (Wahlbeck, 1999, p. 182).

Kurdish diasporas conveniently exemplify what Anderson (1992) has called "longdistance nationalism" (see Wahlbeck, 1992, p. 228). Alinia (2004), studying Kurdish diasporic communities in Sweden, observes that all these shape and reinforce a complex collective Kurdish identity in that particular diasporic context:

The Kurdish identity was formed in opposition to imposed national identities in the countries of origin. Further, in conditions of exile and exclusion the Kurdish identity is mobilized as a resource in order to resist the imposed immigrant identity and survive exclusion and exile. Inwardly, it is constructed through contradictory interactions between Kurdish individuals and groups with different standpoints within the movement. (p. 321)

Furthermore, Alinia observes that, in the face of "racism" and "exclusion" that the Kurdish communities in Sweden feel and experience, they see their diasporic communities as their 
"home" and a "location" where they can reaffirm a sense of belonging to a "we-identity" and an "imagined community that exceeds many national boundaries" (p. 328).

Although several scholars suggest, with reason, that the fragmentations of Kurdish identity in Kurdistan are reproduced among Kurdish diasporans, they have also advanced the argument that Kurdish diasporas have contributed to the reproduction and articulation of a collective and trans-state Kurdish identity (Alinia, 2004; Hassanpour \& Mojab, 2005; Wahelbeck, 1999; van Bruinessen 2000b, 1999). Wahlbeck (1999) observes that despite the differences between Kurdish diasporans in Finland and England, both communities share the wish to return to the homeland Kurdistan, and they both create and maintain Kurdish "transnational social networks" that exceed several continents.

Diasporas have played a decisive role in shaping and reproducing Kurdish nationalism:

The experience of exile has been part and parcel of the history of Kurdish nationalism ... The awareness of Kurdistan as a homeland, and of the Kurds as a distinct people, has often been strongest in those Kurds who lived elsewhere, among people of different languages and cultures. The first Kurdish associations were established in Istanbul and more distant places of exile, by Kurds who had studied in other languages and had been exposed to modern ideas. It was exile that brought educated Kurds of different regional backgrounds together and thereby helped them to imagine Kurdistan as their common fatherland. It was exile that transformed Kurdistan from a vaguely defined geographical entity into a political ideal. (van Bruinessen, 2000b)

According to McDowall (2004), "early advances of national ideas took place largely outside Kurdistan" (p. 455). From the late 1950s onward, Kurdish diasporans started to take advantage of freedom of assembly in Europe and embark on "pan-Kurdish activism," for example through the Kurdish Students Society (1956-1975), with the agenda of Kurdish self-rule (Hassanpour \& Mojab, 2005, p. 219). 
With the strongest wave of Kurdish immigration to Europe and North America in the 1980s, diasporas became locations where many Kurds of one part met Kurds of other parts of Kurdistan for the first time. Cultural occasions, such as the celebration of Nawroz, the Kurdish New Year, on the $21^{\text {st }}$ of March, which is attended by tens of thousands in some places (e.g. Germany), become an expression of belonging to a collective Kurdish identity despite coming from different regions, communities, ages and social groups. Promotion of Kurdish culture and literature has also been the agenda for several cultural institutes, libraries and information centers established in Berlin, Brussels, London, Paris, Stockholm, New York, and Washington (Hassanpour \& Mojab, 2005, p. 221). According to Alinia (2004, pp. 33-34), Kurds from Turkey living in diasporas managed to publish 77 Kurdish periodicals between 1975 and 2003. Since the 1980s, Sweden has become a safe haven for Kurdish exilic writers, poets, and artists. Swedish governments have contributed generously to the maintenance and flourishing of Kurdish language and literature by providing grants to Kurdish writers and artists and supporting them with the publishing and production of their work (see also McDowall, 2004, pp. 458-459).

Kurdish diasporic communities have also been catalysts in the creation and operation of Kurdish media. The first Kurdish periodical, Kurdistan, was published in Cairo in 1898, but it was soon published in European locations. The first Kurdish satellite television, MED-TV (1995-1999), was launched from Europe, and the first Kurdish online activities took place in Western Europe and North America. The next chapter is devoted to a more detailed discussion of Kurdish media and thus I shall refrain from repetition. At this juncture it suffices to say that, until the mid-1990s, social networks among Kurdish diasporic communities were more robust than not only networks linking diasporas and their 
homelands but also networks between the divided parts of the homeland. According to the historian David McDowall,

With modern technology, the Kurds of Europe rapidly discovered they need not be wholly cut off from their fellows in Kurdistan. In the 1970s transistor radio and cassette tapes provided an important channel for political action and cultural communication. These developments, however, were as nothing compared with the information revolution of the 1990s. (McDowall, 2004, p. 459)

\section{New Media Technologies}

In addition to recent political developments and Kurdish diasporas, the new media technologies have strengthened a trans-state or pan-Kurdish identity. Communication technologies foster the creation and strengthening of Kurdish trans-state networks not just from Europe but also from one part of the homeland, Iraqi Kurdistan. Christiane Bird, after traveling throughout Kurdistan in 2002, commented on the fragmentation of the Kurds and at the same time on how this fragmentation might be dealt with after the Kurds have had access to satellite television and the Internet:

The Kurds remain a fractured people on many levels - torn between countries, regions, political parties, tribes, families, dialects, outlooks, the old and the new. And yet, and yet...Modern technology, coupled with oppression, has changed everything. Through satellite communications and the Internet, the Kurds have their own television shows, radio broadcasts, publications, and websites, all of which are theoretically available to every Kurd anywhere in the world ... The Kurds may not have their own physical nation, but they do have an international cyberspace state, along with a quickening sense of national identity that, decades from now, may yet give rise to Pan-Kurds unification-perhaps in the form of a federated Kurdish nation-state. (Bird, 2004, p. 373)

Bird believes that one of the ways in which satellite TV could engender a pan-Kurdish identity is by making Kurdish language varieties mutually intelligible:

many Kurmanji speakers cannot understand Sorani speakers, and vice versa...However, this barrier is breaking down, largely because of television [partly because of war and upheaval] ... Perhaps two-thirds of Iraqi Kurds now have access to satellite dishes, as do many Kurds in Iran and Turkey. (Bird, 2004, p. 143) 
Like Bird, many Kurds and some observers have seen satellite television in particular, but also the Internet, bringing Kurds from different regions and factions closer to each other and mobilising them for staging a mass nationalist movement with the hope of achieving national emancipation. When the first Kurdish satellite television, MED-TV was launched in 1995, a Kurdish newspaper wrote that the step is "more important than all [Kurdish] armed revolutions" (as cited in Hassanpour, 1998, p. 44). MED-TV's director, Hikmet Tabak, has been quoted as saying that Kurds all over the world were excited about the station because "they think this is the first step on the last, long part of the road to the formation of a Kurdish state" (Ryan, 1997, p. 5).

In light of these propositions, one cannot help but ask: why is it that in the case of the Kurds, it is only recently that this strong connection has been made, between a collective Kurdish identity and mass communication technologies? To be more specific, what are satellite television and the Internet capable of doing for the Kurds that other media have failed to do? I will explore answers to this question in the next chapter. 


\section{Chapter 7: Kurdish Media: An Overview}

In the previous chapter I suggested that a cross-border or trans-state Kurdish identity has been strengthening in the past two decades or so primarily due to three factors: political developments in Kurdistan, the expansion of Kurdish diasporas, and the use of satellite television and the Internet among the Kurds. In this chapter it is suggested that the latter is a catalyst in strengthening a cross-border Kurdish identity. Why might this be the case?

Previously, I illustrated that other forms of media such as newspapers and radio or cable television have played crucial roles in the formation and reproduction of national identities and nation-building projects particularly in Europe. Why has this not been the case in Kurdistan? Have the Kurds not had access to these more traditional media forms prior to using satellite television and the Internet? If they have, why have they not been able to embark on constructing a strong pan-Kurdish identity until very recently?

I hypothesize that since the mid-1990s satellite television and the Internet have facilitated a dialogic communication among the Kurds, a development that possibly has contributed to the emergence of a strong and unprecedented cross-border collective Kurdish identity. To examine the plausibility of this hypothesis, I take a brief survey of the development of various Kurdish media from print to the Internet. Through a critical review of the literature on Kurdish media and identity construction, I suggest that research on Kurdish satellite television and the Internet is in short supply. Empirical research on the discourse practices of these media needs to be carried out to understand how and in what ways these media articulate Kurdish identities. The new electronic media provide rich 
contexts within which the dynamics of group identity constructions and reproductions can be studied.

\section{Print}

About two centuries ago, Nali (d. 1855) ${ }^{125}$, a Kurdish poet and Mullah from the Şarezûr region of today's Iraqi Kurdistan, realized the power that one can access by writing in a language that was for the most part only spoken until then. Because he was writing in three languages (Persian, Kurdish, and Arabic), he likened his multilingual collection of poems to ruling over three territories:

Fars $\hat{u}$ Kurd $\hat{u}$ Erab her sêm be defter girtuwe Nali emřo hakimî sê mulke, dîwanî heye

I have captured Persians, Kurds and Arabs with my monograph, Nalî rules over three territories today, [for] he has a dîwan (book of poems) (Dîwanî Nalî, 1976, p. 577, my translation)

In 1890, Haji Ghadir Koyi (Hacî Qadir Koŷ̀), another Kurdish poet and mullah, considered by most nationalists and a number of researchers as the first modern Kurdish nationalist (van Bruinessen, 2003; Hassanpour, 2003a), was vividly aware of the role of the press in nation-building:

A hundred epistles and odes are not worth a penny [any more], Newspapers and magazines have [now] become valuable and respected

(as cited in Hassanpour, 1992, p. 221)

Despite this realization of the importance of writing and print in the life of a nation by poets like Nali and Koyi, the first publication in Kurdish did not appear until the very end of the nineteenth century.

${ }^{125}$ Nali's full name is Mela Xidrî Ehmedî Saweysî Mikaylî. 
Hassanpour (1992) perceives the Kurdish press as "the organ of Kurdish nationalism" (p. 221). To put it differently, the emergence of journalism among the Kurds marks the beginning of their movements for national rights (Ahmadzadeh, 2003, p. 150). The first Kurdish periodical, Kurdistan, was published in Ottoman Cairo, in 1898, by the princely family of Badir Khan (Hassanpour, 1992, p. 221). It was a bilingual (Kurdish Kurmanji-Turkish) periodical that was committed to "[stirring up] feelings in support of the Kurdish people, let by its notable[s] and shykhs [sic]" (McDowall, 2004, p. 90). According to Hassanpour, the paper was initiated in Cairo because it was not granted permission in Istanbul, the seat of the Ottoman Empire. However, the pressure from Istanbul forced the paper to move to Geneva, London and finally to Folkstone, UK (Hassanpour, 1992; see also van Bruinessen, 2000b). ${ }^{126}$

From the printing of the first Kurdish newspaper until 1985, about 145 periodicals were published (Hassanpour, 1992, p. 225), mostly in Iraq using the Kurdish Sorani variety. ${ }^{127}$ According to Hassanpour (1992), by 1985 , private journalism had disappeared and eleven periodicals published in Iraq, Iran and the USSR were state sponsored (p. 224). However, since the mid-1990s a number of privately owned periodicals have appeared in Iran, Turkey and Syria, albeit under strict state censorship. Since 1991, with the formation of the Kurdistan Regional Government in Iraq, hundreds of periodicals, including two dailies ${ }^{128}$ have been published in Iraqi Kurdistan. It is important to note again that the vast majority of these periodicals have used Sorani Kurdish, the dominant variety in Iraq and

\footnotetext{
${ }^{126}$ McDowall (2004) suggests that the newspaper moved to various European locations "possibly because the politically active Badr Khans wanted to be in closer touch with Ottoman exiles in Europe" (p. 90).

${ }_{27}^{27}$ In light of research done after 1990 s, this figure should be revised: the number is higher.

${ }^{128}$ Two of the dailies in Iraqi Kurdistan, Kurdistanî Niwê and Xebat are owned by the two dominant Kurdish organizations in Iraqi Kurdistan, PUK and KDP respectively. Other dailies that have emerged in recent years in Iraqi Kurdistan include Hewlêr Post and Rojname. Azadiya welat is a Kurdish daily newspaper that is published in Istanbul.
} 
Iran. Nearly all the Kurmanji periodicals and books were printed in diasporic communities, particularly in Germany and Sweden, prior to 1991 when Kurmanji publications gained popularity in Iraq and limited printed materials appeared in Turkey. In 1997, about 150 Kurdish periodicals were published worldwide (Newrozi, n.d.).

The press was a catalyst in engendering the first modern nation-states in Europe and America (Anderson, 1991). In the case of Kurdistan, however, due to many obstacles the Kurdish press has not been the mass medium capable of fostering a Kurdish imagined community despite the increase in the number of publications in the last two decades or so. The Kurdish press has faced major difficulties from the very beginning. The state of the Kurdish press up to the end of the 1980 s is summarized as follows:

The Kurdish press is characterised by the absence of enduring dailies, low circulation, poor distribution facilities, dependence on subscription and single copy sales, lack of or insignificant advertising revenue, poor printing facilities, shortage of newsprint, and limited professionalization and specialization. These features are characteristic of the press in developing societies ..., although their persistence and hindering impact on the Kurdish press has been reinforced by the division of the Kurdish speech community and political restrictions on the use of language. (Hassanpour, 1992, p. 276)

Reports as recent as 2005 from Iraqi Kurdistan indicate that Kurdish periodicals have not been able to secure wide audiences and attract advertising revenues, and overcome the linguistic divisions in Kurdistan (Murad, 2005). This is also true of Kurdish books. The population of Iraqi Kurdistan is over four million, but the average run of books is just about 1000.

Kutschera (2005) reports on the political restrictions that the Kurdish press in Iran faces:

The Kurdish press is limited to half a dozen weeklies ... Kurdish journalists acknowledge that self-censorship is a daily routine. "There are many 'red lines', we cannot speak much about the Kurds, and still less about the Iranian Kurds", explains 
a journalist of [Ashti (Peace)], founded in February 2004, suspended during the summer and which has only recently managed to resume publication. "The authorities have asked us not to speak too much of federalism, but we do. We publish articles about countries where federalism is implemented, about the various types of federalism", says a journalist of [Ashti], whose first issue was published on 18 January 2004. "We cannot write directly about the problems of the Iranian Kurds, so we speak of the problems of the other Kurds". "The press law allows us to write roughly $20 \%$ of what we think", concludes a journalist of [Ashti], who describes himself as a "revolutionary". "We walk on the back of a scorpion".

It is interesting to note that in the same report Kutschera talks to a group of Kurdish student activists from the Kurdish city of Sine (Sanandaj), who blame Iranian Kurdish opposition groups outside Iran for not launching a satellite television channel. They believe that a satellite television station can "keep Kurds in touch with each other" (ibid.).

Obstacles to Kurdish publications are closely connected to the issue of illiteracy in Kurdistan where the majority of the population are illiterate especially in their mother tongue (Matras \& Reerschemius, 1991). Hassanpour (1992) suggests that, around the time that the first Kurdish newspaper Kurdistan was published in 1898, about $97 \%$ of the Kurds were not able to read or write in any language. McDowall (2004) refers to the Kurds from Turkey as "a largely illiterate population" in Turkish and particularly in Kurdish (p. 447). Statistical data shows that in the early 1980 s, the average illiteracy rate, in any language, among the urban Iranian Kurds adds up to around 66\% (Koohi-Kamali, 2003, p. 160). ${ }^{129}$ One should expect a much greater rate of illiteracy among the rural Kurds where fewer people have had the opportunity to go to school in any language.

With respect to the level of literacy in Kurdish in Syria, Malmisanij (2006a) writes: "Although there are no definite numbers, Kurdish politicians and writers I have spoken to

\footnotetext{
${ }^{129}$ According to this source, the province of Kurdistan in Iran had the highest rate of illiteracy in the country's urban population (73.5\%). The rate is a little bit lower for other Kurdish-populated provinces: Kermanshah, 62\%, Ilam, 68.1\% and West Azerbaijan 61.7\% (p. 161). Hassanpour (1996) estimates the literacy rate in Kurdistan to be much higher, $50 \%$ by the mid-1990s (p. 66).
} 
have stated that as Arabic is the official alphabet in Syria and is used at all levels of education, the number of Kurds who can read and write in the Latin alphabet is very small" (p. 26). Reporting on the Kurdish literacy situation in Turkey in 2005, Malmisanij (2006b) reports that "very few of the Kurds in Turkey can read and write in Kurdish, most having learned it on their own" (p. 39). Learning Kurdish on their own also applies to the vast majority of Iranian Kurds.

Except for the Sorani Kurdish speakers of Iraq, who have had since 1991 most of their education in Kurdish, the vast majority of Kurds in Iran, Turkey and Syria have not been able to read the Kurdish press. Even within Iraq, until the early 1970s education in Kurdish was neither extended to the Kurmanji speaking regions (e.g. provinces of Mosul and Duhok) nor to those Sorani speakers who lived outside the two provinces of Suleimania and Hawler such as Kirkuk and Khanaqin regions.

Thus, printing in Kurdish mostly has been by small groups of the intelligentsia for larger groups of the intelligentsia. Even for these small groups access to Kurdish print materials was not easy until very recently. For example, conducting his research as recently as 2005, Malmisanij (2006b) writes that

In Turkey the Ministry of Culture and Tourism has 1453 libraries. 1224 of them are public ones. 209 of the public libraries are situated in the 22 provinces with predominantly Kurdish populations. There are no Kurdish books even in the libraries of these predominantly Kurdish provinces. (40)

He also observes that almost all of the few owners and managers of book-publishing houses in Turkey have been persecuted and spent time in jail for putting out Kurdish materials. The situation has not been better in Iran (Hassanpour, 1992) or Syria (Malmisanij, 2006a). In other words, the vast majority of Kurds have not been trained to read and write in their mother tongue, and those who have been learned the language on their own (almost all the 
Kurds from Iran, Turkey and Syria) have not been able to access Kurdish materials easily. Therefore, it seems safe to suggest that the Kurdish press has never been the mass medium that would enable the Kurds to imagine themselves as one community. Despite this, it is safe to suggest that the press shaped the ideas and politics of the intellectuals and activists, who are the architect of nationalism. ${ }^{130}$

\section{Radio and cable television}

With the exception of Kurdistan-Iraq since 1991, the states of Turkey, Iran, Iraq and Syria have nearly always held a monopoly on broadcasting. The first radio broadcast started in the Soviet Union in the Kurdish autonomous region in Trascaucasia (1923-1929) (Hassanpour, 1996, p. 73). The second Kurdish radio broadcasting took place in Iraq in 1939. In Iran, broadcasting in Kurdish started in 1946 when the Kurds and Azerbaijanis of Iran established their autonomous republics without the consent of the Iranian government but with the support of the Soviet Union. This broadcasting came to a halt with the fall of the Kurdish republic (Mahabad Republic). Kurdish broadcasting resumed in Baku, Azerbaijan, in 1949. Assuming that Kurdish broadcasting was established for the purposes of the construction of Soviet socialism, on the recommendation of the United States, the Iranian government started broadcasting in Kurdish in January 1950 (Hassanpour, 1992, p. 285, 1996, p. 74). In Turkey, under the pressure of the EU, broadcasting in Kurdish was legalized in 2002 on the conditions that it would be carried on state radio and television only, and for less than one hour per day (Associated Press, 2002). ${ }^{131}$ In mid-2006, a

\footnotetext{
130 “....intellectuals as well as professionals, notable educators, are crucial to nationalism: so often, they propose the category of the nation in the first place and endow it with symbolic significance" (Smith, 1998, p. 92).

${ }^{131}$ However, according to another source, Bianet, "On 25 January 2004, the Radio and Television Supreme Council (RTÜK) amended Article 4 of RTÜK Law No. 3984 and Law No. 4471, so as to allow 'the broadcast
} 
privately owned terrestrial Kurdish television outlet, Gün TV, and a radio station, Gün Radio, started their broadcasts with limited hours, choice of programming, and under severe restrictions. ${ }^{132}$ Limited Kurdish television programming on state-owned television stations started in Iraq and Iran in the early 1970s. The situation remains relatively unchanged in Iran. Except for clandestine radio broadcasting, which has played an important role in the Kurdish nationalist movements, for the most part radio and cable television have been monopolised by the states that have used their media as tools of assimilation. $^{133}$

In Iraq, Kurdish audiences witnessed a dramatic expansion in publishing and broadcasting following the first Gulf War when the Kurds started to establish a de facto state in northern Iraq. There are currently over twenty television stations and a dozen radio stations in Kurdistan-Iraq. McKiernan (2006) reports that in 2002 "nineteen Kurdish television stations were broadcasting in northern Iraq" (p. 178). The vast majority of these are owned by the two major political parties, PUK and KDP. Although nearly all the other organizations, from the Communist Party of Iraqi Kurdistan to the Islamic Movement in Iraqi Kurdistan, own their local radio and television stations, only PUK and KDP have managed to reach the widest audiences with their satellite television channels.

of traditionally-used different languages and dialects used by Turkish citizens.' . Institutions wanting to broadcast in Kurdish were given permission two years later, but with a daily limit of 45 minutes and a weekly limit of four hours. All programmes must have Turkish subtitles. Radio stations are allowed one hour of Kurdish broadcasting daily and five hours weekly, also with mandatory translation (Bianet, 2007).

${ }^{132}$ The stations are not allowed to broadcast programs with content targeting children. All programming has to be translated into Turkish (Bianet, 2007).

${ }^{133}$ Hassanpour (1996, p. 79) makes an important observation about the state-run Kurdish broadcasting and television services. Although the states have had their own ideological and political agendas for providing these services in Kurdish, it is quite plausible to suggest that Kurdish audiences could have filtered out, and continue to filter out, the host states' propaganda and enjoy Kurdish poetry, music and folk literature. Having worked in at least two of these state-owned radio and television stations I should say that this seems to be an accurate observation. 


\section{Satellite television}

The rise of a pan-Kurdish sentiment has co-occurred with the use of the new electronic mass media, specifically satellite television and the Internet, by the Kurdish organizations, intelligentsia and the public at large. This co-occurrence is not a mere coincidence. A truly Kurdish mass medium seems to have emerged only with satellite television.

The first Kurdish satellite television MED-TV started broadcasting to south and central Asia, North Africa and Europe in 1995 from Europe (Ryan, 1997). It was licensed in Britain and had studios in Belgium, Britain and Sweden. Karim (2006) calls the establishing of MED-TV "one of the most fascinating uses of DBS technology in the Middle Eastern context" (p. 274). He continues, "This is a case of a diaspora within and without the divided homeland attempting to sustain itself and to counter forceful suppression with the use of communications technology" (ibid.). Many observes saw MEDTV as a unique case also because it was possibly the first significant satellite TV channel owned by a stateless and oppressed people (Hearse, 1997). Ryan (1997) reported that the stations was "set up to 'develop Kurdish culture and language and to provide communication for the Kurds"' (as cited in Karim, 1998, p. 10).

Because the station was alleged to be owned and operated by supporters of PKK, the Kurdish organization from Turkey, the channel was harassed by Turkey from its inception (Hassanpour, 1998; Hearse, 1997; Price, 2001; White, 2000, p. 175). ${ }^{134}$ This was not unexpected given the impact of the station:

MED-TV has disturbed Turkey's constitutional blueprint for a pure, sovereign Turkish presence in the 'southeast'. It has established relations with Kurdish viewers not as members of an audience but rather as citizens of a Kurdish state, and, by doing so, it is exercising deterritorialized sovereignty. Every day, viewers

\footnotetext{
${ }^{134}$ PKK is considered a "terrorist" group by Turkey, the US, the EU and a number of other states.
} 
experience the citizenship of a state with its national flag, national anthem, national television and national news agency. Indeed, everyday MED-TV raised the Kurdish flag in about two million homes. (Hassanpour, 1998, p. 66)

The station was also widely watched in Iran, Iraq and Syria (Ryan, 1997). MED-TV's license was revoked in April, 1999 on the charges of "breaching regulations on impartiality" (Wahlbeck, 2002, p. 6). Wahlbeck, however, believes that the main reason for closing MED-TV was that it represented Kurdish identity: "The whole project enraged the Turkish government, which is perhaps not surprising bearing in mind the oppression imposed on the Kurds in Turkey and the Turkish authorities' discontent at any Kurdish cultural expression" (ibid.).

Within a few months, on July 31, 1999, Medya TV started broadcasting from Europe with its main studios in a small town near Brussels. Medya TV, similar to MEDTV, was perceived as Kurdish and Kurds' own channel by the vast majority of Kurds. For example, Birch (2003) reported from Diarbakir, the largest Kurdish populated city in Turkey:

... anybody with enough money to buy a satellite dish and decoder has been able to watch Kurdish programming 24 hours a day, beamed in from the Brussels headquarters of Medya-TV. "Thanks to Medya, our only reason for watching Turkish TV now is to see how much it lies," says Muzaffer, a patron of the cafe. "Only Medya is objective, the eyes and ears of our people."

However, in January 2004, after its content was being examined for five years by French authorities, they refused to grant Medya TV a license. French authorities concluded that Medya TV was a continuation of MED-TV in that it was "making propaganda" for PKK (French court cancels ..., 2004).

The current satellite TV that is managed by the Kurds from Turkey is Roj TV which is licensed by a Danish registered firm. It went on the air on March 01, 2004. Turkey has 
been pressuring Denmark to revoke Roj TV's license because Turkish authorities accuse the station of having ties with the PKK (Schleifer, 2006). In January 2006, 54 mayors of Kurdish-populated towns in Turkey sent a letter to the Danish authorities and urged them to ignore the pressure from Turkey and keep the station. The mayors have been charged with supporting PKK and may face imprisonment (Dozens of DTP ..., 2007). According to the Turkish Daily News, in May 2007, the Danish Radio and Television Council ruled that Turkey's complaints against Roj TV were unfounded and that it will continue to honour the station's licence (Danish council gives ..., 2007). In addition to Roj TV, there is also MMC TV (Mesopotamya Music Channel) which airs Kurdish music-video clips 24 hours a day under the license of Mesoptamya broadcast in Denmark. ${ }^{135}$

Impressed by the impact of the satellite TV stations of the Kurds of Turkey and Iraq (further discussion will follow), three political organizations from Kurdistan-Iran started launching their satellite TV stations in early 2006, eleven years after MED-TV was launched. In January 2004, in an online discussion forum set up by Abdullah Mohtadi, the general secretary of the Komala Party, he explained why Kurds from Iran lagged so much behind other Kurds in launching their satellite TV stations. He wrote that in his party they had been thinking about this for a long time and they had seriously considered it, but that due to financial constraints they had not been able to launch their channel (Mohdadi, 2005). The three TV channels are Komala TV ${ }^{136}$, Rojhelat TV ${ }^{137}$, and Tishk TV ${ }^{138}$ owned by three major Iranian Kurdish political organizations Komala, Komala Party (Revolutionary Organization of the Toilers of Iranian Kurdistan), and KDPI (Democratic Party of Iranian

\footnotetext{
${ }^{135}$ http://www.mmc.tv/

136 http://www.komala.tv/

137 http://www.rojhelat.tv/

138 http://www.tishktv.net/
} 
Kurdistan) respectively. The three stations have their studios in Europe and broadcast to Europe and the Middle East including Kurdistan. The three TV stations are based in Western Europe, airing their programs to Europe and the Middle East including Kurdistan. The Iranian Kurdish channels have fewer programs and a much shorter air time compared to Roj TV and the Iraqi Kurds' satellite stations such as Kurdistan TV. Finally, it is interesting to note that these television stations of the Kurds from Iran were launched at a time when the dispute over the proliferation of uranium between the west and Iran was escalating. In fact, there have been suggestions that the United States is funding the stations (Sina, 2006; 2007b). The spokespersons for at least two of the stations, Tishk TV (Sina, 2006) and Rojhelat TV (Sina, 2007b), have rejected the "accusation."

Figure 4 Photograph of a satellite dish hidden behind a stable in Iranian Kurdistan, in February 2006 (A. S., personal communication, February 15,2006 )

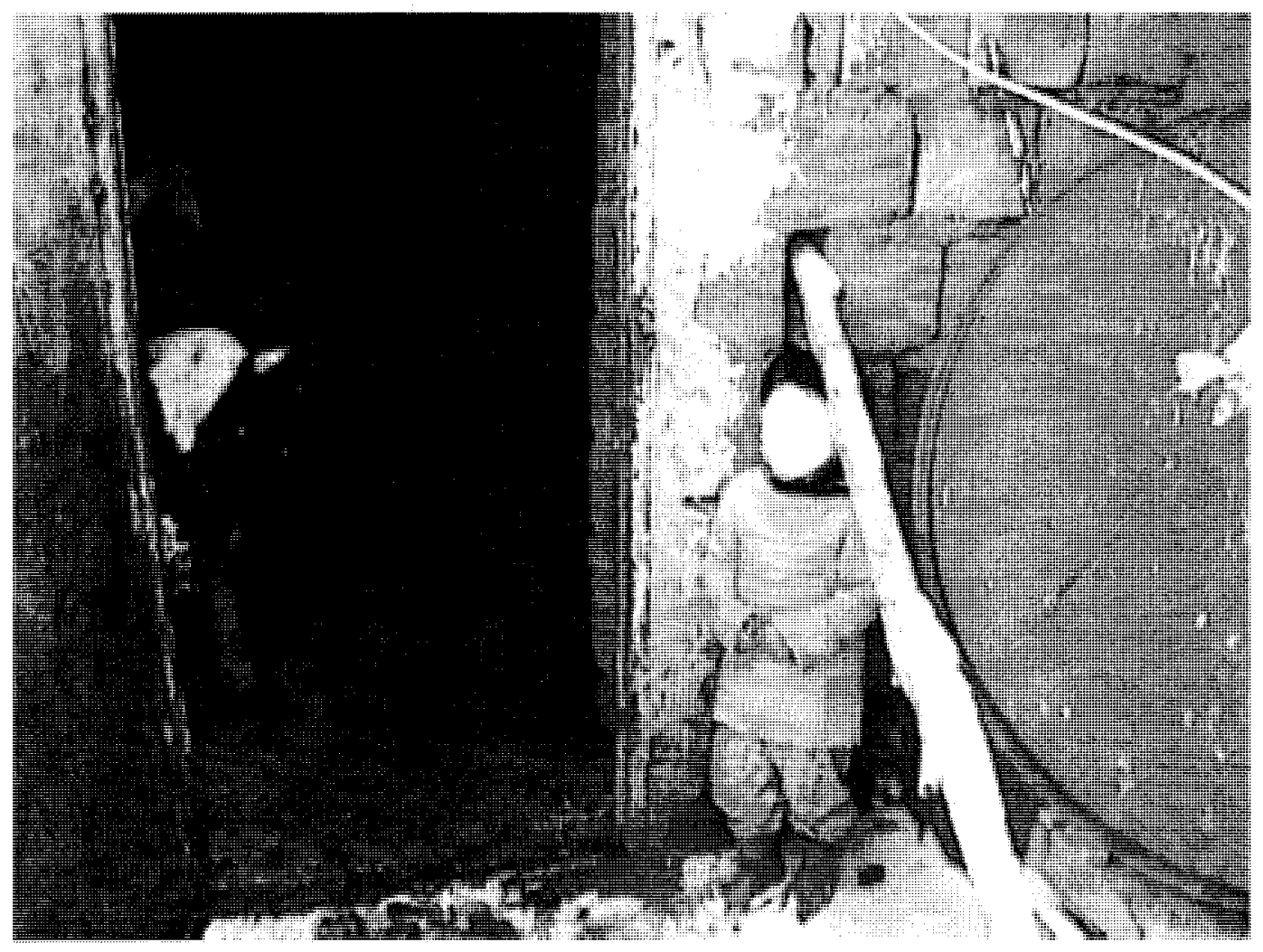


Iraqi Kurds launched their sattelite TV channels (i.e. Kurdistan TV and KurdSat) before the Iranian Kurds. According to the London-based Arabic newspaper, Al-Sharq AlAwsat, "The success of MED-TV propelled the two main Iraqi Kurdish parties to try to duplicate the experience" (Sheikhani, 2004). Two major Kurdish organizations, Kurdistan Democratic Party (KDP) and the Patriotic Union of Kurdistan (PUK) launched their satellite television stations, Kurdistan TV in 1999, and KurdSat in 2000, respectively. According to White (2000), Turkey was very concerned about the political impact of MEDTV, and later Medya TV. Knowing that closing MED-TV did not stop Turkey's Kurds from launching other TV channels (i.e. Medya TV and Mesopotamia TV), Turkey helped the two Kurdish political parties in Iraq to establish their own satellite TV stations in the hope that they would attract Kurdish audiences from Turkey and prevent them from watching Turkish Kurds' stations (pp. 175-179; see also Romano, 2002, p. 143). According to Romano, KDP officials have rejected the assertion and have maintained that KTV's "purpose is simply to give a voice to Iraqi Kurdistan, its people, its reality and its culture" (p. 143). One can expect a similar reply from KurdSat.

The director for KurdSat told Al-Sharq Al-Awsat that the first goal of the station was to address the "Arab street" and the world regarding the Kurdish issue, and the second goal was "to reach the Kurdish communities scattered all over the globe" (Sheikhani, 2004). However, according to the same source, the spokesperson for the other station, Kurdistan TV, assured Asharq Al-Awsat that one of the station's objectives was to promote 
the integrity of Iraq. This way both stations avoided making any explicit statement, in an Arabic newspaper, that would upset Arab nationalism which does have a stake in Iraq.

Kurdistan TV (KTV), the subject of this study, claims that viewers can watch its programs throughout the world. Thus, theoretically, it reaches Kurdish audiences larger than that of most of the other Kurdish satellite TV stations. Except for the other Iraqi Kurdish satellite TV channel, KurdSat, none of the other Kurdish satellite TV stations (i.e. Roj TV, Mesopotamia TV, Tishk TV, Rojhelat TV, Komala TV, Zagros TV) can reach North America or Australia. ${ }^{139}$ KTV can also be watched on the Internet through live streaming service. ${ }^{140}$ Kurdistan TV is also important because it is stationed in Kurdistan under Kurdish self-rule. It does not seem to be facing any obvious financial or political constraints. The head of KDP and the owner of Kurdistan TV is Masoud Barzani, who is the President of Iraqi Kurdistan. This situation understandably adds to the importance of KTV; however, there is a negative side to that. O'Leary \& Salih (2005) suggest that both KTV and KurdSat "are still too close to the two main parties," but at the same time report that the stations" "partisan tilt results from their own deference rather than the instructions of the respective party leaders" (p. 28). ${ }^{141}$

The unique position of Kurdistan-Iraq makes KTV very significant for both cultural and political reasons. Kurdistan-Iraq is the only Kurdish region that Kurds can refer to as the "free Kurdistan" (O'Leary \& Salih, 2005, p. 24). The assertion that the host states have prevented Kurds from achieving freedom and prosperity is widely held among the Kurds

\footnotetext{
${ }^{139}$ However, Roj TV and MMC TV can be viewed via live streaming service on the WWW.

${ }^{140} \mathrm{http} / / / \mathrm{www} . \mathrm{kurdistantv}$.net

${ }^{141}$ Khaled Salih, a political scientist and one of the authors of the article I have quoted here, is able to provide inside knowledge with respect to KDP because at the time of writing the article he was one of the advisors to the KRG in Hawler, Iraqi Kurdistan. For the past few years, he has been the official spokesperson for the KRG.
} 
including the common people. Kurdish nationalists have blamed "others" for the division of Kurdistan, the absence of a state of their own, and the lack of a unified language, culture and identity. But now the Kurds in Iraq have the freedom to articulate their national identity, plan for their language, cultivate their culture and decide on their political fate partly through satellite television stations. KTV is one of the most powerful means of cultural production providing a rich context for studying the dynamics of identity formation in Kurdistan.

KTV is important also because it is not confined to the Kurdistan-Iraq region. It is watched by Kurds from all parts of Kurdistan and diasporic communities (Firouzi, 2005). A look at the press and broadcasting from other parts of Kurdistan indicates that a great number of Kurds follow the news from Iraqi Kurdistan with great interest. KTV is one of the sources of this news. This could be one of the reasons that Kurdistan TV is not welcomed by the governments of Iran and Turkey. KTV has complained about its reporters being harassed in the two countries. Mehmet Eren, Kurdistan TV's Diyarbakir bureau Chief, has reported about the "[constant] pressure" that KTV correspondents endure in Turkey:

Although we totally comply with the legal framework [in Turkey], we can't cover official events, can't get accreditation without a reason, face random and arbitrary pressure such as identity checks etc ... Our focus is on news related to the Kurdish issue in Turkey and such coverage results in increasing pressure and obstruction on us ... Our houses and offices are surveilled by the police. We also received anonymous e-mail threats. (Un, 2007) 
According to Voice of America (2007), KTV correspondents have also been under pressure in Iran. ${ }^{142}$ These examples seem to further indicate the significance of KTV for the Kurds not only in Iraq but also in the neighbouring countries. However, despite its importance, to the best of my knowledge, no empirical study of Kurdistan TV has been carried out to investigate its discourse practices of Kurdish identity formation. The subsequent chapters will do just that.

Figure 5 Photograph of satellite dishes in a Kurdistan village, Sargalu, in Iraq (S. Ahmad, personal communication, July 10, 2007)

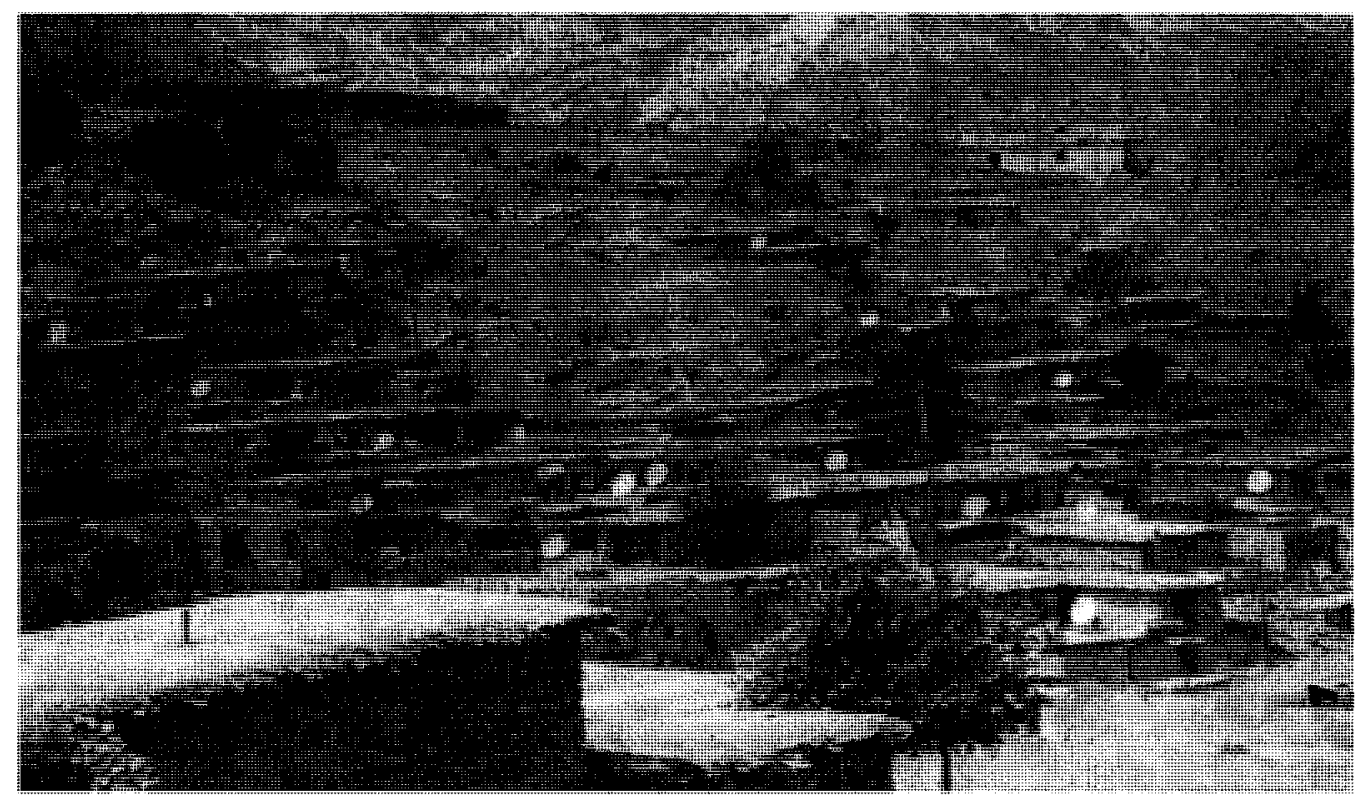

\section{Internet}

Whereas satellite television stations are mostly owned by dominant Kurdish political organizations, the Internet provides alternative communicative spaces to smaller

\footnotetext{
${ }^{142}$ VOA reports that "[Iranian] authorities continue to detain Kia Jahani, a long-time contributor to the Kurdish-language television station, Kurdistan TV. He was arrested on February $24^{\text {th }}$ [of 2007]" (Voice of America, 2007).
} 
organizations, social groups, cultural societies and individuals who play their parts in the processes of identity construction in Kurdistan.

Like satellite television, Internet use started among Kurdish diasporic communities in the mid-1990s. The usage at the beginning was limited and comprised of email use and newsgroup discussions. According to Romano (2002), prior to 1995 there were fewer than 20 Kurdish websites (See also Wahlbeck, 2002, p. 225). Until the early 2000s, very few households had access to computers let alone ISPs in Kurdistan. ${ }^{143}$ Many Kurds from the diaspora were facing difficulties using the Internet for political or cultural activities, because Arabic based Kurdish alphabet was not supported on the web. The vast majority of websites were in English and other European languages spoken by members of the Kurdish diaspora.

In the early 2000 s, two major changes contributed to a great increase in the number of Kurdish web sites and then weblogs. First, Kurdistan started to be served by relatively sufficient ISP services something that until then was in a meagre state especially in Iraq, Syria and Iran. Second, Kurd IT Group ${ }^{144}$, a technical group of Kurdish volunteers, developed the first Unicode-based Kurdish fonts (e.g. Unikurd Web, Tahoma, and so on) and the Windows Kurdish Support program which made Kurdish writing with computers and publishing on the Internet a great deal easier.

One of the first studies of the Internet in connection to the Kurds was presented in a conference paper (Bakker, 1999). In June 2001, using the search engine hotbot.com,

\footnotetext{
${ }^{143}$ No official statistics are available on the exact numbers or percentage of people who had or have access to the Internet in Kurdistan. My observation is mostly based on my personal communication with people in the region about the status of media and communication in Kurdistan. My observation has also been informed by other forms of media reporting on the status of the Internet.

${ }^{144} \mathrm{http}: / /$ www.kurditgroup.org/
} 
Bakker conducted a search for web sites with the word "Kurdistan" in their page title, and the search returned 1,800 items. I conducted the exact search on May 22, 2007, and it returned 658,500 hits, which indicates a dramatic growth of the presence of Kurdistan on the Internet since 2001. It is not clear, however, what percentage of these websites are Kurdish-owned or are for and visited by the Kurds. The website Koord, one of the most reliable Kurdish sources which indexes Kurdish websites, provides links to over "2000 websites" in May 2007.

Research on the use of Internet among the Kurds is scarce in any language. ${ }^{145}$ Bakker (1999), who engages in some brief analysis of Kurdish web sites, underscores the importance of the Internet for enhancing identity among the Kurds. He summarizes his findings as follows:

.... in most cases it is just information (or to be more correct propaganda). But according to the amount of visitors, it is something that is enjoyed very much ...these websites can be important for some groups or individuals, research points in the direction of strengthening identity.

Bakker, however, does not mention the fact that at the time of his research (i.e. 1999) the vast majority of the Kurds living in the Middle East did not have access to the Internet (Romano, 2002, p. 139), and that the majority of the websites, including those that he has investigated (e.g. www.akakurdistan.com), were published in English and other European languages.

Romano (2002) focuses on the ways in which the use of media technology has transferred Kurdish nationalist movement especially among the Kurds of Turkey. Although

\footnotetext{
${ }^{145}$ Amir Hassanpour has researched and written on the development of Kurdish media more than anyone else. However, in his 1996 article "creation of Kurdish media culture" he does not cover the Internet (Hassanpour, 1996). This seems to indicate that at the time the Internet was not relevant among the Kurds. It is also important to note that Hassanpour wrote this particular chapter in mid-1994 (A. Hassanpour, personal communication, August 15, 2008).
} 
he does not engage in detailed analyses of Kurdish Internet either, Romano makes some interesting observations. He notes that Kurds like many other ethnic groups have used email for "organizing nationalist projects" (p. 139). ${ }^{146}$ He also draws attention to the importance of the Internet as "a forum for discussions and arguments on 'forbidden' subjects" (ibid.). Kurds of Turkey used the Internet from their various diasporic communities to make their banned publications available to Kurds inside Turkey. Romano (2002), however, makes no reference to the use of the Internet by Kurds from Iraq, Iran, and Syria.

Mills (2002) looks at the attempts made by the Tibetans, the Chiapas, and the Kurds "to use the Internet to further their identity construction or self-determination projects" (p. 70). In response to those who have viewed the Internet mostly as an internationalizing force, Mills contends that "it is far too soon to declare the end of nationalism and parochial identity" (p. 70). Based on his observation of several websites mainly in English, and without getting into much substantial textual analyses, Mills concludes that the Kurds are using the Internet to maintain their "'logical state' or 'cybernation' known as Kurdistan ... providing common points of contact and sources of instantaneous cultural and political information to its members around the world" (p. 82).

The assertion that the Internet strengthens ethnic and national identities is also echoed in Erikson (2007), who partially focuses on the use of the Internet among the Kurds.

\footnotetext{
${ }^{146}$ As an example, Romano (2002) reports that by using e-mail the Kurds from Turkey managed to stage a simultaneous massive demonstration in the Western capitals in the wake of Abdullah Ocalan's arrest in Kenya, on February 15, 1999. Of course one has to also take into account the popularity and usefulness of telephone in these circumstances. It is also worth noting that in the same article (p. 145) Romano suggests Kurds from Montreal and Toronto had informed him that they were informed about Ocalan's arrest via MEDTV. It should be noted, however, that MED-TV's signals were never received by satellite dishes in North America. Video tapes of MED-TV were available in Canada at the time but these were not fast enough to deliver the news.
} 
Of the four varieties of Internet nationalism which Erikson identifies he places the Kurds' in the "pre-independent" category, and suggests that "it may actually be said that the Kurdish nation reaches its fullest, most consolidated form on transnational websites in the metropolitan languages English, German and French" (p. 9). He also makes a very interesting observation regarding the Kurds, contrary to many other observers who perceive the Kurds as already possessing a national, as opposed to an ethnic, identity. He states that "Kurdish national identity may be said to be in a formative stage" and underscores the "considerable factionalism" and fragmentations among them. He concludes that the "diaspora or virtual nationalism" is unlike the nation-state model of nationalism, in the sense that it is "unstable," because it is not bounded by territory and it is non-homogenous. This should not mean that non-virtual nations are homogenous or that territory guarantees homogeneity. Erikson's observation, however, is significant in that he believes that in order to understand the nation formation of people without a state like the Kurds we need to abandon the classic notion of the nation as a homogenous entity and instead we need to take pluralism as a part of the equation (p. 16).

Erikson's study, like most of the studies discussed earlier, suffers from a methodological shortcoming. His findings are based on Kurdish Internet sources presented in English or other languages other than Kurdish. Non-Kurdish language web sites and resources are often aimed at non-Kurdish speakers, mostly Westerners, as the very website that Erikson has analyzed (kurdishmedia.com) ${ }^{147}$ indicates in its mission statement (Erikson, 2007, p. 9). Although these web sites may also target audiences who do not speak

\footnotetext{
${ }^{147}$ As I write this section, kurdishmedia.com is offline after being hacked by "Turkish sources" (R. Fatah, personal communication, May 19, 2007). Fatah and his colleagues have started a fundraising campaign to gather enough money to design a more secure web site with the same title and mission.
} 
the Kurdish language but identify themselves as Kurds, for example the Kurdish diasporas, their first and foremost aim is to gain support for the Kurdish cause by presenting the Kurdish case to prospective audiences in the "international community," especially the elites in the West, who might somehow benefit the Kurds by influencing their countries' foreign policies. In any case, it is doubtful if the prime objective of the non-Kurdish web sites is to invoke Kurdishness in their audiences since the majority of them may not be Kurds in the first place. In the project of identity formation among a people which considers its language as one of the most important indicators of group identity, media content presented in the native language matters a great deal. Studying the Kurdish language Internet has been neglected.

To sum up, the assertion that both satellite television and the Internet have enhanced identity production among the Kurds remains a plausible hypothesis at best. Much empirical research is needed to test this hypothesis. The hypothesis is based primarily on the assumption that, because the Kurds now have access to these electronic media, they have started to connect with each other more than ever, to rediscover each other, and to become a unified nation. The assumption ignores the question of language, media content, the dynamics of identity formation, and the historical and political realities of Kurds and Kurdistan. These assumptions ignore the fact that connections and becoming aware of others sometimes draw out differences instead of creating commonalities. For example, a Kurdish student from Iran who was studying in Iraqi Kurdistan expressed his disappointment and frustration at the cultural differences that existed between the two parts of Kurdistan. He claimed that he was "homesick" there because he found the Iraqi Kurdistan more "traditional," and "tribal," and that the people there "dressed and ate 
differently, and it was much easier to date girls in Tehran than in Suleimania [, Iraq]" (Watson, 2005, my translation). 


\section{Chapter 8: Discourse Practices of Kurdistan TV (KTV)}

This and the next two chapters look at the satellite television channel Kurdistan TV (henceforth KTV) to investigate the ways in which this channel is used in the construction and articulation of Kurdish identity. I will specificaly focus on discursive practices that are deemed essential in constructing a pan-Kurdish sentiment, by which I mean the creation of a sense of belonging to one people or nation, the Kurds, and their homeland, Kurdistan. Analyses will be carried out according to the CDA method for analysing media discourse that I have introduced in previous chapters. The analysis takes place at three levels: discourse practices analysis (this chapter), textual analysis (the next two chapters), and socio-cultural analysis (discussion and conclusion chapter).

This chapter focuses on analyzing KTV's programming or what can be called discourse practices. I will first expand my description of KTV by presenting the channel's mission declared on its website. This is followed by describing the data on which my analysis of the station is based. Finally, KTV's discourse practice is analyzed including its programs and language use, and the ways these discourse practices contribute to the construction of Kurdish identities.

On its website, KTV is described as follows:

KURDISTAN TV is a Kurdistani Satellite Channel, the first Satellite TV to transmit from the free land of Southern Kurdistan. First programs [sic] were aired on January 17th, 1999.

In addition Kurdish language [sic], KURDISTAN TV aired its programs in Arabic, English, Persian, Turkish, Syriac and Turcoman languages. Some of the language services have been stopped for the time being.

KURDISTAN TV has a public policy, message, [sic] that it tries to apply in all its programs and activities. 
KURDISTAN TV pays attention and encourages dialogue, the free expression of views and has become a fertile ground for the exchange of opposite views.

Viewers all over the world can watch Kurdistan through the following satellites ... (Kurdistan Television, 2006) ${ }^{148}$

This self-describing text from KTV's website identifies Iraqi Kurdistan as "Southern Kurdistan," implying that it is only one part, the southern part, of a greater land, Kurdistan. Furthermore, by characterising "Southern Kurdistan" as "free," the website implies that other parts of Kurdistan (northern, eastern, and western) are not free. The assertion that there is a greater Kurdistan is an indispensable part of the pan-Kurdish nationalist discourse. As an institution owned by a regional Kurdish organization, KTV is not explicit about this pan-nationalistic sentiment, choosing instead to reinforce it in subtle ways. My interest lies in making these subtle ways of constructing a pan-Kurdish identity transparent. In order to do this, these questions are asked: What discursive strategies aiming at constructing national identities are employed on KTV? To what extent are these strategies directed at constructing a pan-Kurdish identity? To put it differently, what aspects of KTV programming serve the purpose of defining a collective identity for all people of Kurdistan? What linguistic and audio-visual tools and elements are used in constructing identities discursively? Finally, what possible explanations could be offered for KTV's discourse practices and discursive constructions pertinent to identity construction?

Figure 6 One of Kurdistan TV's logos displayed periodically between programs

${ }^{148}$ The original text is in English. 


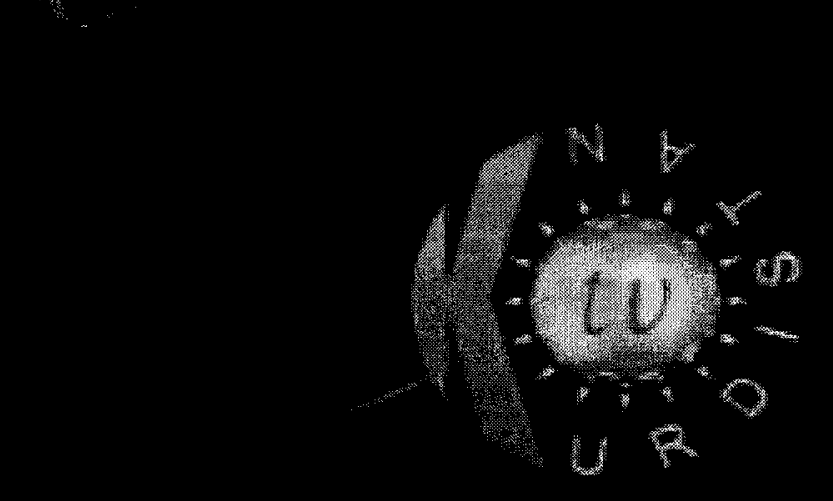

\section{kurdistan tV}

\section{KTV programs}

Fisk \& Hartley (2003) suggest that "the starting point of any study of television must be with what is actually there on the screen" (p. 8). I have been following KTV broadcasting since 2002 . In order to systematically collect data from the station, I have videotaped one week of KTV broadcasting, 168 hours, from August 06 to August 12, 2005. In choosing this week, one criterion in particular has been considered: that the data represent KTV's regular programming as opposed to weeks or time periods during which many shows are devoted to national holidays, such as Nawroz (the New Year) or anniversaries and commemorations, such as the bombardment of Halabja on March 18, 1988. 
KTV airs its programs 24 hours a day, seven days a week. Its daily schedule runs from 8:00 in the morning to midnight, local time (Hawler/Erbil, Iraq) ${ }^{149}$ From midnight until 8:00 a.m., a selection of the same programs is re-aired. Since KTV viewers are located in very different time zones (e.g. Middle East, Europe, Australia and North America) the reruns allow the majority of viewers to watch the same KTV programs. This flexibility in viewing KTV programs is expanded by the fact that even during the original broadcasting period (8:00-24:00) several shows are repeated, such as news, news in brief, weather, and the children's program. Based on their content, KTV programs can be classified into these categories: arts and entertainment, news, children's, current affairs, socio-cultural, history and demography, shows in non-Kurdish languages, and finally other programs. Table 3 shows the distribution of KTV programs over these categories during a typical week.

Arts and entertainment makes up the largest portion of programs aired on KTV (36\%); news (15.2\%), children's (9.4\%), and current affairs concerning political issues of the day $(9.2 \%)$ come next in rank. Programs in languages other than Kurdish (8.5\%), sociocultural—for example, employment, women's issue, youth education, family relations(4.5\%), and history and demography of Kurdistan (2.7\%) make up the next significant grouping. The rest (14.5\%) of the air time is filled with advertising, community announcements, promotions for KTV programs, and special reports. As part of this grouping, locally produced dramas (usually one per year aired during the month of

\footnotetext{
${ }^{149}$ It should be noted that there are occasional irregularities in KTV's programs' airing time or durations.
} 
Ramadan), and films made by internationally acclaimed Kurdish directors such as Bahman Ghobadi $^{150}$ are offered along with dubbed drama series predominantly from South Korea. ${ }^{151}$

Table 3 Distribution of KTV programs during the week of August 06-12, 2005

\begin{tabular}{|c|c|c|c|}
\hline & Description of category & Hours & Percentage \\
\hline $\begin{array}{l}\text { Arts and } \\
\text { entertainment }\end{array}$ & $\begin{array}{l}\text { video clips, concerts, and } \\
\text { entertaining shows }\end{array}$ & 40 h. $20 \mathrm{~min}$ & $36 \%$ \\
\hline News & $\begin{array}{l}\text { including weather, sports, and } \\
\text { business news }\end{array}$ & $17 \mathrm{~h}$. & $15.2 \%$ \\
\hline Children's & $\begin{array}{l}\text { Dubbed cartoons, local production, } \\
\text { Kurdish lessons }\end{array}$ & 10 h. $30 \mathrm{~min}$ & $9.4 \%$ \\
\hline Current affairs & Current political issues & $10 \mathrm{~h} .20 \mathrm{~min}$ & $9.2 \%$ \\
\hline Socio-cultural & $\begin{array}{l}\text { cultural activities, youth and } \\
\text { women issues, education }\end{array}$ & $5 \mathrm{~h}$. & $4.5 \%$ \\
\hline $\begin{array}{l}\text { History and } \\
\text { demography }\end{array}$ & $\begin{array}{l}\text { documentaries on past history of } \\
\text { Kurdistan or current demographic } \\
\text { descriptions of Kurdistan }\end{array}$ & $3 \mathrm{~h}$. & $2.7 \%$ \\
\hline $\begin{array}{l}\text { Languages other } \\
\text { than Kurdish }\end{array}$ & $\begin{array}{l}\text { Arabic, Turcoman, Assyrian, } \\
\text { Hawrami (a distinct variety of } \\
\text { Kurdish) }\end{array}$ & 9 h. $30 \mathrm{~min}$ & $8.5 \%$ \\
\hline Other & $\begin{array}{l}\text { Commercials and announcements, } \\
\text { promotion of KTV programs, } \\
\text { news in picture, special reports, } \\
\text { occasional airing of drama, films } \\
\text { and plays }\end{array}$ & 16 h. $20 \mathrm{~min}$ & $14.5 \%$ \\
\hline Total & & $112^{152}$ & $100 \%$ \\
\hline
\end{tabular}

${ }^{150}$ Bahman Ghobadi, an Iranian Kurd, is the winner of the Camera d'Or at 2000's Cannes Film Festival for his film, A Time for Drunken Horses, set in a part of Kurdistan on the Iran-Iraq border. Turtles can Fly and Half Moon are among his other internationally acknowledged movies.

${ }^{151}$ Since the fall of Saddam Hussein, about 1000 Korean military personnel have been stationed in Iraqi Kurdistan. They have been actively involved in building hospitals, schools and other essential services in the region.

${ }^{152}$ KTV's total airing time in a week is 168 hours. However, for 56 hours of this time KTV re-airs selected programs from the same day. 
In addition to recording KTV broadcasting for one week, I have recorded various shows throughout my active observation of KTV since 2005. For example, I have recorded a show aired on January 07,2007 (Talib, 2007) devoted to audience reaction to KTV's performance. These shows provide useful insights from KTV's personnel and audience, albeit selected viewers, about the aims and objectives of the station and the kind of identity they are committed to maintain or construct. In addition, I have collected published literature and information pertinent to KTV. This literature, along with a number of informal communications with Kurds in Kurdistan and diasporic communities about KTV, will be used for contextualizing the data so that a sufficient intertextual analysis will enrich interpretations of data analyses and final discussions.

\section{KTV programming and the construction of a pan-Kurdish identity}

In what follows, five key questions are asked in order to illustrate the extent to which KTV programming contributes to the construction of a pan-Kurdish identity. These questions focus on whether KTV shows represent the history, geography, current issues, and culture of Iraqi Kurdistan alone or other parts as well. The questions also aim at eliciting whether Kurds from all parts of Kurdistan participate in and contribute to the production of KTV shows.

1. Are there shows that are devoted to the history, demography and geography of other parts of Kurdistan?

2. Does KTV address current issues related to all parts of Kurdistan or Iraqi Kurdistan only? 
3. Whose culture, that of Iraqi Kurdistan alone or all Kurds, is reflected on KTV?

4. Do Kurds other than the Kurds of Iraq contribute to the production of TV programs (e.g. as hosts or hostesses, producers and directors)?

5. Do non-Iraqi Kurds participate in shows and programs as guests, callers, interviewees?

1. Are there shows that are devoted to the history, demography and geography of other parts of Kurdistan?

Close to $50 \%$ of the shows which are devoted to the history and demography of Kurdistan are about either the Greater Kurdistan or other individual parts of Kurdistan (i.e. other than Iraqi Kurdistan). The daily, five-minute program, Emřo le Mêjû da (Today in History), which comes right after the main news broadcast, recounts Kurdistan and world events and historical figures that are deemed important. KTV also broadcasts documentaries on not only the history but also the current demography and geography of Kurdistan. ${ }^{153}$ One significant aspect of these shows is that they are directed and hosted by Kurds from the same region covered in the program (e.g. Iranian Kurdistan). Greater Kurdistan is not only defined by Iraqi Kurds through the lenses of KTV but also by Kurds from other parts who in different ways participate in KTV's programs. Moreover, for many of the viewers this might be the first time that they see their fellow Kurdistanis and are exposed to their language, dialect and pronunciation.

${ }^{153}$ During the week of August 6-12, 2005, the following shows related to the past history of Kurdistan were broadcast: Kurdish principalities in 1515 as part of the history of the Greater Kurdistan, and the history of the ancient Sarim Bag Citadel located near the town of Naghada, Iran. Programs were also devoted to the demography and geography of several Kurdish populated cities in Iran such as Bookan, Sine (Sanandaj), and Marivan. Since January 2007, Kurdish populated cities of Turkey have been the focus of the monthly program Kurdistan, Bajar bi Bajar (Kurdistan, city by city). 
2. Does KTV address current issues related to all parts of Kurdistan or Iraqi Kurdistan only?

According to Bendix \& Liebler (1999), some studies of the role of physical distance on news-media coverage have suggested that "events 'close to home' receive more newsmedia attention, and that coverage decreases with distance" (p. 658). Other studies have shown that news coverage is determined more by the newsworthiness of an event or where it occurs (ibid.). They conclude that both physical and social distance affect the amount of news-media coverage (p. 673).

The data reveal that about $20 \%$ of KTV news covers political and cultural developments that either take place in or are related to other parts of Kurdistan. Examples of these news items include reports on the armed conflict between the Turkish army and the Kurdish rebels from Turkey, social unrest in Iranian Kurdistan, and the Kurdish women activists from Syria visiting the Iraqi Kurdistan parliament. In contrast, other parts of Iraq, including Baghdad, are in the news only when the story is related to Kurdistan (e.g. the state of negotiations between the Kurds and Baghdad over drafting the Iraqi constitution in Baghdad) or when there is heavy fighting and explosions in the capital Baghdad or other parts of Iraq. Overall, KTV news is more concerned with other parts of Kurdistan than the non-Kurdish parts of Iraq.

Whereas all parts of Kurdistan enjoy a considerable representation in KTV news, they are less represented in programs dealing with current affairs. The majority of these programs deal with the current political and social issues of Iraqi Kurdistan. One of the notable programs that is specifically devoted to all parts of Kurdistan, especially Kurdistan of Turkey, is called Ronî, which is a one-hour live talk show. For example, on August 08, 
2005, this show had four guests, each representing one part of Kurdistan. Later, I will return to this show and analyze a few excerpts from the discourse of the participants as examples of discursive constructions of a pan-Kurdish identity.

3. Whose culture, that of Iraqi Kurdistan alone or all Kurds, is reflected on KTV? Sharing a common culture is indispensable to the formation of a national identity (Spencer \& Wollman, 2002, p. 69). In addition to reflecting and representing the history, demography, geography, news and current affairs, KTV programming is devoted to the promotion of arts, particularly music and literature, from all parts of Kurdistan and the diaspora. Prominent Kurdish singers from Turkey (e.g. Shivan Perwer, Kurdistan ${ }^{154}$ Perwer, Birader, Aynur, Xelîl Xemgîn), Iran (e.g. Kamkaran, Nasir Razzazi, Merziye Fariqi, Leila Fariqi, Ezîz Sharux, Mamlê Family), Syria (e.g. Said Gabarî, Bengîn, Narîn Feqê) are featured on KTV frequently. In an interview, Seyid Ehmed Rewandizî, the head of the music section of KTV, says: "I can say with pride that [KTV] is my second home, because through this precious channel we have been able to strengthen our connections with [singers, songwriters and musicians] ${ }^{155}$ from all four parts of Kurdistan" (Saman, 2006).

For a long time, music has been one of the most convenient means of connecting the Kurds and facilitating the expression of a shared sense of belonging. Due to the lack of access to modern communications technology, however, until recent years only a few Kurdish singers and musicians could cross linguistic and geographical boundaries that

\footnotetext{
${ }^{154}$ Kurdistan is also a popular name among the female Kurds.

${ }^{155}$ This speaker like most Kurds use the word hunermend (artiste) to refer mostly to musicians, singers, song writers, and musical instrument players.
} 
made communication among the Kurds difficult if not impossible. Radio broadcasting and audio, and later video cassettes enabled more Kurdish singers to cross some of those boundaries. The major breakthrough at this front, however, has occurred with the introduction of satellite television in Kurdistan. The combination of audio and visual modes of television, freely crossing guarded borders between different parts of Kurdistan, has created a concert hall where tunes from different corners of Kurdistan and Kurdish diasporas have been amplified and then projected to viewers and listeners throughout Kurdistan and the diasporic Kurdish communities.

Besides broadcasting music video clips from all parts of Kurdistan, and in a wide range of Kurdish speech varieties, KTV's entertaining talk shows feature Kurdish artists, who manage to travel to Iraqi Kurdistan. In May 2005, in an interview on KTV, Rasool Nadri, arguably the most famous folk and wedding singer from Iranian Kurdistan said something along the following lines: Kurdish television has brought more respect for singers and musicians in Kurdistan. Before television, singers and musicians were so disrespected that most people were ashamed to sing, and if they did, they were called chawesh, a derogatory term used for wedding singers. Thanks to Kurdish television, the same people nowadays are called hunermend (artiste) a word that was reserved for wellknown poets and painters. ${ }^{156}$ The fact that Nadri was invited to a talk show to express his views on Kurdish music, his contributions and personal life proves his point; that he is not just a wedding singer but an artiste.

\footnotetext{
${ }^{156}$ In an interview with Radio Sweden International, Husain Shukh-Kaman, better known as Birayani Zeze,a Kurdish singer from Iranian Kurdistan, who became famous in the 1960s, confirms Nadri's suggestion that in the past most people in Kurdistan "were mortified to sing. We, [those that sang], were called loti [,a derogatory term for wedding singer]. People would not even allow us to ask for the hands of their girls [Birayani Zeze laughs]... Singing was not something to be proud of at the time. But, now hundreds of people tell me that they wished they had my huner (artistic talent)" (Sina, 2007a).
} 
KTV has contributed to the cultivation and expansion of Kurdish music from all parts of Kurdistan and the diaspora not just by playing music-video clips and inviting the singers and musicians to appear on talk shows but also by broadcasting their concerts. Many Kurdish music lovers in Turkey, Iraq and Syria, who might never be able to go to Iran or abroad, can see and hear Iranian Kurdish singers and musicians on KTV. For example, on August 08, 2005, KTV aired a 50-minute long concert that was performed in Iraqi Kurdistan by Shahin Talabani, an Iranian Kurd residing in Britain. Given all this, one could credit satellite television in Kurdistan, including KTV, with an unprecedented increase in the number of singers and musicians. Later in this study, by analyzing a patriotic song, I will also illustrate how the content of some of these songs contributes to the construction and articulation of collective Kurdish identities.

In addition to music, other art and cultural forms from all over Kurdistan can be viewed on KTV. These forms include, but are not limited to, dance, painting, architecture, sculpture, and poetry reading. For example, on August 09, 2005 one entire show, Dîwan (Collection of poems), was devoted to a poet from Iranian Kurdistan who read from and talked about his collection of poems.

4. Do Kurds other than the Kurds of Iraq contribute to the production of TV programs (e.g. as hosts or hostesses, producers and directors)? A number of the programs that represent other parts of Kurdistan are also directed or hosted by Kurds other than Iraqi Kurds. For example, on August 12, 2005, the weekly show Şev Bêrî (Zamdar, 2005) was hosted by a very popular Syrian Kurdish singer, Said Gabari, whose presence seemed to attract many Syrian Kurds calling from Europe and North 
America into the show. Another show, Kazîwe (Twilight), which was broadcast on August 10, 2005, was directed and hosted by Iranian Kurds (Makhoudi, 2005).

In August 2005, about 10-15\% of children's shows were directed and presented by Iranian Kurds. One show was called Karî Destî̀ (Artworks), which was seven minutes long (out of 45 minutes of children's show), and was aired on August 8 and August 9, 2005. The other show, an Iranian puppet show, which is dubbed into Kurdish by Iranian Kurds, was aired four times during the week, each time for ten minutes. In August 2007, there was an expansion of children shows directed and hosted by Kurds other than Iraqi Kurds. The program Kamo is hosted by a puppet speaking in an unmistakably Mukri dialect of Kurdish from Iran, and it is broadcast for 30 minutes every Thursday. The program features plays, games, music, dance and other activities carried out by children from various Kurdish towns in Iran.

In addition, there is a daily program called Zimanê Kurdî̀ (Kurdish language) (see Figure 7) presented in the Kurmanji accent of Kurds from Turkey. For someone who is knowledgeable about Kurdish it is relatively easy to distinguish accents of Kurmanji speakers from Iraq and Kurmanji speakers from Turkey. Whereas the former has been influenced by Arabic phonetics and pronunciation, the latter demonstrates obvious traces of Turkification. The influence of dominant languages on Kurdish in different countries are also evident in the grammar and more so in the vocabulary. Sorani speakers from Iraq and Iran can be similarly distinguished. More on the importance of language issue on KTV will follow. However, one important point should be stressed at this juncture. Kurdish literate, adult and mostly male nationalists had a sense of pan-Kurdishness at least since the beginnings of the last century. However, satellite television channels, including KTV, have 
made it possible for Kurdish children all over the world to see and hear each other, and in a sense, as it were, discover each other. KTV has been a part of this change.

Figure 7 Kurdish lessons program as a part of children's show on KTV

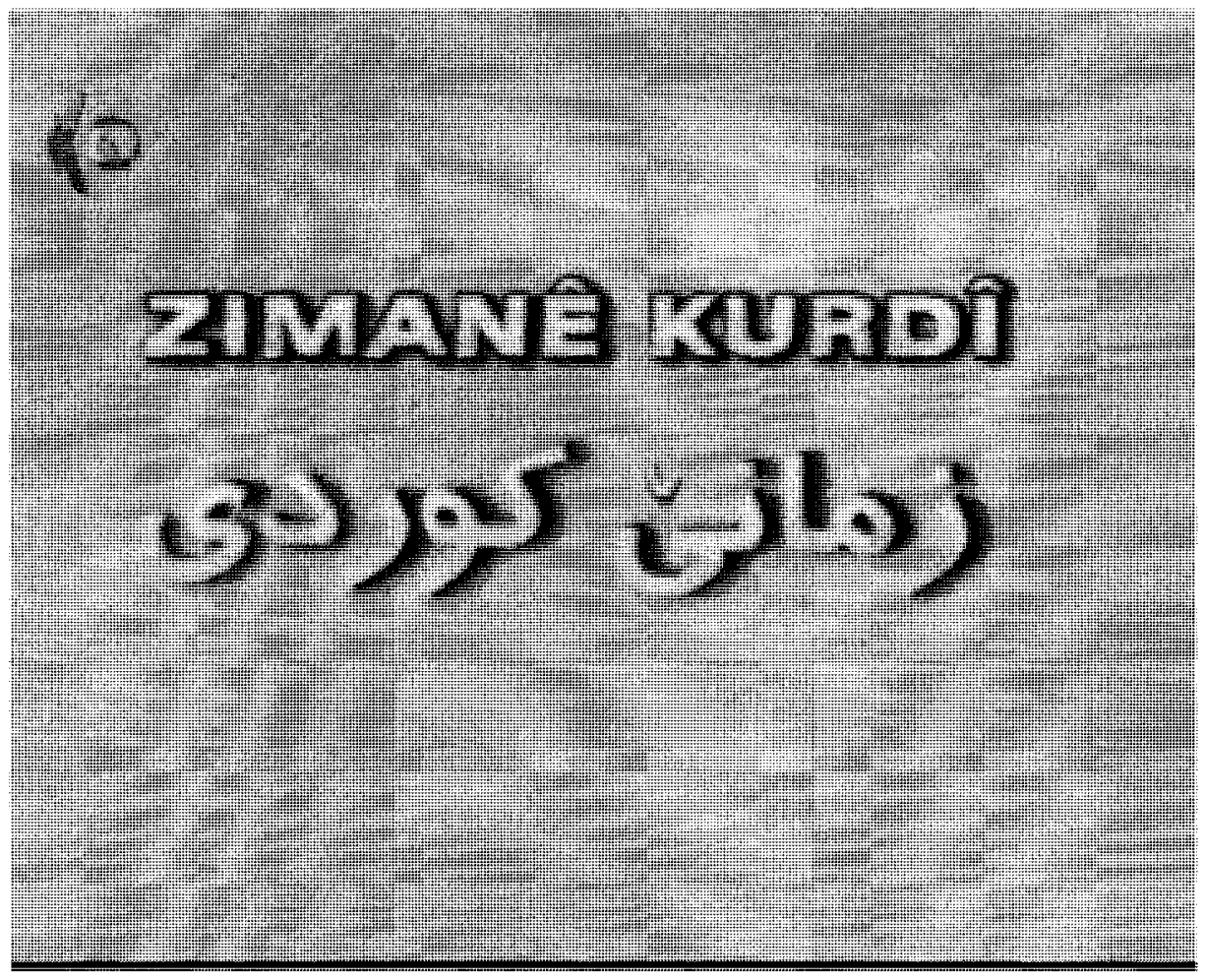

6. Do non-Iraqi Kurds participate in shows and programs as guests, callers, interviewees? Audience participation in programs can be seen in different forms: people who are selected to appear as guests on talk-shows, people who are asked to express their opinions on current social and political issues (e.g. on the street or other public settings), and finally those who contact shows either through phone calls or sending messages by fax and email. Although a considerable number of politicians, artistes and scholars from other parts of Kurdistan appear on various shows of KTV, the current data contains only one example of this where political analysts from four parts of Kurdistan, one in person and three on the phone, were interviewed on the program Ronî (Nawî, 2005). 
KTV broadcasts live programs of both entertaining and also political nature where people can call in and participate either to express opinions, ask questions, request music videos or send regards to their loved ones. Some of the shows that I surveyed during the week of August 6, 2005 included: Keval, a light entertainment show (August 8), Le Kurdistanewe (From Kurdistan), ${ }^{157}$ a political/current affairs show (August 9), Jivana Stranan, music video request show (August 11), and finally Şev Bêrî, a traditional music show (August 12). One of the features of the live shows is that they provide at least two phone numbers, one for callers from Iraqi Kurdistan and the other for callers from elsewhere. My close observation of these live shows indicates that about $50 \%$ of the callers are from Iraqi Kurdistan and the other half from Europe, North America, and Australia. Judging by their accent, it is also evident that the vast majority of those who call from abroad are originally from Iraqi Kurdistan, who could be KDP sympathizers for the most part. Kurds from other parts of Kurdistan, whether residing in the four states or the West, usually call a program when that program is hosted by or has guests from the same region as the callers'. For example, Syrian Kurds were calling into the show Şev Bêrî (Zamdar, 2005) because the host of the show was Said Gabari, a well-known vocalist and folk musician from Syria.

\section{KTV and language use}

What languages are used and how they are used in media are closely connected to the maintenance of language and also to questions of ethnic and national identity (Bulck \& Poecke, 1996; Cormack \& Hourigan, 2007). As I have discussed in previous chapters, next to territory, language has been one of the most significant emblems of Kurdish identity.

\footnotetext{
${ }^{157}$ This program's title had changed to Rastewxo (live) in August 2007.
} 
Two important points should be reiterated. First, there is not a unified Kurdish language; there are Kurdish varieties, especially Sorani and Kurmanji. Second, there are languages other than Kurdish in Kurdistan. Shedding light on the linguistic aspect of broadcasting should be indicative of the kind of identity that is promoted and constructed by KTV. The kinds of language used on KTV could also indicate who is involved in the definition and articulation of Kurdish identity.

Guyot (2007) observes that "television tends to confer legitimacy on any linguistic cause" (p. 39), and that "television can revitalize the cultures and languages of minorities" (ibid.). Television may not be capable of revitalizing cultures or languages on its own, but it does "confer credibility and legitimacy on language" especially on threatened languages (Hassanpour, 1997, p. 924). The Kurdish language has been called a dialect of Persian in Iran, and in Turkey it was banned in all public domains until 1991. To this day, it has no official status in Turkey, Iran and Syria. The fact that Kurdish is the prime language of a television station broadcasting 24 hours a day, seven days a week, legitimizes the status of Kurdish and assists the language to sustain its vitality.

Hassanpour (1998) has referred to MED-TV as a language academy. This can equally be said about KTV. In Turkey, Iran and Syria, Kurdish is neither the medium of schooling nor is it taught as a subject in public schools. Although providing private lessons on Kurdish has been tolerated by governments of Turkey and Iran in recent years, Kurdish courses usually do not last long due to the lack of support from the states (SkutnabbKangas \& Fernandes, forthcoming). KTV provides lessons on the Kurdish alphabet and 
reading. ${ }^{158}$ Furthermore, KTV airs Disney, Japanese, and Russian cartoons dubbed into Kurdish. It is important to note that KTV occasionally airs non-dubbed English cartoons, but cartoons in the dominant languages of the states where Kurds live, such as Persian, Turkish and Arabic are absent on KTV. This can be seen as a strategy of constructing outgroups. KTV airs English cartoons because the English language, unlike Arabic, Turkish and Persian, is not seen as a threat to Kurdish language. English is not only a prestigious and instrumental global language, but it is also the language of Britain and the United States, the two countries that the ruling Kurdish organizations, including KTV's owner, $\mathrm{KDP}$, consider as friends and allies. ${ }^{159}$

Figure 8 Screenshot of a dubbed cartoon in children's program on KTV

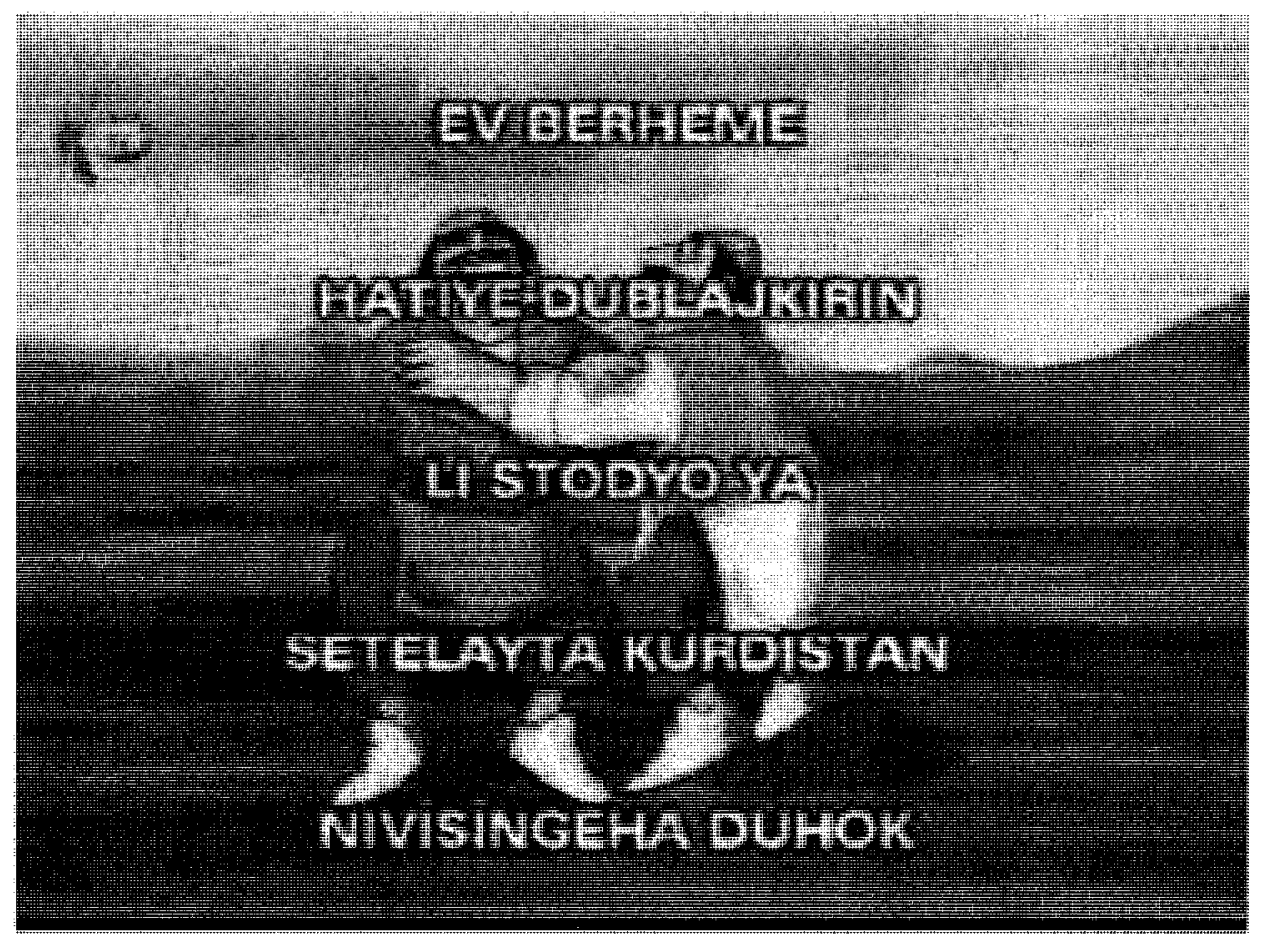

\footnotetext{
${ }^{158}$ Given that the lessons on Kurdish are in the Kurmanji dialect and also in the Latin based alphabet, it is safe to suggest that these lessons are directed at Kurdish audiences in Turkey.

${ }^{159}$ According to a report by the Agence France-Presse, high school and college students in Iraqi Kurdistan prefer to study English instead of Arabic as their second language (Young Iraqi Kurds ..., 2005, p. 12; see also O'Leary \& Salih, 2005, p 28).
} 
KTV fosters mutual intelligibility among Kurdish speech varieties by implementing unique programming techniques. For example, the main newscast is presented by two people, each speaking one of the two major varieties of Kurdish. As a common practice, when the news item is presented by the Sorani speaker, the report accompanying that report is given by a Kurmanji speaker. In addition, there are numerous talk shows which have guests who speak a different Kurdish variety from the host's. ${ }^{160}$ Kurds from various speech communities participate in KTV shows, either by calling in to shows or by being a part of the production or presentation teams. Finally, music clips by artistes from all regions of Kurdistan and the diaspora are aired on KTV daily. In an interview, Heval Ibrahim, a young artist from Iraqi Kurdistan, and a native speaker of Kurmanji, said: "Today, most of the youth in the Badinan region, [whose native tongue is Kurmanji], can understand Sorani thanks to Sorani singers like Zakaria, Eyub Ali, Adnand Karim and many more who sing in both dialects" (Himmati, 2007). Continuous exposure to different Kurdish varieties on KTV and other satellite television stations have made Kurdish varieties much more mutually intelligible. After six months of occasional viewing of satellite TV channels of the Iraqi Kurds, including KTV, an Ottawa resident said that "before I could not understand Iraqi Kurds, but now I do" (Simin Arefi, personal communication, February 16, 2002). Her husband, an engineer working in Ottawa, said: "I am really impressed when I see Iraqi Kurds are able to talk about every subject in Kurdish. I thought you could only do this in Arabic, Persian or Turkish". He said that he has acquired many new words and expressions from KTV and other Kurdish media and that he may not speak Kurmanji, but he has no difficulty understanding it now (Kemal Musulchi, personal communication, February 16,

\footnotetext{
${ }^{160}$ When communicating in different varieties, speakers occasionally run into difficulty understanding each other.
} 
2002). Rebwar Fatah, the director of Kurdish Media (www.kurdmedia.com), in an interview with Roj TV, said that he did not understand Kurmanji prior to watching Kurdish satellite television stations, starting with MED-TV (Ghazi, 2007).

Figure 9 News presented by speakers of the two main Kurdish varieties: Sorani on the left and Kurmanji on the right

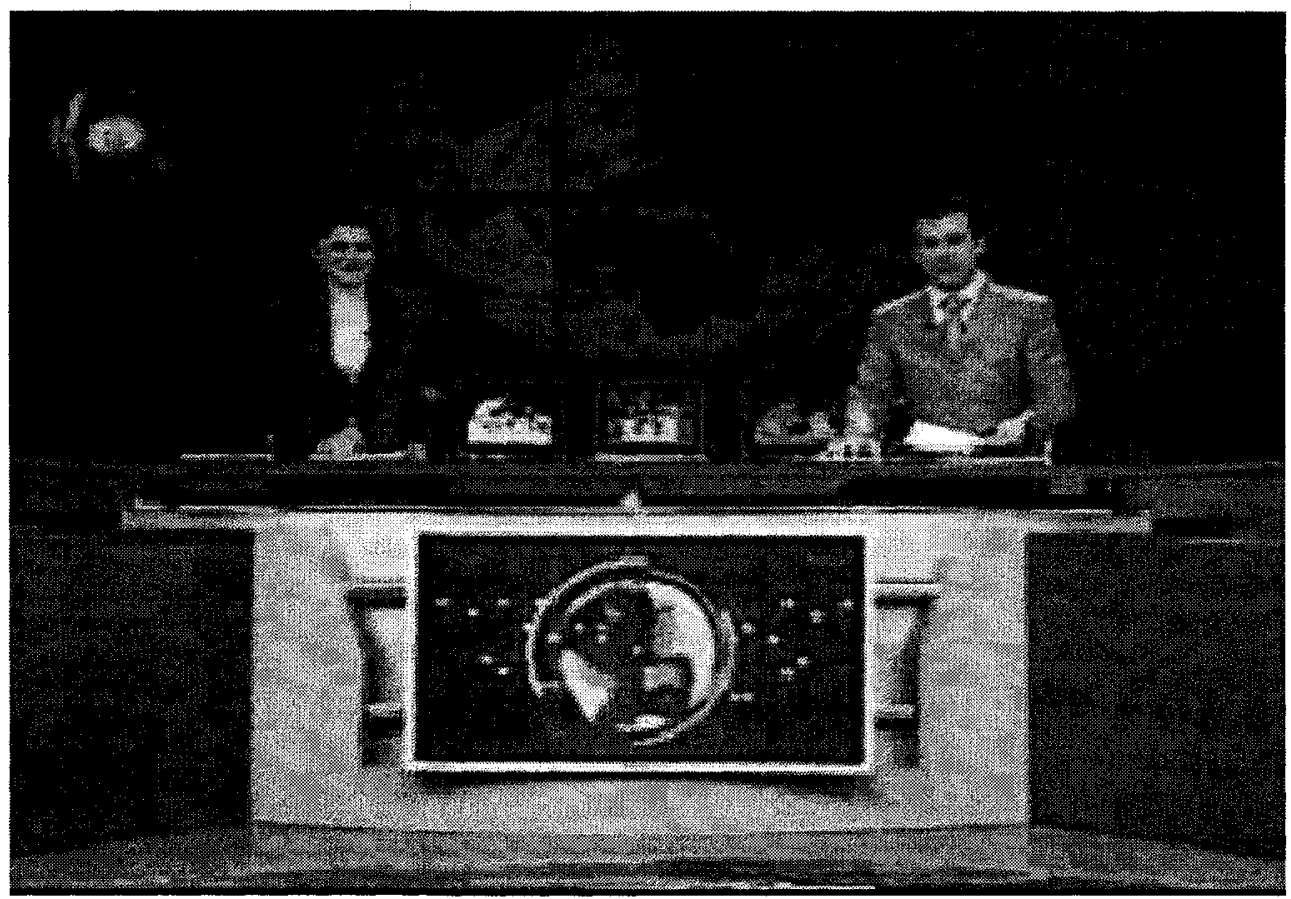

KTV celebrates linguistic diversity. From the French Republic of the late eighteenth century to the Turkish Republic of the early twentieth century and Franco's Spain which lasted well into the mid-1970s, the vast majority of modern nation-building projects have been funnelled by the nation-state ideology, which says that an ideal nation has only one official and promoted language. ${ }^{161}$ Building nations has often involved nation destroying (Connor, 1994). The Kurdish language has been a victim of this suppressive modernist

\footnotetext{
${ }^{161}$ There have been exceptions to this assimilationist nation-building ideology, for example Switzerland.
} 
policy and scheme of nation building. In contrast, KTV, as an agent of nation-building, promotes language diversity in Kurdistan. This is in line with the KRG's public education system which promotes schooling in the mother tongue for at least two Kurdish varieties (i.e. Sorani and Kurmanji) and non-Kurdish and minority languages in the region (Skutnabb-Kangas \& Fernandes, forthcoming). In addition to broadcasting in the two major Kurdish varieties of Kurmanji and Sorani, KTV also produces and airs a one-hour weekly show in the Kurdish variety of Hawrami. In addition to daily Arabic shows and news, KTV also airs weekly programs in Turkomani and Assyrian Neo-Aramaic as the languages of minorities other than Kurds living in Kurdistan (see Figure 10). One could argue that this democratic and pluralistic approach to linguistic diversity in Kurdistan is an indication of the civic, as opposed to ethnic, nature of the national identity that is fostered by KTV. ${ }^{162}$ Figure 10 Screenshot of the opening of the Assyrian program on KTV

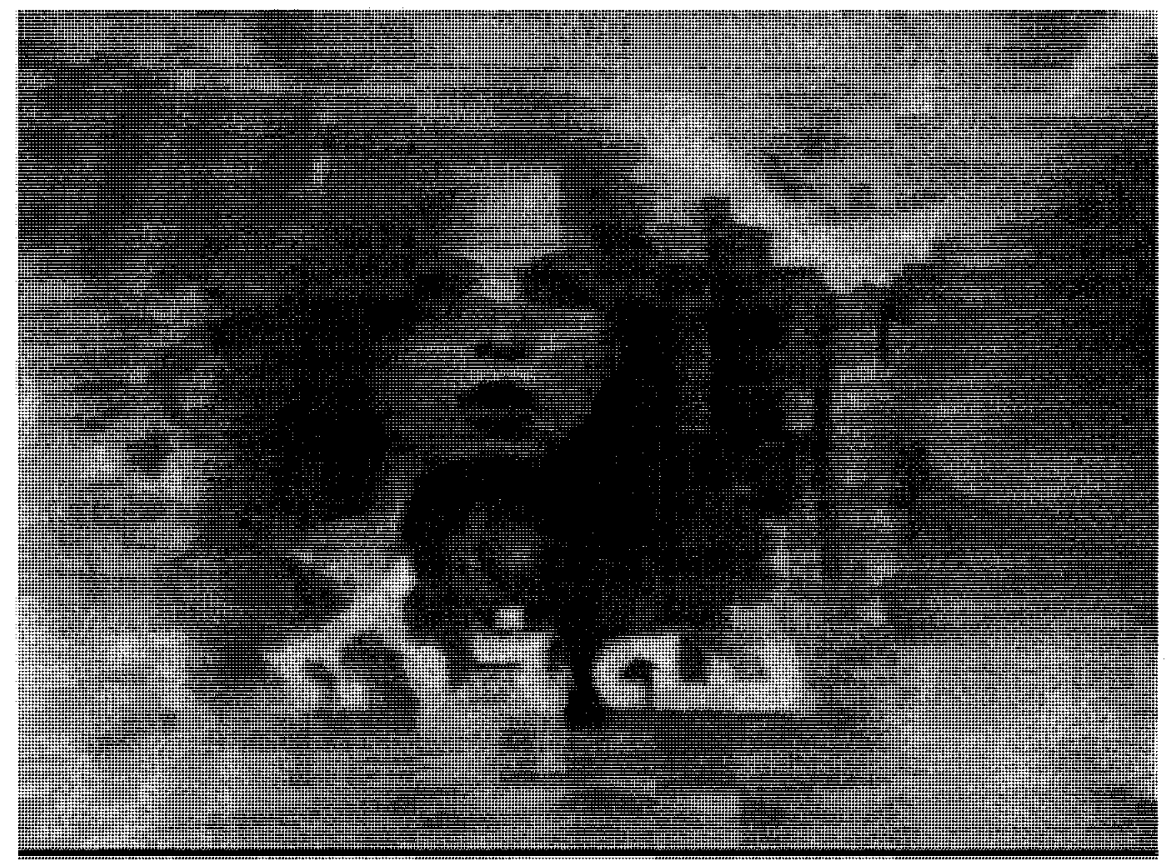

\footnotetext{
${ }^{162}$ In chapter two I have discussed different types of nationalism including civic vs. ethnic nationalism.
} 
In addition to investigating what languages are used in the media and to what extent along with other sings (i.e. audiovisual) it is equally important to analyze and interpret how these semiosis are used to construct identities discursively. This textual analysis of KTV discourse is carried out in the next two chapters. 


\section{Chapter 9: Textual Analysis of KTV}

This chapter focuses on discursive constructions of Kurdish identities on KTV. Particular attention is paid to the construction of a cross-border Kurdish identity. I will carry out detailed textual analysis of texts from KTV programs, such as excerpts from KTV's news, history narratives, talk show discussions, and finally a weather forecast. Given the scope of this study and the kind of detailed analyses that are performed here it is important to limit my data to a manageable body of texts and a limited set of analytical tools that I described in chapter five. The analyses are further informed by several studies of national identity that have used CDA approaches (e.g. Billig, 1995; Bishop \& Jaworski, 2003; Chouliaraki, 1999; Higgins, 2004; Wodak et al., 1999). The objective of this chapter is to illustrate how various components of national identity discourse, or what Wodak et al. (1999) call "semantic-macro areas" of national identity discourse, are realized and materialized in different modes of communication, such as verbal and visual languages (See appendix 1 for a description of these tools).

\section{Discursive construction of a common history}

The program Emřo Le Mêjû da (Today in History) is about seven minutes long and it is aired twice everyday. It provides a brief description of historical events that KTV deems important. These are mostly events that are pertinent to KTV's owner KDP. Major historical events in the neighbouring countries, especially when there is a connection with Kurdistan, and international events (e.g. the World War I and II) are also covered. Aside from events that are directly related to KDP, only certain types of Kurdistani events are 
covered: those that either took place prior to the emergence of modern Kurdish organizations (e.g. Sheik Ubaidalla revolt against the Ottoman Empire in 1880), those that do not have any direct connections to the modern Kurdish organizations other than KDP (e.g. Halabja's chemical bombardment in March 1988), and events and personalities that might have connections to other organizations but have become significant symbols of Kurdish national identity (e.g. the establishment of the Kurdish republic of Mahabad in Iranian Kurdistan in 1945-6). In other words, in constructing a historical identity for Kurdistan, KTV is interested either in events and personalities that are connected to its owner or those events and people that are believed to be parts of a pan-Kurdish nationalist discourse.

Figure 11 Screenshot of the opening of a KTV show, Emřo le Mêjû da (Today in History)

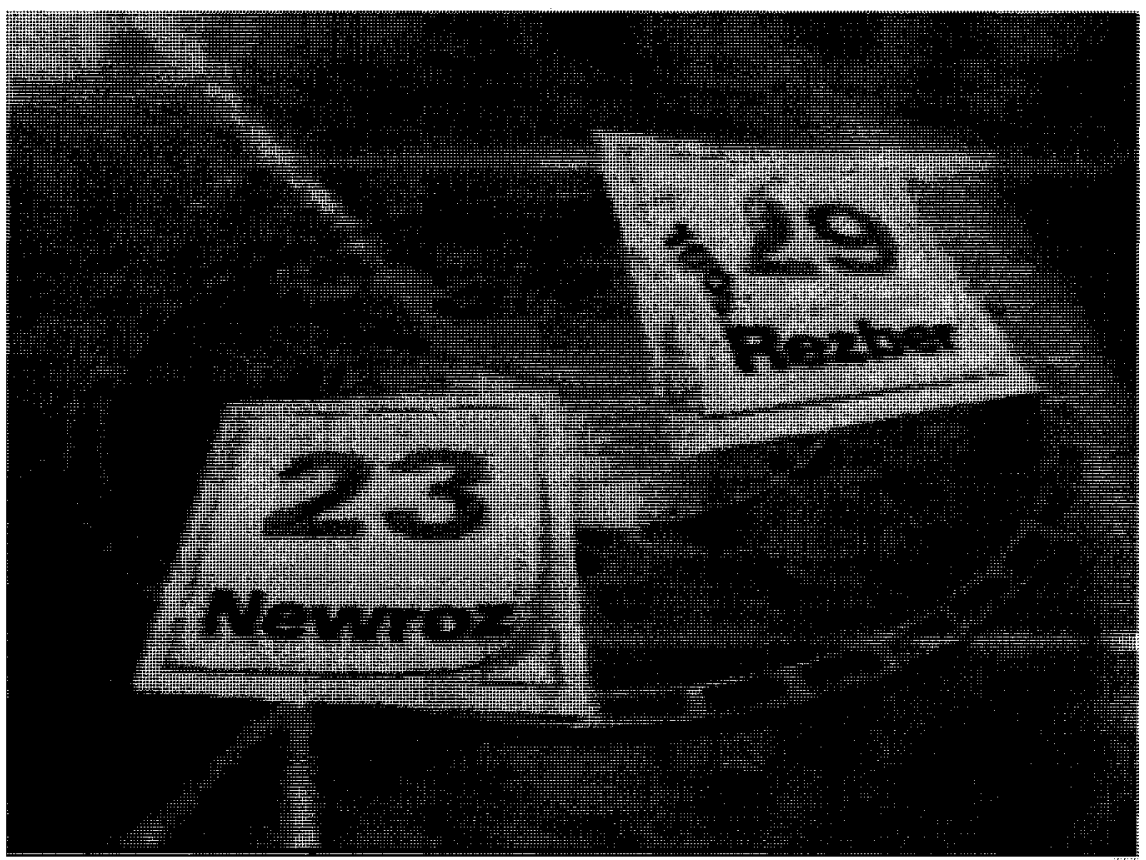


Through the program Emřo le Mêjî da, and other shows, KTV attempts to reconstruct that greater Kurdistan not only through covering pertinent events but also in the ways in which the event is retold and reconstructed discursively. I will briefly look at the reconstruction of one of these events, the Treaty of Sévres, broadcast on August 10, 2005, in the program Emřo le Mêjû da.

On August 10,1920, in a day like today, the Treaty of Sévres was signed. The treaty was signed, [among others], by the Kurdish representative, Pasha Sharif Khandan, and the Allies of World War I. The Ottoman Empire, which had lost the war, signed the treaty as well. The treaty consisted of thirteen sections and 433 articles. Articles 62-64 declared that a Kurdish state be established. For the first time in the contemporary history, the Kurdish question entered the legal and political documents of powerful western nations. The Kurds had embarked on revolutions against the oppression of the Ottoman Empire some time ago. Abdul Salam Barzani was one of the martyred Kurdish leaders, who was hanged by the Ottomans, in Mosul, because of his struggle for securing Kurdish national rights and progress and development.

The Treaty of Sévres was important for the Kurds and also the abolishment of the Ottoman state. But, the discovery of oil in Kurdistan became one of the main factors that prevented the ratification of the treaty especially the articles that promised Kurdish independence. On July 24, 1923, the Treaty of Lausanne annulled the Treaty of Sévres, and prevented the Kurds from achieving their national rights, and the promises that were made to Kurds were scrapped for the sake of serving the interests of the powerful nations.

Furthermore, the Kurds, themselves, were not able to influence the regional and international politics through diplomatic and political pressures to realize their objectives.

Although the Treaty of Lausanne further reaffirmed the division of Kurdistan as a reality, with a series of revolutions, the Kurdish nation refused to accept that reality.

The narrator of this text is at pains to discursively construct a shared history and destiny for all Kurds, albeit at the expense of presenting a true account on a very important international treaty, the Treaty of Sévres. ${ }^{163}$ This narrator achieves this not only by what is said about the Treaty but also via what is omitted and not said about it. The

\footnotetext{
${ }^{163}$ Articles 62-64 of the Treaty of Sévres, which relate to this discussion, are reprinted in McDowall (2004, pp. 464-5).
} 
narrator claims that the treaty promised the establishment of an independent state for all Kurds, because she does not specify which part of Kurdistan was included or excluded in the Treaty. The KTV show aims at discursively constructing Kurds as one people that has shared the same history and destiny for a long time. The narrator does not reveal the fact that the Kurdish state that was promised did not include all the territories that Kurds have inhabited. The Kurdish state, promised in the Treaty of Sévres, was supposed to be established in Turkey's south east or Kurdistan North. It would have not included Iranian Kurdistan, Syrian Kurdistan, the Dersim region in today's Turkey, and the territory that is known today as Iraqi Kurdistan. Albeit, the Treaty "allowed for the adhesion" of the latter to "such a future Kurdish state" (McDowall, 2004, p. 137). KTV's show ignores this historical fact. Instead, throughout the text, the three words Kurds, Kurdish nation, and Kurdistan are used interchangeably to further construct a unified nation with a common territory, history and destiny.

\section{Discursive construction of a common present and future}

The nation is often the main focus of the news (Billig, 1995, p. 117). Through the news, we are told who belong and who do not belong to the nation (ibid.). In relation to KTV, I stated before that a considerable segment of its news concerns other parts of Kurdistan. KTV's Deng û Bas program (news) encourages its audiences to be concerned about the present conditions of all Kurds regardless of where they live. In doing so, however, KTV uses two different languages, one that can be called the language of the autonomist/regionalist Kurdish national identity (e.g. KDP's, the owner of KTV), and the second the language of a cross-border Kurdish identity. Here is an example, which is a news item about unrest in Iranian Kurdistan, in August 2005: 
Following a series of demonstrations and sit-ins by Kurds in Iranian Kurdistan [Kurdistanî Eran] ... in the city of Wirmê, after having a state of emergency for three days in the Islam Abad district, a demonstration was held by the citizens. In response, the Iranian security forces attacked the crowed, and as a result, several people were injured and several others were taken to prison ... (Deng $\hat{u} B a s$, The News, August 12, 2005, my translation).

As with this and other examples of reporting about Kurdistan in Turkey or Syria, the news anchors are consistent with respect to their naming practices. They refer to parts of Kurdistan as being parts of the countries of Turkey, Iran, Iraq and Syria: Iranian Kurdistan (Kurdistanî Êran), and Turkey/Turkish Kurdistan (Kurdistanî Turkîye), and Syrian Kurdistan (Kurdistanî Surîye). This is the language of Kurdish autonomist/regionalist movement (e.g. KDP) which demands autonomy within the states where Kurds reside. The language of a pan-Kurdish nationalist is different in that it constructs Kurdistan as a unified territory and Kurds as one and homogenous nation. Accordingly, pan-Kurdish nationalism promotes the following naming practice: Eastern Kurdistan/Kurds or Kurdistan East, Northern Kurdistan/Kurds or Kurdistan North, and Western Kurdistan/Kurds or Kurdistan North, respectively (Iraqi Kurdistan is referred to as Southern Kurdistan/Kurds or Kurdistan South, or simply as Herêm, meaning the Region). ${ }^{164}$

Whereas the language of pan-Kurdish nationalism is excluded from the news items presented in KTV's studios in Iraqi Kurdistan, it is included in the report

\footnotetext{
${ }^{164}$ There are important differences between the two naming practices: Northern Kurdistan (Kurdistani Bakûr) and Kurdistan North/North of Kurdistan (Bakûrî Kurdistan). Northern Kurdistan could refer to a distinct territory which is not necessarily a part of a larger entity. However, Kurdistan North automatically invokes other parts of the same territory, its south, east and west. Kurdistan North indicates that the place that is referred to as such is a part of a larger territory, Kurdistan. However, it is not clear if all the users of the two terms, who often use them interchangeably, are aware of this subtle difference. It should be noted that Kurdistan North is more commonly used than Northern Kurdistan. I should also stress that some nonnationalist organizations and individual activists may use the language of pan-Kurdism when referring to parts of Kurdistan. They often do so for their belief in the status of the Kurds as a nation entitled to selfdetermination.
} 
accompanying the same news item. The reason is that the reporting is from the diaspora. Kurdistan Hesen (Hassan), a KTV reporter from Stockholm, Sweden, reports on the reaction of Kurds in diaspora to the Kurdish unrest in Iran, as follows:

According to news sources, the Islamic Republic of Iran's violence against the Kurds of the East continues. For this reason, and for the second time, the Joint Committee, which consists of the majority of Kurdish and Kurdistani organizations and parties, the Federation of Kurdistani Communities in Sweden, and Kurdish Platform in Europe, staged a demonstration in ... Stockholm... (Deng $\hat{u}$ Bas, August 12, 2005, my emphasis, my translation)

The language of pan-Kurdish nationalism in this excerpt is evident in that the reporter refers to Iranian Kurdistan as basically the "East," which means East of Kurdistan, implying that the Iranian Kurds' condition and destiny is not separate from that of Iraqi, Turkish or Syrian Kurds. Anything that happens to Kurds anywhere is a concern for all Kurdistan. This pan-Kurdish identity is further strengthened by reporting that "the majority of Kurdish and Kurdistani organizations and parties" have all come together under the direction of a single "joint committee" to support their fellow Kurds in the "east" of Kurdistan. It is interesting to note that the existence of entities like this "joint committee," through which Kurds from different countries could collaboratively act for a Kurdish cause, may have not existed in recent memories in Kurdistan itself. However, to the KTV news program, and also to many Kurdish individuals and organizations including those that are regional and politically autonomist, it is acceptable, common and somewhat natural to have pan-Kurdish sentiments, and also act accordingly, in Kurdish diasporic communities. This could be due to two factors. Pursuing the idea of having a greater Kurdistan could be punishable in Kurdistan as a separatist act and treason; it does not lead to similar consequences for the members of diasporic communities (e.g. Europe, North America, and Australia). The second reason might be that it is only in the West that 
Kurds coming from different parts of Kurdistan are able to freely communicate and interact with each other. Kurdish long-distance or diaspora nationalism seems to be panKurdish, secessionist and separatist more than most nationalist movements in Kurdistan. In addition to constructing a common present among the Kurds, KTV also facilitates the discursive construction of a common future for all Kurds, albeit such a future is to be championed by KDP (KTV's owner). To illustrate this, a few excerpts from the program Ronî (Nawî, 2005), broadcast on August 08, 2005, will be analyzed. In that particular program, representatives from four parts of Kurdistan discussed "Kurdistan region and other parts of Kurdistan," 165 as the title of the show indicated. The representative of Iraqi Kurdistan, Ihsan Amêdî, a KDP representative in Kurdistan parliament, states that other parts of Kurdistan follow the Iraqi Kurdish experience with the hope that one day they could achieve the same:

... When people from Kurdistan, south, north or east, visit Kurdistan, they see that Kurds are the masters of their own homes and land, and they have their own institutions and sovereignty ... [Kurdish people of] Iranian Kurdistan, Turkish Kurdistan and of Syria ... desire to achieve the same ... this is a national struggle for [the recognition] of their national identity ... people here [in Iraqi Kurdistan] are concerned about there, they would like to see [other Kurds] embrace the same development, and they would like to help them [to achieve this] ...

There are three messages in Amêdî’s comment which are shared by the ruling Kurdish parties, especially KDP, in Iraqi Kurdistan: (1) Iraqi Kurdistan is free, autonomous, and prosperous; (2) Kurds from Turkey, Iran and Syria desire the same; (3) Iraqi Kurdistan is concerned about other Kurds and is willing to help them to fulfill their dreams for freedom and autonomy. Since Iraqi Kurdistan is other Kurds' best hope, it follows that it

\footnotetext{
165 "Kurdistan region" is literal translation of "Herêmî Kurdistan," which is the common label used to refer to Iraqi Kurdistan. The expression is so common that many times the word Kurdistan is omitted and people refer to Iraqi Kurdistan simply as Herêm (the region).
} 
is in the interest of all Kurds if the Iraqi Kurdistan experience succeeds in the sense of remaining autonomous within a federal Iraq or even as an independent small Kurdistan. This way, the future of all Kurds has been constructed as being dependent on each other. Iraqi Kurdish authorities, however, do not explicitly ask for the help of other Kurds because this might come across as a sign of weakness, or it may create fear among Iraqi Kurds, or it may shatter the hope among other Kurds who are looking up to Iraqi Kurdistan. Equally significant is the conerns of neighbouring stats as well as the government in Baghdad and also the U.S., which is equally concerned about Turkey. Appeal for support, however, is voiced through Kurds from other parts who are carefully selected by KTV. ${ }^{166}$ For example, in the same show that I have been discussing, Ronî, Arif Zêrevan, a Kurdish journalist from Turkey, talking on the phone from Hawler (Erbil), Iraqi Kurdistan, makes the following statement:

What has been achieved in South Kurdistan has boosted Kurds' morale in all parts of Kurdistan, the North, [Turkey Kurdistan], the West, Kurdistan of Syria, and the East, [Kurdistan] of Iran. In Turkey, Kurds started, gradually, not to be afraid of Turkish soldiers or the PKK guerrillas. Kurds have started to demand their rights openly ...

The Syrian Kurdish guest, Mihemedemîn Mihemed, also on the phone from Hawler, confirms that Iraqi Kurdistan has given Syrian Kurds confidence in their struggle to achieve their rights similar to Iraqi Kurds:

... Kurdish nation in Syria sees a great opportunity too, and it hopes that [its] oppression will end as it ended in another part of Kurdistan ... Kurds from other three parts of Kurdistan are really willing to support their brothers in Iraqi

\footnotetext{
${ }^{166} \mathrm{KTV}$ guests are carefully selected because the guests from other parts of Kurdistan are never from organizations or groups that are known to have ideological differences with KDP, for example Komlala party, and PJAK (The party of Free Life of Kurdistan) of Iranian Kurdistan, or PKK of Turkish Kurdistan. It is important to note that none of the people who appear on KTV are from groups that are involved in armed struggle with the neighbouring states. KTV is well aware that such endorsements will be interpreted as threats to the sovereignty of Iran and Turkey.
} 
Kurdistan ... Kurds today, from other three parts of Kurdistan, Iran, Turkey and Syria, are ready to support and defend this experience of freedom [in Iraqi Kurdistan] ...

These excerpts reveal that KTV is committed to the discursive construction of a common present and future for all Kurds, albeit such a present and future, the destiny of all Kurds, is to be determined by KTV and its owner KDP.

KDP views itself as the true representative of all Kurds and Masoud Barzani, KDP leader, as the leader of not just Iraqi Kurdistan but Kurdistan at large. Again, such propositions are expressed through well known Kurds, such as artists, independent politicians, and writers from other parts of Kurdistan. The program Kazîwe, which is dedicated to cultural issues of Iranian Kurdistan (directed and hosted by Iranian Kurds), provides an example of this (Makhoudi, 2005). In the episode aired on August 10, 2005, Mehdiye Zandi, a well-known radio announcer and also the wife of one of the most famous Kurdish singers, Hassan Zirak, states the following: "God willing, Kurdistan will be triumphant ... Long live Kurds and Kurdistan ... [God save] the President, the leader of all Kurds, Mr. Masoud Barzani ..." There are numerous similar examples on KTV that re-present not only Masoud Barzani but also the entire Barzani family as the leader of all Kurdistan. For example, the main newscast on August 6, 2005, contained the following news item:

Birader, the famous artist from Kurdistan of Turkey, visited the tombs of the eternals $^{167}$ [referring to Masoud Barzani's late father and brother]. Birader said: "we can say that Barzani is the father of the Kurdish nation ... If today, we have a free Kurdistan, it is because of the path that the undying Barzani took... I bow to his path. Long live Kurds and Kurdistan. (My emphasis)

\footnotetext{
${ }^{167}$ The Kurdish term is Mezare Nemiran (Tombs of the Eternals) and it refers to the tombs of Mullah Mustafa Barzani, the father of the current Iraqi Kurdistan president, Masoud Barzani, and also the tomb of his brother Idris Barzani. Foreign dignitaries and special Kurdish guests from other parts of Kurdistan or the diaspora often pay respect to the tombs when visiting Kurdistan, and these visits are occasionally reported in KDP media including KTV.
} 
These are also examples of how KTV discursively constructs a common past and present for all Kurds by tying the past and present of Kurdistan to one single family, Barzani, and by extension the party they lead, KDP, the owner of KTV. Since it is commonly believed that leaders lead groups of people forward and into the future, the discursive construction of a common past and present also contributes to the production of a common future for all Kurds.

\section{Discursive construction of a common Kurdish language}

There is not one Kurdish language. As I have discussed previously, whereas a number of scholars speak of Kurdish languages, others, Kurdish nationalists in particular, speak of Kurdish dialects and claim that there is one single Kurdish language. In this study, I have opted for a more neutral term, Kurdish varieties. In discussing the linguistic fragmentation of the Kurds, I have suggested that some of these varieties (e.g. Kurmanji and Sorani) are as distinct as German and English (Kreyenbroek, 1992, p. 71).

KTV acknowledges the diversity of Kurdish by airing various programs in the two main varieties of Kurmanji and Sorani, a one-hour weekly show in Hawrami, and music video clips in smaller varieties. Despite this, there is an explicit attempt to downplay the differences between the varieties. To KTV, they are only dialects of Kurdish by the virtue of the fact that all the varieties are referred to as Kurdish. For example, whereas the Kurdish lessons in the children's show teach Kurmanji only, the show is simply called Zimanî Kurdî̀ (Kurdish language) as opposed to Kurmanji or Kurmanji Kurdish even though it does not teach Sorani Kurdish at all. This nationalist stance towards Kurdish language is reinforced on KTV's website. The website is multilingual. Kurmanji and Sorani are treated as two languages; each has its own 
navigation button and separate pages. Despite this, both of them are called Kurdish. Visitors can distinguish them by the fact that each "Kurdish" is written in a different alphabet system. The Sorani section is transcribed in the modified Arabic alphabet as كورديى (Kurdish) (in Figure 12, see the far right box in the row under kurdistantv.net). The Kurmanji section is marked by the word Kurdî (Kurdish) which is written in the Latin-based alphabet (see the far left button). Again, the difference between these two Kurdish varieties is acknowledged for a practical reason, which is the dissemination of information, but they are still named the same: Kurdish. Naming matters. Although KTV acknowledges language diversity in Kurdistan, it is still haunted by the powerful and positivist nation-state ideology that one nation has only one language.

Figure 12 KTV's website banner. Different navigation buttons are placed for the two varieties of Kurdish

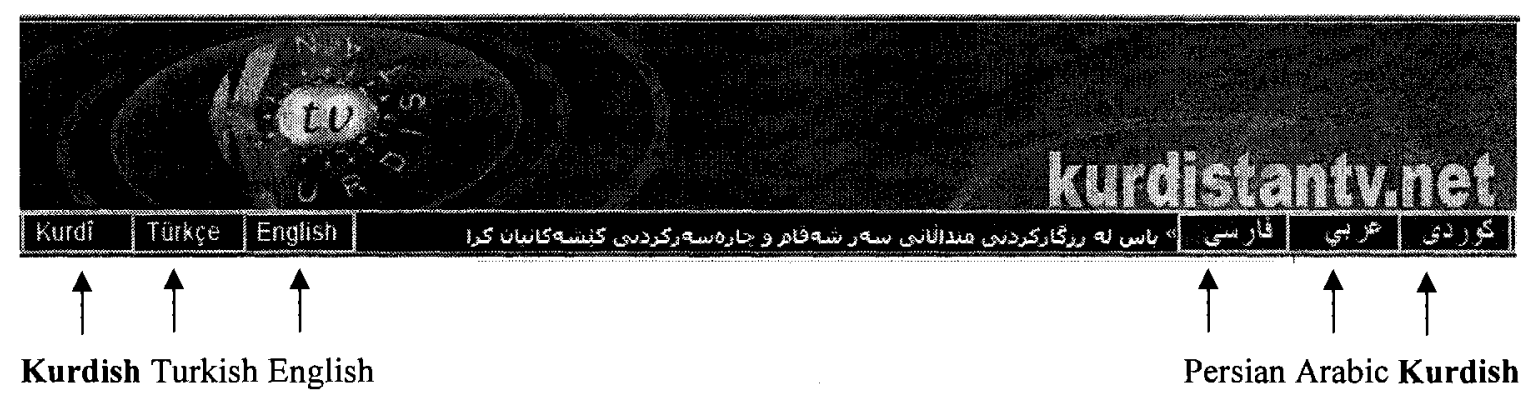

\section{Discursive construction of common national symbols}

National symbols strengthen the ties and bonds among the "like-minded people" of a community (Kuusisto \& Anna-Kaisa, 2001, p. 63). From flags and maps to fairy tales and ways of behaving (Smith, 1991, p. 77), national symbols contribute to the construction of the nation (Geisler, 2005, p. xv). Several symbols that are continuously reproduced on 
KTV are common to and shared by the majority of the Kurds. Among them are the

Kurdish flag, mountains and rural life, dance, and costume.

Among these, none is more significant than the flag in articulating the political

aspirations of the Kurds and in defining their national identity. Reporting from Iraqi

Kurdistan, Thomas (2007) quotes a man: "We wear this flag as a crown on our heads ...

This flag is sign that we are great nation [sic.]." In the Kurdish national anthem, Ey

Reqib, the main verse, which is repeated several times throughout, says: "Let no one say

Kurds are dead, Kurds are living, Kurds are living, and their flag will never fall." When

Masoud Barzani was selected as the president of Iraqi Kurdistan, addressing the

Kurdistan parliamentarians, he pointed to the Kurdish flag next to him, and said: "I was

born under this flag, and I am ready to die under it any minute" (Kurdistan TV, special

broadcast, June 12, 2005). ${ }^{168}$ In May 2004, Karim Nazhadian, an Iranian Kurd, who

\footnotetext{
${ }^{168}$ By saying that he is ready to die under the same Kurdish flag under which he was born, Masoud Barzani means two things: first that he was born in Mahabad, Iranian Kurdistan, in 1945, when for the first time a Kurdish state was established. His father Mullah Mustafa Barzani, one of the most famous Kurdish leaders, had just been driven out of Iraqi Kurdistan with several hundred rebels. He took refuge with the Iranian Kurds in Mahabad. Although an alternative account put forward by KDP claims that he went to Mahabad with the aim of helping the newly established Kurdish republic. Nonetheless, he was appointed as General Barzani and the commander of Kurdistan forces. During this stay of his father in Mahabad, Masoud Barzani was born. Secondly, Masoud Barzani implies that the flag he is standing next to today is the same flag that was hoisted on the roof of the Mahabad Republic's headquarters in 1945. This way he inserts the legitimacy of the Kurdish flag and his leadership not just for Iraqi Kurdistan but for all Kurdistan. In a way he presents himself as the inheritor of the Mahabad Republic and of Kurdish self-determination. What is missing in this imaginary thread, however, is the fact that the flag that today has been popularized as the Kurdish flag is different from the flag of the Mahabad Republic. The description of the flag of the Mahabad Republic is recorded vividly in a poem written by Hemin (1974), a prominent national poet at the time of the Mahabad Republic. There are some differences between the two flags. This current flag is a recent construct. Ignatieff (1993), who traveled to Iraqi and Turkish Kurdistan in the early 1990s, writes: "[Kurdistan] has no flag" (p. 182). He is correct, because at the time there was no common Kurdish flag which could be recognized by the majority of Kurds. There can be little doubt that the current flag is an invention of the Kurdish long-distance (diasporic) nationalism. It started to be displayed in Kurdish gatherings in the diaspora in the late 1980s (e.g. I saw this flag for the first time in 1988 during a Kurdish party in London, Ontario). In 1991, during the first Gulf War, Iraqi Kurds returning from the diaspora introduced it to Iraqi Kurdistan. Finally, the beginning of its popularization throughout Kurdistan coincides with the launching of the first Kurdish satellite television station MED-TV in 1995.
} 
travelled to Iraqi Kurdistan, reportedly died of excitement when he encountered the Kurdish flag for the first time in person (Alay Kurdistan, 2004). The Kurdish flag crosses the linguistic, cultural, organizational, and geographical boundaries that have fragmented the Kurds, and it has become a badge of pan-Kurdish identity.

Although the neighbouring countries continue to have productive economic relations with Iraqi Kurdistan, independent from the Iraqi central government, dealing with the Kurdish flag is no small matter for those states. When a delegation from the Kurdistan Regional Government (KRG) visits Turkey, Iran, Syria or even Baghdad, the Kurdish flag is not displayed in the meetings (Le dîdarî Barzanî ..., 2007). Those states seem to believe that the recognition of the Kurdish flag implies recognizing Kurdish demands for political rights, at least in the form of regional autonomy. Some states have exercised their influence to ban this flag even outside their own territory. ${ }^{169}$

The current Kurdish flag

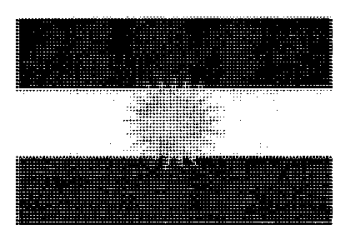

A reconstruction of the Kurdish flag of the Republic of Mahabad, 1945-46

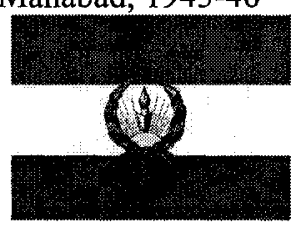

169 In 2003, after the Kurdish Students Association at Carleton University displayed a Kurdish flag in their display case, located in the tunnels of the university campus, the Turkish embassy in Ottawa complained to the Dean of Student Affairs office and asked for the removal of the flag. The Turkish embassy claimed that displaying the Kurdish flag, banned in Turkey along with the Kurdish language, violated and insulted the sovereignty of the Turkish state even though the flag was displayed on the Canadian soil and thousands of miles away from Turkey (Leonard Liberande, Dean of Student Affairs at Carleton University, personal communication, November 10, 2003). 
Figure 13 Screenshot of the news program Deng $\hat{u}$ Bas: Kurdish flag displayed in a meeting with European dignitaries in Iraqi Kurdistan

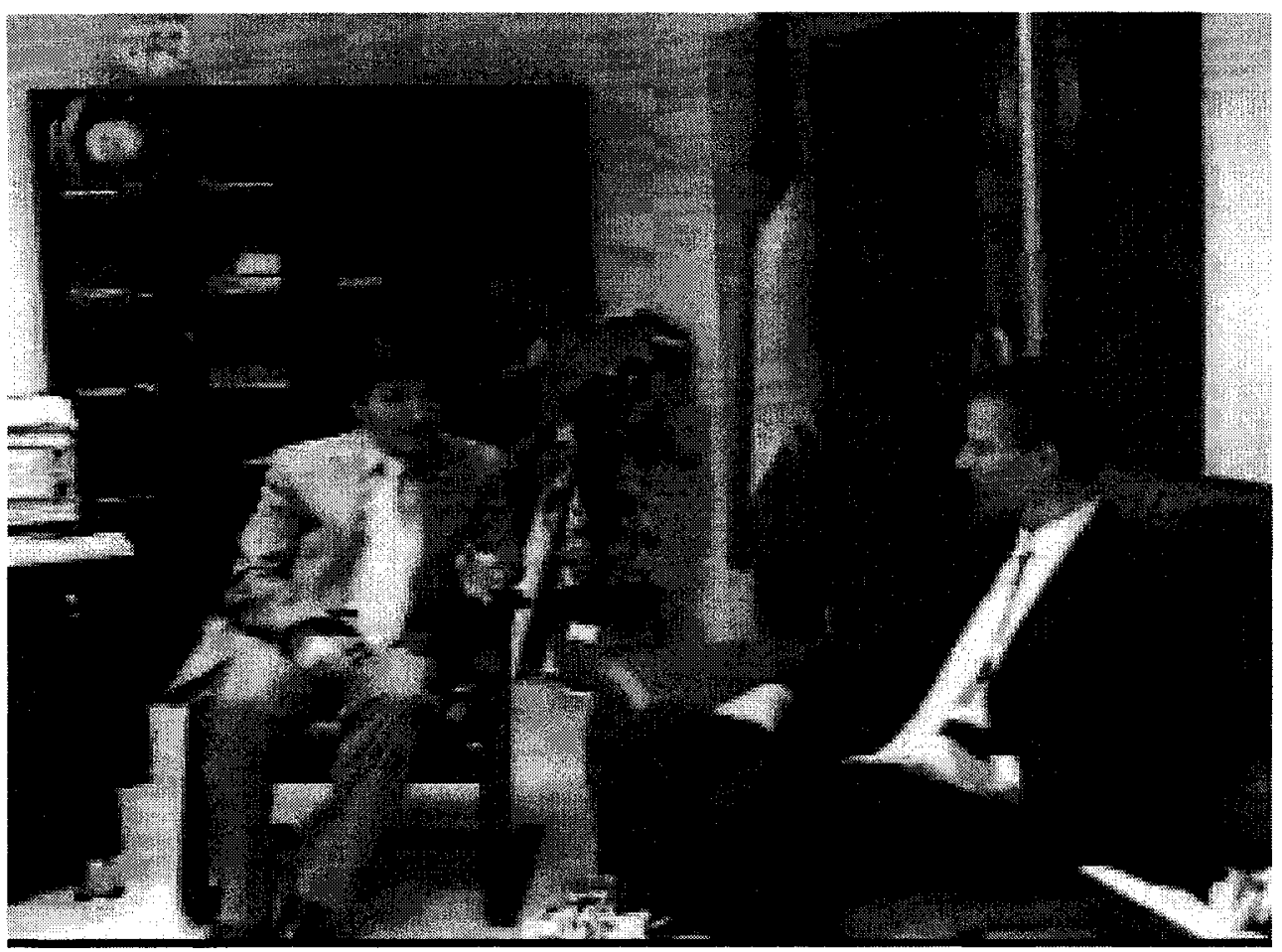

Figure 14 Screenshnot of KTV Sports News. Kurdish flag displayed in a sports center

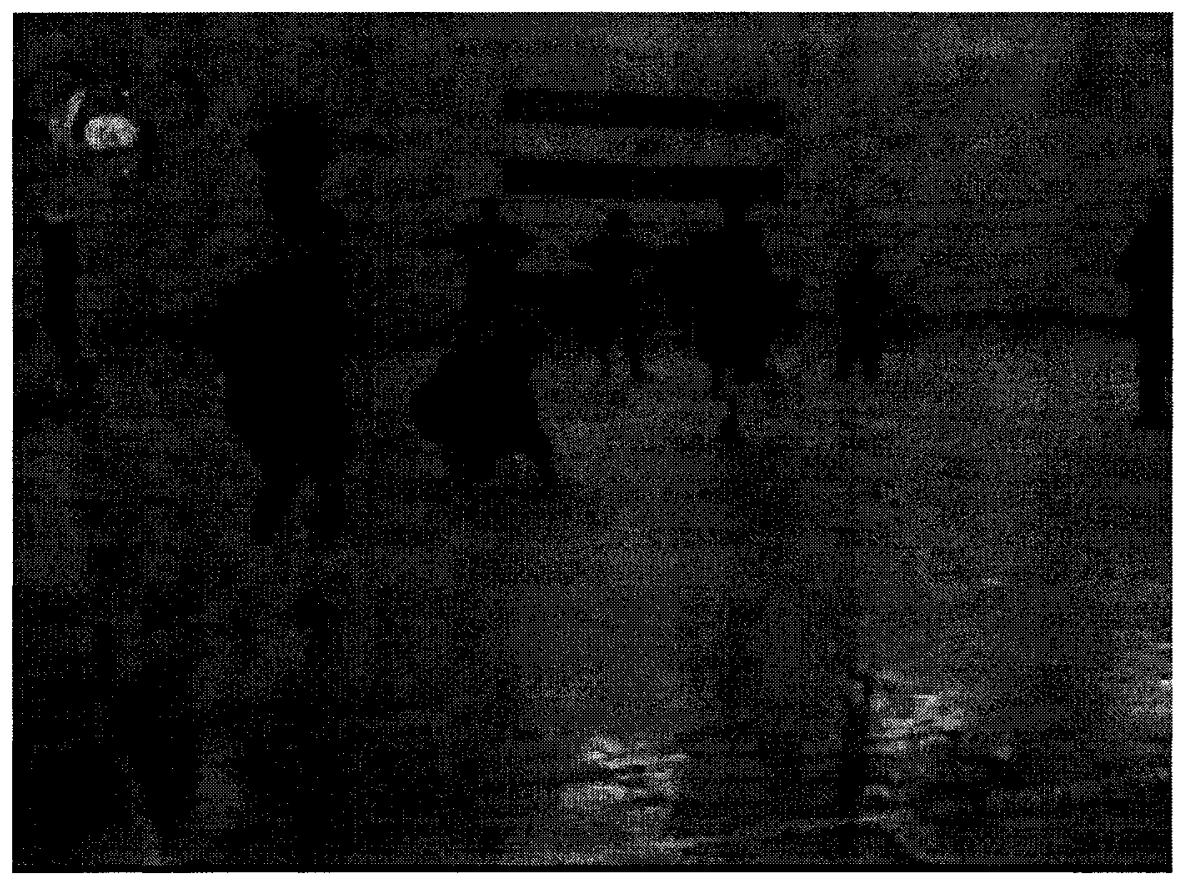


The Kurdish flag is waved freely on KTV every day and almost every hour. It is very rare to see a Kurdish politician or government official from KRG being interviewed on KTV without having the Kurdish flag displayed next to him or her (see Figure 13). The flag is shown waving outside KTV's studios' windows, and in the hands of people dancing whether at weddings or during picnicking. Judging by the discourse of KTV one one gets the impression that the Kurdish flag is waved everywhere and in every hand (e.g. Figure 14).

In addition to being waved and displayed overtly, the Kurdish flag is also reconstructed on KTV by imageries that solely or predominantly are made up of the four colours of the Kurdish flag: red, white, green and yellow. As Kress \& van Leeuwen (2002) note, "colour "means"" (p. 343). The meaning-making potential of colour, however, is generally culturally dependent. For example, when mourning, people in most of Europe and the Middle East wear black, but in northern Portugal brides wear black on the wedding day (ibid.). Colours which are known to people as being associated with specific concepts and events can invoke emotions and reactions.

In the late 1990 s, the city officials of Batman, a Kurdish populated town in Turkey, changed the traffic lights colours to red, yellow, and blue instead of green because green is one of the main colours of the Kurdish flag (see Hassanpour, 1998). In March 2007, eight students in Kurdistan-Turkey were dismissed from school for three days because they used the colours of the Kurdish flag in their artwork (Be hoy bekarhênanî ..., 2007). These colours, however, are used on KTV to reinforce the image of the Kurdish flag (see Figure 15). This is significant for two reasons. First, it reinforces 
the image of the Kurdish flag without having the actual image overused. Secondly, this implicit reconstruction of the Kurdish flag expands the semantic field of the Kurdish flag; many things in Kurdistan look like the Kurdish flag, or vice versa. This further naturalizes, and thus nationalizes, the colours of the flag and the flag itself. A part of being a Kurd or Kurdistani is to associate with this flag.

Figure 15 Screenshots from KTV's children's program and one of the station's logos displayed frequently
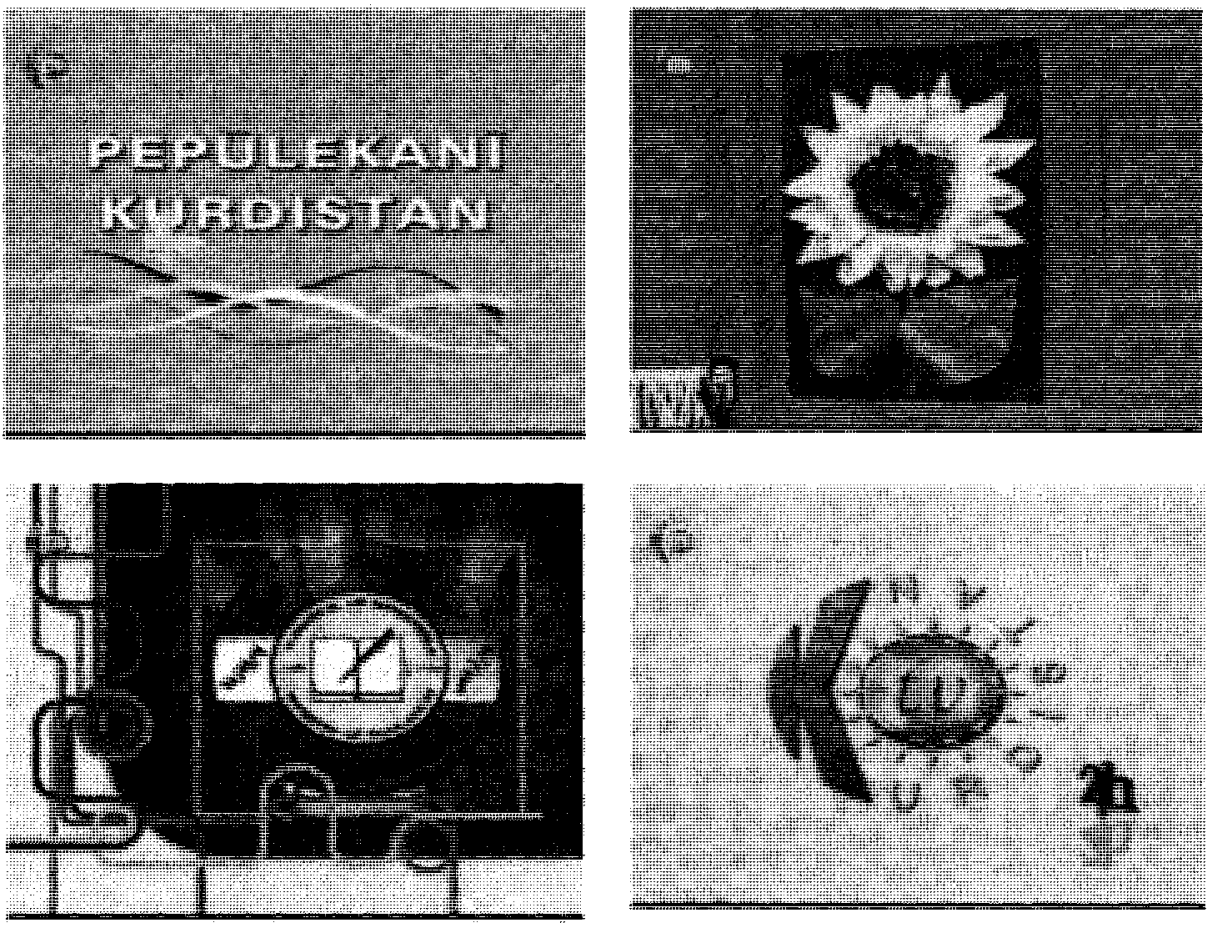

The Kurdish flag is also constructed, reinforced and legitimized through the rhetoric of us versus them. It is not only constructed discursively and popularized in the daily life of the Kurds by having a prominent presence on KTV but also legitimized by ways of not showing, and thus de-legitimizing, the flag of the "other," the Iraqi flag. For instance, on May 8, 2005, KTV broadcast a half-hour program called Alay Êraq [Iraqi Flag] with an explicit and clear message: "we need to throw away the Iraqi flag...We 
need to believe that this flag was buried along with Saddam Hussein's regime". ${ }^{170}$ In a similar vein, O’Leary \& Salih (2005) have noted that the Iraqi flag symbolizes "panArabism" and it is not "inclusive toward Kurds, Turkomans, Christians, or Jews" (p. 35). On KTV, the Iraqi flag appears as part of occasional news items about Baghdad, most of which are related to contested issues between Iraqi Kurdistan and the central government. The frequent display of the Iraqi flag in this particular show is an exception in which the flag of the "other" is constantly juxtaposed with scenes of the previous regimes' police and army abusing and persecuting Kurds. In sum, every nation has a flag, and in the absence of the Iraqi flag, the existence of the Kurdish flag becomes more legitimized and naturalized.

Mountainous landscapes, which are believed to be among the most distinct symbols of Kurdishness (Izady, 1992, p. 188; O'Sheea, p. 2004, p. 162), are common images displayed on KTV. If prior to the emergence of the new electronic media the mountains were among the decisive factors contributing to the cultural fragmentation of the Kurds, today their images serve to construct a common and shared attachment to the same homeland and territory: Kurdistan. The hilly landscape and mountains define the rural life in Kurdistan, as shown on KTV. It should be noted that a large portion of towns and villages of Iraqi Kurdistan, from the capital Hawler (Erbil) to the oil-rich city of Kirkuk, are located on flat lands. However, on KTV, it is the mountains that almost

\footnotetext{
${ }^{170}$ In September 2006, Masoud Barzani, the president of Iraqi Kurdistan issued a decree banning the current Iraqi flag flying over any government building throughout Kurdish region. The move was translated as Iraqi Kurds' bid for declaring independence from Iraq (Turkey wary as ..., 2006). In June 2007, an 80 square Kurdish flag was officially raised over the Kurdistan regional parliament instead of the Iraqi flag. It is important to note that the Kurdish authorities have only opposed raising the current Iraqi flag because they say it is reminiscent of the atrocities that were perpetuated by the previous regime against them (Kurdish flag hoisted ..., 2007). They have asked that Iraqi flag be changed in a way that it would represent Iraq's ethnic, linguistic, and cultural diversity.
} 
always define Kurdish rural life. It seems that the images of rugged hills, hidden valleys, inaccessible caves and defiant peaks symbolize Kurds' long history of struggle and resistance, most of which might have not happened without having the mountains as the strongholds of rebels. Mountainous landscapes connect like-minded Kurds.

Figure 16 Screenshot from a KTV show, Siruştî Kurdistan (Kurdistan Nature)

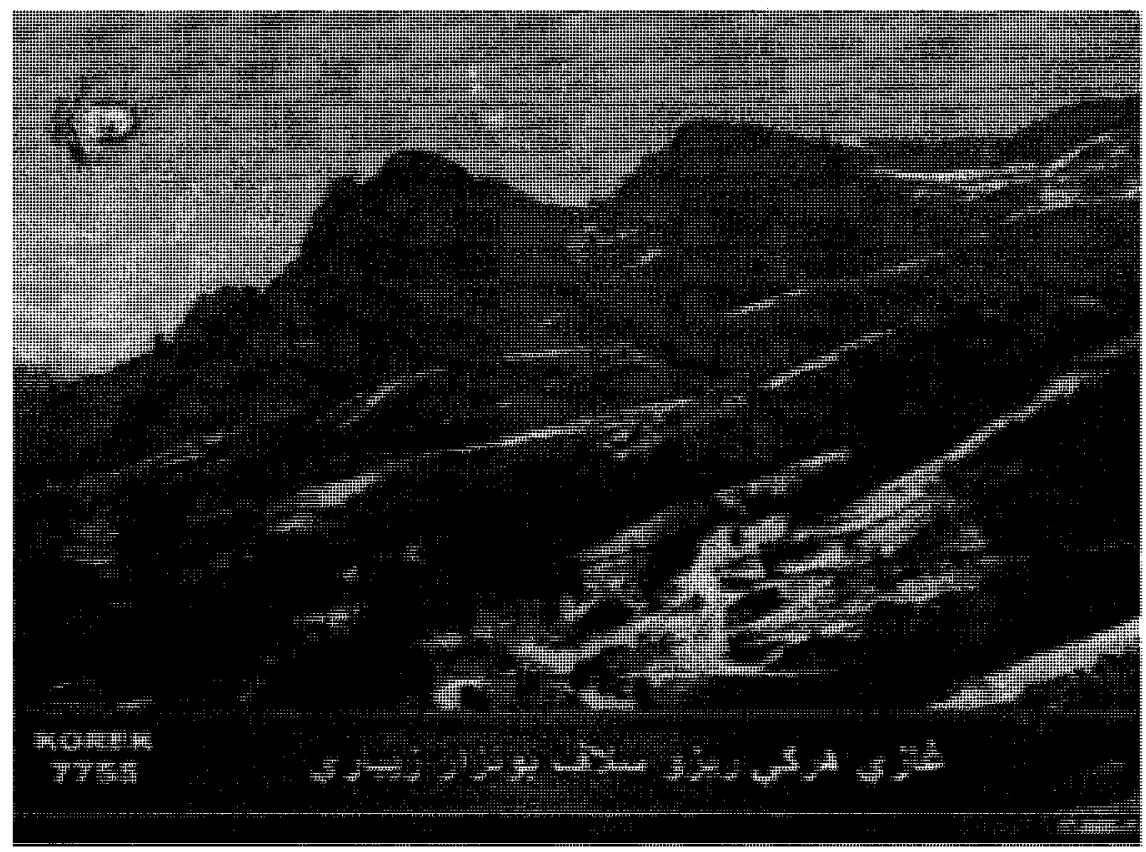

\section{Discursive construction of a common territory and homeland}

Whereas many Kurdish symbols such as the flag, mountains, dance, costume and various customs are explicitly displayed and glorified on KTV, the map or maps of the Greater Kurdistan is rarely shown. ${ }^{171}$ According to Kaiser (2002), "maps of the national homeland help to naturalize and historicize the images being created of the 'primordial

\footnotetext{
${ }^{171}$ Kurdistan does not have fixed and internationally recognized borders. Thus, there have been numerous maps of Kurdistan throughout history (O'Shea, 2004). Nonetheless, all the maps encompass territories within the countries of Turkey, Iraq, Iran, Syria and even Armenia.
} 
nation' and its intimate connection to the sacred soil of its ancestral homeland" (p. 233). The map of the Greater Kurdistan, however, could mean more than this (O'Shea, 2004, p. 186). It could also signify separatist and secessionist ambitions of Iraqi Kurds something that Kurdish leaders have continuously denied. ${ }^{172}$ What the map represents could be the reason for not overtly displaying it on KTV. However, as I will illustrate, the map is reproduced and reinforced instead implicitly and subtly, in both verbal and visual languages. The weather forecast is an interesting site for this semiotic construction.

The weather forecast in the mass media deserves attention because it has become one of the indispensable parts of the news in all forms of news media; people often rely on the weather forecast in their daily lives. Discussing the significant place of the news weather in the British banal nationalist discourse, Billig states,

'The weather' appears as an objective, physical category, yet it is contained within national boundaries. At the same time, it is known that the universe of weather is larger than the nation. There is 'abroad'; there is 'around the world'. These are elsewheres beyond 'our' elsewheres. The national homeland is set deictically in the central place, syntactically replicating the maps of the North Atlantic. All this is reproduced in the newspapers; and all this, in its small way, helps to reproduce the homeland as the place in which 'we' are at home, 'here' at the habitual centre of 'our' daily universe. (p. 117)

Here, I will show that KTV, twice every day, reminds its viewers of their homeland by redrawing the national boundaries of a greater Kurdistan.

\section{Deconstructing the verbal discourse}

In 2005, when reporting the weather, KTV reported the weather of Kurdistan and the rest of the world by presenting alphabetical lists of cities which consisted of two sets. The

\footnotetext{
172 "The maps of Greater Kurdistan have been accepted by Kurds for so long that they have now a power of their own, they have become an espoused political aim as well as a commentary on ethnicity, spatial perceptions (which may now need to be adjusted to fit the map), historical ambition, and irredentism" (O'Shea, 2004, p. 186).
} 
first set encompassed major Kurdish populated cities regardless of what nation-state they actually were located in. The second set included the rest of the world's capital cities including Ankara, Baghdad, Damascus and Tehran. As is evident in the following table, the cities that KTV believes to be Kurdish are presented as belonging to the same category and entity: home. In contrast, the capital cities of the host states (Baghdad, Ankara, Tehran and Damascus) are constructed, in Billig's terms, as abroad and elsewhere, like the rest of the world, different from home.

Table 4 A summary of the list of the cities as presented in KTV's weather forecast in August 2005

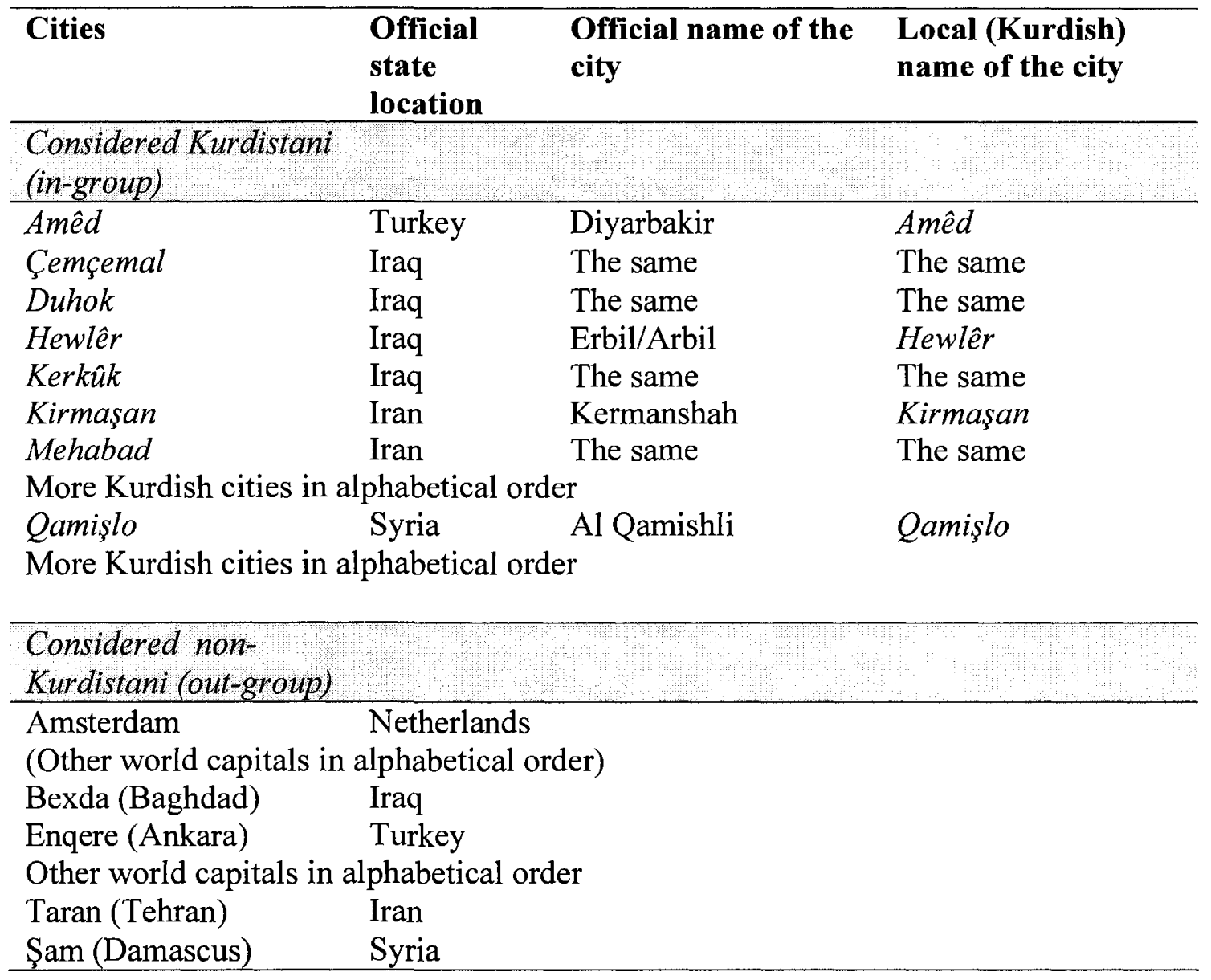


The Greater Kurdistan is mentally constructed also through renaming Kurdish cities. The states where Kurds live have employed both physical and symbolic violence to assimilate the Kurds as part of their modern nation-building projects (Hassanpour, 2003b, p. 116). One of the symbolic violent actions has involved changing, banning and regulating names of people, places, towns, villages, roads and even plants and animals that have borne signs of Kurdishness. For example, according to a BBC report, (Turkey renames ..., 2005), Turkey changed the name of three animals in its southeast (Kurdistan), because the authorities believed that names which made references to Kurdistan and Armenia were "divisive" and against Turkey's "unity". Motivated often by the same nationalist ideology, throughout Kurdistan, one occasionally comes across two names for some villages and towns: the name known to the locals and the name given by the officials of the host states. By choosing the local names of the towns that have two names, KTV reclaims their Kurdishness.

Since January 2006, the weather forecast on KTV has changed. It has become more visual and technically more sophisticated. A list of the cities is still used to report the weather of the world capitals. However, for Kurdistan and the region surrounding it, including the capital cities of the host states, more visuals and images are used. The construction of the map of the greater Kurdistan is still implicit, but, as I will illustrate, it is more visual and more powerful.

\section{Deconstructing the visual discourse}

The forecast for the region and Kurdistan is presented in three camera shots (see Figure 17). The first shot primarily captures the Middle East where the four host states are located. The shot also extends to parts of North Africa (down, left corner), Greece (up, 
left corner) and the Southern Caucasus (top), Afghanistan and Pakistan (right margin). Kurdistan is in the middle of that map, but for now it is invisible. It is important to note that the border lines that separate the host states and which run through Kurdistan are invisible on this map. One reason for that could be the fact that once these lines are drawn Kurdistan will be divided into four parts, something that would go against what this piece of discourse is trying to achieve: re-territorialisation of Kurdistan. The second shot is a close-up of parts of northern and western Kurdistan, incorporating parts of Turkey, Syria and Iraq. The third shot closely captures the southern and eastern parts of Kurdistan, which includes cities located in Turkey, Iraq and Iran. In doing this, KTV subtly, though never explicitly, redraws the map of the Greater Kurdistan.

Figure 17 Visual analysis of KTV's weather forecast

Shot I: A long shot of the region, Kurdistan and surroundings. Note that there are no border lines between the states, for if there were, Kurdistan would have been divided, as it were not.

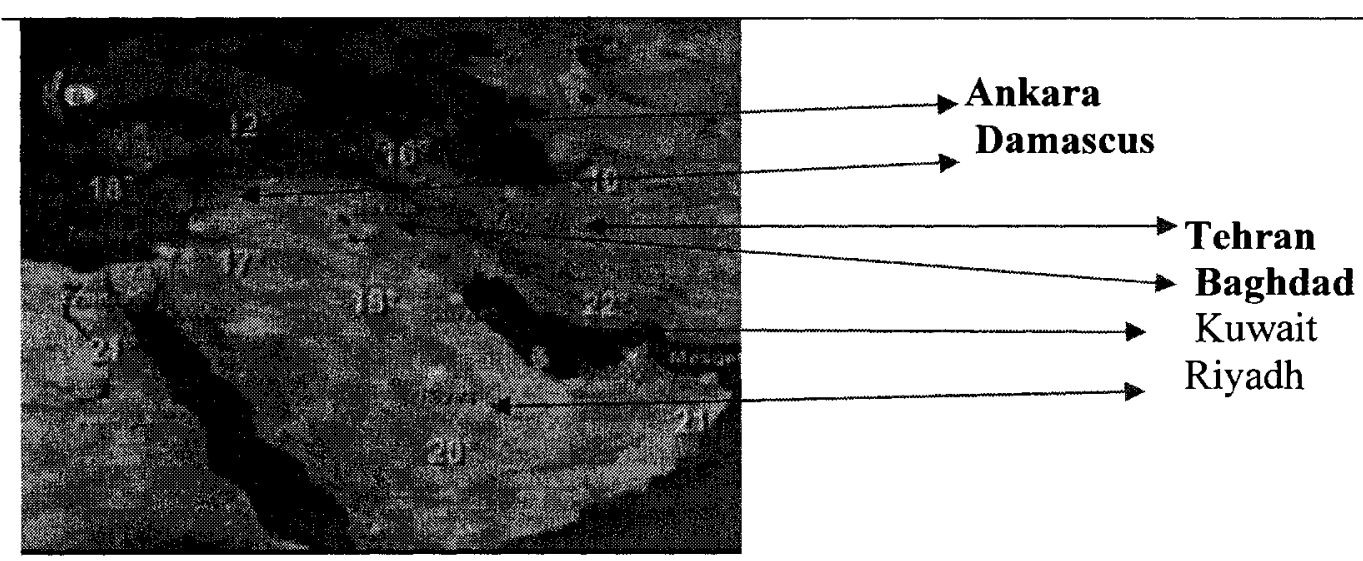




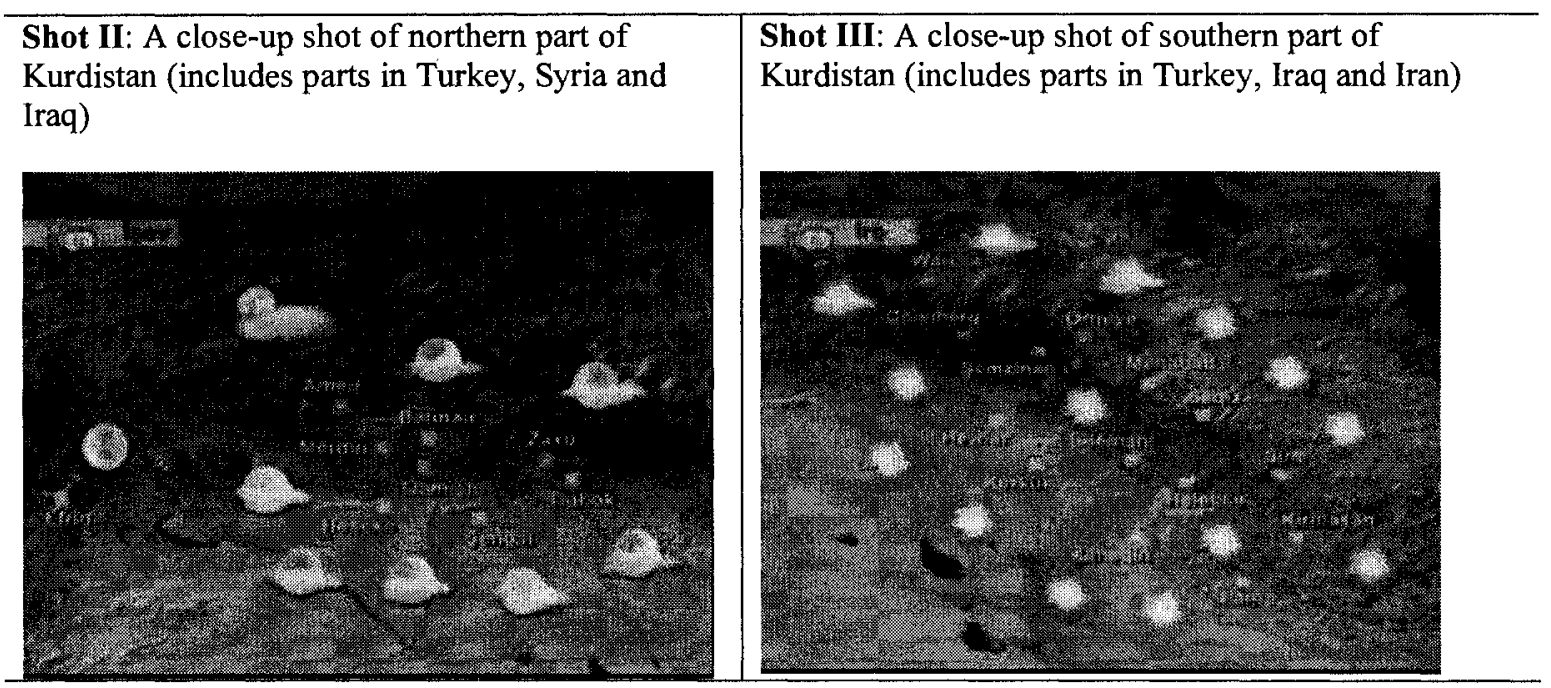

\section{Re-imagining the Greater Kurdistan}

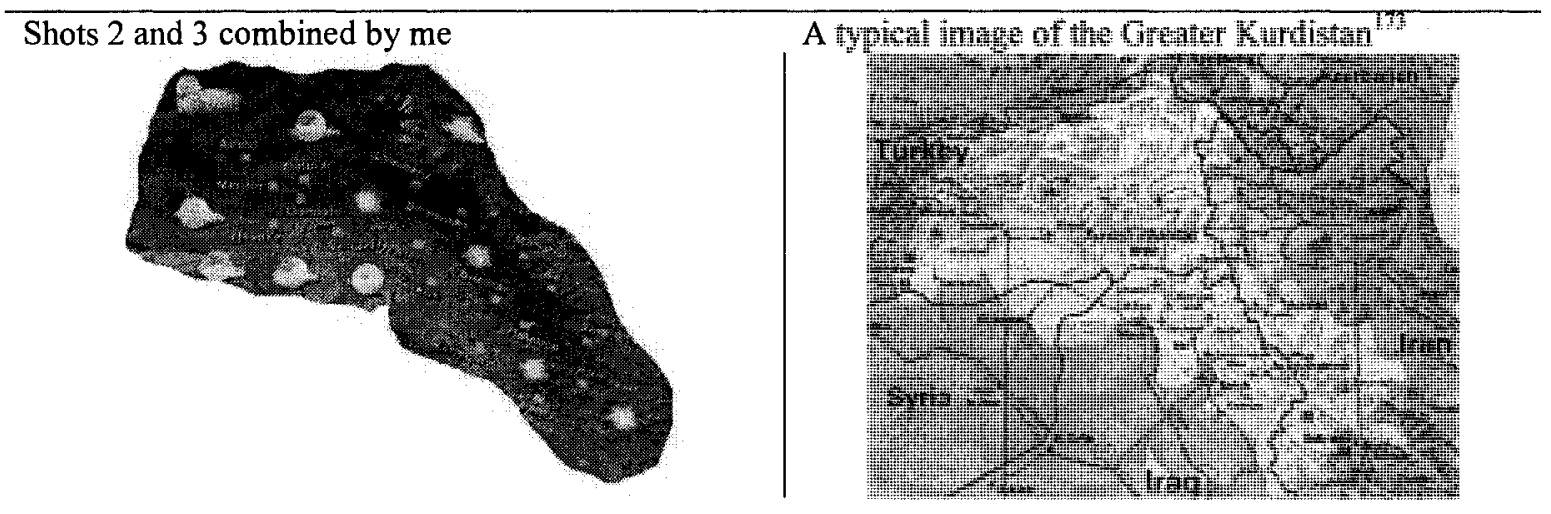

173 Adapted from the Perry-Castaneda Library, Map Collection, University of Taxes. Retrieved January 16, 2006, from http://www.lib.utexas.edu/maps/middle_east_and_asia/kurdish_lands_92.jpg 


\section{Chapter 10: Textual Analysis of a Patriotic Song}

In this chapter I analyze a patriotic song or what is called a patriotic anthem (Sirûdi Nîshtimanî) in Kurdish. I undertake a comprehensive multimodal analysis of the anthem to show in more detail the meaning-making potential of television discourse and the ways it contributes to the construction and reproduction of national identities.

Geisler (2005) observes that national anthems are "part and parcel of [the] myth of blood sacrifice typical of most nascent nationalist movements" (p. xxiv). The same can be said about patriotic and revolutionary songs particularly in times of struggle for national emancipation. They, too, are used to reinforce the idea of blood sacrifice in the name of the nation. Patriotic songs are among the most emotionally charged national symbols that contribute to the creation of national identities and nations. As Anderson (1991) says, "nothing connects us all but imagined sound" (p. 145). When disseminated through a mass medium such as satellite television, popular patriotic songs can engender "an experience of simultaneity," in the sense that they enable members of a geographically dispersed community whose members may never see each other face to face (ibid.), experience a shared sense of belonging to the same entity and at the same time.

The patriotic song Kurdistan has been one of the most frequently aired patriotic songs on $\mathrm{KTV} .{ }^{174}$ It has been aired in times of national crisis and other occasions when

\footnotetext{
${ }^{174}$ An obvious alternative to this text would have been Ey Reqîb or Ay Raghib (O Enemy), the Kurdish national anthem. But, Kurdistan TV does not air the anthem. In the past several years there has been much
} 
mobilizing Kurdish populations for action has been deemed necessary. ${ }^{175}$ Kurdistan is also one of the rare patriotic Kurdish songs featured on the Internet, for example on YouTube (see Figure 18). The lyrics of the song are by Ismail Khormali, a well-known contemporary Kurdish poet whose poems have been made into many songs by numerous Kurdish singers. The singer of this patriotic song, Zakaria Abdullah, who is commonly called by his first name, Zakaria, is a Swedish citizen who originally comes from Iraqi Kurdistan. He is one of the most, if not the most, popular Kurdish singers amongst the Kurdish youth in Iraq, Iran, Turkey, Syria and the diaspora.

My objective in analyzing this song is to illustrate the ways in which it contributes to the discursive and symbolic construction of a pan-Kurdish sentiment. I carry out a multimodal analysis of the music-video clip Kurdistan at three levels: verbal language (linguistic terms and concepts), visual images, and audio. Furthermore, I will underscore the importance of language choice in the song. Although the analytical tools used here have already been discussed, I find it useful to repeat them. I will also use this part of the analysis to introduce most of the analytical tools that have been used in this study in

debate about the status of Ay raghib. A group comprised of traditional nationalists view the anthem as sacred and intertwined with Kurdish national identity. This group believes that the anthem should be maintained as it is. At least two other groups disagree. Religious groups have complained that the lyrics of the anthem disrespect the religious beliefs of the vast majority of Kurdistan people. For example, one of the lines says, "Both our faith and religion are our homeland" (Dîniman u ayinman her nîshtiman). The second group believes that Ay Raghib is ethnocentric and does not represent Kurdistan's ethnic and linguistic diversity. For example, the first line, which is also repeated several times throughout the anthem, says: "O Enemy! The Kurdish-speaking nation is still alive" (Ey Reqîb! Her mawe qewmî Kurd-ziman). Also, there is resentment about the anthem's fictional history which aims to construct the Kurds as descendants of "Media" and "Keyxusrew." It has been suggested that new lyrics should be written for the anthem and there have been attempts to accomplish this task, for example by the prominent Kurdish poet Sherko Bekes in 2006. The intriguing debate over Ay Raghib continues. However, providing a full account of the issue is beyond the scope of this study.

${ }^{175}$ For example, during the parliamentary elections of 2005 in Iraq when Kurdish political parties were campaigning for have as many representatives as possible elected to the Iraqi National Assembly this song was aired on daily basis. It has also been aired at times of national crisis, for example whenever military threats, such as those by Turkey, against Iraqi Kurdistan have been portrayed as imminent. 
addition to showing the relations between different modes of discourse (verbal language and audio-visual). The transcription of translated lyrics and a description of images and music of the song are provided in Table 7.

Figure 18 Screenshot of the song Kurdistan featured on YouTube, Retrieved 2007-07-12 from http://www.youtube.com/watch?v=fN1S_hvQwCc

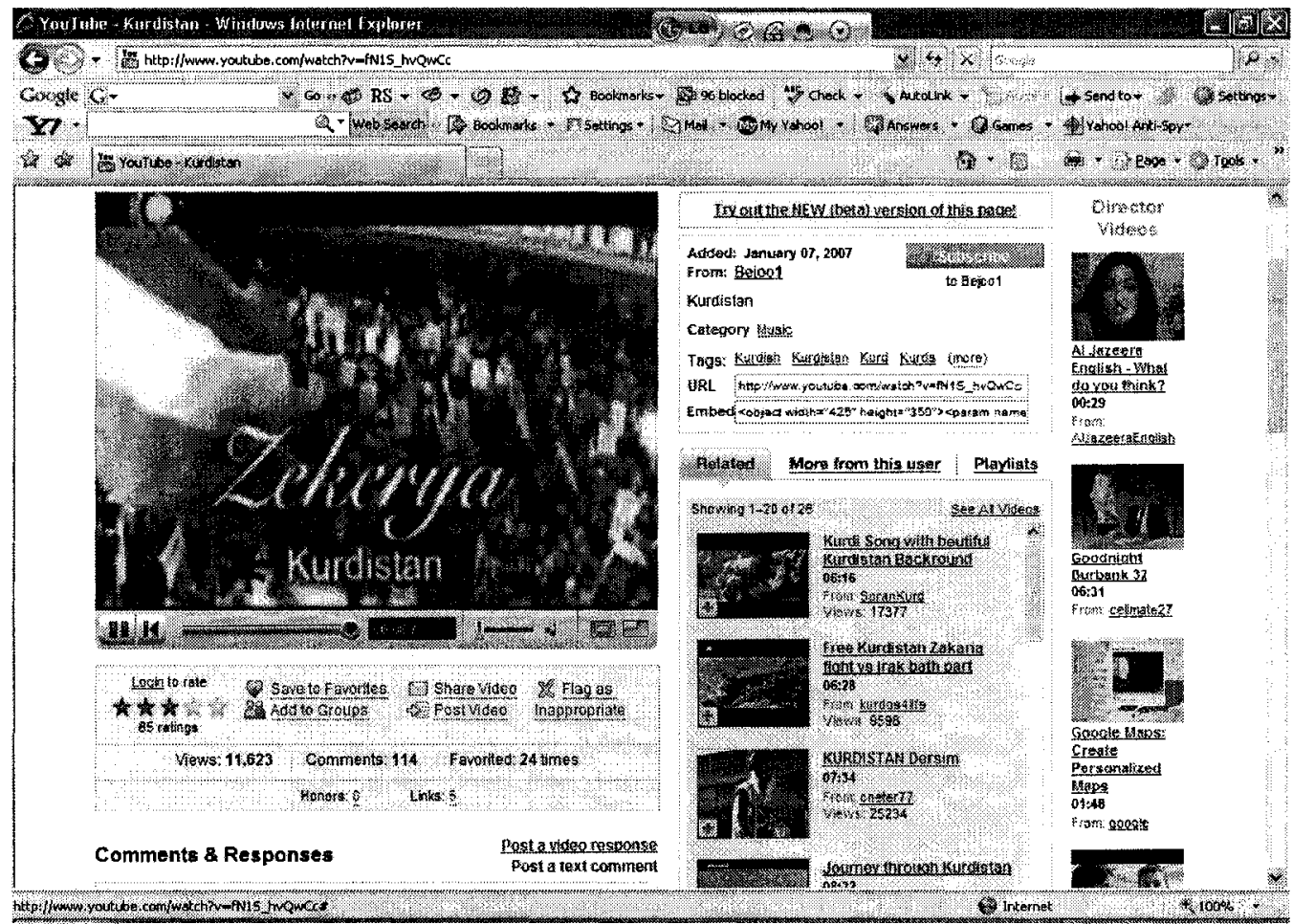

\section{Verbal language}

\section{Naming practices}

Different names, titles and labels given to people, objects and concepts, indicate the attitudes and beliefs of the speakers and writers towards them (Kress \& Fowler, 1979, p. 200). Names not only identify but they could also define things and people; they not only indicate the degree of intimacy with but also distance from people, places and things. Studying the use of naming in the addresses to the nation in Poland, Galasiński \& Skowronek (2001) observe that the practice did not just enable politicians and religious 
leaders to refer to places and persons; the speakers used specific naming also " to construct an ideologically preferred reality. Proper names were used to serve the political purpose of the day" (p. 63).

When it comes to the discourse of national identity, naming the nation and what are believed to be national characteristics and symbols are among the prime naming practices. Billig (1995) says, "Somehow, in ways difficult to articulate, the magic of 'our' name matters to 'us' deeply, whichever nationality 'we' are: it indicates who 'we' are, and, more basically, that 'we' are. In the secular age, the name of the nation is not to be taken in vain" (p. 73, emphasis in original; see also Shnirelman, 2006; Nicolaisen, 1990). For Bourdieu (1992), naming oneself is "the typically magical act through which the particular group - virtual, ignored, denied, or repressed - makes itself visible and manifests, for other groups and for itself, and attests to its existence as a group that is known and recognized" (p. 224). Clearly, naming practices have been indispensable parts of discourses of nationalism. Discussing naming practices in the nationalist discourses of the Québécois and Aboriginal peoples in Canada, Henson (1993) states, "[n]ationalist movements are social movements involved in the definition of a collective identity; they make choices about names" (p. 337).

In the patriotic song, Kurdistan, naming is a significant discursive tool that contributes to the imagination of a collective Kurdish identity and the Greater Kurdistan. The most significant naming practice pertains to the word Kurdistan, which is literally translated as "the land of the Kurds." The states straddling Kurdish territories do not recognize Kurdistan as a distinct territorial unit encompassing parts of Turkey, Iraq, Iran and Syria. In Turkey, for example, the use of the term Kurdistan, regardless of what one 
might mean by it, is illegal and can be considered an act of separatism and thus punishable. Numerous researchers and ordinary people, Kurdish or non-Kurdish, travelling to Iraqi Kurdistan through Turkey, have reported that their documents and laptops have been searched by Turkish border guards for the word 'Kurdistan'. They have been asked to delete instances of the word from their documents and equipment (O'Leary \& Salih, 2005, pp. 3-4). In other cases, documents containing the word have been destroyed altogether. ${ }^{176}$

In this anthem, the word Kurdistan is at the focal position of the title of the song, which is aired on a TV channel called Kurdistan TV. Furthermore, throughout the anthem, which is about five minutes long, the word Kurdistan is repeated ten times. Thus, in addition to naming, repetition also plays an important role in expressing the writer's or singer's strong feeling and belief about his choice of the naming.

But, does the word Kurdistan, in this song, only refer to Iraqi Kurdistan or the Greater Kurdistan, and how can we know this? We can infer from the lyrics and choices of naming that the Kurdistan imagined here is the Greater Kurdistan. The singer assures [Iraqi] Kurdistan that all the Kurdistan regions and towns are with her. Among these are cities and regions that are officially located in Iran, Syria, and Turkey:

\footnotetext{
${ }^{176}$ Ahmad Askandari, an Iranian Kurdish social activist, who is also a Swedish citizen, tells a compelling story in an interview with the Swedish Radio International, Kurdish Service (Sina, 2005). In 2005, Mr. Askandari was invited to the Iraqi Kurdistan to attend a festival held by a women's forum promoting equity and equality in Kurdistan. He was awarded a special trophy by the forum for his activism in promoting Kurdish women's rights. On his way back to Sweden, at a Turkish checkpoint on the Iraqi-Kurdistan and Turkish border Turkish border guards search his belongings. As told by Askandari, the border guards destroyed the only Kurdish newspaper he had brought with him from Kurdistan. They made it clear to him that they did that because the newspaper contained the word "Kurdistan." Askandari describes vividly how the soldiers became "hysterical" when they saw the word "Kurdistan" also written on the trophy, a framed artwork, which he received from the women's forum. The trophy bore the phrase Projy Yeksanî, Hukumeti Herêmî Kurdistan (Equality Project, Kurdistan Regional Government). Now the word Kurdistan did not just denote a geographical location but a political entity, a Kurdish government, as well. Askandari recalls how the soldiers shouted: "We have told you people not to bring these things to our country. There is no such a thing as Kurdistan." The soldiers "violently," under their boots, trampled the trophy (Sina, 2005).
} 
Line 10 You will never give in since your Baban and Badinan are with you

Line 14 We swear by Nawroz, the glorious uprising, and by your hundredsyear long history

At first glance, it seems that the lyrics are only saying that these cities and regions are in solidarity with the Iraqi Kurdistan. However, the use of the possessive pronoun "your" leaves no doubt that these places are imagined as belonging to the same territory: the Greater Kurdistan. The identity that is constructed is a pan-Kurdish identity rather than a regional, Iraqi Kurdish one. This pan-Kurdish identity is not only constructed through unifying all the places that are believed to be Kurdistan, from a pan-Kurdish nationalist perspective, but also through separating these places from the states of which they are officially a part (i.e. Turkey, Iraq, Iran, Syria). Similar to all nationalist discourses, this song not only represents the discourse of in-group solidarity but also the discourse of outgroup differentiation.

Table 5 Naming as reuniting Kurdish towns and regions regardless of the states they are parts of

\begin{tabular}{lll}
\hline Line & Named region and city & $\begin{array}{l}\text { Official location } \\
\text { (state) }\end{array}$ \\
\hline 10 & Baban (region) & Iraq \\
10 & Badînan (region) & Iraq \\
11 & Germian (region) & Iraq \\
11 & Hewlêr (Erbil) (capital city of KRG) & Iraq \\
12 & Efrîn (town) & Syria \\
12 & Mehabad (town) & Iran \\
13 & Qamîshlî (town) & Syria \\
14 & Mardîn (town) & Turkey \\
\hline
\end{tabular}

With respect to naming practices, it is also important to note that the word Kurd/Kurds is used only once, in conjunction with the word Kurdistan, which is used eleven times. This is in a sharp contrast to the Kurdish national anthem, Ay Raghib or Ey 
Reqîb (O Enemy), written in the late 1930s, which constantly repeats the word

Kurd/Kurds but makes no mention of the word Kurdistan. This difference marks a discursive shift in the Kurdish nationalist discourse, particularly in Iraqi Kurdistan, where words like "Kurdistan," "Kurdistanis," and "the people of Kurdistan" have started to be used by the KRG officials and their media instead of the words Kurd or Kurds. This is especially evident in the speeches given by the Kurdish leaders such as Masoud Barzani. This could have two important sociocultural implications. The word Kurd/Kurds identifies an ethnic group (Kurds) whereas Kurdistan identifies a territory with its entire people which could be made up of more than one ethnic group. Thus, whereas the use of the word Kurd/Kurds could for the most part contribute to the reproduction of an ethnic group, the use of the word Kurdistan contributes to the construction of a territorial nation that combines more than one ethnic group who share the same land, Kurdistan. The two choices can also be interpreted as belonging to different kinds of nationalism, ethnic versus civic. There is a deliberate attempt to acknowledge the existence of other ethnic groups in Kurdistan. ${ }^{177}$ One could also suggest that this discursive practice expresses KRG's ambition for more territorial and political autonomy.

\section{Pronouns}

As Fowler \& Kress (1979) suggest, "personal pronouns always deserve notice" (p. 201; see also Wodak et al., 1999; Higgins, 2004). Personal pronouns have proven very fruitful in analyzing discourses of national identity. Billig (1995) observes that "nationalism is,

\footnotetext{
${ }^{177}$ Khaled Salih, the spokesperson for KRG in 2006, in a joint article with O'Leary writes: “...Kurdistan and its parties are ... as civic nationalist in disposition as the English, French, Danes, and Arab liberals, and unlike the latter they have proved themselves to be such in government. Within Kurdistan, minority rights in language, schooling, and religion have been protected. All citizens ... are equals and treated as such. Kurdistani is not synonym with Kurd ..." (O’Leary \& Salih, 2005, p. 34).
} 
above all, an ideology of the first person plural. The crucial question relating to national identity is how the nation 'we' is construed and what is meant by such construction" ( $p$. $70)$.

In the song Kurdistan, several pronouns are used: "we," "you," and "them." The "we" pronoun is inclusive, including the singer and the people of Kurdistan who are overtly presented in the visual images: the crowed on the street protesting, Peshmarga or Peşmerge ("Kurdish freedom fighters"), college students, newly trained Kurdistan military, and Kurdistan parliamentarians. There are eleven instances of "we" and seven instances of the corresponding possessive pronouns ("our," "ours"). Thus, the findings here are consistent with other studies that have identified "we" as the most prominent pronoun contributing to the construction of solidarity and unity in a nation (Billig, 1995; Wodak et al., 1999).

The use of "you," however, in this anthem, is not so straightforward. Fowler \& Kress (1979) tell us that "'you" is, as might be expected, complementary in meaning and usage to "I/we"; as every piece of language has an explicit or implicit source, so does it have an implicit or explicit addressee" (p. 203). The challenge in this anthem is that there are two addressees, Kurdistan and the "other" (e.g. 'tyrants'—enemies of Kurdistan). It appears that Fowler \& Kress (1979) has realized this complexity with the usage of "you" since they are quick to suggest that "'you' needs to be discussed in the context of speech acts performed upon an addressee" (p. 203).

In the context of this anthem, "you" and its corresponding possessive "your" refers to Kurdistan (lines 7-14, 16-18, 25-28) and at other times refers to the "out-group" (e.g. "tyrants") (lines 22, 23). 
Line 7 For your sake we will remain vigilant Kurdistan!

Line 8 Our existence is your existence, and your existence is ours!

Line 9 We'll sacrifice our lives for your existence and freedom Kurdistan!

Line 10 You will never give in since your Baban and Badinan are with you

Line 11 Every stone and tree of your Germian and Hewler are with you

Line 12 You will never give in since your Afrîn and Mehabad are with you

Line 13 The people of your Qamîshli and Mardîn are with you Kurdistan!

Line 14 We swear by Nawroz, the glorious uprising, and by your hundredsyear long history

Line 16 We will never forget you Kurdistan, you are in our hearts

Line 17 You are our breath, you are our existence

Line 18 Do not worry, we will never allow them to burn down this spring of yours

Line 19 We will never allow them [to] hurt the already anguished mothers of martyrs, Kurdistan!

Line 20 The tyrants must never think of staying in our land; it will be their dream

Line 21 No matter how many palaces you built in our mountains, Kurdistan is not yours

Line $22 \quad[\mathrm{X}]$ enophon and Alexander the Great tried before you, but failed and left

Line 23 Your conspiracies will fail

Line 25 Raise your head Kurdistan, Kurds are now united and strong

Line 26 Your children are ready to defend you

Line 27 Nobody can prevent you from smiling and living

Line 28 We'll sacrifice our lives for your existence and freedom Kurdistan! Kurdistan!

Why is the "other" not just referred to as "they" or "them" as is the case in line 20 or "their" in line 21? One reason for that might be the fact that most of the anthem has a confrontational theme. As discussed earlier there is a strong presupposition from the beginning of the anthem that Kurdistan had been treated badly previously and now it is under threat and thus it needs to be defended against "tyrants." The image of a strong Kurdistani people who are ready to stand up to the threat is built both linguistically and visually throughout the anthem. Thus, addressing the "other" as "you" instead of "them" or "they" in a few occasions could be intentional to illustrate that the Kurds are resolved 
and ready to confront the "tyrants." This comes out clearly through some of the lyrics (e.g. lines 19-28).

In addition to the confrontational "you," and direct naming choices such as "tyrants," the out-group is also referred to as "them," for example in lines 19 and 20.

Line 19 We will never allow them [to] hurt the already anguished mothers of martyrs, Kurdistan!

Line 20 The tyrants must never think of staying in our land; it will be their dream

Whereas the inclusive "we" and the solidarity "you" (addressing the homeland) serves constructing a we-group, the confrontational "you" and 'them' pronouns construct a them-group. Nonetheless, they are all contributing to the construction of a distinct Kurdish identity.

\section{Tense}

Another central component of the modal function of language is tense (Fowler \& Kress, 1979 , p. 207). According to Fowler \& Kress, different uses of tense are neither arbitrary nor neutral; they indicate different orientations toward the phenomena that are talked or written about. For example, present tense "signals certainty, unquestionableness, continuity, universality" (p. 207). Fairclough (2001), in a similar vein, suggests that the simple present tense form "is one terminal point of expressive modality, a categorical commitment of the producer to the truth of the propositions" (p. 129). Dunmire (1997) cites Fleischman asserting that "the greater the likelihood that a situation will be realized, i.e. the closer to 'reality' the speaker perceives it as being, the closer to 'now' (=present) will be the tense used to represent it" (p. 234). In contrast, the past tense will be used when things are desired to remain in the past and not to be of current concern. As Fowler 
\& Kress suggest, "Temporal 'distance' nearly always conveys modal 'distance"” (1979, p. 207).

In the song Kurdistan, most of the utterances are structured either in the simple present tense or their verbs are accompanied by the modal auxiliary "will" which is indicative of the continuity of the nation into the future. In contrast, events of the past are often implied rather than presented in the past tense. For example, line 2 (i.e. Listen to the tombstone and grave of the martyrs that are calling) refers to martyrs who are clearly gone, but interestingly enough, according to the lyrics, they are still alive, still defending Kurdistan, because their verbal action of "cry" is in the simple present tense. Mountains "cry" presently as well, as in line 3 : Listen to the heart and chest of your mountains that are calling. All parts of Kurdistan, located in four nation-states, "are with [the homeland]" presently (lines 10-13):

Line 10 You will never give in since your Baban and Badinan are with you Line 11 Every stone and tree of your Germian and Hewlêr are with you Line 12 You will never give in since your Afrîn and Mehabad are with you Line 13 The people of your Qamîshlî and Mardîn are with you Kurdistan!

Line 25 illustrates the strongest expression of a Kurdish patriotic nationalist discourse which declares that "Kurds are united and strong now." While the utterance presupposes that the Kurds were weak before, because they were disunited, through the use of the expressive modality cue of "are" and the time adverb "now" the continuity of the nation is expressed with great certainty.

Next to the simple present tense, another primal grammatical element of modality that is used in this anthem is the modal auxiliary "will" (lines $6,7,9,10,12,16,18,19$, $20,23,28)$. It can express certainty and self-assurance about both present and future 
situations and events. For example, in lines 10 and 12 (and by extension, through ellipses, in lines 11 and 13) it is an expression of self-assurance that Kurdistan "will never give in" since other parts of Kurdistan (Iran, Turkey, Syria) are "with" the Iraqi Kurdistan. This way, the auxiliary "will" contributes to the imagination of a greater Kurdistan as a common goal for all Kurds regardless of which state they live in. But, "will" can also signal willingness, with a high degree of probability, on the part of a speaker to embark on an action; it declares a serious promise (e.g. lines 6-9, 16, 18, 19):

Line 6 We will be in the front lines and defend you Kurdistan!

Line 7 For your sake we will remain vigilant Kurdistan!

Line 8 Our existence is your existence, and your existence is ours!

Line 9 We'll sacrifice our lives for your existence and freedom Kurdistan!

Line 16 We will never forget you Kurdistan, you are in our hearts

Line 18 Do not worry, we will never allow them to burn down this spring of yours

Line 19 We will never allow them [to] hurt the already anguished mothers of martyrs, Kurdistan!

In these lines, the patriotic loyalty to the motherland is renewed by promising to

Kurdistan that it will be protected against the "tyrants." In addition to a promise, "will" also seems to be a declaration of threat against the "tyrants." This way "will," on the one hand, contributes to the imagination of a common present and future among the in-group members, and on the other hand, it contributes to the construction of the out-group.

\section{Metaphors}

According to Lakoff \& Johnson (1980), "the essence of metaphor is understanding and experiencing one kind of thing in terms of another" (p. 5, see also Fairclough, 2001, p. 119). For example in the sentence, he spends time with her family, English speakers understand the importance of time in terms of their common understanding of the value of money which can also be spent, saved or wasted. A crucial point to be raised here is 
that there is no apparent connection between time and money, but what brings them together is the perception which is based on cultural assumptions and also feelings that are mostly shared between humans from the same culture. On the importance of metaphor in our discursive practices, Lakoff \& Johnson (1980) state that, "Since much of our social reality is understood in metaphorical terms, and since our conception of the physical world is partly metaphorical, metaphor plays a very significant role in determining what is real for us" (p. 146). In other words, we understand the world and conceptualize reality in part in terms of metaphors. As Wodak et al. (1999, p. 44) illustrate, metaphors play an important role in "the mental construction of nation" by implying in-group "sameness and equality," on the one hand, and out-group differences and inequality, on the other. Finally, it is also important to note that metaphors are context and culture-sensitive. For example, the expression time is money might be quite alien to another culture where people are less preoccupied with time. The cultural and context sensitivity of metaphors have implications for the study of the discursive construction of national identity. Metaphors that contribute to the formation of imagined communities could be different from one context to the next.

There are different kinds of metaphors one of which is personification. According to Wodak et al. (1999), "Personification attributes a human form to an abstract entity and thus constitutes a widely-used mean of realizing a constructive strategy, demanding, for example, identification with an anthropomorphized nation" (p. 43). Drawing on Michael Billig, Chouliaraki observes that "Personification and the concomitant attribution of intense human feelings to the nation metaphorize relations within the nation as 
relationships of kinship, of family, thus further forging a sense of imagined community among its members (Chouliaraki, 1999, p. 49). ${ }^{178}$

In the song Kurdistan one of the prominent personification metaphors employed is family, as in "Your children are ready to defend you [Kurdistan]" (line 26). In Kurdish, the homeland is female and a mother, and it is commonly referred to, particularly in patriotic poems and songs, as Daykî Nî̀shtiman or Daykî Weten (the motherland), as is the case in many other languages (Wodak et al. 1999, p. 45). In some other languages one can speak of the fatherland, but this is never the case in Kurdish. In this song, the homeland is personified as a mother who is dearly loved: "We will never forget you Kurdistan, you are in our hearts" (line 16), "you are our breath, you are our existence" (line 17). In order to show their love for their motherland, many of her children (martyrs) sacrificed themselves for her "freedom" (lines 2, 19), and now more children, according to the song, are willing to do the same (line 26):

Line 2 Listen to the tombstone and grave of the martyrs that are calling Line 19 We will never allow them [to] hurt the already anguished mothers of martyrs, Kurdistan!

Line 26 Your children are ready to defend you

In order to convince the "children" to "sacrifice" their lives for the motherland, it is essential to make them believe in two things. First that the motherland is like their mother, that they love her wholeheartedly and that without her they will be orphans and

${ }^{178}$ On the importance of family metaphor, Bloor \& Bloor (2007) state: "just as the family metaphor has been used to express solidarity and inspire unity, it has also been widely applied, sometimes explicitly, to reject other groups (p. 76) ... Lexical items are important here [e.g. brother, children, sister, father, mother] because their use trigger[s] conceptual image: the family as a self-contained group of loving and mutually supportive members united against the outside world" (p. 77). 
homeless. And, second that the existence of the homeland, the mother, is threatened. The motherland needs to be defended. The very suggestion that Kurdistan needs to be defended presupposes the existence of a continuous threat against Kurds and Kurdistan.

\section{Presuppositions}

A presupposition is "a proposition that is tacitly assumed to be true for another proposition to be meaningful"' (van Dijk, 1993, p.251). A presupposition is an assertion that is implied rather than explicitly and overtly stated. Consider this example from van Dijk (1993, p. 256) which had originally appeared in a British paper: “... we have to be more brisk in saying no, and showing the door to those who are not British citizens and would abuse our hospitality and tolerance" (my emphasis). In this example, it is presupposed that the British are "hospitable" and "tolerant," and therefore, claims of mistreatment that might be put forward by minorities become irrelevant and unfounded. In situations like this, presuppositions can be "manipulative" and ideological, although there are other times when they can be "sincere" (Fairclough, 2001, p. 154). In this example from van Dijk, and elsewhere, however, presuppositions can be ideological when "what they assume has the character of "common sense in the service of power" (ibid.). In addition to their ideological significance, presuppositions also deserve attention in discourse analysis because they are crucial features of the intertextuality of texts (Fairclough, 1995a, p. 14). In other words, presuppositions are features of texts that have been constructed before, in other times and in other texts but, nonetheless, they have become integrated parts of the meaning-making structure of the text in question.

In the song Kurdistan, there are several presuppositions that work towards crafting the Kurdish nationalist discourse. One that I have already alluded to is that 
Kurdistan is threatened today as it has always been: "we will never allow them [to] burn down this spring of yours" (line 18), "we will never allow them [to] hurt ..." (line 19), and "nobody can prevent you from smiling and living," (line 27). The presupposition that Kurdistan is threatened legitimates the song's proposition that it needs to be defended, it needs to be loved, and more lives should be sacrificed for its sake. The proposition that Kurdistan should be defended is also strengthened by two other presuppositions in lines 18 and 27, which I just quoted. That Kurdistan, which entails Iraqi Kurdistan here, is free, lives in its spring and is "smiling." Given the long history of Kurdish oppression, it will be such a shame not to protect this "free Kurdistan."

The other presupposition is that Kurdistan is ancient and it has a proud past: "we swear by ... hundred-year long history" (line 14), and “...hundreds of years [of] freedom" (line 15). The presupposition that Kurdistan has existed for hundreds of years and that it has been free in the past works towards legitimating the proposition that Kurdistan deserves to exist not only now, and in the future, but also to be free, again. Side by side with this discursive construction of a free Kurdistan in the past, we can detect presuppositions that work around the construction of a not very distant past when Kurdistan was occupied, oppressed, disunited and weak: "the tyrants must never think of staying in our land" (line 20), "no matter how many palaces you built in our mountains, Kurdistan is not yours" (line 21), and "raise your head Kurdistan, Kurds are now united and strong" (line 25).

\section{Overlexicalization}

Overlexicalization (Fowler \& Kress, 1979, p. 211) or "overwording" (Fairclough, 2001, p. 115) refers to a high level use of words and lexical items that are synonymous, near- 
synonymous or semantically close enough to contribute to the construction of an idea, theme and point of preoccupation. As Fowler \& Kress assert, for a critical analysis of discourse it is important to consider overlexicalization because this linguistic tool "points to areas of intense preoccupation in the experience and values of the group which generates it, allowing the linguist to identify peculiarities in the ideology of that group" (Fowler \& Kress, 1979, p. 211-212). ${ }^{179}$ Clustering the lexicon of this song into several categories which are often parts of nationalist discourses allows us to map out some important peculiarities of the Kurdish nationalist ideology that is represented in this song (Table 6).

As shown in Table 6, using this analytical tool of over-lexicalization, we can tease out the lexical elements that effectively realize some of the core concepts of the Kurdish nationalist discourse. They are: common present and future, common memory and history (ancient history, glorious past, sufferings of the past), common territory, common national characteristics (love of the homeland, unique Kurdish traits, equating the nation with the family), invented traditions and shared symbols, solidarity and unity, and finally differences with others. Some of these invented traditions and symbols (e.g. flag and so on) are expressed more clearly and frequently in the visual images, which I will turn to shortly.

The verbal language in this text contributes to the construction of an imagined Kurdistan community that is ancient, has a glorious past, but then it was occupied, divided and oppressed. The verbal language also aims at conveying the message that

\footnotetext{
${ }^{179}$ Fairclough (2001) calls this analytical tool overwording and defines it as "an unusually high degree of wording often involving many words which are near synonyms. Overwording shows preoccupation with some aspect of reality—which may indicate that it is a focus of ideological struggle" (p. 115).
} 
although the threat against Kurdistan continues, there is no worry because its loyal children are ready to defend it by risking their lives as they have done in the past. Kurdistan is stronger than ever, because its people are united now, they are proud of their recent freedom in Iraqi Kurdistan, and they are hopeful of enjoying a prosperous future. These lyrics, however, do not tell the whole narrative of Kurdish nationalism in Iraq. There is more into this narrative. For example, it heralds to the audiences that Kurdistan is enjoying its "spring" season, which is a metaphor for Kurdistan freedom and revival. Yet, we know that this is not the case; three parts of Kurdistan are not in the same situation as Iraqi Kurdistan. This is where images add important meaning to the content of the lyrics. 


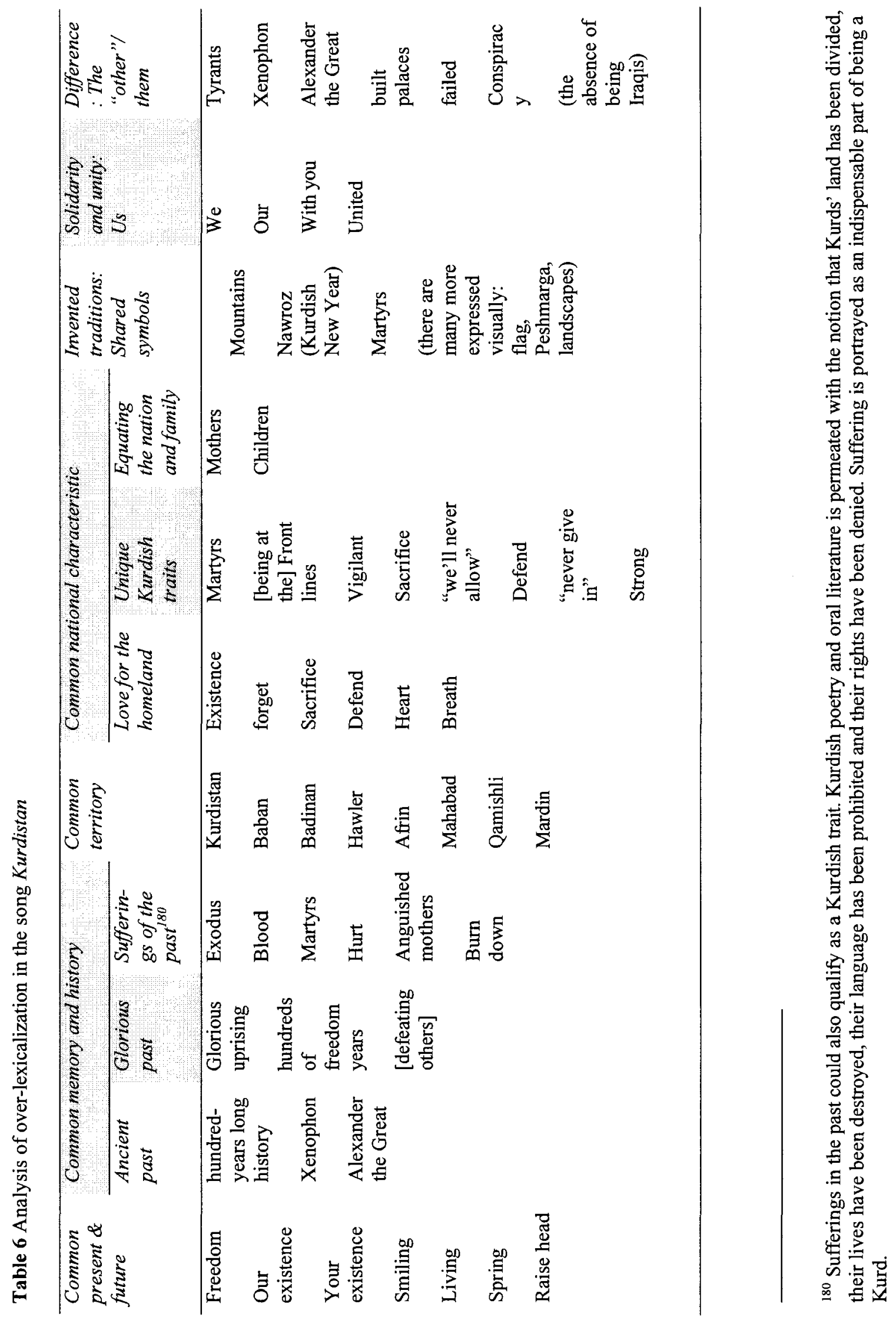




\section{Visual images}

One of the first concerns in the area of multimodal analysis is: what kinds of relations exist between different modes of meaning-making or communication (i.e. verbal language, image and sound)? For example, with respect to this song we can ask: do images reinforce, summarize, expand or negate what the lyrics say?

Figure 19 A scene from the video clip Kurdistan shows a close-up of a young boy standing on the shoulder of an adult and with the Kurdish flag painted on his face

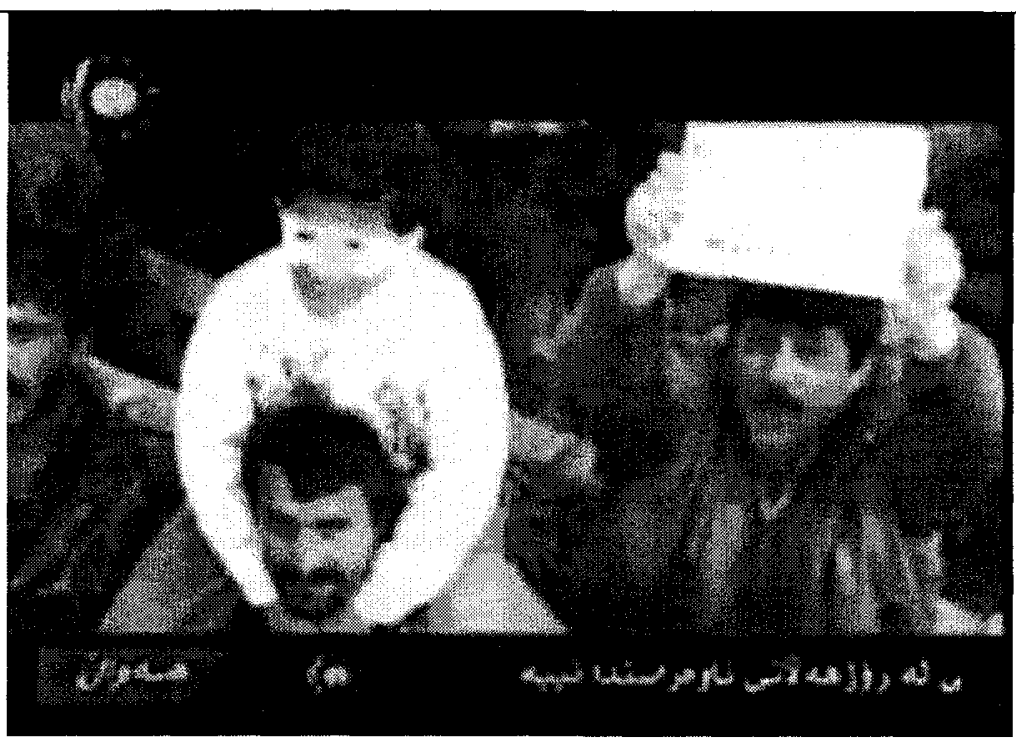

Modes usually have two kinds of relations: elaborative or extensive (van Leeuwen, 2005, p. 77). The relation is elaborative when messages and content in one mode are restated in another mode for the purpose of explaining the content, exemplifying or summarizing it (ibid.). The relation between different modes is extensive when the content expressed in one mode is expanded and added to by another mode. 
Most of the images in this song are elaborations of the lyrics, as one might expect, because music video clips are commonly made for songs that have already been recorded (Martinec, 2000, p. 313). There are different kinds of elaboration, such as explanation, exemplification, and extension. For example, as shown in Figure 20, lyrics in line 2 are explained in images:

Figure 20 Elaboration of lyrics in images by way of explanation

\begin{tabular}{lll}
\hline \multicolumn{1}{c}{ Lyrics } & & Image \\
\cline { 1 - 1 } $\begin{array}{l}\text { Listen to the tombstone and } \\
\text { grave of the martyrs that are } \\
\text { calling* }\end{array}$ & $\begin{array}{l}\text {-A group of women in black } \\
\text { are sitting around a coffin; } \\
\text { Close-up of an elderly } \\
\text { woman wiping her tears }\end{array}$ & \\
& &
\end{tabular}

The lyrics express a basic nationalistic message: Kurdish martyrs, who have sacrificed their lives for Kurdistan, are calling upon all the Kurds to do the same: to follow their path. The accompanying messages, in two shots, by showing women in black and crying around a coffin, elaborate the message of the lyrics: (1) those martyrs had mothers and families who have mourned the loss of their loved ones. They were just like us; (2) we hear the martyrs' call through the crying and wailing of the grief-stricken mothers. It is not easy to ignore them.

In addition to this kind of elaboration, which happens to be explanatory, there are other examples of elaboration that shed light on some of the ambiguities of the lyrics by exemplifying the content of the lyrics. This is shown in Figure 21. 
Figure 21 Elaboration of lyrics in images by way of exemplification

\begin{tabular}{|c|c|}
\hline Lyrics & Image \\
\hline $\begin{array}{l}\text { Your children }{ }^{181} \text { are ready to } \\
\text { defend you }\end{array}$ & $\begin{array}{l}\text {-Kurdish soldiers marching; } \\
\text { students in a classroom; } \\
\text { close-up of a woman } \\
\text { wearing headphones at a } \\
\text { meeting }\end{array}$ \\
\hline
\end{tabular}

In the lyrics it is not clear who the nation-defending children are. The images exemplify the children of the nation: Kurdish soldiers, school youth, and public servants. In combination with other images, the visual part of the song seems to convey the idea that whereas in the past the Peshmarga were the main force fighting for Kurdistan, today Kurdish nationalism has turned into a mass movement.

Figure 22 Elaboration of lyrics in images by way of extension

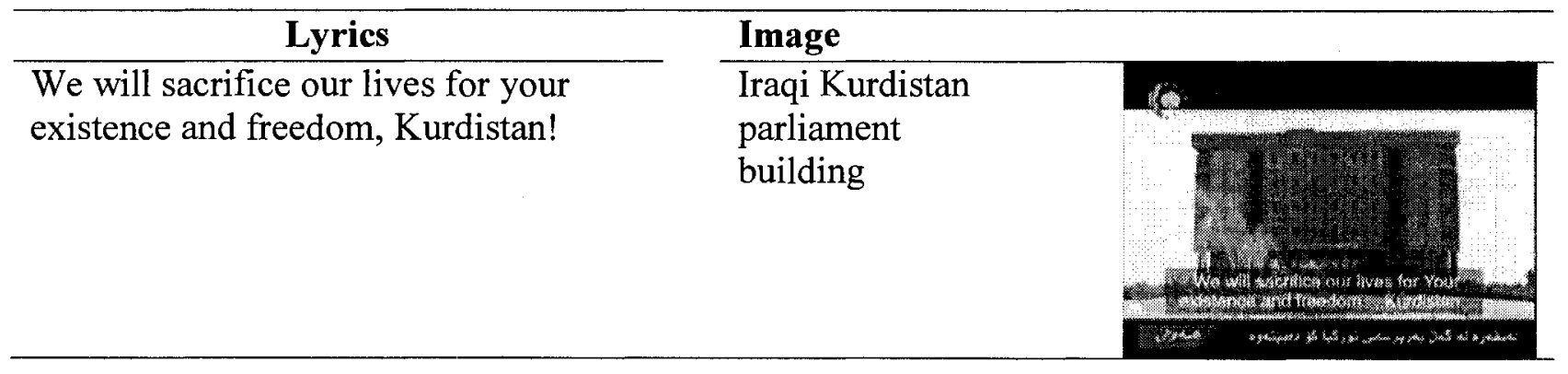

In addition to elaboration, there are also images that are extensions of the lyrics, in the sense that they add new but related content to what is expressed in other modes (e.g. the verbal language). The lyrics make no explicit reference to Iraqi Kurdistan, and judging by the verbal language of the lyrics, one becomes convinced that the Kurdistan

\footnotetext{
${ }^{181}$ In the caption the word "rolekanit," which means your children, has been translated as "your sons."
} 
that is represented throughout this song is a greater Kurdistan. ${ }^{182}$ However, images of the Iraqi Kurdistan parliament building (see Figure 22), Kurdish police in uniform, and even images of Kurdish university students graduating, unmistakably identify Iraqi Kurdistan and not other parts. One could argue that the two modes, verbal and visual, betray each other because the lyrics construct a greater Kurdistan, yet the images remind the viewer that the Kurdistan that is really talked about, at least partially, is Iraqi Kurdistan. However, there is another plausible explanation for this extensive relation between the two modes. Although it is Iraqi Kurdistan that is "free" and "smiling" and enjoying its "spring" season, the existence of this small Kurdistan depends on the support of other parts of Kurdistan. At the same time, the existence of this small "free Kurdistan" has given and will continue to give confidence and hope to all Kurdistan and even the Kurdish diasporic communities. This discursive practice with seemingly two different ideological objectives, one producing an Iraqi/smaller Kurdistan and the other producing a greater Kurdistan, runs through most of KTV's discourses. I will illustrate this later, when discussing excerpts from KTV's news and talk shows.

\section{Music}

In the music video Kurdistan, the music elaborates the content expressed in both the lyrics and images. To illustrate this, the song can be divided into four stages, based on the changes and transitions the music goes through.

The video clip opens with marching music that possesses a powerful and angry tune, which is typical of Kurdish patriotic and revolutionary songs and anthems. The music and its tune are an elaboration of the lyrics "we will be in the front lines and 
defend you Kurdistan!" and images of Peshmarga, mountains, large crowds of people marching in the streets, waving Kurdish flags and hands thrown in the air as a sign of chanting slogans. In the second stage, when the lyrics encourage [Iraqi] Kurdistan not to succumb to threats because it is not alone and other parts of Kurdistan are with her, the music changes into a slower rhythm with a soft and melancholy tune, typical of Kurdish love songs. ${ }^{183}$ The tune is an elaboration of the images, which exemplify other parts of Kurdistan. The music in the third stage falls into a joyful tune with a faster rhythm, a tune and rhythm that are commonly used in Kurdish dance music. This music elaborates the content of the lyrics and images which celebrate the free state of [Iraqi] Kurdistan and the people's renewal of allegiance and loyalty to the motherland. The fourth stage of the song is marked by yet another melody which has a slow rhythm and a melancholy tune. It again elaborates the content of the lyrics and images which recall the past oppressions of the Kurds and occupation of Kurdistan. In the final stage, the music changes back to the music of the opening scenes, a marching music with a revolutionary tune. This is an elaboration of the content of the lyrics and images that define and represent a Kurdistan that is proud of its free part (Iraq), and that Kurdistan, as a whole, is strong, united, and vigilant, and ready to defend itself.

A final note should be made regarding the language use in this song. The song is performed in the two major Kurdish varieties, Sorani and Kurmanji. Although the singer's mother tongue is Sorani, he performs the fourth stage of the song in Kurmanji. Singing in the two varieties has been a deliberate act by nationalist singers to alleviate the existing linguistic fragmentation in Kurdistan, and consequently construct the image of a

\footnotetext{
${ }^{183}$ This tune is close to pastoral music.
} 
unified Kurdish people and a greater Kurdistan. In the late 1980s, Nasser Razzazi, from Iranian Kurdistan, popularized singing in several Kurdish speech varieties, such as Sorani, Kurmanji, Hawrami, and Gorani/Kirmashani. Since then, especially among diasporic communities, many singers have joined the practice. Singing in two or more varieties, in the same song or anthem, as is the case in the song Kurdistan, however, is a recent phenomenon. This is another sign of Kurds becoming closer to each other and becoming more able to communicate their fears, affections and dreams in each other's languages and voices rather than in isolated regional dialects alone. 


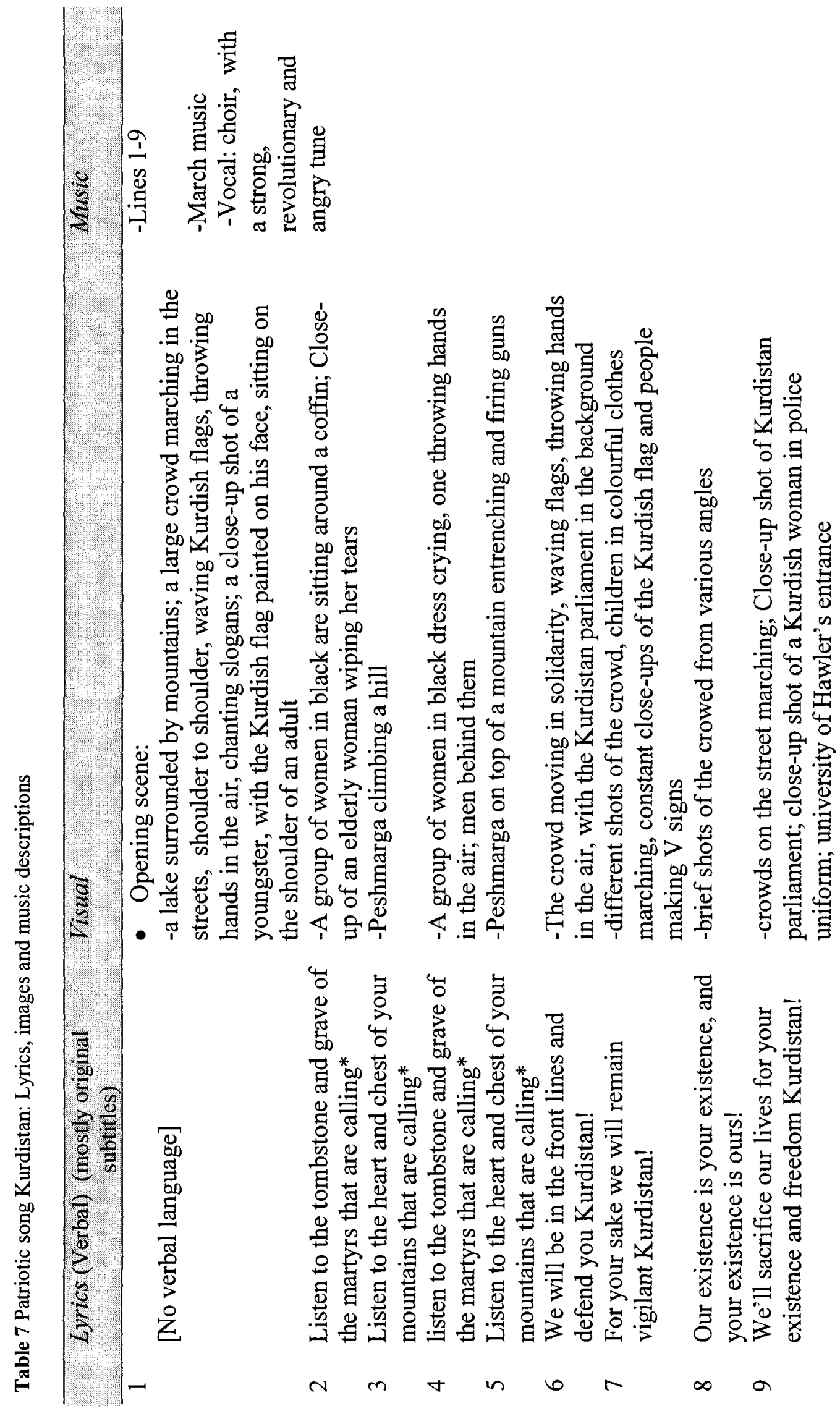



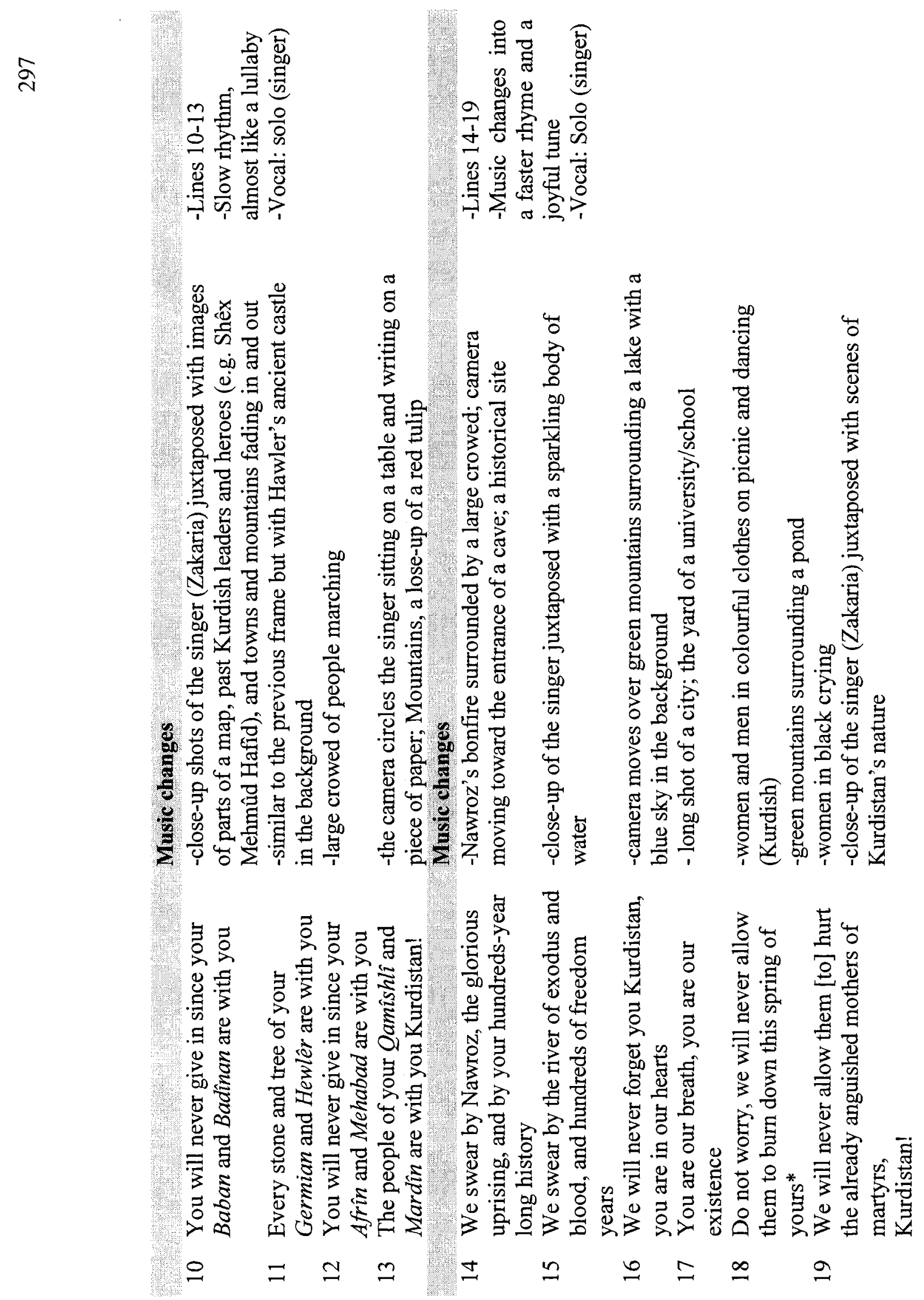


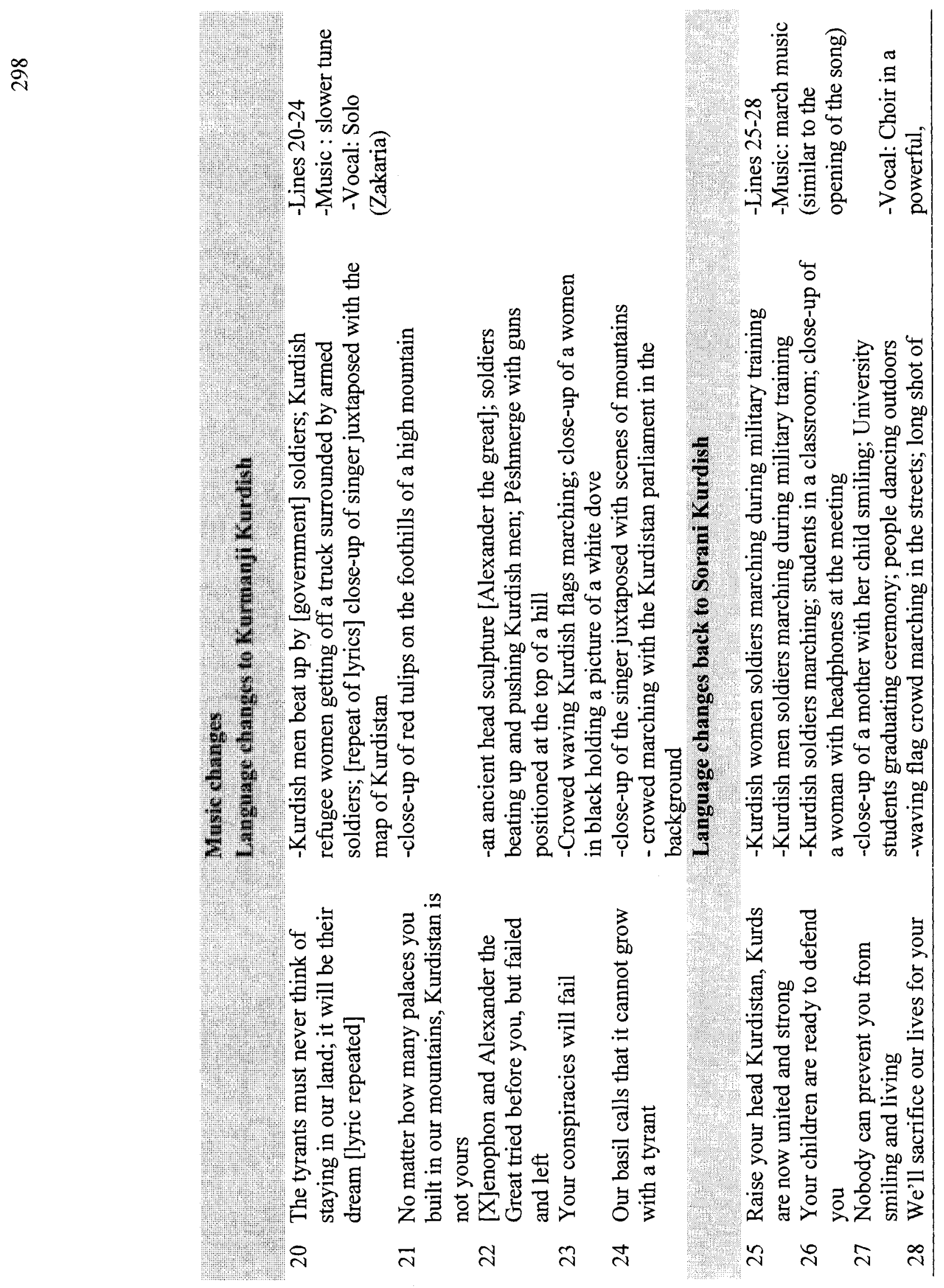


बे
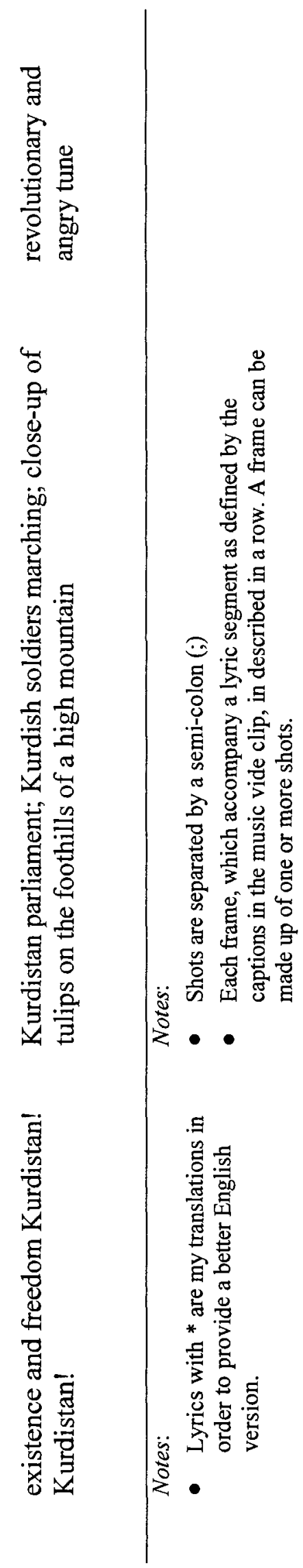


\section{Chapter 11: Discourse Practices of Kurdish Internet}

In the previous chapters, I looked at Kurdistan TV's programs and analyzed the discursive construction of Kurdish identities that are enabled and disseminated by the channel. I illustrated that KTV's discourse of national identity to a large extent reflects its owner's interests and ideologies. Owned by a regional political organization, KTV mainly constructs a regional and Iraqi Kurdish identity, but at the same time it engages in subtle and implicit discursive constructions of a cross-border Kurdish identity. Overall, the channel's discourse practices are carried out within the ideological framework and political interests of its owner, Kurdistan Democratic Party (KDP).

The purpose of this and the next chapter is to investigate how Kurds use the Internet to present themselves and to construct, negotiate and articulate their identities. The Kurdish Internet is important insofar as it gives voice to those who cannot afford to broadcast on satellite television channels, which are exclusively owned by dominant Kurdish political organizations. Thus, unless I find it useful for the purpose of contextualization, in this and the next chapter I will not be concerned with online activities of the Kurdistan Regional Government in Iraq or the major Kurdish political parties. Instead I will be focusing on smaller political organizations, interest groups, and individuals.

I assume that the Internet provides alternative communicative spaces for different discourse practices and discursive constructions of Kurdish identities. I also assume that, in contrast to KTV, Kurdish cyber activities are in significant ways devoted to explicit 
and overt construction and reproduction of a cross-border and pan-Kurdish identity. Finally, it is assumed that because online communication within a community in important ways depends on a shared language, Kurds might seem more fragmented than unified judged by their online activities. To test the validity of these assumptions the following three questions are posed: (1) What are the main features or constituents of the Kurdish Internet? (2) What roles could these constituents play in the processes of negotiation and articulation of Kurdish identities? (3) Are the discourse practices fostered by the Kurdish online resources unifying or further fragmenting Kurdish identity? I will start answering these questions after introducing my data.

The Internet data for this study have been accumulated during the past decade of my active observation of Kurdish online activities. They consist of various screen shots and content of the following internet sources: Kurdish web directories, websites, chatrooms, weblogs and forums. In addition, my data encompass personal communications with webmasters, chat-room administrators (moderators) and webloggers (bloggers). The data also consist of a two-hour video recording of an online session of Kurdish bloggers on the Internet chat service Paltalk on April 14, 2004. Furthermore, the data are accompanied by various media outlets' reports and interviews about Kurdish online activities. Finally, the data for this study are enriched by my personal involvement in online activities from 1998 which has enabled me to gain some useful inside knowledge about the affordances and also constraints of the Internet with respect to Kurdish online activities. ${ }^{184}$

\footnotetext{
${ }^{184}$ In 1998, under the pseudonym Ashti, I started one of the first Kurdish websites, Mahabad Homepage, and maintained it for about two years. In the summers of 2001 and 2003, for about two months, on weekly basis, I hosted a chat-room dedicated to Kurdish literature and language on the Internet chat service
} 
In what follows I will provide an overview of Kurdish cyber activities or the major constituents of Kurdish Internet. I am particularly interested in identifying alternative voices in platforms such as websites, chat rooms, weblogs and forums (discussion groups) that do not seem to be owned by the dominant Kurdish political organizations or the host states but rather by individuals, social activists and interest groups. To locate these internet sources I have mainly relied on Kurdish web directories such koord.com which in May 2007 indexed about 2500 websites and 6500 links to Kurdish Internet sources (B. Naghib, personal communication, May 24, 2007). ${ }^{185}$ I have divided these websites and online sources into the following categories: websites, chatrooms, weblogs, and other constituents (Erikson, 2007). To avoid repetition and in order not to take up too much space in the text I will cite websites and Internet sources either by their titles or authors. The URL and other details about these sources will be provided in the main bibliography.

\section{Websites}

The website Koord (see Figure 23) provides links to about 2500 websites (B. Naghib, personal communication, May 24, 2007). These websites range from personal to organizational and from entertainment-oriented to political. Approximately $10 \%$ of these websites are affiliated with the major Kurdish political organizations. The rest of the websites belong to smaller Kurdish organizations (i.e. those that do not own satellite

Paltalk. In 2004, I started blogging in Kurdish sporadically and under more than one pseudonym. At the beginning of 2007, I launched a filter blog on which I continue to provide links to online news and resources related to Kurdish communication and language (Kurdish Communication, 2007).

${ }^{185}$ Other notable Kurdish web directories include Kurdland and Kurdlinx. The first Kurdish Internet directory was Malper (webpage/website) that started in 1997. Although the website is still online it has not been updated for several years. The word Malper, coined by Nasser Sina, the current director of Radio Zayele, the Radio Sweden International-Kurdish Service, has been widely accepted in all Kurdish speech varieties as a synonym for the English word website. 
television channels or other major media outlet such as dailies), different individuals and groups of Kurdish intelligentsia (e.g. women activists, human rights groups) and ordinary individuals. These groups and individuals use the Internet either as a platform for advancing their political and social interests or expressing and articulating their cultural identity (i.e. Kurdishness), personal beliefs, anxieties and nostalgia for the homeland. As I will show shortly, websites are used as libraries, publishing houses, distribution systems of print materials, online news agencies, broadcasting facilities, alternative and personal communicative spaces.

Figure 23 A screenshot of the website Koord. Retrieved December 20, 2006, from http://www.koord.com

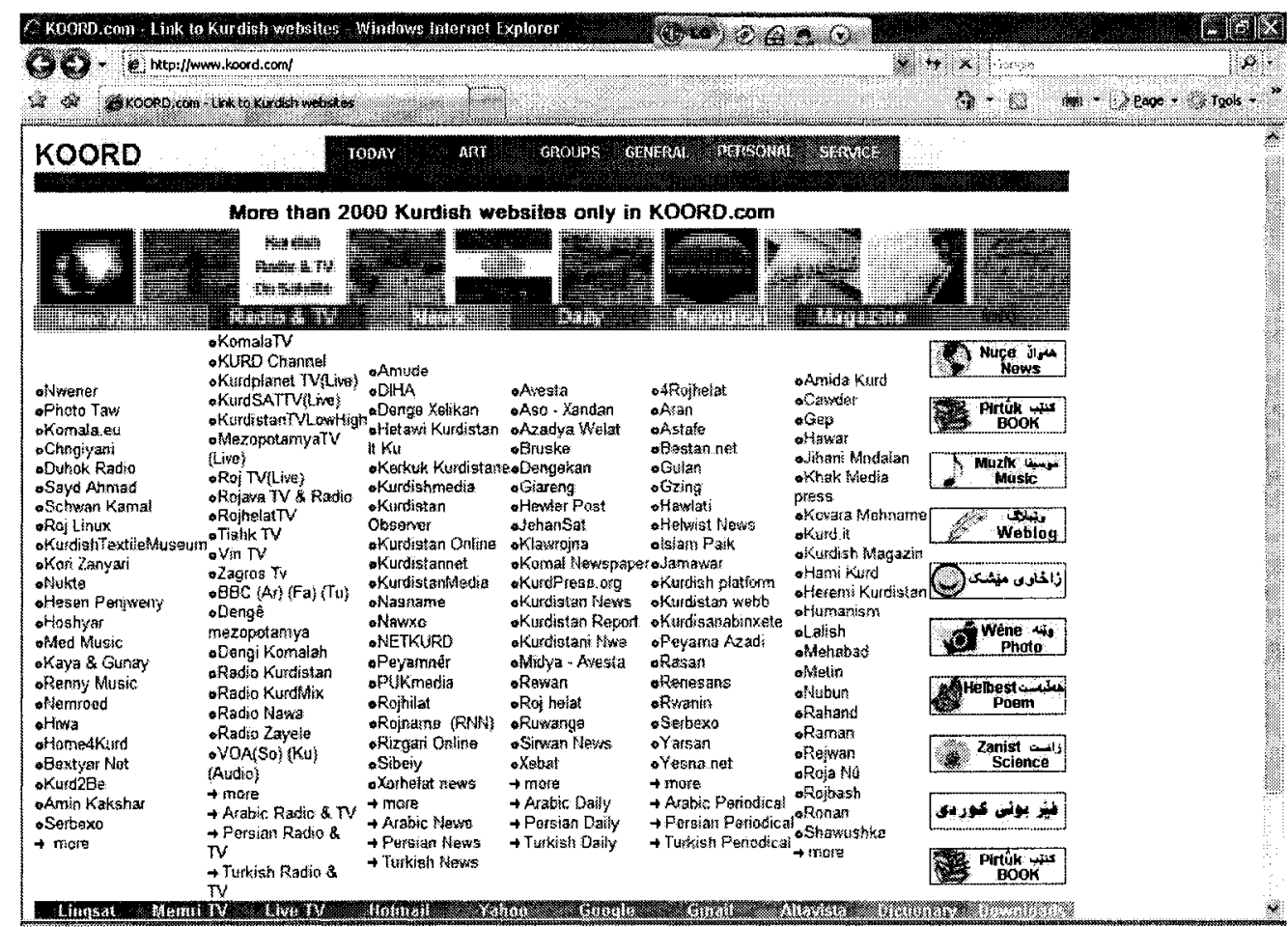

\section{Websites as libraries and distribution systems for print materials}

As noted earlier in my discussion of Kurdish media, Kurdish publishing and journalism have suffered since its inception from the lack of adequate distribution systems 
(Hassanpour, 1996, p. 71). The Internet has enabled Kurdish writers, publishers, distributors and readers to overcome this obstacle in important ways. For example, there are several websites from which it is possible to download the newest books that are published both in Kurdistan and the diaspora. Some of the notable websites that provide free access to Kurdish books are Nefel, Amude, Koord, and Kitêbxaney Kurdî. It should be noted, however, that because the medium of the first and second websites is Kurmanji Kurdish, the books they carry are only in that Kurdish language variety. In contrast, most of the books that are available for downloading on the third and fourth websites are in Sorani Kurdish. This is an example that indicates the fragmentation of Kurdish online activities across linguistic lines, a theme that I have encountered throughout my analysis.

The website that provides free access to the largest collection of Kurdish books is Kitêbxaney Kurdî (The Kurdish Library) (see Figure 24). In June 2007, the website had 896 books available for download, mostly in PDF format, and free of charge. ${ }^{186}$ The logo of the website, in the top left corner, reads: "This library belongs to everyone, [but] no one owns it." The books are made available with the permission of the copyright holders (B. Hasan, personal communication, April 18, 2007). The webmaster of this site, Behroz Hasan, a university student residing in Denmark, in an interview with the Kurdistan Post reveals his purpose in hosting this website: "I believe that books make up an important part of any nation's culture; therefore, they deserve more attention" (Mihemed, 2006, p. 12). This indicates that Hasan's volunteer work to distribute Kurdish books is a conscious act of national identity construction. The vast majority of the books are published in Iraqi Kurdistan and they are all in Sorani Kurdish.

\footnotetext{
${ }^{186}$ On January 03, 2008, the number of books on this site increased to 1010.
} 
Figure 24 A screenshot of the website Kitêbxaney Kurdî (The Kurdish Library). Retrieved June 28, 2007, from http://www.pertwk.com/pertwk ${ }^{187}$

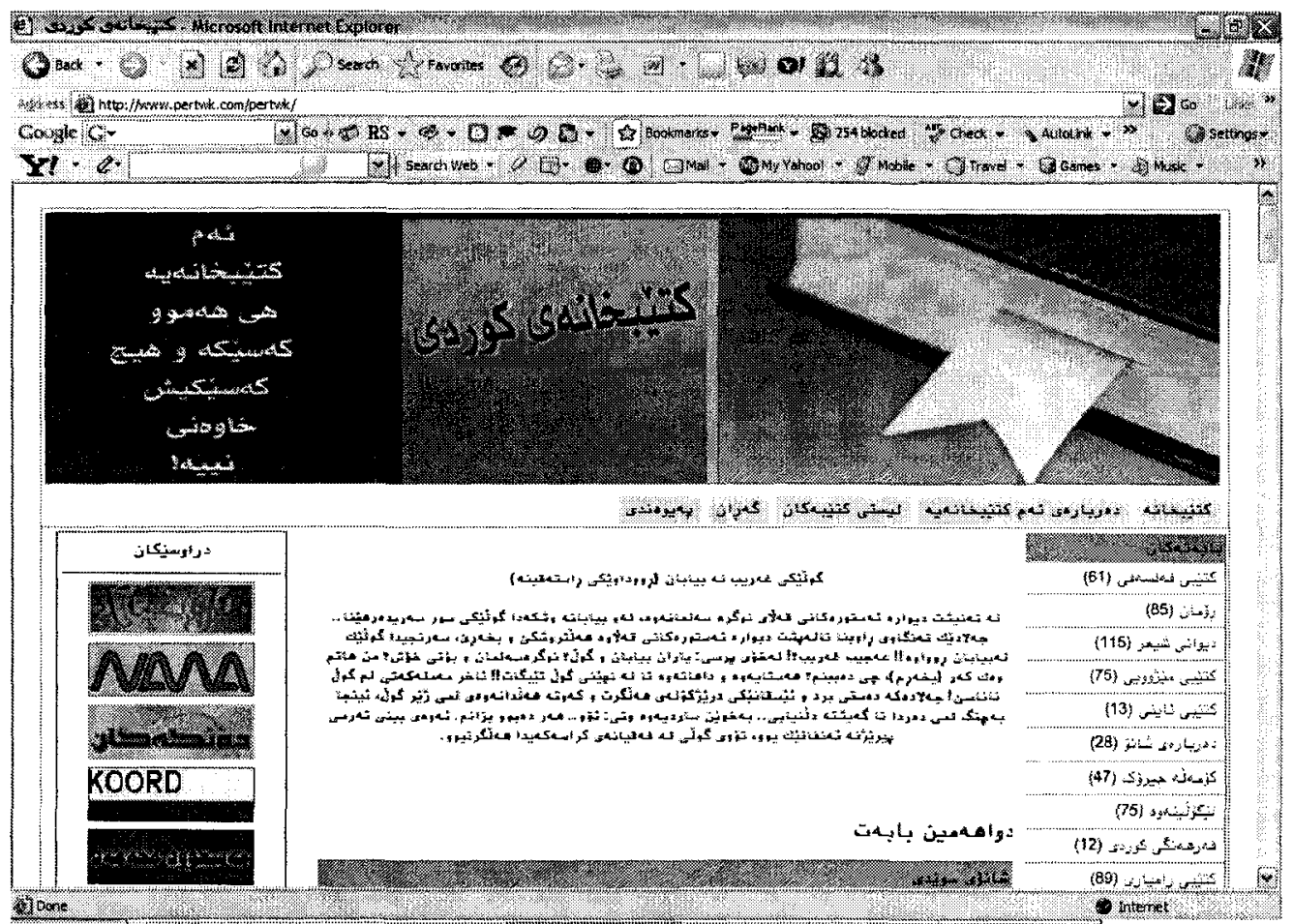

On the impact of this website, Hasan says that more and more writers and publishers are willing to offer their books for free distribution on his website, but he also agonizes over the fact that the majority of people who visit the website are from the Kurdish diasporic communities rather than Kurdistan or Kurdish communities living in the Middle East. He believes that the main reason for this is the fact that people living in Kurdistan have limited access to the Internet (Mihemed, 2006, p. 12).

Despite the limited access to the Internet within Kurdistan, it is difficult to underestimate the usefulness of a website like this and its place in the nation-building

${ }^{187}$ The Kurdish word pertwk in the website's URL means book. 
project. Only about a decade ago many Kurdish readers were taking many risks to obtain one or two of these books, particularly in places like Iran, Syria and Turkey. ${ }^{188}$ Until very recently, even members of Kurdish diasporic communities could not easily access Kurdish printed materials. On top of the costs associated with purchasing and shipping books, most of which were obtained from Iraqi Kurdistan, one had to wait months to receive them by mail. Many times mailed books would never arrive at their intended destinations. Now the same readers have thousands of books at their finger tips thanks to the Internet.

In addition to books and monographs, many Kurdish periodicals are distributed, redistributed or reproduced on the Internet (e.g. magazine: Raman; weekly broadsheet: Azadiya Welat; daily newspaper: Xebat). In many instances, visitors to these sites not only access the online version of these periodicals, for example in HyperText Markup Language (HTML) format, but they can also see what the print version looks like by downloading the Portable Document Format (PDF) of the publication. Nearly all these periodicals, including access to their archives, are made available to visitors without any charge.

\section{Websites as dailies and news agencies}

The Internet has not only helped with the distribution of printed materials including Kurdish magazines and newspapers, it also has given rise to online news websites that have no print version (e.g. Avesta Kurd and Renesans) (See Figure 25 for another example, Rizgarî Online). The technology has also enabled a website such as Renesans to have its audiences react to news items and featured articles by leaving comments on the

\footnotetext{
${ }^{188}$ This still involves risks in Turkey.
} 
website. This has enabled readers from different diasporic Kurdish communities and different regions of Kurdistan to interact with the webmasters and more importantly with each other. Audiences can experience a sense of shared belonging not only by being involved in the ritual of reading the same thing simultaneously, in Anderson's term (1991), but also by discussing and debating about the same issues that concern them.

Figure 25 A screenshot of the website Rizgari Online (Emancipation Online). Retrieved July 03, 2007, from http://kurdish.rizgari.com ${ }^{189}$

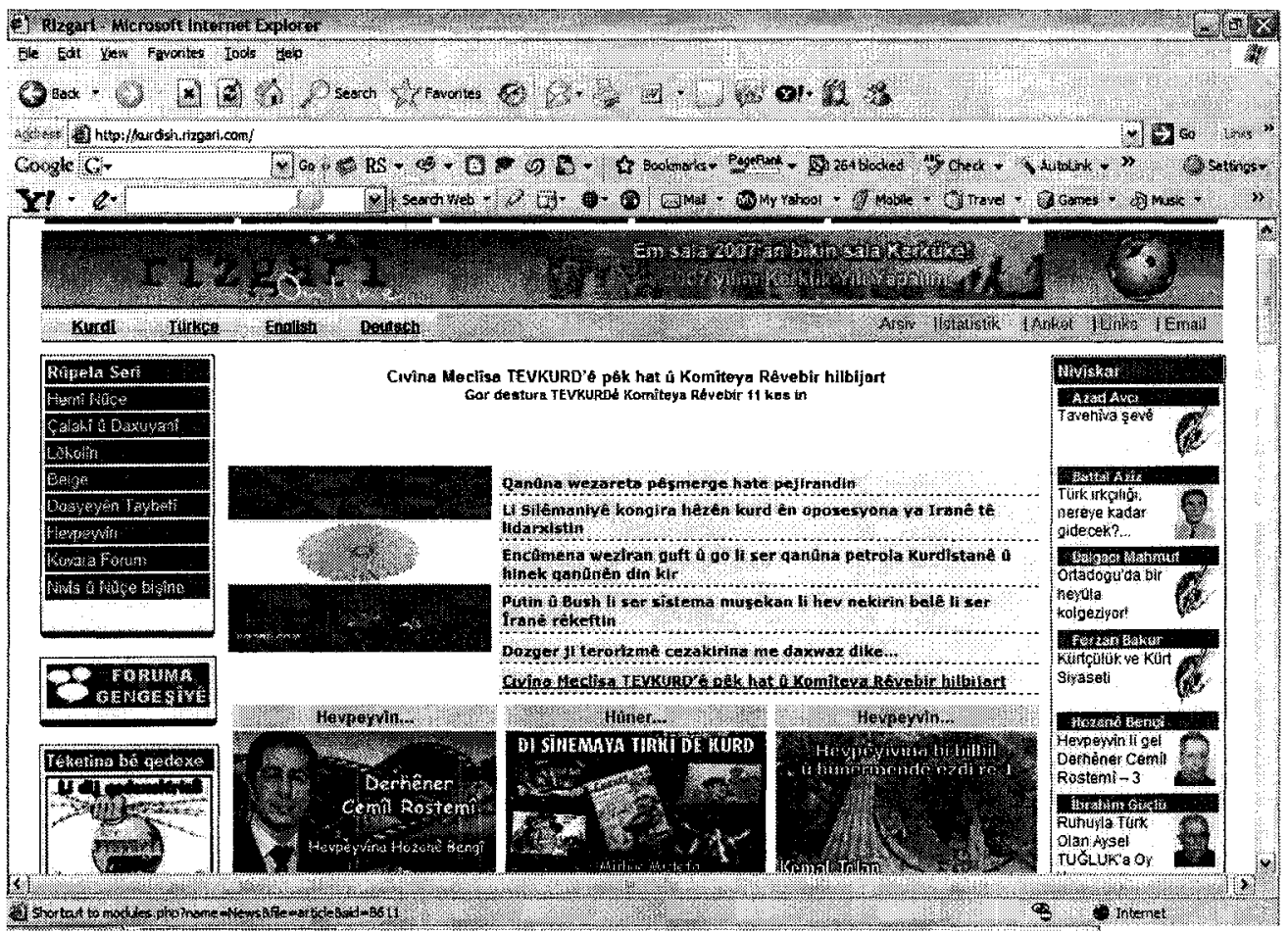

In addition to online dailies devoted to news and commentaries, there are also news agencies which did not exist prior to the emergence of the Internet. One of the most popular news agencies is Peyamner: Ajansî Hewal u Bediwadachûnî Kurdistan (The

${ }^{189}$ The website Rizgari Online is hosted in Europe by Kurds from Turkey and it offers news in Kurdish Kurmanji, Turkish, English and Deutsch. The website was hacked by "Turkey nation," on December 4, 2007. 
Reporter: Kurdistan News Agency) (PNA), which was established in 2005 (see Figure 26). As the Kurdish website with the most visitors (Sina, 2007), PNA operates from Iraqi Kurdistan, but provides news from throughout Kurdistan and diasporas, in several languages (Kurdish-Sorani and Kurmanji, Arabic, Persian, Turkish and English). It covers a whole range of issues and news from current political affairs and news interest stories to arts and entertainment.

Figure 26 A screenshot of the website $P N A$. Retrieved June 28, 2007, from http://www.peyamner.com/default.aspx?l=1

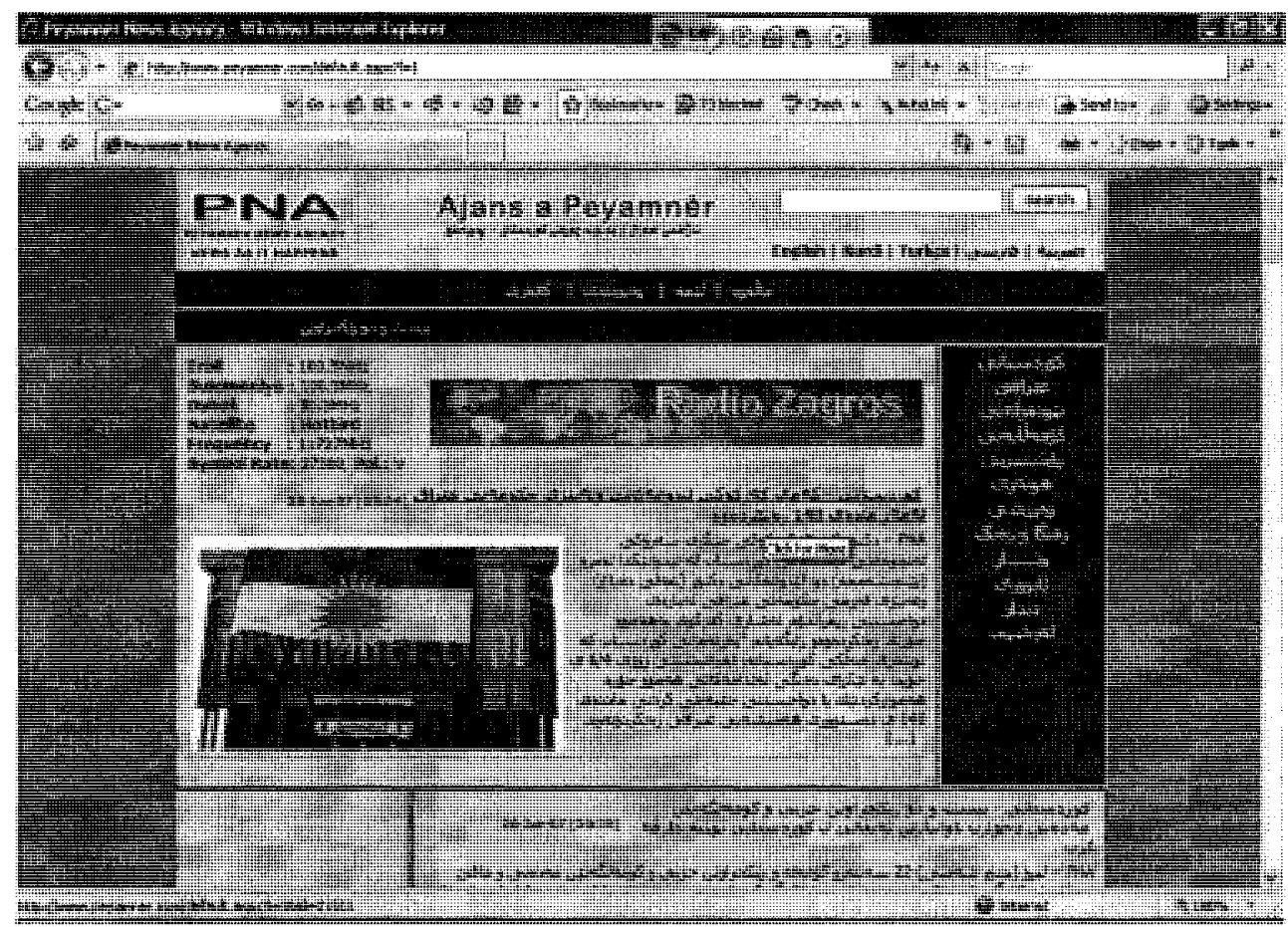

\section{Websites as broadcasting facilities}

Except for the two satellite TV channels Kurdistan TV and KurdSat, which are owned by the two dominant Kurdish political organizations in Iraqi Kurdistan, no other Kurdish radio or television station could have been received worldwide, if it were not for the Internet. Prior to 1991, no Kurdish broadcasting was permitted in Turkey or Syria, and in 
Iran and Iraq governments held monopolies on radio broadcasting. Kurdish-owned radio stations belonging to Kurdish political parties and were operating clandestinely, usually from mountainous hideouts, and were received on short-wave receivers. The Internet has changed this. Now, most political organizations have either live or archived broadcasts available to their audiences worldwide (e.g. Dengê Mezopotamya). There are also privately owned radio stations broadcasting from Iraqi Kurdistan via the Internet such as Radio Nawa. From diasporas, among popular radio stations one should mention Zayele, Swedish Radio International, Kurdish service, Radio Rojawa, and Radio Kurdland. In addition to the fact that everyone with access to the Internet can listen to live programs from these radio stations, in many cases, s/he can also go back and listen to archived radio shows. The availability of these shows in MP3 format ${ }^{190}$ has also made it easy to download them, save them or redistribute them via email.

In addition to a number of radio stations, most of the major Kurdish TV stations can be viewed on the Internet as well. A number of these TV channels provide live streaming broadcast on the Internet (e.g. Roj TV) and in this way, they have managed to reach those audiences who may not have access to a satellite dish or those who live in some parts of the world where the signal of some channels cannot be received at all (e.g. Roj TV cannot be received by satellite in North America). Those TV stations that do not provide live streaming broadcast (e.g. Komala TV) make a selection of their programs available for viewing and downloading on their websites. Having access to TV broadcasting on the Internet is important especially for those who either cannot own satellite dishes or cannot freely use them, for example in Iranian and Turkish Kurdistan.

\footnotetext{
${ }^{190}$ MP3 is a digital audio encoding format. It is designed in a way that an audio file (e.g. a song) in this format requires much less amount of data.
} 
McDowall (2004) observes that "in Kurdistan, Turkish security forces had for some years been smashing satellite dishes" (p. 460).

The Internet is also the easiest and most economical way of broadcasting audiovisual clips that can be created on personal computers. In addition to hundreds of Kurdish websites and weblogs that offer free download of audio and video files, ranging from songs to images of Kurdish rebels, the Kurds also take full advantage of audio-video sharing websites such as YouTube. ${ }^{191}$

\section{Websites as alternative communicative spaces}

One of the greatest features of the Internet is its capability to amplify alternative but otherwise marginal voices (Bargh \& McKenna, 2004, p. 573; Mautner, 2005, p. 813). Andrew Shapiro has talked about "control revolution" to capture the idea that the Internet has enabled individuals and disenfranchised groups to communicate outside the realm of nation-states and major media corporations (Mills, 2002, p. 74). This is certainly true of the Kurdish Internet. On the one hand, Kurdish opposition groups have utilized the Internet, along with other media at their disposal, including satellite television. On the other hand, with the use of the Internet, voices different from the dominant political parties have been able to reach Kurdish audiences in unprecedented ways.

These alternative voices range from smaller political groups that have minimum presence in the daily political life in Kurdistan (e.g. Yekyetî Nîshtimanî Demokratî Kurdistan, YNDK-Democratic National Union of Kurdistan), social activists and NGO

\footnotetext{
${ }^{191}$ To show the extent to which Kurds have been able to use a file-sharing facility lie YouTube, on October 05, 2007, I conducted a search on YouTube with the query "Kurd or Kurdistan." The search returned over 60,000 hits. This is a considerable figure compared to the number of hits that on the same day were returned for the following queries: "Canada or Canadian," 155,000, "Iran and Iranian," 145,000, and "Palestine or Palestinian," 44,200.
} 
members (e.g. Nawendî CHA--The Centre of Halabja against Anfalazation and Genocide of Kurds [sic.], and Jin-Kurdish Women Network), and individuals. Among these, there are websites that openly advocate pan-Kurdism and the idea of establishing a greater Kurdistan (detailed analysis will follow). Other alternative voices are ordinary individuals who often use their web sites for personal use, cultural activities and also political propaganda. A great number of these personal websites are very explicit about identifying themselves as pan-Kurdish. They often express patriotic emotions towards Kurds and Kurdistan by displaying the Kurdish flag, the map of Greater Kurdistan and playing patriotic songs and video clips (I will provide more detail on these semiotic practices in the next chapter).

Figure 27 A screenshot of the website Jin--Kurdish Women Network. Retrived July 10, 2006, from http://gulagenim.com ${ }^{192}$

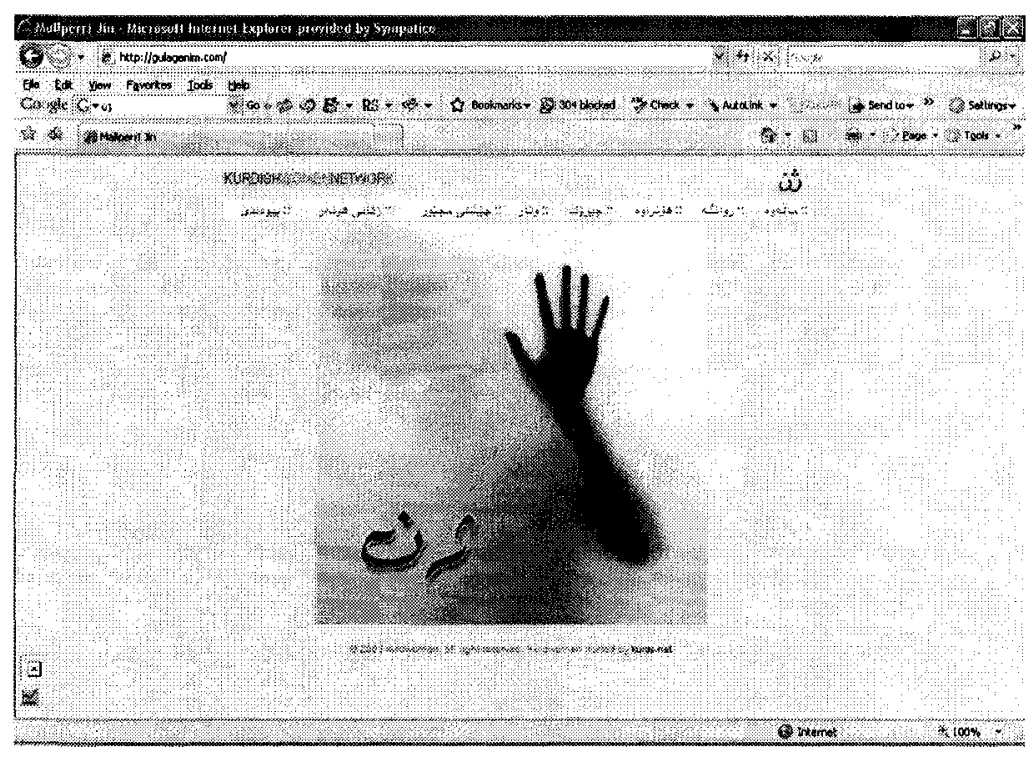

Finally, among the alternative Kurdish voices using the Internet, there are websites that appear to be very serious about the status of Kurds and Kurdistan and

\footnotetext{
${ }^{192}$ Jin-Kurdish Women Network is devoted to news, literature and debates on the status of Kurdish women.
} 
engage in related debates on political, social and cultural issues daily (e.g. Kurdistan Net and Bo Rojhelat-For the East ${ }^{193}$ ). Many of these web sites claim to be independent from Kurdish political parties. In fact, they direct a great portion of their writing and content against the dominant Kurdish political parties and criticize them for being parochial, nonKurdistani and corrupt. Addressing the current Iraqi president, Jalal Talabani, who is also the leader of one of the two most powerful Kurdish organizations in Iraq (PUK), the title of an article on Kurdistanpost, on July 07, 2007, reads: "Talabani! We are all tired of you because you are the implacable enemy of all of us [all Kurds]." As shown in Figure 28, this biting title is reinforced by images of Talabani crossed with a black marker as a strong sign of rejection.

Figure 28 A screenshot of the website Kurdistan Post displaying Jalal Talabani's (the Iraqi President) portrait. Retrieved July 08,2007 , from http://kurdistanpost.com/index.php?id $=374^{194}$

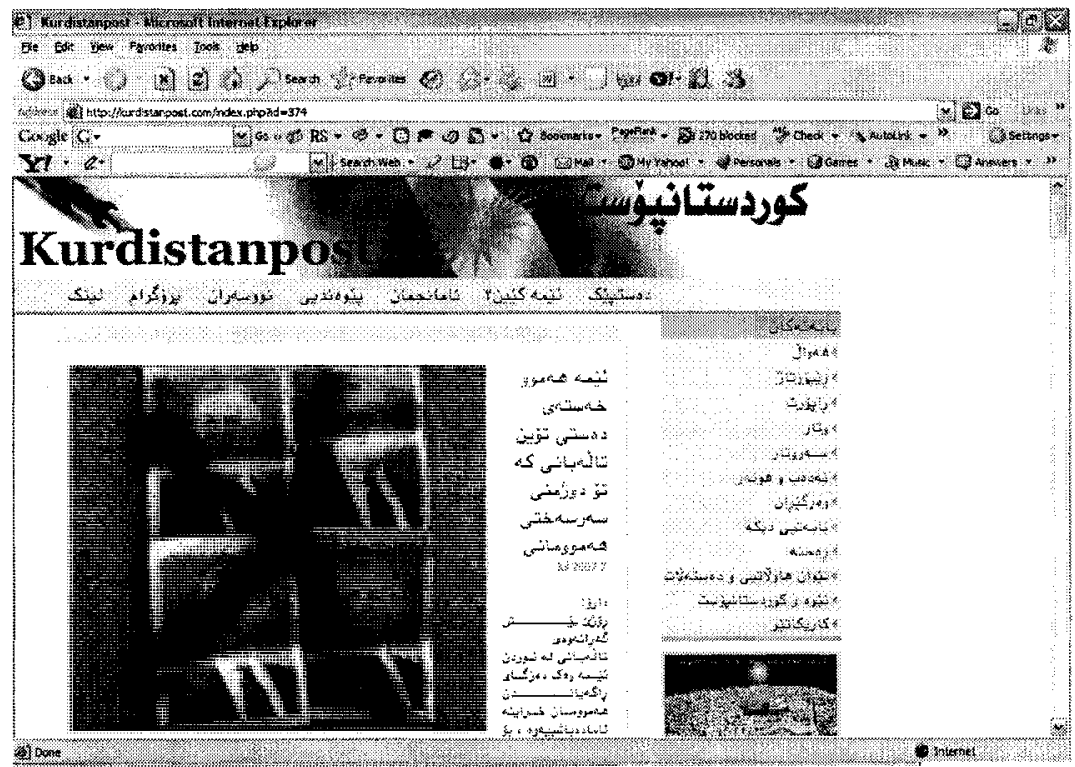

\footnotetext{
${ }^{193}$ The word rojhelat (the east) in the title of the website refers to eastern (Iranian) Kurdistan.

${ }^{194}$ Talabani's crossed out picture accompanies a commentary with the title: "We are all tired of you Talabani, because you are our worst enemy".
} 
In another article titled "The leader of all Kurdistan," Kurdistanpost accuses Masoud Barzani, the Serok (President) of Iraqi Kurdistan, of treason and stealing Kurdistan's wealth (see Figure 29). It is mocking him for portraying himself as the President of all Kurdistan and apparently not being satisfied with being called the leader of Iraqi Kurdistan alone. The caption in the image accompanying this article reads: "Let me see how clean your tail is" implying that he and other dominant regional Kurdish leaders in Iraq are corrupt and hiding the truth from their people.

Figure 29 A screenshot of the website Kurdistan Post featuring Masoud Barzani on September 23, 2007. Retrieved September 24, 2007, from http://kurdistanpost.com/index.php?id=1642

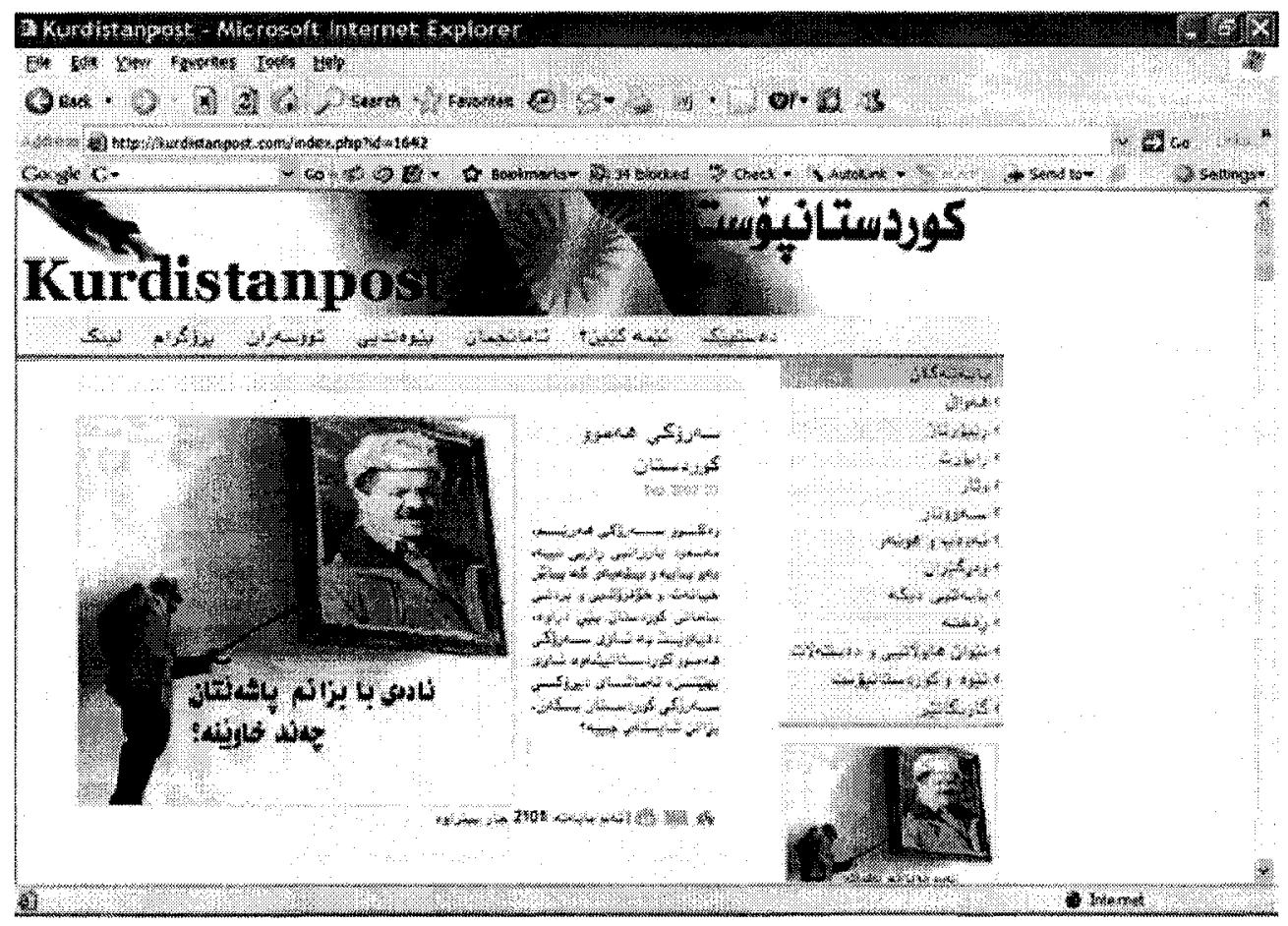




\section{Chat rooms}

The chat room is another significant feature of Kurdish Internet. While chat rooms are among the most popular sites where pan-Kurdism is constructed, they are indicative of Kurdish fragmentation.

Text-based chat rooms are the oldest forms of real-time online synchronous communication among a group (many-to-many). Most people associate this system with Internet Relay Chat (IRC). Throughout the world IRC has been facing a fierce competition with voice and video chatting systems in recent years. Among the Kurds, however, IRC has never been popular. There are a number of text-only-based chat rooms devoted to chatting in Kurdish, but, visiting them in various times of the day and night, one finds the vast majority of them either empty or at best attracting only two dozen participants (see Figure 30). Another feature of these text-only-based chat rooms is that they are predominantly used by youths for casual interaction and not for discussing social or political matters. Despite this, most chat rooms are very restrictive on what language can be used for chatting: Kurdish only. Most of the chat rooms are extremely nationalist.

Although being persistent about the use of Kurdish in their domain, it is not easy to chat in text in these chat rooms because most of them do not support the Kurdish Arabic-based script. The writing script is nonstandard and idiosyncratic, a mixture of the characters from the Kurdish Latin-based writing system and English. The majority of participants from Iraqi, Syrian, and Iranian Kurdistan cannot write in the Latin-based Kurdish properly and the Kurds from Turkey are much more comfortable writing in Turkish. As a result most of them tend to write Kurdish in Roman characters and this makes communication difficult, at least for people who are not familiar with the writing 
conventions of a given chat room. If there were a unified Kurdish writing system, the situation might be very different. The absence of such a common writing system seems to be the main factor that has caused the Kurdish text-based chat rooms to lag considerably behind the voice and video activated chat rooms in popularity.

Figure 30 A screenshot of KURD CHAT, an IRC (text-based) Kurdish chat room. Retrieved October 23, 2007, from http://www.kurdchat.net/kurdchat/login.php

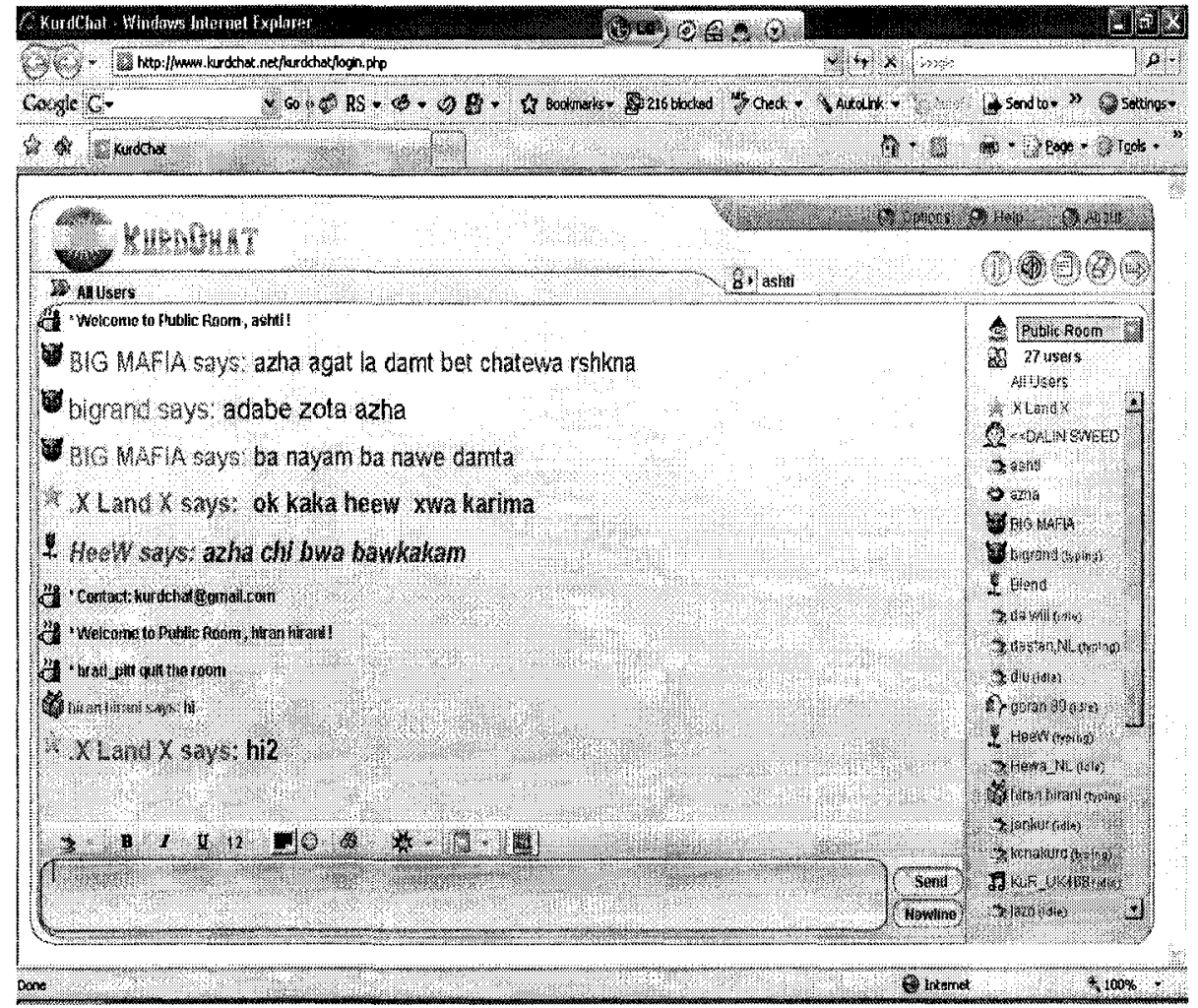

In contrast to the text-only-based chat rooms, real-time online voice and video chat rooms are popular among the Kurdish Internet users. Of the popular protocols Paltalk is the one that attracts the vast majority of Kurdish chat room users. As long as one does not mind banner ads at no cost, she/he can participate in chat rooms or create her own room, set her own theme and set of rules. As shown in Figure 31, on July 05, 
2007, under the category "Ethnic Groups," there were 51 rooms listed under the subcategory "Kurdish," compared to 70 rooms under "African-American," 24 rooms under "Hispanics," and one room under "Native American."

Figure 31 A screenshot of Paltalk's directory of chat rooms for "Ethnic Groups." The right column shows the number of Kurdish rooms on Paltalk on July 05, 2007. Retrieved July 05, 2007, from http://www.paltalk.com

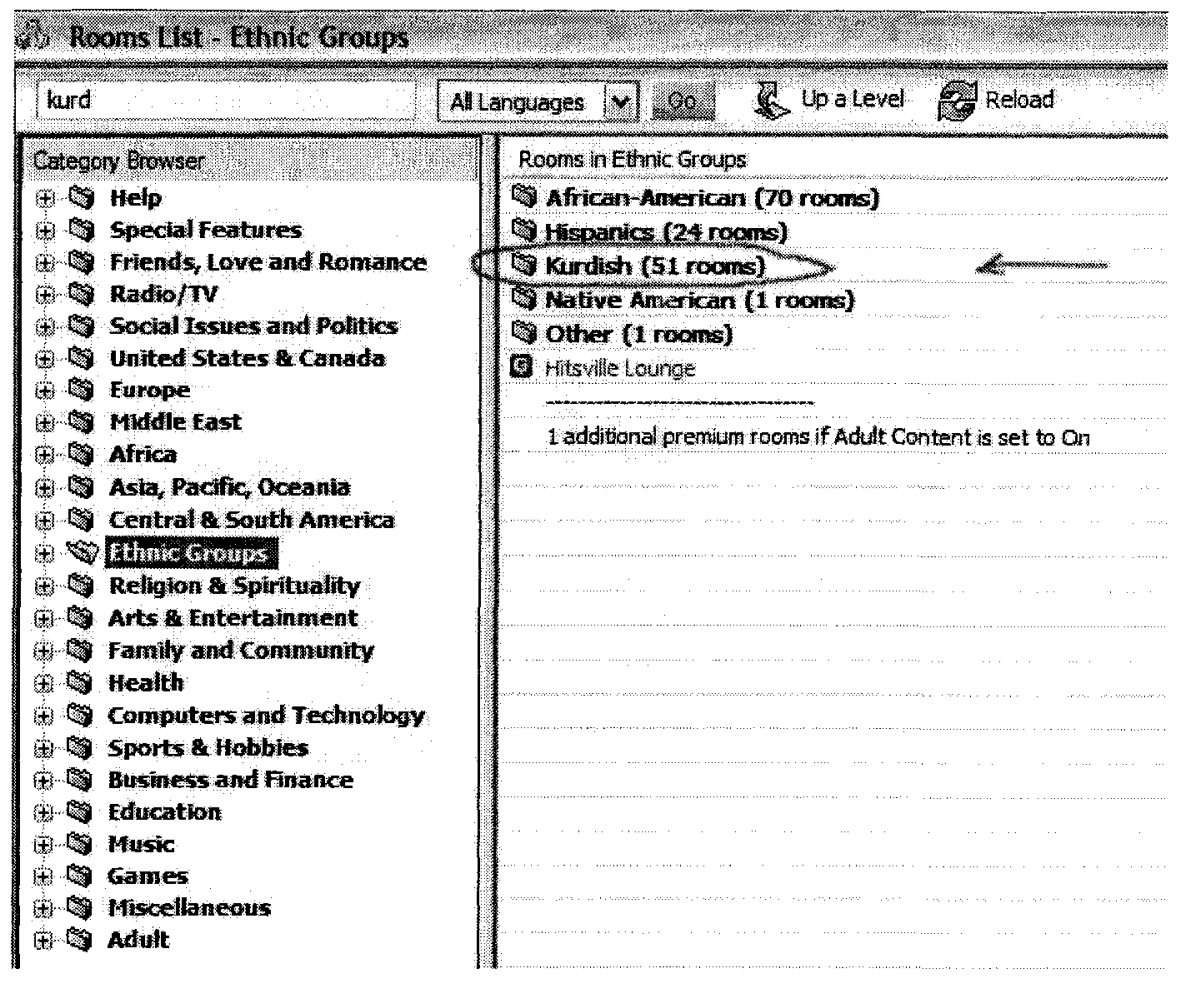

The number of participants in each room could vary from a few people to 250 , the maximum capacity. ${ }^{195}$ Figure 32 shows that on February 03, 2007, over 1000 people were participating in Kurdish chat rooms. ${ }^{196}$ Of these people, 649 were gathered in three rooms with the same title, Kurdistan United, because the maximum capacity for each

${ }^{195}$ Only chat rooms that are offered at no charge have the limited capacity of 250 people.

${ }^{196}$ It should be noted that this observation has been made before mid-night Europe time during which most Kurds living in Europe and the Middle East are online. After mid-night, the usual Paltalk users are North American Kurds who are much fewer in numbers. 
room is only 250 participants. ${ }^{197}$ With the help of several volunteers acting as moderators in different rooms, the rooms were connected by a network of computers in order to have all the 649 people participate simultaneously in the same discussion (A. Ahmad, personal communication, July 06,2007$){ }^{198}$ Theoretically, all the people logged into a room can listen to others and they can also talk. However, in reality, many people never have a chance to talk because of time constraints.

Figure 32 A screenshot of Paltalk showing the list of Kurdish chat rooms. Retrieved February 03, 2007, from http://www.paltalk.com

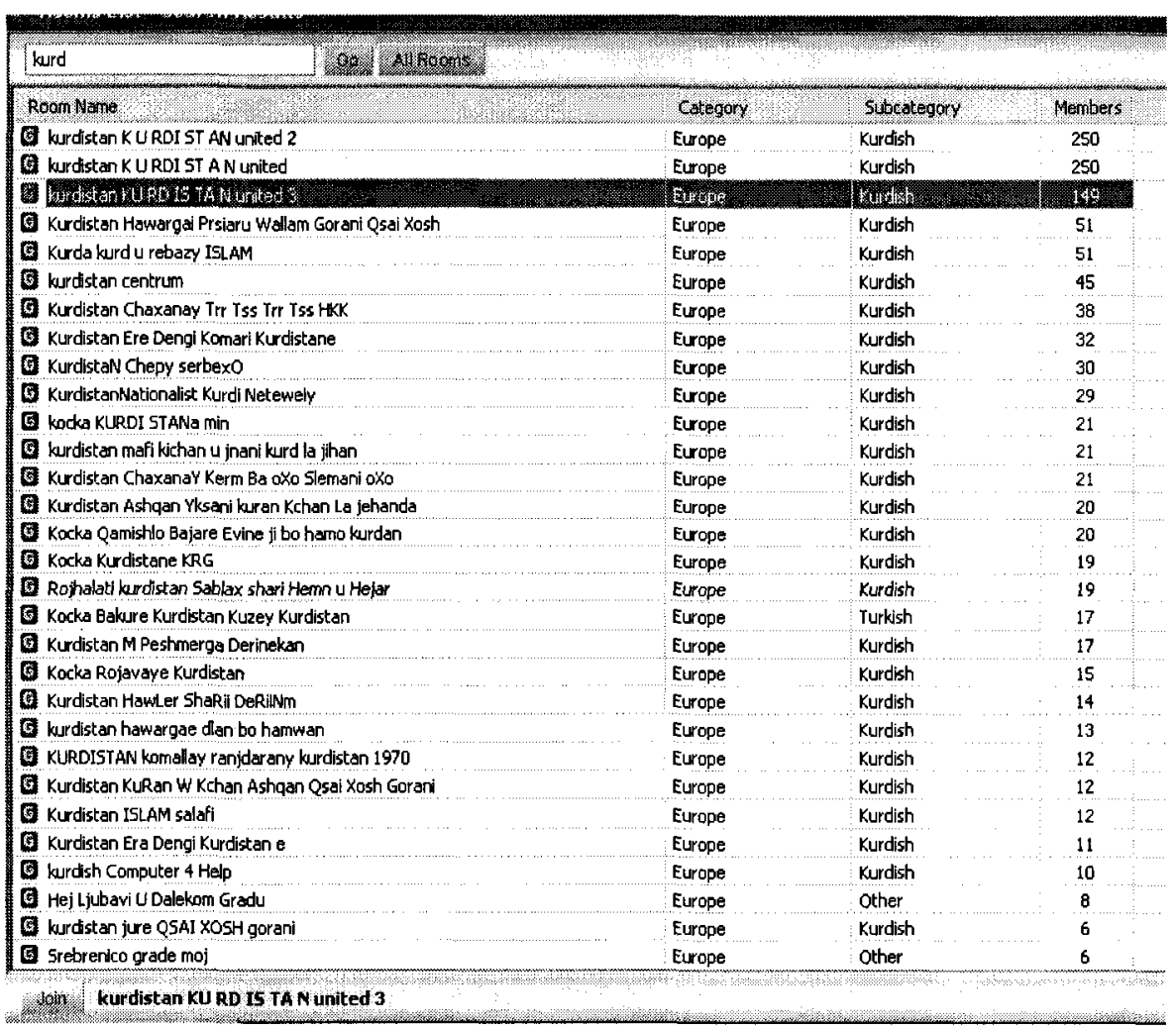

${ }^{197} 250$ people per room is what the free module allows. Once one is subscribed to Paltalk.com and pays a small monthly fee, rooms' capacity reaches 1000 people.

${ }^{198}$ Aram Ahmad is the username and nickname of one of the main moderators (they are called administrators in Paltalk) of the chat-room Kurdistan United. 
However, not all the rooms listed in Figure 32 are as popular as Kurdistan United, nor do all of them concern themselves with impassioned discussions on the history, culture and politics of Kurdistan. There are rooms that are solely devoted to jokes, absurdity and silliness. For example, the title of the $7^{\text {th }}$ room on the list in Figure 32 reads, Kurdistan Chaxanay Trr Tss ... (Kurdistan: Farting Café). Other rooms provide virtual spaces for political parties' sympathizers, young people who gather to spend time chatting and playing music, and finally those who either offer or need high-tech help. The same diversity of use and online activities can be found regarding websites, weblogs and forums. This confirms findings by other researchers, for example Bernal (2006), studying the Eritrean online activities, who writes: "The sensibilities of farce and the absurd coexist on Dehai [an Eritrean online forum] along with sincere patriotism and utopian yearnings for Eritrea's bright future" (p. 171).

\section{Weblog (Blog)}

A weblog or a blog is a personal webpage that is easy to use, at no cost, and it is supposed to be updated with new entries, called posts, frequently. A number of other characteristics set the blog apart from regular websites. First, blog entries, called posts, often are automatically date-stamped. Second, they are organized in reversechronological order so that the latest post comes first, at the top of the other posts. Third, readers can reply to posts by leaving comments. Finally, posts on a blog are automatically archived, again in a chronological order. Blogs can consist of plain texts, still pictures (photoblog), audio files or videos (vblogs) (Somolu, 2007; Miller \& Shepherd, 2004). One who blogs (verb) is a blogger (noun). 
The exponential growth of blogs has captured the attention of many researchers (Miller \& Shepherd, 2004). The first blogs emerged between 1994 and 1998 (Gurak, Antonijevic, Johnson, Ratliff, \& Reyman, 2004). With the release of several types of blogging software in 1999 (e.g. Pitas, Blogger) the number of blogs proliferated. From a few hundreds, the number of blogs reached over 4 million in 2003 (Herring, Sheidt, Sabrina, \& Wright, 2004), about 50 million in 2005 (Riley, 2005) and over 70 million in 2007 (Somolu, 2007).

Figure 33 A screenshot of the first Kurdish weblog Gulagenim. Retrieved December 12, 2005, from http://gulagenim.blogspot.com/2005/12/blog-post.html

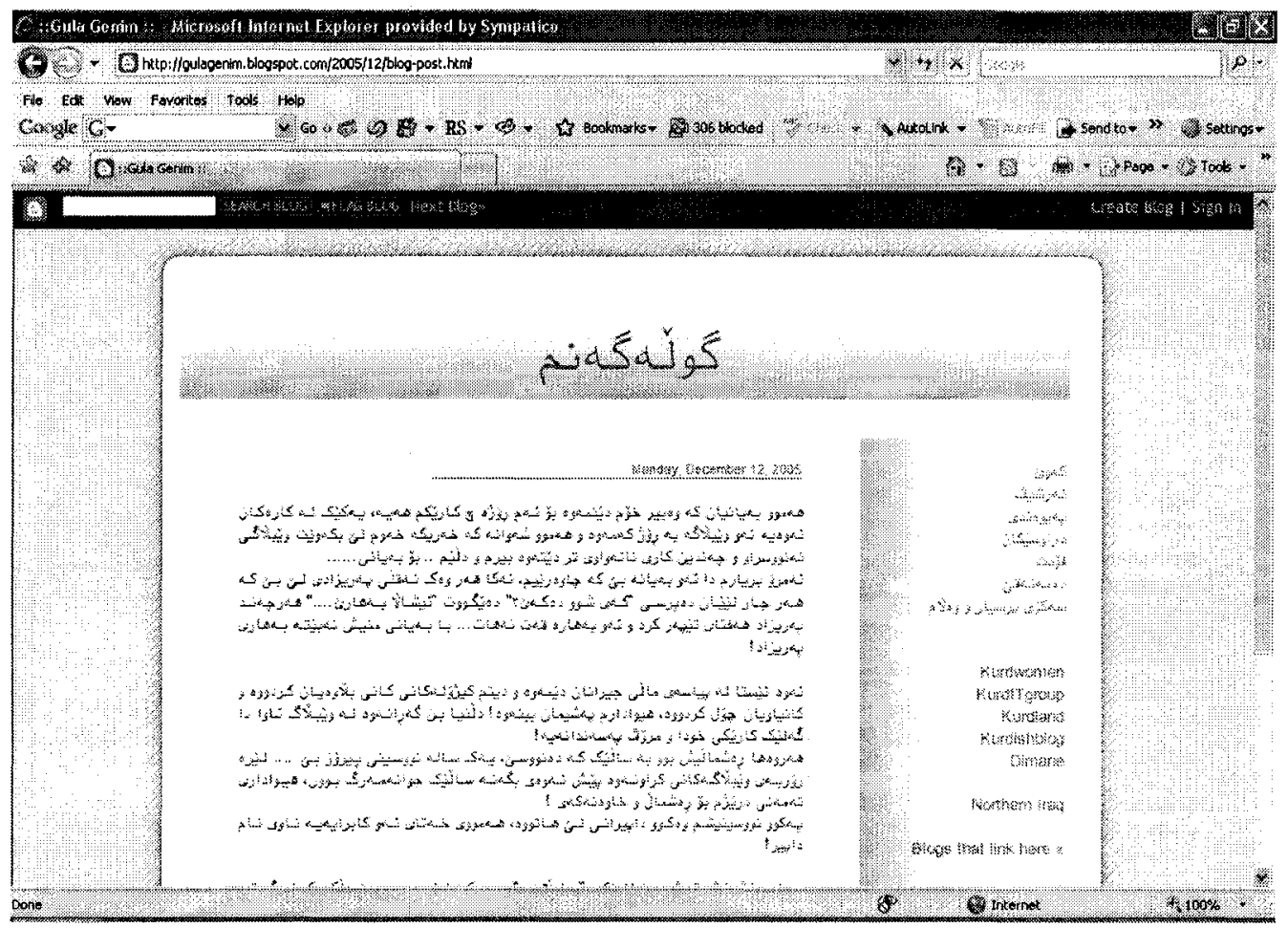

Perhaps the first blog written in Kurdish is Gulagenim (Wheat Flower), which was launched by a blogger with the same nickname on May 26, 2002 (http://www.gulagenim.blogspot.com). Within a few months after Gulagenim's first post 
there were over three-dozen Kurdish weblogs. ${ }^{199}$ The number of Kurdish blogs reached 100 by the early 2004 and 150 by the middle of 2006 (Sina, 2007). In October 2007, the website Koord had a list of 400 blogs managed by Kurds writing in Kurdish and also other languages such as English.

However, the majority of blogs were short-lived (Ahmadi, 2004). Gulagenim, who also was instrumental in designing, modifying and organizing the first Kurdish weblogs, identifies several reasons for the weblogs not becoming popular among the Kurds:

laziness, the challenge of using this new medium which does take some effort, not knowing the mother tongue, and more important than all of this is the fear of being attacked at a personal level when you identify yourself as the author. Weblog is a medium without limits and when you reveal your identity [as the author of your writing] you will become the target of insults by those who do not like your ideas. And this discourages those who start writing. (Ahmadi, 2004, my translation)

As a Kurdish woman, Gulagenim draws our attention to two crucial points with respect to Kurdish composition on weblogs. The first point relates to freedom of expression. The Internet has been commonly viewed as a space where communicative events can take place without many political, social and cultural restrictions. For example, one can hide her or his true identity but still express her or his views on weblogs (Somolu, 2007, p. 483). Also, the Internet has been praised for its ability to foster democratization by giving voice to marginalized people, on the one hand, and enabling interaction among the citizens and between writers and readers or producers and audiences, on the other (Simone, 2006). However, Herring et al. (2004) suggest that "a 'democratizing' technology does not automatically result in social equality, and points to the importance

\footnotetext{
${ }^{199}$ A list of these weblogs were made available on Gulagenim's weblog. Retrieved December 15, 2005, from http://members.allstream.net/gmawaran/bloglist.html.
} 
of social and cultural factors surrounding technology adoption and use." Kurdish writers have often faced persecution in their own homeland. Kurdish women have also suffered from the domination of the patriarchy in Kurdistan (Mojab, 2003). In the next chapter I will show that blogging does provide a safe space where Kurdish women could amplify their voices, as groups of African women have done (Somolu, 2007), but at the theoretical level, it is also important to reiterate that having access to a medium alone does not automatically engender freedom of expression or "democratic" values.

In addition to the lack of individual freedom, which could discourage someone from writing publicly, Gulagenim, in her writing, reveals another obstacle that discourages Kurdish bloggers: their struggle with writing in the mother tongue. The vast majority of Kurds who have gone to school, especially those from Turkey, Iran and Syria, have neither had Kurdish as the medium of instruction nor had it as a subject taught in the public school system. Their discomfort in writing in Kurdish might be the most important difficulty that Kurdish bloggers face. In her first entry on May 26, 2002, Gulagenim wrote: "Let's write in Kurdish. [This is] the first step in Kurdish blogging."

However, based on bloggers' writings, one can infer that writing in Kurdish is not easy, even for committed bloggers such as Gulagenim who has learned reading and writing in her mother tongue on her own. Gulagenim writes that when for the first time she tried to write in Kurdish, she felt that she had difficulty finding words and realized that until then she had only known how to speak the language and not to write it. In the next chapter I will analyze Gulagenim's writing and another Kurdish blog to elucidate their attitudes towards writing in their mother tongue. 
Despite these obstacles to blogging in Kurdish, a sharp increase in the number of Kurdish blogs occurred at the end of 2006 and the beginning of 2007 when the website Kurdblogger was launched. This new platform for the first time made it very easy to blog and write in Kurdish Sorani. Displaying the Kurdish flag and the current date according to the calendar exclusively used by pan-Kurdish nationalists are clear indications that the first and only Kurdish blogging software is devoted to the construction of a cross-border Kurdish identity. These and more overt signs of Kurdishness seem to have been the motivators for hundreds of bloggers to sign up on Kurdblogger. In July 2007, there were over 1000 blogs on Kurdblogger. It is important, however, to note that there are Kurdish bloggers who blog and write on English, Persian, Turkish or Arabic platforms.

Overall, blogging (especially written blogs as opposed to video blogs, audio blogs or photo blogs), like other features of the Internet, have provided Kurds with means of writing in and promoting their language. But, at the same time, the difference in the writing systems of the two major Kurdish varieties is reinforced in blogging. Very few, if any, Turkish Kurds blog, because most of them cannot read or write in Kurdish. Of those who have managed to learn how to read and write in their mother tongue, as many Iranian Kurds have done so, blog in isolation from Kurdish Sorani bloggers.

\section{Other features of the Kurdish Internet}

On the Internet, Kurds also use forums, electronic mailing lists, email and instant messaging services. Recently emerged social networking tools such as MySpace and Facebook have also started to be used by Kurdish individuals and groups. A survey of pro-Kurdish groups on Facebook in October 2007 showed that the group "Support an Independent Kurdistan" had 1,306 members (See Figure 34). This is a relatively small 
number for a people with over 30 million population worldwide. ${ }^{200}$ The use of these services by Kurds, however, is very recent and will take a while to see a considerable presence on these social media services.

Figure 34 A screenshot of Facebook showing a few pro-Kurdish groups. Retrieved October 24, 2007, from http://www.facebook.com/s.php?n=-1\&k=200000010\&q=Kurdistan

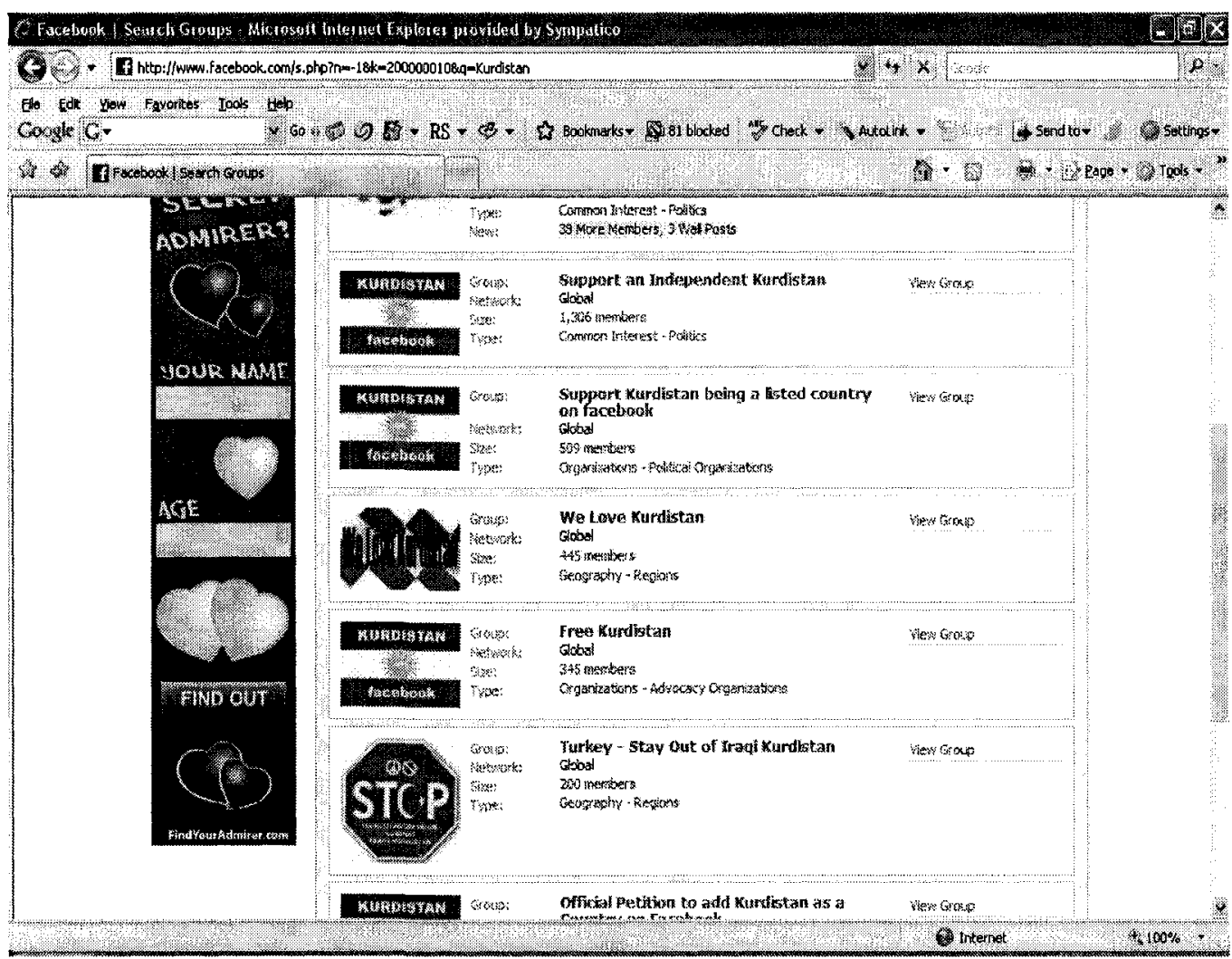

Among these social networking tools the forum seems to be the tool used interactively the most for the promotion of a Kurdish cross-border identity that I am concerned about here. Forums are web-based message and discussion boards to which

\footnotetext{
${ }^{200}$ There are pro-Palestinian groups with over 20,000 members.
} 
original messages or replies to them can be posted. Most forums require registration and adhere to certain etiquettes of discussion and dialogue.

The emergence of these forums among the Kurds is quite recent. Some forums are strictly devoted to the exchange of general information and entertainment, such as personal relationship, health, interest stories, music, computers (e.g. Malî Kurdan/Home $4 \mathrm{Kurd}$ ), but there are also forums that emphasize discussions on the political, cultural and social issues of Kurdistan, for example the forum Roj Bash Kurdistan (Good Day Kurdistan) (see Figure 35). The Figure shows that the forum is organized in several categories that are listed in the left column. The first category on the list, "Kurdistan," with 740 topics, has received 11,170 posts. It is important to note, however, that the vast majority of the posts on this forum are in English. According to Alexa, a web company which measures traffic for websites, except for some visitors from Turkey and yet fewer from Iran and Iraq, Kurds from the west, especially the UK and the Scandinavian countries, make up the majority of the forum's visitors. In contrast, the forum Kurdish Love, which uses Kurdish Sorani as its main medium, attracts well over $50 \%$ of its users and visitors from Iran and Iraq. Another forum, Baydigi, which uses Turkish and Kurdish Kurmanji as its main languages, has over $80 \%$ of its visitors and users from Turkey. Language is one of the main factors that determines the type and size of audiences that Internet sources attract. In the next chapter and through textual analysis I will further underline the significance of language in investigating online activities in general and in the practices of national identity construction in particular. 
Figure 35 A screenshot of the forum Roj Bash Kurdistan. Retrieved October 18, 2007, from http://northerniraq.info/forums/index.php

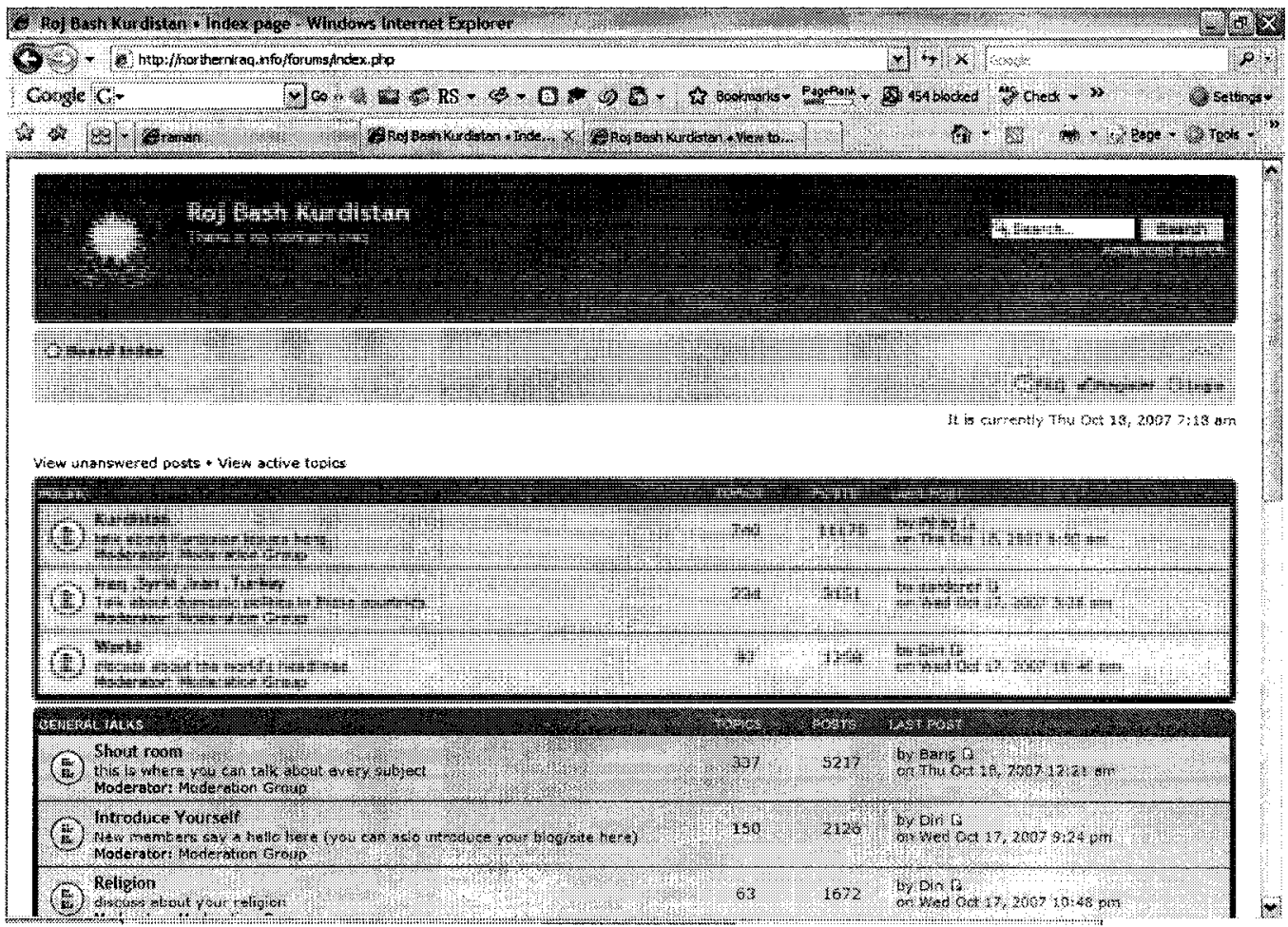




\section{Chapter 12: Textual Analysis of Kurdish Internet}

In the previous chapter, I described the main constituents of the Kurdish Internet. Among them were websites, chat rooms, weblogs and social networking services such as forums and Facebook. I showed that, in contrast to the traditional mainstream media -- including television -- the Internet has amplified marginalized voices that are excluded from the discursive domains of the dominant Kurdish political organizations.

In this chapter, I carry out textual analysis of the verbal language and images of various Internet constituents (e.g. websites, chat rooms, weblogs, forums, and social networking services such as YouTube). My objective is to locate the discursive strategies that are used on the Internet to define and construct Kurdish identities. The focus of the investigation at this level is captured in this broad question: How do Kurdish online resources use language and images to define and present Kurdish collective identities?

To analyze the discourse of the Internet, I will continue using the analytical tools from my analysis of television discourse. For example, by focusing on naming practices I will highlight the significance of words and labels in the URLs of websites and Internet sources. In addition, I will use analytical tools such as vector (definition will follow) in the composition of images and the visual organization of Internet sources. I will also utilize discourse analytical tools that are specific to the structure of the Internet, such as links or hyperlinks. I will explore the organization and distribution of hyperlinks on websites to show that the very structure of the Internet could contribute to discourses of national identity construction. 
The main components of national identity discourse are as follows: A common past and history, present and future, language(s), national symbols, and territory and homeland. ${ }^{201}$ In the subsequent pages, I will present analyses of the discursive constructions that contribute to the articulation of these aspects of Kurdish national identities.

\section{Discursive construction of a common history}

As Martin \& Wodak (2003) note, "[i]dentities need founding myths and certain pasts, which they can integrate easily and positively" (p. 11). Somehow deeper roots in the past make peoples' claims to greatness at present more legitimate. On the Internet, the Kurds are often defined as an ancient nation that has inhabited the same homeland, Kurdistan, since time immemorial.

As discussed earlier, a powerful myth that has become an indispensable part of the Kurdish nationalist discourse is the idea that today's Kurds are the descendents of the Medes, an ancient people, who established the Median Empire (728-550 B.C.) (Hassanpour 1992, p. 49; Kreyenbroek, 1992, p. 70). This myth is reproduced over and over on the Internet in various forms and modes, for example in English, on the website Kurdistanica: The Encyclopaedia of Kurdistan, and in Kurdish, on the website Kurdistan Parliament [Iraq]. Individual Kurds also contribute to the reproduction of this myth, either on their personal websites, for example Dyako, or on public video sharing websites such as YouTube. For example, Figure 36 captures a screenshot of the opening of a video called Median Empire and Fall of Nineveh available on YouTube. The image features a

\footnotetext{
${ }^{201}$ I have discussed these in details in the previous chapters.
} 
Kurdish flag providing the background for the phrase "Median History (Kurdish)." ${ }^{202}$ The word "Kurdish" is put in brackets after the phrase "Median history." The history of Medes is taken to be the same as the history of the Kurds. It is presupposed that today's Kurds are descendants of the Medes. ${ }^{203}$

Figure 36 A screenshot of the video Median Empire and [the] fall of Nineveh. Retrived October 11, 2007, from http://ca.YouTube.com/watch? $\mathrm{v}=2 \mathrm{Lf}$ W9ADw4A
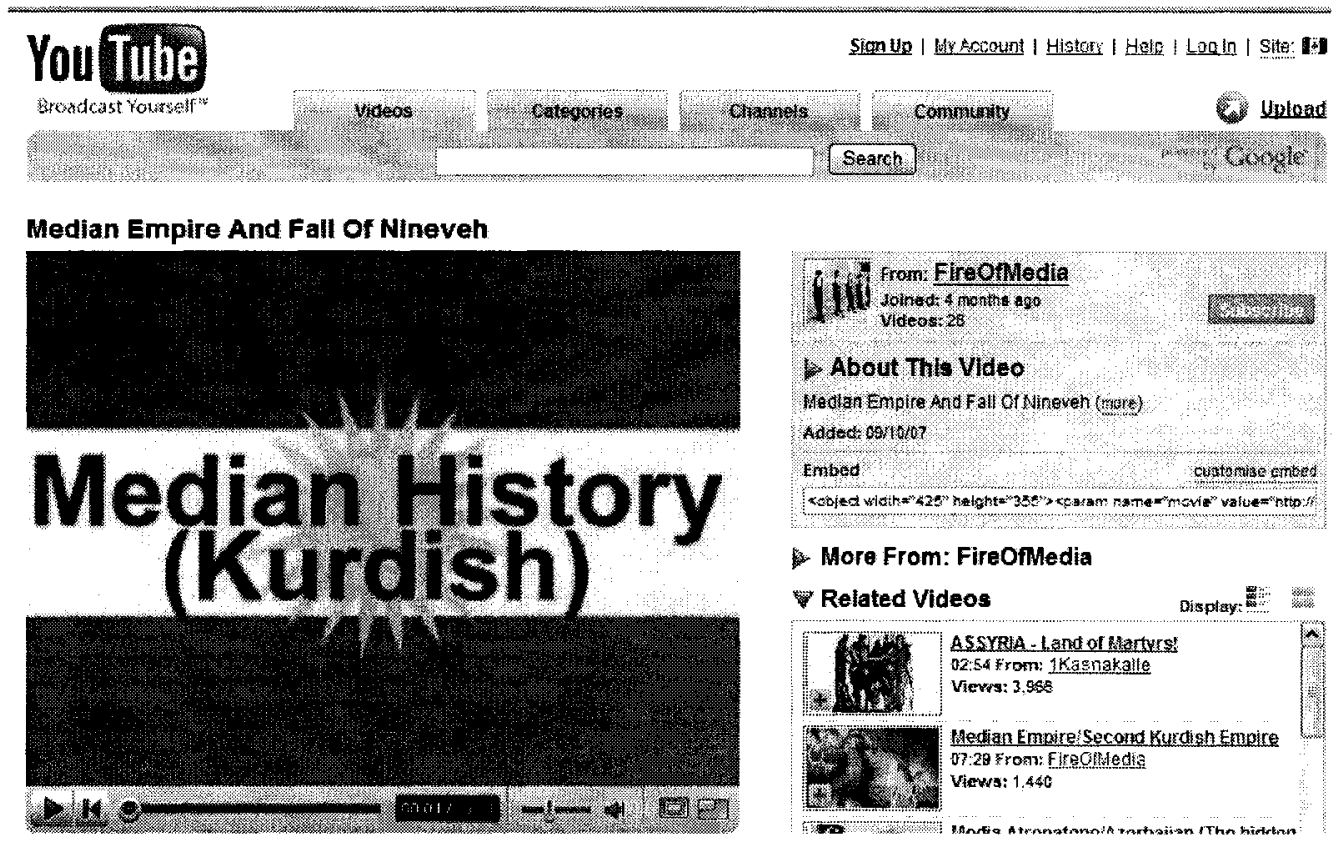

A primordial and glorious history of the Kurds and Kurdistan is also constructed in the images of ancient and historical sites and monuments, some of which, interestingly enough, Armenians, Turks, Assyrians and other ethnic groups and nationalities claim as theirs. For example, out of the over 100 videos on YouTube that are devoted to the history of Kurds and Kurdistan, "Kurdish history, Kurdistan history" is the most viewed

\footnotetext{
${ }^{202}$ For some unknown reason the title of the video on the screen is different from the title it is given on YouTube.

${ }^{203}$ For further information on whether Kurds are descendents of the Medes see Izady (1994).
} 
video. $^{204}$ The video has upset some non-Kurdish viewers because apparently it has identified some Armenian and Turkish sites as Kurdish. This is apparent in the comments left by viewers of the video clip. ${ }^{205}$ A poster, with the username kurdsaresupergay, writes: "the buildings shown in [this] video are mostly [in] turkey [, and] they are either turkish, armenian or arabic built [sic]. How can kurds [sic] build a church?" Another poster, "davidwhitman," writes: "many of the pictures in this film are of Armenian Churches and monuments, not Kurdish." In contrast to posts like these, almost all the posts by the Kurds praise the video, which is indicative of the nationalist sentiment among Kurdish Internet users.

Disputes over archaeological artefacts or historical personalities to prove peoples' greatness have often been a part of nationalist discourses (Wodak et al., 1991, p. 1). This is an example of what Rudolf Burger (cited in Wodak et al., 1991) has called the "nationalist dilation of time" (ibid.). The strategy of historicizing the nation has inundated all nationalist discourses. It expands the nation "into a transhistorical, and thus eternal, entity" (ibid.). What is significant here in relation to the construction of Kurdish national identity is that the narrative identifies one single historical root for a fragmented people. Connecting the Kurds to one common past and common myth, such as the Median Empire, contributes to the construction of a single Kurdish identity, a pan or cross-border identity. Furthermore, this discursive strategy of historicizing the nation suggests that since all Kurdistan was once ruled by one powerful empire, it should be ruled as one

\footnotetext{
${ }^{204}$ The video was posted on June08, 2006, and in one year was viewed about 50,000 times, and it generated about 1,300 comments. Many of these comments are plain racial slurs exchanged between Kurds, Turks, and Armenians. Most comments in the form of postings exchanged between Kurds and Turks were overtly racist.

${ }^{205}$ Most users who upload video clips on YouTube allow viewers to leave comments in reaction to the video. Viewers can also rate the video clip and report issues related to the appropriateness of the clip for the intended audience as well.
} 
single nation-state today. As Fishman (1989) suggests, "The heirs of past greatness deserve to be great again" (p. 276). The historicization of Kurdish identity and the glorification of a unified Kurdish nation in the past are calls for the establishment of Greater Kurdistan.

In addition to an ancient glorious past, a nation is also built on memories of common sufferings and sacrifices that its members have made as a people (Renan, 1990; Smith, 1999). One of these common sufferings in the Kurdish history is the division of Kurdistan. The idea that Kurds and Kurdistan have been unwillingly divided among at least four nation-states has been ingrained in the Kurdish nationalist discourse so much so that the division of Kurdistan can be evoked simply by expressions like çiwar parçe (four pieces), çiwar beş (four parts) or even çiwar (four) alone in particular contexts. ${ }^{206}$ For example, whether intentionally or not, the presence of the number four in the URL of the following web sources playfully evokes the image of a Kurdistan that is divided into four parts: home4kurd.com, it4kurd.com, chat4kurdistan.com, best4kurd.net, bamo4kurd.com, voice4kurd.com, links4kurd.tk, kurd4all.nl, kurd4voice.net. Of course because of the way it is pronounced number 4 also denotes the preposition "for" in the context of URLs, for example in visas4america.com or canadahomes4sale.com. However, in the Kurdish context, " 4 " in a URL could mean more than a preposition because the number connotes the division of Kurdistan. Thus, it is plausible to suggest that 4 means both the preposition and number 4 in the URL of Kurdish websites. ${ }^{207}$ In some URLs, however,

\footnotetext{
${ }^{206}$ Fewer Kurds prefer to think that there are penc besh (five parts) or penc parche (five pieces), as opposed to four parts or pieces, of Kurdistan: Turkish, Iraqi, Iranian, Syrian, and Armenian/Azerbaijani.

${ }^{207}$ The webmasters of at least two websites, IT 4 Kurd and Home 4 Kurd, have confirmed this observation (IT 4 Kurd Group, personal communication, February 21, 2008; Home 4 Kurd, personal communication, February 22, 2008).
} 
for example in kurd4voice.net, 4 clearly does not mean the preposition "for"; it makes reference to the concept of Kurdistan being divided into four parts, and as such 4 is a salient discursive tool contributing to the construction of a cross-border Kurdish identity.

Figure 37 shows the banner of one of these websites, home $4 k u r d$ which is a forum. The Kurdish title of the website is Mali Kurdan (Kurds' Home). The notion of home is elaborated in the drawing of a house placed on the right side of the banner. Number 4 is written on the door of the house. The idea of being divided into four parts is reinforced in the four panes of each window. The semiotic representation of a panKurdish ideology is strengthened by the map of Greater Kurdistan placed behind the Kurdish title of the website parallel to the website's address. This virtual homeland is symbolised further by the Kurdish flag placed on the left side of the banner. Overall, this banner is a clear example of how discursive tools (linguistic and visual) are used to imagine a pan-Kurdish identity and construct the virtual Kurdish nation.

Figure 37 A screenshot of the banner of the forum Mali Kurdan (Home of Kurds). Retrieved august 07 , 2007, from www.home4kurd.com

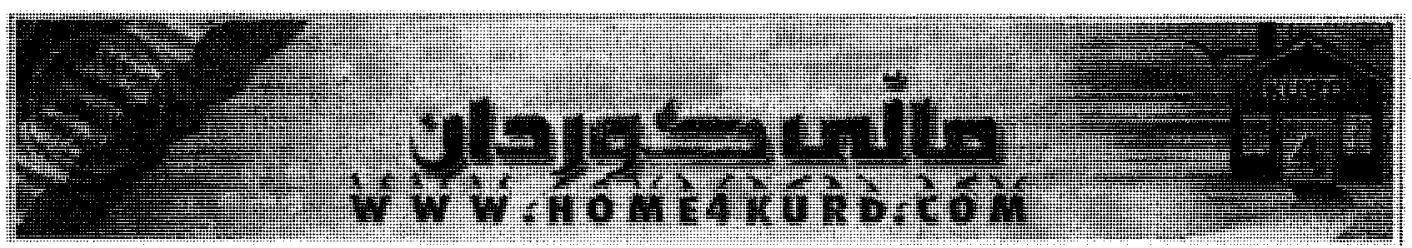

A common Kurdish experience of sacrifice and suffering is also reproduced in remembering a number of events that have occurred in modern times. Among these are major nationalist revolts such as Said Reza's revolt in 1925 in Turkey, the Kurdish Republic of Mahabad in 1945-46 in Iran, and the Barzani rebellion in Iraq from the late 1950 s to 1975 . In addition to the images and accounts of these events, which symbolize 
Kurdish heroism and sacrifice, images of being a victim of history is also strong in the Kurdish nationalist discourse. Among these are images of Halabja and the mass exodus (about two million) of the Iraqi Kurds in 1991.

The prevalent ancient history of Kurdistan constructed on the Internet is similar to the history constructed on KTV. For both, Kurds and Kurdistan have always existed. However, when it comes to modern history and more recent shared memories, there are some important differences. The discourse of the Internet is overtly pan-Kurdish and it is more inclusive. According to KTV's discourse, after the proliferation of Kurdish political parties during and after the Second World War, modern Kurdish history is synonymous with the history of KDP (KTV's owner). Other political parties from all parts of Kurdistan are often excluded in KTV's narrative of Kurdish history. On the Internet, however, the history of Kurdistan includes most of the Kurdish nationalist parties and heroes whether they are regional or pan.

For example, Figure 38 shows a screenshot of a video on the history of Kurdistan posted on YouTube. It includes the leaders of various Kurdish political parties and rebellions from all parts of Kurdistan. These national heroes, some dead and some alive, along with some of the most powerful national symbols in this image (e.g. map of the Greater Kurdistan, mountains and the Kurdish flag) make up the Kurdish modern history. This example indicates that pan-Kurdish identity is more prevalent and explicit on the Internet compared to KTV and perhaps other television stations that are owned by regional political organizations. As I illustrated in the previous chapters, Kurdish identity on KTV is constructed and represented within the overall ideological framework of the station which is defined by its owner's main political goal: securing autonomy for the 
Kurdish region within the state of Iraq. In contrast, a video on You'Tube can be posted by any individual or group who has access to the Internet. The Internet has enabled individuals and groups to sidestep the political constraints that have been imposed on the expressions of a cross-border Kurdish identity by both the dominant Kurdish organizations and the four nation-states of Turkey, Iraq, Iran and Syria. This is an example in point showing the amplification of Kurdish marginalized voices.

Figure 38 A screenshot of the video clip "Kurdistan and Kurd Liberation" on YouTube. Retrieved August 05, 2007, from http://www. YouTube.com/watch?v=PrMVwKsxZOw

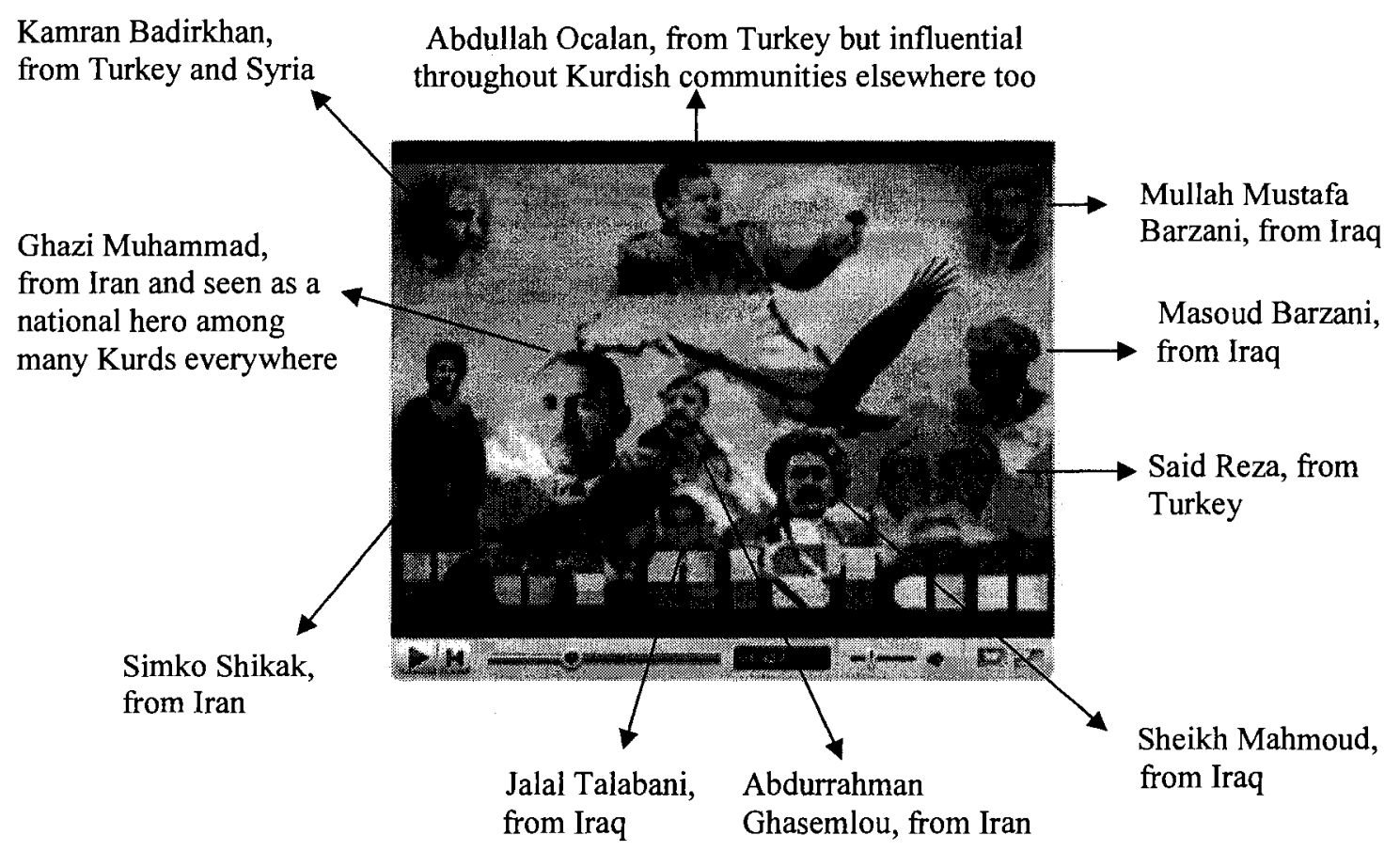

The presentation of the history of Kurds and Kurdistan on the Internet is also different from KTV's in that the former is sometimes overtly racist. For example, the video The Median Empire and the Fall of Nineveh, which I have already mentioned, visually reconstructs the conflicts between the Assyrian Empire and the Medes. In this video the Assyrians are portrayed as invaders, ruthless and barbarous. At the same time, 
the Medes' invasion and burning of Nineveh and beheading of the Assyrian king is celebrated as a noble act, an example of the danger involved in the discourse practices of "othering," which is said to be a characteristic of nationalist discourses (Brubaker, 2004, p. 40; Billig, 1995, p. 66). It is this process of othering and the creation of differences between "us" and "them" that makes nationalist discourses hospitable to racist attitudes and ideologies. There is, however, a difference between how far this discourse of othering can be taken on the Internet versus a controlled medium such as KTV. Control over the content of the Internet has proven to be extremely difficult if not impossible. In contrast, KTV's content is controlled by its owner, KDP. ${ }^{208}$

\section{Discursive construction of a common present and future}

According to Fishman (1989), "[the] heirs of triumphant unity in the past must themselves be united in the present and future" (p. 276). A nation is built not only on common memories rooted in the past but also the existence of consent and the "will" among its members to live together at present and into the future (Renan, 1990, p. 19). Kurdish online activities represent and construct a common present and future for all Kurds.

Thanks to the Internet over a dozen daily news websites have emerged within the past several years. They inform Kurds throughout the world about the current events of Kurdistan. The first Kurdish news agency, Peyamner, which I talked about in the previous chapter, emerged over the Internet. As is evident in its description, the website

\footnotetext{
${ }^{208}$ This is not to suggest that KDP's nationalist discourse could be immune from racist ideologies. However, winning the hearts and minds of the minorities in the region, such as Assyrians and Turkomans, has been very crucial in determining the balance of power in the region. KTV cannot afford to be racist but an unknown individual on the Internet can.
} 
is committed to the construction or reproduction of a cross-border Kurdish identity. The website's description says:

This website is prepared and launched from the capital of Kurdistan. It strives to deliver the news as it happens to the people of Kurdistan and the world ...We work around the clock to deliver the truth about Kurdistan to the readers from the three major cultures of Arab, Turk and Persian so that they become aware of the good intentions of the people of Kurdistan... [Peyamner] wants to be a strong and firm bridge for connecting readers from the four parts of the homeland... (Peyamner News Agency, 2005, my translation, my emphasis)

First, the statement recognizes Hawler, where Peyamner's office is based, as the capital of all Kurdistan and not Iraqi Kurdistan alone: "This website is prepared and launched from the capital of Kurdistan". Secondly, the website seeks to explain the Kurdish issue not just to Arabs of Iraq but also to Arabs of Syria, Turks of Turkey and Persians of Iran; it aims at representing all Kurds to all their "others." The text presupposes that the readers from the three dominant cultures have not been informed well about Kurdish demands and circumstances. Finally, the last sentence leaves no doubt that Peyamner is committed to the construction of a pan-Kurdish or cross-border Kurdish identity because it "wants to be a strong and firm bridge for connecting readers from the four parts of the homeland." This is why it provides news in the two main Kurdish varieties, as well as English, Arabic, Turkish and Persian. Informing non-Kurds about the Kurdish issue is seen as one of the Kurdish Internet's primary functions. Several English-only websites, for example, are operating with this objective (e.g. Kurdmedia.com, kurdistanobserver.com). Furthermore, it is important to note that there are a considerable number of news websites that cover cultural, social and political events from all parts of Kurdistan (e.g. kurdistannet.org, rizgari.com, azadiyawelat.com, renesans.nu, rojhelat.se). 
These websites, similar to Peyamner, present themselves as voices for all Kurds regardless of where they are located or who owns them.

The construction of a common present contributes to the formation of a common future among the Kurds. In other words, once it becomes a common belief that all Kurds share the same experience of oppression and denial, then they may think that they have a common fate and future. It seems natural for people with common problems to seek common solutions. Figure 39 illustrates what that common solution for Kurds might be. Diri Shaswar, a poster on the forum Rojbash Kurdistan: There is no Northern Iraq, envisions the future when the four parts of Kurdistan are reunited. According to his redrawing of the map of the region, in 2007, Iraqi Kurdistan was going to become independent, in 2010 Syrian Kurdistan is going to join the independent small Kurdistan, in 2015 Iranian Kurdistan will be annexed to Kurdistan, and finally, in 2020 there is going to be an independent greater Kurdistan. In addition to the map, the phrase under the maps, "United We Stand" is also significant. The two words "united" and "we" elaborate the solidarity and oneness image of Kurdistan constructed in the maps. Furthermore, the colour of the three words (green, yellow and red) invokes the image of the Kurdish flag. Regardless of how sophisticated or naïve this semiotic envisioning of the future of Kurdistan by a young Kurdish-Norwegian might be, it speaks to the pan-Kurdish ideology that Kurdish emancipation depends on the solidarity of at least four parts of Kurdistan. 
Figure 39 The construction of a common Kurdish future on the forum Roj Bash Kurdistan (Good Day/Morning Kurdistan): There is no northern iraq [sic]. Retrieved July 10, 2007, from http://www.northerniraq.info/forums/viewtopic.php?f $=1 \& t=2471$

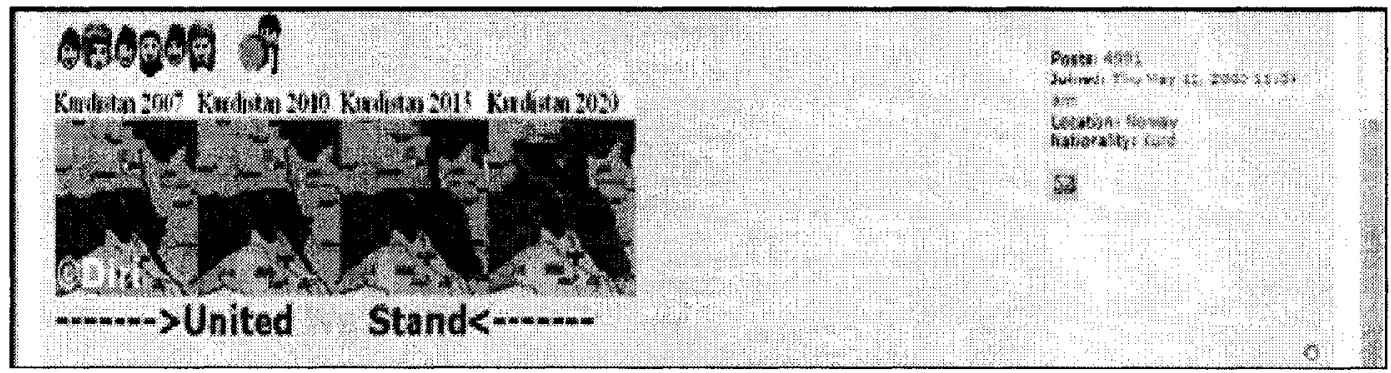

\section{Discursive construction of a common Kurdish language}

I have discussed in previous chapters that language is seen as a decisive symbol of national identity in the Kurdish nationalist discourse because, more than any other ethnic or national characteristic, it separates Kurds from the dominant ethnic groups of Turkish, Arab and Persian (Vali, 2003, p. 100; McDowell, 2004, p. 9; Kreyenbroek \& Allison, 1996, p.1). I have also discussed that what is often referred to as the Kurdish language encompasses a group of speech varieties some of which (e.g. Kurmanji, Sorani, Hawrami and Zaza) are not mutually intelligible in many contexts (Kreyenbroek, 1992). The linguistic fragmentation is reinforced on the Internet (Warschauer, 2002). Some scholars find the Internet to be a savior of minority and endangered languages (Fraser, 1994), but others believe that the Internet fragments peoples and communities along linguistic lines (Schaap, 2004). This paradox is well exemplified in the case of Kurdish speech varieties.

The Internet has been used to maintain, promote and teach Kurdish. Although Kurdish sources use many languages, Kurdish Kurmanji and Sorani are the primary languages of the Kurdish Internet. About a dozen websites effectively use the multimode feature of the Internet (i.e. text, animation and sound) to teach Kurdish to both children 
and adults. ${ }^{209}$ Interestingly, all these websites offer open access to their materials. There seems to be a genuine commitment to the maintenance and promotion of Kurdish language as a vital feature of Kurdish identity. For example, the website Fêrbûnî Zimanî Kurdî (Kurdish Language Learning) (see Figure 40) displays the following slogan: "Language is identity ... Kurdish lessons are steps towards the fortification of Kurdish language." The website $\mathrm{Nefel}$ displays this prominent message on its banner, in Kurmanji: "Kurdish is a sight for sore eyes. Kurds! Preserve your language." ${ }^{210}$ This indicates how important the Kurdish language is in defining Kurdishness.

Holding the mother tongue as a major part of national identity goes against Anderson's (1991) view that, though the nation is imagined in language, it matters very little what language may serve this function (p. 133). For Anderson (1991) the nation was not imagined in any language per se but in print language, and that print language could even be the language of the colonizer and the "other," for example in the case of Ghana. ${ }^{211}$ For many Kurds, however, Kurdishness is imagined in the Kurdish language. ${ }^{212}$

\footnotetext{
${ }^{209}$ The directory Koord provides a list of these websites. koord.com/weblanguage/fer buni kurdi.htm.

${ }^{210}$ The Kurdish Kurmanji text says, Kurdî bînahiya chavên me ye. Kurdino zimanê xwe biparêzn!

211 "Nothing suggests that Ghanaian nationalism is any less real than Indonesian simply because its national language is English rather than Ashanti" (Anderson, 1991, p. 133).

${ }^{212}$ I hesitate to say that Kurdishness is imagined in the mother tongue for the majority of Kurds. It is wellknown that, because their language was banned for decades, Kurds from Turkey including the leaders of the most nationalistic organizations (e.g. Abdullah Ocalan, the leader of PKK) talk and write in Turkish most of the time. In this case, Kurdishness is imagined in Turkish. However, it is equally important to point out that even these organizations and leaders that cannot communicate in the Kurdish language put the right of the Kurds to be educated in their language at the top of their political demands.
} 
Figure 40 A screenshot of the website Fêrbûnî Zimanî Kurdî (Learning the Kurdish Language). Retrieved October 30, 2007, from http://www.kurdi.fi

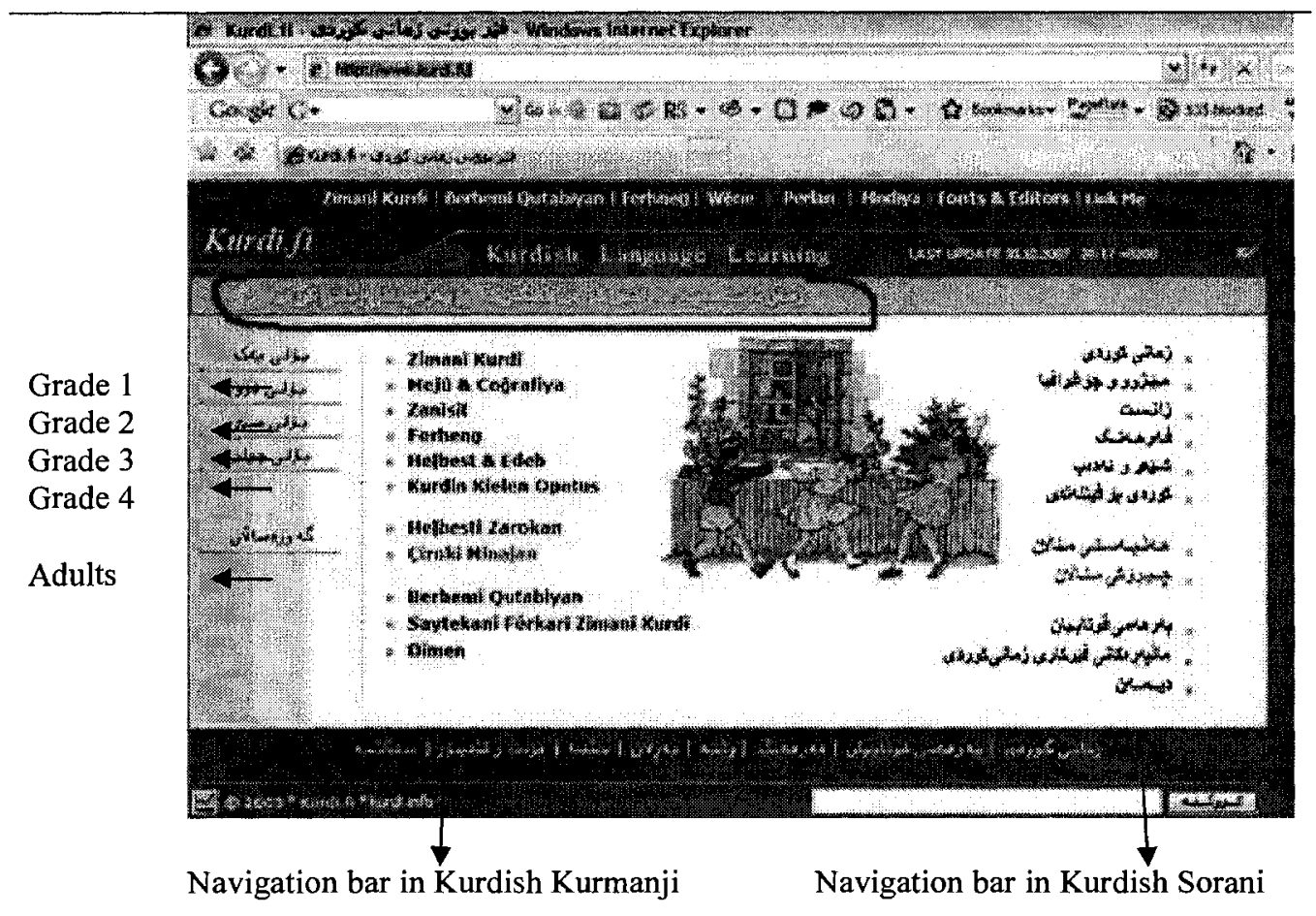

The idea that writing in Kurdish is an indispensable component of Kurdishness

and that the Internet has facilitated writing in Kurdish comes through vividly on weblogs.

The first Kurdish blogger, Gulagenim, in the first post on her blog with the same

name/title writes: "Let's write in Kurdish. [This is] the first step in Kurdish blogging"

(2002a, my translation). In another entry, Gulagenim writes passionately about her

experience of writing in Kurdish:

They never taught me [how to write in Kurdish] ... For me, writing in Kurdish is still like a childhood dream that has not come true, and now as an adult I am approaching it with hesitation and trepidation; I am afraid that I might make too many mistakes, become a stranger with myself ... with my language. (2002b, my translation) 
Gulagenim uses her blog as a space for practicing writing in Kurdish and overcoming the fear of writing in her mother tongue. In a chat room session devoted to Kurdish blogging (Kurdish Bloggers' Session, 2004), Gulagenim admits that prior to blogging she did not know how to write in Kurdish and that the medium has encouraged her and enabled her to write and learn her first language.

Leyla, another Kurdish blogger, echoes Gulagenim's concern:

I have been thinking about what Gulagenim has said that writing in the mother tongue comes with a unique sensation. I have been thinking about the uncertainty and nervousness that I experience every time I want to write in Kurdish ... (Leyla, 2002a, my translation)

Despite difficulties, the two bloggers have continued writing in Kurdish. In fact they have become the veterans of Kurdish blogging and one wonders what keeps motivating them to write. ${ }^{213}$ When admitting the fact that writing in Kurdish is so difficult that it pushes her to quit, Leyla writes:

But, I cannot quit ... Language is a part of me. Words are mirrors that reflect my ideas and feelings ... Without [our] language we are nothing ... A language is as important as a country, history and flag ... Language is a part of our personality ... Language is identity ... To express your inner thoughts and feelings ... you need the language of feelings and the soul; no language is closer to one's feelings and soul than the mother tongue... When writing we might make mistakes ... We may not have a rich vocabulary... but, let's not quit; let's continue [writing] ... (ibid, my translation)

For Leyla, language is important as a national symbol in defining a people; it is also a decisive factor in defining a person. This idea that the mother tongue is a strong link between the individual and the nation has been advocated by prominent scholars of nationalism and language as well. Fishman (1989) states:

\footnotetext{
${ }^{213}$ Although some researchers only refer to the popularity of weblogs and how about 40,000 of them are created on daily basis, other scholars have noted that most of these blogs are abandoned after a short period of time (e.g. months or even days) (Miura \& Yamashita, 2007). The fact that the two Kurdish blogs have been active for about six years is remarkable.
} 
The essence of a nationality is its spirit, its individuality, its soul. This soul is not only reflected and protected by the mother tongue but, in a sense, the mother tongue is itself an aspect of the soul, a part of the soul, if not the soul made manifest." (p. 276, emphasis in original)

Fishman has referred to the rediscovering of the mother tongue as an "intellectual rebirth" (p. 283). It seems that Leyla and Gulagenim have experienced just that by blogging in Kurdish. McLuhan (1960), discussing the impact of the printing press on writing in the mother tongue writes: "Perhaps also the ability to see one's mother tongue in uniform and repeatable technological dress creates in the individual reader a feeling of unity and power that he shares with all other readers of that tongue" (McLuhan, 1960, p. 571 , emphasis in original).

Along with writing, speaking Kurdish has also been enhanced by the Internet. Aram Ahmad, one of the moderators of the most popular Kurdish chat room, Kurdistan United, suggests that many of the people who are regular speakers in that chat room had difficulty discussing political and social issues in Kurdish at the beginning (A. Ahmed, personal communication, July 06, 2007). ${ }^{214}$ This is especially true of the Kurds from Iran, Turkey and Syria who are educated in languages other than their mother tongue. In most of the Kurdish chat rooms, including Kurdistan United, speaking in Kurdish is a must. Speaking in those chat rooms in any other language is considered non-Kurdish behaviour and is not tolerated. At times like this, the chat room moderator usually gives the non-Kurdish user a warning indicating that $\mathrm{s} /$ he cannot use languages other than Kurdish. Users who ignore the warning can either be suspended for a while, meaning

\footnotetext{
${ }^{214}$ In Kurdish chat-rooms, except for well-known people such as politicians, entertainers, and writers, most people do not identify themselves by their real names.
} 
they can still be in the room but they cannot send messages, or they can be bounced from the room for at least 24 hours.

The Internet has also fostered the maintenance and promotion of Kurdish speech varieties such as Hawrami and Zazaki, which have fewer speakers compared to Kurmanji and Sorani. There are several websites, for example Hawraman, that actively use the Hawrami Kurdish variety and promote its status. Other webpages, such as Dibistana Kurdî̀ (Kurdish School), use Dimli as their communication medium and they teach the language. It is important to note that while these websites are very keen in presenting Hawrami or Zazaki as distinct languages, they do insist on their Kurdishness. ${ }^{215}$ Figure 41 illustrates that, although the webpage is devoted to teaching Zazaki/Dimli, it is a part of the website Dibistana Kurdî (Kurdish School). ${ }^{216}$

The Internet provides the means by which Kurdish varieties are promoted but at the same time it seems to be reinforcing the differences between Kurdish language varieties. Previously, I suggested that by broadcasting in different Kurdish speech varieties, Kurdistan TV might gradually enable Kurdish viewers to understand varieties other than their own and this might make communication easier among such viewers. However, this is not the case with the Internet. Most Kurdish chat rooms are separated along linguistic lines. For example, very few Kurmanji speakers, who encompass about $70 \%$ of the Kurdish speakers in the world, participate in the most popular Kurdish chat

\footnotetext{
${ }^{215}$ There are, however, some Zaza nationalists who consider Zazas as a non-Kurdish people/nation.

${ }^{216}$ Previously I have talked about some internal tensions among the Kurdish elites over the status of Kurdish varieties. On the one hand, there are those who consider Hawrami and Zazaki as languages distinct from Kurdish. At the other end of the spectrum, there are Sorani and Kurmanji elites who consider Hawrami and Zazaki as dialects of Kurdish. Finally, there are those who call for two things: (1) the right of the speakers to determine the status of their speech variety (i.e. its Kurdishness or otherwise); (2) the right to be educated in the mother tongue regardless of whether the speakers consider their tongue to be a Kurdish variety or not.
} 
room, Kurdistan United, dominated by Sorani speakers (A. Ahmed, personal communication, July 06, 2007). Kurmanji speakers including those from Iraq have their own separate chat rooms. Linguistic fragmentation, albeit of a different kind, is also evident in weblogs. Here the fragmentation is caused by different alphabet systems. For example, almost all the bloggers who have subscribed to Kurd Blogger, be they speakers of Sorani, Hawrami, or Kurmanji Kurdish, write in the Arabic modified alphabet. This practicality separates the Kurds of Turkey, who write in the Latin modified alphabet, from the Kurds of Iran and Iraq.

Figure 41 A screenshot of the website Dibistana Kurdî: Dimlî/Zazakî (Kurdish School: Dimli/Zazaki). Retrieved January 15, 2007, from http://modersmal.skolutveckling.se/nordkurdiska/zazaki/start.htm

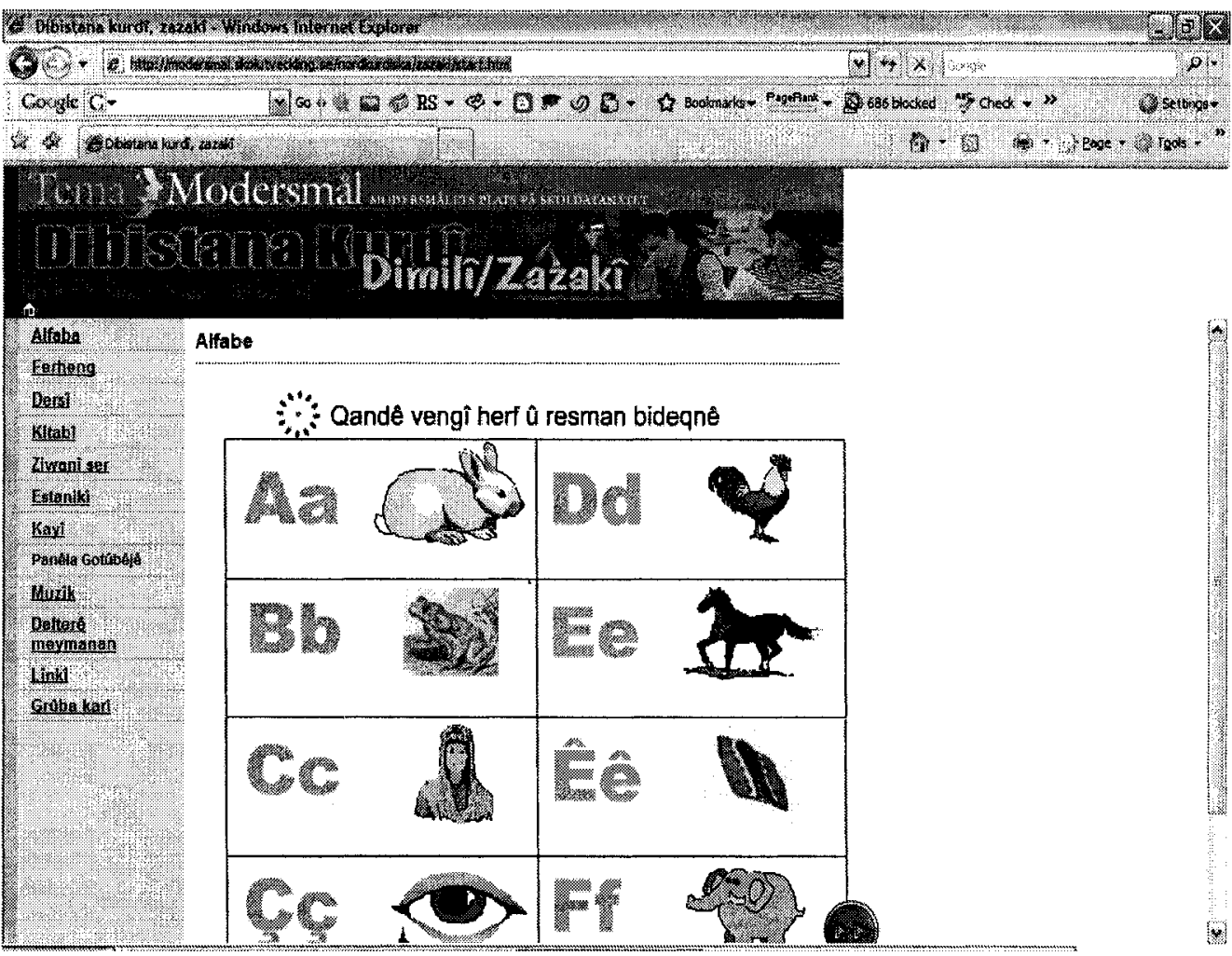




\section{Discursive construction of common national symbols}

Whereas varieties of language can be a fragmenting factor, national symbols are among the most common homogenizing forces. In this section, I use the concepts of given and new information (Goodman, 1996) and vectors to examine the visual location and presentation of images and links to national symbols (such as the flag, patriotic songs, folk and popular songs, and images of mountainous landscapes in Kurdistan) on Kurdish websites.

The most striking common national symbol on the homepage and banner of Kurdish websites, weblogs, forums and chat rooms is the flag (see Figures 42,43 and 44). On the top banner of the website Koord, which is the most comprehensive Kurdish Internet directory and therefore one of the most frequently visited websites, the Kurdish flag is placed in the centre (see Figure 42). Placing the flag in the middle of the banner is only one way in which the flag is given prominence.

Figure 42 The top banner of the website Koord. Retrieved December 17, 2006, from http://www.koord.com

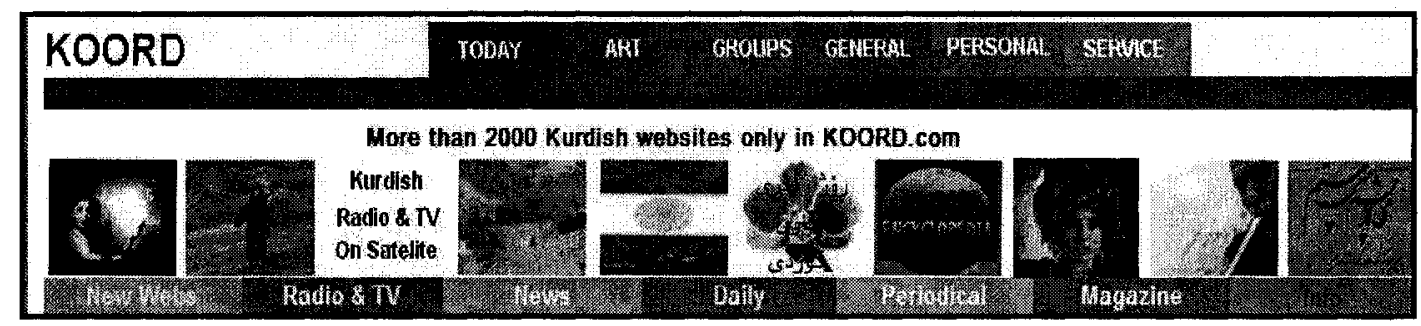

Figure 43 illustrates the top banner of the website Islam Paik (Messenger of

Islam). Here, several observations can be made about the position of the flag on websites.

First, the position of the flag on the right side of the banner is significant. Generally, in English writing, the given information comes first followed by the new information 
(Goodman, 1996, p. 55). This principle is also applicable to websites. On English websites, the navigation menu is the given, common and familiar information, and is placed on the left side of the homepage. Kurdish Sorani is written from right to left. Thus, what is placed on the right, the flag, is the given, common and familiar information. A powerful presupposition is embedded here: the Kurdish flag is considered a common and familiar symbol of Kurdishness. It is also significant to note that the flag is depicted in a waving position which denotes movement and activity, a sign of Kurdish identity being on the move and in the process of becoming. ${ }^{217}$

Figure 43 The top banner of the website Islam Paik. Retrieved December 13, 2006, from http://www.islamipail.org

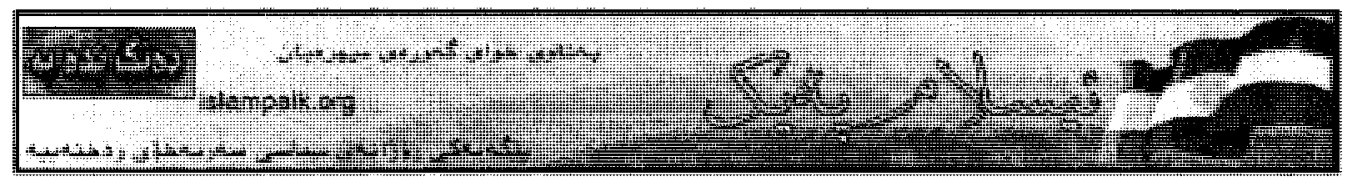

The flag in this banner also acts as a vector. According to Kress \& van Leeuwen (1996, p. 56), vectors are "lines which lead the eye" when looking at an image. They guide the viewer to look at the components of a visual composition in a particular sequence; they show the narrative pattern in an image. ${ }^{218}$ In the banner of the website Islam Paik (see Figure 43), the Kurdish flag, as a familiar symbol to Kurdish viewers, acts as a vector to lead the eyes to the title of the website: ئيسلام بِيك (Islampaik) and from

\footnotetext{
${ }^{217}$ There are also numerous websites on which waving Kurdish flags are presented as animations.

${ }^{218}$ According to Kress \& van Leeuwen (1996, p. 56), vectors are helpful to "visually realize different ways in which objects and their relations can be represented" (ibid.).
} 
there to the rest of the banner. ${ }^{219}$ Here the flag is not only a national symbol, but it also leads audiences' online reading and viewing activities. The flag marks both the website and the discursive practices it fosters as Kurdish.

There is one more position in which the symbolic importance of the flag is indicated: in the address bar of websites (see Figure 44). Many websites have the Kurdish flag as part of their URL; the image of the Kurdish flag is placed in the URL bar preceding the website's address. In this case, the flag is placed on the left side of the homepage, or the URL address bar, because the address is written in a left to right script (i.e. English). In this case too, the flag is again the given information and the familiar and common Kurdish national symbol. The flag is again leading the eyes.

Figure 44 The Kurdish flag preceding the URL of Kurdistan Net: www.kurdistannet.org

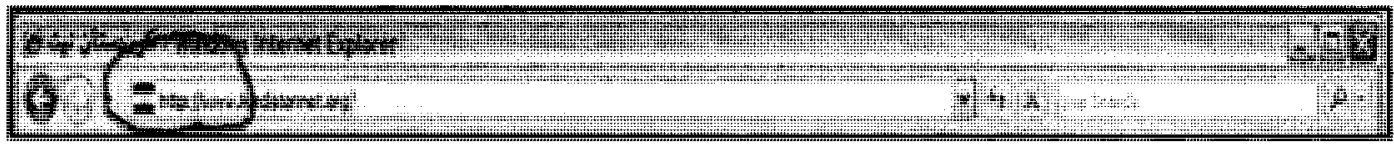

Along with the flag, other national symbols, such as audio and video clips of patriotic anthems and folk and popular music, and images of national heroes, mountains and rural Kurdistan, are prominent on Kurdish websites, weblogs and forums. Sometimes all these symbols are presented on the banner of a single website, for example Koord where just the top banner encompasses a number of Kurdish symbols in addition to the

\footnotetext{
${ }^{219}$ In the rest of this banner, after the flag, the title of the website becomes the vector. It leads eyes to the rest of the components of the banner possibly in this order: first, the line at the top of the page which says, "be nawî xuway gewrey mikreban (in the name of the great and compassionate God)," second, the dark blue box in the far left corner, which says, "deng bide (vote)," third, the title of the website in English, and finally, the line under the title which says, "pêgeyekî rojaney siyasî serbexoy rexneyîye ([Islam Paik] is an independent, critical and political daily source)."
} 
flag (see Figure 44). The black and white picture placed at the far left side is linked to the music video of one of the most popular Kurdish patriotic songs, Her Kurd Buyn u Her Kurd Debin (We Have Always Been Kurds, and We'll Remain Kurds), written and performed by Iraqi Kurds. ${ }^{220}$ The next image, showing a girl dressed in red and standing in a typical Kurdish rural landscape, is linked to the music video, Berîvan (milkmaid), of Leila Fariqi, a female singer from Iranian Kurdistan and well-liked throughout Kurdistan (Tomi, n.d.). In the song, Fariqi sings in both main Kurdish varieties of Sorani and Kurmanji. Kurdish bilingual singing has become a deliberate expression of panKurdishness, and it has been interpreted as a way of defying fragmentation among the Kurds. It is believed that singing in both major speech varieties brings the Kurmanji and Sorani closer to each other and makes communication among the speakers of the two varieties easier (Himmati, 2007). ${ }^{221}$

The hyperlink next to Fariqi's is labeled "Kurdish Radio \& TV on Satellite," which leads to a comprehensive list of Kurdish radio and TV stations with complete information on their frequency and so forth. It is safe to suggest that hyperlinks to Kurdish satellite television channels are among the most common on Kurdish websites

\footnotetext{
${ }^{220}$ The lyrics of this anthem are by the late Ibrahim Ahmed, a well-known Kurdish poet, novelist, essayist and politician who also happened to be Jalal Talabani's (Iraqi President) father-in-law.

${ }^{221}$ Any firm judgement on the validity of this hypothesis should be based on solid fieldwork and research that seeks to investigate Kurdish speakers' experiences with exposure to different Kurdish varieties. Having said that, it should be stressed that Kurdish singers believe that singing in different Kurdish varieties brings those varieties closer to each other and it will make them more mutually intelligible. For example, Heval Ibrahim, a Kurmanji singer, is quoted as saying, "I think it is wonderful that Sorani singers sing in [Kurmanji] and [Kurmanji] singers sing in Sorani, because when Sorani singers sing in Kurmanji they manage to have their Kurmanji audience listen to the Sorani songs as well. Kurmanji audiences end up memorizing the Sorani songs and this way they start understanding Sorani ... Today, most of the youth in [Kurmanji speakers region] can understand Sorani thanks to singers like Zakaria, Eyub Ali, Adnan Karim and many more who sing in both varieties" (Himmati, 2007, p. 17, my translation). Is this quote really saying that bilingual singing will make the varieties mutually intelligible, or is it simply claiming that it will increase bilingualism among the audience?
} 
and weblogs indicating the importance of satellite technology among the Kurds, as I argued in previous chapters.

The next image on the banner (Figure 42) is hyperlinked to a cheerful song, Şahjina Rojhelatê, by one of the most popular singers among the Kurdish youth, Zakaria Abdullah (Topecik, n.d.). Although a native speaker of Sorani, Zakaria sings this song in Kurmanji. With both lyrics and images, Zakaria takes a virtual trip through most of the towns, cities and regions of the Greater Kurdistan and says of each stop: "lê rinde, lê rinde" (it is so beautiful, it is so beautiful). The rest of the images on the banner of the website Koord are linked to Kurdistan's landscapes (see Figure 45), Kurdistan Encyclopedia, Kurdish calendar, ${ }^{222}$ and Kurdish folk music. The last box on the right side of the banner is linked to a single artwork consisting of traditional Persian handwriting. Written artfully in both Persian and Kurdish, the artwork quotes Rene Descartes' famous saying: "I think, therefore I am." The connotation here seems to be that for Koord, cyber activities are acts of thinking and purposeful practices of identity representations and reproductions.

\footnotetext{
${ }^{222}$ The making and reproducing of Kurdish calendar is another discursive strategy to construct Kurdish nation as primordial and ancient. The Kurdish year in the year 2007 was 2707.
} 
Figure 45 A typical landscape of Kurdistan (the region Alan located on the official border between Iran and Iraq, close to the town of Sardasht in Iranian Kurdistan. Retrieved October 19, 2006, from http://koord.viewbook.com/id/2558/cc9a602b732c44eb343blb0b6ecba743

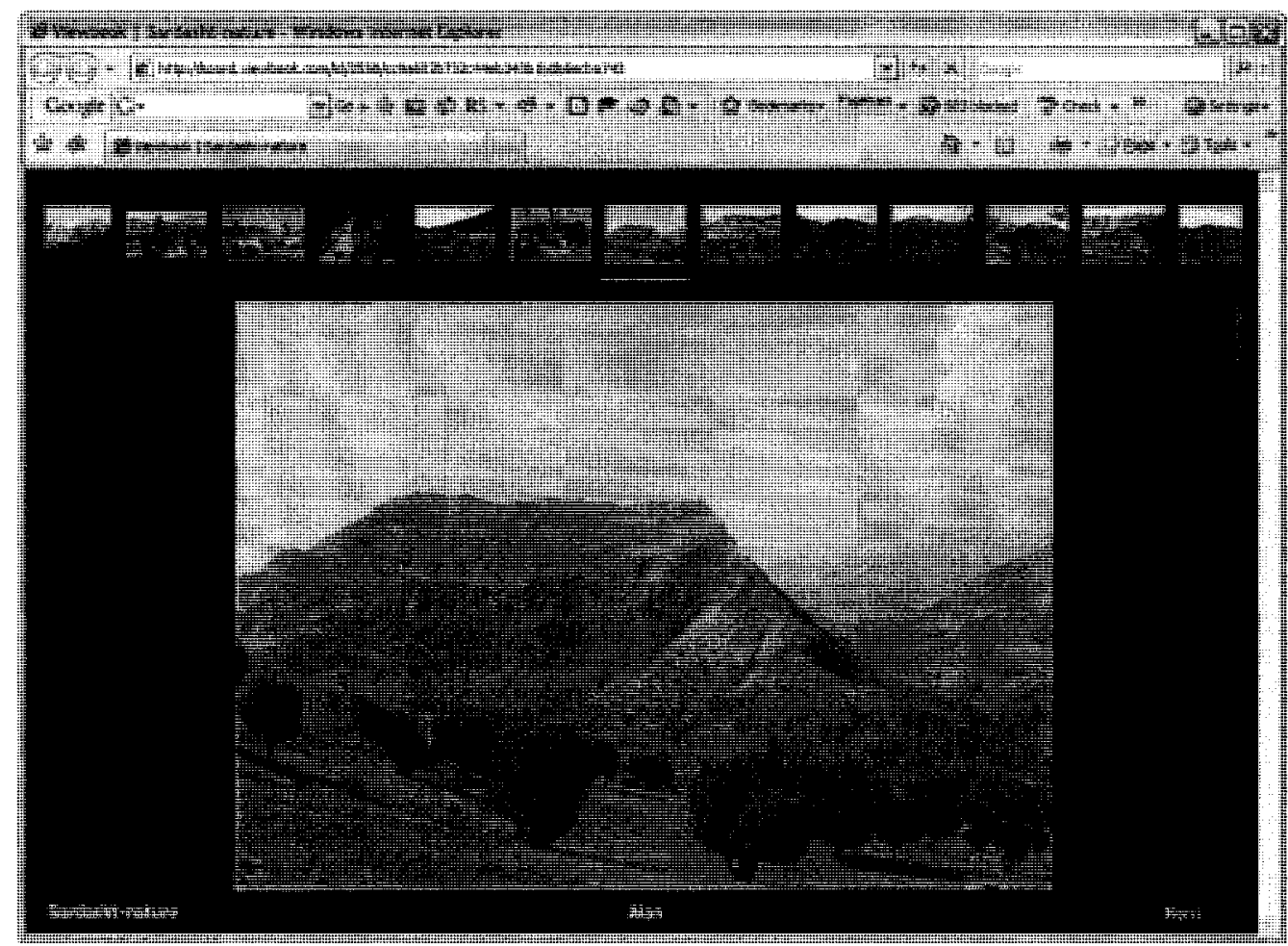

\section{Discursive construction of a common territory and homeland}

One of the most salient discursive means of constructing and reproducing the Kurdish

homeland on the Internet is an extensive use of the word "Kurdistan," which is still prohibited in places like Turkey (for details see chapter six). A Google search for the word "Kurdistan" in the title of webpages, conducted on July 10, 2007, returned about 300,000 hits. This number is significant considering the fact that the same search for the name of an independent nation-state like Tajikistan returned about 700 hits. $^{223}$

"Kurdistan" also appears in the URL of thousands of websites (e.g. Kurdistanpress.com, kurdistannet.org, kurdistanpost.com, akakurdistan.com, kurdistan4news.com,

\footnotetext{
${ }^{223}$ The same search returned about 55,000,000 hits for "Canada," 5,000,000 for "Turkey," 700,000 for "Palestine," and 270,000 for "Nairobi."
} 
kurdistanonline.com). This high usage of the word Kurdistan on the Internet represents and reproduces a cross-border Kurdish identity in that it invokes a common and shared territory for Kurds, a territory that encompasses lands from at least four nation-states (i.e. Turkey, Iraq, Iran and Syria).

In my analysis of KTV, I reported that the map of a greater Kurdistan and its discursive and semiotic reconstruction is subtle. On the Internet, however, the map of Greater Kurdistan is displayed over and over, and in different shapes, colours and sizes. ${ }^{224}$ Since the map is often presented visually on the Internet, it is important to see what prominence is given to it on websites. Looking at banners is particularly interesting because the banner is usually the most stable fixture of a webpage.

Figure 46 illustrates how the map is placed at the focal position of three websites. On the first top banner, which belongs to a small pan-Kurdish organization, Partî Serbestî Kurdistan (Kurdistan Independent [sic] Party), the map is placed in a circle that is almost wrapped in the Kurdish flag. The second banner belongs to the website Rizgarî Online, owned by diasporic Kurds of Turkey living in the Netherlands. ${ }^{225}$ Here the map of Kurdistan is placed on a globe on the right hand side of the banner. On the third banner, again the map is given a prominent position by being situated this time in the centre. The centrality of the map is reinforced by the fact that it has captured the undivided attention of the women in the banner on both sides. The distribution of four colours of the Kurdish flag in the banner reinforces the image of a unified pan-Kurdish identity (i.e. the colour

\footnotetext{
${ }^{224}$ There are maps of Iraqi Kurdistan but not in its entirety. These maps show the part of Iraqi Kurdistan that is administered by the Kurdistan Regional Government only, not all the regions of Iraqi Kurdistan that are considered parts of Kurdistan in the Kurdish nationalist discourse. The map of the Greater Kurdistan, however, includes all the places with considerable Kurdish population. There are also maps that exaggerate greatly the size of the Kurdish populated territories. These maps have been even more controversial. ${ }_{225}$ This observation with respect to the location of the website is based on the fact that Dutch is one of the languages of the websites, the others being Kurdish and English.
} 
white is expressed in the snowy mountains in the background, green, red and yellow are underlined by their use in the map, the title of the website (Kurdish www) and finally the women's headscarves.

Figure 46 Examples of the map of the Greater Kurdistan placed on the banner of three websites: Partî Serbestî Kurdistan (Kurdistan Independence Party), Rizgarî Online, and Kurdish WWW, respectively from top to bottom.
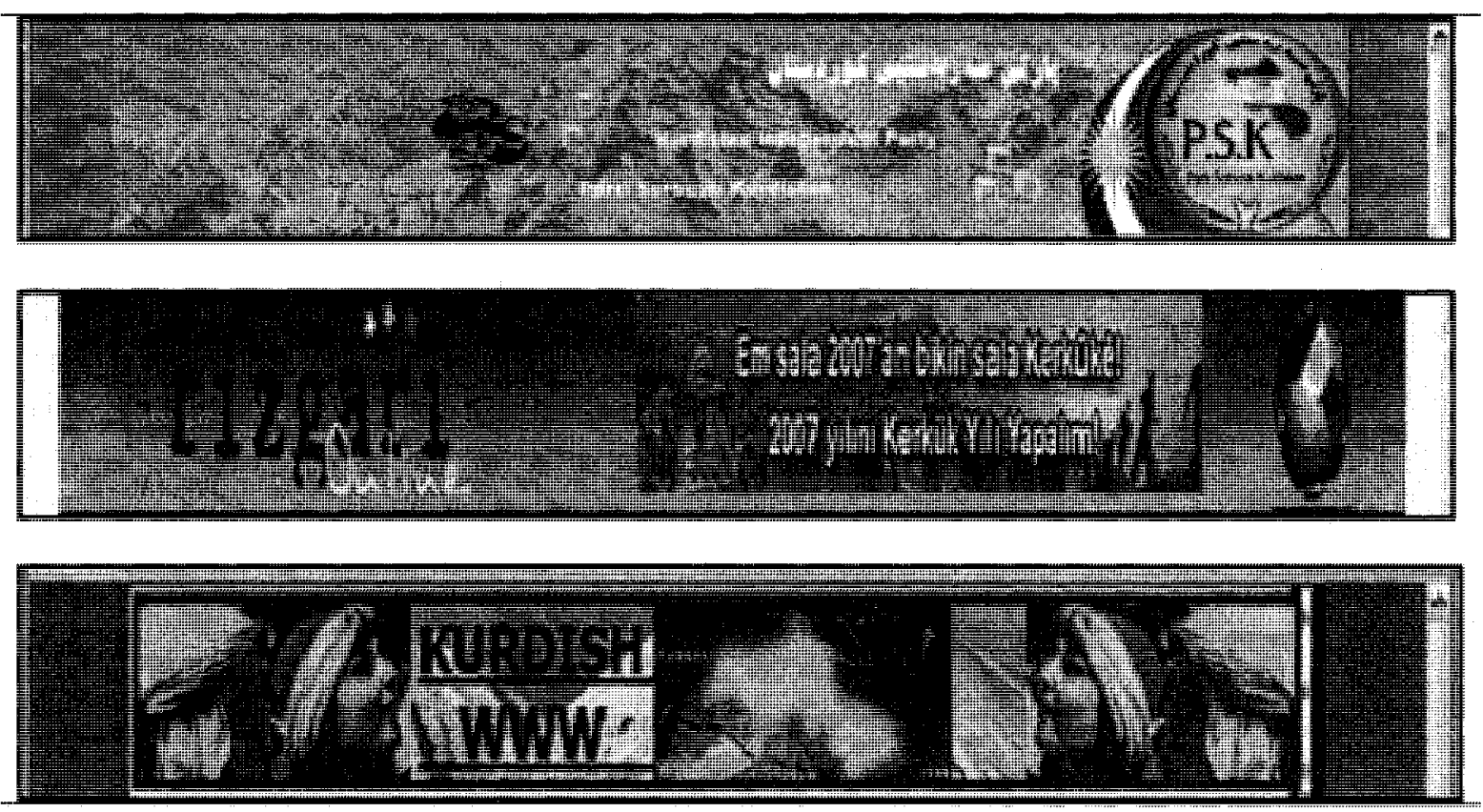

By examining the links or hyperlinks of websites and online sources we can see who is included and who is excluded in the collective identity that is being expressed. Links lead viewers of one webpage to other pages on the same website or more importantly to other websites and web resources. According to Sorapure (2003), "links can be read as expressing meaningful connections or relations" (p. 14). In fact, it has been suggested that "an important component of critical literacy for Web readers is learning how to interpret [links]" (ibid.). Halavais (2000) has effectively demonstrated that "while 
nation borders seem to be less intrusive on the web than they are in earlier networked media, the resilience of cultural structures is demonstrated in the organization of this new medium" (p. 8). ${ }^{226}$ Examining the hyperlinks of 4000 websites from sixteen countries, Halvais (2000) observes that the actual national borders had a direct effect on the distribution of hyperlinks and where they were linked to. That is, for the most part, websites provided links to online resources that were from the same nation and located within the same physical national borders. Based on this connection between hyperlinks and the borders of the homeland, we can look at a website's hyperlinks to see how borders of the nation are drawn. ${ }^{227}$

There are several web directories (e.g. Kurdland, Koord, Legoorin, and Kurdlinks) that provide hyperlinks to thousands of websites and Kurdish online resources in different Kurdish speech varieties (i.e. Kurmanji, Sorani, Hawrami, Zazaki), English or Swedish, belonging to Kurds from different parts of the world. The important thing is that the websites that are indexed on these directories not only carry content relating to Kurds and Kurdistan, but the vast majority of them are also pro-Kurdish in the sense of being sympathetic to calls for the cultural and political rights of the Kurds. The Kurdish websites and online sources that are connected reinforce each other's discursive constructions of a common Kurdish identity.

\footnotetext{
${ }^{226}$ Halvais (2000) draws on Karl Deutsch's notion of communicative flows, which suggested that these flows (e.g. postal services) are measurable and they could indicate where the borders of the nation are drawn in the imagination of its members.

${ }^{227}$ This finding illustrates the importance of Halavais' (2000) call: "an attempt to describe the social impacts of the internet must include some indication of the structure of this medium" (p. 24).
} 
Figure 47 A screenshot of the most popular links on the website Koord. The Kurdish affiliations of the links (Turkish, Iraqi, Iranian or Syrian) are identified. Retrieved July 10, 2007, from http://www.koord.com

\begin{tabular}{|c|c|c|c|}
\hline $\begin{array}{r}\text { Belonging to Kurds } \\
\text { from } \\
\end{array}$ & Links or & n Koord & $\begin{array}{l}\text { Belonging to Kurds } \\
\text { from }\end{array}$ \\
\hline $\begin{array}{r}\mathrm{IN} \\
\mathrm{IN} \\
\mathrm{D} \\
\mathrm{IQ} \\
\mathrm{IQ} \\
\mathrm{T} \\
\mathrm{T} \\
\mathrm{S} \\
\mathrm{IN} \\
\mathrm{IN} \\
? \\
\mathrm{IQ} \\
\\
\mathrm{T} \\
\mathrm{T} \\
\mathrm{IN} \\
\mathrm{IQ} \\
\mathrm{D}\end{array}$ & 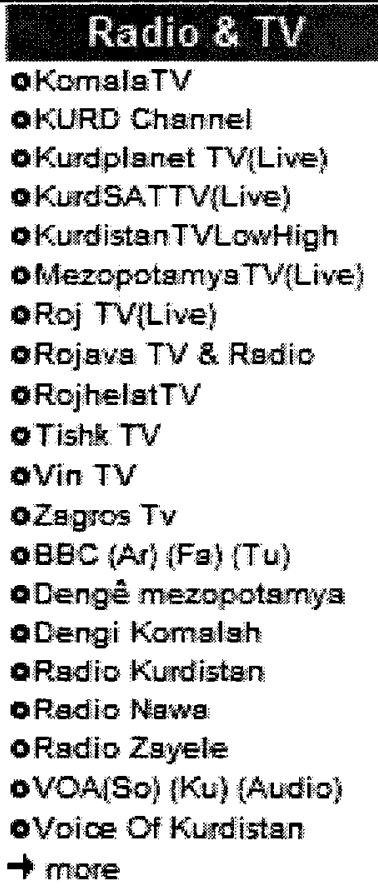 & 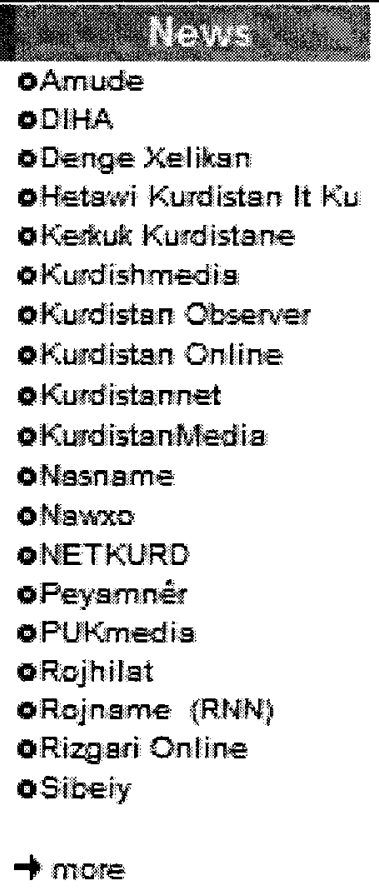 & $\begin{array}{l}\mathrm{S} \\
\mathrm{T} \\
\mathrm{T} \\
\mathrm{IQ} \\
\mathrm{IQ} \\
\mathrm{D} \\
\mathrm{D} \\
\mathrm{IQ} \\
\mathrm{IQ} \\
\mathrm{IN} \\
\mathrm{T} \\
\mathrm{IQ} \\
\mathrm{T} \\
\mathrm{IQ} \\
\mathrm{IQ} \\
\mathrm{IN} \\
\mathrm{D} \\
\mathrm{T} \\
\mathrm{IQ}\end{array}$ \\
\hline
\end{tabular}

Figure 47 shows a partial screenshot of hyperlinks provided on the website Koord. These links, shown in two columns in the middle of figure 47, are connected to the most popular online Kurdish news sources (the left column), and television and radio stations (the right column). In the far left and right columns, I have indicated each link's affiliation with different Kurds (e.g. of Iran, Iraq, Syria, Turkey, and diasporas). The Figure shows that links are connected to news and entertainment sources that belong to and are managed by Kurds from different parts of Kurdistan, in addition to Kurds from diasporic communities. This shows that the very structure of the Internet (i.e. hyperlinks) 
has been utilised to symbolize expressions of a cross-border Kurdish identity, of the awareness that Kurdistan and Kurdish nation are divided, and of the desire to be more connected and to communicate more effectively. The image of a greater Kurdistan is reconstructed infinitely in the minds of those who visit one of the most reliable and commonly used Kurdish Internet directories. 


\section{Chapter 13: Discussion and Conclusion}

As discussed earlier, the particular version of CDA that I have adopted in this study enables analysis of media discourse at three levels: discourse practices, text, and sociocultural context. The previous five chapters were devoted to the first and second levels of analysis. My analyses at these two levels have described and interpreted the communicative events and discursive constructions facilitated by KTV and the Internet. This has enabled me to show how and out of what Kurdish national identities are constructed, and who constructs them. In this chapter, I attend to the third level of analysis, the explanation of identity discursive constructs in light of the socio-cultural and political contexts that bear upon these discourse formations. At this level of analysis, I attempt to explain why identities are constructed the way they are and what the implications of these constructions might be. In addition to my socio-cultural and political analysis of identity discursive constructs on KTV and the Internet, I will briefly discuss some research implications based on the findings of this study.

\section{Socio-cultural Aspects of KTV}

\section{Recapturing KTV's background}

KTV belongs to one of the oldest and largest political parties in Kurdistan-Iraq, Kurdistan Democratic Party (KDP). KDP's leader, Masoud Barzani, is the "President" of the Iraqi Kurdistan region. His nephew, Nechirawan Barzani, is the Prime Minister of the Kurdistan Regional Government (KRG). In KRG, KDP shares power with the other, rival, major organization, Patriotic Union of Kurdistan (PUK), and a number of other 
smaller organizations, albeit in limited measure. PUK's leader, Jalal Talabani, is the current Iraqi president. At the same time, since the fall of Saddam Hussein, high ranking members of KDP have been key players on the Iraqi political scene, both in the Iraqi National Assembly and the Iraqi cabinets. ${ }^{228}$

$\mathrm{KDP}$, as with all major Kurdish organizations, is a regional organization that seeks autonomy for the Kurds in its region, Iraq. It has not identified itself either as a separatist or a pan-Kurdish nationalist organization. In response to the occasional "separatist" charges it faces, ${ }^{229} \mathrm{KDP}$ leaders have continued to declare openly and officially that they have no ambition for the establishment of an independent "smaller" Kurdistan (Kurdistan-Iraq) or a greater Kurdistan. In 2003, Masoud Barzani, in a statement originally published in the Arabic-language newspaper, $A l-T a$ 'akhi, wrote:

"We will make every effort to defend a united Iraq providing that it is a federal, parliamentary, and democratic Iraq" (Barzani, 2003; see also O'Leary 2002). ${ }^{230} \mathrm{KDP}$ 's official stance on Iraq, Iraqi Kurds, and other Kurds, is presented in the following excerpt from KDP's self-descriptive text, which can be found on many websites of KDP:

Preservation of unity and integrity of Iraq is an aim of the party... the rights of the Kurds in neighbouring countries can only be guaranteed through democratic and peaceful means within the boundaries of states in which the Kurds live. Furthermore, the KDP has always adopted the policy of non-intervention in the internal affairs of neighbours [sic]. (General information on KDP, n.d.)

\footnotetext{
${ }^{228}$ For example, since the fall of Saddam Hussein, Hoshyar Zebari, a high ranking member of KDP, has been the Iraqi Foreign Minister.

${ }^{229} \mathrm{KDP}$ is not alone in being labelled a separatist; almost all Kurdish organizations and nationalists have gone through this experience.

${ }^{230}$ In an interview with the Turkish newspaper, $A k s ̧ a m$, Jalal Talabani, the second most influential Iraqi Kurd, and the current president of Iraq, declared: "I have never thought of establishing a Kurdish state or separating Kurdistan from Iraq" (Talabani: Le jiyanim da ..., 2005).
} 


\section{Contentions within KTV/KDP discourse}

My analyses in this study show that the representation of Iraq beyond Iraqi Kurdistan is minimal on KTV. Most of KTV's discourse practices and discursive constructs represent Iraqi Kurdistan as a free, autonomous, and even independent small Kurdistan. At the same time, a great number of KTV discourse practices aim at constructing and reproducing a cross-border Kurdish identity. In contrast, minimal space is given to the articulation of an Iraqi identity. How does one account for the paradox which saturates KTV's discourse? This is an important and interesting question when we realize that the majority of observers, including Kurdish organizations, believe that establishing a greater Kurdistan is not imminent, realistic, or practical (O'Leary \& Salih, 2005, p. 15). Furthermore, the states of Turkey, Iran and Syria continue to refuse any kind of autonomy for the Kurds because they believe that this will bring the Kurds one step closer to claiming an independent greater Kurdistan (ibid.). In other words, having any pan-Kurdish ambition could seriously damage regional movements and efforts to guarantee some political and cultural rights for the Kurds in countries other than Iraq as well.

\section{Dialogic analysis of discourse}

According to Steinberg (1999), from a positivist perspective, representation processes are perceived as competitions between actors with very separate discursive fields, and the process of meaning-making in language is straightforward, an "uncomplicated process of sending and receiving messages" (p. 739). From a CDA perspective, however, discourses are not only social, ideological, and embedded in situation, they are also dynamic, interactional and multivocal (Fairclough, 1995a, pp. 54-5). Discourses are characterized by "textual heterogeneity," which "can be seen as a materialization of social and cultural 
contradictions and as important evidence of reinvestigating these contradictions and their evolution" (Fairclough, 1995a, p. 60).

A discourse is often the site of struggle among actors who compete for hegemony and legitimation of their own ideologies. The competition for hegemony between two or more ideologies could take place within the same discursive field, often that of the dominant ideology (Steinberg, 1999). For example, studying British cotton spinners' contentious actions in the 1820 s and 1830 s, Steinberg (1999) observes that

Rather than deploying a distinct economic discourse against political economy, or employing an alternative such as cooperationism, the spinners struggled within this hegemonic genre to establish the legitimacy of their claims. Contention was thus not between predominantly two distinct discourses or frames, but rather within a discursive field largely not of their own choosing. (p. 769)

Subsequently, Steinberg calls for a kind of discourse analysis that focuses on the ways in which “... challengers seek to legitimate hegemonic genres within a field while appropriating pieces to inflect it with their own subversive meanings" (p. 751). Discourses are heterogeneous, and they are inundated with tensions. Tensions within discourses of identity do not necessarily result in producing monolithic and separate identities; they may foster the construction and reproduction of multiple identities that are in a constant dialogue, albeit from very different power positions.

\section{Politics of national identity construction on KTV}

In the case of KTV, discursive strategies constructing a cross-border Kurdish identity inflect the discursive field of the regional Kurdish nationalism of KDP with its own language and signs. All Kurdish satellite TV stations belong to regional and autonomous Kurdish organizations. In other words, pan-Kurdism lacks a distinct discursive field of its own mediated by satellite television. Thus, within the same discursive field of the 
dominant Kurdish regional nationalism, which KTV discourse is a prime example of, individuals who support pan-Kurdism appropriate pieces of that discourse to legitimize its own ideology.

This theoretical position, however, invokes several questions: is KTV management aware of the presence of pan-Kurdish ideology within its discourses? If so, why is it allowed? What are the cultural and political implications of a strong panKurdish sentiment for KDP, Iraqi Kurdistan and other Kurds?

It is safe to suggest that the presence of pan-Kurdish discursive practices is not a secret to KTV management. There are times when pan-Kurdish sentiments are flagged on KTV quite explicitly. For example, on January 07,2007 , in the live program, Rapirs $\hat{\imath}$ (Opinion Survey), audiences were asked to call in and express their views on the following question: "Has KTV been successful in carrying out its national message"? In defining KTV's "national message" the host of the show read the following from a text:

At the time when the entire Kurdish nation from all parts of Kurdistan was hoping to find themselves on KTV screen, KTV chose to carry a message that would satisfy a large segment of the people of [Iraqi] Kurdistan and also Kurdish nation in other parts of Kurdistan and the diaspora. (Talib, 2007, my translation)

The host of Rapirsî is very explicit about the "national message" of KTV: KTV is committed to represent Kurds from everywhere, to become the image and voice of Kurdishness, and to facilitate discourse practices of defining Kurdish identities.

Some suggestions can be made as to why KTV, which is owned by a regional and Iraqi Kurdish organization, promotes a cross-border Kurdish identity. Giving voice to a cross-border Kurdish identity on KTV is not only inevitable but also beneficial for KTV. Van Bruinessen (2000a) observes that a pan-Kurdish sentiment has existed in Kurdistan for a couple of centuries, even though, until recently, it was only an elitist preoccupation 
(p. 10). Horowitz (1992), pointing out that Kurdish organizations have sought regional autonomy or secession for separate Kurdistans since WWII, suggests: "It is no secret that a good many Kurds advocate the creation of a Kurdistan out of portions of several independent states" (p. 122). Given the fact that cross-border Kurdish sentiments are deeply rooted in the Kurdish psyche, it may not be in the interest of KTV to prevent its expressions. KTV is not the sole definer of Kurdish identity; there are several other Kurdish satellite TV stations such as Roj TV, which advocate pan-Kurdism. In other words, KTV faces competition from other satellite TV channels to capture the attention of the largest audiences in Kurdistan and Kurdish diasporic communities. To satisfy its audiences, KTV allows its discourse to be inflected with the ideas and signs of panKurdism.

Having a wider audience among the Kurds from other parts of Kurdistan is beneficial to KTV or, to be more precise, to its owner, KDP with Barzani as its leader. Iraqi Kurdistan has always felt threatened by the powerful neighbouring states of Turkey and Iran, which have sizable Kurdish populations of their own and are not interested in having a powerful Kurdish state in their neighbourhood. These states believe that the existence of an autonomous Kurdistan will motivate other Kurds to demand the same thing. To prevent any serious threat against Iraqi Kurdistan (i.e. military incursion into Iraqi Kurdistan), KDP seeks the support of other parts of Kurdistan. In the case of any imminent threat from the neighbouring states, KDP could use its influence among the Kurds of other parts of Kurdistan to put pressure on their respective states not to intervene in the Iraqi Kurdistan's affairs. For example, in April 2007, the top military general of Turkey threatened that that armed forces would enter the Kurdistan-Iraq 
territory in pursuit of PKK rebels, who are stationed in the mountains of Iraqi Kurdistan. Masoud Barzani was reported by Reuters as saying that "Iraqi Kurds would interfere in Turkey's mainly Kurdish cities if Ankara interfered in northern Iraq" (Aqrawi, 2007).

It seems that Barzani had good reason to believe that attacks on Iraqi Kurdistan would not be without reaction from other Kurds. For example, in April 2007, in response to Turkey's apparent intention of incursion into Iraqi Kurdistan, Hilmi Aydogdu, the leader of the largest Kurdish-based "legal" party in Turkey, Democratic Society Party, said: "any attack on Kirkuk [Kurdistan-Iraq] would be considered an attack on Diyarbakir [the largest Kurdish city in Turkey]" (Turks charge Kurd ..., 2007). This example illustrates that Barzani deems important the support that the governing body in Iraqi Kurdistan has gained from Kurds living outside Iraqi Kurdistan. KDP uses KTV to strengthen this support by disseminating discourses, images and symbols that appeal to many Kurdish nationalists around the world, who aspire to establish a greater Kurdistan state. Thus, alongside a regional Kurdish identity, KTV subtly fosters discursive constructions of a cross-border Kurdish identity.

\section{Socio-cultural aspects of Kurdish Internet}

My analysis of the Kurdish Internet has revealed that the medium facilitates a number of discursive strategies contributing to the construction and reproduction of a cross-border Kurdish identity along with local and regional identities. More importantly, the analysis has shown that the Internet has given voice to those whose views and ways of constructing Kurdish identity are often at odds with both the nationalist discourses of the major Kurdish organizations and the discourse of the nation-states of Turkey, Iran, Iraq and Syria. Furthermore, in an unprecedented way, the Internet has facilitated a 
continuous and largely healthy dialogue among the Kurds from various regions and diasporic communities. However, this observation needs to be contextualized in light of the economic and political situation of the Kurds and Kurdistan.

Whereas expressions of cross-border Kurdishness and the construction of a greater Kurdistan are usually subtle on KTV, they are explicit and prevailing on the Internet. There are powerful and emotionally charged symbols and linguistic constructions that are shared by the vast majority of online Kurdish discourses. Among these are the Kurdish flag, the map of the Greater Kurdistan, images of a common memory that is both glorious and painful, images of common national heroes, and a great preoccupation with Iraqi Kurdistan from all walks of life. The fate of the Iraqi Kurdistan has become a shared and common concern and hope for most Kurds and thus a force of bonding.

\section{Internet access in Kurdistan}

Despite the role of the Internet in the articulation and dissemination of Kurdish identity constructs, the Internet is not as accessible as satellite television for the Kurds for both economic and socio-political reasons. ${ }^{231}$ The World Bank has declared that electronic media such as the Internet "put unequal beings on an equal footing and that makes it the most potent democratizing tool ever devised" (Bernal, 2006, p. 176). The Kurdish case proves that the issue is not so straightforward. For a long time Kurdistan has been among the most underdeveloped regions in Turkey, Iraq, Iran and Syria (McDowell, 2004, pp. $258,477)$. Underdevelopment in Kurdistan seems to have had a direct impact on the extent to which people own computers or are technically literate to use them. The vast

\footnotetext{
${ }^{231}$ Although a much greater number of people in Kurdistan watch satellite television than use the Internet, it does not mean that satellite dish owners are free of persecution in Turkey, Syria or Iran.
} 
majority of Kurdish people cannot be consumers of information or entertainment on the Internet let alone producers of Internet content (Sina, 2007). Lacking either advertising revenue or financial support from public institutions, until recently, many Kurdish websites were technically unsophisticated or short-lived (ibid.). ${ }^{232}$

Use of the Internet among Kurds started in Kurdish diasporic communities. Even today, Kurds living in Europe and North America by far make up the majority of webmasters, bloggers, forum and chat room administrators and moderators. The Kurds living in Kurdistan face several difficulties when it comes to using the Internet. The digital divide, the difference between the haves and have-nots regarding having access to the Internet, certainly applies to Kurdistan. There are still millions of people who do not have personal computers in their homes. Of those who have computers, fewer people have access to the Internet. When available, Internet connection is slow and at the same time expensive (Mills, 2002, p. 85).

\section{Kurdish Internet and censorship}

Researchers have underscored the freedom of expression that many diasporic communities enjoy on the Internet (Bernal, 2006, p. 166). ${ }^{233}$ However, internet users face censorship both inside and outside Kurdistan. As Mills (2002, p. 78) notes, many states impose censorship on Internet usage to prevent political and social activism. Kurds from Turkey and Iran and Syria in particular have often claimed to suffer from this state

\footnotetext{
${ }^{232}$ The observation is made by Behzad Naghib, the webmaster of the Kurdish web directory Koord (Sina, 2007).

${ }^{233}$ For example, Bernal (2006) notes that, "as a communicative space, cyberspace offers considerable freedom from censorship as well as from violence. In fact, I would argue that for Eritreans the possibility of exploring ideas without fear of official reprisal or violence is one of the underlying attractions of Internet commutations" (p. 166).
} 
practice of curtailing freedom of expression. ${ }^{234}$ The censorship measures can take various forms. Sometimes specific websites are filtered and stopped from being viewed inside a country. Other times there may be persecution or arrest of journalists, bloggers or people who contribute materials from the Kurdish regions to websites and online activities. ${ }^{235}$ Kurdish online activities are also troubled by hacking and online intrusion. On numerous occasions, individuals who identify themselves as Turkish interrupt discussions in progress in chat rooms (see Figure 48). ${ }^{236}$ In addition, hacking on Kurdish websites has become routine. In 2007, close to a dozen popular websites were hacked, such as Dengekan, Kurdgoal, Kurdish Media, and Rizgari online (see Figure 49). The hacking is also extended to non-Kurdish websites that acknowledge the existence of Kurdistan and its flag. For example, in February 2007, the website EU Minority was hacked because it carried a page titled "Poster of 100 European Nations" containing the Kurdish flag as a representation of Kurdistan and Kurds of Turkey. As an explicit declaration of the website being hacked the map of "the European minorities" was replaced with a colourful map of Turkey (see Figure 50). These virtual violent activities have turned the Internet into a symbolic battleground between Kurdish and Turkish ultra-nationalists. On September 18, 2007, the online Kurdish daily Renesans reported that within one week, “in retaliation for Turkey's attacks on Kurdish websites, a group of Kurdish hackers,

\footnotetext{
${ }^{234}$ On April 06, 2004, Index Online reported that "Two Kurdish-language news websites based in Germany - www.amude.com and www.qamislo.com - which provide news, pictures and video clips of demonstrations by the country's Kurdish minority, were banned by the government of Syria in mid-March." According to the same source, at the time Syria only had two ISPs and they were both controlled by the Syrian government.

${ }^{235}$ On December 2003, Reporters without Borders (2004) reported that a Syrian Kurdish student named Shagouri was arrested "for sending an e-mail newsletter from a banned site www.thisissyria.net." According to the source, Shagouri was kept in solitary confinement and tortured for at least seven months. ${ }^{236}$ These individuals sometimes highjack the microphone in a chat room or they start text messaging insulting Kurds.
} 
'Gold Hackers,' hacked 100 official/governmental Turkish websites with the domain .gov.tr" (Menaf, 2007).

Figure 48 Sample of Turkish text intrusion into the Kurdish chat room Kurdi Neteweyi (Kurdish Nationalist) on the protocol Pal Talk. Retrieved March 17, 2007, from http://www.paltalk.com ${ }^{237}$

II Bebegim oL II: NEKADAR KURT VARSA HEPSININ OLUSUINU DIRISINI SIKEYIM AMINA KODUMUN PICLERI
NE MUTLU TURKUM DIYENE ATATUR
II Bebegim OL II: NEKADAR KURT VARSA HEPSININ OLUSUNU DIRISINI SIKEYIM AMINA KODUMUN PICLERI
NE MUTLU TURKUM DIYENE ATATUR
II Bebegim OL II: NEKADAR KURT VARSA HEPSININ OLUSUNU DIRISINI SIKEYIM AMINA KODUMUN PICLERI
NE MUTLU TURKUM DIYENE ATATUR
II Bebegim OL II: NEKADAR KURT VARSA HEPSININ OLUSUNU DIRISINI SIKEYIM AMINA KODUMUN PICLERI
NE MUTLU TURKUM DIYENE ATATUR
II Bebegim OL II: NEKADAR KURT VARSA HEPSININ OLUSUNU DIRISINI SIKEYIM AMINA KODUMUN PICLERI

Figure 49 Being hacked the homepage of the Kurdish website Dengekan is covered with a map of Turkey and its flag. Retrieved July 04, 2007, from http://www.dengekan.com

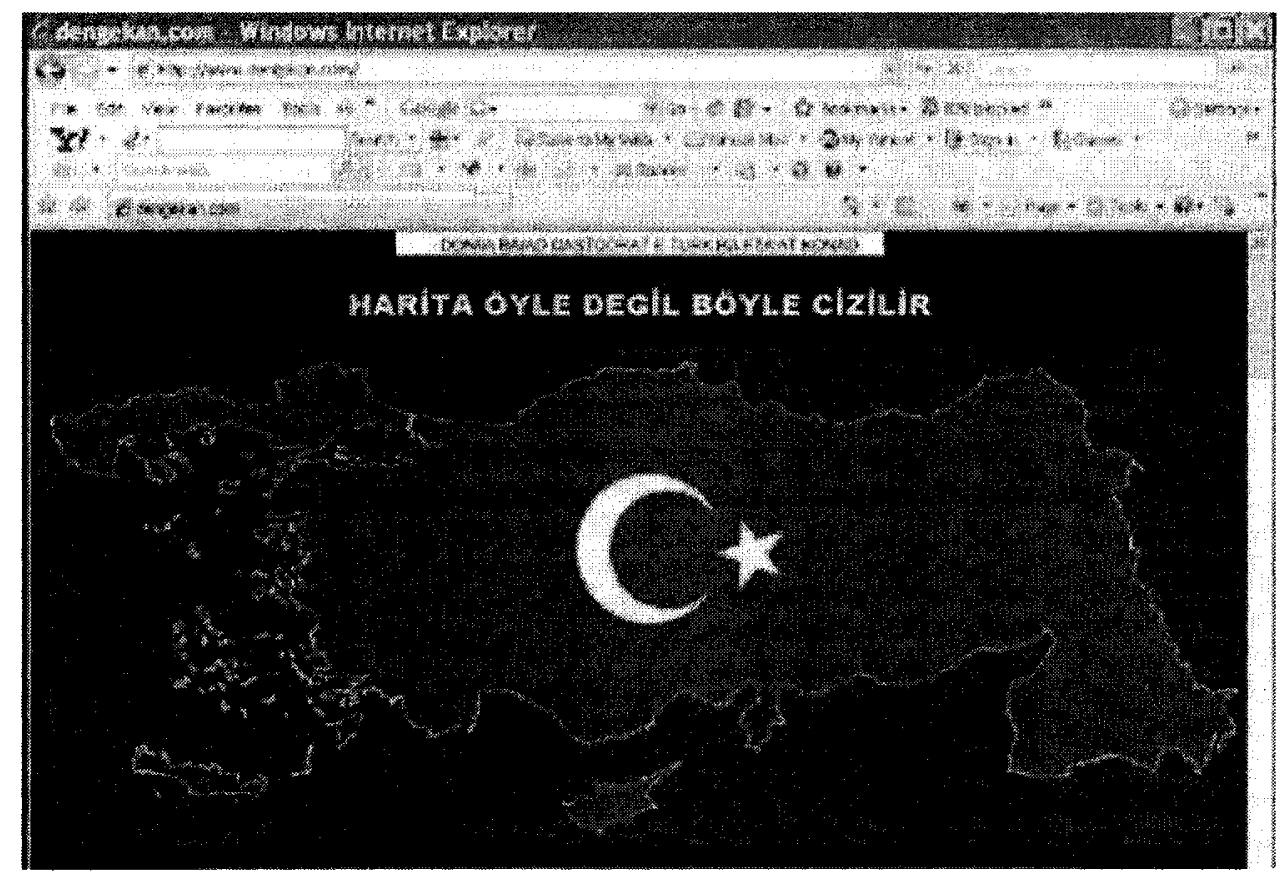

${ }^{237}$ The text in Turkish combines two sentences. In one the intruder swears at "all Kurds." In the second, s/he quotes a famous nationalistic saying by Ataturk: "Ne mutlu 'Turkum' diyene," which means "Happy is the one who says, "I'm a Turk". 
Figure 50 A non-Kurdish website, EU Minority, is hacked for carrying the Kurdish flag and using the word Kurdistan. Rretrieved February 30, 2007, from eurominority.org/version/eng/projects-shop-nationwhole.asp

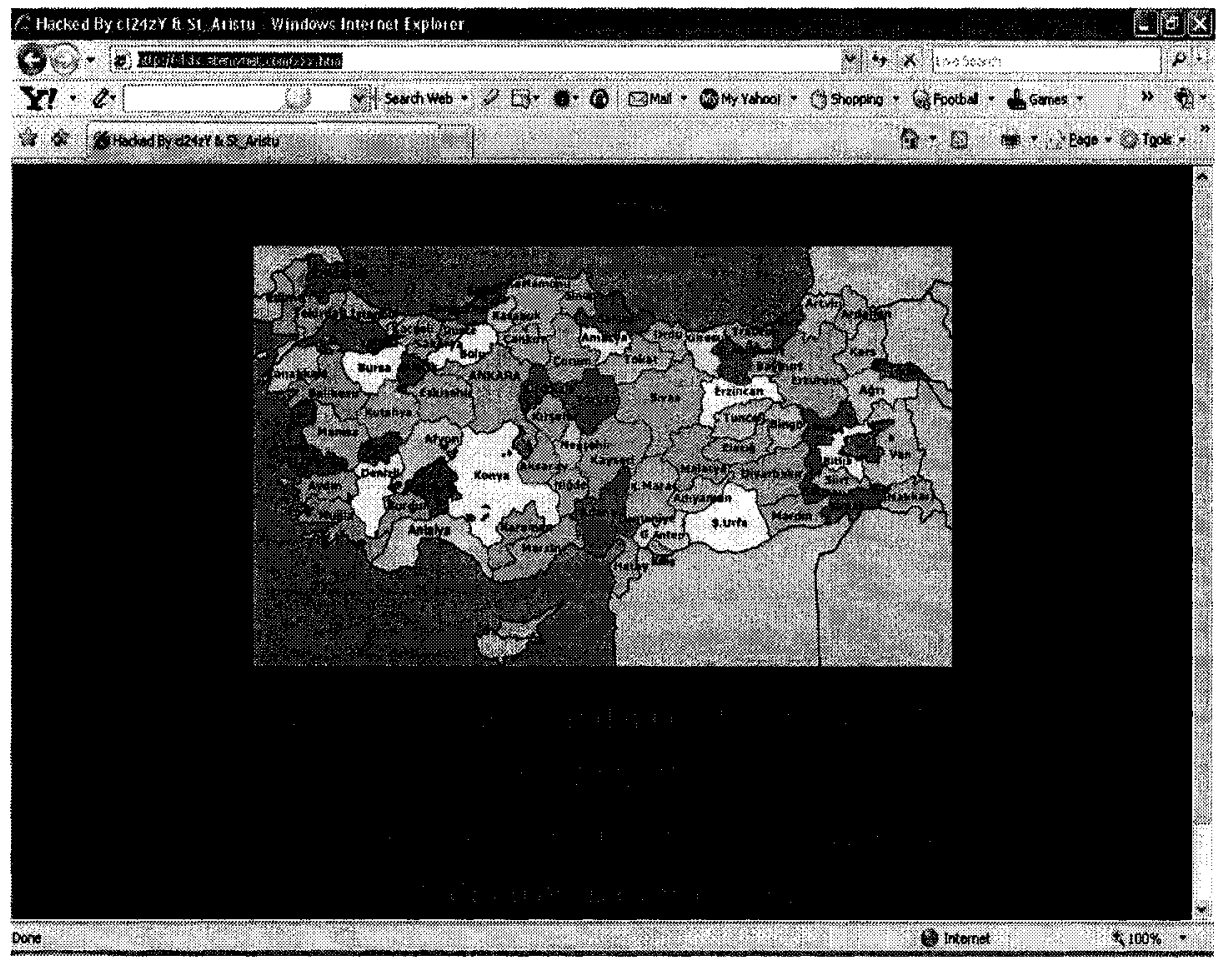

\section{The proliferation of the Internet in Kurdistan}

Despite the limitations and barriers that the Kurdish Internet has been facing, there has been a considerable growth in Kurdish online activities. In the early 2000 s there were just over two dozen websites launched from the Kurdish region, while in 2007 the number of websites, blogs and forums launched from Kurdish regions, particularly Iraqi Kurdistan, has reached the hundreds if not thousands. There has been a proliferation of Internet cafes in Kurdish towns in Turkey, Iraq and Iran. As early as 2003, a reporter from the city of Hawler, Iraqi Kurdistan, confirmed that, "while most Kurdish families cannot afford to buy a computer, Internet cafes are quickly catching on" (Kurds retain link ..., 2003). In the past few years, news and information about newest developments and courses offered 
in the area of information technology (IT) have found their way into Kurdish periodicals and publications in the region. ${ }^{238}$

Other indicators point to the presence of cyber activities in the cultural, social and political dimensions of Kurdish identity. This is the case inside Kurdistan, but even more so outside Kurdistan. Other forms of Kurdish media, such as print, television and radio, more and more rely on websites for news and general information as well as a channel for strengthening their contact and communications with audiences (e.g. Qadir, 2007; No 'legal' demonstration ..., 2005). The vast majority of periodicals, radio and TV stations publicize their website addresses and email accounts. Some prominent periodicals such as the weekly Hawlati, published in Iraqi Kurdistan, rerun selections from Kurdish websites (e.g. Le malperekanewe, 2004, p. 16). A quick survey of websites, forums and weblogs that invite viewers to leave comments in reaction to the contents of these sources (e.g. Renesans, Kurdistan Net) indicates that the number of people who talk, listen, watch, read and write from Kurdistan has increased considerably.

The vast majority of Kurdish online activities initiated and maintained from the West are manifestations of what Anderson (1992) has called long-distance nationalism. Rebwar Fatah, the director of the most prominent pro-Kurdish English website claims that his website Kurdish Media, which is only in English, has not only influenced the overall perception of Kurdish identity among non-Kurdish observers but also the Kurdish elites and politicians throughout Kurdistan (Ghazi, 2007). Aram Ahmed, one of the main moderators of the chat room Kurdistan United, which according to him is visited by "a

\footnotetext{
${ }^{238}$ In 2004, the weekly Hawlati devoted at least one full page (out of 15-16 pages) to IT news and announcements. Similar pages can be found in periodicals published in Iranian Kurdistan (e.g. Said Shukri, 2006). In the same year, a book titled Rêberî Saite Kurdîyekan (Guide to Kurdish Sites) was published in Suleimania, Iraqi Kurdistan.
} 
considerable number of Kurdish youth from the homeland" and many more from diasporic communities, credits the chat room with raising awareness about critical issues that concern Kurds from "all parts of Kurdistan" (A. Ahmed, personal communication, July 06, 2007). Examples of critical issues mentioned by Ahmed include publicizing human rights violations committed by the states straddling Kurdistan and also by the Kurdish administration in Iraqi Kurdistan, exposing corruption among Kurdish political parties and "non-patriotic" attempts that instigate disunity in Kurdistan, and protesting honour killing and other forms of violence against Kurdish women. ${ }^{239}$

Kurdish online activities confirm more important observations that have been made by analysts with respect to the place of the Internet in the processes of group identity formations and reifications. Discourse practices on the Internet are saturated with dichotomies (e.g. Mills, 2002; Erikson, 2007). On the one hand, the Internet helps dispersed peoples to imagine themselves as nations and enables the disenfranchised to amplify their voices and further their causes. On the other hand, because online activities can bypass the limitations that states and major corporations impose on communicative spaces, individuals end up sharing less information and instead they become more selective as to what to read, watch and listen to (Mills, 2002, p. 74). In other words, we do not need to consume information in groups as much as we did or still do when watching television or movies. Now, we can select our own news feeds and blogs to read on our personal computer profiles.

\footnotetext{
${ }^{239}$ Ahmed reports that the chat room also helps to organize demonstrations and peaceful campaigns that sometimes have direct impact of socio-cultural and political issues in Kurdistan. For example, Ahmed believes that Kurdistan United had a decisive role in mobilizing public opinion both in Kurdistan and diasporas to put pressure on KDP to release a political prisoner, Kemal Said Qadir, a Kurdish-Austrian, who was jailed in Iraqi Kurdistan because of insulting Masoud Barzani in his writings.
} 
This is certainly the case for Kurdish Internet users. The webmaster of the most popular Kurdish Internet directory observes that often people select websites to visit based on ideological affiliations or personal interests (Sina, 2007). Furthermore, Kurdish Internet users are fragmented along linguistic lines. The vast majority of Kurds from Iran and Iraq may never visit websites of Kurds from Turkey because these websites are either in Turkish or a different Kurdish variety written in a different alphabet system. Instead, there are websites that use English as either their prime medium (e.g. Kurdish Media) or in conjunction with Kurdish, Turkish, Persian or Arabic (e.g. Peyamner). These websites seem to be able to overcome the linguistic fragmentation more effectively than web sources that are only in Kurdish (Erikson, 2007). ${ }^{240}$

The Internet is a mass medium that fosters conformity but also diversification, at the same time. While it links and reconnects populations dispersed globally, it fosters the formation of smaller and smaller communities locally (Becker \& Wehner, 2001). The Kurdish Internet is no exception. However, there is no reason for believing that the Kurds may become further fragmented as a result of using the Internet. Prior to using the Internet, the Kurds were deeply fragmented already. The evidence presented in this study indicates that in collaboration with other mass media, particularly satellite television, the Internet has started to bring millions of dispersed Kurds closer to each other. It cannot be denied that due to language fragmentation the Internet's full potential for facilitating communication among the Kurds has not been sufficiently realized. However, as the Internet's audio-visual features improve on social networking tools such as YouTube and

\footnotetext{
${ }^{240}$ Erikson (2007) has made a similar observation: "It may actually be said that the Kurdish nation reaches its fullest, most consolidated from on transnational websites in the metropolitan languages of English, German and French" (p. 9). I am personally not sure about the latter two since the number of web sources using those languages are very few compared to those using English.
} 
Facebook, it will become easier for Kurds from different speech varieties to share more of their experiences without depending entirely on the written text or even the verbal language.

It is also important to note that some of the fragmentations that the Internet fosters ought to be celebrated. The amplification of local and sub-local voices, for example those of Hawrami and Zazaki speakers, is among them. Similar to the discourse of Kurdish identity on KTV, this discourse is not homogenous on the Internet either. The Internet has not been, and it may never be, a homogenous force fostering a unified Kurdish language and culture. However, the Internet has furthered a system of signification through which the Kurds from different countries and diasporic communities have started to advance the construction and reproduction of a shared Kurdish history, culture, territory, national symbols, and a present and future. At the same time, the Internet has fostered the revitalization and maintenance of more regional and local Kurdish identities.

\section{Summary}

This dissertation has focused on the interface between national identities, discourses, and communication technologies. I have investigated the ways the Kurds use satellite television and the Internet to reproduce, disseminate and articulate discursive and semiotic constructions of their collective identities. Situating my research within the interdisciplinary approach of Critical Discourse Analysis, I have carried out analyses of television and the Internet discourses at three levels. At the discourse practice level, I have mapped the types of television programs and internet constituents used for the practices of identity construction. At the textual analysis level, I have carried out multimodal and micro analyses of verbal language, images and music. Finally, at the 
socio-cultural level, findings from the previous levels of analysis are explained in light of the historical and political contexts that bear upon the discursive constructions of identity. Investigation of Kurdish media discourses in processes of identity formation reveals that Kurdish identity is simultaneously pan-Kurdish and regional, cultural and political, individual and collective. Although there is not one single Kurdish identity, it can be said that within the last decade or so, Kurds from everywhere have started to know more about themselves and their "Others" than they have ever known. They have started to communicate dialogically. Thus, it is safe to suggest that a strong pan-Kurdish identity has started to emerge alongside several regional identities.

I am not suggesting that satellite television and the Internet are the only factors, or the main factors, in stimulating this development in Kurdish identity. Many cultural and socio-political changes in the region have contributed to this change. ${ }^{241}$ The emergence, growth, and use of satellite TV and the Internet are interwoven with the cultural and socio-political events and structures that have had some connection with the Kurds and Kurdistan. Nor do I wish to suggest that a strong cross-border Kurdish identity could lead to the establishment of an independent Greater Kurdistan. This possibility remains extremely remote. Nonetheless, it is important to remind ourselves that all nations are first imagined before they are built on the ground, and even then, they continue to be reimagined and reconstructed in language, images and sounds that connect us. Satellite

\footnotetext{
${ }^{241}$ Among these events and changes is the immigration of Kurds from Turkey to the West in the 1960s and later in the 1980s following the Turkish military coupe. Iraqi and Iranian Kurds joined Kurdish diasporic communities from the 1980 s during and in the aftermath of the Iraq-Iran war. Another major change affecting the Kurds was the First Gulf War in 1991 and then the invasion of Iraq by the US and its allies in 2003. The Kurds of Iraq have been governing themselves since 1992 and they have also become a source of hope for the Kurds from other countries. Finally, Turkey's application for full membership in the European Union submitted in the early 1990s was followed by some positive changes to the Kurdish issue in that country.
} 
television and the Internet have provided the communicative space for the Kurds to do just that.

Given the complexity of the socio-political context which bears upon the formation of Kurdish identity, it is not possible to predict for certain how far this new identity formation will go and what the socio-political consequences will be. One major reason for this uncertainty is that when human beings come into contact, they do not just start sharing similarities, they also notice differences. Kurds have lived under different hegemonic cultures for at least a century. Seeing their fellow Kurds on television or communicating with them on the Internet after all this time might make them realize how different they are from each other instead of bringing them closer. More communication might actually cause them to abandon aspirations for the establishment of a greater Kurdistan state or belonging to a cross-border Kurdish identity. Thus, for instance, Iranian Kurds might realize that they share more with the rest of the Iranians than with Kurds from Turkey or Syria. On the other hand, people often politicize their identities when they are rejected, oppressed and persecuted for who they are. The Kurds might continue to look at their internal differences in a positive light as long as their rights are denied by the states where Kurds live. At least in the near future, if not for longer, the shared experience of oppression will continue to provide a fertile ground for satellite television and the Internet to foster the formation of a stronger collective and national identity.

The strengthening of a collective sense of belonging among the Kurds may have two positive effects. First, it may prevent the Kurds from being used as pawns against each other by the host states and others. Also, the host states may realize that if they do 
not treat their Kurds fairly, irredentism, the attempt to make a state out of Kurdish regions from four nation-states, might grow stronger. ${ }^{242}$ The formation of a pan-Kurdish identity seems to be in the interest of everyone and thus should be welcomed as a positive development. In 1997, when the Zapatistas used the Internet to amplify their voice to the world successfully, it was suggested that the Internet helped the Zapatistas shed more ink than blood in making themselves heard. It is hoped that the use of satellite television and the Internet alongside other socio-political factors will have similar consequences for the Kurds and for other oppressed groups as well.

\section{Research Implications}

This study has implications for furthering our understanding of the interface between media, identities and discourses. I will discuss these implications under the three headings communication technologies, national identities, and positive critical discourse analysis.

\section{Communication technologies}

The findings in this study indicate that, far from being agents of homogenizing the world, satellite television and the Internet have enabled non-state actors and marginalized minorities to reify both their regional/local and their cross-border identities in unprecedented ways. The findings also underscore the differences between the two media in their resourcefulness for semiotic and discursive constructions of identity. Television is primarily an aural and visual medium transcending literacy barriers; the Internet, while offering communication in these two modes, is heavily dependent on the written mode.

\footnotetext{
${ }^{242}$ McDowall (2004) suggests: "Turkey, Iraq and Iran will be unable to repel the information offensive [from the new Kurdish media]. Furthermore, they will find that this [sic] form of assault on their centralized and ideological battlements much more threatening than guerilla operations" (p. 459).
} 
On television, identity is defined and articulated within the overall ideological framework and political interests of the owners, for example a dominant Kurdish political party. On the Internet, however, disenfranchised groups and individuals can also participate in practices of identity construction and bring to light nuances of Kurdish identities.

The findings also show that a comprehensive analysis of media discourses in the processes and practices of identity formation needs to take into account not only the form and content of the media but also the socio-cultural and political contexts within which media discourses are produced and consumed. What each medium is capable of is closely connected to the context. In the late 1700 s, the printing press contributed to the formation of the modern nation-states; today, the electronic media are used by minorities and nations without a state of their own in their projects of building communities and collective identities. Furthermore, mass communication technologies and cross-border connections among peoples of the world have made it much more difficult for authoritarian states to ignore the rights of their national and minority groups and their demands for recognition.

\section{National identities}

The nation-state ideology which conceives of a nation as homogenous and unified in every sense is no longer tenable (See Erikson, 2007). In each nation there is a multiplicity of group identities from national to ethnic, cross-border to local, and religious to linguistic. This is particularly true of a nation without a state like the Kurds. Schlesinger (1991), suggests that “...the stateless nation is judged to be of special significance as a prototype of potentially innovative forms of post-nation-state affiliation, as an exemplar of flexible networking, and as offering multiple identities and allegiances to its 
inhabitants" (p. 267). Discursive representations of a stateless nation like Kurds illustrates that the electronic mass media are suitable communicative spaces for the construction, articulation and dissemination of multiple national and ethnic identities.

\section{Positive Critical Discourse Analysis}

The findings also show that a positivist approach to discourse is not capable of taking into account the contentions with which discourses are saturated. Adapting a dialogic analysis of discourse is a more effective analytical approach to delineate the multiplicity and heterogeneity of identities. The CDA approach adapted in this study has proven to be very effective in accounting for important aspects of media discourse such as content and form in addition to the socio-cultural and political contexts within which identity constructions are produced and consumed. The approach accounts for the complexity of identity construction in media discourses that are saturated with contentions and nuances. CDA started, and it has largely remained, as a research approach aimed at making transparent the discourse and ideologies of the powerful in order to create discourse awareness among the oppressed. However, in recent years it has been suggested that CDA needs to go beyond this by investigating other types of discourse practices such as social movements, human rights activities and identity construction practices (Luke, 2002). Beyond making the ideologies of domination transparent, discourse analysts also need to examine how emancipating discourses work and what others can learn from these discourse practices that successfully resist or transcend attempts at domination and control (Martin, 2003, 2000). It is hoped that this study contributes to this line of research. 
This study has shown that CDA is a productive research approach for studying an oppressed people's practices of national identity construction as mediated by electronic mass media and their discourses. Previous research investigating the discursive constructions of identities articulated and disseminated via satellite television and the Internet has been scarce. Electronic mass media discourses, given their rapid progress and development and their sophisticated ways of producing and disseminating words, images and sounds, should become indispensable parts of studies that attempt to expand our understanding of the complexity and dynamism of identities. Further research on the interface between identity, media and discourse, using a critical and interdisciplinary approach like CDA, is needed to appreciate the hybridity of media discourses, the multiplicity of identities, and the heterogeneity of communities. It is hoped that further study will contribute to our understanding of what identities are, how and why they are created, who creates them, and what the implications of their reproductions and constructions might be. 


\section{Appendix 1}

\section{Semantic macro-areas of national identity and linguistic realizations}

\section{Semantic macro-areas of national identity}

(1) The discursive construction of a common past and history including, (a) myths of an ancient origin that indicates not only the uniqueness and purity but also continuity and timelessness of the nation (Hall, 1992), (b) shared memories of tragic but proud past experiences and also shared memories of a glorious past, (c) a common political history.

(2) The discursive construction of a collective and shared present and future. This includes expressions of "'citizenship', 'political achievements', 'present and future political virtues/values"” (de Cillia et al., 1999, p. 159).

(3) The discursive construction of a common language. Discursive practices under this heading could include several features such as: (a) the ways that languages or speech varieties of a nation are labeled so as to signal the recognition of language diversity or suppress such realities; (b) the ways that language or languages are used with respect to vocabulary, pronunciation and grammar (e.g. practices of language purification, standardization and homogenization). A nationalist discourse often attempts to suppress language diversity among a people but at the same time aims for widening the gap between languages, between one's national language and others'.

(4) The discursive construction of national symbols and "invented traditions" (Hobsbawm, 1988). These include national symbols such as national anthems, flags, maps, rituals and public ceremonies all of which "make historical confusion and 
defeats understandable; they transform disorder into community" (Wodak et al., 1999, p. 24).

(5) The discursive construction of a common culture which encompasses various aspects of a community's life such as religion, arts, music, sports and everyday culture such as clothing and food. ${ }^{243}$ In the previous chapter, I discussed several ways in which KTV contributes to the articulation of a common Kurdistani culture. To avoid repetition, I will not discuss this aspect again.

(6) The discursive construction of a common territory. In addition to a clearly defined homeland, a nationalist discourse also encompasses particular physical aspects of the territory such as landscapes (e.g. mountains), architecture and nature in general, particular features of the physical landscape such as mountains, architecture, historical cites and so forth.

\section{Linguistic realizations}

\section{Naming practices}

Different names, titles and labels given to people, objects and concepts, indicate the attitudes and beliefs of the speakers and writers towards them (Kress \& Fowler, 1979, p. 200). Names not only identify but they could also define things and people; they not only indicate the degree of intimacy with but also distance from people, places and things. Studying the use of naming in the addresses to the nation in Poland, Galasiński \& Skowronek (2001) observe that the practice did not only enable politicians and religious leaders refer to places and persons, rather the speakers used specific naming " to

\footnotetext{
${ }^{243}$ Under the heading "a common culture," Wodak et al. (1999) include language. However, since language plays such a central role in defining Kurdish identity, I have treated language under a separate heading.
} 
construct an ideologically preferred reality. Proper names were used to serve the political purpose of the day" (p. 63).

When it comes to the discourse of national identity, naming the nation and what is believed to be national characteristics and symbols are among the prime naming practices. Billig (1995) says, 'Somehow, in ways difficult to articulate, the magic of 'our' name matters to 'us' deeply, whichever nationality 'we' are: it indicates who 'we' are, and, more basically, that 'we' are. In the secular age, the name of the nation is not to be taken in vain" (p. 73, emphasis in original; see also Shnirelman, 2006; Nicolaisen, 1990). For Bourdieu (1992), naming oneself is "the typically magical act through which the particular group - virtual, ignored, denied, or repressed - makes itself visible and manifests, for other groups and for itself, and attests to its existence as a group that is known and recognized" (p. 224). Clearly, naming practices have been indispensable parts of discourses of nationalism. Discussing naming practices in the nationalist discourses of the Québécois and Aboriginal peoples in Canada, Henson (1993) states, "[n]ationalist movements are social movements involved in the definition of a collective identity; they make choices about names" (p. 337).

\section{Pronouns}

As Fowler \& Kress (1979) suggest, "personal pronouns always deserve notice" (p. 201; see also Wodak et al., 1999; Higgins, 2004), personal pronouns have proven very fruitful in analyzing discourses of national identity. Billig (1995) observes that "nationalism is, above all, an ideology of the first person plural. The crucial question relating to national identity is how the nation "we' is construed and what is meant by such construction" ( $p$. 70). 


\section{Tense}

Another central component of the modal function of language is tense (Fowler $\&$ Kress, 1979, p. 207). According to Fowler \& Kress, different uses of tense are neither arbitrary nor neutral; they indicate different orientations toward the phenomena that are talked or written about. For example, present tense "signals certainty, unquestionableness, continuity, universality" (p. 207). Fairclough (2001), in a similar vein, suggests that the simple present tense form "is one terminal point of expressive modality, a categorical commitment of the producer to the truth of the propositions" (p. 129). Dunmire (1997) cites Fleischman asserting that "the greater the likelihood that a situation will be realized, i.e. the closer to 'reality' the speaker perceives it as being, the closer to 'now' (=present) will be the tense used to represent it" (p. 234). In contrast, the past tense will be used when things are desired to remain in the past and not to be of current concern. As Fowler \& Kress suggest, "Temporal 'distance' nearly always conveys modal 'distance'” (1979, p. 207).

\section{Metaphors}

According to Lakoff \& Johnson (1980), "the essence of metaphor is understanding and experiencing one kind of thing in terms of another" (p. 5, see also Fairclough, 2001, p. 119). For example in the sentence, he spends time with her family, English speakers understand the importance of time in terms of their common understanding of the value of money which can also be spent, saved or wasted. A crucial point to be raised here is that there is no apparent connection between time and money, but what brings them together is the perception which is based on cultural assumptions and also feelings that are mostly shared between humans from the same culture. On the importance of metaphor in our discursive practices, Lakoff \& Johnson (1980) state that, "Since much of 
our social reality is understood in metaphorical terms, and since our conception of the physical world is partly metaphorical, metaphor plays a very significant role in determining what is real for us" (p. 146). In other words, we understand the world and conceptualize reality in part in terms of metaphors. As Wodak et al. (1999, p. 44) illustrate, metaphors play an important role in "the mental construction of nation" by implying in-group "sameness and equality," on the one hand, and out-group differences and inequality, on the other. Finally, it is also important to note that metaphors are context and culture-sensitive. For example, the expression time is money might be quite alien to another culture where people are less preoccupied with time. The cultural and context sensitivity of metaphors have implications for the study of the discursive construction of national identity. Metaphors that contribute to the formation of imagined communities could be different from one context to the next.

There are different kinds of metaphors one of which is personification. According to Wodak et al. (1999), "Personification attributes a human form to an abstract entity and thus constitutes a widely-used mean of realizing a constructive strategy, demanding, for example, identification with an anthropomorphized nation" (p. 43). Drawing on Michael Billig, Chouliaraki observes that "Personification and the concomitant attribution of intense human feelings to the nation metaphorize relations within the nation as relationships of kinship, of family, thus further forging a sense of imagined community among its members (Chouliaraki, 1999, p. 49). ${ }^{244}$

\footnotetext{
${ }^{244}$ On the importance of family metaphor, Bloor \& Bloor (2007) state: "just as the family metaphor has been used to express solidarity and inspire unity, it has also been widely applied, sometimes explicitly, to reject other groups (p. 76) ... Lexical items are important here [e.g. brother, children, sister, father, mother] because their use trigger[s] conceptual image: the family as a self-contained group of loving and mutually supportive members united against the outside world" (p. 77).
} 


\section{Presuppositions}

A presupposition is "a proposition that is tacitly assumed to be true for another proposition to be meaningful" (van Dijk, 1993, p.251). A presupposition is an assertion that is implied rather than explicitly and overtly stated. Consider this example from van Dijk (1993, p. 256) which had originally appeared in a British paper: “... we have to be more brisk in saying no, and showing the door to those who are not British citizens and would abuse our hospitality and tolerance" (my emphasis). In this example, it is presupposed that the British are "hospitable" and "tolerant," therefore, claims of mistreatment that might be put forward by minorities become irrelevant and unfounded. In situations like this, presuppositions can be "manipulative" and ideological, although there are other times when they can be "sincere" (Fairclough, 2001, p. 154). In this example from van Dijk, and elsewhere, however, presuppositions can be ideological when "what they assume has the character of "common sense in the service of power"" (ibid.). In addition to their ideological significance, presuppositions also deserve attention in discourse analysis because they are crucial features of the intertextuality of texts (Fairclough, 1995a, p. 14). In other words, presuppositions are features of texts that have been constructed before, in other times and in other texts but, nonetheless, they have become integrated parts of the meaning-making structure of the text in question.

\section{Overlexicalization}

Overlexicalization (Fowler \& Kress, 1979, p. 211) or "overwording" (Fairclough, 2001, p. 115) refers to a high level use of words and lexical items that are synonymous, nearsynonymous or semantically close enough to contribute to the construction of an idea, theme and point of preoccupation. As Fowler \& Kress assert, for a critical analysis of 
discourse it is important to consider overlexicalization, because this linguistic tool "points to areas of intense preoccupation in the experience and values of the group which generates it, allowing the linguist to identify peculiarities in the ideology of that group" (Fowler \& Kress, 1979, p. 211-212). Fairclough (2001) calls this analytical tool overwording and defines it as "an unusually high degree of wording often involving many words which are near synonyms. Overwording shows preoccupation with some aspect of reality - which may indicate that it is a focus of ideological struggle" (p. 115). 


\section{References}

Abdullah, Z. (2004). Kurdistan [Videorecording]. Erbil, Kurdistan-Iraq: Kurdistan TV.

Ackah, W., \& Newman, J. (2003). Ghanaian Seventh Day Adventists on and offline. In K. H. Karim (Ed.), The media of diaspora (pp. 203-214). London: Routledge.

AFP. (2005, July 15). Rioting erupts in Iranian hotbed of Kurdish nationalism. Retrieved July 17, 2005, from http://www.payvand.com/news/archive/6-05.html

Aguado, L. D. (1990). The national liberation movement of the Kurds in the Middle East. In R. R. Premdas, S. W. R. de A. Samarasinghe, \& A. B. Anderson (Eds.), Secessionist movements in comparative perspective (pp. 153-164). New York: St. Martin's Press.

Ahmadi, M. (2004). Wêblogî Kurdî: Dîmane le gel Gulper (Kurdish weblog: Interview with Gulper). Retrieved October 28, 2004, from http://wwww.dimane.com/index.php?subaction=showfull\&id=1098976917\&archi ve

Ahmadzadeh, H. (2003). Nation and novel: A study of Persian and Kurdish narrative discourse. Uppsala: Uppsala Universitet.

Ainsworth, S., \& Hardy, C. (2004). Critical discourse analysis and identity: Why bother? Critical Discourse Studies, 1(2), 225-259.

Aksoy, A., \& Robins, K. (2003). Banal transnationalism: The difference that television makes. In K. H. Karim (Ed.), The media of diaspora (pp. 89-104). London: Routledge.

Alay Kurdistan. (2004, June 08). Mukryan. Retrieved July 02, 2004, from http://mukryan.blogspot.com

Alexa: The web information company.(1996). Retrieved October 18, 2007, from http://www.alexa.com

Alinia, M. ((2004). Spaces of diasporas: Kurdish identities, experiences of otherness and politics of belonging. Göteborg, Sweden: Göteborg University.

Almasude, A. (1999). The new mass media and the shaping of Amazigh identity. In J. Reyhner, G. Cantoni, R. N. St. Clari \& E. P. Yazzie (Eds.), Revitalizing indigenous languages (pp. 117-128). Flagstaff, Arizona: Northern Arizona University. 
Amnesty International. (2007, February 16). Iran: Fear of torture or ill treatment/ arbitrary arrest: Adnan Hassanpour. Retrieved March 10, 2007, from http://asiapacific.amnesty.org/library/Index/ENGMDE130172007?open\&of=EN $\underline{\mathrm{G}-346}$

Amnesty International. (2005). Syria: Kurds in the Syrian Arab Republic one year after the March 2004 events. Retrieved April 10, 2006, from http://web.amnesty.org/library/Index/ENGMDE240022005?open\&of=ENG-SYR

Amude. (n.d.). Retrieved December 15, 2006, from http://www.amude.net/epirtuk/index.html

Anderson, B. (1992). Long-distance nationalism: World capitalism and the rise of identity politics. Conference papers (Working paper 5.1). Conference on Nation, National Identity, Nationalism, September 10-12, 1992. University of California, Centre for German and European Studies.

Anderson, B. (1991 [1983]). Imagined communities: Reflections on the origin and spread of nationalism (Rev. ed.). London: Verso.

Appadurai, A. (1996). Modernity at large: Cultural dimensions of globalization. Minneapolis, Minn.: University of Minnesota Press.

Aqrawi, S. (2007, April 14). Iraq Kurdish PM seeks to calm Turkey-Kurd tensions. Reuters. Retrieved April 15, 2007, from http://www.alertnet.org/thenews/newsdesk/L14502248.htm

Ashuri, T. (2005). The nation remembers: National identity and shared memory in television documentaries. Nations and Nationalism 11 (3), 423-442.

Associated Press. (2002, November 20). Turkey to air limited Kurdish programs. Retrieved June 10, 2006, from http://www.flashbulletin.de/2002/eNovember 21 .htm\#6

Avesta Kurd. (n.d.). Retrieved December 15, 2006, from http://www.avestakurd.net Azadiya Welat (n.d.). Retrieved August 13, 2007, from http:/www.azadiyawelat.com

Baár, M., \& Ritivoi, A. D. (2006). The Transylvanian Babel: Negotiating national identity through language in a disputed territory. Language \& Communication, 26, 303-217.

Bakhtin, M. (1986). Speech genres and other late essays. C. Emerson \& M. Holquist (Eds.). (V. W. McGee trans.) Austin: University of Texas Press. 
Bakhtin, M. (1984). Problems of Dostoevsky's poetics. (C. Emerson trans.). Minneapolis: University of Minnesota Press.

Bakhtin, M. (1981). The dialogic imagination: Four essays. M. Holquist (Ed.). Austin: University of Texas Press.

Bakker, P. (1999). New nationalism: The Internet Crusade. Paper prepared at the 2001 International Studies Association Annual Convention. Retrieved May 20, 2003, from http://www.tamilnation.org/selfdetermination/nation/bakker.pdf

Balakrishnan, G. (1996). The national imagination. In G. Balakrishnan (Ed.), Mapping the nation (pp. 198-213). London: Verso.

Barbrook, R. (1992). Broadcasting and National Identity in Ireland. Media, Culture \& Society, 14(2), 203-227.

Bargh, J. A. \& McKenna, K. Y. A. (2004). The internet and social life. Annual Review of Psychology, 55, 573-590.

Barth, F. (1969). Ethnic groups and boundaries. In F. Barth (Ed.), Ethnic groups and boundaries: The social organization of culture difference (pp. 9-37). Boston: Little Brown.

Barzani, M. (2003, December 26). Iraqi Kurdish claim for federalism: A Kurdish-Arab partnership. Retrieved October 24, 2004, from http://www.kurdistan.tv

Barzinji, H. M. (2004). Rêberî Saite Kurdîyekan (Guide to Kurdish Sites). Peyv: Suleimania [Iraqi Kurdistan].

Baydigi Forum. (2006). Retrieved October 14, 2007, from http://www.bydigi.com

BBC. (1999, February 19). Kurdish arrests 'reach 1000'. Retrieved December 15, 2005, from http://news.bbc.co.uk/2/hi/europe/282492.stm

Be hoy bekarhênanî rengî kesk u sor u zerd 8 mindalî Kurd le xwêndin dûr dexrênewe (Because of using the green, red and yellow colours eight Kurdish students are expelled from school) (2007, March 06). Midya, 280, p. 4.

Becker, B., \& Wehner, J. (2001). Electronic networks and civil society: Reflections on structural changes the public sphere. In C. Ess (Ed.), Culture, technology, communication: Towards an international global village (pp. 67-85). Albany, NY: SUNY Press.

Bell, A., \& Garret, P. (Eds.) (1998). Approaches to media discourse. Oxford: Blackwell Publishers. 
Bendix, J., \& Liebler, C. M. (1999). Place, distance, and environmental news: Geographic variation in newspaper coverage of the spotted owl conflict. Annals of the Association of American Geographers, 89(4), 658-676.

Benítez, J. L. (2006). Transnational dimensions of the digital divide among Salvadoran immigrants in the Washington DC metropolitan area. Global Networks, 6(2), 181199.

Benke, G., \& Wodak, R. (2003). The discursive construction of individual memories: How Austrian "Wehrmacht" soldiers remember WWII. In J. R. Marin \& R. Wodak (Eds.), Re/reading the past: Critical and functional perspectives on time and value (pp. 115-38). Amsterdam: John Benjamins.

Bernstein, M. (2005). Identity politics. Annual Review of Sociology, 31, 47-74.

Bhabha, H. K. (Ed.) (1990). Nation and narration. London: Routledge.

Bianet. (2007, November 20). Diyarbakir broadcaster harassed over Kurdish-language programming; radio station on trial over song. International Freedom of Expression Exchange. Retrieved November 21, 2007, from http://egypt.ifex.org/en/content/view/full/87783/index.html

Billig, M. (1995). Banal nationalism. London: Sage.

Birch, N. (2003, October 3). Turkish Kurds, watching satellite TV, warily eye Kirkuk. Eurasianet. Retrieved October 24, 2004, from http://www.eurasianet.org/departments/insight/articles/eav041003 pr.shtml

Bird, C. (2004). A thousand sighs, a thousand revolts: Journeys in Kurdistan. New York: Ballantine Books.

Bishop, H., \& Jaworski, A. (2003). 'We beat 'em': Nationalism and the hegemony of homogeneity in the British press reportage of Germany versus England Euro 2000. Discourse \& Society, 14(3), 243-271.

Black, G. (1993). Genocide in Iraq: The Anfal Campaign Against the Kurds: A Middle East Watch report. New York: Human Rights Watch.

Blommaert, J. (2005). Discourse: A critical introduction. Cambridge: Cambridge University Press.

Blommaert, J. (1996). Language and nationalism: Comparing Flanders and Tanzania. Nations and Nationalism, 2(2), 235-256.

Bloor, M., \& Bloor, T. (2007). The practice of critical discourse analysis: An introduction. London: Hodder Arnold. 
Breuilly, J. (1996). Approaches to nationalism. In G. Balakrishnan (Ed.), Mapping the nation (pp. 146-174). London: Verso.

Bo Rojhelat. (2006). Retrieved December 15, 2006, from http://www.4rojhelat.org

Bourdieu, P. (1991). Language and symbolic power. J. Thompson (Ed.), (G. Raymond \& M. Adamson, Trans.). Cambridge: Harvard University Press.

Bourdon, J. (2003). Some sense of time: Remembering television. History \& Time, 15(2), 5-35.

Boyd-Barrett, O. (2000). Pan-Arab satellite television: The dialectics of identity. In H. Tumber (Ed.), Media power, professionals and policies (pp. 314-331). London: Routledge.

Brewer, J. D. (2006). Memory, truth and victimhood in post-trauma societies. In G. Delanty \& K. Kumar (Eds.), The Sage handbook of nations and nationalism (pp. 214-224). London: Sage.

Brookes, H. J. (1995). 'Suit, tie and a touch of juju'--the ideological construction of Africa: a critical discourse analysis of news on Africa in the British press. Discourse \& Society, 6(4), 461-494.

Brookes, R. (1999). Newspapers and national identity: The BSE/CJD crisis and the British press. Media, Culture \& Society, 21, 247-263.

Brubaker, R. (2004). Ethnicity without groups. Cambridge: Harvard University Press.

Bulk, H. V. d., \& Poecke, L. V. (1996). National language, identity formation and broadcasting: Flanders, the Netherlands and German-speaking Switzerland. European Journal of Communication, 11(2), 217-233.

Bulloch, J., \& Morris, H. (1992). No friends but the mountains: The tragic history of the Kurds. New York: Oxford University Press.

Butler, J. G. (2002). Television: Critical methods and applications $\left(2^{\text {nd }}\right.$ ed.). London: Lawrence Erlbaum Associates.

Calhoun, C. J. (1997). Nationalism. Minneapolis: University of Minnesota Press.

Calhoun, C. J. (Ed.). (1994). Social Theory and the Politics of Identity. Oxford: Blackwell.

Calhoun, C. J. (1993). Nationalism and ethnicity. Annual Review of Sociology, 19, 21139. 
Castells, M. (1997). The power of identity. Oxford: Blackwell.

Chan, B. (2005). Imagining the homeland: The Internet and diasporic discourse of nationalism. Journal of Communication Inquiry, 29(4), 336-368.

Chouliaraki, L. (1999). Media discourse and national identity: Death and myth in a news broadcast. In R. Wodak \& C. Ludwig (Eds.), Challenges in a changing world: Issues in Critical Discourse Analysis (pp. 37-62). Wien: Passagen Verlag.

Chouliaraki, L., \& Fairclough, N. (1999). Discourse in late modernity: Rethinking Critical Discourse Analysis. Edinburgh: Edinburgh University Press.

Ciment, J. (1996). The Kurds: State and minority in Turkey, Iraq and Iran. New York: Facts On File, Inc.

Cohen, R. (1997). Global diasporas: An introduction. Seattle: University of Washington Press.

Collins, R. (1990). Culture, communication \& national identity: The case of Canadian television. Toronto: University of Toronto Press.

Connor, W. (1994). Ethnonationalism: The quest for understanding. Princeton: Princeton University Press.

Cooper, R. (1989). Language planning and social change. New York: Cambridge University Press.

Cormack, M. (2000). Minority languages, nationalism and broadcasting: The British and Irish examples. Nations and Nationalism, 6(3), 383-398.

Cormack, M. (1993). Problems of minority language broadcasting: Gaelic in Scotland. European Journal of Communication, 8, 101-117.

Cormack, M., \& Hourigan, N. (Eds.) (2007). Minority language media: Concepts, critiques, and case studies. Clevedon: Multilingual Matters.

Costa, J. (2003). Catalan linguistic policy: Liberal or illiberal? Nations and Nationalism, 9(3), 413-432.

Cottle, S. (1998). Analysing visuals: Still and moving images. In A. Hansen, S. Cottle, R. Negrine \& C. Newbold (Eds.), Mass Communication Research Methods (pp. 189224). New York: New York University Press.

Creeber, G. (2004). "Hideously white": British television, glocalization, and national identity. Television \& New Media, 5(1), 27-39. 
Crystal, D. (1997). English as a global language. Cambridge: Cambridge University Press.

Crystal, D. (2006). Language and the internet $\left(2^{\text {nd }}\right.$ ed). Cambridge, UK: Cambridge University Press.

Dahlman, Carl (2002). The political geography of Kurdistan. Eurasian Geography and Economics, 43(4), 271-299.

Dalby, A. (2002). Language in danger. London: Penguin.

Danish Council gives green light for Roj TV broadcasts. (2007, May 5). Turkish Daily News. Retrieved May 17, 2007, from

http://www.turkishdailynews.com.tr/article.php?enewsid=72434

Dascal, M. (2003). Identities in flux: Arabs and Jews in Israel. In G. Weiss \& R. Wodak (Eds.), Critical discourse Analysis: Theory and interdisciplinarity (pp. 150-166). New York: Palgrave Macmillan.

de Cillia, R., Reisigl, M. \& Wodak, R. (1999). The discursive construction of national identities. Discourse \& Society, 10(2), 149-173.

Dengekan. (n.d.). Retrieved July 4, 2007, from http://www.dengekan.com

Dengê Mezopotamya: Dengê azadî $\hat{u}$ şaristanîyê (The voice of Mesopotamia: The voice of freedom and civilization) (n.d.). Retrieved December 23, 2006, from http://www.denge-mezopotamya.com

Demertzis, N., Papathanassopoulos, S., \& Armenakis, A. (1999). Media and nationalism: The Macedonian question. Press/Politics, 4(3), 26-50.

Deutsch, K. (1966). Nationalism and communication: An inquiry into the foundations of nationality $\left(2^{\text {nd }}\right.$ ed.). New York: M.I.T. Press.

Deutsch, K. (1953). The growth of nations: Some recent patterns of political and social integration. World Politics, 5(2), 168-195.

De Vos, G. A. (1995). Ethnic pluralism: Conflict and accommodation. In L. RomanucciRoss \& G. A. De Vos (Eds.), Ethnic identity: Creation, conflict, and accommodation ( $3^{\text {rd }}$ ed.) (pp. 15-47): London: Altamira Press.

Dibistana Kurdî (Kurdish School). (n.d.).Retrieved January 15, 2007, from http://modersmal.skolutveckling.se/nordkurdiska/zazaki/start.htm 
Dixon, J., \& Durrheim, K. (2000). Displacing place-identity: A discursive approach to locating self and other. British Journal of Social Psychology, 39, 27-44.

Diyako. (n.d.). Retrieved August 10, 2006, from http://www.geocities.com/dyako700/imad.html

Dîwanî Nalî (1976). Dîwanî Nalî: Mela Xidrî Ehemedî Shaweysî Mikaylî. Lêkolînewe u lêkdanewey Mela Ebdulkerîmî Muderris u Fatih Ebdulkerîm. Mihemmdê̂ Mela Kerîm piya chotewe. [The collection of nali's poetry]. Baghdad: Kurdish Academy Press.

Dozens of DTP mayors face jail over Roj TV letter. (2007, April 4). Today's Zaman. Retrieved May 17, 2007, from http://www.todayszaman.com/tzweb/detaylar.do?load $=$ detay\&link $=107375 \&$ bolum $=103$

Drummond, P., Paterson, R. \& Willis, J. (Eds.) (1993). National identity and Europe: The television revolution. London: BFI Publishing.

Dunmire, P. L. (1997). Naturalizing the future in factual discourse: A critical linguistic analysis of a projected event. Written Communication, 14(2), 221-264.

Edebiyatî Kajîk (n.d.). Kokirdnewey Hawrê Baxewan (Kajîk literature. Compiled by Hawre Bakhawan). Retrieved January 30, 2007, from http://www.bakhawan.com/hawdocs/EdebiyatiKAJYK.pdf

Edwards, J. (1985). Language, society and identity. Oxford: Basil Blackwell.

Eggins, S. (1994). An introduction to systemic functional linguistic. New York: Continuum.

Entessar, N. (2007). Competing national identities: The Kurdish conundrum in Iran. In C. G. MacDonald \& C. A. O'Leary (Eds.), Kurdish identity: Human rights and political status (pp. 189-200). Tallahassee: University Press of Florida.

Erikson, T. H. (2007). Nationalism and the Internet. Nations and Nationalism, 13(1), 117.

EU Minority. (n.d.). Retrieved February 30, 2007, from http://www.eurominority.org/version/eng/projects-shop-nation-whole.asp

Eveland, W. P. (2003). A "mix or attributes" approach to the study of media effects and new communication technologies. Journal of Communication, September issue?, 395-410. 
Fairclough, N. (2006). Semiosis, ideology and mediation: A dialectical view. In I. Lassen, J. Strunck \& T. Vestergaard (Eds.), Mediating ideology in text and image: Ten critical studies (pp. 19-36). Amsterdam: John Benjamins.

Fairclough, N. (2003). Analysing discourse: Textual analysis for social research. London: Routledge.

Fairclough, N. (2001). Language and power ( $2^{\text {nd }}$ ed.). New York: Longman.

Fairclough, N. (1996). A reply to Henry Widdowson's 'Discourse analysis: a critical view.' Language and Literature, 5(1), 49-56.

Fairclough, N. (1995a). Media discourse. London: Arnold.

Fairclough, N. (1995b). Critical discourse analysis: The critical study of language. London: Longman.

Fairclough, N. (1992). Discourse as social change. Cambridge: Polity Press.

Fairclough, N. (1989). Language and power. New York: Longman.

Fairclough, N., \& Wodak, R. (1997). Critical discourse analysis. In T. van Dijk (Ed.), Discourse studies: A multidisciplinary introduction (Vol. 2). Discourse and social interaction (pp. 258-284). London: Sage.

Fernandes, D. (2007). The Kurdish and Armenian genocides: From censorship and denial of recognition? (n.d.): Apec förlag.

Fêrbûnî Zimanî Kurdî (Kurdish Language Learning) (2005). Retrieved October 30, 2007, from http://www.kurdi.fi

Fichte, J. G. (1986). Addresses to the German Nation. (R. F. Jones and G. H. Turnbull trans., G. A. Kelly Ed.). New York: Harper Torch Books.

Findahl, O. (1989). Language in the age of satellite television. Journal of Communication, 4, 133-159.

Firouzi, T. (2005). Kordestane Iran: Zire pousheshe televizyonhaye mahvareyi tahte setam va sarkoub e hokumate markazi (Iranian Kurdistan: Under the coverage of satellite television, oppressed and suppressed by the central government). Retrieved November 13, 2005, from http://www.peiknet.com/1384/06mehr/page/312kord.htm

Fishman, J. (2002). The primordialist-constructivist debate today: The language-ethnicity link in academic and in everyday-life perspective. In Daniele Conversi (Ed.), 
Ethnonationalism in the Contemporary World: Walker Connor and the Study of Nationalism (pp. 83-91). London: Routledge.

Fishman, J. (1991). Reversing language shift. Clevedon, U.K.: Multilingual Matters.

Fishman, J. (1989). Language and ethnicity in minority sociolinguistic perspective. Clevedon: Multilingual Matters Ltd.

Fisk, J., \& Hartley, J. (2003). Reading television ( $2^{\text {nd }}$ ed.). London: Routledge.

Flowerdew, J. (1999). Description and interpretation in critical discourse analysis. Journal of Pragmatics, 31, 1089-1099.

Foucault, M. (1972). The archaeology of knowledge. (M. S. Smith trans.). London: Tavistock Publications.

Fowler, R. (1991). Language in the news: Discourse and ideology in the press. London: Routledge.

Fowler, R., Hodge, B., Kress, G., \& Trew, T. (1979). Language and control. London: Routledge \& Kegan Paul.

Fraser, F. (1994, January 1). The Participation of aboriginal and other cultural minorities in cultural development. Canadian Journal of Communication, 19(3). Retrieved February 15, 2003, from http://www.cjconline.ca.proxy.library.carleton.ca/viewarticle.php?id=252

Fraser, S. (2007, April 10). Turkish prime minister warns Iraqi Kurdish leader not to threaten Turkey. The Independent. Retrieved April 20, 2007, from http://news.independent.co.uk/europe/article2437271.ece

Freeden, M. (1998). Is nationalism a distinct ideology? Political Studies, XLVI Arabic Numerals here, 728-765.

French court cancels Medya TV's broadcasting license. (2004, February 12). Retrieved January 10,2005 , from http://www.clandestineradio.com/crw/news.php?id $=\& \operatorname{stn}=684 \&$ news $=287$

Galasiński, D., \& Skowronek, K. (2001 ). Naming the nation: A Critical analysis of names in Polish political discourse. Political Communication, 18, 51-66.

Galbraith, P. (2005). Kurdistan in federal Iraq. In B. O'Leary, J. McGarry, \& K. Salih, The future of Kurdistan in Iraq (pp. 268-281). Philadelphia: University of Pennsylvania Press.

Geertz, C. (1973). The interpretation of cultures: Selected essays. New York: Basic Books. 
Geisler, M. E. (2005). National symbols, fractured identities: Contesting the national narrative. Hanover: University Press of New England.

Gellner, E. (1997). Nationalism. New York: New York University Press.

Gellner, E. (1983). Nations and nationalism. Ithaca, NY: Cornell University Press.

Gellner, E. (1981). Nationalism. Theory and Society, 10(6), 753-776.

General information on KDP. Retrieved October 15, 2005, from http://www.kdp.se/?do=what

Ghazi, H. (Producer) (2007, August 20). Ruwange [Television Broadcast]. Copenhagen: Roj TV.

Ghobadi, B. (Director) (2004). Turtles can fly. [Motion picture]. Iran-Iraq: IFC Films.

Gilbert, P. (1998). The philosophy of nationalism. Boulder, Colo.: Westview Press.

Golden, K. S. (1999). What is ethnicity? A comparative analysis of conflict in postcommunist societies. In National Political Science Review, 7, 137-153.

Goodman, S. (1996). Visual English. In S. Goodman \& D. Graddol (Eds.), Redesigning English: New texts, new identities (pp. 38-105). London: The Open University.

Griffiths, A. (1993). Pobol y Cwm: The construction of national and cultural identity in a Welsh-Language soap opera. In P. Drummond, R. Paterson \& J. Willis (Eds.), National identity and Europe: The television revolution (pp. 9-24). London: BFI Publishing.

Government of Newfoundland and Labrador-Canada. (2005, January 10). Canadian flag restored to provincial government buildings. Retrieved February 10, 2005, from http://www.releases.gov.nl.ca/releases/2005/exec/0110n05.htm

Guibernau, M. (1999). Nations without state: Political communities in a global age. Oxford: Polity Press.

Guibernau, M. (1996). Nationalisms: The nation-state and nationalism in the twentieth century. Oxford: Polity Press.

Gulagenim. (2002a, May 26). Retrieved March 15, 2004, from http://www.gulagenim.blogspot.com/2002 0526 gulagenim archive.html

Gulagenim. (2002b, July 04). Retrieved March 15, 2004, from http://www.gulagenim.blogspot.com/2002 0704 gulagenim archive.html 
Gunter, M. M. (2005). The Kurdish minority identity in Iraq. In M. Shatzmiller (Ed.), Nationalism and minority identities in Islamic societies (pp. 264-281). London: McGill-Queen's University Press.

Gurak, L., Antonijevic, S., Johnson, L., Ratliff, C., \& Reyman, J. (2004). Introduction: Weblogs, rhetoric, community, and culture . In L.J. Gurak, S. Antonijevic, L. Johnson, C. Ratliff, \& J. Reyman (Eds.), Into the blogosphere: Rhetoric, community, and culture of weblogs. Retrieved July 15, 2006, from http://blog.lib.umn.edu/blogosphere/introduction.html

Guyot, J. (2007). Minority language media and the public sphere. In M. Cormack \& N. Hourigan (Eds.), Minority language media: Concepts, critiques, and case studies (pp. 34-52). Clevedon: Multilingual Matters.

Habermas, J. (1994). The past as future. Cambridge: Polity Press.

Hackett, R. (1991). News and dissent: The press and the politics of peace in Canada. Norwood, N.J.: Abex.

Halavais, A. (2000). National borders on the World Wide Web. New Media \& Society, $2(1), 7-28$.

Hall, J. (2006). Structural approaches to nations and nationalism. In G. Delanty \& K. Kumar (Eds.), The Sage handbook of nations and nationalism (pp. 33-43). London: Sage.

Hall, J. (1993). Nationalisms: Classified and explained. Daedalus, 122, 1-28.

Hall, S. (1992). The question of cultural identity. In S. Hall, D. Held \& T. McGrew (Eds.), Modernity and its futures (pp. 273-316). Cambridge: Polity Press in association with the Open University.

Hall, S. (1980). Encoding/decoding. In P. Willman, S. Hall, D. Hobson \& A. Lowe, Andrew (Eds.), Culture, media, language: Working papers in cultural studies, 1972-79 (pp. 128-138). London: University of Birmingham.

Halliday, M. A. K. (1994): Introduction to functional grammar. London: Edward Arnold.

Halloran, J. D. (1998). Ethnic minorities and television. Gazette, 60(4), 305-324.

Hammersley, M. (1997). On the foundations of critical discourse analysis. Language \& Communication, 17(3), 237-248.

Hargreaves, A. G., \& Mahdjoub, D. (1997). Satellite television viewing among ethnic minorities in France. European Journal of Communication, 12(4), 459-477. 
Hartley, J. (2004). Television, nation, and indigenous media. Television \& New Media, 5, $7-25$.

Hassanpour, A. (2003a). Diaspora, homeland and communication technologies. In In K. H. Karim (Ed.), The media of diaspora (pp. 76-88). London: Routledge.

Hassanpour, A. (2003b). The making of Kurdish identity: Pre-20th century historical and literary discourses. In A. Vali (Ed.), Essays on the origins of Kurdish nationalism. Costa Mesa: Mazda Publishers Inc.

Hassanpour, A. (1998). Satellite footprints as national borders: MED-TV and the extraterritoriality of sate sovereignty. Journal of Muslim Minority Affairs, 18(1), 53-72.

Hassanpour, A. (1997). Language and television. In H. Newcomb (Ed.), Encyclopaedia of television (Vol. 1, pp. 923-926). Chicago: Fitzroy Dearborn Publishers.

Hassanpour, A. (1996). The creation of Kurdish media culture. In P. Kreyenbroek \& C. Allison (Eds.), Kurdish Culture and Identity (pp. 48-84). London, Zed Books Ltd.

Hassanpour, A. (1992). Nationalism and language in Kurdistan. San Francisco: Mellon Press.

Hassanpour, A., \& Mojab, S. (2005). Kurdish diaspora. In M. Ember, C. R. Ember, \& I. Skoggard (Eds.), Encyclopaedia of diasporas: Immigrant and refugee cultures around the world (Vol. 1, pp. 214-224). New York: Kluwer Academic.

Hassanpour, A., Skutnabb-Kangas, T., \& Chyet, M. (1996). The non-education of Kurds: A Kurdish perspective. International Review of Education, 42(4), 367-379.

Hastings, A. (1997). The construction of nationhood: Ethnicity, religion and nationalism. Cambridge: Cambridge University Press.

Hawraman. (n.d.). Retrieved June 10, 2006, from http://www.hawraman.com

Hays, J. E. (2000). Radio nation: Communication, popular culture, and nationalism in Mexico, 1920-1950. Tucson: University of Arizona Press.

Hazel, K. (2001). The media and nationalism in Quebec: A complex relationship. Journalism Studies, 2(1), 93-107.

Hearn, J. (2006). Rethinking nationalism: A critical introduction. New York: Palgrave Macmillan. 
Hearse, P. (1997, June 6). Kurdish satellite TV's second anniversary. Green Left Weekly, p. 27. Retrieved October 27, 2004, from http://www.greenleft.org.au/back/1997/276/276p27.htm

Hejar (Abdulrahman Sharafkandi) (1990). Henbane Borîne: Ferhenge Kurdi-Farsi (Henbane Borine: Kurdish-Persian Dictioanry). Tehran: Soroush.

Held, D., McGrew, A., Goldlatt, D., \& Perraton, J. (1999). Global transformations. Politics, economics and culture. Stanford: Stanford University Press.

Hemin (1974). Tarîk u rûn (Dark and light). Bexda (Baghdad): Binkey Pêshewa (Peshewa Publishing).

Herring, S.C., Kouper, I., Scheidt, L.A., \& Wright, E.L. (2004). Women and children last: The discursive construction of weblogs. In L.J. Gurak, S. Antonijevic, L. Johnson, C. Ratliff, \& J. Reyman (Eds.), Into the blogosphere: Rhetoric, community, and culture of weblogs. Retrieved July 15, 2006, from http://blog.lib.umn.edu/blogosphere/women and children.html

Herring, S. C., Sheidt, L. A., Sabrina, B., \& Wright, E. (2004). Bridging the Gap: A Genre Analysis of Weblogs. Proceedings of the 37th Hawaii International Conference on System Sciences.

Higgins, M. (2004). The articulation of nation and politics in the Scottish press. Journal of language and politics, 3(3), 463-483.

Himmati, H. (2007, September 18). Sitranbêj Heval Ibrahîm: Êstaş metĥ̂ Êraq dekem (Singer Heval Ibrahim: I still praise Iraq). Midya, (12) 307, p. 17.

Hobsbawm, E. (1990). Nations and nationalism since 1780: Programme, myth, reality. Cambridge: Cambridge University Press.

Hobsbawm, E. (1988). Introduction: Inventing traditions. In E. Hobsbawm \& T. Ranger (Eds.), The Invention of tradition (pp. 1-14). Cambridge: Cambridge University Press.

Hodge, R., \& Kress, G. (1993). Language as ideology ( $2^{\text {nd }}$ ed.). London: Routledge.

Hodge, R., \& Kress, G. (1988). Social semiotics. Cambridge: Polity Press.

Home 4 Kurd. (n.d.). Retrieved August 07, 2007, from www.home4kurd.com

Hoosan, D. (1994). Ex-Soviet identities and the return of geography. In D. Hoosan (Ed.), Geography and national identity (pp. 134-140). Oxford: Blackwell. 
Horowitz, D. L. (1992). Irredentas and secessions: Adjacent phenomena, neglected connections. In A. D. Smith (Ed.), Ethnicity and nationalism (pp. 118-130). New York: E. J. Brill.

Howard, J. A. (2000). Social psychology of identities. Annual Review of Sociology, 26, 367-93.

Howell, W. J. Jr. (1992). Minority-language broadcasting and the continuation of Celtic culture in Wales and Ireland. In S. H. Riggins (Ed.), Ethnic minority media: An international perspective (pp. 217-242). London: Sage.

Hroch, M. (2006). Modernization and communication as factors of nation formation. In G. Delanty \& K. Kumar (Eds.), The Sage handbook of nations and nationalism (pp. 21-32). London: Sage.

Huchinson, J. (1999). Re-interpreting cultural nationalism. Australian Journal of Politics and History, 45(3), 392-407.

Huchinson, J., \& Smith, A.D. (Eds.) (1994). Nationalism. Oxford: Oxford University Press.

Hull, G. A., \& Nelson, M. E. (2005). Locating the semiotic power of multimodality. Written Communication, 22(2), 224-261.

Human Rights Watch-Middle East. (1995): Iraq's crime of genocide: The Anfal campaign against the Kurds. New Haven: Yale University Press.

Iedema, R. (2000). Analyzing film and television. In T. van Leeuwen \& C. Jewitt (Eds.), The handbook of visual analysis (pp. 183-204). London: Sage.

Ignatieff, M. (1993). Blood and belonging: Journeys into the new nationalism. New York: Farrar, Straus and Giroux.

Index Online. (2004, April 06). Access to two Kurdish websites blocked. Retrieved October 24, 2004, from http://www.indexonline.org/indexindex/20040406_syria.shtml

İñigo-Mora, I. (2004). On the use of the personal pronoun we in communities. Journal of Language and Politics, 3(1), 27-52.

Innis, H. (1951). The bias of communication. Toronto: University of Toronto Press.

Institut Kurde de Paris. (2005). Massud Barzani unanimously elected President of Iraqi Kurdistan. Retrieved December 16, 2005, from http://www.institutkurde.org/en/publications/bulletins/bulletins.php?bul=243\#1 
International Constitutional Law. (1992). Iran-constitution. Retrieved July 10, 2006, from http://www.servat.unibe.ch/icl/ir00000 html

Internet-user held in solitary for seven months for e-mailing a newsletter (2003, December 31). Retrieved June 04, 2005, from http://www.rsf.org/article.php3?id_article $=8941$

Internet world stats: Usage and population statistics (2007). Internet world users by language. Retrieved December 24, 2007, from http://www.internetworldstats.com/stats $7 . h t m$

Islam Paik. (n.d.). Retrieved May 15, 2007, from http//www.islampaik.org

IT 4 Kurd Group. (n.d.). Retrieved August 10, 2007, from http://www.it4kurd.com

Ivanov, W. (1926). Notes of the Ethnology of Khurasan. The Geographical Journal, 67(2), 143-158.

Izady, M. (1994). Are Kurds descended from the Medes? Retrieved December 20, 2006, from http://www.kurdistanica.com/english/history/articles-his/his-articles-08.html

Izady, M. (1992). The Kurds: A concise handbook. Washington, D. C.: Taylor \& Francis.

Jackson, S. J., \& Ponic, P. (2001). Pride and prejudice: Reflecting on sport heroes, national identity, and crisis in Canada. Culture, Sport, Society, 4(2), 43-62.

Jenkins, O. B. (2001). The Kurdish peoples. Retrieved July 10, 2006, from http://www.orvillejenkins.com/peoples/kurds.html

Jenson, J. (1993). Naming nations: Making nationalist claims in Canadian public discourse. Canadian Review of Sociology and Anthropology, 30(3), 337-350.

Jin-Kurdish Women Network. (2003). Retrived July 10, 2006, from http://gulagenim.com

Joseph, J. E. (2004). Language and identity: national, ethnic, religious. New York: Palgrave Macmillan.

Kaiser, R. J. (2002). Homeland making and the territorialization of national identity. In Daniele Conversi (Ed.), Ethnonationalism in the Contemporary World: Walker Connor and the Study of Nationalism (pp. 229-247). London: Routledge.

Kaldor, M. (2004). Nationalism and globalization. Nations and Nationalism, 10(1-2), $161-177$.

Karim, K. H. (2006). Nation and diaspora: Rethinking multiculturalism in a transnational context. International Journal of Media and Cultural Politics, 2(3), 267-282. 
Karim, K. H. (2004). Re-viewing the 'national' in 'international communication': Through the lenses of diaspora. The Journal of International Communication, 10(2), 90-109.

Karim, K. H. (2003). Mapping diasporic mediascapes. In K. H. Karim (Ed.), The media of Diaspora (pp. 1-17). London: Routledge.

Karim, K. H. (1998). From ethnic media to global media: Transnational communication networks among diasporic communities. Paper for Strategic Research and Analysis: Canadian Heritage.

Karner, C. (2005). The 'Habsburg dilemma' today: Competing discourses of national identity in contemporary Austria. National Identities, 7(4), 409-432.

Kedouri, E. (1993). Nationalism (4 $4^{\text {th }}$ ed.). Oxford: Blackwell.

Kennedy, J. (2004). A Switzerland of the north? The nationalistes and bi-national Canada. Nations and Nationalism, 10(4), 499-518.

Kilborn, R. (1993). 'Speak my language': Current attitude to television subtitling and dubbing. Media, Culture and Society, 15, 641-660.

Kitêbxaney Kurdî (n.d.). Retrieved June 15, 2007, from http://www.pertwk.com/pertwk

Kluver, A. R. (2001). New media and the end of nationalism: China and the US in a war of words. MOTS Pluriels, 18. Retrieved October 05, 2005, from http://www.arts.uwa.edu.au/motspluriels/MP1801ak.html

Knudson, J. W. (1998). Rebellion in Chiapas: Insurrection by Internet and public relations. Media, Culture \& Society, 20, 507-518.

Kohn, H. (1945). The idea of nationalism. NewYork: Macmillan.

Komala TV. (n.d.). Retrieved December 18, 2006, from http://www.komalah.tv

Koohi-Kamali, F. (2003). The political development of the Kurds in Iran: Pastoral nationalism. New York: Palgrave.

Koord. (n.d.). Retrieved December 20, 2006, from http:/www.koord.com

Kress, G. R. (2003). Literacy in the new media age. London: Routledge.

Kress, G. R., \& van Leeuwen, T. (2002). Colour as a semiotic mode: Notes for a grammar of colour. Visual Communication, 1(3), 343-368. 
Kress, G. R., \& van Leeuwen, T. (2001). Multimodal discourse: The modes and media of contemporary communication. London: Arnold.

Kress, G. R., \& van Leeuwen, T. (1996). Reading images: The grammar of visual design. London: Routledge.

Kreyenbroek, P. (1996). Religion and religions in Kurdistan. In P. Kreyenbroek \& C. Allison (Eds.), Kurdish culture and identity, (pp. 85-110). London: Zed Books.

Kreyenbroek, P. (1992). On the Kurdish language. In In P. G. Kreyenbroek \& S. Sperl (Eds.), The Kurds: A contemporary overview (pp. 68-83). London: Routledge.

Kreyenbroek, P., \& Allison, C. (1996). Introduction. In P. Kreyenbroek \& C. Allison (Eds.), Kurdish culture and identity, (pp. 1-6). London: Zed Books.

Kreyenbroek, P., \& Allison, C. (Eds.) (1996). Kurdish culture and identity. London: Zed Books.

Kurd Goal. (n.d.). Retrieved November 02, 2007, from http://www.kurdgoal.com

Kurd Blogger. (2006). Retrieved February 15, 2006, from http://www.kurdblogger.com

Kurdish history, Kurdistan history (n.d.). [Videorecording]. Retrieved December 16, 2006, from http://ca.youtube.com/watch?v=3EgqqUDzkt0

Kurdish Bloggers' Session. (2004, March 14). [Video recording]. http://www.paltalk.com

Kurdish Communication. (2007). Retrieved August 15, 2007, from http://kurdishcommunication.blogspot.com/2007 0701 archive.html

Kurdish flag hoisted over regional parliament in north Iraq (2007, June 05). Assyrian International News Agency. Retrieved June 6, 2007, from http://www.aina.org/news/20070605141350.htm

Kurdish Love. (2006). Retrieved October 10, 2007, from http://love.sherwan.net/viewforum.php?id=41

Kurdish Media. (n.d.). Retrieved January 02, 2007, from http://www.kurdmedia.com

Kurdish WWW. (n.d.). Retrieved May 10, 2007, from http://www.kurdishwww.com/2007/s/Directory

Kurdistanica: The Encyclopaedia of Kurdistan. (n.d.). History. Retrieved October 15, 2006, from http://kurdistanica.com/english/history/histroy-frame.html 
Kurdistan and Kurd Liberation. (n.d.). [Videorecording]. Retrieved August 05, 2007, from http://www.youtube.com/watch?v=PrMVwKsxZOw

Kurdistan Net. (1999). Retrieved October 13, 2005, from http://www.kurdistannet.info

Kurdistan Parliament. (n.d.). Mêjûy Kurdistan (History of Kurdistan). Retrieved September 2007, from http://www.kurdistanparliament.org/default.aspx?page $=$ sitecontents $\& c=$ Kurdistan-History

Kurdistan Television. (2006). About us. Retrieved March 10, 2006, from http://www.kurdistantv.net/info.asp?ser $=20 \& c e p=9$

Kurdland. (1998). Retrieved July 15, 2004, from http://www.kurdland.com

Kurdlinx. (2007). Retrieved February 10, 2007, form http://www.kurdlinx.com

Kurds retain link to cyber world (2003, January 22). Gulf News. Retrieved October 03, 2004, from http://www.gulfnews.com/Articles/news.asp?ArticleID=74745

Kutschera, C. (2005). Iran: A Kurdish awakening. Retrieved December 20, 2006, from http://www.chris-kutschera.com/A/Kurds-Iran.htm

Kuusisto, Anna-Kaisa (2001). Territoriality, symbolism and the challenge. Peace Review, 13(1), 59-66.

Kymlicka, W., \& Patten, A. (2003). Language rights and political theory. Annual Review of Applied Linguistics, 23, 3-21.

Kymlicka, W., \& Straehle, C. (1999). Cosmopolitanism, nation-states, and minority nationalism: A critical review of recent literature. European Journal of Philosophy, 7 (1), 65-88.

Lakoff, G., \& Johnson, M. (1980). Metaphors we live by. Chicago: University of Chicago Press.

Landes, J. B. (2001). Visualizing the nation: Gender, representation, and revolution in eighteenth-century France. Ithaca and London: Cornell University Press.

Law, A. (2001). Near and far: Banal national identity and the press in Scotland. Media Culture and Society, 23(3), 299-317.

Le dîdarî Barzanî u Muttekî da rega be helkirdinî alay Kurdistan nedra (In the meeting between Barzani and Mutteki the Kurdistan flag was not allowed). (2007, May 06). Renesans News. Retrieved May 06, 2007, from http://renesans.nu/articles.php?id $=2377$ 
Le malperekanewe (From the websites) (2004, November 3). Hawlati, p. 16.

Leyla. (2002a, July 04). Retrieved March 15, 2004, from http://wera.blogspot.com/2002/07/blog-post_04.html

Lemke, J. (2002). Travels in hypermodality. Visual Communication l(3), 299-325.

Lemke, J. (1995). Textual politics: Discourse and social dynamics. London: Taylor and Francis.

Luke, A. (2002). Beyond science and ideology critique: Developments in Critical Discourse Analysis. Annual Review of Applied Linguistics, 22, 96-110.

Luke, A. (1989). Literacy, textbooks and ideology: Postwar literacy instruction and the mythology of Dick and Jane. London: The Falmer Press.

Luther, C. A. (2002). National identities, structure, and press images of nations: The case of Japan and the United States. Mass Communication \& Society, 5(1), 57-85.

MacDonald, C. G., \& O'Leary, C. A. (Eds.) (2007). Kurdish identity: Human rights and political status. Tallahassee: University Press of Florida.

Macgilchrist, F. (2006). Positive discourse analysis: Contesting dominant discourses by reframing the issues. Critical Approaches to Discourse Analysis Across Disciplines, 1(1), 74-94. Retrieved January 10, 2007, from http://www.cadaad.org

MacGregor, R. M. (2003). I am Canadian: National identity in beer commercials. The Journal of Popular Culture, 37(2), 276-286.

Macken-Horarik, M. (2004). Interacting with the multimodal text: Reflections on image and verbiage in ArtExpress. Journal of Visual Communication, 3(1), 5-26.

Madianou, M. (2005). Mediating the nation: News, audiences and the politics of identity. London: UCL Press.

Malper. (1997). Retrieved January 01, 2004, from http://kurdistanpress.com/malper

Maguire, J., Poulton, E., \& Possamai, C. (1999). The war of the words? Identity politics in Anglo-German press coverage of EURO 96. European Journal of Communication, 14(1), 61-89.

Mahabad homepage. (1998). Retrieved August 2007, from http://www.geocities.com/Paris/Tower/4454/index.html

Makhoudi, K. (Producer). (2005, August 10). Kazîwe [Television broadcast]. Tehran: Kurdistan TV, Tehran Office. 
Malešević, S. (2006). Nationalism and the power of ideology. In G. Delanty \& K. Kumar (Eds.), The Sage handbook of nations and nationalism (pp. 307-319). London: Sage.

Malmisanij, M. (2006a). The past and the present of book publishing in Kurdish language in Syria. Next Page Foundation. Retrieved July 15, 2007, from http://www.npage.org/article127.html

Malmisanij, M. (2006b). The past and the present of book publishing in Kurdish language in Turkey. Next Page Foundation. Retrieved July 10, 2007, from http://www.npage.org/article126.html

Marouf, H. (2007, March 14). Mer SAT u goristan TV! (Sheep SAT and cemetery TV!). Hawlatî, p. 12.

Martin, J. R. (2000). Close reading: Functional linguistics as a tool for critical discourse analysis. In L. Unsworth (Ed.), Researching language in schools and communities (pp. 275-302). London: CASSELL.

Martin, J. R., \& Rose, D. (2003). Working with discourse: Meaning beyond the clause. London: Continuum.

Martin, J. R., \& Wodak, R. (2003). Introduction. In J. R. Martin \& R. Wodak (Eds.), Re/reading the past: Critical and functional perspective on time and value (pp. 118). Amsterdam: John Benjamins.

Martinec, R. (2000). Construction of identity in Michael Jackson's Jam. Social Semiotics, $10(3), 313-329$.

Massy, D., Allen, J., \& Sarre, P. (Eds.). (1999). Human geography today. Cambridge: Polity Press.

Matras, Y., \& Reerschemius, G. (1991). Standardization beyond the state: The cases of Yiddish, Kurdish and Romani. In U. V. Gleich and E. Wolff (Eds.), Standardization of national languages: Symposium on language standardization, 2-3 February 1991. Hamburg: UNISCO Institute for Education.

Mautner, G. (2005). Time to get wired: Using web-based corpora in critical discourse analysis. Discourse \& Society, 16(6), 809-828.

May, S. (2001). Language and minority rights: Ethnicity, nationalism and the politics of language. Harlow: Longman.

Mcdonald, M. (2003). Exploring media discourse. London: Arnold. 
McDowall, D. (2004). A modern history of the Kurds ( $3^{\text {rd }}$ ed.). London: I. B. Tauris.

McDowall, D. (1992). The Kurds: A nation denied. London: Minority Rights Group.

McKiernan, K. (2006). The Kurds: A people in search of their homeland. New York: St. Martin's Press.

McLuhan, M. (1964). Understanding media: The extensions of man. New York: Mentor Books.

McLuhan, M. (1962). The Gutenberg galaxy: The making of typographic man. Toronto: The University of Toronto Press.

McLuhan, M. (1960). Effects of the improvements of communication media. The Journal of Economic History, 20 (4), 566-575.

Median Empire and [the] fall of Nineveh. (2007). [Videorecording]. Retrieved October 11, 2007, from http://ca.youtube.com/watch?v=2Lf W9ADw4A

Menaf, M. (2007, September 18). Le yek hefte da hekeranî Kurd 100 malperî fermî Turkiayan hak kird (In one week, Kurdish hackers hacked 100 Turkish official websites) Retrieved September 20, 2007, from http://www.renesans.nu

Meyrowitz, J. (1997). Shifting worlds of strangers: Medium theory and changes in "them" versus "us". Sociological Inquiry, 67(1), 59-71.

Meyrowitz, J. (1994). Medium theory. In D. Crowley \& D. Mitchell (Eds.), Communication theory today (pp. 50-77). Cambridge, England: Polity Press.

Meyrowitz, J. (1985). No sense of place. New York: Oxford University Press.

Mihemed, S. (2006, August). Behruz Hesen: Debwaye dezga roshinbîryekanî Kurdistan saitêkî wekî [Pertûk] yan dabimezrandaye (Bahruz Hasan: Kurdistan cultural institutions should have established a website similar to Pertwk.com). Kurdistan Report, 26, p. 12.

Miller, C., \& D. Shepherd (2004). Blogging as social action: A genre analysis of the weblog. In L.J. Gurak, S. Antonijevic, L. Johnson, C. Ratliff, \& J. Reyman (Eds.), Into the blogosphere: Rhetoric, community, and culture of weblogs. Retrieved January 15, 2007, from http://blog.lib.umn.edu/blogosphere/blogging_as_social_action_a genre analysis of the weblog.html

Mills, K. (2002). Cybernations: Identity, self-determination, democracy and the "Internet Effect" in the emerging information order. Global Society, 16(1), 69-87. 
Milroy, J. (2001). Language ideologies and the consequences of standardization. Journal of Sociolinguistics, 5(4), 530-555.

Miura, A., \& Yamashita, K. (2007). Psychological and social influences on blog writing: An online survey of blog authors in Japan. Journal of Computer-Mediated Communication, 12(4), Retrieved November 27, 2007, from http://icmc.indiana.edu/vol12/issue4/miura.html

Mohtadi, A. (2005, January 01). Wituwêjî xiwêneranî Dîmane le gel Ebdulllay Muhtedî [A dialogue between Dimane's readers and Abdullah Mohtadi]. Retrieved January 15, 2005, from http://www.komala.org/kurdi/vetvez/2005-01-01AbaMDimaneh.htm

Mojab, S. (2001). Women of a non-state nation: The Kurds. Costa Mesa, Calif.: Mazda.

Morley, D. (2004). Broadcasting and the construction of the national family. In R. C. Allen \& A. Hill, The television studies reader (pp. 418-441). London: Routledge.

Morley, D. (2000). Home territories: Media, mobility and identity. London: Routledge.

Morley, D. (1992). Television, audiences and cultural studies. London: Routledge.

Murad, I. (24 April, 2005). An ordinary Friday. The [Hawler] Globe, p. 3.

Nairn, T. (1997). Faces of nationalism: Janus revisited. London: Verso.

Natali, D. (2005). The Kurds and the state: Evolving national identity in Iraq, Turkey, and Iran. Syracuse, N.Y.: Syracuse University Press.

Natali, D. (2002). Kurdayetî in the late Ottoman and Qajar empires. Critique: Critical Middle Eastern Studies, 11(2), 177-199.

Nawendî CHA--The Centre of Halabja against Anfalazation and Genocide of Kurds [sic.]. (2002). Retrieved August 15, 2006, from http://nawandihalabja.com

Nawî, N. (Producer). (2005, August 08). Ronî (Clear) [Television broadcast]. [Hawler, Kurdistan-Iraq]: Kurdistan TV.

Najari, S. (2008, March). Zimanî mîdiyakan u erkî qursî neteweyî (The language of the media and the heavy national responsibility). Mahabad: Social, Cultural \& Literary Magazine, 84, pp. 30-31.

Nabaz, J. (1985). Kurdistan u shorishekey: Zincîre witarêke salî 1971 be zimanî Almanî le Berlîn bo Kurd u dostanî Kurd xwêndrawetewe. Kurdo le Almanîyewe kirdûye be Kurdî. [Kurdistan and its revolution. A series of lectures delivered in German, 
in Berlin, in 1971 for the Kurds and friends of the Kurds. Translated into Kurdish by Ali Kurdo.] Hewlêr, Kurdistan-Iraq: Aras Publishing House.

Nefel. (n.d.). Retrieved October 30, 2007, from http://www.nefel.com

Newrozi, R. (n.d.). Panoramaya sed sal ji dîroka rojnamevaniya Kurdî: 22, 04, 1898-22, 04, 1998 (A panorama of Kurdish journalism's story in one hundred years: 22, 04, $1898-22,04,1998)$. Retrieved May 12, 2006, from http://www.amude.net/kurdi/100-sal-rojnamevaniya-kurdi.pdf

Nicolaisen, W. F. H. (1990). Place names and politics. Names, 38, 193-207.

No 'legal' demonstration prevented, Erbil governor says (2005, November 9). The [Hawler] Globe [Weekly English broadsheet published in Iraqi Kurdistan], p. 3.

Nogué, J., \& Vicente, J. (2004). Landscape and national identity in Catalonia. Political Geography, 23, 113-132.

Ockey (2001) McJihad: Globalization and the future of nationalism. Political Science, 53(1), 56-66.

Öktem, K. (2004). Incorporating the time and space of the ethnic 'other': nationalism and space in Southeast Turkey in the nineteenth and twentieth centuries. Nations and Nationalism, 10(4), 2004, 559-578.

O'Leary, B., \& Salih, K. (2005). The denial, resurrection, and affirmation of Kurdistan. In Brendan O'Leary, John McGarry \& Khaled Salih, The future of Kurdistan in Iraq (pp. 3-43). Philadelphia: University of Pennsylvania Press.

O'Leary, C. (2002, December). The Kurds of Iraq: Recent history, future prospects. MERIA Journal, 6 (4). Retrieved April 14, 2005, from http://meria.idc.ac.il/journal/2002/issue4/jv6n4a5.html

Olson, R. (1991). Five stages of Kurdish nationalism: 1880-1980. Journal of Muslim Minority Affairs, 12(2), 391-409.

O'Shea, M. T. (2004). Trapped between the map and reality: Geography and perceptions of Kurdistan. New York : Routledge.

Qadir, S. (17 July, 2007). Interpol mêrdî shewboy destgîr kirduwe u brîtaniash deydatewe be kurdistan (The Interpol has arrested Shewbo's husband and Britain will extradite him to Kurdistan). Media, p. 14. Retrieved July 20, 2007, from http://www.yndk.com

Paltalk. (n.d.). Retrieved July 01, 2001, from http://www.paltalk.com 
Partî Serbestî Kurdistan (Kurdistan Independence Party). (n.d.). Retrieved November 15, 2006, from http://www.psk2006.org

Patten, A. (2001). Political theory and language policy. Political Theory, 29(5), 691-715.

Peyamner News Agency (2005). Ême (About us). Retrieved December 15, 2005, from http://www.peyamner.com/Default.aspx?a=a

Phillipson, R. (2000). Integrative comment: Living with vision and commitment. In R. Phillipson (ed.), Rights to language: Equality, power, and education (264-278). Mahwah, NJ: Erlbaum.

Phillipson, R., Rannut, M., \& Skutnabb-Kangas, T. (1995). Introduction. In T. SkutnabbKangas, R. Phillipson \& M. Rannut (Eds.), Linguistic human rights: Overcoming linguistic discrimination (pp. 1-22). Berlin: Nouton de Gruyter.

Pietikäinen, S., \& Dufva, H. (2006). Voices in discourses: Dialogism, critical discourse analysis and ethnic identity. Journal of Sociolinguistics, 10(2), 205-224.

Poster, M. (1999). National identities and communications technologies. The Information Society, 15, 235-240.

Prevent ethnic conflict. (2006). Retrieved July 14, 2006, from http://www.petitiononline.com/azeri/

Price, M. E. (2001). Satellite broadcasting as trade routes in the sky. In Joseph M. Chan \& Bryce T. McIntyre (Eds.), In search of boundaries: Communication, nationstates and cultural identities (pp. 146-167). Westport, CT: Abex Publishers.

Price, M. E. (1995). Television: The public sphere and national identity. Oxford: Clarendon Press.

Radio Kurdland (Kurdland Radio). (n.d.). Retrieved December 22, 2006, from http://en.kurdland.com/text.asp?id=1001

Radio Rojawa (Western [Syrian Kurdistan] Radio). (n.d.). Retrieved December 20, 2006, from http://rojavatv.org.uk/radio/radio.htm

Radio Nawa. (n.d.). Retrieved December 20, 2006, from http://www. radionawa.com $/ \mathrm{ku} /$ news/NewsDetail.aspx?id=11134

Raman. (n.d.). Retrieved August 13, 2007, from http://www.raman-media.net

Randal, J. C. (1997). After such knowledge, what forgiveness? My encounters with Kurdistan. New York: Farrar, Straus and Giroux. 
Renan, E. (1990). What is a nation? In H. K. Bhabha (Ed.), Nation and narration (pp. 822). London: Routledge.

Renesans. (n.d.). Retrieved December 16, 2006, from http://www.renesans.nu

Reporters Without Borders. (2004, February 16). Reporters Without Borders calls on Syrian president for release of journalism student. Retrieved October 24, 2004, from http://www.rsf.org/article.php3?id_article $=9261$

Ricento, T. (2003). The discursive construction of Americanism. Discourse \& Society, 14 (5), 611-637.

Riggins, S. H. (1997). The rhetoric of othering. In S. H. Riggins (Ed.), The language and politics of exclusion (pp. 1-30). London: Sage.

Riggins, S. H. (Ed.) (1992). Ethnic minority media: An international perspective. Newbury Park: Sage Publications.

Riley, D. (2005, April 14). Number of blogs now exceeds 50 million worldwide. Retrieved May 20, 2005, from http://www.blogherald.com/2005/04/14/numberof-blogs-now-exceeds-50-million-worldwide

Rizgarî Online (Emancipation Online). (n.d.). Retrieved July 03, 2007, from http://kurdish.rizgari.com

Roj Bash Kurdistan (Good Day Kurdistan): There is no northern Iraq. (n.d.). Retrieved October 18, 2007, from http://northerniraq.info/forums/index.php

Rojhelat TV. (2006). Retrieved December 18, 2006, from http://www.rojhelattv.com

Roj TV. (n.d.). Retrieved May 10, 2006, from http://www.roj.tv

Romaine, S. (2000). Language in society: An introduction to sociolinguistics $\left(2^{\text {nd }}\right.$ ed.). New York: Oxford University Press.

Romano, D. (2006). The Kurdish nationalist movement: Opportunity, mobilization, and identity. Cambridge: Cambridge University Press.

Romano, D. (2002). Modern communications technology in ethnic nationalist hands: the case of Kurds. Canadian Journal of Political Science, 35(1), 127-149.

Ryan, N. (1997 March). Med-TV newsflash. Wired, 4-9.

Said Shukri, I. (2006, July). "Kanî Kamputêr" u erke ferhengîyekanî (Kani Computer and its cultural responsibilities). Mahabad: Social, Cultural and Literary Magazine, 64 , pp. $40-41$. 
Samarasinghe, S. W. R. de A. (1990). Introduction. In R,. R. Premdas, S. W. R. de A. Samarasinghe, \& A. B. Anderson (Eds.), Secessionist movements in comparative perspective (pp. 1-29). New York: St. Martin's Press.

Sami, K. (2006). Seid Ehmed Rewandizî le dîdarî Kurdistan Anline da (Said Ehmed Rewandizî in an interview with Kurdistan Online). Retrieved May 20, 2007, from http://www.chopy.net/hewallekan/66-2006/seyid\%20ahmed-kurdonlain.htm

Sarup, M. (1993). An introductory guide to post-structuralism and postmodernism $\left(2^{\text {nd }}\right.$ ed.). Athens: The University of Georgia Press.

Saussure, F. (1959). Course in general linguistics. New York: McGraw-Hill Book Company.

Schaap, F. (2004). Links, lives, logs: Presentation in the Dutch blogosphere. In L. J. Gurak, S. Antonijevic, L. Johnson, C. Ratliff, \& J. Reyman (Eds.), Into the blogosphere: Rhetoric, community, and culture of weblogs. Retrieved July 15, 2006, from http://blog.lib.umn.edu/blogosphere/links lives_logs_pf.html

Schiller, N. G., \& Fouron, G. E. (2001). Georges woke up laughing: long-distance nationalism and the search for home. Durham: Duke University Press.

Schleifer, Y. (2006, April 21). Denmark, again? Now it's under fire for hosting Kurdish TV station. The Christian Science Monitor. Retrieved June 10, 2006, from http://www.csmonitor.com/2006/0421/p01s01-woeu.html

Schlesinger, P. (2000). The nation and communicative space. In H. Tumber (Ed.), Media power, professionals and policies (pp. 99-115). London: Routledge.

Schlesinger, P. (1999). Changing spaces of political communication: The case of the European Union. Political Communication, 16, 263-279.

Schlesinger, P. (1991). Media, state and nation: Political violence and collective identities. London: Sage.

Scriven, M., \& Roberts, E. (2003). Fragmentation of the nation: National identity and television in France and Britain at the turn of the twentieth century. In M. Scriven \& E. Roberts (Eds.), Group identities on French and British television (pp. 1-12). New York: Berghahn Books.

Scollon, R. (1999). Official and unofficial discourses of national identity: Questions raised by the case of contemporary Hong Kong. In R. Wodak \& C. Ludwig (Eds.), Challenges in a changing world: Issues in Critical Discourse Analysis (pp. 21-35). Wien: Passagen Verlag. 
Seidlhofer, B. (2003). Critical discourse analysis. In B. Seidlhofer (Ed.), Controversies in applied linguistics (pp. 125-168). Oxford: Oxford University Press.

Seroki hemû Kurdistan (2007, September 23). Retrieved September 23, 2007, from http://kurdistanpost.com/index.php?id=1642

Sheikhani, S. (2004). Iraqi Kurdish satellite channels: From media obscurity to the dream of international broadcasting. Translational Broadcasting Studies, 12. Retrieved December 10, 2006, from http://www.tbsjournal.com/kurdish.htm

Sheyholislami, J. (2007). Yesterday's "separatists" are today's "resistance fighters":

Mainstream media as agents of hegemony. In J. Bernardo, G. López \& P. Sancho (Eds.), Critical discourse analysis of the mass media of communication (pp. 95110). Valencia: Universitat de València.

Sheyholislami, J. (2001). Yesterday's "separatists" are today's "resistance fighters": A critical discourse analysis of the representation of Iraqi Kurds in the New York Times and the Globe and Mail. Unpublished master's thesis, Carleton University, Ottawa, Ontario, Canada.

Shnirelman, V. (2006). The Politics of a Name: Between Consolidation and Separation in the Northern Caucasus. Acta Slavica Iaponica, Tomus 23, 37-73.

Siddiqui, H. (February 21, 1999). Finding the mix of home and homeland. Toronto Star, A13.

Silverstone, R. (1999). Why study the media? London: Sage.

Simone, M. (2006). CODEPINK alert: Mediated citizenship in the public sphere. Social Semiotics, 16(2), 345-364.

Sina, N. (Producer). (2007a, January 01). Wituwêj le gel Husên Shuxkeman (Interview with Hussein Shukhkaman). Zayele (Echo) [Radio Broadcast]. Stockholm: Radio Sweden International, Kurdish Service. Retrieved January 10, 2007, from http://www.sr.se/cgibin/International/programsidor/artikel.asp?ProgramID=2200\&Artikel=1246513

Sina, N. (Producer). (2007b, February 12). Zayele (Echo) [Radio Broadcast]. Stockholm: Radio Sweden International, Kurdish Service. Retrieved February 15, 2007, from http://www.sr.se/cgi-bin/International/programsidor/index.asp?ProgramID =2200

Sina, N. (Producer). (2006, February 28). Wituwêj le gel Shaho Husênî, yekêk le berpirsanî Tishk TV (Interview with Shao Husseini, one of the Tishk TV's executives). Zayele (Echo) [Radio Broadcast]. Stockholm: Radio Sweden International, Kurdish Service. Retrieved April 10, 2006, from http://www.sr.se/rs/red/grupp/kur/sounds/Zayele-TishkTV.ram 
Sina, N. (Producer). (2005, December 19). Zayele (Echo) [Radio Broadcast]. Stockholm: Radio Sweden International, Kurdish Service. Retrieved July 15, 2006, from http://www.sr.se/cgi-bin/International/programsidor/index.asp?ProgramID=2200

Skutnabb-Kangas, T. \& Bucak, S. (1994). Killing a mother tongue: How the Kurds are deprived of linguistic human rights. In T. Skutnabb-Kangas \& R. Phillipson (Eds.), Linguistic human rights: Overcoming linguistic discrimination (pp. $347-$ 370). Berlin: Mouton de Gruyter.

Skutnabb-Kangas, T. \& Fernandes, D. (upcoming). Kurds in Turkey and in (Iraqi) Kurdistan - a comparison of Kurdish educational language policy in two situations of occupation. Unpublished paper.

Smith, A. (1999). Myths and memories of the nations. Oxford: Oxford University Press.

Smith, A. (1998). Nationalism and modernism. London: Routledge.

Smith, A. (1996). LSE centennial lecture: The resurgence of nationalism? Myth and memory in the renewal of nations. The British Journal of Sociology, 47(4), 575598.

Smith, A. (1991). National identity. Reno: University of Nevada Press.

Smith, A. (1983). Theories of nationalism ( $2^{\text {nd }}$ ed.). London: Duckworth.

Smith, J. (Ed.) (1998). Media policy, national identity and citizenry in changing democratic societies: The case of Canada. Durham: Canadian Studies Center, Duke University.

Somolu, O. (2007). 'Telling our own stories': African women blogging for social change. Gender \& Development, 15(3), 477-489.

Sondermann, K. (1997). Reading politically: National anthems as textual icons. In T. Carver and M. Hyvärinen (Eds.), Interpreting the political: New methodologies (pp. 128-42). London: Routledge.

Sorapure, M. (2003). Screening moments, scrolling lives: Diary writing on the web. Biography, 26(1), 1-23.

Spencer, P., \& Wollman, H. (2002). Nationalism: A critical introduction. London: Sage Publication.

Steinberg, M. (1999). The talk and back talk of collective action: A dialogic analysis of repertoires of discourse among nineteenth-century English cotton spinners. American Journal of Sociology, 105(3), 736-80. 
Stieve, T. (2005). National identity in Niagara Falls, Canada and the United States. Tijdschrift voor Economische en Sociale Geografie, 96(1), 3-14.

Straubhaar, J. (2002). (Re)asserting national television and national identity against the global, regional and local levels of world television. In J. M. Chan \& B. T. McIntyre (Eds.), In search of boundaries: Communication, nation-states and cultural identities (pp. 181-206). London: Ablex Publishing.

Stupples, P. (2003). Visual icons and cultural identity. Third Text, 17(2), 127-139.

Sutherland, C. (2005). Nation-building through discourse theory. Nations and Nationalism, 11(2), 185-202.

Symmons-symonolewicz, K. (1965). An attempt at a comparative typology. Comparative Study in Society and History, 7(2), 221-230.

Taha, Y. (2006, October 10). Be pêy failêkî hizbî Be's, 43 pisporî perwerdeyî Kurd karyan bo nehêshtinî zimanî Kurdî kirduwe Awêne [According to a Baath party's document, 43 Kurdish educators have worked towards terminating the Kurdish language], Awene, 1, 15, Retrieved October 15, 2006, from http://www.awene.com

Talabani: Le jiyanim da bîrm le damezrandinî dewletî Kurdî yan ciyakirdnewey Kurdistan le Êraq nekirdotewe (I have never thought of establishing a Kurdish state or separating Kurdistan from Iraq). (2005, June 19). Peyamnêr News Agency. Retrieved June 25, 2005, from http://www.peyamner.com/article.php?id=13712\&lang=kurdish

Talib, N. (Producer). (2007, January 07). Rapirsî (Opinion Survey) [Television broadcast]. [Hawler, Kurdistan-Iraq]: Kurdistan TV.

Talib, N. (Producer). (2005, August 10). Emro Le Mêjû̉ Da [Television broadcast]. [Hawler, Kurdistan-Iraq]: Kurdistan TV.

Taras, R. (1998). Nations and language-building: Old theories, contemporary cases. Nationalism \& Ethnic Politics, 4(3), 79-101.

Teo, P. (2004). Ideological dissonances in Singapore's national campaign posters: A semiotic deconstruction. Visual Communication, 3(2), 189-212.

Teo, P. (2000). Racism in the news: A critical discourse analysis of news reporting in two Australian newspapers. Discourse and society, 11(1), 7-8, 10-28, 39-48.

The Washington Post. (1999). Who are the Kurds? Retrieved July 14, 2006, from http://www.washingtonpost.com/wp-srv/inatl/daily/feb99/kurdprofile.htm 
Thomas, G. (2007, June 12). Kurds: Grateful to America, want homeland. The Christian Broadcasting Network. Retrieved June 12, 2007, from http://www.cbn.com/CBNnews/174989.aspx

Thussu, D. K. (2000). International communication: Continuity and change. London: Arnold.

Tollefson, J. W. (1991). Planning language, planning inequality: Language policy in the community. London: Longman.

Tomi, E. G. (n.d.). Berîvan (Milkmaid). [Videorecording]. Retrieved December 17, 2006, from http://www.koord.com

Toolan, M. (2002) (Ed.). Critical discourse analysis: Critical concepts in linguistics. New York: Routledge.

Topecik, C. (n.d.). Şahjina Rojhelatê (The queen of the East) [Videorecording], Retrieved December 17, 2006, from http://www.koord.com

Triandafyllidou, A., \& Wodak, R. (2003). Conceptual and methodological questions in the study of collective identities: An introduction. Journal of Language and Politics, 2(2), 205-223.

Turkey renames 'divisive' animals. (2005, March 08). BBC News. Retrieved March 15, 2005, from http://news.bbc.co.uk/2/hi/europe/4328285.stm

Turkey wary as Iraqi Kurds hoist Kurdish flag (2006, September 16). Turkish Daily News. Retrieved October 14, 2006, from http://www.turkishdailynews.com.tr/article.php?enewsid=54110\&mailtofriend $=1$

Turks charge Kurd with inciting hatred: Politician made remarks about Iraq. (2007, February 27). The Washington Post. Retrieved February 15, 2007, from http://www.washingtonpost.com/wpdyn/content/article/2007/02/23/AR2007022301909 pf.html

Turner, C. (2006). Nation and communication. G. Delanty \& K. Kumar (Eds.), The Sage handbook of nations and nationalism (pp. 205-213). London: Sage.

Tyrwhitt-Drake, H. (1999). Resisting the discourse of critical discourse analysis: Reopening a Hong Kong case study. Journal of Pragmatics, 31, 1081-1088.

Un, A. (2007, April 4). Kurdistan TV correspondents under pressure. Bianet: Independent Communication Network. Retrieved April 7, 2007, from http://eski.bianet.org/2006/11/01 eng/news $94186 . \mathrm{htm}$ 
Vali, A. (2003). Genealogies of the Kurds: Constructions of nation and national identity in Kurdish historical writing. In A. Vali (Ed.), Essays on the origins of Kurdish nationalism (pp. 58-105). Costa Mesa: Mazda Publishers Inc.

Vali, A. (1998). The Kurds and their "others": Fragmented identity and fragmented politics. Comparative Studies of South Asia, Africa and the Middle East, 18(2), 82-95.

van Bruinessen, M. (2003). Ehmedî Xanî's Mem û Zîn and its role in the emergence of Kurdish national awareness. In A. Vali (Ed.), Essays on the origins of Kurdish nationalism (pp. 40-57). Costa Mesa: Mazda Publishers Inc.

van Bruinessen, M.(2000a). Kurdish ethno-nationalism versus nation-building states: Collected articles. Istanbul: The ISIS Press.

van Bruinessen, M. (2000b). Transnational aspects of the Kurdish question. Working paper, Robert Schuman Centre for Advanced Studies, European University Institute, Florence. Retrieved November 13, 2004, from http://www.let.uu.nl/ martin.vanbruinessen/personal/publications/transnational K urds.htm

van Bruinessen, M. (1999) The Kurds in movement: migrations, mobilisations, communications and the globalisation of the Kurdish question. Islamic area studies, working paper series, no. 14. Tokyo: Islamic Area Studies Project Management Office.

van Bruinessen, M. (1992). Kurdish society, ethnicity, nationalism and refugee problems. In P. G. Kreyenbroek \& S. Sperl (Eds.), The Kurds: A contemporary overview (pp. 33-67). London: Routledge.

van Den Bos, M., \& Nell, L. (2006). Territorial bounds to virtual space: Transnational online and offline networks of Iranian and Turkish-Kurdish immigrants in the Netherlands. Global Networks, 6(2), 201-220.

van den Berghe, P. (1995). Does race matter? Nations and Nationalism, 1(3), 357-68.

van Dijk, T. A. (1998). Ideology: A multidisciplinary approach. London: Sage.

van Dijk, T. A. (1993a). Elite discourse and racism. London: Sage Publications.

van Dijk, T. A. (1993b). Principles of critical discourse analysis. Discourse \& Society, $4(2), 249-283$.

van Dijk, T. A. (1988). News analysis: Case studies of international and national news in the press. Hillsdale, N.J.: Lawrence Erlbaum Associates. 
van Leeuwen, T. (2005). Multimodality, genre and design. In S. Norris \& R. H. Jones (Eds.), Discourse in action: Introducing mediated discourse analysis (pp. 73-94). London: Routledge.

van Leeuwen, T. (1996a). Moving English: The visual language of film. In S. Goodman \& D. Graddol (Eds.), Redesigning English: New texts, new identities (pp. 81-105). London: The Open University.

van Leeuwen, T. (1996b). The representation of social actors. In C. R. Caldas-Coulthard \& M. Coulthard (Eds.), Texts and practices: Readings in critical discourse analysis (pp. 32-70). London: Routledge.

van Leeuwen, T., \& Jewitt, C. (Eds.) (2000). The handbook of visual analysis. London: Sage.

Vertovec, S. (1999). Conceiving and researching transnationalism. Ethnic and Racial Studies, 22(2), 447-462.

Voice of America. (2007, April 4). Iran's Kurdish media crackdown. Retrieved April 20, 2007, from http:/www.voanews.com/uspolicy/2007-04-06-voa3.cfm

Wahby, T., \& Edmonds, C. J. (1966). A Kurdish-English dictionary. Oxford: Oxford University Press.

Wahlbeck, Ö. (2002). The concept of diaspora as an analytical tool in the study of refugee communities. Journal of Ethnic and Migration Studies, 28(2), 221-238.

Wahlbeck, Ö. (1999). Kurdish diasporas: A comparative study of Kurdish refugee communities. London: Macmillan.

Waisbord, S. (2004). Media and the reinvention of the nation. In J. D. H. Downing, D. McQuail, P. Schlesinger, and E. Wartella (Eds.), The Sage handbook of media studies (pp. 375-392). London: Sage.

Warschauer, M. (2001). Millennialism and media: Language, literacy, and technology in the 21 st century. AILA Review 14, 49-59.

Warschauer, M. (2000). Language, identity, and the Internet. In B. E. Kolko, L. Nakamura \& G. B. Rodman (Eds.), Race in cyberspace (pp. 151-170). New York: Routledge.

Watson, I. (2005, May 09). Neighboring Kurds travel to study in Iraq. National Public Radio. Retrieved May 10, 2005, from http://www.npr.org/templates/story/story.php?storyId $=4528599$

Watson, I. (1996). The Irish language and television: national identity, preservation, restoration and minority rights. British Journal of Sociology, 47(2), 255-274. 
Watts, M. J. (1999). Collective wish images: Geographical imaginaries and the crisis of national development. In D. Massey, J. Allen \& P. Sarre (Eds.), Human Geography Today (pp. 85-113). Malden, Mass.: Polity Press.

Weiss, G., \& Wodak, R. (2003). Introduction: Theory, interdisciplinarity and critical discourse analysis. In G. Weiss \& R. Wodak (Eds.), Critical discourse Analysis: Theory and interdisciplinarity (pp. 1-32). New York: Palgrave Macmillan.

White, P. (2000). Primitive rebels or revolutionary modernizers? The Kurdish national movement in Turkey. London: Zed Books.

Widdowson, H. G. (2004). Text, context, pretext: Critical issues in discourse analysis. Oxford: Blackwell.

Widdowson, H. G. (1995). Discourse analysis: A critical view. Language and Literature, $4(3), 157-72$.

Widdowson, H. G. (1998). The theory and practice of Critical Discourse Analysis. Applied Linguistics, 19 (1), 136-151.

Wiley, S. B. C. (2004). Rethinking nationality in the context of globalization. Communication Theory, 14(1), 78-96.

Williams, K. (2003). Constructing the national: Television and Welsh identity. In In M. Scriven \& E. Roberts (Eds.), Group identities on French and British television (pp. 34-40). New York: Berghahn Books.

Williams, L. (1999). National identity and the nation state: Construction, reconstruction and contradiction. In K. Cameron (Ed.), National identity (pp. 7-18). Exeter (Eng.): Intellect.

Williams, R. (1974). Television: Technology and cultural form. New York: Schocken Books.

Wittgenstein, L. (1958). Philosophical investigations. Oxford: Basil Blackwell.

Wodak, R. (2006). Discourse-analytic and socio-linguistic approaches to the study of nation(alism). In G. Delanty \& K. Kumar (Eds.), The Sage handbook of nations and nationalism (pp. 104-17). London: Sage.

Wodak, R. (2002). Fragmented identities: Redefining and recontexualizing national identity. In P. Chilton \& C. Schäffner (Eds.), Politics as text and talk: Analytic approaches to political discourse (pp. 143-169). Amsterdam: John Benjamins. 
Wodak, R. (1995). Critical Linguistics and Critical Discourse Analysis. In J. Verschuren, J. Ostman \& J. Blommaert (Eds.), Handbook of Pragmatics-Manual (pp.204210). Amsterdam: John Benjamins.

Wodak, R., \& Ludwig, C. (1999). Introduction. In R. Wodak \& C. Ludwig (Eds.), Challenges in a changing world: Issues in Critical Discourse Analysis (pp. 1119). Wien: Passagen Verlag.

Wodak, R., \& Meyer, M. (Eds.) (2001). Methods of critical discourse analysis. London: Sage.

Wodak, R., de Cillia, R., Reisigl, M., \& Mitten, R. (1999). The discursive construction of national identities. Edinburgh: Edinburgh University Press.

Wogan, P. (2001). Imagined Communities reconsidered: Is print-capitalism what we think it is? Anthropological Theory, 1(14), 403-418.

Xebat. (n.d.). Retrieved August 13, 2007, from http://www.xebat.net

Yavuz, M. H. (2005). Kurdish nationalism in Turkey. In M. Shatzmiller (Ed.), Nationalism and minority identities in Islamic societies (pp. 229-261). London: McGill-Queen's University Press.

Yekyetî Nîshtimanî Demokratî Kurdistan. (2001). Retrieved July 10, 2006, from http://www.yndk.com

Yildiz, K. (2004). The Kurds in Iraq: The past, present and future. London: Pluto Press.

Yoshimi, S. (2003). Television and nationalism: Historical change in the national domestic TV formation of postwar Japan. European Journal of Cultural Studies, 6(4), 4509-487.

Young Iraqi Kurds choose English over Arabic. (2005, May 29). The [Hawler] Globe, p. 12.

Young, L., \& Fitzgerald, B. (2006). The power of language: How discourse influences society. London: Equinox.

Young, L., \& Harrison, C. (2004). Systemic functional linguistics and critical discourse analysis: Studies in social change. London: Continuum.

Yule, G. (1996). Pragmatics. Oxford: Oxford University Press.

Yumul, A., \& Uzkirimli, U. (2000). Reproducing the nation: 'banal nationalism' in the Turkish press. Media, Culture \& Society, 25(6), 787-804. 
Zamdar, K. (Producer). (2005, August 12). Şev Bêrî [Television Broadcast]. [Hawler, Kurdistan-Iraq]: Kurdistan TV.

Zayele (Echo) [Sweden Radio International, Kurdish Service]. (n.d.). Retrieved August 15,2004 , from http://sr.se/cgibin/International/programsidor/artikel.asp?ProgramID=2200\&Artikel=546439

Zimmer, O. (2003). Boundary mechanisms and symbolic resources: Towards a processoriented approach to national identity. Nations and Nationalism, 9(2), 173-193.

Zimmerman, A. (1994). Kurdish broadcasting in Iraq. Middle East Report, (July-August), 20-21. 